\title{
Binuclear late transition metal complexes with pyrazole based compartmental ligands: Scaffolds for cooperative organometallic transformations
}

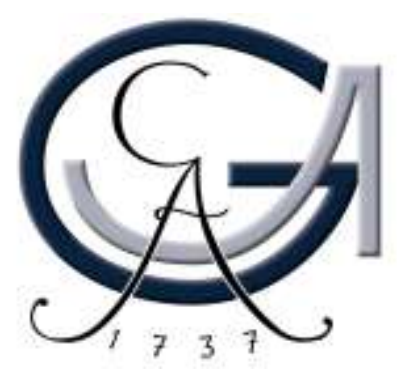

Dissertation

for the award of the degree

“Doctor of Philosophy” Ph.D. Division of Mathematics and Natural Sciences of the Georg-August-Universität Göttingen

within the doctoral program Catalysis for Sustainable Synthesis (CaSuS)

of the Georg-August University School of Science (GAUSS)

submitted by

Michael Kojo Ainooson

from Accra, Ghana

Göttingen 2014 
i. Prof. Dr. F. Meyer

ii. Prof. Dr. P. Vana

iii. Prof. Dr. D. Stalke

Date of the oral examination: 25/07/2014 
I hereby declare that the dissertation, "Binuclear late transition metal complexes with pyrazole based compartmental ligands; Scaffolds for cooperative organometallic transformations" is my original research work and has not been submitted to any other university for the award of a degree. This work was undertaken from 2010-2014 under the supervision of Prof. Dr. Franc Meyer, in the Institute of Inorganic Chemistry, Georg-August-Universität Göttingen, Germany.

Göttingen 2014. 


\section{Table of Contents}

1 Introduction .........................................................................................................

2 Bimetallic catalysts for enhancing efficiency in olefin polymerization ............................. 1

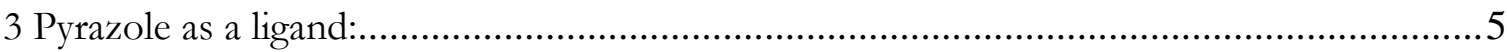

3. 1 Compartmentalized 3,5-bridging pyrazole scaffolds .............................................. 7

3.1. 1 Unsymmetric 3,5-substituted bridging environments ....................................

3.1. 2 Symmetric 3,5-substituted bridging environments..................................... 8

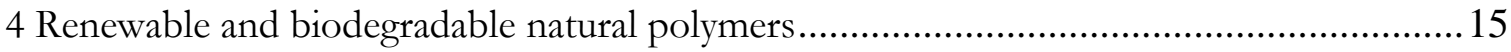

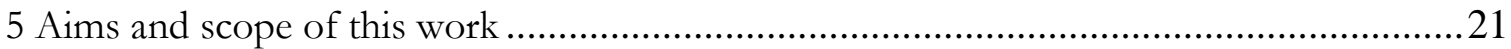

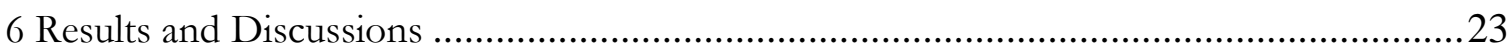

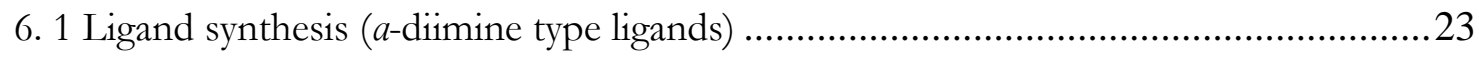

6. 2 Further insights into the formation of the unusual tetrapalladium complex ..............24

Olefin coupling reactions with tetrapalladium complex ............................................44

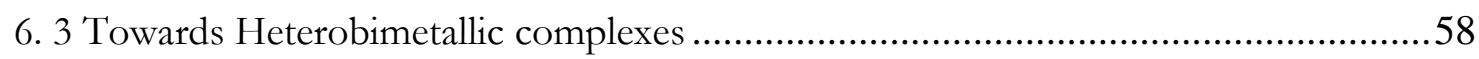

6.3. 1 Mononuclear palladium(II) complexes as templates to heterobimetallic complexes

6.3. 2 Mononuclear nickel(II) $\sigma$-aryl complexes as templates to heterobimetallic

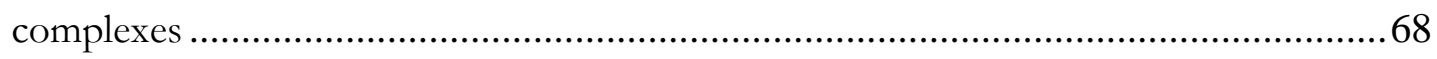

6.3. 3 Synthesis towards heterobimetallic palladium(II)-rhodium(I) complexes............77

6.3. 4 Homobimetallic palladium(II) $\eta^{3}$-allyl complex precursors ................................79

6.3. 5 Heterobimetallic palladium(II)-rhodium(I) complexes ..................................87

6. 4 Tetranuclear zinc(II) complexes of $a$-diimine type ligands as catalysts for polymerization of rac-D,L-lactide to poly D, L-lactide, a bio-renewable polymer.............104

6.4. 1 Synthesis and characterization of tetranuclear zinc(II) complexes .................... 104

6.4. 2 Polymerization of D,L-lactide to heteroatactic polylactide ..............................109

6. 5 Homobimetallic $\left[\mathrm{Rh}_{2}\left(\mathrm{O}_{2} \mathrm{CR}\right)_{4}\right]$ complexes of $a$-diimine type ligands ......................116

7 Trimethylsilyl cyclopentadienyl/indenyl/fluorenyl pyrazolyl tethered derivative ligands as precursors for the synthesis of group 4 metal complexes............................................... 119

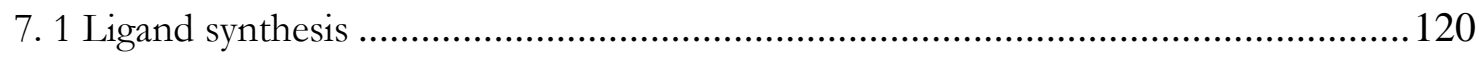

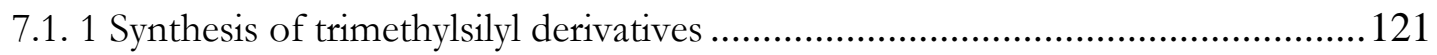

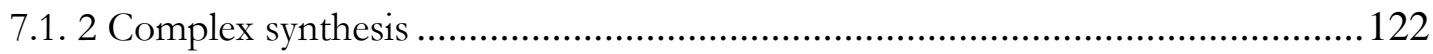

$8 \mathrm{NHC}$ and cyclopentadienyl/indenyl/fluorenyl pyrazolyl tethered derivative ligands ........126 


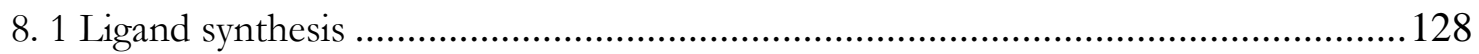

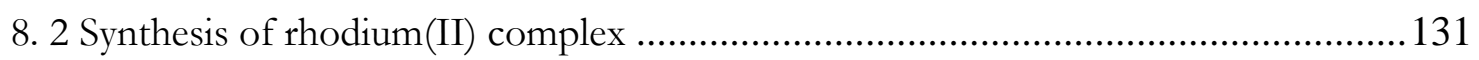

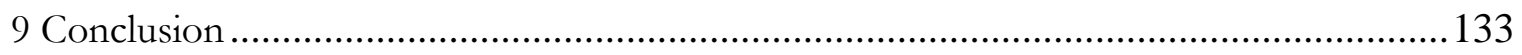

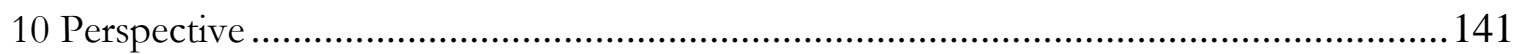

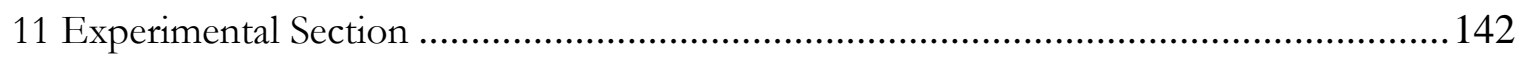

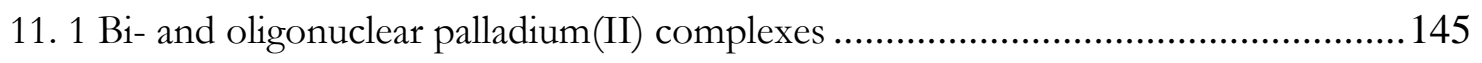

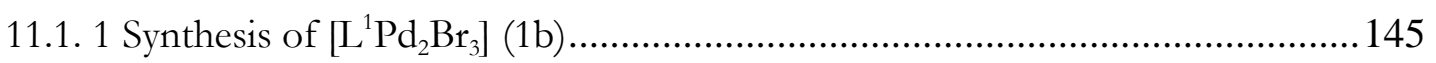

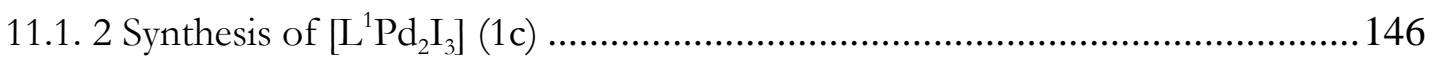

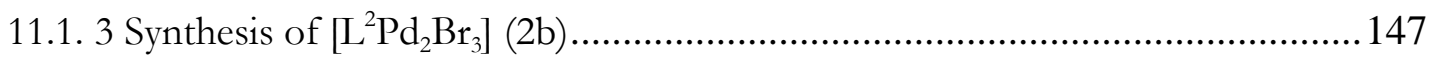

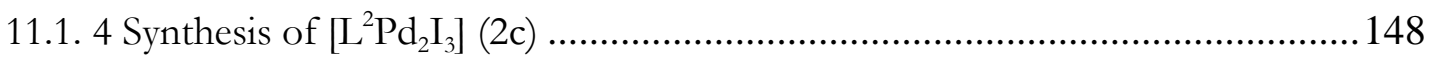

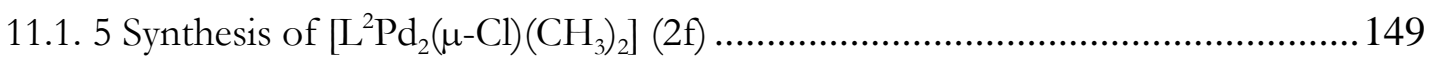

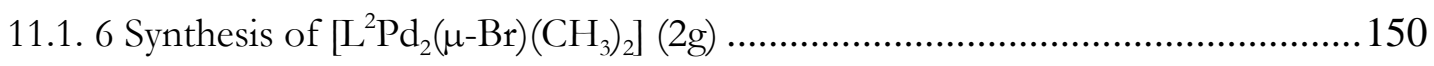

11.1. 7 Synthesis of $\left[\mathrm{L}_{2}^{2}\left\{\mathrm{CH}_{3} \mathrm{Pd}\right\}_{2}\left\{\mathrm{CH}_{3} \mathrm{PdCl}\right\}\left(\mathrm{Sn}\left(\mathrm{CH}_{3}\right)_{3} \mathrm{Cl}\right)\right](2 \mathrm{~h}) \ldots \ldots \ldots \ldots \ldots \ldots \ldots \ldots \ldots \ldots . . . . . . . . . . .151$

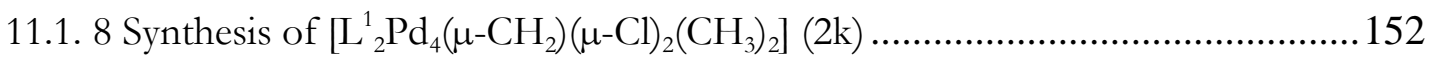

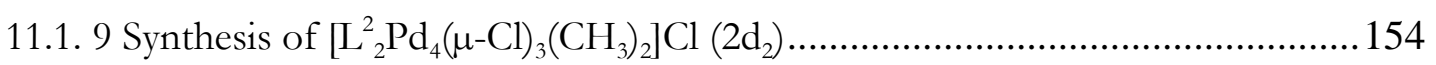

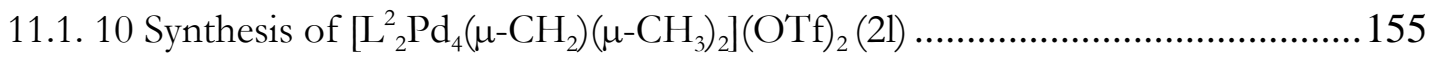

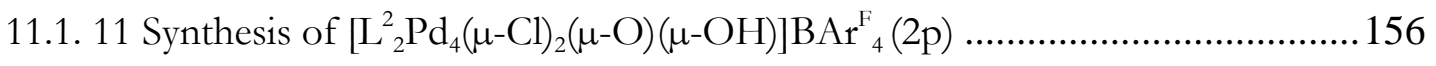

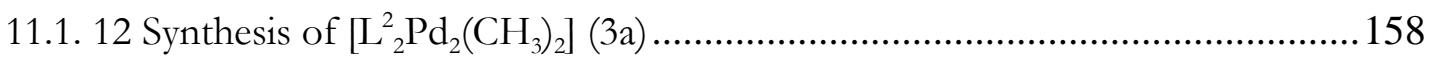

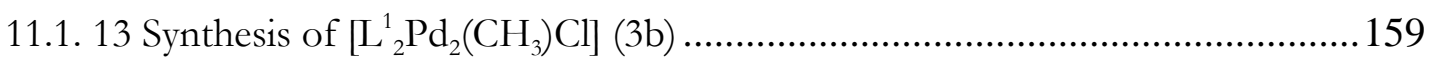

11. 2 Mononuclear palladium(II) complexes ................................................................. 160

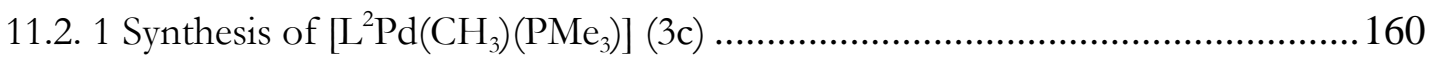

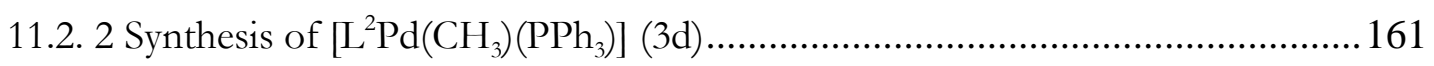

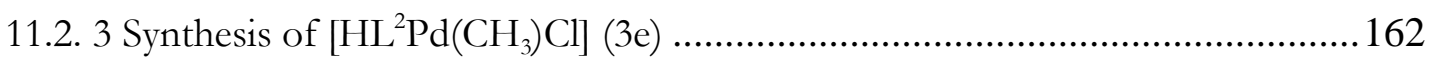

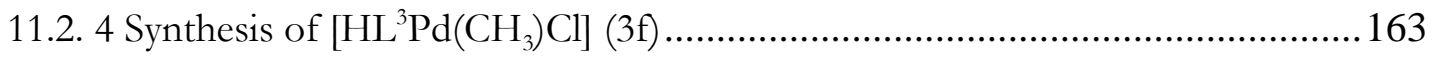

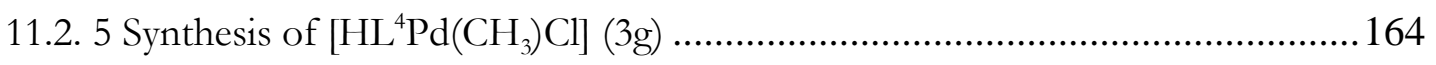

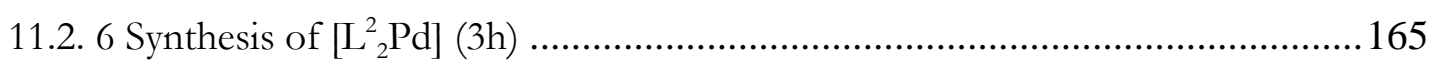

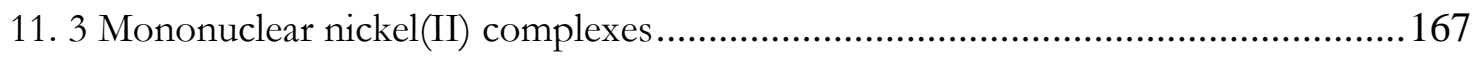

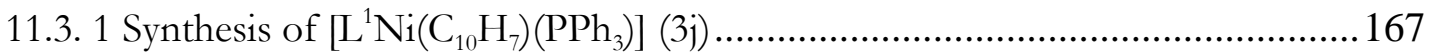

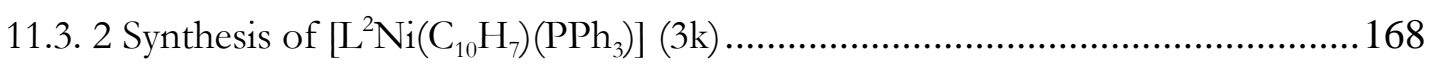

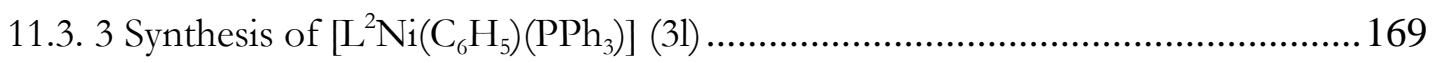

11. 4 Homobimetallic palladium(II) $\eta^{3}$-allyl complexes ................................................. 171

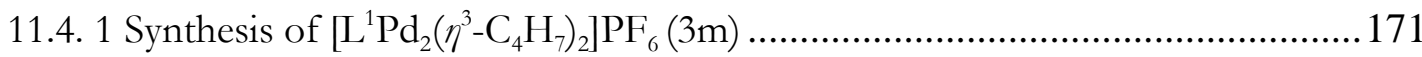




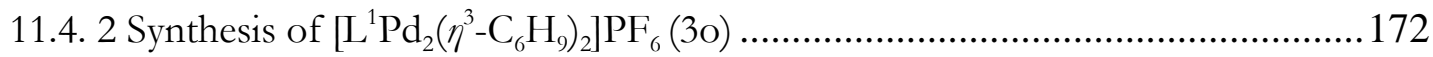

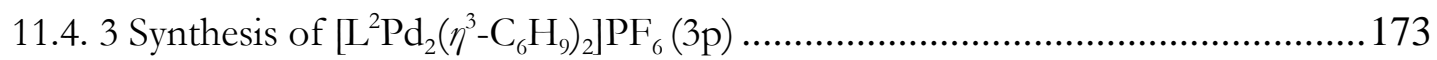

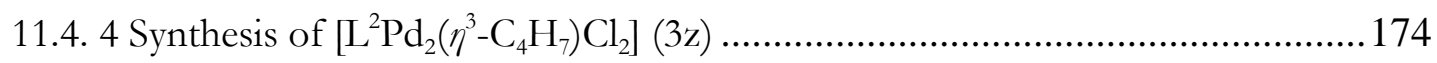

11. 5 Heterobimetallic palladium(II)-rhodium(I) complexes ......................................176

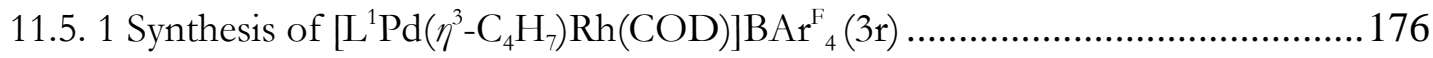

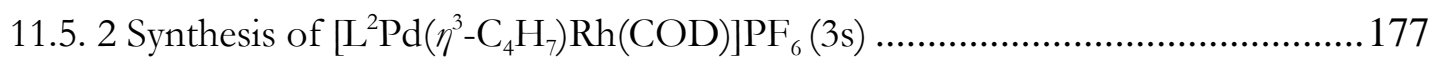

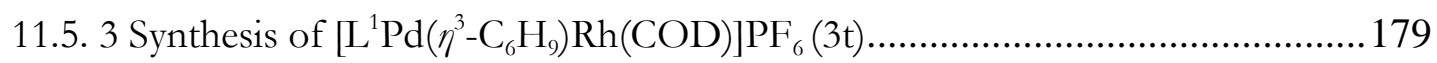

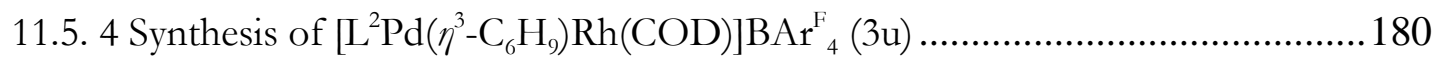

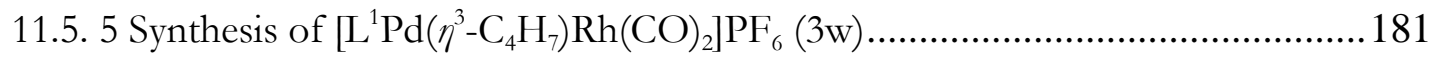

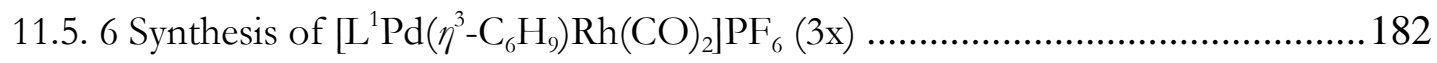

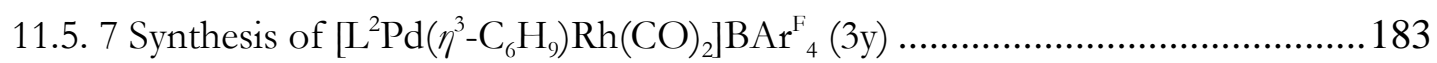

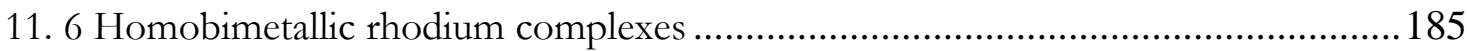

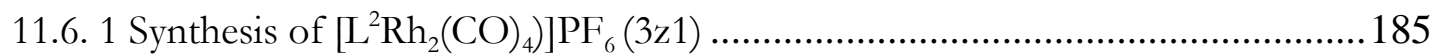

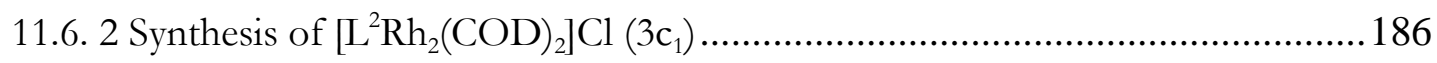

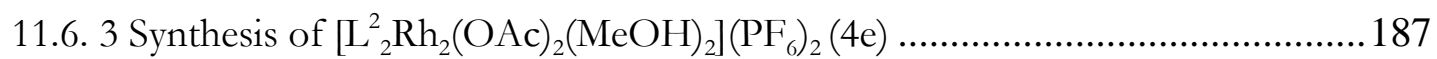

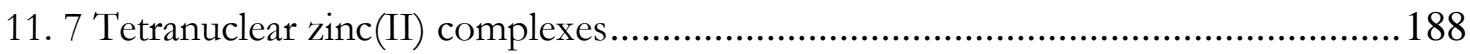

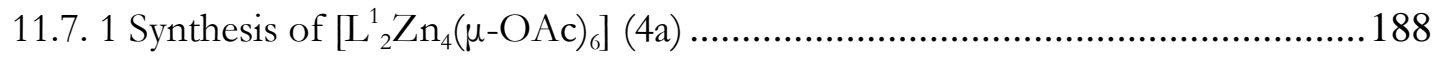

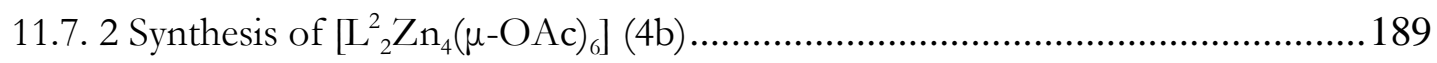

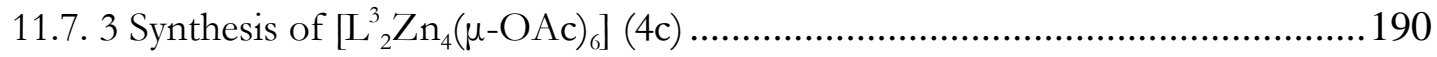

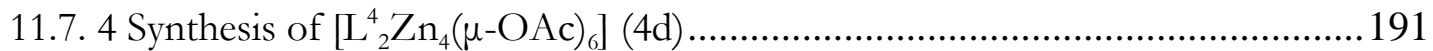

11. 8 Bis-cyclopentadienyl/indenyl/fluorenyl-tethered pyrazolyl ligands........................192

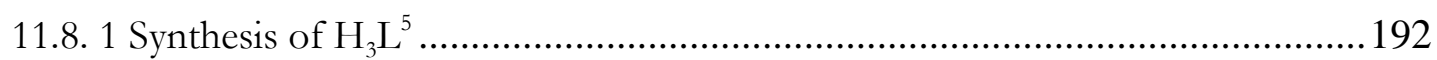

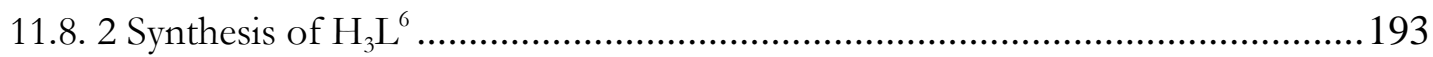

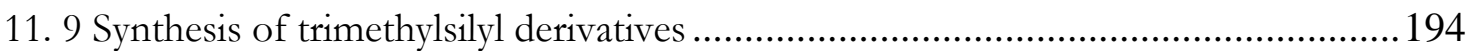

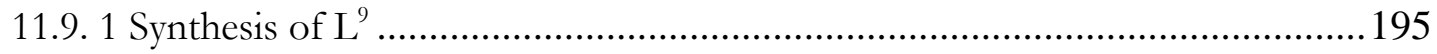

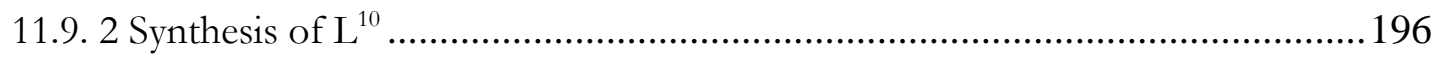

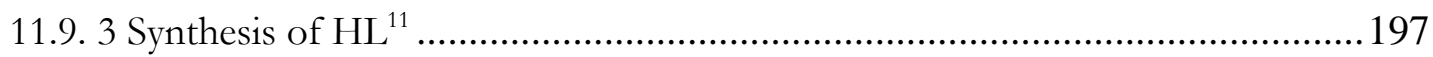

11. 10 Heteroleptic N-Heterocyclic carbene and fluorenyl/indenyl pyrazolyl tethered

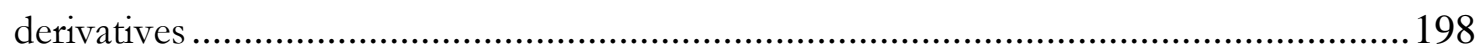

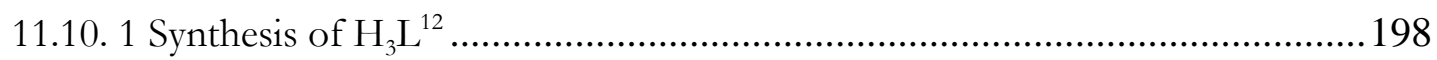

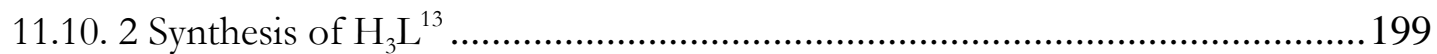

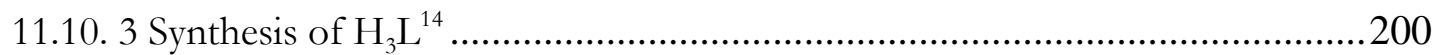

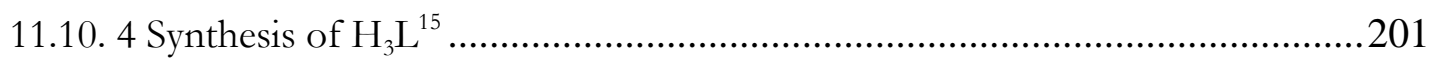




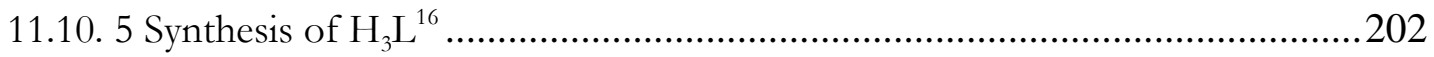

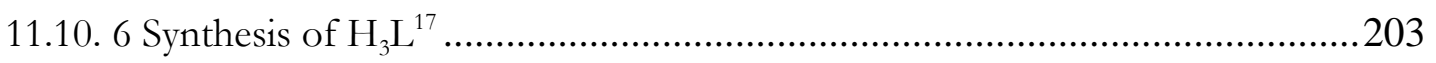

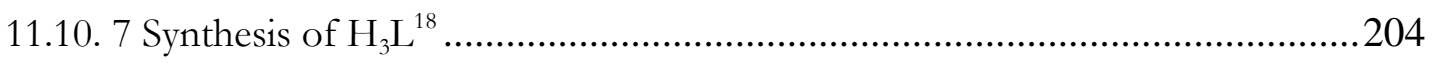

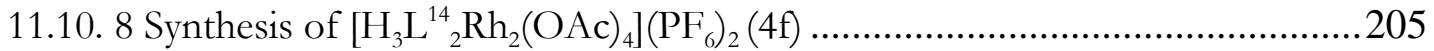

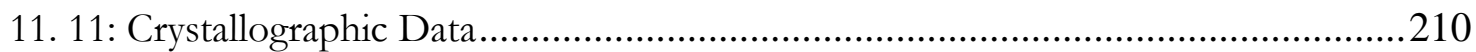

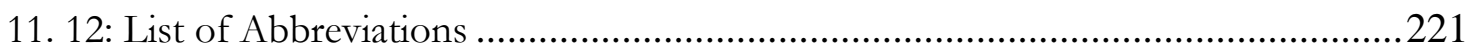

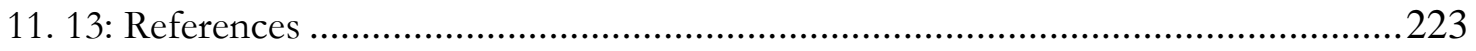





\section{Introduction}

A number of catalysts used in organometallic chemistry require two adjacent accessible coordination sites at a single catalytically active metal ion for activating two substrates $(\mathbf{X}$ and $\mathbf{Y})$ and bringing them in close spatial proximity (I). In addition, in instances where two sites between two adjacent metal ions have tunable metal-metal separation, some other possibilities exist. One possibility is the activation two substrates $\mathbf{X}$ and $\mathbf{Y}$ on each respective metal and bringing them in close proximity (II); or the possibility of a multisite covalent or non-covalent interactions with a single substrate (III). The prospect also exists from the use of two different metal ions in a heterobimetallic system where each metal adjusts to a specific substrate or plays a defined role in the catalytic cycle.

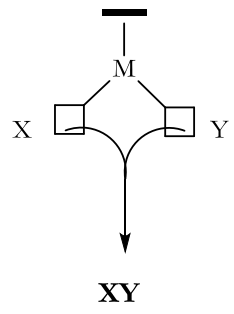

I

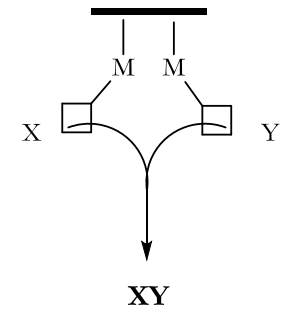

II

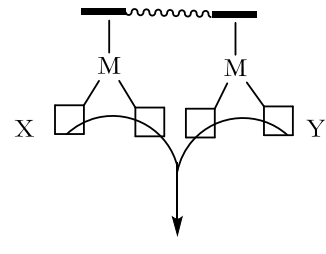

$\mathbf{X Y}$

III

In nature, enzymes make use of synergetic effect of two or more proximate metal ions to achieve very efficient one-pot tandem catalysis. ${ }^{1,2,3}$ Recent years have seen efforts in the development of catalysts that make use of cooperative interactions between metals with proximate centres. ${ }^{4}$ Examples of such cooperative effects have been explored in bi-functional catalysis, double substrate activation and cascade reactions. ${ }^{5,67}$ Bimetallic catalysts most especially, have been explored as a means of enhancing catalyst efficiency.

\section{Bimetallic catalysts for enhancing efficiency in olefin polymerization}

Bimetallic catalysts have been shown to sometimes lead to greater activity and selectivity usually not obtained with the respective mononuclear analogues. ${ }^{8,9,10,11}$ The range of catalytic reactions 
Introduction and literature

which explore metal cooperativity in bimetallic complexes are diverse, a few of which include, hydroformylation, ${ }^{12,13}$ olefin polymerization ${ }^{14,15}$ olefin-metathesis ${ }^{16,17,18,19}$ and other reactions. ${ }^{20,21,22}$

\section{Olefin polymerization}

Monometallic olefin polymerization catalysts can generally be classed into early or late transition metal catalysts precursors. The early transition metal catalysts precursors have general subclasses as metallocenes, ${ }^{23,24}$ and ansa-metallocenes $(\mathbf{I}),{ }^{25,26}$ constrained geometry catalysts $(\mathbf{I I})^{27}$ and phenoxyimine catalysts (III) ${ }^{28,29}$
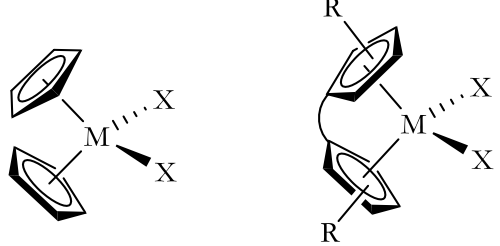

Metallocenes and ansa-metallocenes $\mathrm{M}=(\mathrm{Ti}), \mathrm{Zr}$

I<smiles>[Y]C1C2C=C[Si]1N2[R]</smiles>

Constraint Geometry $\mathrm{M}=\mathrm{Ti},(\mathrm{Zr})$

II
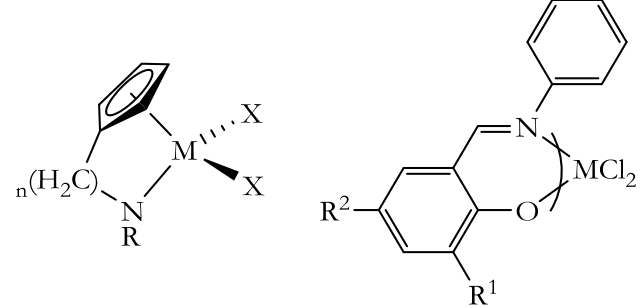

Phenoxyimines $\mathrm{M}=\mathrm{Ti},(\mathrm{Zr})$

III

The field of olefin polymerization has seen a lot of research geared towards the use of ligand scaffolds capable of hosting metal ions in close proximity, and exploring electronic coupling and cooperativity between the metal centres in bimetallic complexes.

The bimetallic catalyst precursors usually are extensions of the monometallic precursors bridged by alkyl or aryl functionalities..$^{30,31,32,33,34,35}$ One such prominent example of homobimetallic early transition metal polymerization precatalyst that make use of cooperative interactions between two proximate centers (A), is the binuclear constrained geometry catalyst (IV) reported by Marks and co-workers. ${ }^{30,36}$ 
Introduction and literature

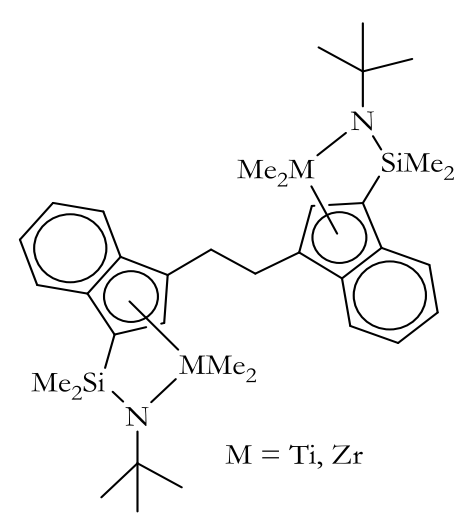

IV

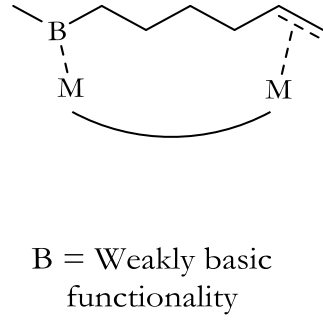

A

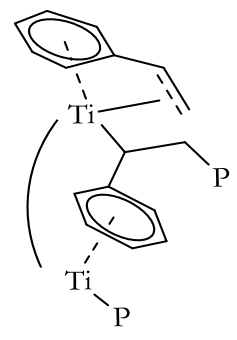

B

This binuclear catalyst shows cooperative $\mathrm{Ti} \cdots$ arene interactions which significantly enhances homopolymerization rates, modifies enchainment regioselectivity and also greatly increases comonomer enchainment selectivity (eg. B). ${ }^{36}$ Other reports of heterobimetallic metallocenes that make use of two distinct active sites working in concert have been reported Barnhart et.al. ${ }^{37}$ Green and co-workers have reported the use of a bridged metallocene ( $\mathbf{V})$, used in ethylene polymerization reactions. The complex gives an activity of $8.72 \times 10^{2} \mathrm{~kg} \mathrm{PE} /\left(\mathrm{mol}_{\mathrm{M}} \cdot \mathrm{h}\right)$, which is intermediate between that of the mononuclear complexes $\mathrm{Cp}_{2} \mathrm{ZrCl}_{2}\left(3.57 \times 10^{3} \mathrm{~kg} \mathrm{PE} /\left(\mathrm{mol}_{\mathrm{Zr}} \cdot \mathrm{h}\right)\right)$ and $\mathrm{CpTiCl}_{3}\left(2.52 \times 10^{2} \mathrm{~kg} \mathrm{PE} /\left(\mathrm{mol}_{\mathrm{Ti}} \cdot \mathrm{h}\right)\right)$. This activity is attributed to the ability of the two sites to act independently, thus giving the combined effect of an averaged activity.

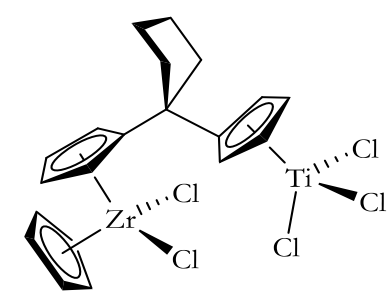

V

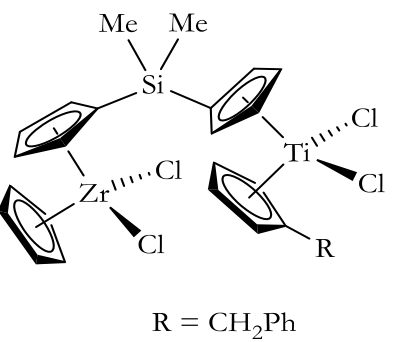

VI

The heterobimetallic complex (VI) is active in the polymerization of ethylene with activities up to $8.15 \times 10^{2} \mathrm{~kg} \mathrm{PE} /\left(\mathrm{mol}_{\mathrm{M}} \cdot \mathrm{h}\right) .{ }^{38}$ Molecular weight and molecular weight distributions of polymers generated from the bimetallic complex were much higher (with PDI $=2.0-3.0$ ) than those obtained from the mononuclear $\mathrm{Cp}_{2} \mathrm{ZrCl}_{2}$ complex $(\mathrm{PDI}=1.7)$ under similar conditions. This difference was attributed to interactions between the two different metal centers, but no mechanistic insight was reported. 


\section{Introduction and literature}

On the other part of the spectrum, late transition metal complexes for olefin oligomerization and polymerization have been the subject of various investigations, ${ }^{39,40,41,42,43,44,45}$ notably due to their less oxophilic nature and their ability to catalyze the copolymerization of olefins with polar comonomers. Late transition metal complexes are usually prepared from a combination of soft and hard donor groups with $\mathrm{N}^{\wedge} \mathrm{N} / \mathrm{N}^{\wedge} \mathrm{N}^{\wedge} \mathrm{N},{ }^{46,47} \mathrm{P}^{\wedge} \mathrm{N} / \mathrm{P}^{\wedge} \mathrm{P}^{48,49} \mathrm{P}^{\wedge} \mathrm{O},{ }^{50,51}$ and $\mathrm{O}^{\wedge} \mathrm{N}^{\wedge} \mathrm{N}$ or $\mathrm{O}^{\wedge} \mathrm{N}^{40}$ chelates in a neutral or anionic ligand environment. Late transition metal catalysts, which involve neutral or monoanionic ligands, can generally be classed into $a$-diimine (VII), ${ }^{52,53,54}$ bis(imino)pyridine (VIII), ${ }^{5,56,57}$ phenoxyimine ${ }^{58,59,60,61}$ (IX) catalysts and the more recent arylsulfonate type catalysts $(\mathbf{X}){ }^{62}$<smiles></smiles>

$\alpha$-diimine

$\mathrm{M}=\mathrm{Ni},(\mathrm{Pd})$

$\mathrm{X}=\mathrm{Cl}$

VII

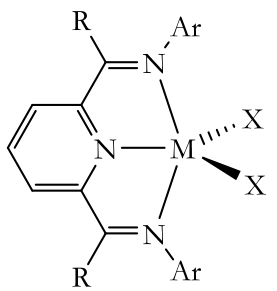

Bis(imino)pyridine

$\mathrm{M}=\mathrm{Fe},(\mathrm{Co})$

$\mathrm{X}=\mathrm{Cl}$

VIII

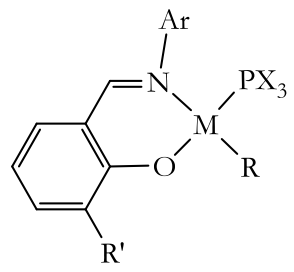

Phenoxyimine

$\mathrm{M}=\mathrm{Ni}$

$\mathrm{R}=\mathrm{Me}, \mathrm{Ph}$

$\mathrm{X}=\mathrm{Me}, \mathrm{Ph}$

IX

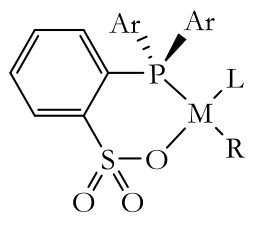

Arylsulfonate

$\mathrm{M}=\mathrm{Ni},(\mathrm{Pd})$

$\mathrm{R}=\mathrm{Ph}, \mathrm{Me}$

$\mathrm{L}=\mathrm{PPh}_{3}, \mathrm{DMSO}$

A number of bimetallic systems, which mimic these pre-existing mononuclear complexes, have since been reported. ${ }^{63,64,65,66,67,68,69,70,71,72}$ An example of a bimetallic system with an $\mathrm{N}^{\wedge} \mathrm{N}$ donor is complex (XI) developed by Luo et. al. ${ }^{73}$

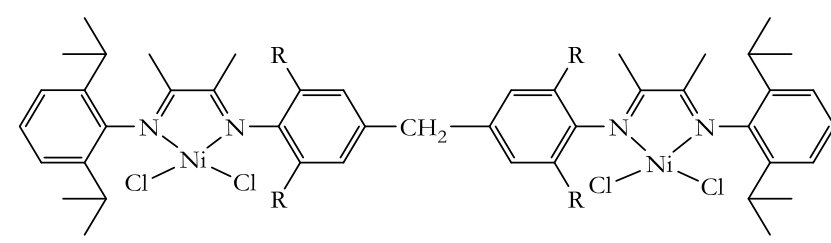

$\mathrm{R}=\mathrm{Me}, \mathrm{Et},{ }^{\mathrm{i}} \mathrm{Pr}$

$\mathbf{X I}$

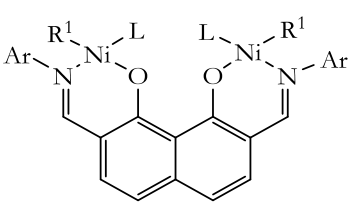

$\mathrm{R}^{1}=\mathrm{CH}_{3}, \mathrm{C}_{10} \mathrm{H}_{7}, \mathrm{R}=\mathrm{CH}_{3}, \mathrm{C}_{6} \mathrm{H}_{5}$

$\mathrm{L}=\mathrm{PMe}_{3}, \mathrm{PPh}_{3}$

$\operatorname{Ar}=2,6-\left({ }^{i} \mathrm{Pr}\right)_{2}-\mathrm{C}_{6} \mathrm{H}_{3}$

XII

In this complex, the binuclear catalyst exhibits relatively higher activities $\left(\mathrm{R}=\mathrm{CH}\left(\mathrm{CH}_{3}\right)_{2} ; 1.84\right.$ $\mathrm{kg} /(\mathrm{g} \mathrm{Ni} \mathrm{h}), \mathrm{R}=\mathrm{CH}_{2} \mathrm{CH}_{3} ; 1.66 \mathrm{~kg} /(\mathrm{g} \mathrm{Ni} \mathrm{h})$ in the polymerization of ethylene, a marked departure from that of the mononuclear complexes which gives activities of $\left(\mathrm{R}=\mathrm{CH}\left(\mathrm{CH}_{3}\right)_{2}\right.$; 
$\left.0.70 \mathrm{~kg} /(\mathrm{g} \mathrm{Ni} \mathrm{h}), \mathrm{R}=\mathrm{CH}_{2} \mathrm{CH}_{3}\right) 1.42 \mathrm{~kg} /(\mathrm{g} \mathrm{Ni} \mathrm{h})$. They attribute structural differences between the various complexes as being responsible for significant increase in activity of the bi- and multinuclear catalysts.

Also, the binuclear naphthylimine nickel(II) catalysts (XII), which has a rigid ligation is shown to have twice the activity for homo polymerization of ethylene and also introduces more alkyl branches than the corresponding mononuclear analogues. ${ }^{74}$ Ethylene copolymerization with unresponsive acrylates with this catalyst gives up to $11 \%$ comonomer incorporation. Although there is decreased activity in the presence of additives, the catalyst remains three times more active than the mononuclear analogues.

What is clear in all these approaches is that having ligands capable of hosting two different metals in a binucleating scaffold at an appropriate distance is vital for cooperative metal interactions. Most especially when the ligands have two adjacent donor atoms capable of acting as a bridging functionality as found in nitrogen heterocycles such as 1,2,4-triazoles, ${ }^{75,76}$ pyridazines, ${ }^{77,78} 1,2,4,5$-tetrazines ${ }^{79}$ and pyrazoles. ${ }^{80}$ It has been proposed that the optimum separation between two metal centres; for one-step catalysis or the close binding of two reactants to the adjoining metal centres should be between 3.5-6.0 $\AA$ even when there is no direct interaction between the metal centres. ${ }^{81}$ Pyrazoles, remain one of such versatile ligands, found to hold metals units at an appropriate distance $(2.4-4.6 \AA)^{82,83}$ to direct metal-metal interactions; but close enough for cooperativity and allowing for some degree of electronic coupling through the ligand system.

\section{Pyrazole as a ligand:}

The chemistry of ligands bearing the pyrazole motif has been extensively studied in literature in the past decades and has been the subject of several reviews. ${ }^{84,85,86,87,88,89}$ The pyrazole ring due it its ease of synthesis, can be prepared with various substituent on different positions on the pyrazole ring. Pyrazole derivatives have the ability to span adjacent metals at a favourable distance. $^{90,91}$ This has made the pyrazole motif one of the most versatile heterocycles, with the ability to incorporate various groups such as amino alkyls, ${ }^{92,93,94,95}$ aromatics, ${ }^{96,97,98}$ borates $^{99,100,101}$ and polydentate groups..$^{102,103,104}$ The $1 H$ pyrazole is usually the starting point of most pyrazole based ligands. 


\section{Coordination modes of $1 \mathrm{H}$ pyrazole ligands}

Upon deprotonation of the $1 H$ pyrazole ligand, the pyrazolate anion is known to coordinate to metals in diverse coordination modes through the two nitrogens or its $\pi$-system ${ }^{105,106,107,108,109}$ to elements in the s-block, ${ }^{110,111}$ p-block, ${ }^{112,113}$ d-block ${ }^{114,115,116,117,118}$ as well as lanthanides. ${ }^{113,119}$ Some of the diverse coordination modes adopted by the pyrazole motif are shown in Scheme 3. 1.<smiles></smiles><smiles>[Y][Y]1([AlH2])C=CCN1</smiles>

$\kappa^{1}$

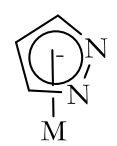

$\eta^{5}$

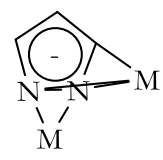

$\kappa^{2}: \eta^{3}-\mu$

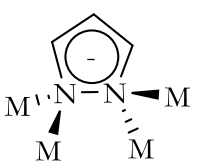

$\kappa^{1}: \kappa^{1}: \kappa^{1}-\mu_{4}$

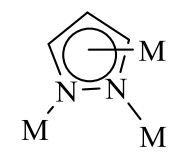

$\kappa^{1}: \kappa^{1}: \eta^{5}-\mu_{3}$

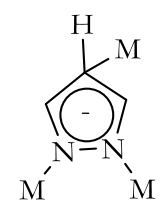

$\kappa^{1}: \kappa^{1}: \eta^{1}-\mu_{3}$

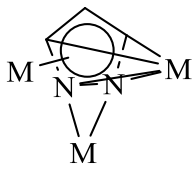

$\kappa^{2}: \eta^{4}: \eta^{5}-\mu_{3}$<smiles>[Y]n1cccn1</smiles>

$\kappa^{1}$<smiles>[Y]n1cc([AlH2])cn1</smiles>

$\kappa^{1}: \kappa^{1}-\mathrm{C} \mu$

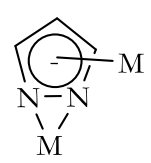

$\kappa^{2}: \eta^{5}-\mu$
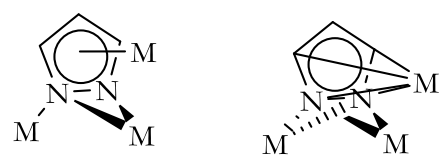

$\kappa^{1}: \kappa^{2}: \eta^{5}-\mu_{3}$<smiles>[Y]c1cn[nH]c1</smiles>

$\kappa^{1} \mathrm{C}$

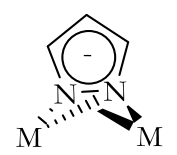<smiles>[AlH2]c1ccnnn1</smiles>

$\kappa^{2}: \eta^{1}-\mu$
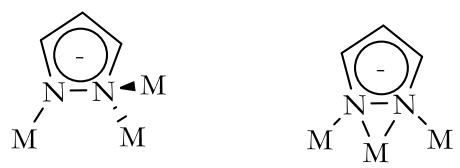

$\kappa^{1}: \kappa^{1}: \kappa^{1}-\mu_{3}$

$\kappa^{1}: \kappa^{1}: \kappa^{2}-\mu_{3}$ 


\section{1 Compartmentalized 3,5-bridging pyrazole scaffolds}

The use of 3,5-disubstituted pyrazolate ligands has been one of the widely explored strategies for controlling coordination behaviour. ${ }^{121,122,123,124}$ By introducing substituents with additional donor groups, stability is enhanced due to the chelating effect of the multidentate binding sites. One of the widely explored synthetic routes to pyrazoles is mostly through the condensation of hydrazines with 1,3-diketones or using an acyl precursor. ${ }^{125,126,127}$ (Scheme 3.1. 1)
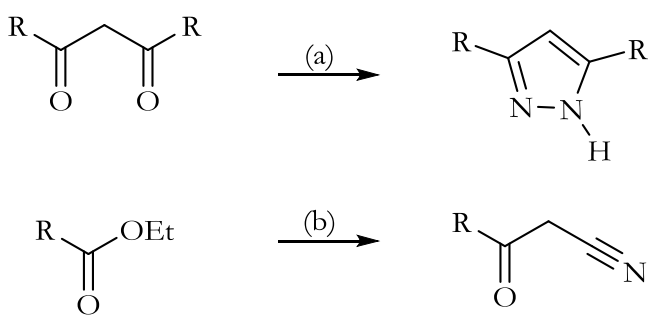<smiles>[R]c1cc(N)n([TlH])n1</smiles><smiles>[R]C(C)=O</smiles><smiles>[R]C(=O)C=C([R])C=C([R])N(C)CC</smiles><smiles>[R]c1cc([R])[nH]n1</smiles>

Scheme 3.1. 1: Conditions: (a) $\mathrm{N}_{2} \mathrm{H}_{4} \cdot \mathrm{H}_{2} \mathbf{0}$, reflux, ethanol (b) R'CHO, THF, reflux (c) $\mathrm{N}_{2} \mathrm{H}_{4} \cdot \mathrm{H}_{2} \mathrm{O}$, ethanol, reflux (d) $\mathrm{R}^{\prime} \mathrm{CO}_{2} \mathrm{Me}, \mathrm{NaOMe}$, toluene, reflux (e) $\mathrm{R}^{\prime} \mathrm{C}(\mathrm{OMe})_{2} \mathrm{NMe}_{2}$, reflux (g) $\mathrm{N}_{2} \mathrm{H}_{4} \cdot \mathrm{H}_{2} \mathrm{O}$, reflux, ethanol

The 3,5-disubstituted pyrazole bridges can take the form of a symmetrical environment, where both substituents on the 3,5-positions are identical, or an unsymmetrical environment where the ligand substituents in the 3,5-positions have different donor functionalities.

\subsection{Unsymmetric 3,5-substituted bridging environments}

Pyrazolate based ligands with 3,5-substituted side arms on the heterocycle have been established as one of the valuable synthons for the preparation of highly compartmentalized bi- and oligonuclear metal complexes. ${ }^{124}$ More especially when the aim is to have a heteroleptic ligand environment that is capable of discriminating between two different metal ions. 


\section{Introduction and literature}

Although the use of unsymmetrical ligands usually poses a problem with the formation of positional isomers, it is not in case in XIII. The unsymmetric ligand XIII which features a soft $\mathrm{P}^{\wedge} \mathrm{N}$ site and an adjacent $\mathrm{N}_{2} \mathrm{~S}_{2}$ donor site was reported by Konrad et. al. ${ }^{128}$ This ligand in the heterobimetallic NiPd complex houses the palladium(II) centre in the $\mathrm{P}^{\wedge} \mathrm{N}$ compartment. The unsymmetric complex (XIV) which features a soft $\mathrm{P}^{\wedge} \mathrm{N}$ site and an adjacent $\mathrm{N}^{\wedge} \mathrm{N}$ donor site reported by Akita and co-workers ${ }^{129}$ on the other hand has the ability to undergo switched metal arrangements.

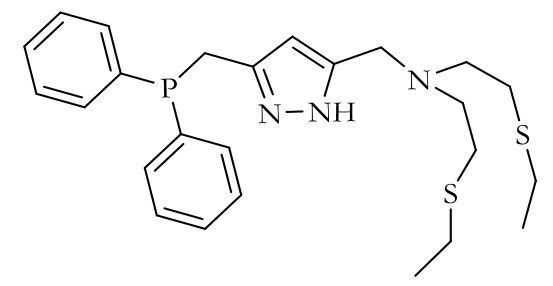

XIII

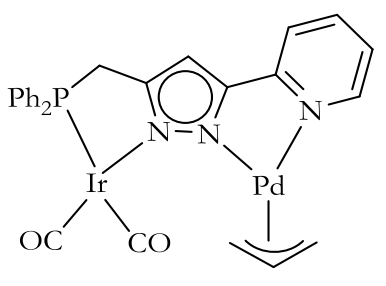

XIV

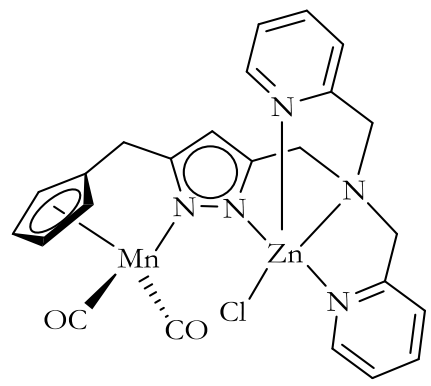

XV

In addition, a highly preorganized bimetallic complex (XV) combines an organometallic fragment and Werner type coordination environment in a heterobimetallic MnZn system and shows interesting redox properties as has been reported by Röder et. al. ${ }^{130}$ The pyrazole moiety due to its versatile nature can also feature symmetric bridging ligand environments.

\subsection{Symmetric 3,5-substituted bridging environments}

The use of such a symmetrical ligand system does not pose much of a challenge concerning the formation of positional isomers, but can pose a major challenge in the preparation of heterobimetallic complexes. A number of symmetrical bridging pyrazolate ligand environments, which have the potential to provide two cis vacant coordination sites for effective cooperation of activation of substrates have been investigated. Various groups such as alkyl amino groups ${ }^{131,132,133,134}$ phosphane, ${ }^{135,136,137}$ NHC carbenes, ${ }^{138,139,140}$ cyclopentadienyl groups, ${ }^{141}$ phenoxyimines, ${ }^{142}$ etc. can append to the 3,5-positions. 
<smiles>c1ccc(P(Cc2cc(CP(c3ccccc3)c3ccccc3)[nH]n2)c2ccccc2)cc1</smiles>

XVI

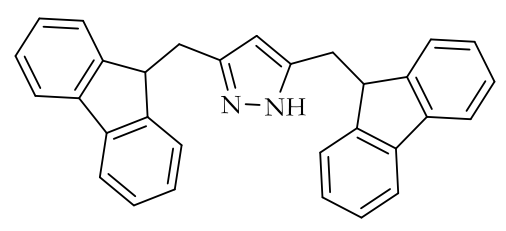

XVII

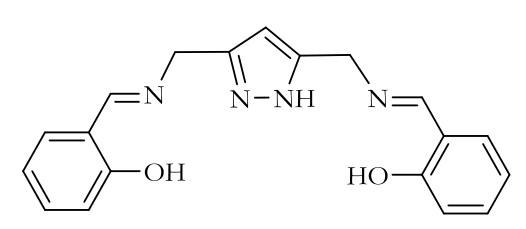

XVIII

For instance, bimetallic palladium(II) and rhodium(I) complexes of the binucleating PNNHP ligand (XVI) were prepared using metal transfer or by direct reactions. An early example is the dirhodium carbonyl adduct $\left[\left(\mu-x^{2}: x^{2}-\mathrm{PNNP}^{\mathrm{Py}}\right)\left\{\mathrm{Rh}(\mathrm{CO})_{2}\right\}\right] \mathrm{BF}_{4}$ reported by Bosnich et. al. ${ }^{143}$ The ligand forms rigid complexes with the metals within cooperative distance but also preventing metal-metal bond formation. Akita and co-workers ${ }^{144}$ have also reported heterobimetallic complexes of the PNNP ligands $\left(\left[(C O D) \operatorname{Ir}^{\mathrm{I}}(\mathrm{PNNP}) \operatorname{Rh}^{\mathrm{I}}(\mathrm{COD})\right]\left(\mathrm{BF}_{4}\right)\right)$. Carbon monoxide easily substitutes the COD ligands and the resulting catalysts precursors used in alkyne hydrogenation and alkene hydroformylation reactions.

Cyclopentadienyl substituted pyrazolyl ligands (XVII) have been prepared and its binuclear manganese(I) complex isolated and structurally characterized. ${ }^{141}$ Likewise, their indenyl and fluorenyl lithium salt analogues have been isolated and characterized by Röder et. al. ${ }^{145}$ Tetranuclear Mn complexes of the ligand (XVIII) reported by Okawa and co-workers ${ }^{142}$ feature two phenoxyimine units on the 3,5-positions of the pyrazole. Important variations in the nature of the side arm (XIX, XX and $\mathbf{X X I}$ ) allow for fine-tuning of the metal-metal distance in binuclear complexes.

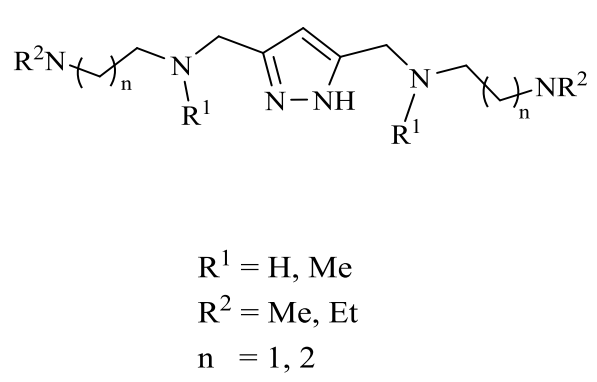

XIX

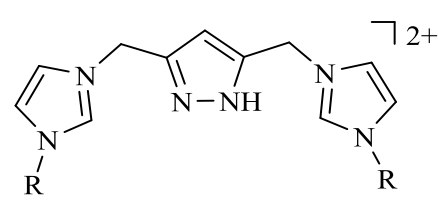

$\mathrm{R}=$ alkyl, aryl

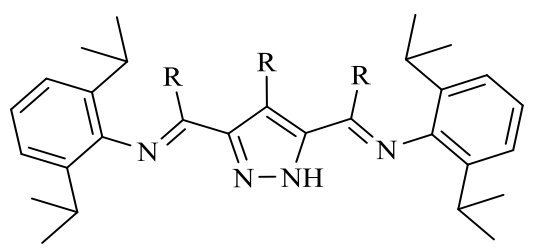

$\mathrm{R}=\mathrm{H}, \mathrm{Me}, \mathrm{Ph}$

XX

XXI

For example, complexes bearing alkyl amino appendages (XXII) and (XXIII) model the urea amino hydrolase (E.C.3.5.1.5), which contains two proximate nickel(II) ions within the active site. 


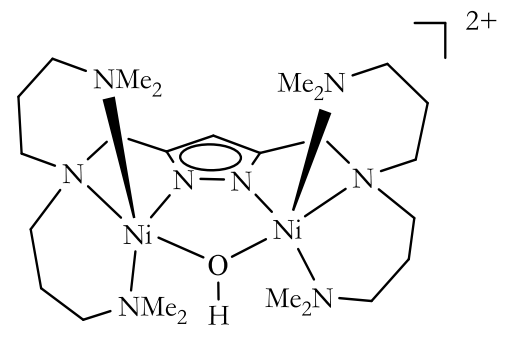

XXII

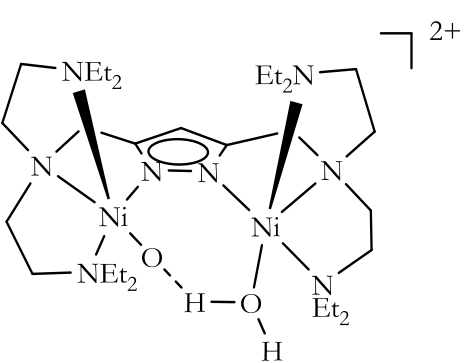

XXIII

Complex XXII, with its longer side arms forms six-membered chelate rings with $\mathrm{Ni} \cdots \mathrm{Ni}$ separation of approximately $3.5 \AA$, while XXIII with its shorter arms give five membered chelate rings with $\mathrm{Ni} \cdots \mathrm{Ni}$ separation $>4.0 \AA \AA^{146}$ Analogous copper(II) complexes with bridging hydroxide and acetate groups with metal-metal separation of 3.54 and $4.09 \AA$ respectively have been reported. ${ }^{147}$ The use of N-heterocyclic carbene (NHC) substituted pyrazole derivatives have also been reported. ${ }^{148,149}$ Meyer et. al. ${ }^{150}$ have reported on tetrasilver(I) complexes of pyrazolatebridged compartmental NHC ligands (XXIV-XXV). These ligands provide two binding pockets and gives rise to unique multinuclear $\mathrm{Ag}(\mathrm{I})-\mathrm{NHC}$ complexes.

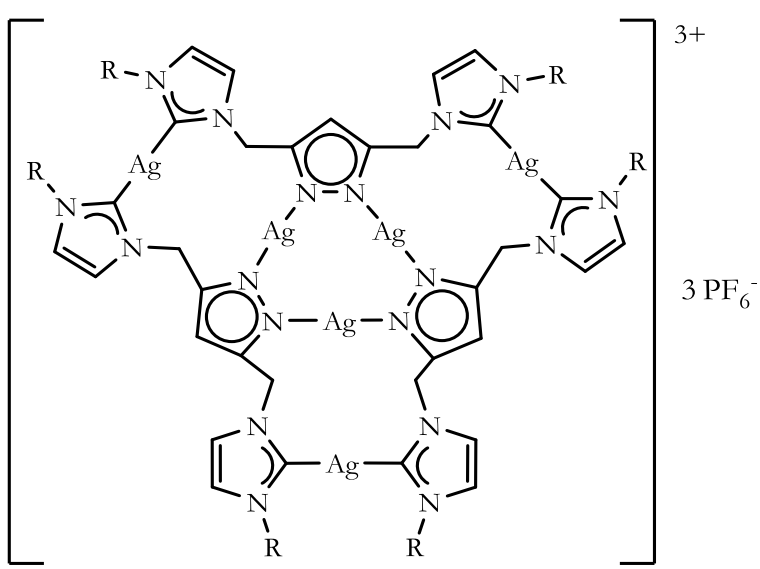

XXIV

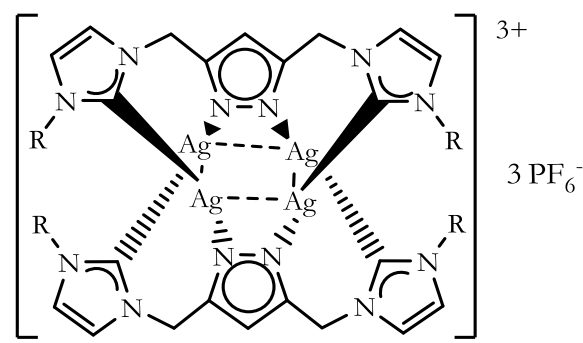

XXV

The pyrazole NHC ligands are able to form different interactions ranging from ionic to covalent interactions, and in the past few years research has shown the ability of NHC ligands to react and stabilize elements across the periodic table. Similar pyrazole bridged dinuclear complexes of ruthenium(II) and rhodium(III) with NHC have been reported by Reindl et. al., ${ }^{138}$ the metalmetal distances reported are in the range of 3.85-3.92 $\AA$ and no electronic coupling between the metal centres was observed. 
A series of pyrazole-based ligands that possess appended imine donor sidearm and two adjacent binding compartments (XXI) akin to the a-diimine type have been explored by Meyer ${ }^{151}$ and other investigators. ${ }^{152}$

Bi- and oligonuclear nickel(II) and palladium(II) complexes (Scheme 3.1.2. 1) after activation with MAO are active catalysts in olefin polymerization, with the nickel(II) complexes generally more active than the palladium(II) complexes. These catalysts also produce high molecular weight polyethylene with $\mathrm{M}_{\mathrm{n}}$ values to the tune of $3.5 \times 10^{5}$ and polydispersity around 2.5. In addition, the nickel(II) complex $\left(\mathbf{X X I}^{\mathrm{a}}\right)$ after activation with $\mathrm{MAO}$ serves as highly active catalysts for the polymerization of norbornene. ${ }^{153}$

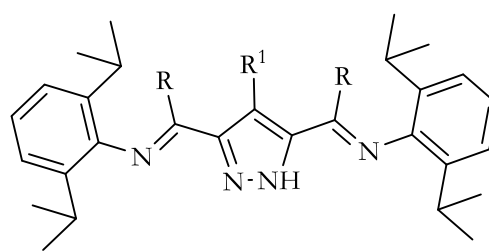

XXI
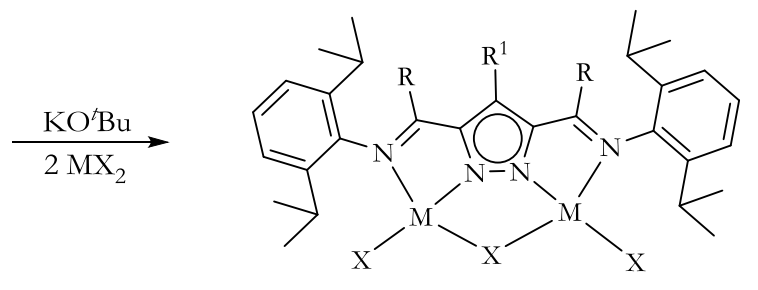

$$
\begin{aligned}
& \mathrm{M}=\mathrm{Ni}\left(\mathbf{X X I}^{\mathbf{a}}\right), \mathrm{Pd}\left(\mathbf{X X I}^{\mathbf{b}}\right) \\
& \mathrm{X}=\mathrm{Cl}, \mathrm{R}=\mathrm{H}, \mathrm{Me}, \mathrm{R}^{1}=\mathrm{H}, \mathrm{Me}, \mathrm{Ph}
\end{aligned}
$$

Scheme 3.1.2. 1: Bimetallic variants of $\alpha$-diimine type catalysts used in olefin polymerization reactions

When treated with $\mathrm{SnMe}_{4}, \mathbf{X X I}^{\mathrm{b}}$; $\left(\mathrm{R}=\mathrm{R}^{1}=\mathrm{Me}\right)$ forms an unusual tetrametallic complex $\left(\mathbf{X X I}^{\mathrm{c}}\right)$ which features terminal $\mathrm{CH}_{3}$ and bridging $\mu-\mathrm{CH}_{2}$ groups, the first of its kind. ${ }^{154}$

The authors proposed a stepwise mechanism leading to the formation of $\left(\mathbf{X X I}^{\circ}\right)$ based on data obtained from NMR time scale experiments. In the proposed scheme, treating $\mathbf{X X I}^{\mathbf{b}}$ with approximately $30 \mathrm{~mol}$ equivalent $\mathrm{SnMe}_{4}$, the authors were able to detect the formation of two intermediates, a $C_{\mathrm{s}}(\mathbf{1})$ and a $C_{2 \mathrm{v}}$ intermediate (2) leading to the formation of $\mathbf{X X I}^{\mathbf{c}}$ (Scheme 3.1.2. 2). They also reported that the build up and decay of the different intermediates reach their maxima after 6 and $10 \mathrm{~h}$ respectively. ${ }^{154}$ 
Introduction and literature

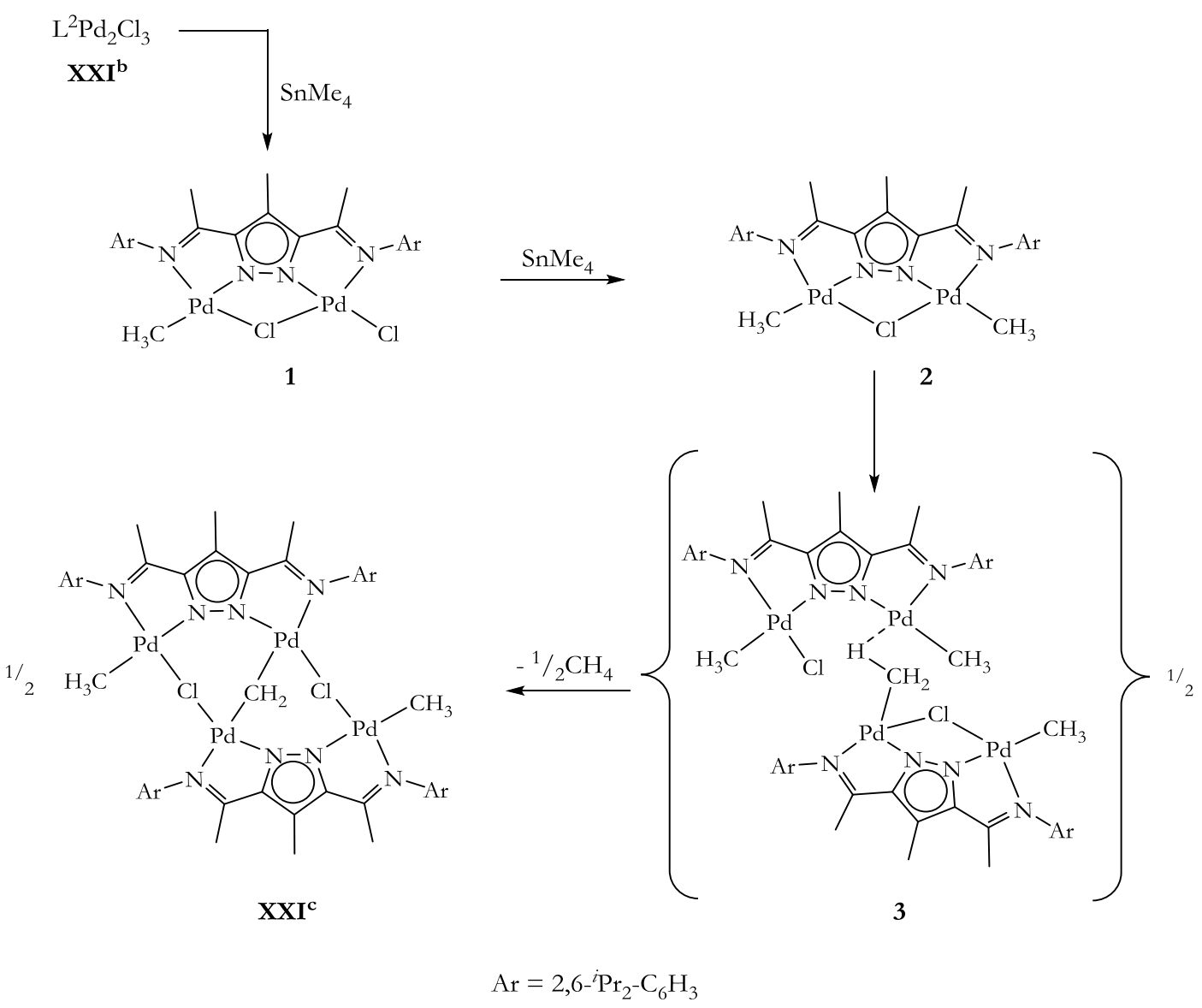

Scheme 3.1.2. 2: Proposed scheme leading to the formation of XXI'154

Although the formation of a $C_{\mathrm{s}}$ and $C_{2 \mathrm{v}}$ symmetric products leading to the formation of the tetrapalladium core were proposed based on ${ }^{1} \mathrm{H}$ NMR spectroscopic data, not much attempts were made at trapping and isolating these intermediates. Due to the transient nature of these intermediates, they react further to give other reaction products. In addition, the authors did note the formation of a second but unidentified product, which is formed with excess $\mathrm{SnMe}_{4}{ }^{154}$

This unique tetrapalladium complex $\mathbf{X X I}^{\mathbf{c}}$ also shows intriguing reactivity with simple olefins like ethylene to form mostly $\mathrm{C}_{3}$ and $\mathrm{C}_{4}$ products. In order to determine the origin of $\mathrm{C}$ atoms in the $\mathrm{C}_{3}$ and $\mathrm{C}_{4}$ products, ${ }^{13} \mathrm{C}$ ethylene $\left({ }^{13} \mathrm{C}_{2} \mathrm{H}_{4}\right)$ coupling reactions were performed (Scheme 3.1.2. 3). The results showed that all the $\mathrm{C}_{4}$ products were labeled in contrast to the propene, the major product that contained only two ${ }^{13} \mathrm{C}$ labels. The authors proposed that this was most likely assembled from a molecule of ethylene and an unlabeled $\mathrm{C}$ atom originating from $\mathbf{X X I}^{\mathbf{c}}$ (either $\mathrm{CH}_{3}$ or $\left.\mu-\mathrm{CH}_{2}\right) \cdot{ }^{154}$ 


$$
{ }^{13} \mathrm{C}_{2} \mathrm{H}_{4} \stackrel{\mathbf{X x I}^{\mathrm{c}}}{\longrightarrow} \begin{gathered}
\mathrm{CH}_{4} \\
\text { (traces) }
\end{gathered} \underbrace{\mathrm{CH}^{13} \mathrm{C}_{2} \mathrm{H}_{6}}+\overbrace{13}^{13}+\overbrace{13}^{13}+\overbrace{13}^{13}+\overbrace{13}^{13}+\overbrace{13}^{13}
$$

Scheme 3.1.2. 3: Olefins resulting from the reaction of XXIc with ${ }^{13} \mathrm{C}_{2} \mathrm{H}_{4} .{ }^{154}$

The treatment of the a-diimine type ligand (XXI) with a base in the presence of a metal salts does not always lead to the formation of compounds of the type $\mathbf{X X I}^{\mathrm{a}}$ and $\mathbf{X X I}^{\mathrm{b}}$. With nickel(II) salts, oligonuclear aggregates of $\left[\mathrm{Ni}_{2}{ }_{2}(\mathbf{X X I}) \mathrm{X}_{3}\right]_{\mathrm{x}}(\mathrm{X}=\mathrm{Cl}, \mathrm{Br})$ are formed in this complex, here the metal ions are six-coordinate and in a high spin state. ${ }^{151}$ The formation of dimers such as $\left[\mathrm{L}_{2} \mathrm{M}_{2}\right]^{2+}$ have been observed in some cases and reported. ${ }^{155,156}$ Sachse et. al. ${ }^{157}$ have reported instances where the $a$-diimine type ligands yields $\mathrm{Cu}_{6}$ complexes which feature an unusual $\left\{\mathrm{Cu}_{6}\left(\mu_{4}-\mathrm{O}\right)_{2}\right\}$ bitetrahedral core. Also, the structural and magnetic variability of cobalt(II) complexes of the $a$ diimine type complexes have been reported. ${ }^{158}$

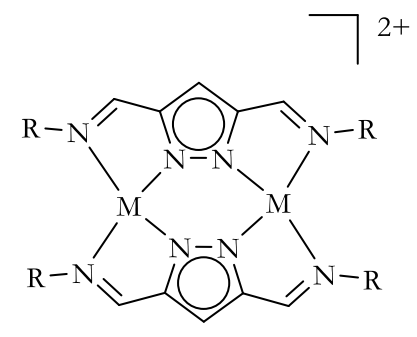

XXVI

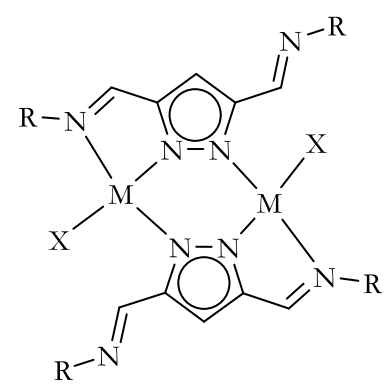

XXVII

\section{$\mathbf{L}_{2} \mathbf{M}_{2}$}

In addition, mononuclear anionic complexes of the $a$-diimine type ligands $\mathrm{K}^{+}\left[\mathrm{LPt}(\mathrm{Ph})_{2}\right]^{-}\left(\mathbf{X X I}^{\mathrm{d}}\right)$ have been reported by Chen and co-workers. ${ }^{152}$ The mononuclear complex $\mathrm{K}^{+}\left[\mathrm{Lt}(\mathrm{Ph})_{2}\right]^{-}$reacts with $\mathrm{CuCl}$ to give a dimeric heterobimetallic $\left.\left\{\mathrm{LPt}(\mathrm{Ph})_{2}\right]_{2} \mathrm{Cu}_{2}\right\}\left(\mathrm{XXI}^{\mathrm{e}}\right)$ (Scheme 3.1.2. 4). 
Introduction and literature<smiles>CC(=[W])c1n[nH]c(C(C)=[W])c1C</smiles>

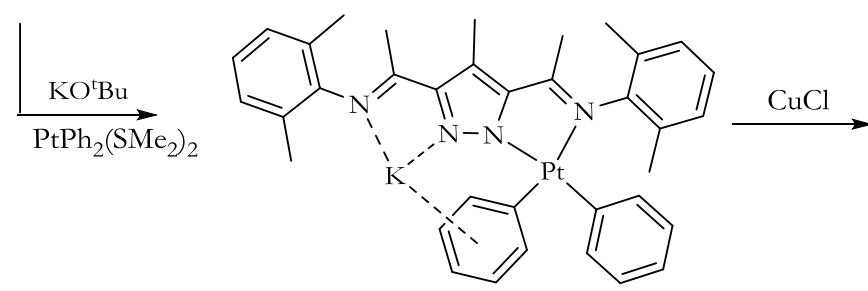

$\mathbf{X X I}^{\mathrm{d}}$

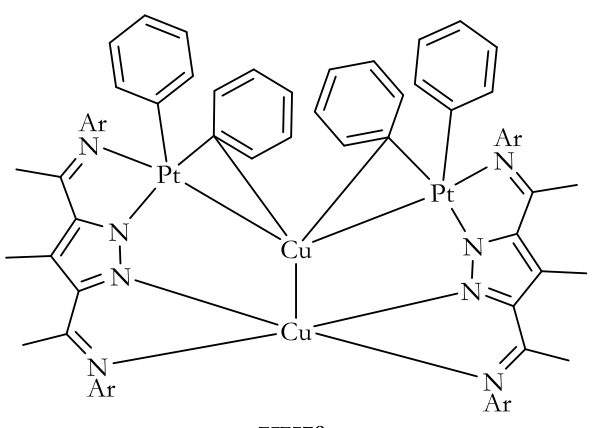

$\mathrm{XXI}^{\mathrm{e}}$

Scheme 3.1.2. 4: Preparation of mononuclear monoanionic Pt and heterobimetallic Cu-Pt complex ${ }^{152}$

The heterobimetallic complex exhibits $\mathrm{Pt} \rightarrow \mathrm{Cu}$ dative bonds, $\mathrm{Cu}-\mathrm{Cu}$ contacts as well as a dynamic behaviour in solution. ${ }^{152}$ 


\section{Renewable and biodegradable natural polymers}

The use of biodegradable/bio-based materials is not only a benign way of protecting the environment, but also a possible alternative to depleting petrochemical feedstock. ${ }^{159,160,161}$

Biodegradable materials offer new uses in biomedical applications, most especially, the use of surgically implantable devices and use in drug delivery systems. ${ }^{162,163,164}$ However, packaging remains one of the most dominant applications of bio-based plastics. Some of the bio-based polymers studied include polyhydroxyalkanoate (PHA), of which the most common member is polyhydroxybutyrate (PHB), ${ }^{165,166,167}$ and polylactic acid (PLA) ${ }^{168}$ The use of PLA's and their copolymers have been of interest for some time now. Lactide is produced from the dehydration of lactic acid, which is obtained from renewable resources such as corn or sugar beet (Scheme 4 . 1).

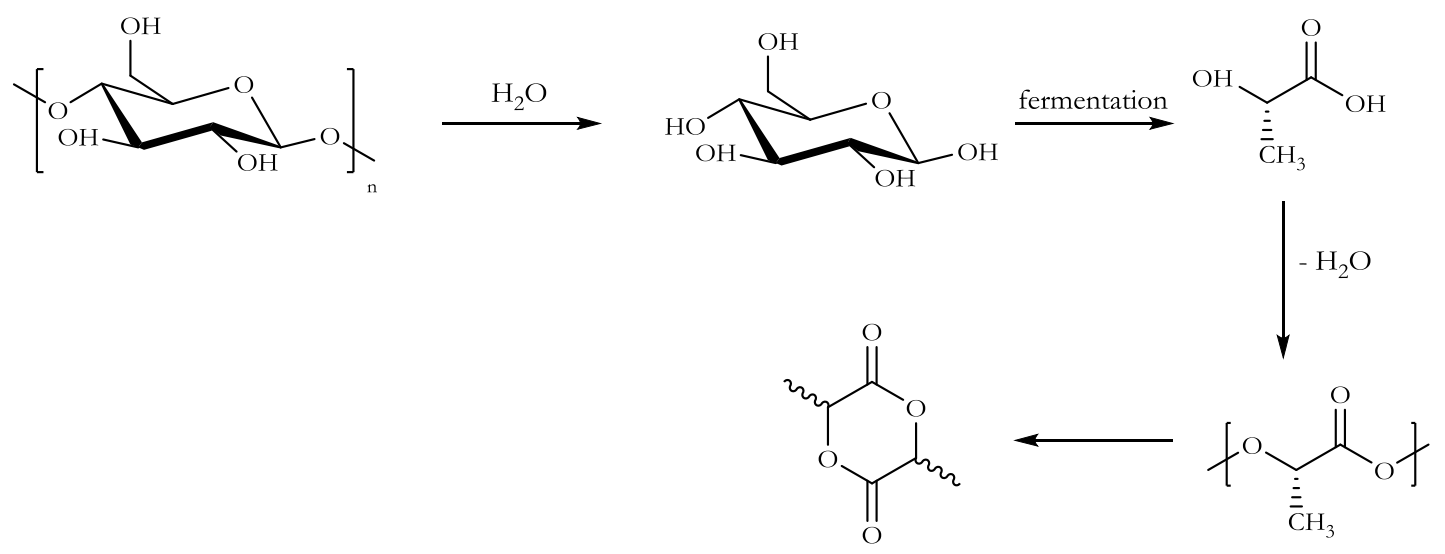

Scheme 4. 1: Synthesis of lactide monomer from natural resources

There are three isomers of lactide, L-lactide, D-lactide and meso-lactide. The pure L- and D-lactide form crystalline isotactic polymers. The ring opening polymerization (ROP) of lactide has been one of most efficient routes in the commercial production to PLA. ${ }^{169,170,171}$ Commercial production of PLA is still in its infancy with commercial examples of PLA's marketed under trade names such as Ingeo from NatureWorks LLC® (CargillDow) ${ }^{172}$ and LACEA® (Mitsui, Japan). Among the ROP processes, which include anionic, cationic, organocatalytic and coordination insertion, the coordination-insertion mechanism is gaining prominence. ${ }^{173}$ The mechanism for the ROP of cyclic esters as initially proposed by Dittrich and Schulz, ${ }^{174}$ involves a three-step coordination-insertion mechanism as shown in Scheme 4. 2. 

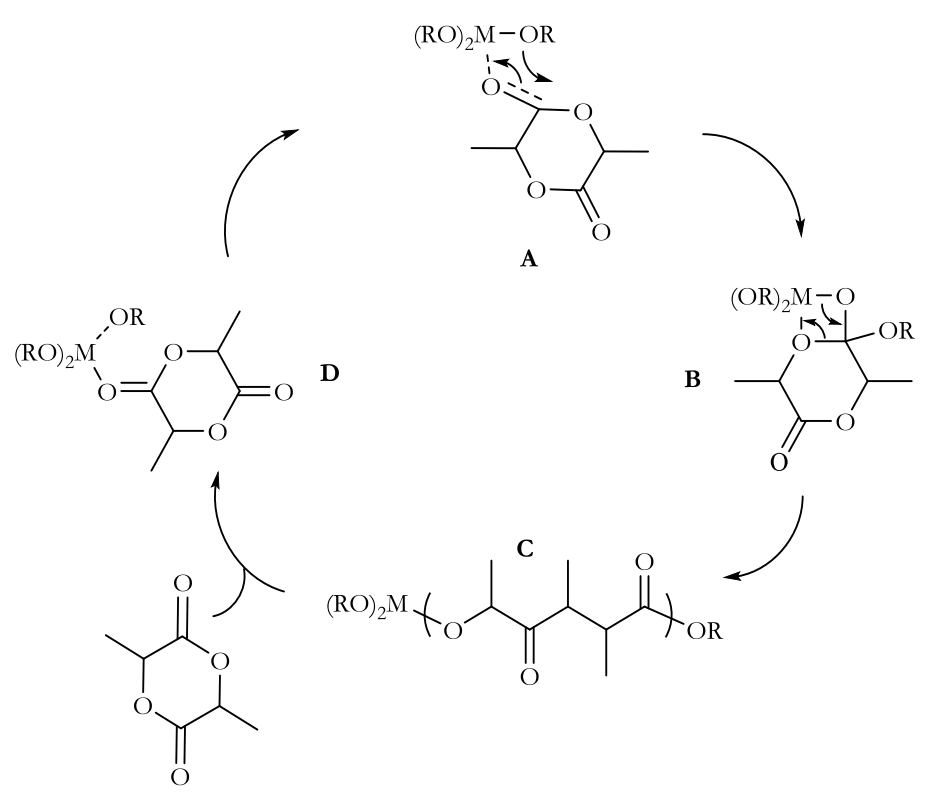

Scheme 4. 2: Coordination-insertion mechanism of lactide polymerization using metal-alkoxide catalysts ${ }^{175}$

The initiation of the reaction involves a nucleophilic attack of the alkoxide at the carbonyl (A) which leaves the monomer heterocycle intact $(\mathbf{B})$. A rearrangement takes place, which orients the acyl oxygen closer to the metal centre $(\mathbf{C})$. This eventually results in another metal alkoxide (D) which can insert into another monomer unit. A practical demonstration of this mechanism at work can be found in the work of Kricheldorf et. al. ${ }^{176}$ and Teyssié et. al. ${ }^{177}$ on the polymerization of different lactones using $\mathrm{Al}(\mathrm{O} \imath \mathrm{Pr})_{3}$ as initiators.

Two competing reactions are known to influence the stereochemistry of the resulting polymer product. The first mechanism, the chain end control mechanism, occurs when the stereochemistry of the inserted monomer plays a major role in the stereochemistry of the subsequent insertion. This is predominant in complexes that make use of sterically bulky ligands that crowd the active site. The second mechanism, the enantiomorphic site-control mechanism is mostly dependent on the chirality of the ancillary ligand. ${ }^{178}$ Some of the more common polymer microstructures include, isotactic L-PLA, produced with the utilization of pure L-lactide, syndiotactic PLA, and heteroatactic PLA.

A number of transition metal complexes have been reported for the ring opening polymerization of rac D,L-lactides, some of these include group 3 and lanthanide based complexes, ${ }^{179,180,181,182}$ which are good initiators for the ROP of lactide. In addition, metals such as $\mathrm{Ca},{ }^{183,184,185} \mathrm{Mg},{ }^{186,187}$ $\mathrm{Al}^{188} \mathrm{Sn}^{189,190}$ and other metal initiators have been studied over the past few decades. 
Zinc-based initiators are more robust and have the ability to resist the presence of protic impurities in the polymerization medium. A number of zinc-based initiators have been developed for the ROP of lactic acid. ${ }^{191,192}$ Since the nature of the ancillary ligand plays a major role in the stereospecific architecture of PLA, the past decades have seen the development of various catalyst systems that have the potential to initiate the stereo controlled ring opening polymerization of lactides (ROP).

Ligand families generally employed with mostly group 2 and group 10 metals can generally be classed as anionic, neutral, and cationic/activated complexes. ${ }^{193} \mathrm{~A}$ number of reviews give extensive details on ligand classes and metals, which have been employed in the synthesis of PLA. ${ }^{193,194}$ These ligand classes involve the use of $\beta$-diiminate (BDI), ${ }^{195,196}$ pyrazolate and tris(pyrazolyl)borate (TPB) ligands, ${ }^{197,198}$ phenolates, ${ }^{199,200}$ bis(phosphinoimine)methane, ${ }^{201} \mathrm{~N}$ heterocyclic carbenes, ${ }^{202,203}$ and ligands featuring other heterocyclic and amido side arms. ${ }^{204}$

\section{$\beta$-diiminate (BDI):}

The work of Coates in the use of BDI complexes (XXVIII) was a game changer as far as this ligand class was concerned. This class of complexes are remarkably active for the stereocontrolled ROP of $r a c$-LA and enabled the formation of heteroatactic-enriched PLA. ${ }^{205}$

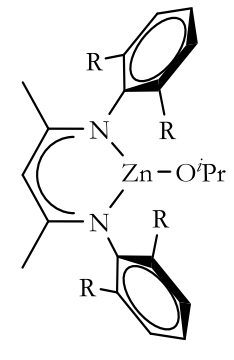

$\mathrm{R}={ }^{i} \operatorname{Pr}$

XXVIII

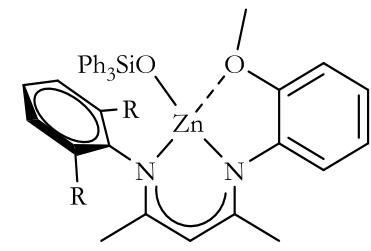

$\mathrm{R}={ }^{i} \operatorname{Pr}$

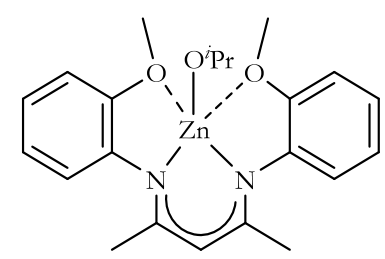

XXX

Attempts to improve the BDI catalysts by modification of the ligand have seen some groups such as Gibson and co-workers ${ }^{206}$ installing an ether appendage to generate a new class of ligand. The zinc complex (XXIX) is active for the ROP of rac-lactide and gives conversions of up 90\% but lacks control in polydispersity. Complex (XXX), a modification of (XXIX), reported by Chisholm et. al. ${ }^{207}$ at $1 \%$ catalyst loadings is active in lactide polymerization and able to maintain control of polydispersity, but also lacks stereochemical control. 


\section{Phenolates:}

Another example of ligand class used is phenolates. The work of Hillmyer and Tolman pioneered the use of zinc complexes featuring bulky amino-phenolate based $\mathrm{N}^{\wedge} \mathrm{N}^{\wedge} \mathrm{O}$-tridentate ancillary ligands (XXXI). This family of complexes show remarkable activities for the nonstereocontrolled ROP of rac-LA. The poly rac-lactide obtained exhibits narrow polydispersities $(\mathrm{PDI}=1.34-1.42)$ even at low catalyst loadings. For example even at $0.15 \%$ catalyst loading, $96 \%$ conversion is obtained in 5 min. ${ }^{208}$

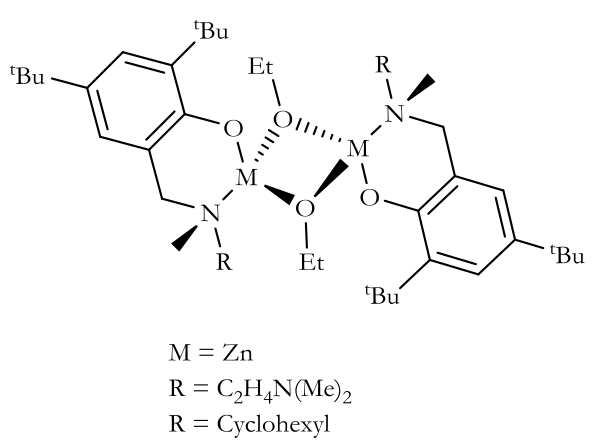

XXXI

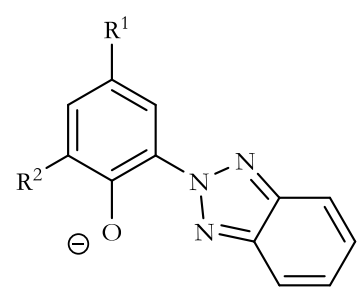

XXXII

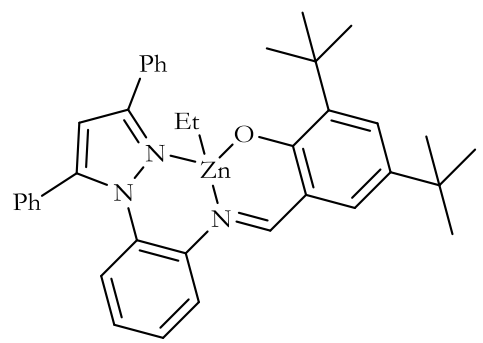

XXXIII

Sobota and co-workers ${ }^{209}$ used the same ligand backbone with zinc as in (XXXI), but only varied the complex/alcohol combination using benzyl alcohol and butanol in place of ethanol. The catalyst gives up to $98 \%$ conversions in $120 \mathrm{~min}$ with narrow molecular weight distributions $(\mathrm{PDI}=1.09)$. The zinc complexes incorporating the bis(amine)benzotriazole phenoxide ligand (XXXII) reported by Sung et. al. ${ }^{210}$ is active in the polymerization of rac-lactide to poly-PLA in a well-controlled manner with PDI $(<1.13)$ and affords isotactic polymers. Wang and coworkers $^{211}$ have also reported on the zinc complex of a phenoxyimine ligand with a pendant pyrazole unit (XXXII). The zinc complex is catalytically active for lactide polymerization at $80^{\circ} \mathrm{C}$ at high catalyst loadings, but lacks stereochemical control. It also produces low molecular weight polymers (PDI $=1.3$ ). Other similar aminophenolates bearing one or two pyrazolyl donor functionalities have also been reported. ${ }^{212}$

\section{Neutral ligands:}

The zinc alkoxide catalyst supported by N-heterocyclic carbene (XXXIV) rapidly polymerizes rac-lactide to heterotactic enriched PLA in $\mathrm{CH}_{2} \mathrm{Cl}_{2}$ at $25^{\circ} \mathrm{C}$, whiles the free $\mathrm{NH}$-carbene on the 
other hand also yields highly isotactic enriched PLA. ${ }^{213}$ The chiral complex $(\mathbf{X X X V})$, generated in situ by the action of diethyl zinc on the chloro analogue, does not yield the desired stereochemical control , although it is active in the polymerization of rac-lactide. ${ }^{214}$

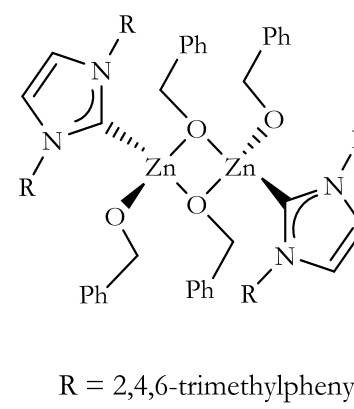

XXXIV

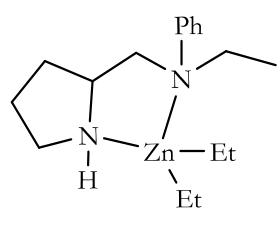

XXXV

Pyrazole based ligand frameworks have also been reported in the ROP of cyclic esters.

\section{Pyrazolates and tris(pyrazolyl) borate (TPB) ligands:}

Complexes of pyrazole based ligands with zinc have been used for the ROP of cyclic esters. The work of Chisholm on the use of TPB (XXXVI) as useful ligands for lactide polymerization inspired other investigators into its potential.

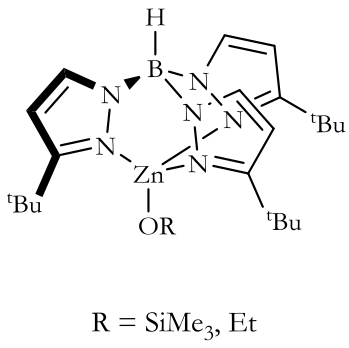

XXXVI<smiles>CC[Te]12(N=C(C)C=C(C)O1)c1ccccc1-n1c(C)cc(C)[n+]12</smiles>

XXXVII

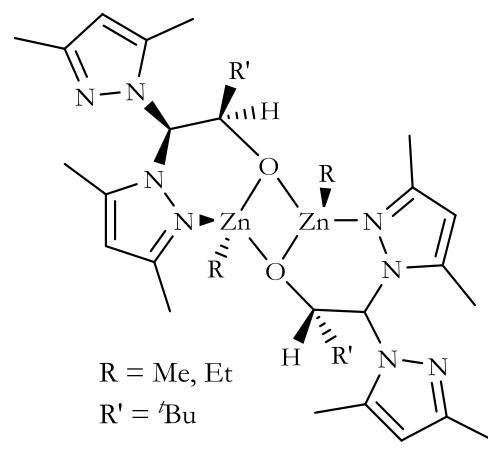

XXXVIII<smiles></smiles>

XXXIX

For example, XXXVII is highly active in ROP of rac-lactide at ambient temperature in the presence of benzyl alcohol with $96 \%$ conversion. It also leads to polymerization of $100 \mathrm{~mol}$ 
equivalent rac-lactide in 1-3 min. $^{215}$ The chiral alcohol scorpionate (XXXVIII) acts a single component catalyst in the polymerization of L-lactide to low molecular weight polymers in $87 \%$ conversion in $1 \mathrm{~h}$ at $65^{\circ} \mathrm{C}$. It also produces heterotactic enriched PLA's with $P_{r}$ up to $0.77 .^{216}$ The work of Carpentier et. al. ${ }^{217}$ resulted in the isolation of the $\mathrm{N}^{\wedge} \mathrm{N}^{\wedge} \mathrm{N}$ pyrazolyl zinc complex (XXXIX). This complex demonstrates very high activity and low polydispersities $(<1.40)$ at low catalyst loadings and achieves complete conversion in $30 \mathrm{~h}$ at room temperature. 


\section{Aims and scope of this work}

The aims and scope of this work include:

(a) To carry out further mechanistic investigations into the formation of the unique tetrapalladium complex $\mathbf{X X I}^{\mathbf{c}}$, this would include efforts at isolating and characterizing the proposed intermediates leading to the formation of $\mathbf{X X I}^{\mathbf{c}}$.

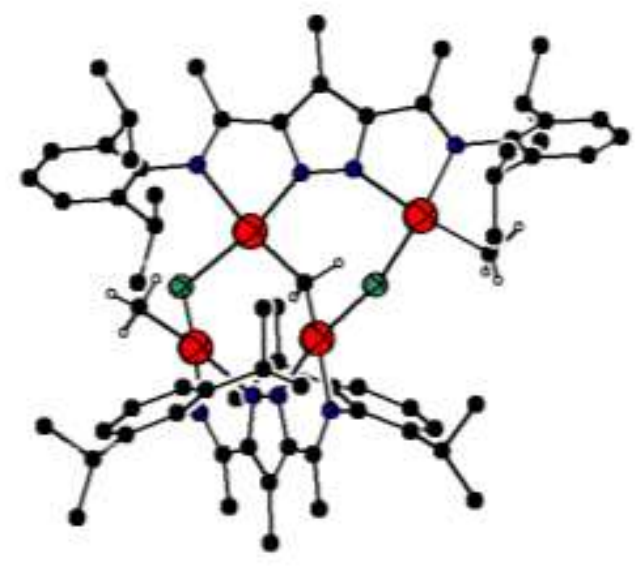

Fig. 5. 1: The unusual tetrapalladium complex XXIc

Attempts would also be made at isolating the second but unidentified side product that is formed in excess $\mathrm{SnMe}_{4}$ and longer reaction times. In addition, attempts would be made at establishing the origin of the unlabeled carbon atom in olefin coupled reactions of labeled ethylene with $\mathbf{X X I}^{\mathbf{c}}$. Last but not the least; further investigations would be carried out on the olefin coupling ability of $\mathbf{X X \mathbf { I } ^ { \mathbf { c } }}$ with other olefins.

(b) Preparation of heterobimetallic complexes of palladium(II) and rhodium(I) using the symmetrical 3,5-disubstituted $a$-diimine like pyrazolyl ligand and investigation of their catalytic activity in a number of organometallic transformation reactions. 
Aims and scope

(c) To prepare zinc(II) complexes of the a-diimine like pyrazolyl scaffolds as catalyst precursors for the polymerization of rac-lactide to polylactide, a bio-renewable polymer.

(d) While the use of symmetrical 3,5-disubstituted pyrazolyl ligands is well known, the use of unsymmetric 3,5-pyrazolyl bridging environments remain scarce. One of the aims of this work is to prepare novel unsymmetric cyclopentadienyl, indenyl, and fluorenyl 3,5-disubstituted pyrazolyl bridging ligands. These ligands would be used for the preparation of heterobimetallic early transition metal complexes. These complexes in turn, would be screened as catalyst precursors for olefin polymerization.

(e) As an extension to work on unsymmetric 3,5-pyrazolyl bridging environments, another aim would be the preparation of a novel class of highly compartmentalized, unsymmetric 3,5-substituted bridging ligands which feature N-heterocyclic carbene and indenyl/fluorenyl side arms as ligands capable of bridging two organometallic fragments and capable of hosting metals in different oxidation states. 


\section{Results and Discussions}

\section{1 Ligand synthesis ( $\alpha$-diimine type ligands)}

The dialdehyde precursor, B was synthesized using established synthetic protocols ${ }^{218,219,145}$ as shown below (Scheme 6.1.1).
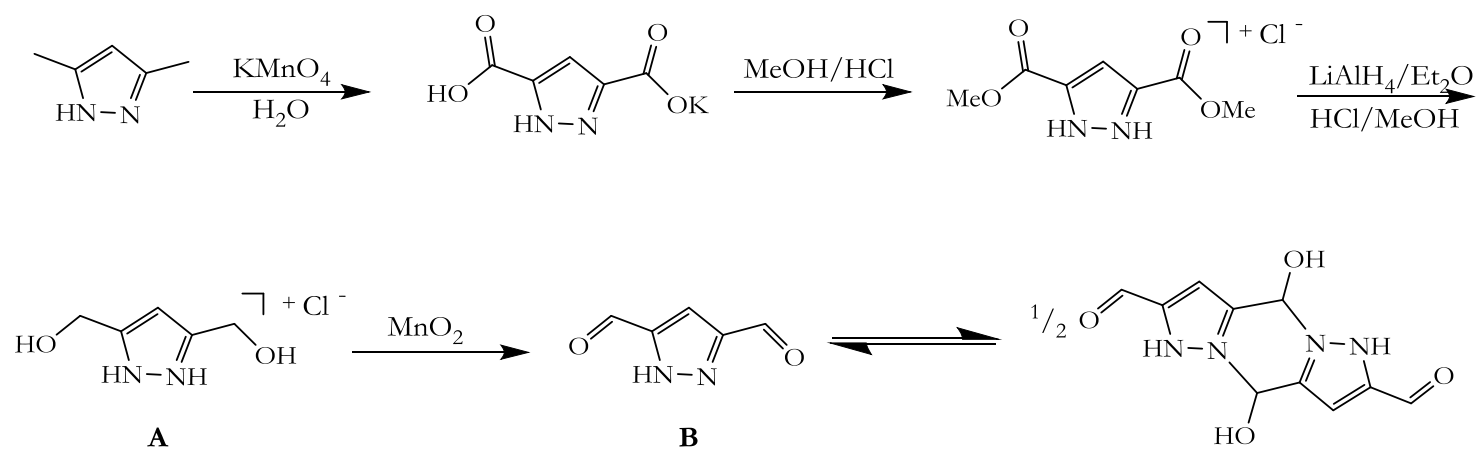

Scheme 6.1.1: Synthetic route to B

The diketone precursor, $\mathbf{C}$ was synthesized using slightly modified preexisting procedures. ${ }^{220,151}$ Toluenesulfonylazide was generated in situ under cold conditions by treating toluensulfonylchloride with $\mathrm{NaN}_{3}$ at $0^{\circ} \mathrm{C}$. This mixture added to a previously stirring mixture of $2.0 \mathrm{~mol}$ equivalent acetylacetone and $\mathrm{K}_{2} \mathrm{CO}_{3}$ (1.0 mol equivalent). The reaction was allowed to stir for $48 \mathrm{~h}$, after which a $1.0 \mathrm{M}$ solution of $\mathrm{HCl}$ was added and the mixture stirred for a further $24 \mathrm{~h}$. After evaporation of the solvent, the crude product was recrystallized from boiling toluene, and $\mathbf{C}$ was obtained in ca $60 \%$ yield.

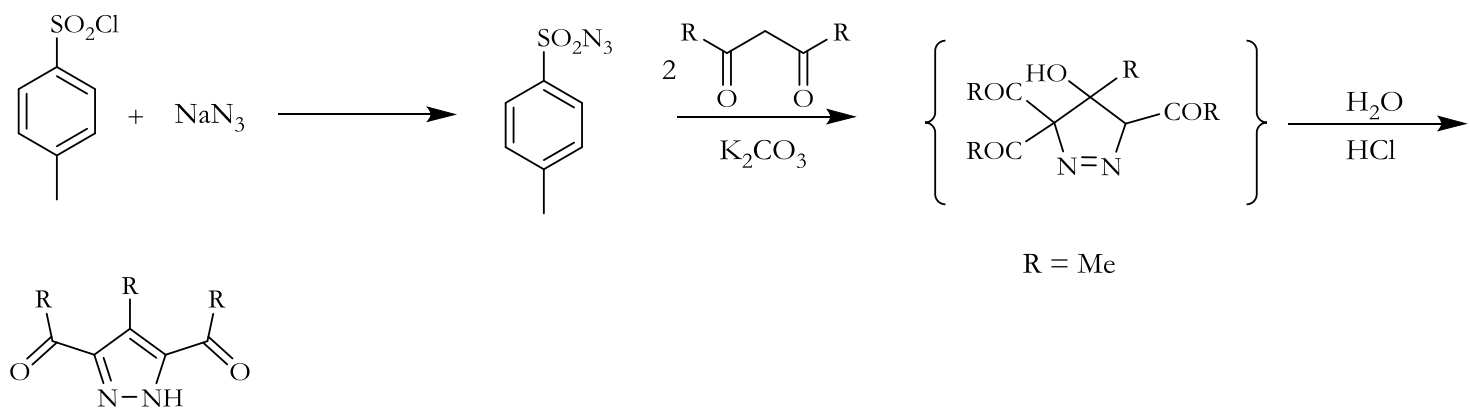

C

Scheme 6.1.2: Scheme showing a slightly modified synthetic route to C 


\section{Results and Discussions}

The Schiff base condensation of $\mathbf{B} / \mathbf{C}$ with the appropriate amine (Scheme 6.1.3) affords the imine products in good to excellent yields after refluxing in toluene for $72 \mathrm{~h}$ with added weak acid catalyst (p-toluenesulfunic acid).

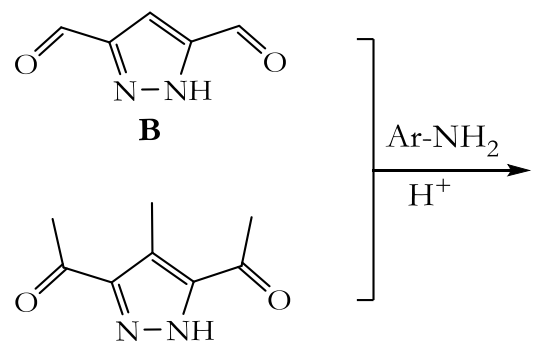

C

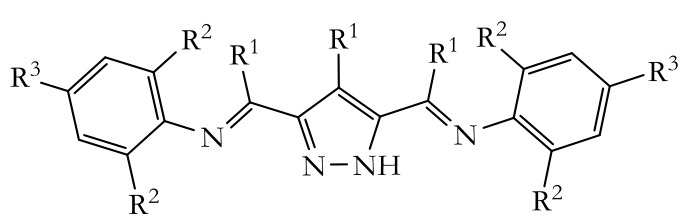

$\mathrm{HL}^{1}: \mathrm{R}^{1}=\mathrm{H}, \mathrm{R}^{2}={ }^{i} \mathrm{Pr}, \mathrm{R}^{3}=\mathrm{H}$

$\mathbf{H L}^{2}: \mathbf{R}^{1}=\mathrm{Me}, \mathrm{R}^{2}={ }^{i} \mathrm{Pr}, \mathrm{R}^{3}=\mathrm{H}$

$H_{L^{3}}: \mathrm{R}^{1}=\mathrm{Me}, \mathrm{R}^{2}=\mathrm{Me}, \mathrm{R}^{3}=\mathrm{H}$

$\mathrm{HL}^{4}: \mathrm{R}^{1}=\mathrm{R}^{2}=\mathrm{R}^{3}=\mathrm{Me}$

Scheme 6.1.3: Pyrazolyl bridging $\alpha$-diimine type ligands used in this study

\section{2 Further insights into the formation of the unusual tetrapalladium complex}

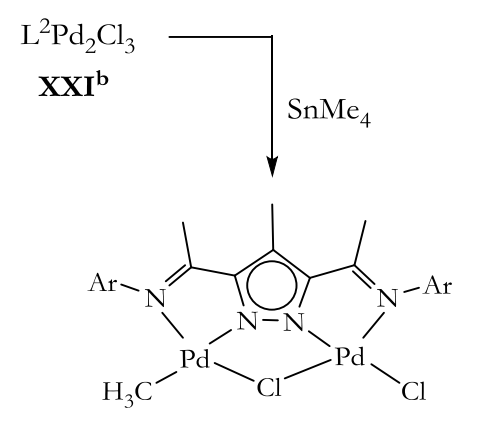

1

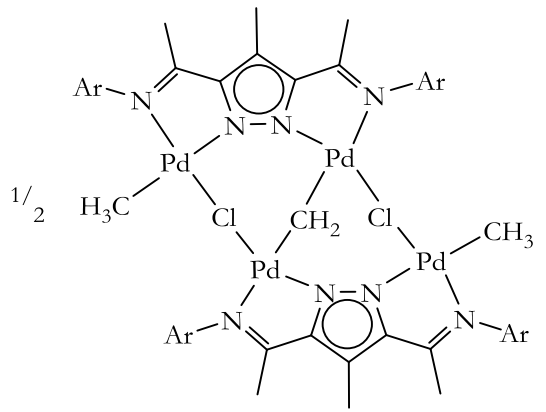

$\mathbf{X X I}^{\mathrm{c}}$
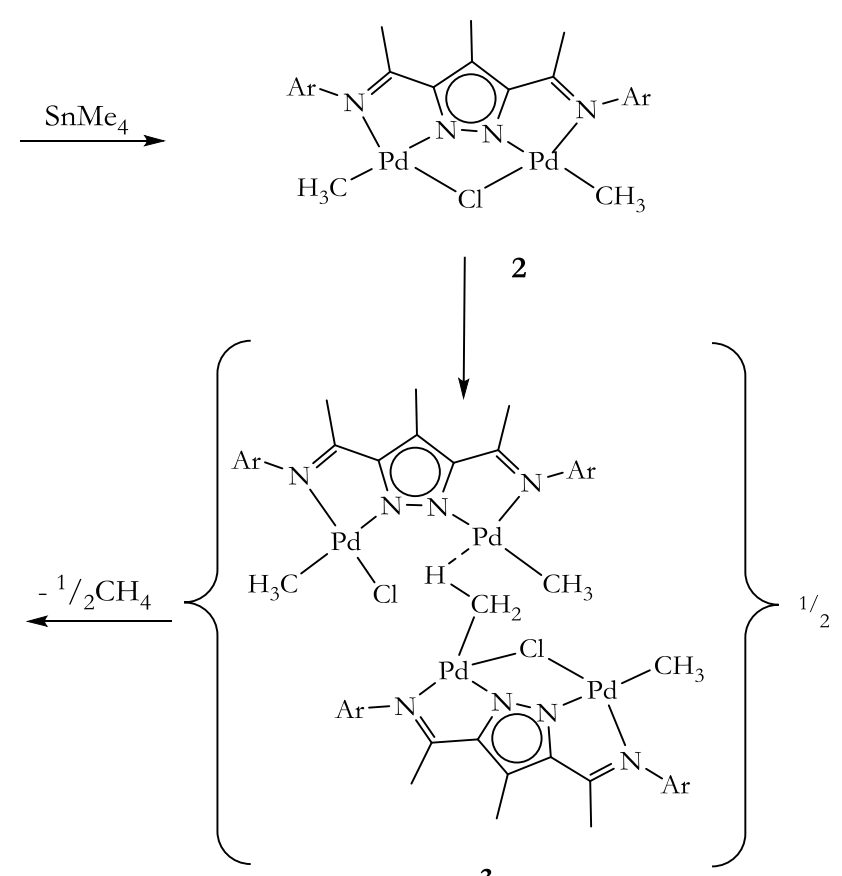

3

$$
\mathrm{Ar}=2,6-{ }^{i} \mathrm{Pr}_{2}-\mathrm{C}_{6} \mathrm{H}_{3}
$$


Scheme 6.2. 1: Proposed scheme leading to the formation of the unusual tetrapalladium complex ${ }^{154}$

In the proposed mechanism leading to the formation of unique tetrapalladium complex $\mathbf{X X I}^{\mathbf{c}}$, (Scheme 6.2.1) by treating $\left[\mathrm{L}^{2} \mathrm{Pd}_{2} \mathrm{Cl}_{3}\right]\left(\mathbf{X X I}^{\mathrm{b}}\right)$ with $30 \mathrm{~mol}$ equivalent $\mathrm{SnMe}_{4}$, the authors detected the sequential formation of two intermediates $\left(C_{\mathrm{s}}(\mathbf{1})\right.$ and a $\left.C_{2 \mathrm{v}}(\mathbf{2})\right)$ leading to the formation of the tetranuclear palladium complex. NOESY correlations of the isopropyl methyl groups showed the presence of palladium bound methyl groups in both intermediates. Using DOSY experiments, the molecular size of the intermediates were different, although within a narrow range. ${ }^{154}$ Although the formation of a $C_{\mathrm{s}}$ and $C_{2 \mathrm{v}}$ symmetric intermediates leading to the formation of the tetrapalladium core were proposed, not much attempts were made at trapping and isolating these intermediates. Due to the transient nature of these intermediates, they react further to give other reaction products. In addition, the authors did note the formation of a second but unidentified product, which forms in excess $\mathrm{SnMe}_{4} \cdot{ }^{154}$

As follow up investigation into the formation of $\mathbf{X X I}^{\mathbf{c}}$ formed from the reaction of $\left(\mathbf{X X I}^{\mathrm{b}}\right)$ with $\mathrm{SnMe}_{4}$, a series of experiments were set up. One of them involved expanding the scope of palladium salts used to cover bromide and iodides (Scheme 6.2. 2), to investigate if the formation of the tetrapalladium complex is reproducible with other halides or exclusive to chlorides.

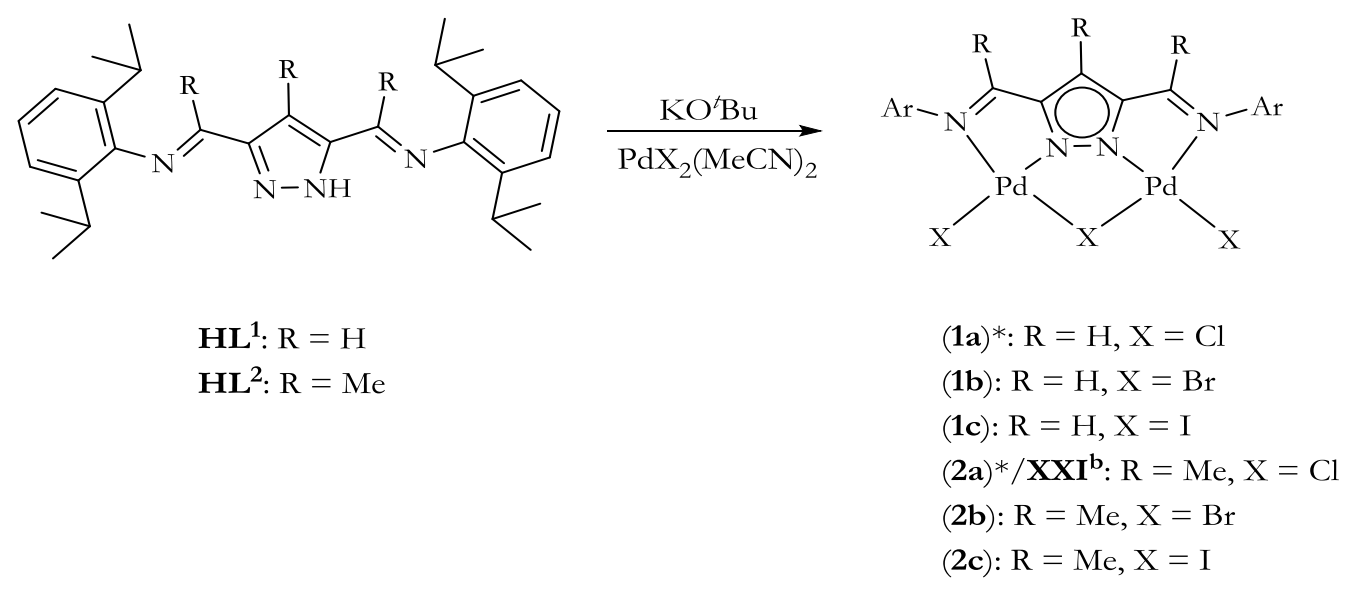

Scheme 6.2. 2: Synthetic scheme for the preparation of complexes 1a-2c (* previously reported complexes)

By treating a potassium salt solution of the ligand $\left(\mathbf{L}^{1} / \mathbf{L}^{2}\right)$ with $2.0 \mathrm{~mol}$ equivalent of the appropriate palladium(II) salts, the analogous $\left[\mathrm{L}^{x} \mathrm{Pd}_{2} \mathrm{Br}_{3}\right](\mathbf{1 b}, \mathbf{2 b})$ and $\left[\mathrm{L}^{x} \mathrm{Pd}_{2} \mathrm{I}_{3}\right](\mathbf{1} \mathbf{c}, \mathbf{2} \mathbf{c})$ were isolated in moderate to good yields (36-71\%). The complexes were characterized by ${ }^{1} \mathrm{H}$ and ${ }^{13} \mathrm{C}$ NMR, IR spectroscopy, ESI-MS and elemental analysis. 


\section{Results and Discussions}

The ${ }^{1} \mathrm{H}$ NMR spectrum of $1 \mathbf{c}$ is shown in Fig. 6.2. 1. The $\mathrm{CH}_{3}{ }^{\text {iPr }}$ group is observed as a pair of doublets at 1.18 and $1.41 \mathrm{ppm}\left({ }^{3} J_{\mathrm{HH}}=6.9 \mathrm{~Hz}\right)$, while the $\mathrm{CH}^{\mathrm{Pr}}$ group is observed as a septet at $3.30 \mathrm{ppm}$. On the other hand, the $\mathrm{CH}=\mathrm{N}$ group is observed as a singlet at 7.72 ppm, and the $\mathrm{CH}^{\mathrm{Pz}}$ is observed at $6.91 \mathrm{ppm}$.

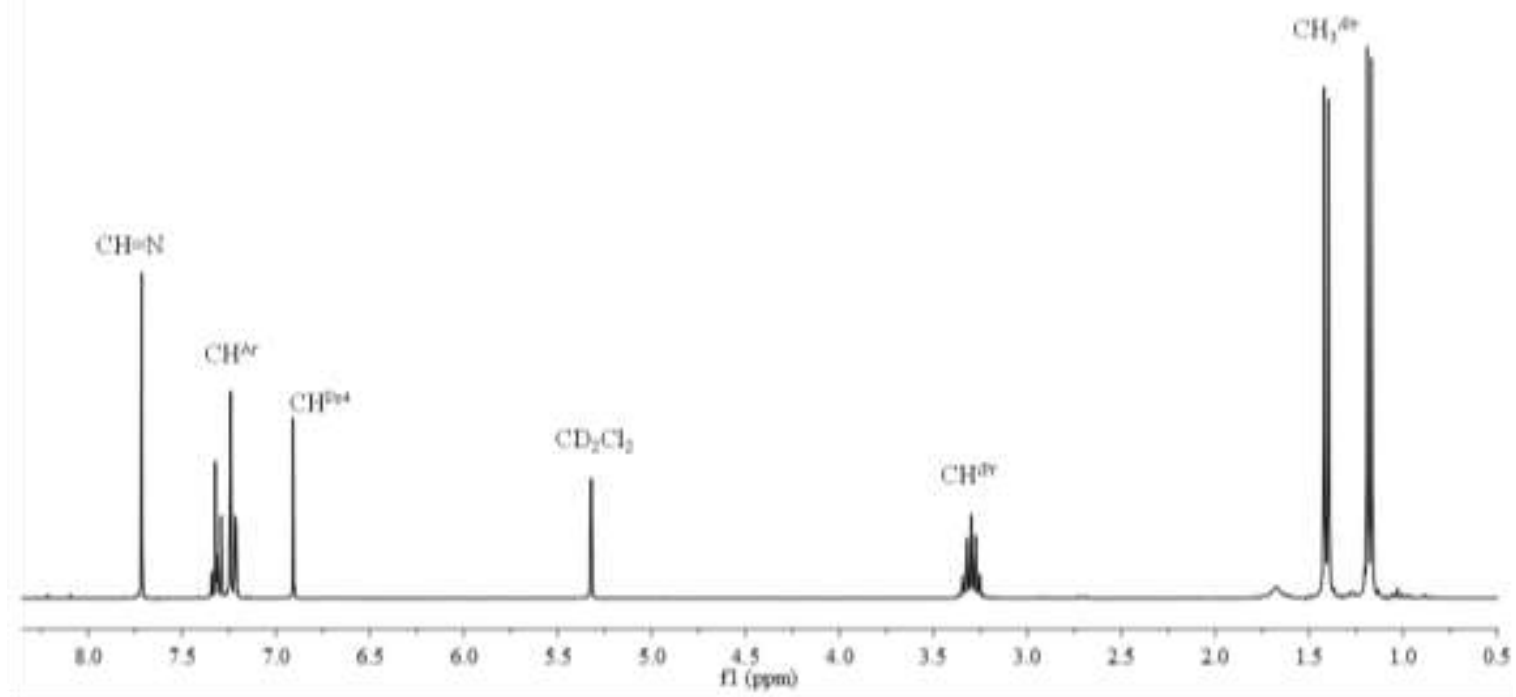

Fig. 6.2. 1: ${ }^{1} \mathrm{H}$ NMR spectrum of $1 \mathrm{c}$ measured in $\mathrm{CD}_{2} \mathrm{Cl}_{2}$ at room temperature

The ${ }^{1} \mathrm{H}$ NMR spectrum chemical shifts of the bromo (1), 2b) and iodo (1c, 2c) complexes are comparable to the chloro analogues $(\mathbf{1} \mathbf{a}, \mathbf{2 a})$. For instance, the $\mathrm{CH}=\mathrm{N}$ peak are observed at $\delta: 7.73$ and 7.71 for $\mathbf{1 b}$ and $\mathbf{1 c}$ respectively, compared to $8.29 \mathrm{ppm}$ in the free ligand, HL ${ }^{1}$. The $\mathrm{CH}^{\mathrm{Pz} 4}$ is also shifted upfield to 7.01 and $6.91 \mathrm{ppm}$ in $\mathbf{1 b}$ and $\mathbf{1 c}$ respectively compared to $7.30 \mathrm{ppm}$ in the free ligand $\left(\mathbf{H L}^{1}\right)$, an indication of coordination of the metal ion to the ligand. Table 6.2. 1 compares the chemical shifts observed for the chloro (2a), bromo (2b), and iodo complexes $(\mathbf{2 c})$ of $\mathbf{H L}^{2}$.

Table 6.2. 1: Table comparing the chemical shifts of complexes $2 \mathrm{a}, 2 \mathrm{~b}$ and $2 \mathrm{c}$

\begin{tabular}{|c|c|c|c|}
\hline & {$\left[\mathrm{L}^{2} \mathbf{P d}_{2} \mathrm{Cl}_{3}\right](2 \mathrm{a})^{*}$} & {$\left[\mathrm{~L}^{2} \mathbf{P d}_{2} \mathrm{Br}_{3}(2 \mathrm{~b})\right.$} & {$\left[\mathbf{L}^{2} \mathbf{P d}_{2} \mathbf{I}_{3}(2 \mathrm{c})\right.$} \\
\hline $\mathrm{CH}_{3}{ }^{\mathrm{Pz} 4}$ & $2.51(\mathrm{~s})$ & $2.50(\mathrm{~s})$ & $2.52(\mathrm{~s})$ \\
\hline $\mathrm{CH}_{3} \mathrm{C}=\mathrm{N}$ & $2.19(\mathrm{~s})$ & $2.18(\mathrm{~s})$ & $2.17(\mathrm{~s})$ \\
\hline $\mathrm{CH}_{3}{ }^{\mathrm{IPr}}$ & $1.19\left(\mathrm{~d}, 3 \int_{\mathrm{HH}}=4.8 \mathrm{~Hz}\right)$ & $1.19\left(\mathrm{~d}, 3 J_{\mathrm{HH}}=6.9 \mathrm{~Hz}\right)$ & $1.15\left(\mathrm{~d}, 3 J_{\mathrm{HH}}=6.9 \mathrm{~Hz}\right)$ \\
\hline $\mathrm{CH}_{3}{ }^{i \mathrm{Pr}}$ & $1.44\left(\mathrm{~d}, 3 J_{\mathrm{HH}}=4.8 \mathrm{~Hz}\right)$ & $1.44\left(\mathrm{~d}, 3_{\mathrm{HH}}=6.7 \mathrm{~Hz}\right)$ & $1.45\left(\mathrm{~d}, 3 J_{\mathrm{HH}}=6.9 \mathrm{~Hz}\right)$ \\
\hline
\end{tabular}

*NB : The preparation and characterization of $\mathbf{2 a}$ has been reported elsewhere and would not be covered here. 


\section{Results and Discussions}

Although very little differences are observed in the chemical shifts in the ${ }^{1} \mathrm{H}$ NMR spectrum, differences in the $\mathrm{CH}_{3} \mathrm{C}=\mathrm{N}$ stretching vibrations are observed in the IR spectrum. For instance, the $\mathrm{CH}_{3} \mathrm{C}=\mathrm{N}$ peaks for $2 \mathbf{b}$ and $2 \mathbf{c}$ are observed at $1559 \mathrm{~cm}^{-1}$ and $1546 \mathrm{~cm}^{-1}$ respectively, due to decreased $\mathrm{Pd}-\mathrm{X}$ bond strength in moving from bromine to iodine. The ESI mass spectra data for $2 \mathrm{a}-2 \mathrm{c}$ show a common fragmentation pattern of $[\mathrm{M}-\mathrm{X}]^{+}$peaks, although in the case of the iodide complexes, $\mathrm{m} / \mathrm{z}$ fragments due to high molecular aggregates $m / z 2026(100 \%)$ for $\left[\mathrm{L}_{2}^{2} \mathrm{Pd}_{4} \mathrm{I}_{5}\right]^{+}$are also observed. Having prepared the bromo and iodo complexes in addition to their chloro analogues, methylations of the complexes with $\mathrm{SnMe}_{4}$ were carried out (Scheme 6.2. 3).
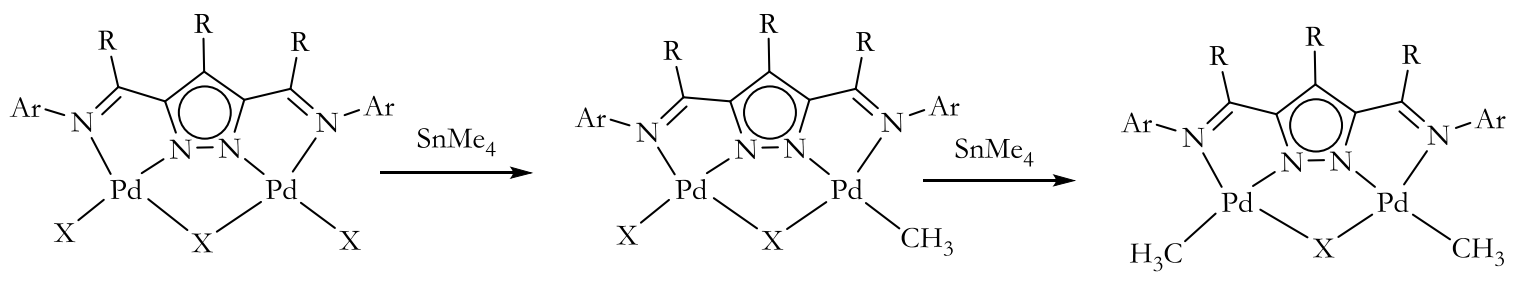
(1) : $\mathrm{R}=\mathrm{H}, \mathrm{X}=\mathrm{Cl}$
(1b): $\mathrm{R}=\mathrm{H}, \mathrm{X}=\mathrm{Br}$
(1c): $\mathrm{R}=\mathrm{H}, \mathrm{X}=\mathrm{I}$
(2a): $\mathrm{R}=\mathrm{Me}, \mathrm{X}=\mathrm{Cl}$
(2b): $\mathrm{R}=\mathrm{Me}, \mathrm{X}=\mathrm{Br}$
(2c): $\mathrm{R}=\mathrm{Me}, \mathrm{X}=\mathrm{I}$

(2d): $\mathrm{R}=\mathrm{Me}, \mathrm{X}=\mathrm{Cl}$

(2e): $\mathrm{R}=\mathrm{Me}, \mathrm{X}=\mathrm{Br}$

(2f): $\mathrm{R}=\mathrm{Me}, \mathrm{X}=\mathrm{Cl}$

$\mathrm{Ar}=2,6-{ }^{i} \mathrm{Pr}_{2}-\mathrm{C}_{6} \mathrm{H}_{3}$

Scheme 6.2. 3: Preparation of single and double methylated palladium(II) complexes

Beginning with 2a, varying 2a:SnMe ${ }_{4}$ molar ratios and reaction times were employed in

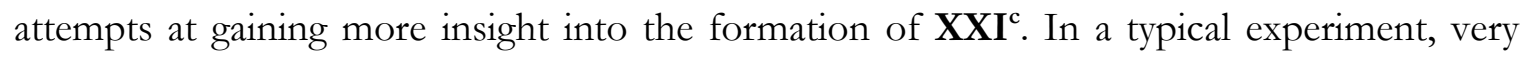
dilute solutions of $\mathrm{SnMe}_{4}$ was added to a stirring $\mathrm{CH}_{2} \mathrm{Cl}_{2}$ solution of $\left[\mathrm{L}^{2} \mathrm{Pd}_{2} \mathrm{Cl}_{3}\right](\mathbf{2 a})$ and the reaction monitored by ${ }^{1} \mathrm{H}$ NMR spectroscopy, in attempts at observing and isolating the previously proposed $C_{\mathrm{s}}(\mathbf{2} \mathbf{d})$ and $C_{2 \mathrm{v}}(\mathbf{2 f})$ methyl bound palladium intermediates.

In one such experiment, $1.0 \mathrm{~mol}$ equivalent of $\mathrm{SnMe}_{4}$ was added to a $\mathrm{CH}_{2} \mathrm{Cl}_{2}$ solution of $\mathbf{2 a}$ and the reaction monitored. After $8 \mathrm{~h}$, the ${ }^{1} \mathrm{H}$ NMR spectrum of the reaction mixture (Fig. 6.2. 2), shows two different peaks for a methyl group $\left(\mathrm{CH}_{3}{ }^{\mathrm{Pd}}\right)$. The two $\mathrm{CH}_{3}{ }^{\mathrm{Pd}}$ peaks are observed at -0.03 and $0.04 \mathrm{ppm}$ in a ratio (1:1.4). This is in line with the proposal that the formation of these intermediates reaches their maxima within 6-10 hr respectively. ${ }^{154}$ The ${ }^{1} \mathrm{H}$ NMR spectrum of the reaction mixture points to the formation of the $C_{s}$ and the $C_{2 \mathrm{v}}$ 
Results and Discussions

symmetry intermediate products $\mathbf{2} \mathbf{d}$ and $\mathbf{2} \mathbf{f}$ respectively. The former (2d) showing methyl peaks $\left(\mathrm{CH}_{3}{ }^{\mathrm{Pd}}\right)$ at $0.04 \mathrm{ppm}$ and two separate signals for $\mathrm{CH}_{3} \mathrm{C}=\mathrm{N}$ group at $2.152 .18 \mathrm{ppm}$, whiles the $\mathrm{CH}_{3}{ }^{\mathrm{Pz} 4}$ peak is observed at $2.50 \mathrm{ppm}$. The $C_{2 \mathrm{v}}$ symmetric product $2 \mathbf{f}$, on the other hand shows $\mathrm{CH}_{3}{ }^{\text {Pd }}$ peak at $-0.03 \mathrm{ppm}$ and a single peak for $\mathrm{CH}_{3} \mathrm{C}=\mathrm{N}$ at 2.13 , whiles the $\mathrm{CH}_{3}{ }^{\mathrm{z} 4}$ peak is observed at $2.47 \mathrm{ppm}$. The difference in $\mathrm{CH}_{3}{ }^{\mathrm{Pd}}$ peaks for the two intermediates is due to stronger donor groups on the $C_{2 \mathrm{v}}$ product compared to $C_{\mathrm{s}}$ symmetric product.

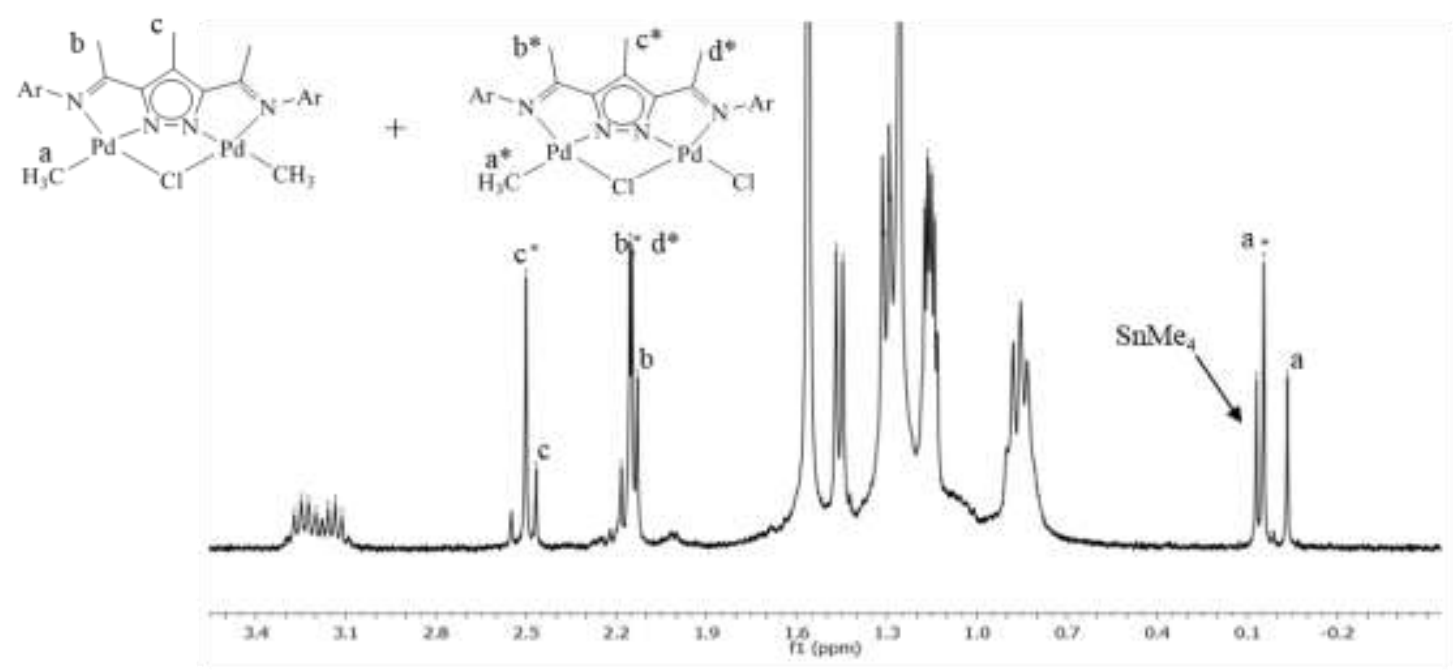

Fig. 6.2. 2: ${ }^{1} \mathrm{H}$ NMR spectrum (selected window) showing the formation of the $C_{\mathrm{s}}$ symmetric (2d)(*)and $C_{2 \mathrm{v}}$ (symmetric product (2f) after $8 \mathrm{~h}$ measured in $\mathrm{CDCl}_{3}$ at room temperature

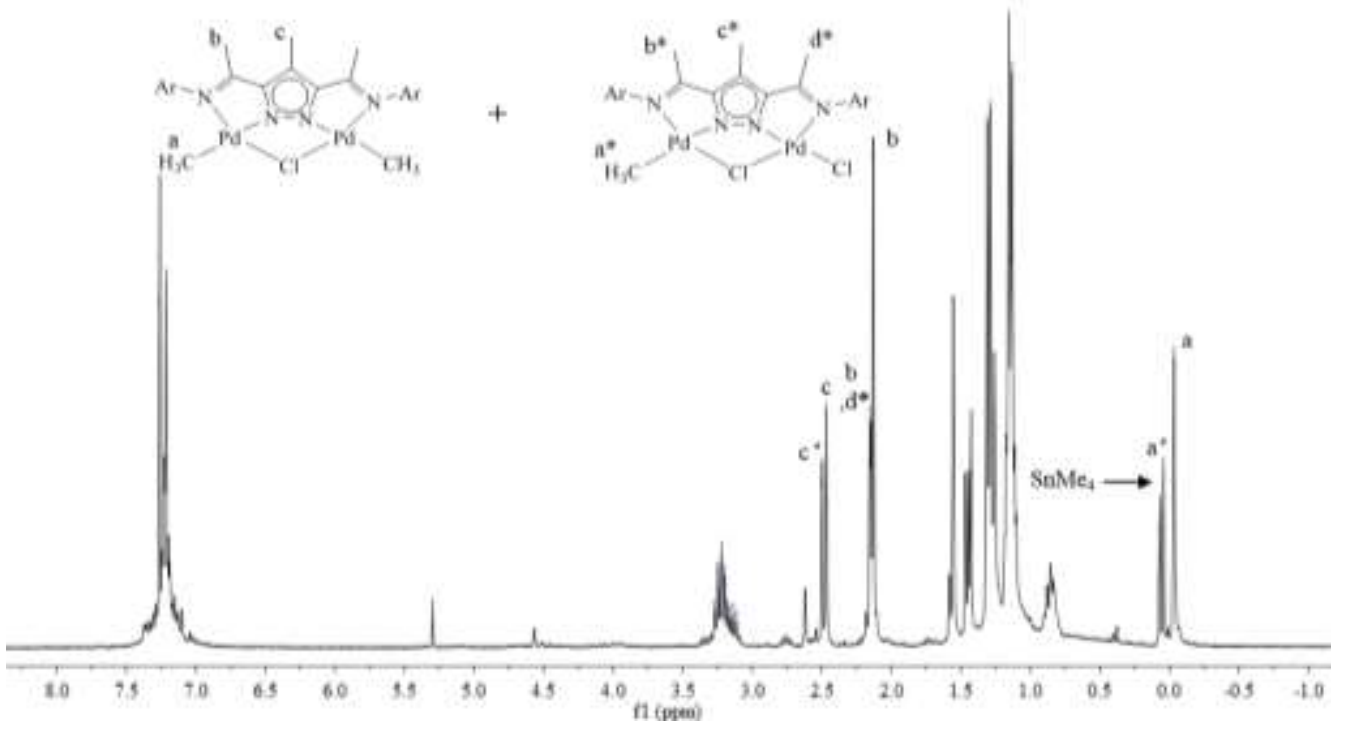

Fig. 6.2. 3: ${ }^{1} \mathrm{H}$ NMR spectrum showing changes in signal intensity of $2 \mathrm{~d}\left(^{*}\right)$ and $2 \mathrm{f}$ symmetric products after $16 \mathrm{~h}$ measured in $\mathrm{CDCl}_{3}$ at room temperature 
With longer reaction times $(>12 \mathrm{~h})$, the $\mathrm{CH}_{3}{ }^{\mathrm{Pd}}$ peak at $0.04(\mathbf{2 d})$ diminishes, whiles the $\mathrm{CH}_{3}{ }^{\mathrm{Pd}}$ peak at -0.03 (2f) intensifies, thus, showing the further conversion of $\mathbf{2} \mathbf{d}$ to $\mathbf{2 f}$. The ratio of the two peak intensities changes over a $16 \mathrm{~h}$ period (Fig. 6.2. 3). Table 6.2. 2 compares selected ${ }^{1} \mathrm{H}$ chemical shift environments for the educt (2a), as well as the $C_{\mathrm{s}}(\mathbf{2 d})$ and $C_{2 \mathrm{v}}(\mathbf{2} \mathbf{f})$ intermediate products.

Table 6.2. 2: Table comparing ${ }^{1} \mathrm{H}$ NMR spectral shifts for educt (2a) and intermediates (2d and 2f)

\begin{tabular}{|c|c|c|c|}
\hline & {$\left[\mathrm{L}^{2} \mathbf{P d}_{2} \mathrm{Cl}_{3}\right](2 \mathrm{a})$} & {$\left[\mathrm{L}^{2} \mathrm{Pd}_{2}(\mu-\mathrm{Cl})\left(\mathrm{CH}_{3}\right) \mathrm{Cl}\right](2 \mathrm{~d})$} & {$\left[\mathrm{L}^{2} \mathrm{Pd}_{2}(\mu-\mathrm{Cl})\left(\mathrm{CH}_{3}\right)_{2}\right](2 \mathrm{f})$} \\
\hline $\mathrm{CH}_{3}{ }^{\mathrm{Pz}} 4$ & $2.51(\mathrm{~s})$ & $2.40(\mathrm{~s})$ & $2.47(\mathrm{~s})$ \\
\hline $\mathrm{CH}_{3} \mathrm{C}=\mathrm{N}$ & $2.19(\mathrm{~s})$ & $2.15(\mathrm{~s}), 2.18(\mathrm{~s})$ & $2.13(\mathrm{~s})$ \\
\hline $\mathrm{CH}_{3}{ }^{\mathrm{Pr}}$ & $1.19\left(\mathrm{~d}, 3_{\mathrm{HH}}=4.8 \mathrm{~Hz}\right)$ & $1.14\left(\mathrm{~d}, 3_{\mathrm{HH}}=6.7 \mathrm{~Hz}\right)$ & $1.15\left(\mathrm{~d}, 3_{\mathrm{HH}}=6.9 \mathrm{~Hz}\right)$ \\
\hline $\mathrm{CH}_{3}{ }^{\mathrm{Pr}}$ & $1.44\left(\mathrm{~d}, 3_{\mathrm{HH}}=4.8 \mathrm{~Hz}\right)$ & $1.30\left(\mathrm{~d}, 3_{\mathrm{HH}}=6.7 \mathrm{~Hz}\right)$ & $1.30\left(\mathrm{~d}, 3_{\mathrm{HH}}=6.9 \mathrm{~Hz}\right)$ \\
\hline & & $1.46\left(\mathrm{~d}, 3_{\mathrm{HH}}=6.7 \mathrm{~Hz}\right)$ & \\
\hline $\mathrm{CH}_{3}{ }^{\mathrm{Pd}}$ & - & $0.04(\mathrm{~s})$ & $-0.03(\mathrm{~s})$ \\
\hline
\end{tabular}

Differences are observed in the $\mathrm{CH}_{3}{ }^{\mathrm{Pr}}$ groups of the educt (2a) and intermediate complexes (2d and $\mathbf{2 f}$ ). In $\mathbf{2 a}$, the $\mathrm{CH}_{3}{ }^{\text {Pr }}$ is observed as two doublets at 1.19 and $1.44 \mathrm{ppm}$, compared to 2d, which has three $\mathrm{CH}_{3}{ }^{\text {ipr }}$ groups at 1.14, 1.30 (new) and $1.44 \mathrm{ppm}$. The $C_{2 \mathrm{v}}$ symmetric product $2 \mathbf{f}$ on the other hand features two $\mathrm{CH}_{3}{ }^{\text {iPr }}$ groups as a pair of doublets at 1.14 and $1.30 \mathrm{ppm}$. Thus, reflecting the gradual change in symmetry and increasing electron density at the palladium(II) centre on the conversion of $\mathbf{2 a}$ to $\mathbf{2} \mathbf{d}$ and subsequently to $\mathbf{2 f}$. The chemical shifts observed are identical to experimental data obtained by A. Sachse. ${ }^{221}$

When the experiment was repeated using benzyl chloride in place of $\mathrm{CH}_{2} \mathrm{Cl}_{2}$ as a solvent, again, a mixture of the singly and doubly methylated products were isolated as well as the formation of $\left[\mathrm{L}_{2} \mathrm{Pd}\right]$ side product. Other chlorinated solvents such as chlorobenzene also gave similar results. The formation of methylated products is, however, not observed when non-chlorinated solvents such as ether and THF are used.

In another experiment, the amount of $\mathrm{SnMe}_{4}$ used was reduced to 0.75 mol equivalents from the initial $1.0 \mathrm{~mol}$ equivalent and the reaction monitored in attempts at forming only the $C_{\mathrm{s}}$ symmetric product $\mathbf{2 d}$ (Scheme 6.2. 4). 
<smiles></smiles>

$\mathrm{XXI}^{\mathrm{b}} / 2 \mathrm{a}$

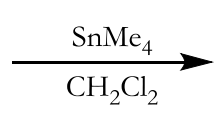

$2 d$

Scheme 6.2. 4: In situ preparation of the single methylated complex $2 \mathrm{~d}$ from $2 \mathrm{a}$

After $18 \mathrm{~h}$, the reaction was worked up. Two products were obtained, an orange powder and a dark green filtrate. The dark green filtrate was later identified as the tetrapalladium complex with the characteristic $\mu-\mathrm{CH}_{2}$ and $\mathrm{CH}_{3}{ }^{\text {Pd }}$ observed at 3.98 and 0.06 ppm respectively in the ${ }^{1} \mathrm{H}$ NMR spectrum $\left(\mathrm{CDCl}_{3}\right)$. The orange powder on the other hand, had no bridgingn $\mu-\mathrm{CH}_{2}$ but featured a broad $\mathrm{CH}_{3}$ peak at $0.10 \mathrm{ppm}\left(\mathrm{CH}_{3}{ }^{\mathrm{Pd}}\right)$ (Fig. 6.2.4). This peak at $0.10 \mathrm{ppm}$ correlates with a methyl group peak at $-1.31 \mathrm{ppm}$ in the ${ }^{13} \mathrm{C}$ NMR spectrum and confirmed by DEPT90, DEPT-135, and ${ }^{1} \mathrm{H}_{-}{ }^{13} \mathrm{C}$ HMBC experiments as a $\mathrm{CH}_{3}$ group with no multiple bond correlations. In addition, $\mathrm{CH}_{3}{ }^{2 \mathrm{Pr}}$ peaks at $\delta: 1.14,1.31$, and $1.46 \mathrm{ppm}$ are observed. In $2 \mathrm{~d}$, the $\mathrm{CH}_{3}{ }^{\mathrm{Pd}}$ peak is observed as a sharp singlet at $\delta: 0.04$.

Also two different $\mathrm{CH}_{3} \mathrm{C}=\mathrm{N}$ peaks were observed at $2.14 \mathrm{ppm}$ and $2.17 \mathrm{ppm}$, pointing to an asymmetric ligand environment. The ESI-MS shows $m / z$ values of high molecular aggregates at $1529(50 \%)$ for $\left[\mathrm{L}_{2}^{2} \mathrm{Pd}_{4}(\mu-\mathrm{Cl})_{3}\left(\mathrm{CH}_{3}\right)_{2}\right]^{+}$and 1410 (25\%) for $\left[\mathrm{L}_{2}^{2} \mathrm{Pd}_{4}\left(\mathrm{CH}_{3}\right)\right]^{+}$fragments respectively. Based on spectroscopic data the formation of a complex of the nature $\left[\mathrm{L}_{2}^{2} \mathrm{Pd}_{4}(\mu-\mathrm{Cl})_{3}\left(\mathrm{CH}_{3}\right)_{2}\right] \mathrm{Cl}\left(\mathbf{2} \mathbf{d}_{2}\right)$, formed from the dimerization of $\mathbf{2} \mathbf{d}$ is proposed.

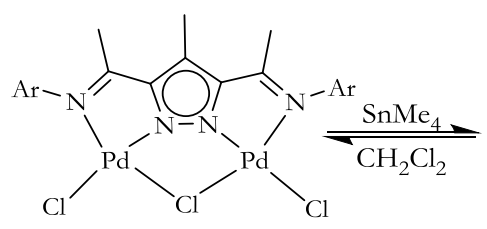

$2 a$

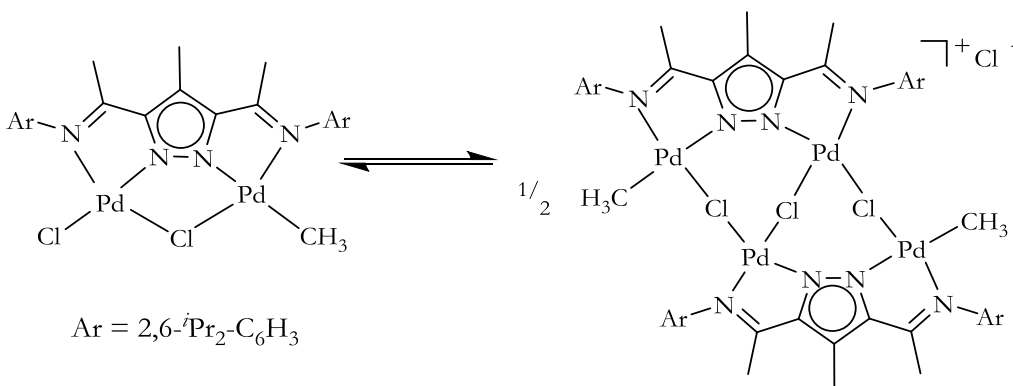

$2 d$
$2 \mathrm{~d}_{2}$ 
All attempts at crystallizing $\mathbf{2} \mathbf{d}$ and $\mathbf{2} \mathbf{d}_{\mathbf{2}}$ failed. When left in solution, $\mathbf{2} \mathbf{d}_{\mathbf{2}}$ undergoes rearrangement to form the parent compound $2 \mathrm{a}$ in the absence of $\mathrm{SnMe}_{4}$, but reacts further to form $\mathbf{X X I}{ }^{\mathbf{c}}$ in the presence of $\mathrm{SnMe}_{4}$ (Fig. 6.2.4). It is however stable $\left(\mathbf{2} \mathbf{d}_{2}\right)$ in the solid state and can be kept at room temperature for several days.

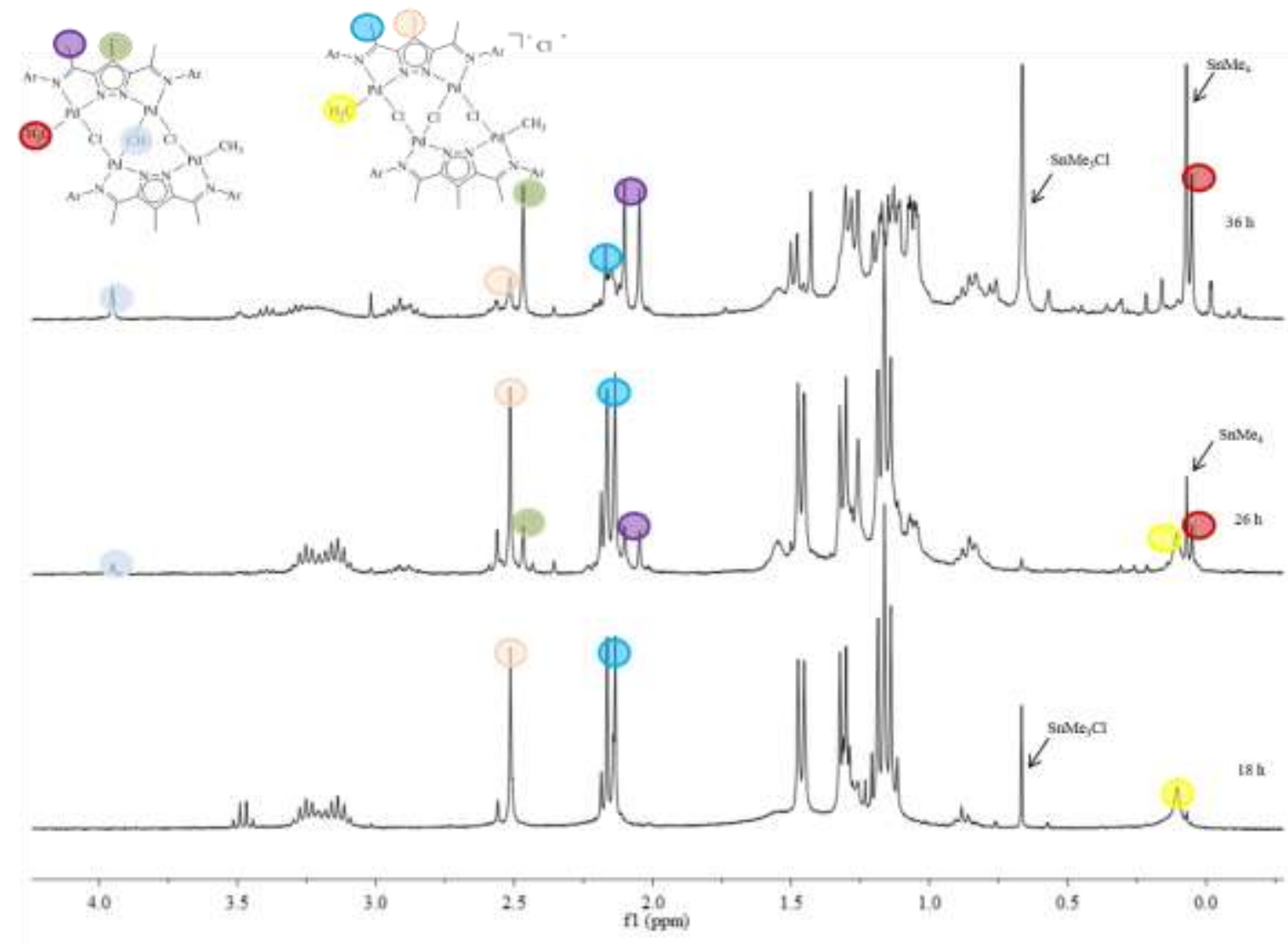

Fig. 6.2.4: ${ }^{1} \mathrm{H}$ NMR spectra (selected window) showing the sequential formation of XXIc from $2 \mathrm{~d}_{2}$ measured in $\mathrm{CDCl}_{3}$ at room temperature

A dilute $\mathrm{CDCl}_{3}$ solution of $\mathrm{SnMe}_{4}$ was added to a $\mathrm{CDCl}_{3}$ solution of $\mathbf{2} \mathbf{d}_{2}$ in a NMR tube and the reaction monitored continuously. The gradual formation of the tetrapalladium complex $\mathbf{X X I}^{\mathrm{c}}$ is observed after $26 \mathrm{~h}$, until eventually becoming the major product after $36 \mathrm{~h}$ (Fig. 6.2.4). In the light of this new observation, similar experiments were set up using the analogous bromo and iodo complexes in attempts at shedding more light on the formation of these intermediates. 
Results and Discussions

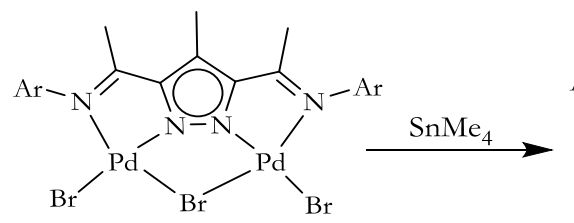

$2 \mathrm{~b}$

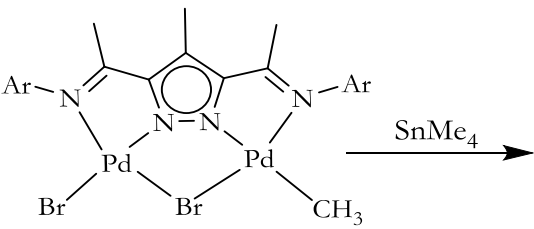

$\mathrm{Ar}=2,6-{ }^{i} \mathrm{Pr}_{2}-\mathrm{C}_{6} \mathrm{H}_{3}$

$2 \mathrm{e}$

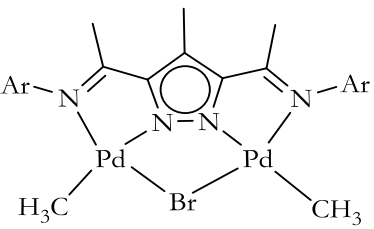

$2 \mathrm{~g}$

Scheme 6.2. 6: Scheme showing the sequential formation of $2 \mathrm{~g}$ from $2 \mathrm{e}$

Repeated experiments were performed using $\left[\mathrm{L}^{2} \mathrm{Pd}_{2} \mathrm{Br}_{3}\right](\mathbf{2} \mathbf{b})$ in place of $\left[\mathrm{L}^{2} \mathrm{Pd}_{2} \mathrm{Cl}_{3}\right](\mathbf{2 a})$. This later gave further credence to the formation of $C_{\mathrm{s}}$ and $C_{2 \mathrm{v}}$ symmetric intermediates. By treating a $\mathrm{CH}_{2} \mathrm{Cl}_{2}$ solution of $\mathbf{2 b}$ initially with $1.0 \mathrm{~mol}$ equivalent of $\mathrm{SnMe}_{4}$, no change in the ${ }^{1} \mathrm{H}$ NMR spectrum was observed after several days. However, when the concentration of $\mathrm{SnMe}_{4}$ was increased to 90 equivalents, it was possible to observe the sequential formation of $\left[\mathrm{L}^{2} \mathrm{Pd}_{2}(\mu-\mathrm{Br})\left(\mathrm{CH}_{3}\right) \mathrm{Br}\right](\mathbf{2 e})$ and $\left[\mathrm{L}^{2} \mathrm{Pd}_{2}(\mu-\mathrm{Br})\left(\mathrm{CH}_{3}\right)_{2}\right](\mathbf{2 g})$ (Scheme 6.2. 6). The figure below is a representative ${ }^{1} \mathrm{H}$ NMR spectrum of the reaction mixture after $24 \mathrm{~h}$.

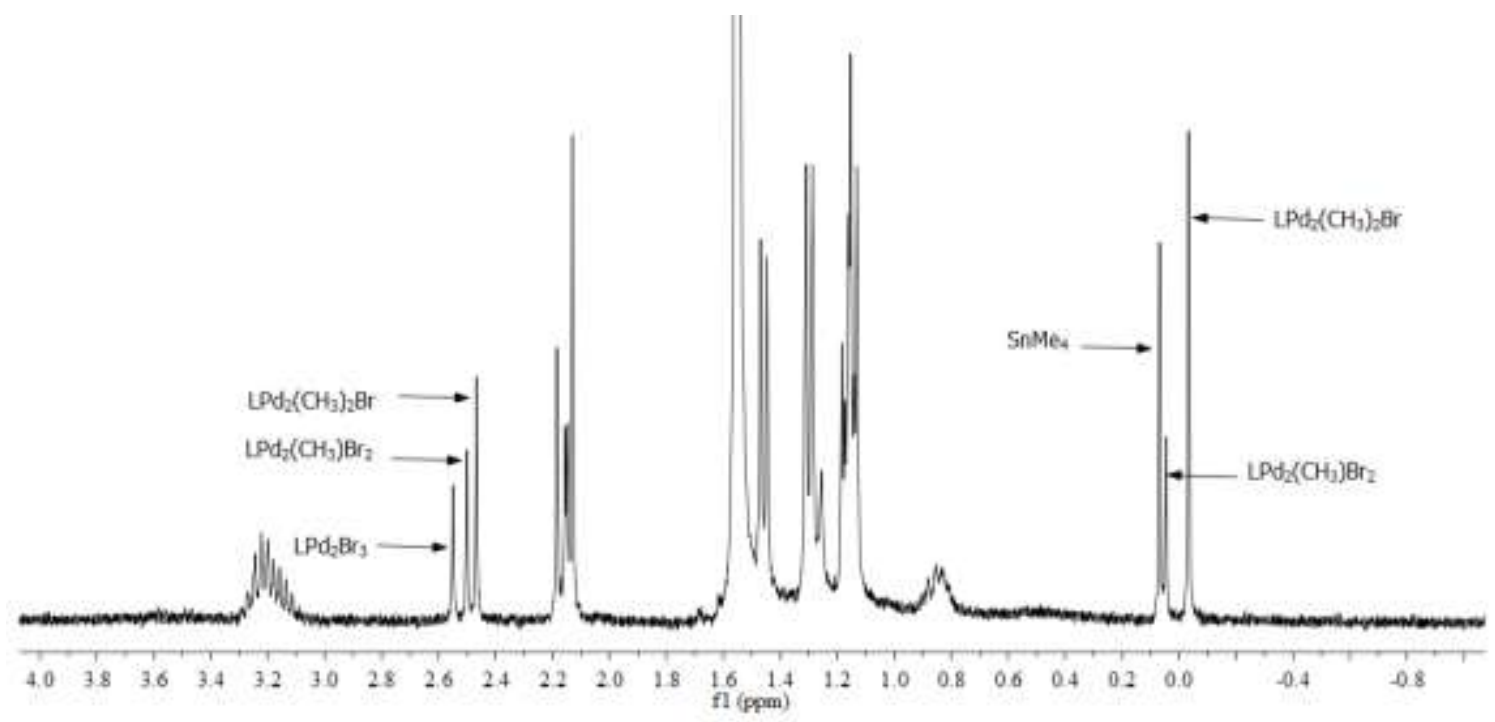

Fig. 6.2. 5: ${ }^{1} \mathrm{H}$ NMR spectrum (selected region) of reaction mixture showing the educt, $C_{\mathrm{s}}$, and $C_{2 \mathrm{v}}$ symmetric products measured in $\mathrm{CDCl}_{3}$ at room temperature

The educt (2b), a $C_{\mathrm{s}}(\mathbf{2 e})$ and a $C_{2 \mathrm{v}}(\mathbf{2 g})$ symmetric products are observed (Fig. 6.2. 5). The ${ }^{1} \mathrm{H}$ NMR spectrum peaks for the three different $\mathrm{CH}_{3}{ }^{\mathrm{P}_{z 4}}$ groups at 2.55, 2.50 and $2.47 \mathrm{ppm}$ are assigned for the compounds $\mathbf{2 b}, \mathbf{2 e}$ and $\mathbf{2 g}$ respectively, reflecting the increase in electron density on the pyrazole ring. Like the chloro analogues, two different methyl peaks $\left(\mathrm{CH}_{3}{ }^{\mathrm{Pd}}\right)$ are observed at 0.04 and $-0.03 \mathrm{ppm}$ for $2 \mathrm{e}$ and $2 \mathrm{~g}$ respectively. In a similar fashion, the peak intensities for $\mathrm{CH}_{3}{ }^{\text {dd }}$ for $2 \mathrm{e}(0.04 \mathrm{ppm})$ diminish in intensity with time, whiles that for $2 \mathbf{g}$ (- 
$0.03 \mathrm{ppm}$ ) increases until eventually becoming the only $\mathrm{CH}_{3}{ }^{\mathrm{Pd}}$ peak. When the reaction is continued for long periods (more than 3 weeks), the reaction still terminates at the $C_{2 \mathrm{v}}$ symmetric product. Further heating at $40^{\circ} \mathrm{C}$ for 2 weeks gave no further products, pointing to the kinetic and thermodynamic stability of this complex. The $C_{2 \mathrm{v}}$ symmetric product $2 \mathrm{~g}$ was characterized by $1 \mathrm{D}$ and 2D NMR experiments.

The ${ }^{1} \mathrm{H}$ NMR spectrum of $2 \mathbf{g}$ shows the $\mathrm{CH}_{3}{ }^{\mathrm{Pd}}$ peak as a singlet at $-0.03 \mathrm{ppm}$ and peaks at 2.13 and 2.47 for $\mathrm{CH}_{3} \mathrm{C}=\mathrm{N}$ and $\mathrm{CH}_{3}{ }^{\mathrm{P} 4}$ groups respectively in $\mathrm{CDCl}_{3}$. In addition, the two $\mathrm{CH}_{3}{ }^{\text {iPr }}$ groups are observed as two doublets at 1.14 and $1.30 \mathrm{ppm}$. The ${ }^{1} \mathrm{H}$ NMR spectrum chemical shifts observed for $\mathbf{2} \mathbf{g}$ are identical to that observed for the chloro analogue $\mathbf{2 f}$.

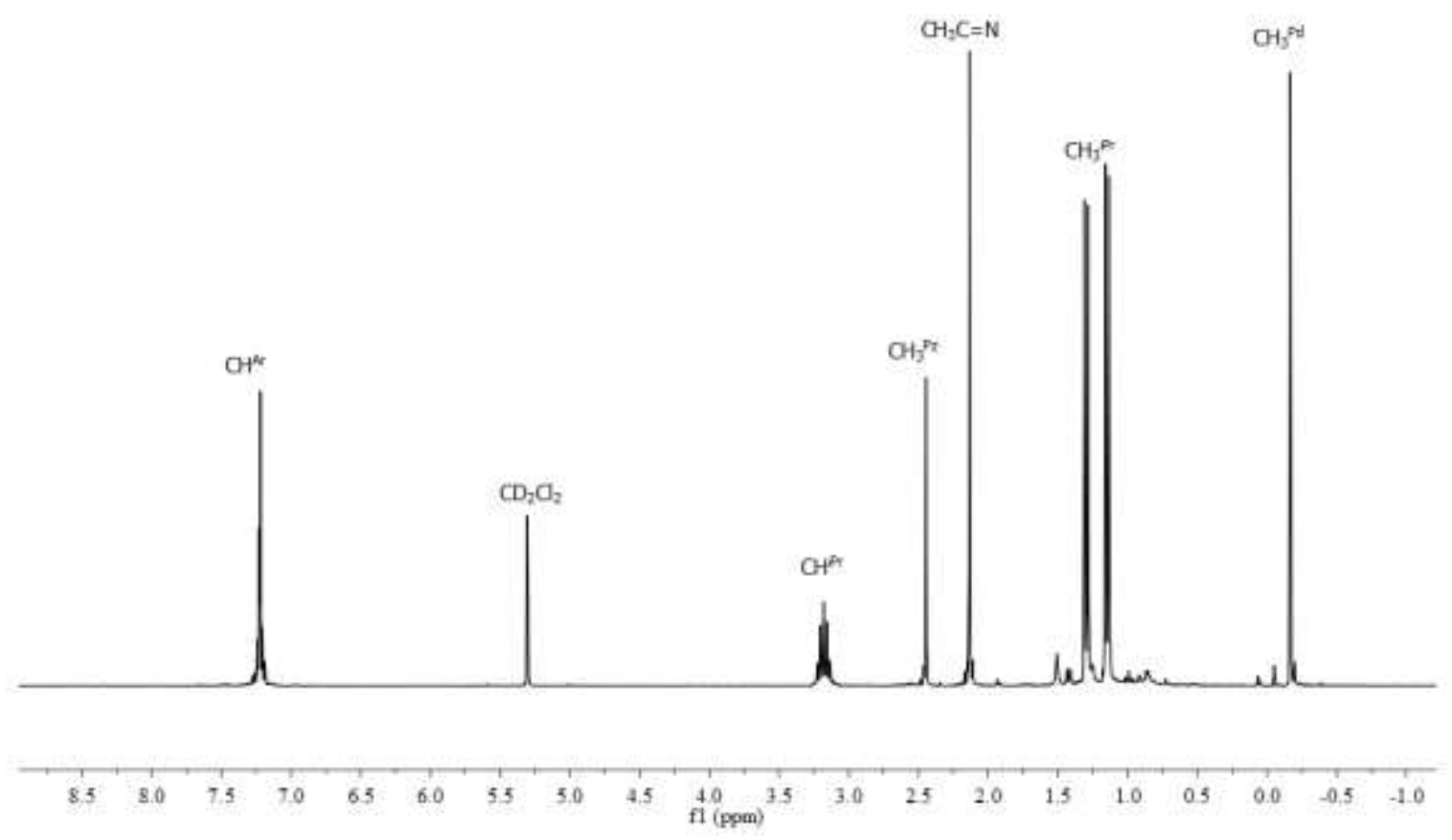

Fig. 6.2. 6: ${ }^{1} \mathrm{H}$ NMR spectrum of the $C_{2 \mathrm{v}}$ symmetric product $2 \mathrm{~g}$ measured in $\mathrm{CD}_{2} \mathrm{Cl}_{2}$ at room temperature

Complete assignment of the ${ }^{1} \mathrm{H}$ and ${ }^{13} \mathrm{C}$ peaks were made with ${ }^{1} \mathrm{H}-{ }^{1} \mathrm{H}$ COSY,${ }^{1} \mathrm{H}_{-}{ }^{13} \mathrm{C}$ HSQC (Fig. 6.2. 7), ${ }^{13} \mathrm{C}$ and ${ }^{1} \mathrm{H}_{-}{ }^{13} \mathrm{C}$ HMBC NMR experiments. The $\mathrm{CH}_{3}{ }^{\text {Pd }}$ peak at $(-0.03 \mathrm{ppm})$ correlates to a $\mathrm{CH}_{3}{ }^{\text {Pd }}$ peaks at $1.96 \mathrm{ppm}$ in the ${ }^{13} \mathrm{C}$ NMR spectrum, as well as the $\mathrm{CH}_{3} \mathrm{C}=\mathrm{N}$ peak which is observed in the ${ }^{13} \mathrm{C}$ NMR spectrum at $172 \mathrm{ppm}$. 
34

Results and Discussions

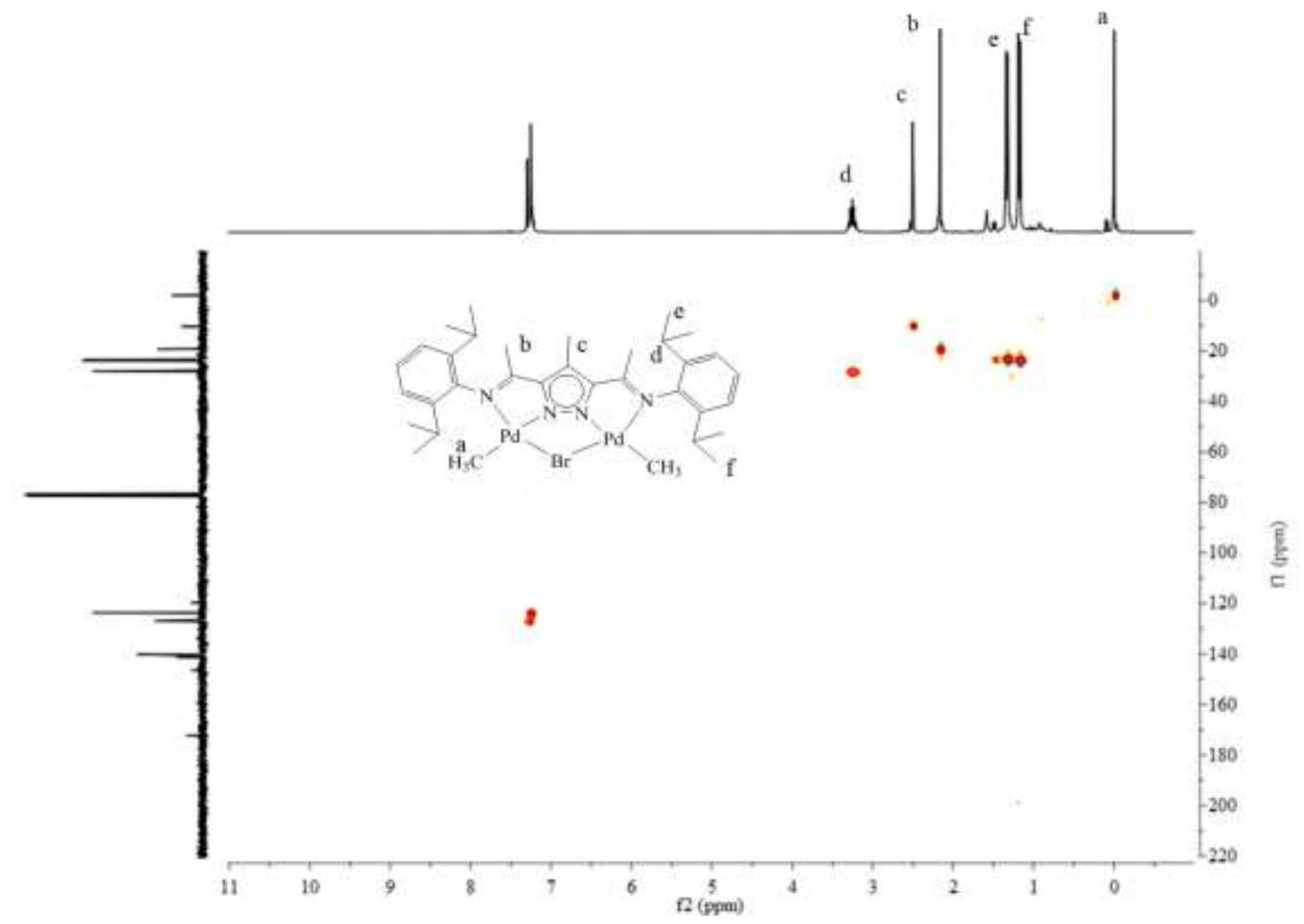

Fig. 6.2. 7: ${ }^{1} \mathrm{H}-{ }^{13} \mathrm{C}$ HSQC NMR spectrum for $2 \mathrm{~g}$ measured in $\mathrm{CDCl}_{3}$ at room temperature

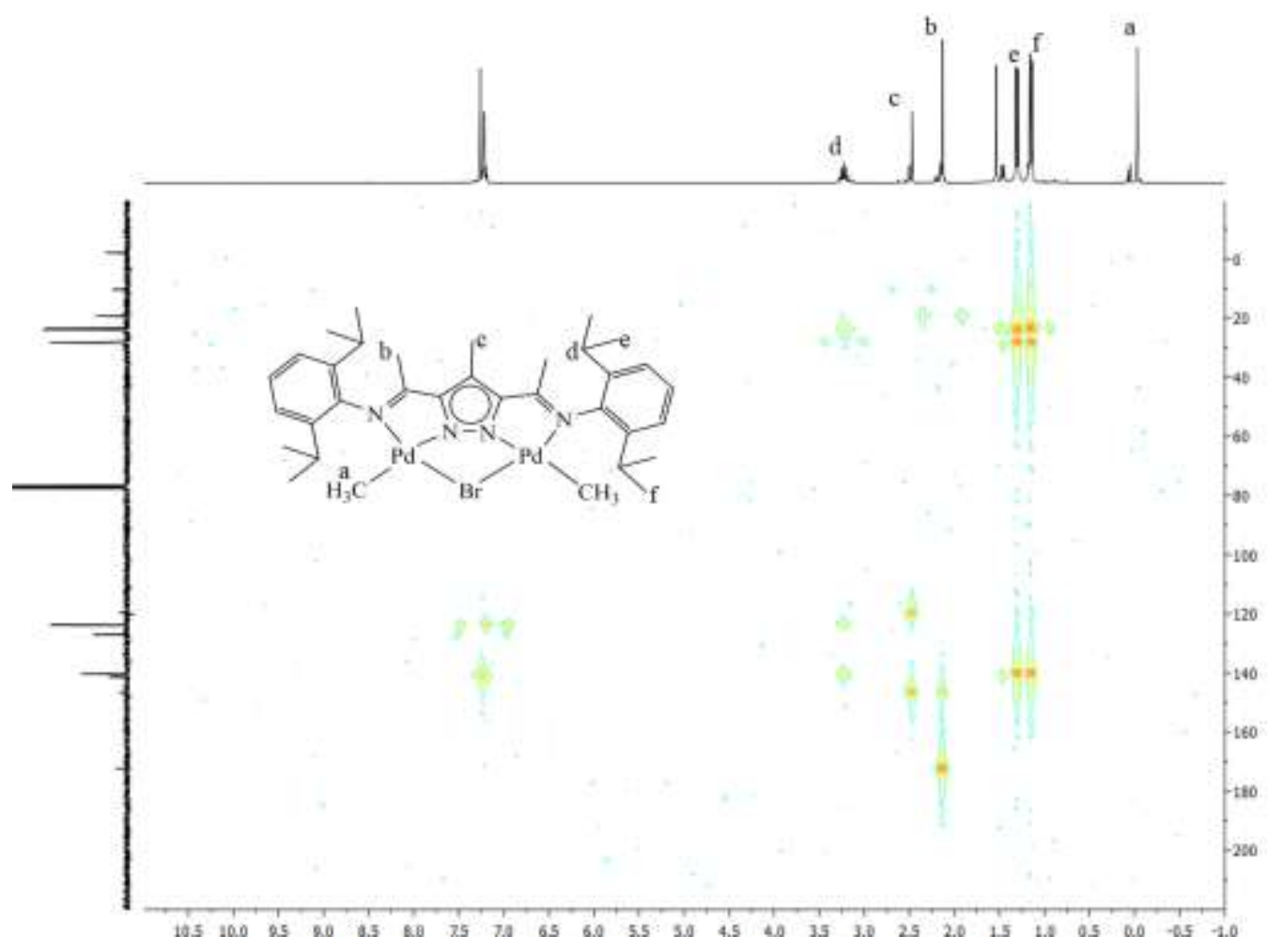

Fig. 6.2. 8: ${ }^{1} \mathrm{H}-{ }^{13} \mathrm{C}$ HMBC NMR spectrum for $2 \mathrm{~g}$ measured in $\mathrm{CDCl}_{3}$ at room temperature 
The ESI-MS of $\mathbf{2 g}$ (Fig. 6.2. 9) shows $\mathrm{m} / \mathrm{z}$ fragment of $725(22 \%)$ for $[\mathrm{M}-\mathrm{Br}]^{+}$. The figure below (Fig. 6.2. 9) shows the observed (left) and simulated (right) isotopic distribution pattern for the $[\mathrm{M}-\mathrm{Br}]^{+}$fragment.
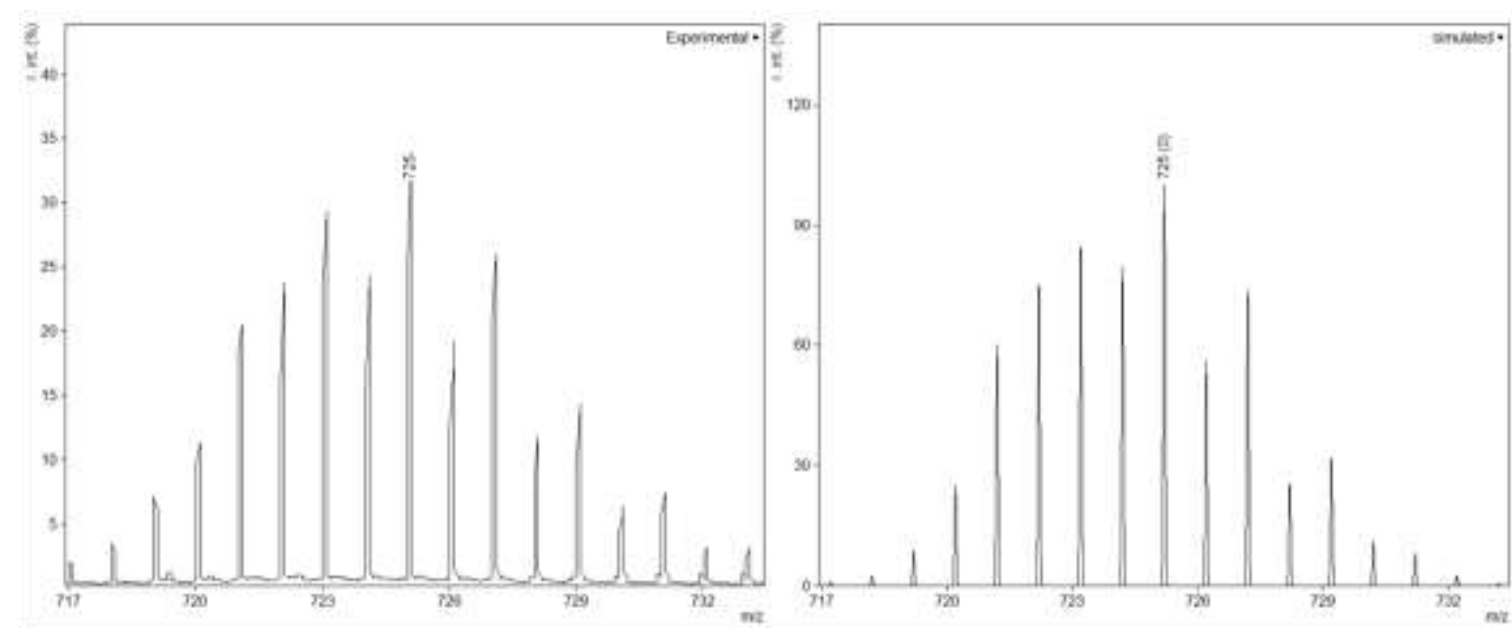

Fig. 6.2. 9: ESI mass spectra of 2g, showing the observed (left), and simulated (right) isotopic distribution pattern

The formation of the $C_{2 \mathrm{v}}$ symmetry product $2 \mathrm{~g}$ is evident, attempts at obtaining single crystals suitable for single crystal X-ray crystallography proved futile.

Considering the fact that methylation of $\mathbf{2} \mathbf{b}\left[\mathrm{L}^{2} \mathrm{Pd}_{2} \mathrm{Br}_{3}\right]$ only terminates at the $C_{2 \mathrm{v}}$ product $\mathbf{2} \mathbf{g}$ $\left[\mathrm{L}^{2} \mathrm{Pd}_{2}\left(\mathrm{CH}_{3}\right)_{2} \mathrm{Br}\right]$, it does not come as a surprise that $2 \mathrm{c}\left[\mathrm{L}^{2} \mathrm{Pd}_{2} \mathrm{I}_{3}\right]$ does not undergo methylation with $\mathrm{SnMe}_{4}$. It is contended that, palladium like platinum, a 'class b' metal (soft acid) has greater bond dissociation energy of the order ( $\mathrm{M}-\mathrm{Cl}>\mathrm{M}-\mathrm{Br})$ which results in more stable complexes in bromides than in chlorides in solution and it is a solution phenomena. 222,223

In this case however, it can be argued that the formation the more strong $\mathrm{Sn} \cdots \mathrm{Cl}$ bond in $\mathrm{SnMe}_{3} \mathrm{Cl}$ acts as a thermodynamic driving force.

As a follow up on the previously made observation that the addition of a large excess of $\mathrm{SnMe}_{4}$ results in the formation of a second but unidentified product, experiments were carried out in attempts at observing and isolating this product. In one such experiment, 40 equivalents $\mathrm{SnMe}_{4}$ were added to a $\mathrm{CH}_{2} \mathrm{Cl}_{2}$ solution of $\mathbf{2 a}$ with stirring for $48 \mathrm{~h}$ (Scheme 6.2. 7). 


\section{Results and Discussions}

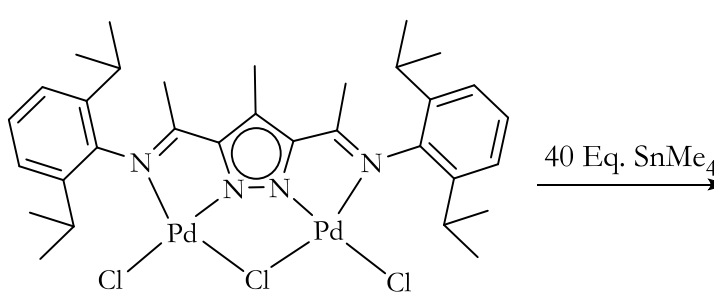

$2 a$

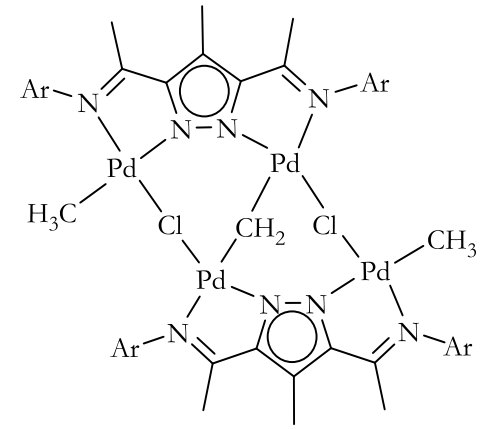

$\mathbf{X X I}^{\mathbf{c}}$

Scheme 6.2. 7: Formation of previously unidentified side product $2 \mathrm{~h}$ with excess $\mathrm{SnMe}_{4}$ and longer reaction time

After $48 \mathrm{~h}$, the reaction was worked up and all volatiles removed. The ${ }^{1} \mathrm{H}$ NMR spectrum of the reaction mixture showed the formation of the tetrapalladium complex $\left(\mathbf{X X I}^{\circ}\right)$. Also, the characteristic signal for the bridging $\mu-\mathrm{CH}_{2}$ is observed at $3.89 \mathrm{ppm}$. However, two new $\mathrm{CH}_{3}{ }^{\mathrm{P} 4}$ peaks were observed downfield at 2.88 and $2.91 \mathrm{ppm}$, a departure from the ${ }^{1} \mathrm{H}$ NMR spectrum peak of $2.49 \mathrm{ppm}$ that is usually observed for the $\mathrm{CH}_{3}{ }^{\mathrm{Pz}}{ }^{2}$ in $\mathbf{X X I}{ }^{\mathbf{c}}$.

A DOSY NMR experiment performed at $298 \mathrm{~K}$ showed a mixture of two distinct compounds, although these two products differed in their diffusion coefficients $\left(7.74 \times 10^{-10}\right.$ $\mathrm{m}^{2} \mathrm{~s}^{-1}$ for $\mathbf{2 h}$ as against $0.85 \times 10^{-9} \mathrm{~m}^{2} \mathrm{~s}^{-1}$ for $\mathbf{X X I} \mathbf{I}^{\mathrm{C}}{ }^{154}$ The unidentified product $\mathbf{2 h}$ precipitates as a pale yellow powder with the addition of hexane. Crystals of this new compound were obtained by the slow evaporation of a $\mathrm{CH}_{2} \mathrm{Cl}_{2} /$ hexane solution of the complex at room temperature.

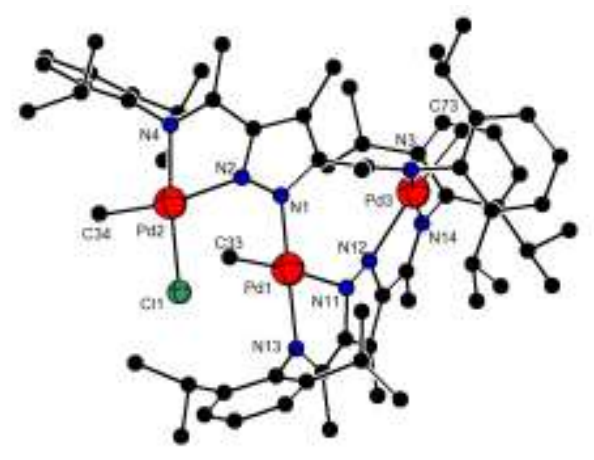

Fig. 6.2. 10: Molecular structure of $2 \mathrm{~h}$ ( $\left(\mathrm{SnMe}_{3} \mathrm{Cl}\right.$ omitted), all $\mathrm{H}$ atoms omitted for clarity

Single crystal X-ray structure showed it to be a complex of the nature $\left[\mathrm{L}_{2}^{2}\left\{\mathrm{CH}_{3} \mathrm{Pd}\right\}_{2}\left\{\mathrm{CH}_{3} \mathrm{PdCl}\right\}\left(\mathrm{Sn}\left(\mathrm{CH}_{3}\right)_{3} \mathrm{Cl}\right)\right]$ (2h) (Fig. 6.2. 10). A molecule of $\mathrm{SnMe}_{3} \mathrm{Cl}$ cocrystallizes in the asymmetric unit (not shown). The compound crystallizes in the $P 21 / \mathrm{c}$ 
space group. The compound has two ligands bound to three palladium(II) centres in a severely twisted ligand environment.

This new compound $\mathbf{2 h}$ has no $\mu-\mathrm{CH}_{2}$ or $\mu-\mathrm{Cl}$ environments but features three different $\mathrm{CH}_{3}{ }^{\mathrm{Pd}}$ in a bis-chelate ligand environment. One of the $\mathrm{CH}_{3}{ }^{\mathrm{Pd}}$ is strongly shielded by two rings of the aryl side arms. There is however no significant difference in the Pd-C bond lengths between the three $\mathrm{CH}_{3}{ }^{\text {Pd }}$ environments. The interplanar angle formed by the two pyrazolyl rings is severely twisted at $72.4^{\circ}$. Selected bond lengths $[\AA]$ and bond angles $\left[{ }^{\circ}\right]$ are given in Table 6.2.3.

Table 6.2. 3: Selected bond lengths $[\AA]$ and bond angles $\left[{ }^{\circ}\right]$ for $2 \mathrm{~h}$

\begin{tabular}{llll}
\hline \multicolumn{3}{c}{ Bond lengths $[\AA]$} & \multicolumn{1}{c}{ Bond angles [ $\left.{ }^{\circ}\right]$} \\
\hline $\operatorname{Pd}(1)-\mathrm{N}(1)$ & $2.017(5)$ & $\mathrm{N}(1)-\mathrm{Pd}(1)-\mathrm{C}(33)$ & $89.32(2)$ \\
$\operatorname{Pd}(1)-\mathrm{C}(33)$ & $2.031(5)$ & $\mathrm{N}(1)-\mathrm{Pd}(1)-\mathrm{N}(11)$ & $94.50(17)$ \\
$\operatorname{Pd}(2)-\mathrm{C}(34)$ & $2.019(5)$ & $\mathrm{C}(33)-\mathrm{Pd}(1)-\mathrm{N}(11)$ & $175.78(2)$ \\
$\operatorname{Pd}(2)-\mathrm{N}(4)$ & $2.067(5)$ & $\mathrm{N}(13)-\mathrm{Pd}(1)-\mathrm{N}(11)$ & $78.34(17)$ \\
$\operatorname{Pd}(3)-\mathrm{C}(73)$ & $2.037(6)$ & $\mathrm{C}(34)-\mathrm{Pd}(2)-\mathrm{N}(4)$ & $93.10(2)$ \\
\hline
\end{tabular}

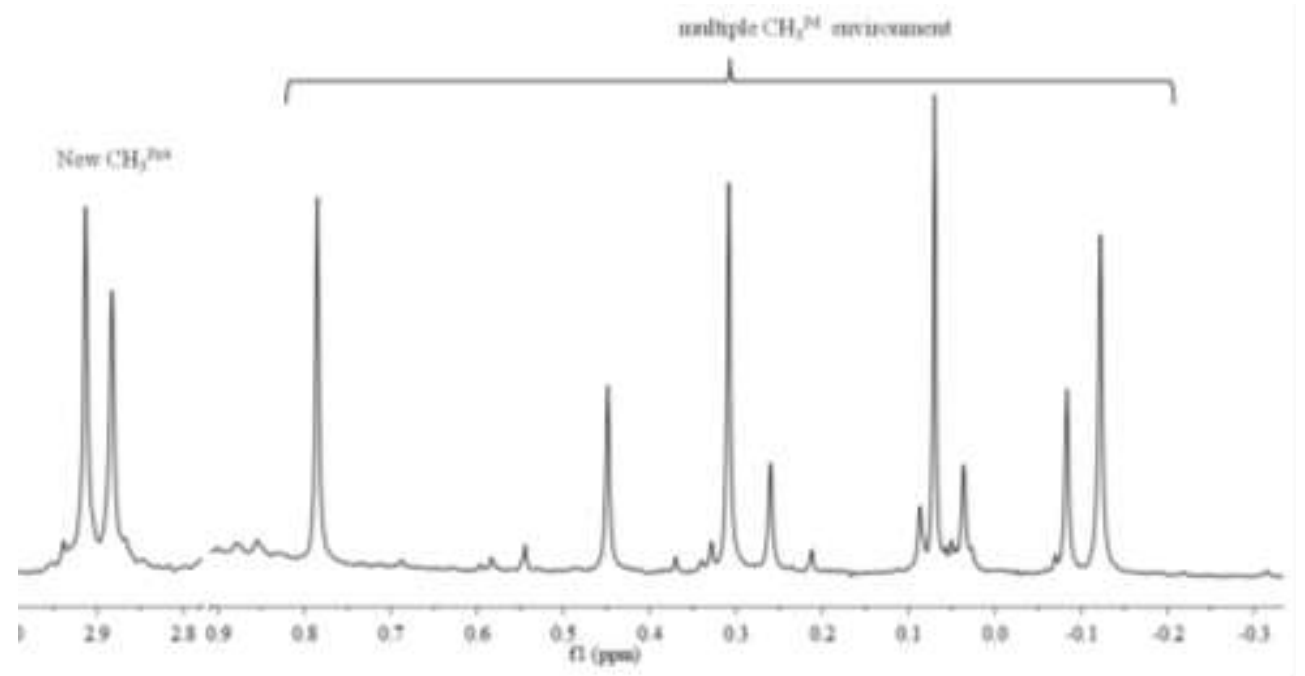

Fig. 6.2. 11: ${ }^{1} \mathrm{H}$ NMR spectrum (selected window) of $3 \mathrm{~h}$ showing the different $\mathrm{CH}_{3}{ }^{\mathrm{Pd}}$ and $\mathrm{CH}_{3}{ }^{\mathrm{Pz} 4}$ environments measured in $\mathrm{CDCl}_{3}$ at room temperature

The ${ }^{1} \mathrm{H}$ NMR spectrum of $\mathbf{2 h}$ shows multiple $\mathrm{CH}_{3}{ }^{\text {Pd }}$ environments at $\delta:-0.12,-0.08,0.31$, and $0.45 \mathrm{ppm}$, due to isomers formed from the chloride ligand adopting a cis or trans 


\section{Results and Discussions}

orientation in relation to the imine (Fig. 6.2. 11). In addition, two $\mathrm{CH}_{3}{ }^{\mathrm{Pz} 4}$ peaks are observed downfield at 2.88 and $2.91 \mathrm{ppm}$. This is departure from the ${ }^{1} \mathrm{H}$ NMR spectrum peak of 2.49 ppm observed for the $\mathrm{CH}_{3}{ }^{\mathrm{P}_{\mathrm{z}}}$ of the tetrapalladium complex (in $\mathrm{CDCl}_{3}$ ).

The ESI-MS of $\mathbf{2 h}$ also shows patterns with $m$ / z values of 1329 (55\%), 1314 (20\%) and 1299 $(100 \%)$ which can be assigned to $\left[\mathrm{L}_{2}^{2} \mathrm{Pd}_{3}\left(\mathrm{CH}_{3}\right)_{3}\right]^{+}, \quad\left[\mathrm{L}_{2}^{2} \mathrm{Pd}_{3}\left(\mathrm{CH}_{3}\right)_{2}\right]^{+}$and $\left[\mathrm{L}_{2}^{2} \mathrm{Pd}_{3}\left(\mathrm{CH}_{3}\right)\right]^{+}$ fragments respectively. Surprisingly by treating the $C_{2 \mathrm{v}}$ intermediate $\mathbf{2} \mathbf{f}$ with excess $\mathrm{SnMe}_{4}$ for $72 \mathbf{h}, \mathbf{2 h}$ is again formed. This confirms that the formation of $\mathbf{2 h}$ is indeed influenced by excess $\mathrm{SnMe}_{4}$ and longer reaction times.

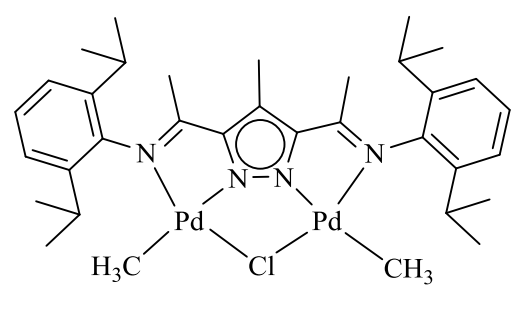

$2 \mathbf{f}$
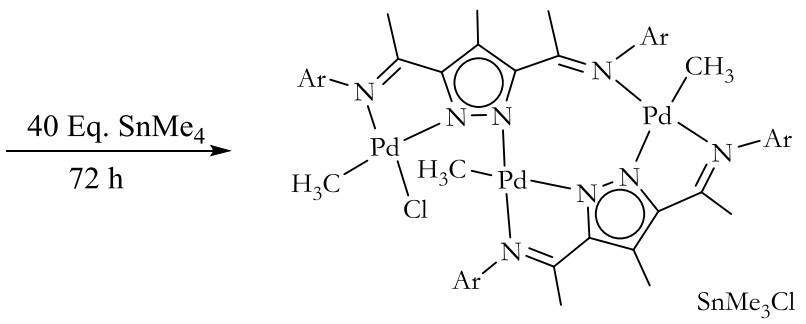

$2 \mathrm{~h}$

Scheme 6.2.8: Scheme showing the formation of $2 \mathrm{~h}$ from treatment of $2 \mathrm{f}$ with excess $\mathrm{SnMe}_{4}$

The formation of $\mathbf{2 h}$ is a competing reaction route to the formation of the tetrapalladium complex, $\mathbf{X X I}$, since the addition of excess $\mathrm{SnMe}_{4}$ to $\mathbf{X X I}^{\mathbf{c}}$ does not result in the formation of $\mathbf{2 h}$, but both are formed concurrently in the same reaction medium. The higher the concentration of $\mathrm{SnMe}_{4}$ and longer reaction time applied, the greater the proportion of $\mathbf{2 h}$ formed in relation to the tetrapalladium complex.

In a separate experiment, single crystals of another side product of the nature $\left[\mathrm{H}_{2} \mathrm{~L}_{2}{ }_{2} \mathrm{Pd}\right]\left[\mathrm{Sn}\left(\mathrm{CH}_{3}\right)_{2} \mathrm{Cl}_{2}\right]_{2}$ (2i) were isolated, however not enough material was available for further characterization. The product $\mathbf{2} \mathbf{i}$ was isolated from a solution containing single crystals of $\mathbf{X X I}^{\mathbf{c}}$ submitted for analysis. In $\mathbf{2} \mathbf{i}$, the two of the imine nitrogen atoms are protonated in a $\left[\left(\mathrm{HL}^{2}\right)_{2} \mathrm{Pd}\right]^{2+}$ cationic complex with two $\left[\mathrm{Sn}\left(\mathrm{CH}_{3}\right)_{2} \mathrm{Cl}_{3}\right]^{-}$counterions. This point to the possible release of $\mathrm{HCl}$ in the reaction sequence. The molecular structure is shown in Fig. 6.2. 12. As well as selected bond lengths and angles given in Table 6.2. 4. 


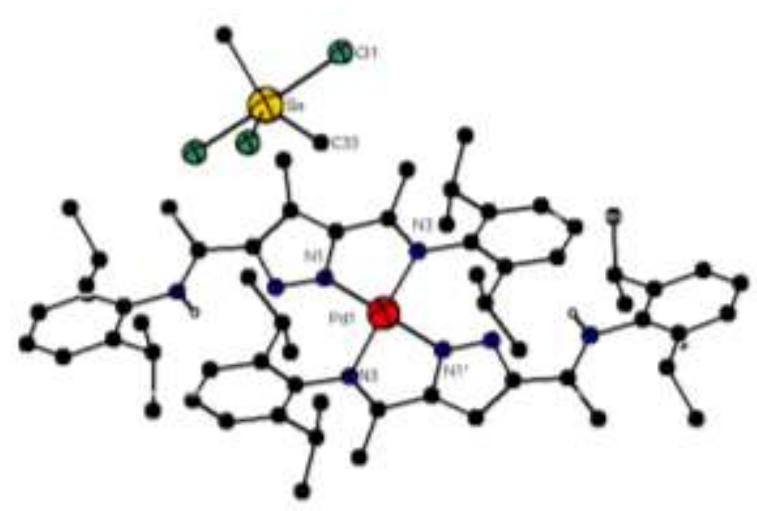

Fig. 6.2. 12: Molecular structure of $2 \mathrm{i}$, most $\mathrm{H}$ atoms and one $\left[\mathrm{Sn}\left(\mathrm{CH}_{3}\right)_{2} \mathrm{Cl}_{3}\right]^{-}$molecule, omitted for clarity

The coordination environment around the palladium centre in $2 \mathbf{i}$ is perfectly square planar, the sum of the angles making up the square plane defined by the atoms $\mathrm{N}(1) /\left(\mathrm{N}\left(1^{\prime}\right) / \mathrm{N}(2) / \mathrm{N}(2)\right.$ equalling $360^{\circ}$. The interplanar angle defined by the aryl ring and the pyrazole ring with each ligand is nearly perpendicular at $85.7^{\circ}$. The $\operatorname{Pd}(1)-\mathrm{N}(1)$ and $\operatorname{Pd}(1)-$ $\mathrm{N}(3)$ bond distance are $1.99 \AA$ and $2.04 \AA$ respectively. Selected bond lengths $[\AA]$ and bond angles $\left[{ }^{\circ}\right]$ are given in Table 6.2. 4.

Table 6.2. 4: Selected bond lengths $[\AA \AA]$ and bond angles $\left[{ }^{\circ}\right]$ for $2 \mathrm{i}$

\begin{tabular}{llll}
\hline \multicolumn{3}{c}{ Bond lengths $[\AA]$} & \multicolumn{1}{c}{ Bond angles $\left[^{\circ}\right]^{\prime}$} \\
\hline $\operatorname{Pd}(1)-\mathrm{N}(1)$ & $1.995(2)$ & $\mathrm{N}(1)-\mathrm{Pd}(1)-\mathrm{N}(1)$ & $180.00(1)$ \\
$\operatorname{Pd}(1)-\mathrm{N}(3)$ & $2.041(2)$ & $\mathrm{N}(1)-\mathrm{Pd}(1)-\mathrm{N}(3)$ & $78.79(10)$ \\
$\mathrm{Sn}(1)-\mathrm{C}(33)$ & $2.108(5)$ & $\mathrm{C}(5)-\mathrm{N}(3)-\mathrm{C}(7)$ & $121.20(2)$ \\
$\mathrm{Sn}(1)-\mathrm{Cl}(1)$ & $2.6560(9)$ & $\mathrm{C}(7)-\mathrm{N}(3)-\mathrm{Pd}(1)$ & $122.10(18)$ \\
\hline
\end{tabular}

A third crop of crystals isolated after several days from the same reaction medium showed a completely different ${ }^{1} \mathrm{H}$ NMR spectrum. Crystalline material obtained showed only a single peak for the $\mathrm{CH}_{3}{ }^{\mathrm{Pd}}$ group at $0.27 \mathrm{ppm}$. Attempts to isolate crystals suitable for X-ray crystallography failed. The ESI-MS of this complex shows no large molecular aggregates as seen for $\mathbf{2 h}$. However, common $\mathrm{m} / \mathrm{z}$ distributions such as 759 (20\%), 725 (100\%) and 693 $(100 \%)$ which can be assigned to $\left[\mathrm{L}^{2} \mathrm{Pd}_{2}\left(\mathrm{CH}_{3}\right)_{2} \mathrm{Cl}\right]^{+},\left[\mathrm{L}^{2} \mathrm{Pd}_{2}\left(\mathrm{CH}_{3}\right)_{2}\right]^{+}$, and $\left[\mathrm{L}^{2} \mathrm{Pd}_{2}\right]^{+}$respectively are observed. DOSY NMR experiments were made on the obtained complexes. 


\section{Results and Discussions}

The diffusion coefficients obtained for the observed complexes and intermediates are listed in Table 6.2. 5. An example of a DOSY spectrum is that of $2 \mathrm{~g}$ shown in Fig. 6.2. 13, the DOSY spectrum shows only one level diffusion rate and small signals from solvents such as $\mathrm{CD}_{2} \mathrm{Cl}_{2}$.

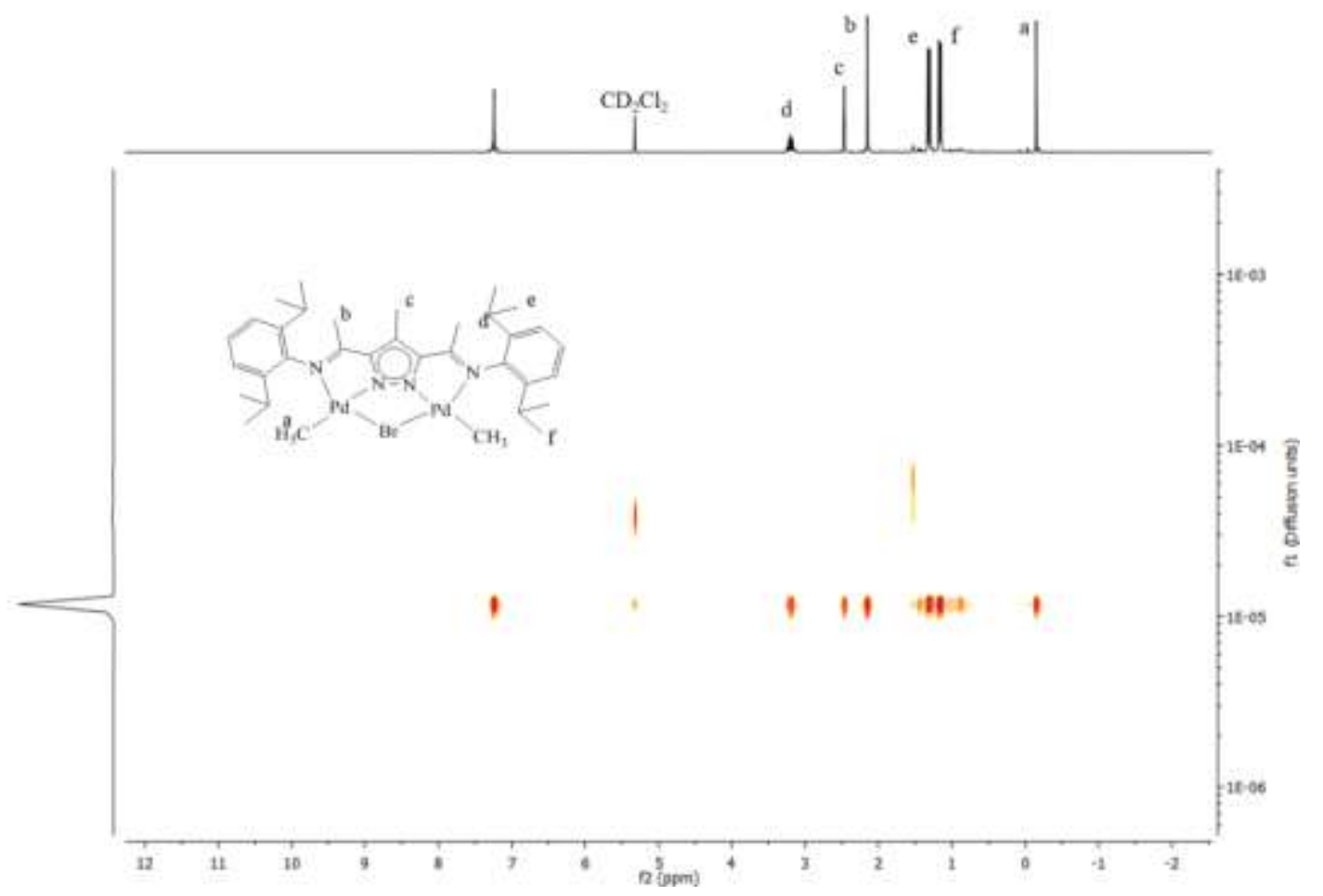

Fig. 6.2. 13: DOSY NMR spectrum of $2 \mathrm{~g}$ measured in $\mathrm{CD}_{2} \mathrm{Cl}_{2}$ at room temperature

Table 6.2. 5: Table of diffusion constants for the various palladium complexes

\begin{tabular}{|c|c|c|c|}
\hline Compound & $\begin{array}{c}\text { (diffusion units)/ } \\
\mathrm{cm}^{2} \mathrm{~s}^{-1}\end{array}$ & (D) $/ \mathrm{m}^{2} \mathrm{~s}^{-1}$ & $\begin{array}{l}\log \text { (diffusion } \\
\text { units) } / \mathrm{m}^{2} \mathrm{~s}^{-1}\end{array}$ \\
\hline$\left[\mathrm{L}^{2} \mathrm{Pd}_{2} \mathrm{I}_{3}\right](2 \mathrm{c})$ & $1.00 \times 10^{-5}$ & $1.00 \times 10^{-9}$ & -9.00 \\
\hline$\left[\mathrm{L}^{2} \mathrm{Pd}_{2}(\mu-\mathrm{Cl})\left(\mathrm{CH}_{3}\right)_{2}\right](\mathbf{2 f})$ & $1.00 \times 10^{-5}$ & $1.00 \times 10^{-9}$ & -9.00 \\
\hline$\left[\mathrm{L}^{2} \mathrm{Pd}_{2}(\mu-\mathrm{Br})\left(\mathrm{CH}_{3}\right)_{2}\right](2 \mathbf{g})$ & $1.29 \times 10^{-5}$ & $1.29 \times 10^{-9}$ & -8.89 \\
\hline$\left[\mathrm{L}_{2}^{2}\left\{\mathrm{CH}_{3} \mathrm{Pd}\right\}\left\{\mathrm{CH}_{3} \mathrm{PdCl}\right\}\left(\mathrm{Sn}\left(\mathrm{CH}_{3}\right)_{3} \mathrm{Cl}\right)\right](\mathbf{2 h})$ & $7.74 \times 10^{-6}$ & $7.74 \times 10^{-10}$ & -9.91 \\
\hline
\end{tabular}

Diffusion coefficient $\left(\mathrm{m}^{2} \mathrm{~s}^{-1}\right)$ values of $1.29 \times 10^{-9}$ were obtained for $2 \mathrm{~g}$ compared to $1.00 \mathrm{x}$ $10^{-9} \mathrm{~m}^{2} \mathrm{~s}^{-1}$ for $\mathbf{2 f}$. The diffusion coefficient of $\mathbf{2} \mathbf{f}$ is smaller compared to that of $\mathbf{2} \mathbf{g}$ due to the larger size of the bromide compared to the chloride. As expected, the diffusion coefficient for $\mathbf{2 f}$ and $\mathbf{2} \mathbf{g}$ is of a magnitude larger compared to $\mathbf{2 h}\left(7.74 \times 10^{-10} \mathrm{~m}^{2} \mathrm{~s}^{-1}\right)$. 
The possibility of the methylene bridge originating from the insertion of methylene chloride into a low valent palladium species can be ruled out as experiments performed in $\mathrm{CD}_{2} \mathrm{Cl}_{2}$, $\mathrm{CDCl}_{3}$ and chlorobenzene, all yield the tetrapalladium unit $\mathbf{X X I}^{\mathbf{c}}$. It must however be stressed that the formation of $\mathbf{X X I}^{\mathrm{c}}$ is dependent on the use of chlorinated solvents. Based on observed results, a modified scheme (Scheme 6.2.9) to explain the formation of the observed products is shown below.
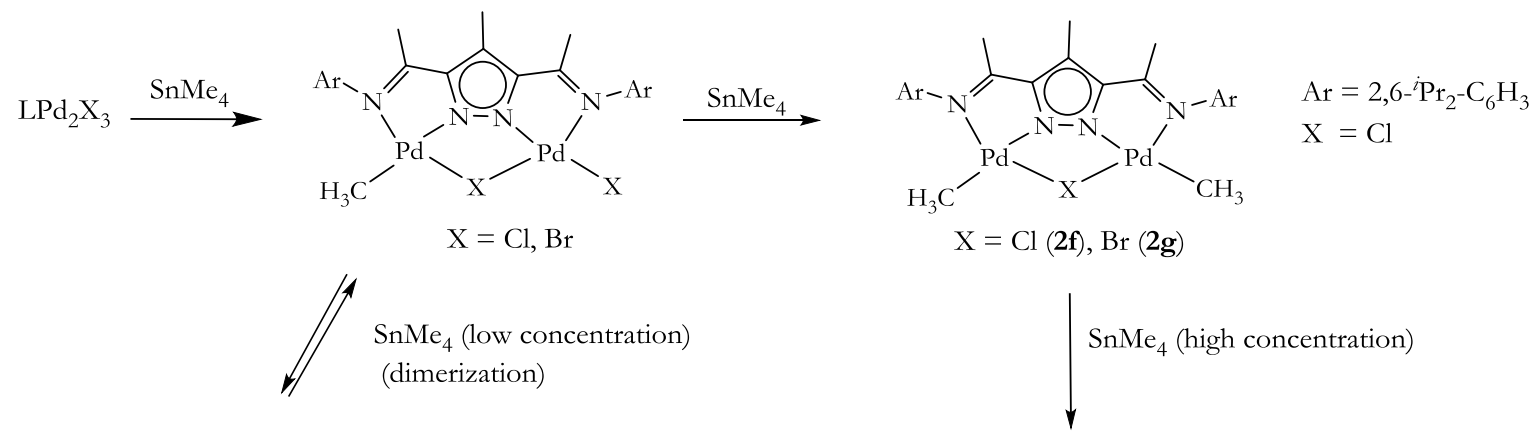

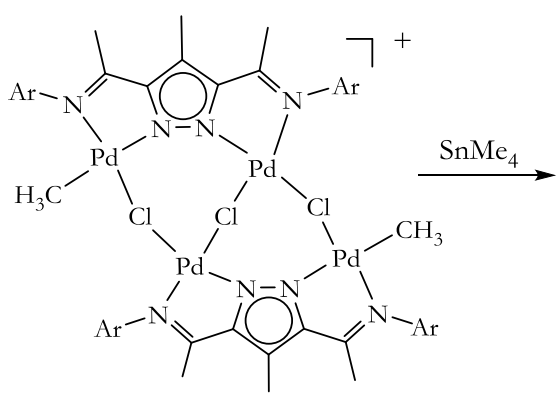

$2 d_{2}$

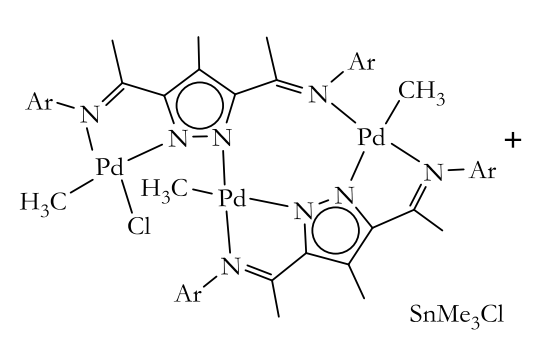

$2 \mathrm{~h}$

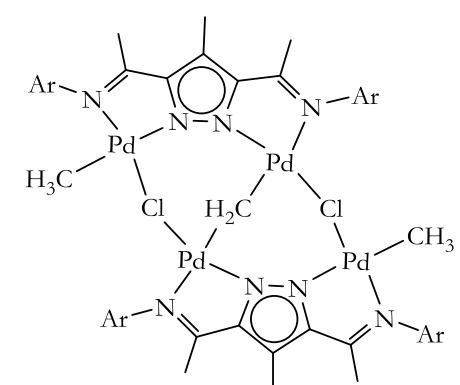

$\mathbf{X X I}^{\mathrm{c}}$

Scheme 6.2.9: Reaction scheme to the formation of XXIc

At low $\mathrm{SnMe}_{4}$ concentrations, the $C_{\mathrm{s}}$ symmetric product dimerizes to form $\mathbf{2} \mathbf{d}_{2}$, which is in a reversible equilibrium with the $C_{\mathrm{s}}$ symmetric product. In the presence of $\mathrm{SnMe}_{4}$, it reacts further to form a mixture of $\mathbf{2 h}$ and $\mathbf{X X I}^{\mathbf{c}}$.

Using 1a, it was possible to isolate the tetrapalladium derivative of $\mathrm{L}^{1}\left[\mathrm{~L}_{2}^{1} \mathrm{Pd}_{4}\left(\mu-\mathrm{CH}_{2}\right)(\mu\right.$ $\mathrm{Cl}_{2}\left(\mathrm{CH}_{3}\right)_{2}$ ] (2k) after $18 \mathrm{~h}$ in $39 \%$ yield. A second yet to be identified side product $2 \mathbf{j}$ is formed in $38 \%$ yield. 
Results and Discussions

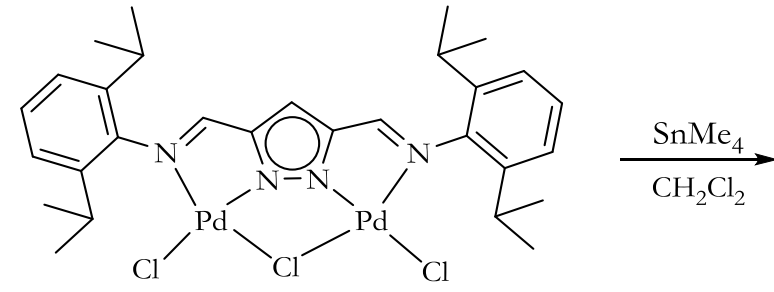

$1 a$

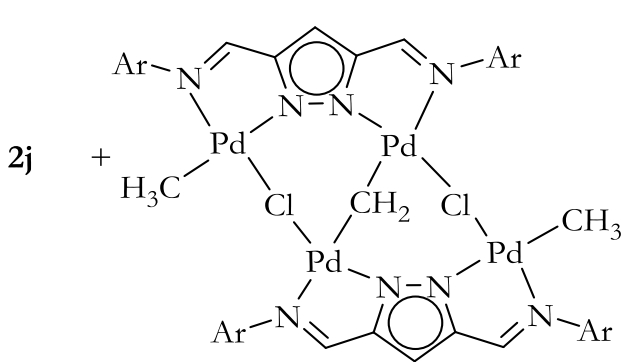

$2 \mathrm{k}$

Scheme 6.2. 10: Synthetic scheme for the preparation of $2 \mathrm{k}$

In $\mathbf{2 k}$, the bridging $\mu-\mathrm{CH}_{2}$ is observed at $4.23 \mathrm{ppm}$ whiles the $\mathrm{CH}_{3}{ }^{\mathrm{Pd}}$ is observed at $-0.03 \mathrm{ppm}$, compared to $\mathbf{X X I}^{\mathbf{c}}$ where the $\mu-\mathrm{CH}_{2}$ is observed at $3.96 \mathrm{ppm}$ and the $\mathrm{CH}_{3}{ }^{\text {Pd }}$ peak at $0.06 \mathrm{ppm}$ (in $\mathrm{CDCl}_{3}$ ). The $\mathrm{CH}^{\mathrm{Pz}}$ is observed as a singlet at $6.98 \mathrm{ppm}$, whiles the $\mathrm{CH}=\mathrm{N}$ peaks are observed as singlets at 7.91 and 8.04 ppm respectively (Fig. 6.2. 14).

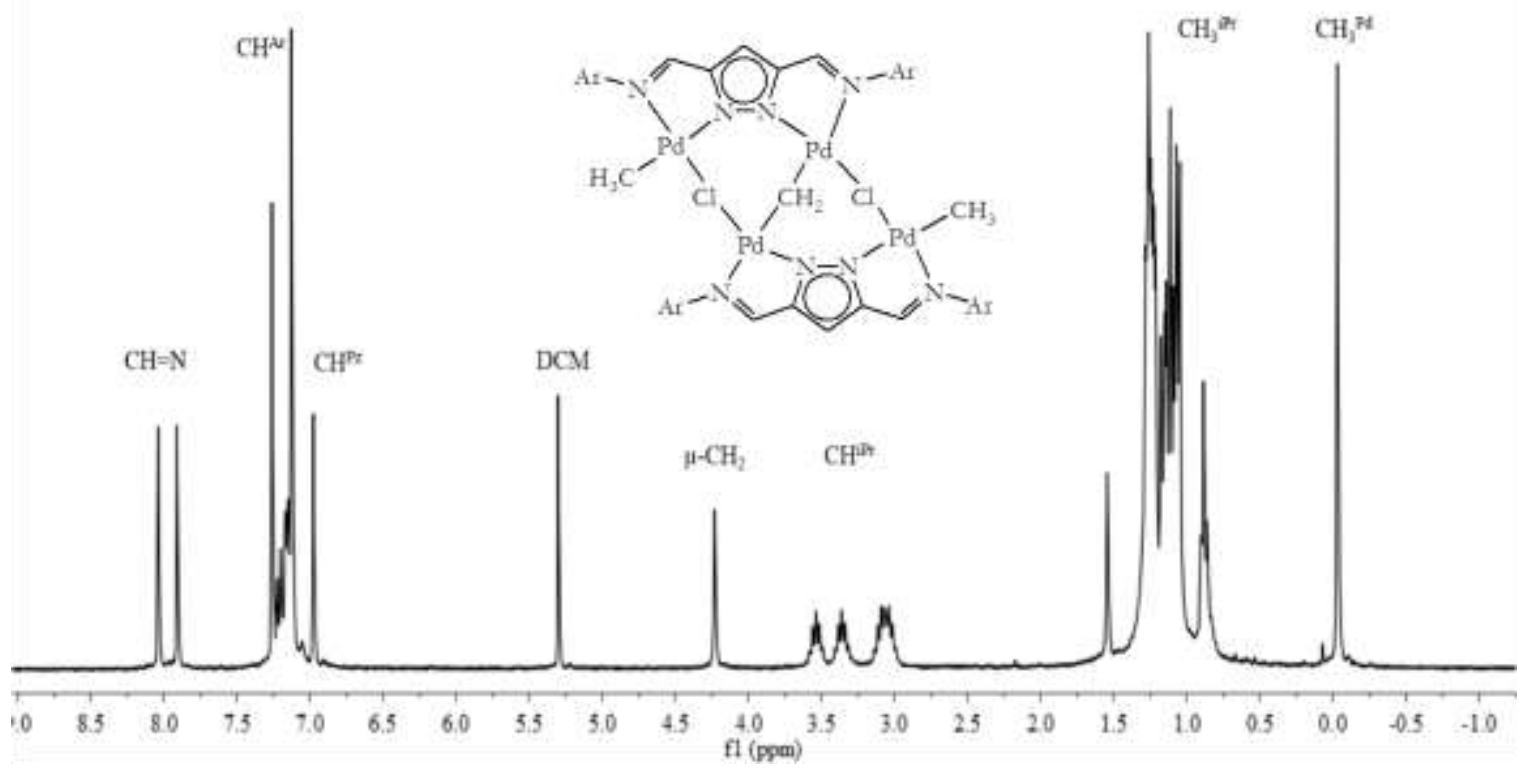

Fig. 6.2. 14: ${ }^{1} \mathrm{H}$ NMR spectrum of $2 \mathrm{k}$ measured in $\mathrm{CDCl}_{3}$ at room temperature

Crystals of $\mathbf{2 k}$ were obtained by the slow diffusion of hexane into a $\mathrm{CH}_{2} \mathrm{Cl}_{2}$ solution of the complex at $-10^{\circ} \mathrm{C}$. The molecular structure of $\mathbf{2 k}$ is shown in Fig. 6.2. 15. The complex crystallizes in the $P 21 /$ c space group. 


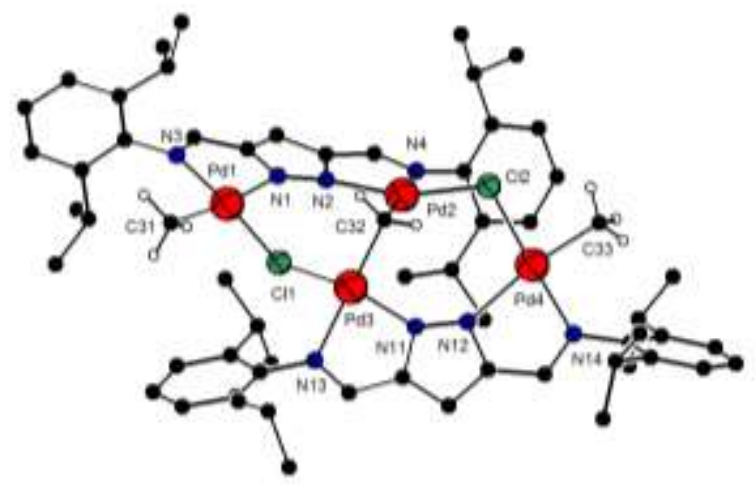

Fig. 6.2. 15: Molecular structure of $2 \mathrm{k}$ with most $\mathrm{H}$ and solvents omitted for clarity

The coordination around the palladium(II) centres in $\mathbf{2 k}$ is a distorted square planar with two squares connected at one corner by a $\mu-\mathrm{CH}_{2}$. The bridged $\operatorname{Pd}(2) \cdots \operatorname{Pd}(3)$ bond distance is 3.00 $\AA$ in the imine (2k), compared to $3.27 \AA$ in $\mathbf{X X I}^{\mathbf{c}}$. Thus, the flexibility of the $\mu-\mathrm{CH}_{2}$ allows for the expansion of the $\mathrm{Pd} \cdots \mathrm{Pd}$ distance in this complex. The torsional angle formed by the two Pd centres and the two pyrazolyl nitrogen atoms (Pd-N-N-Pd) is less $\left(30.5^{\circ}\right.$ ) in $\mathbf{2 k}$ compared to $\mathbf{X X I}^{\mathbf{c}}\left(50.1^{\circ}\right)$. In addition, the bite angle $\mathrm{N}-\mathrm{Pd}-\mathrm{N}$ in $\mathbf{2 k}\left(78.8^{\circ}\right)$ is slightly greater than that of $\mathbf{X X I}^{\mathbf{c}}\left(76.0^{\circ}\right)$. The Pd-C(sp $\left.)^{3}\right)$ distance, 2.024(4) $[\AA]$ is comparable to that found for other Pd-C bonds. ${ }^{224,225}$
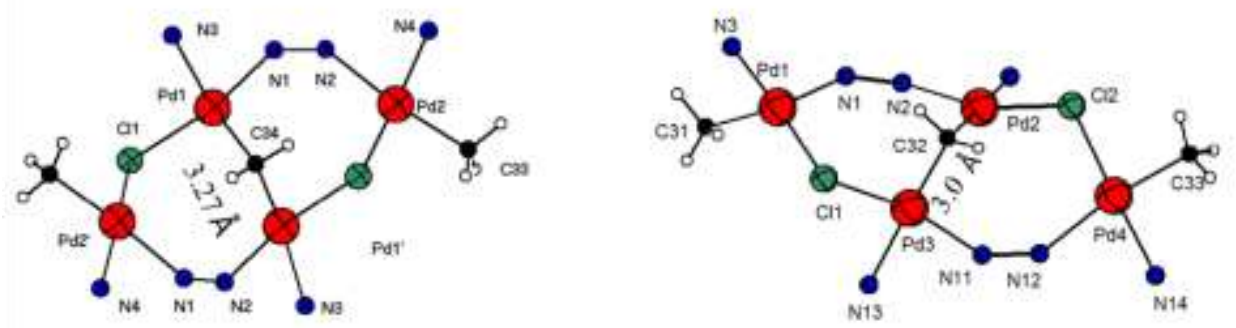

Fig. 6.2. 16: Drawings comparing the bond lengths of the bridged palladium atoms in XXIc (left) and 2k (right)

Although the $\mathrm{Pd} \cdots \mathrm{Pd}$ distance in $\mathbf{2} \mathbf{k}$ is $3.00 \AA$, there appears to be no basis to speculate the presence of a $\mathrm{Pd} \cdots \mathrm{Pd}$ metal bond from the formal electron count on the $\mathrm{Pd}$ atoms. The $\mathrm{Pd} \cdots \mathrm{Pd}$ distance is in the range of other reported bridged palladium(II) complexes. ${ }^{226,227,228} \mathrm{In}$ addition, the $\operatorname{Pd}(2)-C(32)-\operatorname{Pd}(3)$ angle in $\mathbf{2 k}\left(98.6^{\circ}\right)$ is less acute compared to other complexes with metal-metal bonds $\left(75-78^{\circ}\right)$ with bridging $\mu-\mathrm{CH}_{2}$ group. ${ }^{229,230}$

However it is still in the in the range of $\mu-\mathrm{CH}_{2}$ complexes, which have no metal-metal bonds 


$$
\text { Results and Discussions }
$$

$\left(89-123^{\circ}\right) .{ }^{231}$ Selected bond lengths and bond angles for $\mathbf{2 k}$ are given in Table 6.2. 6 .

Table 6.2. 6: Selected bond lengths $[\AA \AA]$ and bond angles $\left[{ }^{\circ}\right]$ for $2 \mathrm{k}$

\begin{tabular}{|c|c|c|c|}
\hline Bond lengths $[\AA ̊]$ & & Bond angles & \\
\hline $\operatorname{Pd}(1)-C(31)$ & $2.023(4)$ & $\operatorname{Pd}(2)-C(32)-\operatorname{Pd}(3)$ & $98.57(170)$ \\
\hline $\operatorname{Pd}(1)-\mathrm{N}(1)$ & $2.185(3)$ & $\mathrm{N}(1)-\mathrm{Pd}(1)-\mathrm{Cl}(1)$ & $103.75(9)$ \\
\hline $\operatorname{Pd}(1)-\mathrm{Cl}(1)$ & $2.2983(10)$ & $\mathrm{C}(32)-\mathrm{Pd}(2)-\mathrm{Cl}(2)$ & $88.75(12)$ \\
\hline $\operatorname{Pd}(2)-\operatorname{Pd}(3)$ & $3.008(4)$ & $\mathrm{C}(32)-\mathrm{Pd}(2)-\mathrm{N}(2)$ & $98.27(14)$ \\
\hline
\end{tabular}

As stated earlier, this complex constitutes only $39 \%$ of the reaction product. A second competing reaction product $2 \mathbf{j}$ was isolated (38\%). However, the lack of a crystal structure from this complex leaves room for speculation, $2 \mathbf{j}$ lacks a $\mu-\mathrm{CH}_{2}$ bridge and is possibly analogous to the compound $\left[\mathrm{L}_{2}^{2}\left\{\mathrm{CH}_{3} \mathrm{Pd}\right\}_{2}\left\{\mathrm{CH}_{3} \mathrm{PdCl}\right\}\left(\mathrm{Sn}\left(\mathrm{CH}_{3}\right)_{3} \mathrm{Cl}\right)\right](\mathbf{2 h})$ formed with excess $\mathrm{SnMe}_{4}$.

\section{Olefin coupling reactions with tetrapalladium complex}

Previous work done on this unique complex $\mathbf{X X I}^{\mathbf{c}}$ shows it actively dimerizes ethylene to a mixture of propenes and butenes (Scheme 6.2.11). The major product formed with ${ }^{13} \mathrm{C}$ labelled ethylene $\left({ }^{13} \mathrm{C}_{2} \mathrm{H}_{4}\right)$ is propene, which contained only two ${ }^{13} \mathrm{C}$ labels, with the origin of the unlabeled $\mathrm{C}_{1}$ unit purported to have come from either a $\mathrm{CH}_{3}$ or $\mu-\mathrm{CH}_{2}$ unit of the complex. ${ }^{154}$

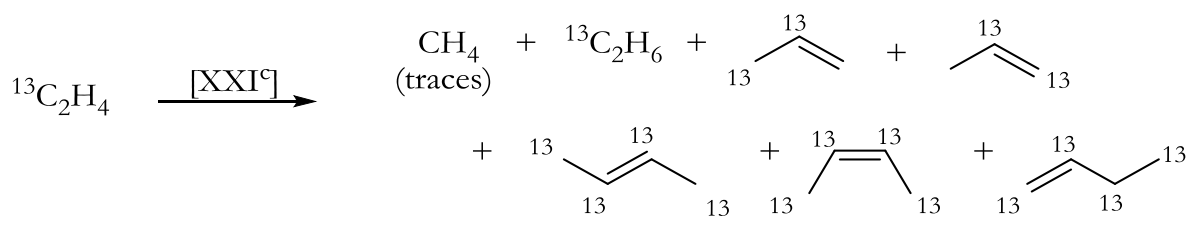

Scheme 6.2.11: Olefins resulting from the reaction of XXIc with ${ }^{13} \mathrm{C}_{2} \mathrm{H}_{4}{ }^{154}$

This motivated the testing of its reactivity towards a range of other olefins (Scheme 6.2.12). 


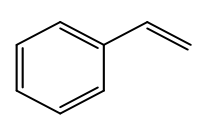

$$
\mathrm{NC}^{11}
$$<smiles>C=CC(=O)OC</smiles><smiles>O=C1C=CCCC1</smiles>

Scheme 6.2.12: Range of olefins tested in coupling reactions with $\mathrm{XXI}^{c}$

Results obtained showed that solutions of the complex with olefins alone fail to give any observable products when monitored over several days. Activated olefins such as tetracyanoethylene and tetrachloroethylene were also used in an attempt to obtain stable complexes. However, these failed to yield any reliable results as the spectrum of products obtained were difficult to interpret; ESI-MS neither yielded any reliable data.

However, in the presence of chloride abstracting reagents, notable changes in the spectrum are observed. Tests with two different chloride abstracting reagents were performed, mainly $\mathrm{NaBAr}_{4}{ }_{4}$ and $\mathrm{AgOTf}$. It therefore seems plausible, that with the addition of AgOTf, there is abstraction of the halide to form a highly reactive but unstable cationic $\left[\mathrm{L}_{2}^{2} \mathrm{Pd}_{4}\left(\mu-\mathrm{CH}_{2}\right)(\mu\right.$ $\left.\left.\mathrm{CH}_{3}\right)_{2}\right]^{2+}$ complex (2I) (Scheme 6.2.13).

$$
\begin{aligned}
& {\left[\mathrm{L}_{2}^{2} \mathrm{Pd}_{4}\left(\mu-\mathrm{CH}_{2}\right)\left(\mu-\mathrm{Cl}_{2}\right)\left(\mathrm{CH}_{3}\right)_{2}\right] \stackrel{2 \mathrm{AgOTf}}{\underset{\mathrm{CH}_{2} \mathrm{Cl}_{2}}{\longrightarrow}}\left[\mathrm{L}_{2}^{2} \mathrm{Pd}_{4}\left(\mu-\mathrm{CH}_{2}\right)\left(\mu-\mathrm{CH}_{3}\right)_{2}\right](\mathrm{OTf})_{2}} \\
& \mathbf{X X I}^{\mathrm{c}} \\
& 21
\end{aligned}
$$

Scheme 6.2.13: Scheme for the reaction of XXIc with AgOTf to form 21

Partial characterization of 21 by ${ }^{1} \mathrm{H}$ and ${ }^{13} \mathrm{C}$ NMR spectroscopy was made as well as ESI-MS, which showed a dominant $m / \%$ peak at $1474(100 \%)$ which can be assigned to $\left[\mathrm{L}_{2}^{2} \operatorname{Pd}_{4}(\mu\right.$ $\left.\left.\mathrm{CH}_{2}\right)\left(\mu-\mathrm{CH}_{3}\right)_{2}\left(\mathrm{H}_{2} \mathrm{O}\right)_{2}\right]^{2+}$.

In 21, the $\mathrm{CH}_{3}{ }^{\mathrm{Pd}}$ and bridging $\mu-\mathrm{CH}_{2}$ peaks are observed at 0.03 and $4.15 \mathrm{ppm}$ respectively, whiles the $\mathrm{CH}_{3} \mathrm{C}=\mathrm{N}$ groups are observed as a singlet at $2.18 \mathrm{ppm}$ and $\mathrm{CH}_{3}{ }^{\mathrm{P} 4}$ at $2.53 \mathrm{ppm}$. This point to a symmetric ligand environment, compared to peaks at $0.06\left(\mathrm{CH}_{3}{ }^{\mathrm{Pd}}\right), 3.96(\mu-$ $\left.\mathrm{CH}_{2}\right), 2.05\left(\mathrm{CH}_{3} \mathrm{C}=\mathrm{N}\right), 2.10\left(\mathrm{CH}_{3} \mathrm{C}=\mathrm{N}\right)$ and $2.47\left(\mathrm{CH}_{3}{ }^{\mathrm{P}_{2}}\right)$ ppm in the educt $\mathbf{X X I}^{\mathbf{c}}$.

To test if $\mathbf{2 1}$ is a reactive intermediate, two sets of experiments were performed. The first experiment involved treating a 1:0.8 mixture of $\mathbf{X X I}^{\mathbf{c}}$ and styrene- $d_{8}$ with 2 equivalents AgOTf. The reaction sequence was monitored at room temperature over several hours. After $5 \mathrm{hr}$ when all styrene- $d_{8}$ is depleted, a new $\mu-\mathrm{CH}_{2}$ is observed at $4.15 \mathrm{ppm}$. In a control 


\section{Results and Discussions}

experiment, treatment of $\mathbf{X X I}^{\mathbf{c}}$ with 1.5 equivalent $\mathrm{AgOTf}$ in the absence of styrene sees a gradual build up again of this new $\mu-\mathrm{CH}_{2}$ and a new $\mathrm{CH}_{3}{ }^{\text {Pd }}$ peak at $4.15 \mathrm{ppm}$ and $0.03 \mathrm{ppm}$ respectively (Fig. 6.2.17).

These peaks are the same as those observed for 21. The intensity of this new $\mu-\mathrm{CH}_{2}$ diminishes with time, with the concomitant formation of methane, whiles the unreacted $\mu$ $\mathrm{CH}_{2}$ remains unchanged.
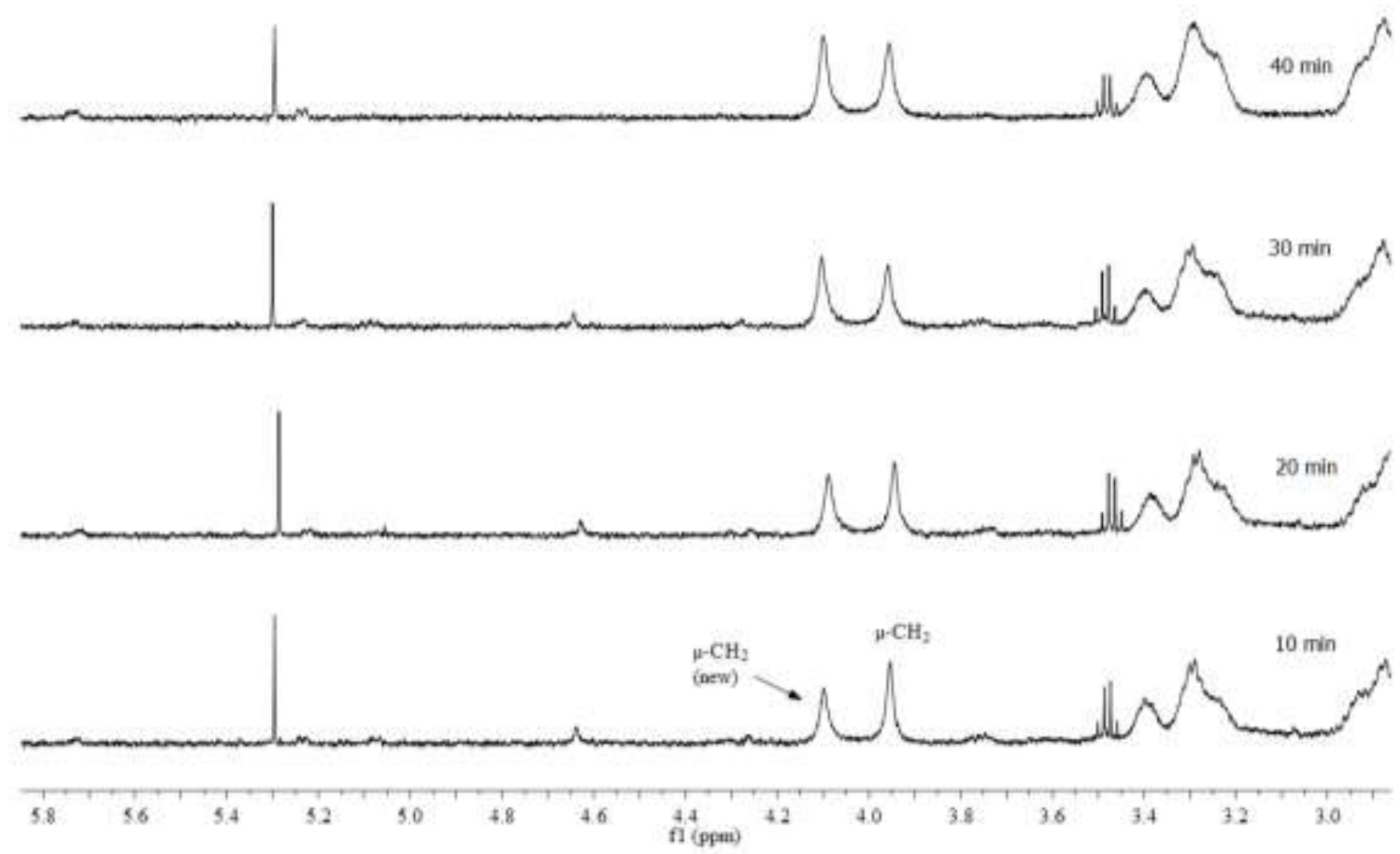

Fig. 6.2. 17: Stacked ${ }^{1} \mathrm{H}$ NMR spectra showing the formation of a new $\mu-\mathrm{CH}_{2}$ (21) environment from XXIc after addition of $\mathrm{AgOTf}$ with time measured in $\mathrm{CDCl}_{3}$ at room temperature

In another experiment, $\mathbf{X X I}^{\mathbf{c}}$ was treated with 2 mol equivalents $\mathrm{AgOTf}$ at room temperature in $\mathrm{CDCl}_{3}$ to form again $\mathbf{2 1}$ and the $\mathrm{AgCl}$ precipitate quickly filtered over celite.

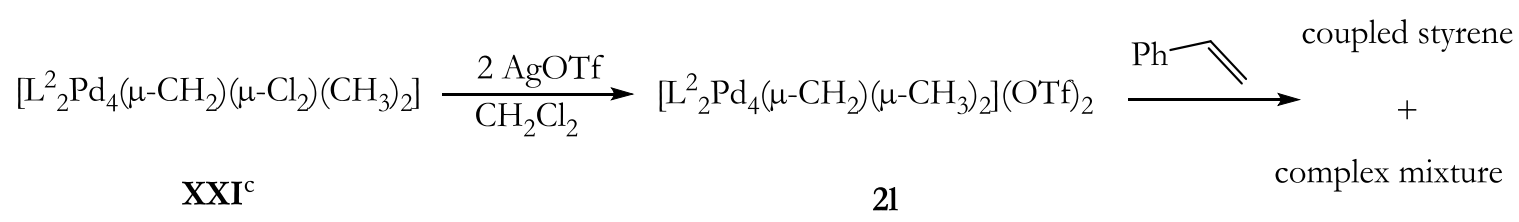


With the subsequent addition of styrene to 21 , a new $\mathrm{CH}_{3}$ environment forms at $1.90 \mathrm{ppm}$, with the concomitant depletion in the signal intensity of the $\mu-\mathrm{CH}_{2}$ in 21 (Fig. 6.2. 18).

However, when AgOTf is added as the last step to a mixture of $\mathbf{X X I}^{\mathbf{c}}$ and excess styrene, no new $\mu-\mathrm{CH}_{2}$ environment is observed, thus the formation of $\mathbf{2 l}$ is not observed. This suggests the $\mu-\mathrm{CH}_{2}$ group is immediately coupled to the olefin upon chloride abstraction. In addition, with the addition of a chloride-abstracting agent, an increase in signal intensity at $5.30 \mathrm{ppm}$ (same shift as $\mathrm{CH}_{2} \mathrm{Cl}_{2}$ ) is observed, possibly pointing to a pathway, which may involve the reductive elimination of $\mathrm{CH}_{2} \mathrm{Cl}_{2}$.

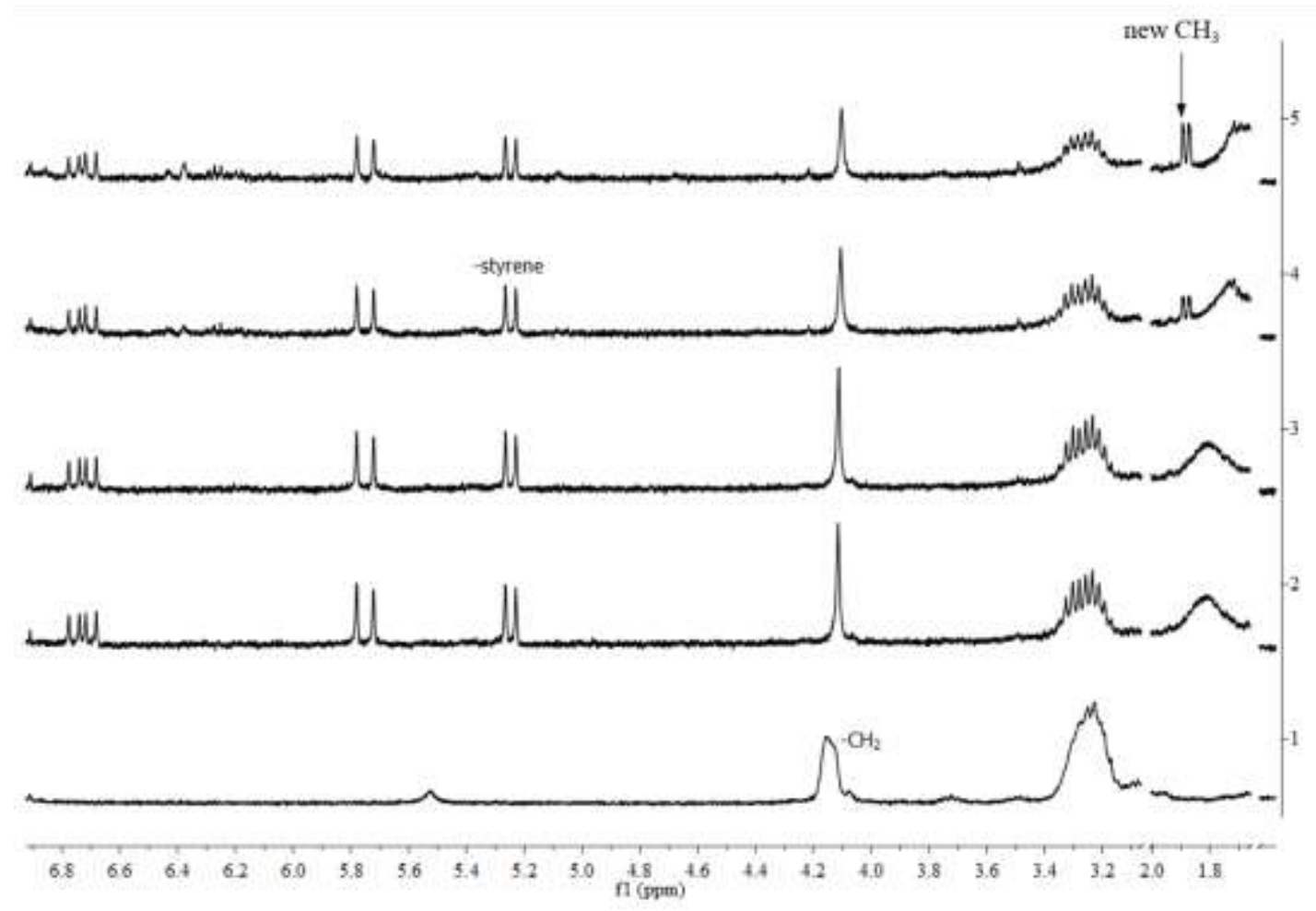

Fig. 6.2. 18: ${ }^{1} \mathrm{H}$ NMR spectra showing the depletion of the new $\mu-\mathrm{CH}_{2}$ environment in 21 and subsequent formation of a new $\mathrm{CH}_{3}$ environment after addition of styrene measured in $\mathrm{CDCl}_{3}$ at room temperature over a $4 \mathrm{~h}$ period

After workup, the crude reaction mixture was obtained as yellow oil. The ${ }^{1} \mathrm{H}$ NMR spectrum of this product (Fig. 6.2.19) shows two well separated sets of olefin signals which can be assigned to free styrene and a modified styrene molecule. This modified styrene molecule has strong correlations in the olefin region to the new $\mathrm{CH}_{3}$ environment at $1.90 \mathrm{ppm}$. 


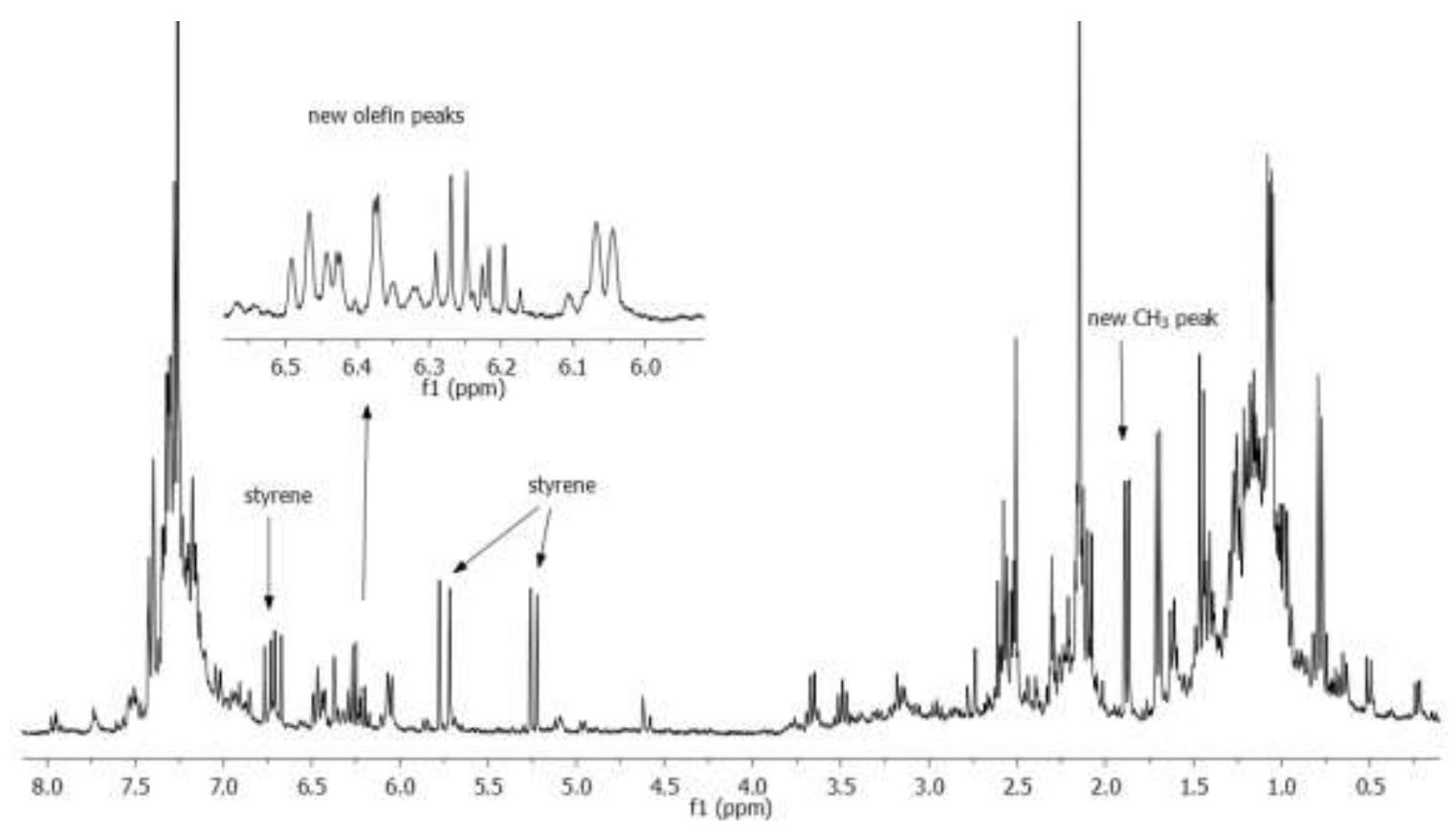

Fig. 6.2. 19: ${ }^{1} \mathrm{H}$ NMR spectrum of crude reaction mixture after treatment of $\mathrm{XXI}^{\mathrm{c}}$ with AgOTf in the presence of styrene measured in $\mathrm{CDCl}_{3}$ at room temperature

When styrene- $d_{8}$ is used in place of normal styrene, there appears to be extensive scrambling of this $\mathrm{CH}_{3}$ environment at $1.90 \mathrm{ppm}$. In both cases, the initial bridging $\mu-\mathrm{CH}_{2}$ at $3.96 \mathrm{ppm}$ is also evidently missing from the ${ }^{1} \mathrm{H}$ NMR spectrum.

The product was later identified by NMR analysis to be propenylbenzene. Detailed analysis of the spectrum shows that both $E$ - and $Z$-forms of the propenylbenzene are formed in a 50:50 ratio. The ${ }^{1} \mathrm{H}$ assignments for the cis and trans isomers are shown (red) and their ${ }^{13} \mathrm{C}$ correlations (blue) (Fig. 6.2. 20).
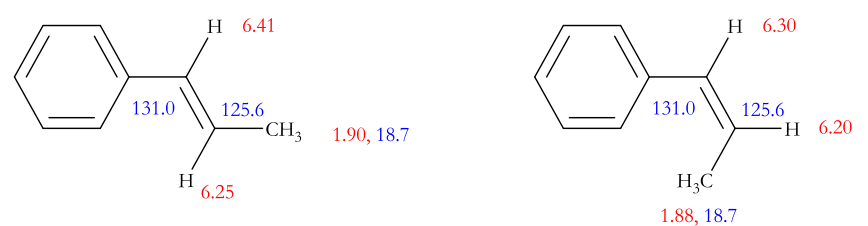

Fig. 6.2. 20: ${ }^{1} \mathrm{H}$ and ${ }^{13} \mathrm{C}$ NMR chemical shifts for cis and trans propenylbenzene

Based on results obtained and using styrene- $d_{8}$ in place of styrene, the origin of the bridging $\mu-\mathrm{CH}_{2}$ unequivocally is from the $\mu-\mathrm{CH}_{2}$ in $\mathbf{X X I}^{\mathbf{c}}$. The ${ }^{1} \mathrm{H}$ NMR spectrum of the deuterated propenylbenzene shows scrambling/deuterium exchange in the methyl protons as shown in Fig. 6.2. 21 (right). 
<smiles>[2H]C([2H])=C([2H])C1=C([2H])C([2H])C([2H])C([2H])=C1[2H]</smiles><smiles>[2H]/C(C[18O])=C(/[2H])c1c([2H])c([2H])c([2H])c([2H])c1[2H]</smiles>

Scheme 6.2.15: Scheme showing the formation of $(E / Z)$-prop-1-en-1-ylbenzene
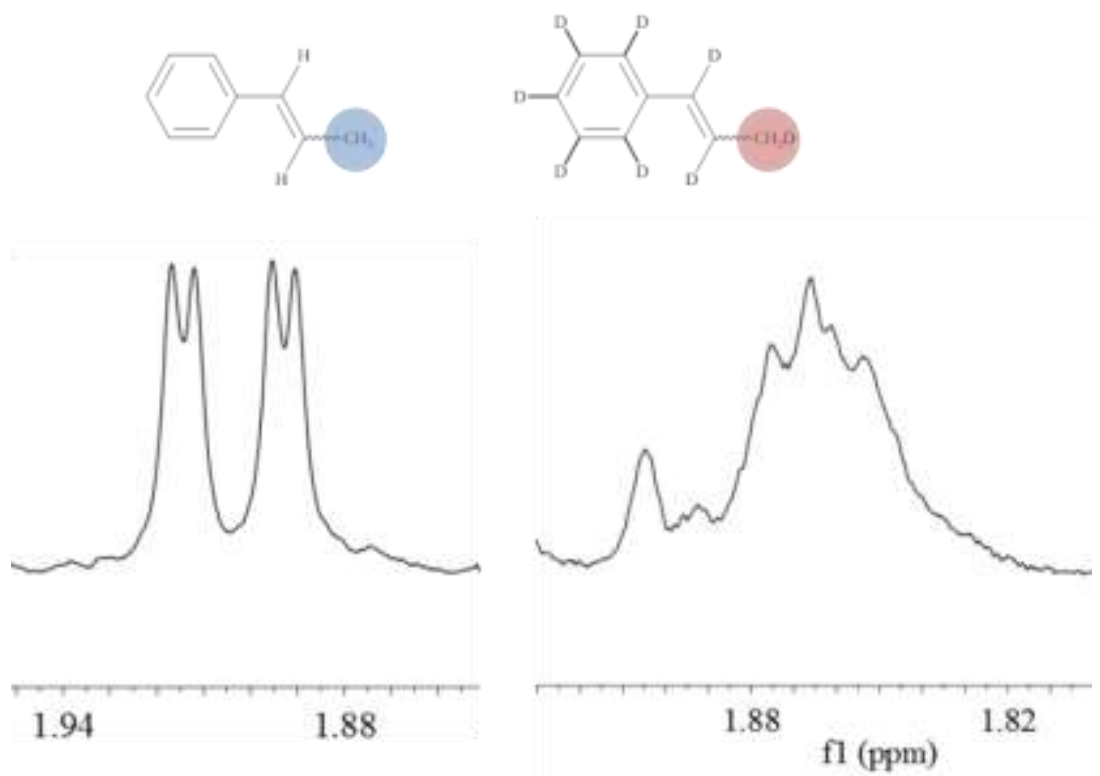

Fig. 6.2. 21: ${ }^{1} \mathrm{H}$ NMR spectra showing the $\mathrm{CH}_{3}$ region of propenylbenzene formed from deuterated styrene (right) and normal styrene (left) measured in $\mathrm{CDCl}_{3}$ at room temperature

To gain more insights in the mechanism involved in the transfer of the $\mu-\mathrm{CH}_{2}$ to the olefin, further kinetic studies were conducted. In a variable temperature experiment, the transfer of $\mu-\mathrm{CH}_{2}$ is only observed at temperatures exceeding $10^{\circ} \mathrm{C}$, at lower temperatures, transfer does not take place, neither is the formation of $\mathrm{Pd}-\mathrm{H}$ species observed at low temperatures. The sequential formation of propenylbenzene from styrene and $\mathbf{X X I}^{\mathbf{c}}$ was monitored over a $24 \mathrm{~h}$ period. The graphical representation of several decays within the complex with the addition of chloride abstracting agents and styrene are shown in (Fig. 6.2. 22 and Fig. 6.2. 23). 
Results and Discussions

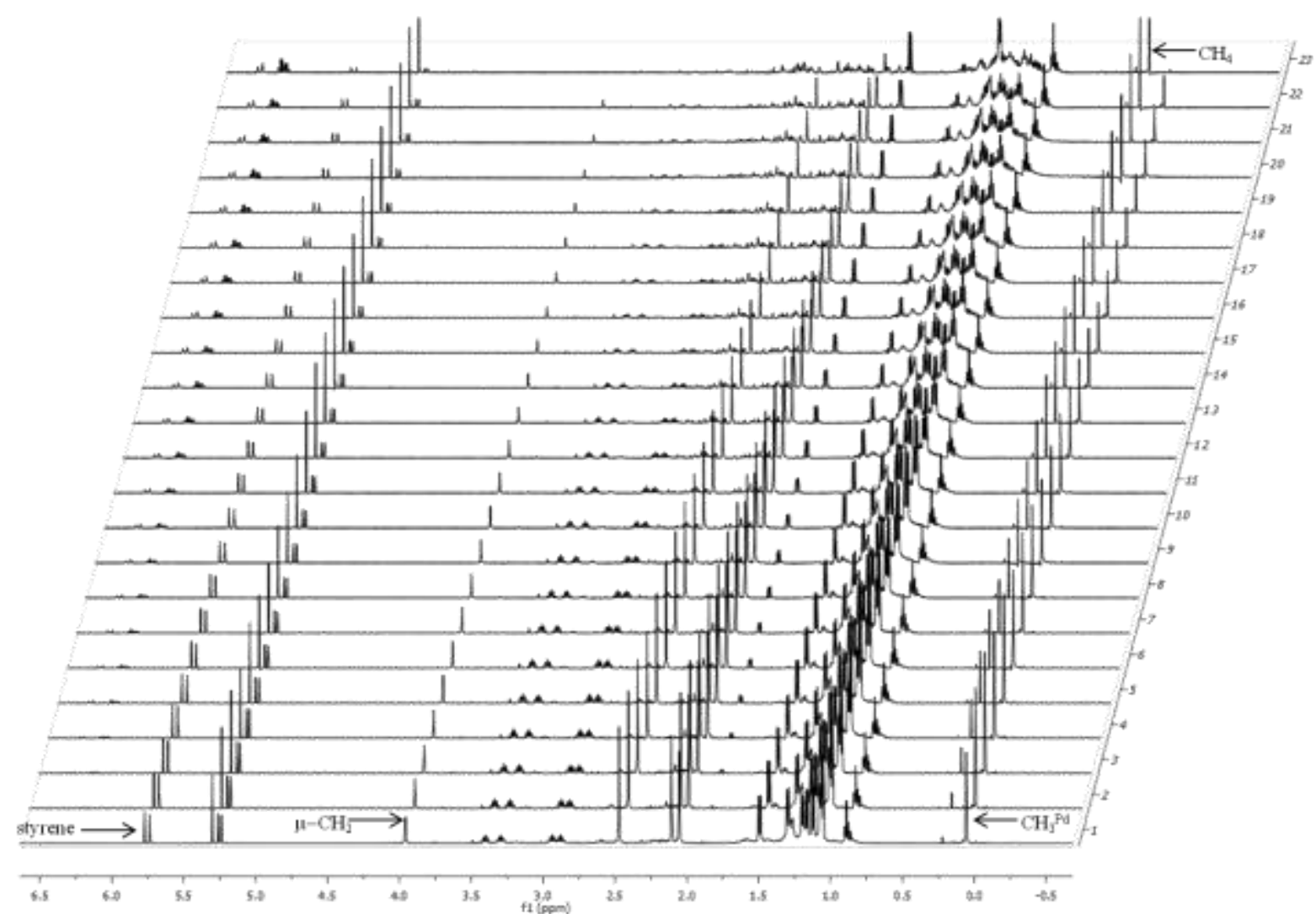

Fig. 6.2. 22: Stacked ${ }^{1} \mathrm{H}$ NMR spectra showing the formation propenylbenzene and depletion of the $\mu-\mathrm{CH}_{2}$ in $\mathrm{XXI}^{\mathrm{c}}$ measured in $\mathrm{CDCl}_{3}$ at room temperature over a $24 \mathrm{~h}$ period

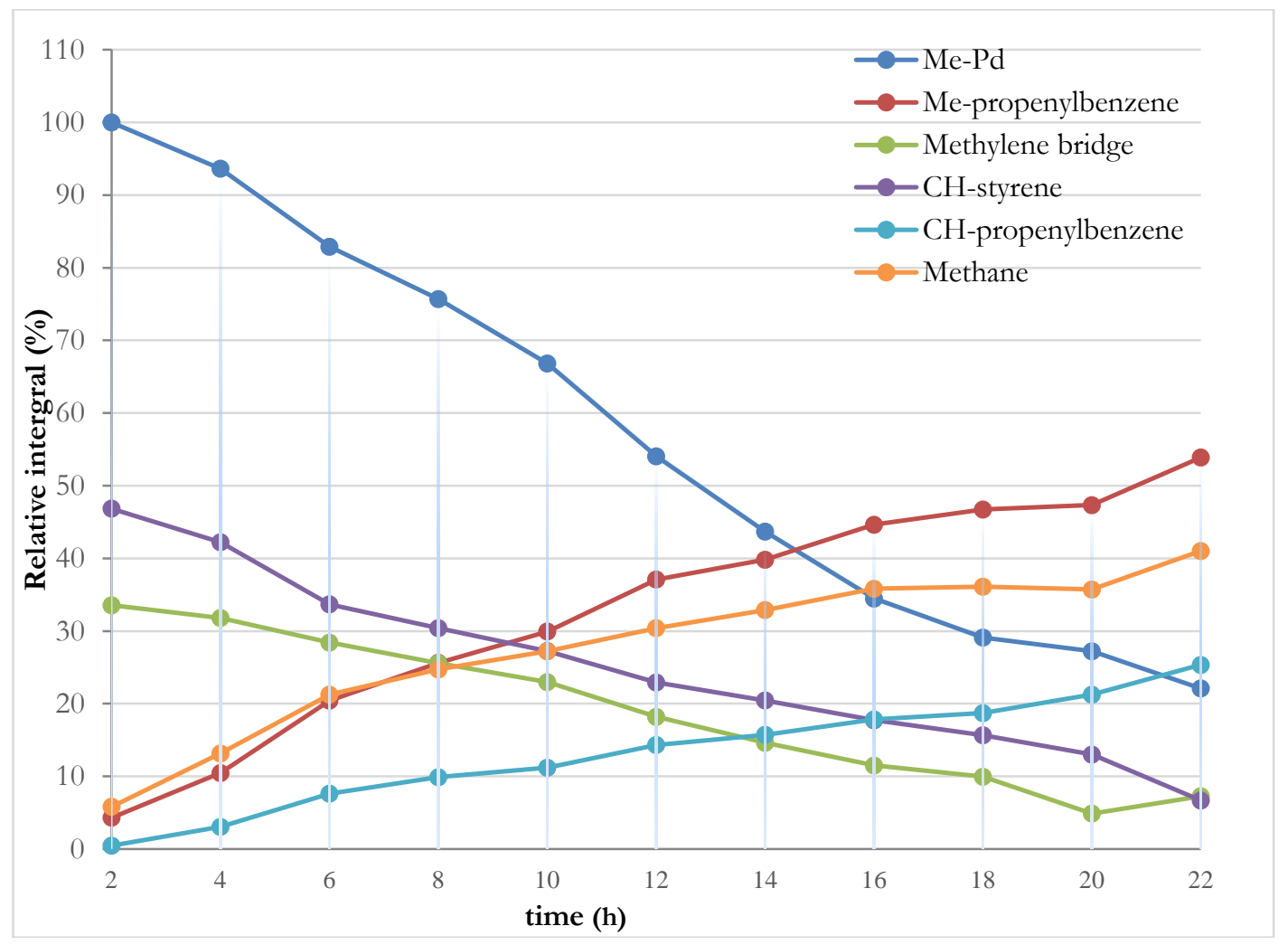

Fig. 6.2. 23: Graphical representation of decays in XXIc and subsequent propenylbenzene formation from styrene after activation measured in $\mathrm{CDCl}_{3}$ at room temperature 
From the graphical representation, it is observed that the formation of propenylbenzene has a direct relation to the release of $\mathrm{CH}_{4}$ from the reaction. An inverse relation is observed between the rise in propenylbenzene formation with the rate of depletion of the $\mu-\mathrm{CH}_{2}$ and the depletion of styrene. In addition, the rate of depletion of the $\mu-\mathrm{CH}_{2}$ is proportional to the rate of consumption of styrene. Generally, the complete consumption of styrene required $c a$ 24 h. Table 6.2. 7 summarize attempts at investigating further, the scope of olefins that are reactive towards $\mathbf{X X I}^{\mathrm{c}}$.

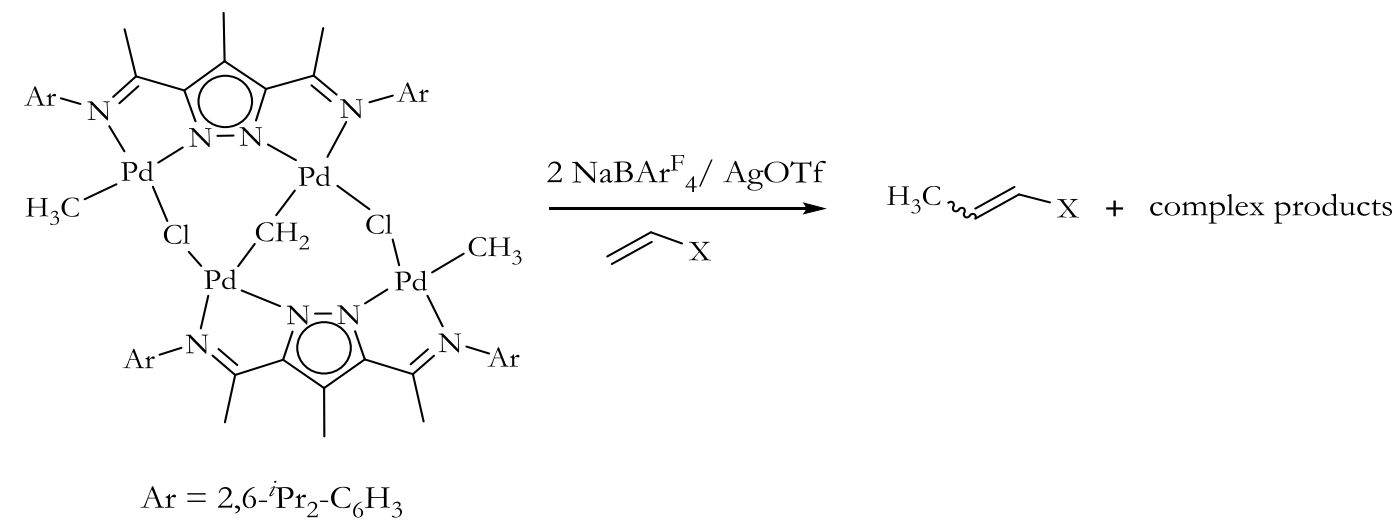

$\mathbf{X X I}^{\mathrm{c}}$

Scheme 6.2.16: Olefin coupling reactions of XXIc after activation

Table 6.2. 7: Table of results of olefin coupling reactions and conversion (\%) obtained with XXIc

Substrate

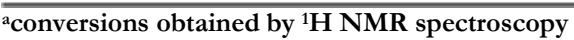

The general observations are that, $\mathbf{X X I}^{\mathbf{c}}$ is active towards different olefins, ranging from aliphatic to cyclic, electron deficient as well as electron rich olefins. 


\section{Results and Discussions}

Generally, conversions are better with terminal olefins compared to cyclic olefins, as seen in conversions of $77-98 \%$ observed with styrene and acrylonitrile, compared to $34 \%$ conversion in the case of cyclohexenone. Electron deficient olefins generally give lower conversion in relation to the use of electron rich olefins. In addition, irrespective of the olefin used, 2,1insertion product is favoured.

The crude reaction after olefin coupling was workup by drying under high vacuum overnight, followed by gradient elution (ether/methanol) on a micro column, which results in the isolation of a number of fractions/products (Scheme 6.2.17).

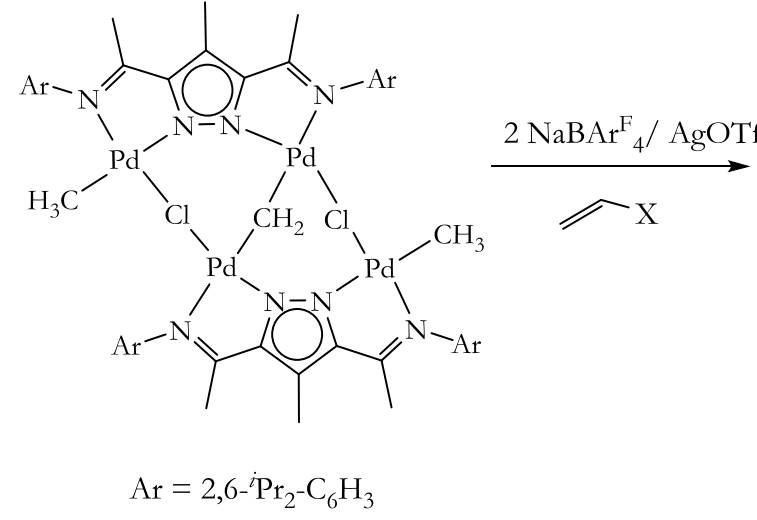

$\mathbf{X X I}^{\mathbf{c}}$

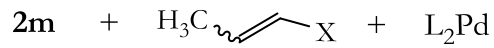

rearrangement
$2 \mathrm{p}(? ? ?)$

(new product)

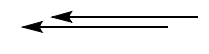

20

Scheme 6.2.17: Scheme showing the formation of rearrangement products after activation

An $\mathrm{L}_{2}^{2} \mathrm{Pd}$ product is eluted from the column first with ether. This was confirmed by ${ }^{1} \mathrm{H}$ NMR spectroscopy and ESI-MS of the product with $m$ /z values at 1073(100\%) which can be assigned to $\left[\mathrm{L}_{2} \mathrm{Pd}\right]^{+}$. Another fraction $(2 \mathrm{~m})$ was washed from the column using methanol. The ${ }^{1} \mathrm{H}$ NMR spectrum of $2 \mathrm{~m}$ was monitored over a period of $24 \mathrm{~h}$. Although $2 \mathrm{~m}$ initially showed only one $\mathrm{CH}_{3}{ }^{\text {Pd }}$ peak at $0.73 \mathrm{ppm}$, further changes takes place.

There is the loss of methane, followed by the appearance of three different $\mathrm{CH}_{3}{ }^{\mathrm{Pd}}$ peaks at

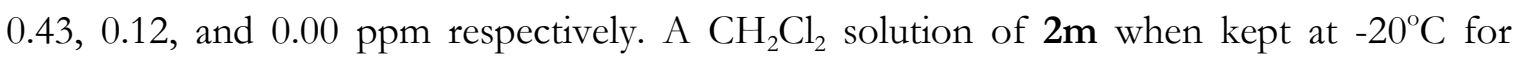
several weeks results in the isolation of bright red crystals (2o) that are stable only at low temperature. Effervescence occurs with the addition of $\mathrm{CDCl}_{3}$ to crystals of $2 \mathbf{o}$.

The ${ }^{1} \mathrm{H}$ NMR spectra of crystals of 20 obtained shows an upfield proton at $-3.78 \mathrm{ppm}$, which is of low intensity. However, with time, in addition to the peak at $-3.78 \mathrm{ppm}$, a new ${ }^{1} \mathrm{H}$ NMR 
peak is observed further downfield at $14.4 \mathrm{ppm}$. The ${ }^{1} \mathrm{H}$ peak at $-3.78 \mathrm{ppm}$ disappears altogether, leaving only the downfield peak at $14.4 \mathrm{ppm}$ as observed in a new product $\mathbf{2} \mathbf{p}$. There is a loss of one $\left[\mathrm{BAr}_{4}^{\mathrm{F}}\right]^{-}$counterion in the transition from 20 to $2 \mathrm{p}$. That is, in $2 \mathrm{p}$, the integration of the $\left[\mathrm{BAr}_{4}^{\mathrm{F}}\right]^{-}$protons is halved (from $24 \mathrm{H}$ to $12 \mathrm{H}$ ) in relation to $2 \mathrm{o}$ (Fig. 6.2. 24). The instability of 20 therefore hampered its thorough characterization.

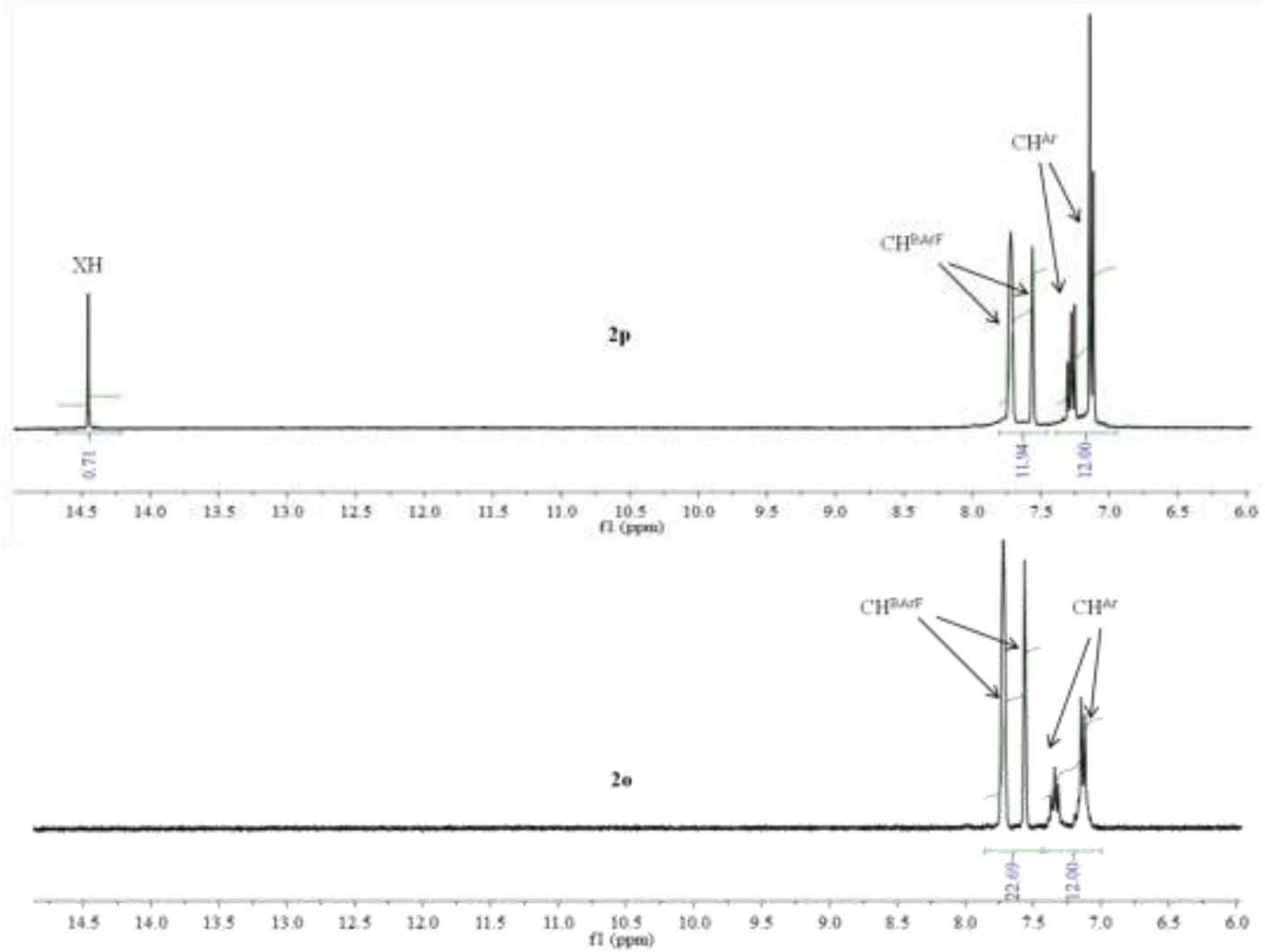

Fig. 6.2. 24: ${ }^{1} \mathrm{H}$ NMR spectra of the aromatic region of complexes $2 \mathrm{p}$ and 20 measured in $\mathrm{CDCl}_{3}$ at room temperature

In $2 \mathbf{p}$, the $\mathrm{CH}_{3}^{\text {iPr }}$ groups are observed as two doublets at 1.14 and $1.30 \mathrm{ppm}$ (1.14 and 1.41 in $\mathbf{X X I}^{\mathrm{b}}$ ). The shift to a higher field in one of the $\mathrm{CH}_{3}^{\text {ipr }}$ pointing to the possibility that $2 \mathrm{p}$ has stronger electron donating groups.

The downfield ${ }^{1} \mathrm{H}$ NMR spectrum signal initially suspected to be an $\mathrm{NH}$ proton, but a ${ }^{1} \mathrm{H}$ ${ }^{15} \mathrm{~N}$ HMBC NMR experiment ruled out this possibility since no correlation between this ${ }^{1} \mathrm{H}$ signal and the nitrogen atoms are observed.

Good crystals of $2 \mathbf{p}$ suitable for single crystal X-ray crystallography were obtained after keeping a $\mathrm{CH}_{2} \mathrm{Cl}_{2}$ solution of the complex at $-20^{\circ} \mathrm{C}$ for several months. From the crystal structure (Fig. 6.2. 25), the downfield ${ }^{1} \mathrm{H}$ signal at $14.4 \mathrm{ppm}$ without ambiguity is assigned to a hydroxide proton. In $2 \mathrm{p}$, there are two bridging $\mu-\mathrm{Cl}$, a $\mu-\mathrm{OH}$, and a $\mu-\mathrm{O}$ group. The compound crystallizes with a molecule of $\left[\mathrm{BAr}_{4}^{\mathrm{F}}\right]^{-}$counterion, to balance the +2 oxidation 


\section{Results and Discussions}

state on all four palladium atoms. The Pd $\cdots \mathrm{Pd}$ bond lengths in this complex is very close at $3.14 \AA$ and the Pd-O bond average bond length of $1.96 \AA$ (Table 6.2. 8) are within the range of other reported palladium hydroxide bridged complexes. ${ }^{232,233}$

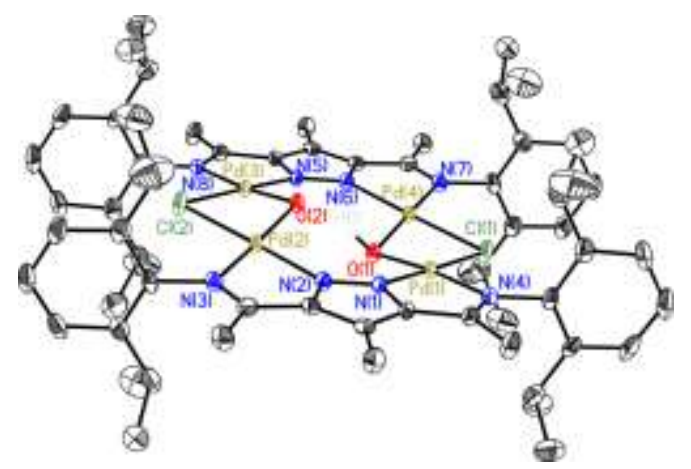

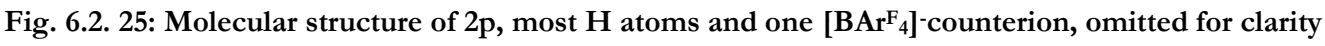

Table 6.2. 8: Selected bond lengths $[\AA \AA]$ and bond angles $\left[{ }^{\circ}\right]$ for $2 \mathrm{p}$

\begin{tabular}{llll}
\hline \multicolumn{3}{c}{ Bond lengths $[\AA]$} & Bond angles [ $\left.{ }^{\circ}\right]^{\prime}$ \\
\hline $\mathrm{Pd}(1)-\mathrm{Pd}(2)$ & $3.145(7)$ & $\mathrm{Pd}(1)-\mathrm{O}(1)-\mathrm{Pd}(2)$ & $106.59(13)$ \\
$\mathrm{Pd}(2)-\mathrm{O}(2)$ & $1.962(3)$ & $\mathrm{N}(1)-\mathrm{Pd}(1)-\mathrm{N}(4)$ & $79.83(13)$ \\
\hline
\end{tabular}

The ESI-MS data for $2 \mathbf{p}$ further supports the observed structure, $m / z$ distribution of 1497 $(5 \%)$ and $749(100 \%)$ assigned to $\left[\mathrm{M}+1 \mathrm{H}-\mathrm{BAr}_{4}^{\mathrm{F}}\right]^{1+}$ and $\left[\mathrm{M}+2 \mathrm{H}-\mathrm{BAr}^{\mathrm{F}}{ }_{4}^{2+}\right.$ respectively are observed as shown in (Fig. 6.2. 26).

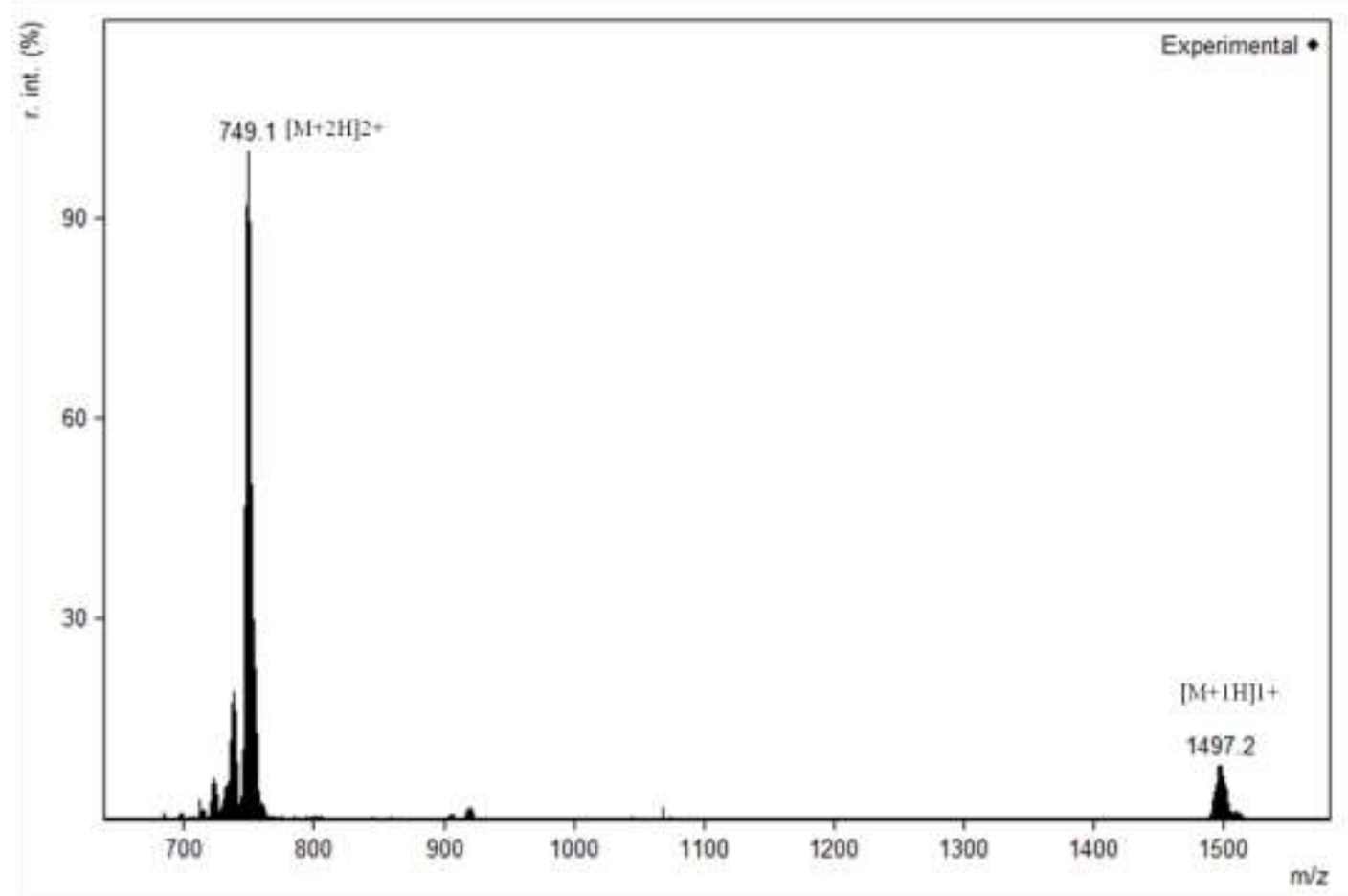

Fig. 6.2. 26: ESI mass spectrum of $2 p$ showing the $m / z$ distributions 
Results and Discussions

The observed and simulated isotopic distribution patterns are shown in Fig. 6.2. 27.
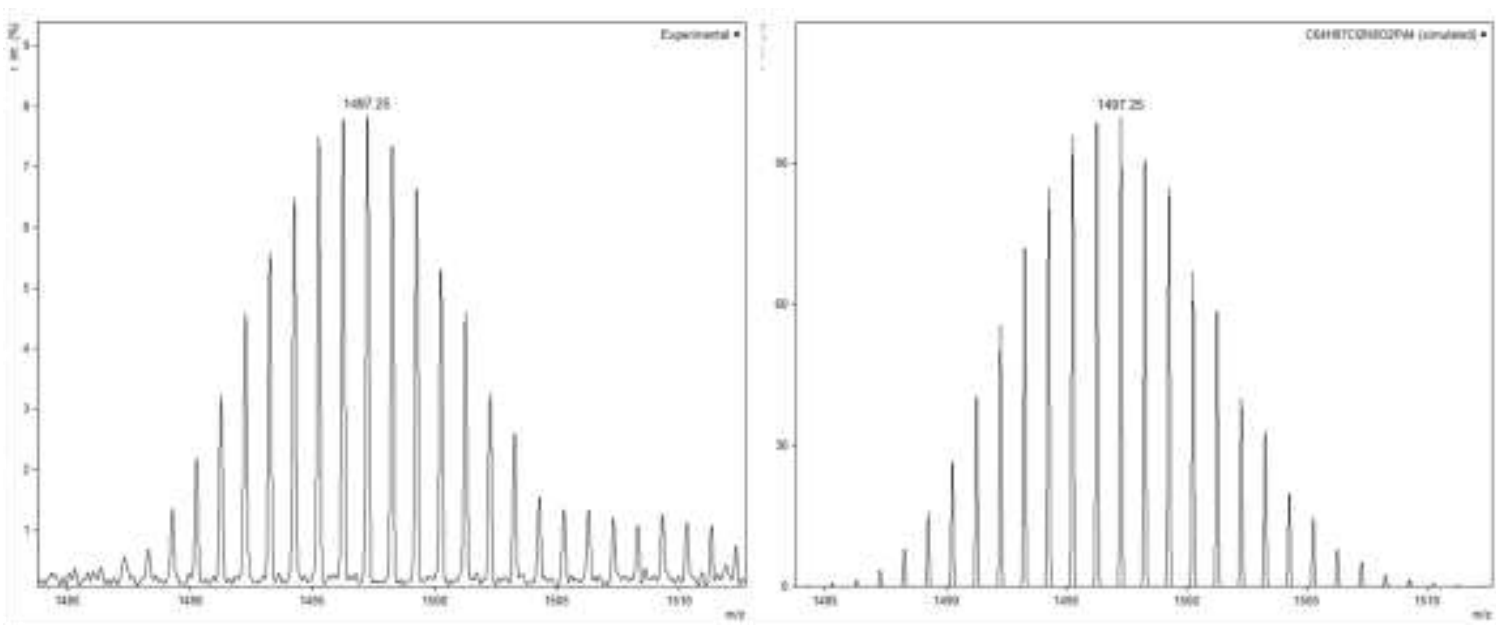

Fig. 6.2. 27: ESI(+) mass spectra of 2p showing observed (left) and simulated (right) isotopic distribution patterns

Irrespective of the nature of the olefin used, the same product $2 \mathrm{p}$ is observed. The complete ${ }^{1} \mathrm{H}$ and ${ }^{13} \mathrm{C}$ NMR assignments of $2 \mathrm{p}$ are shown in Fig. 6.2. 28 and Fig. 6.2. 29 respectively, and are in good agreement with the single crystal X-ray structure.

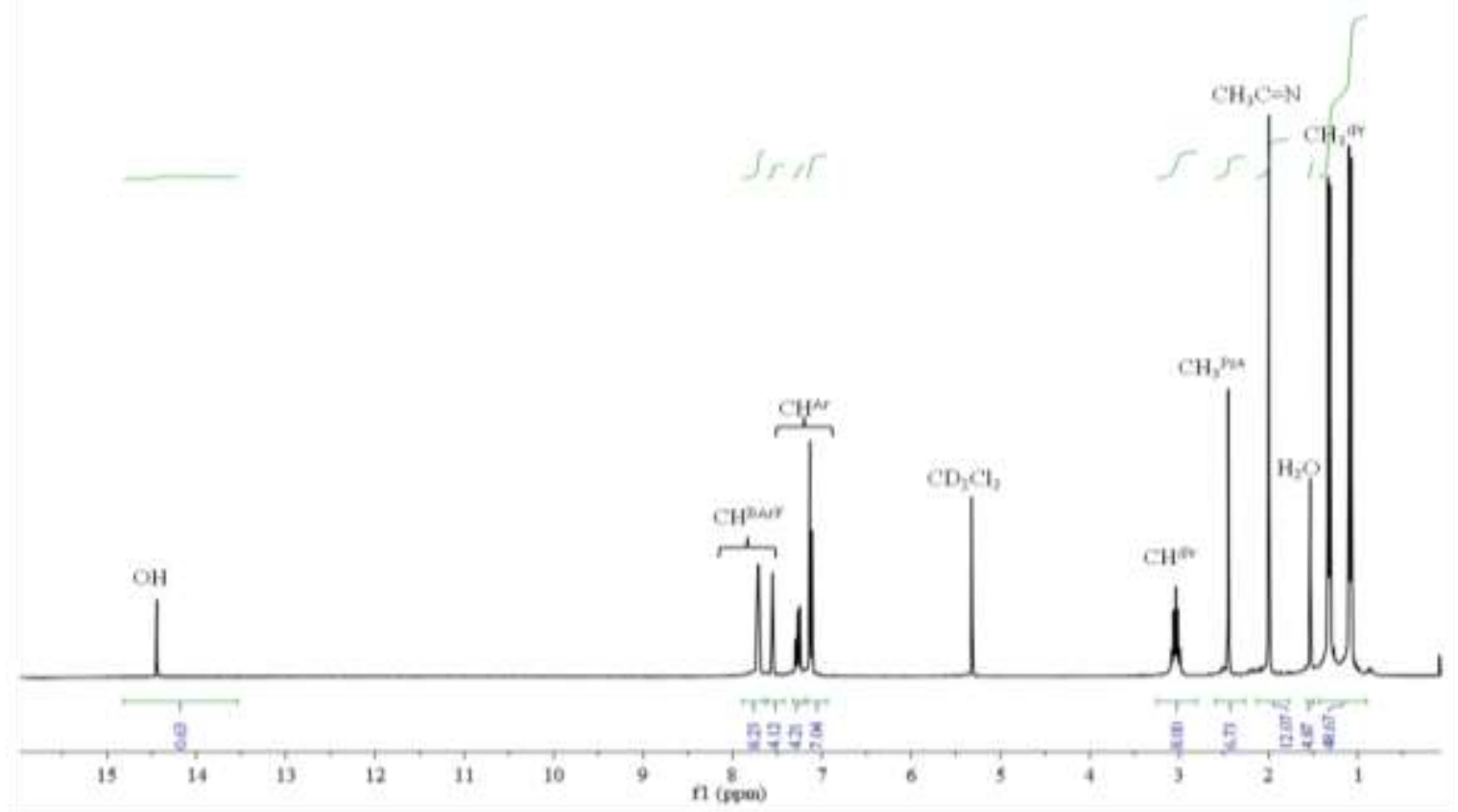

Fig. 6.2. 28: ${ }^{1} \mathrm{H}$ NMR spectrum of $2 \mathrm{p}$ measured in $\mathrm{CD}_{2} \mathrm{Cl}_{2}$ at room temperature 


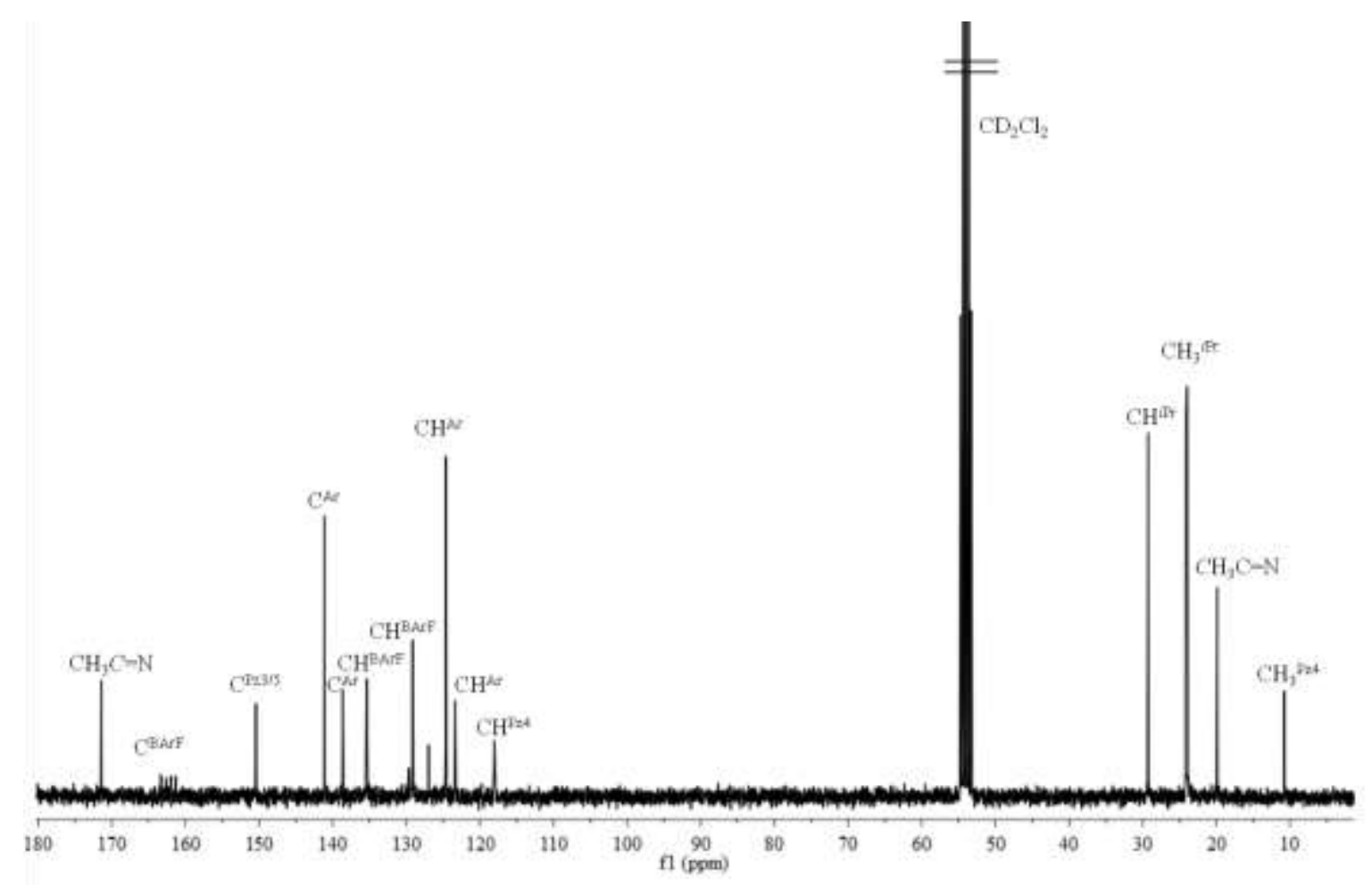

Fig. 6.2. 29: ${ }^{13} \mathrm{C}$ NMR spectrum of $2 \mathrm{p}$ measured in $\mathrm{CD}_{2} \mathrm{Cl}_{2}$ at room temperature

The ${ }^{13} \mathrm{C}$ NMR spectrum of $2 \mathrm{p}$ shows a very simple spectrum with peaks at 10.6, 19.7, 23.7/23.9 and 29.1 ppm which can be assigned to $\mathrm{CH}_{3}{ }^{\mathrm{Pz} 4}, \mathrm{CH}_{3} \mathrm{C}=\mathrm{N}, \mathrm{CH}_{3}{ }^{\text {ipr }}$ and $\mathrm{CH}^{\mathrm{ipr}}$ groups respectively. In addition, only a single peak is observed for the imine carbon at $171.2 \mathrm{ppm}$ (Fig. 6.2. 29). No hydrogen bond interactions were observed in the IR spectrum.

A formulated route to the formation of $2 \mathrm{p}$ is shown in Scheme 6.2.18. A cationic complex is generated when $\mathbf{X X I}^{\mathbf{c}}$ is treated with AgOTf or with an alkali-metal borate salt $\left(\mathrm{NaBAr}_{4}^{\mathrm{F}}\right)$. This causes the $\mathrm{CH}_{3}$ groups to move into bridging positions whiles still keeping the $\mu-\mathrm{CH}_{2}$ intact, followed by the coordination of adventitious water. This is corroborated by the ${ }^{1} \mathrm{H}$ NMR spectrum of 21 , which shows the signal for the $\mu-\mathrm{CH}_{3}$ and $\mu-\mathrm{CH}_{2}$ at $0.03 \mathrm{ppm}$ and 4.15 ppm compared to $0.05 \mathrm{ppm}$ and $3.96 \mathrm{ppm}$ in $\mathbf{X X I ^ { \mathbf { c } }}$ (in $\mathrm{CDCl}_{3}$ ). In addition, the formation of such a complex is observed in the ESI-MS with a major $m /$ z peak at $1474(100 \%)$ which can be assigned to $\left[\mathrm{L}_{2}^{2} \mathrm{Pd}_{4}\left(\mu-\mathrm{CH}_{2}\right)\left(\mu-\mathrm{CH}_{3}\right)_{2}\left(\mathrm{H}_{2} \mathrm{O}\right)_{2}\right]^{2+}$. In the presence of an olefin, the $\mu-\mathrm{CH}_{2}$ is coupled to the olefin, as demonstrated previously. After coupling of the $\mu-\mathrm{CH}_{2}$, the highly unstable complex is stabilized by the presences of chloride anions present in the chlorinated solvent due to the loss of the $\mu-\mathrm{CH}_{2}$, thus reforming the bridging $\mu-\mathrm{Cl}$. 
Results and Discussions
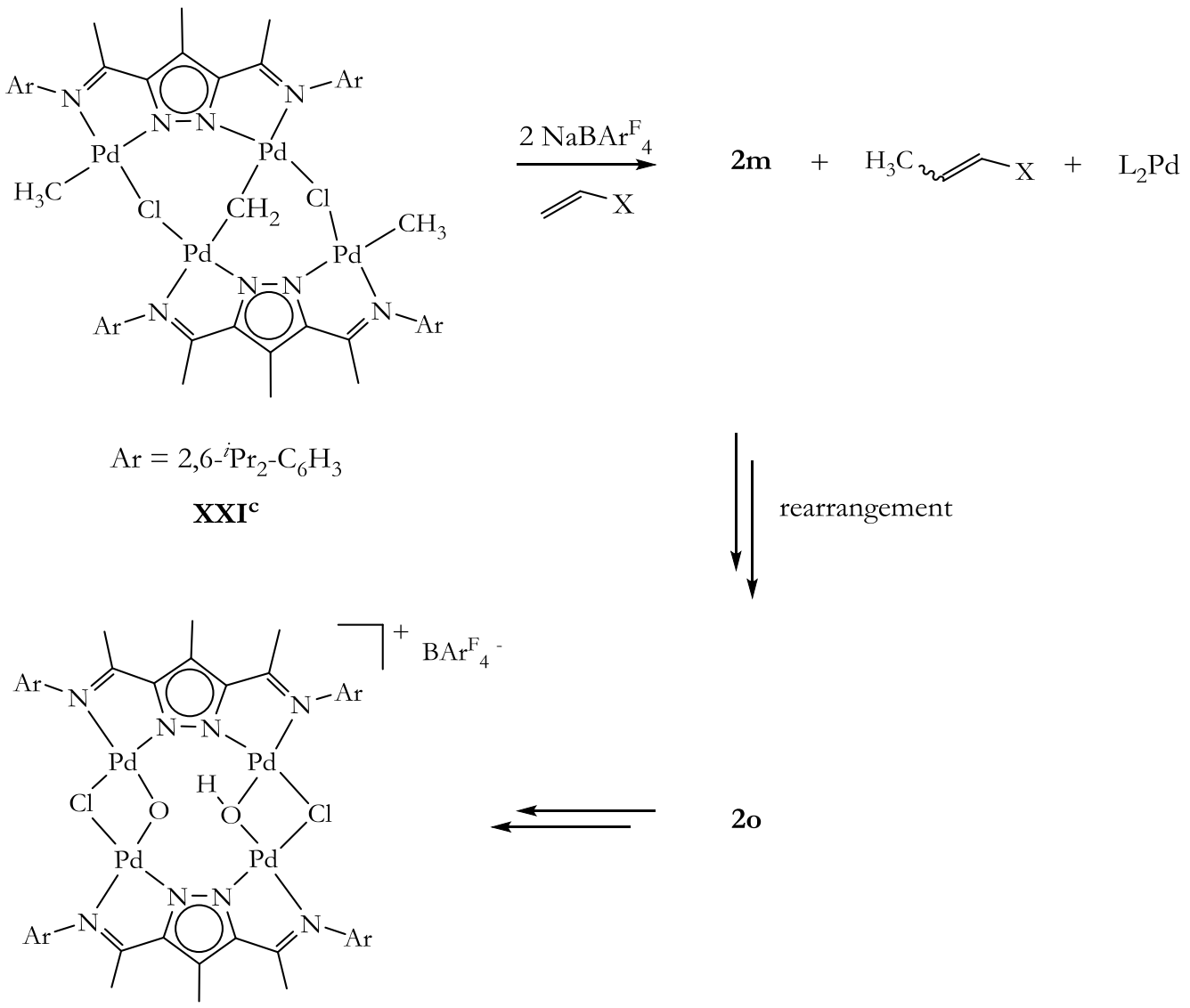

$2 p$

(new product)

Scheme 6.2.18: Reaction sequence leading to the formation of $2 p$

Through a series of reactions not yet well understood, there is the eventual formation of 20 and subsequently to the final product $2 \mathbf{p}$.

It is worth noting that the observed reaction sequence is reproducible irrespective of the nature of the chloride abstracting agent used $\left(\mathrm{AgOTf} / \mathrm{NaBAr}^{\mathrm{F}}\right.$ ), thus possibly ruling out the role of $\mathrm{Ag}^{+}$ions as a redox agent. 
Results and Discussions

\section{3 Towards Heterobimetallic complexes}

The concept of having two different metals in close proximity in transition metal complexes has been of interest for some time now. A heterobimetallic complex can have each metal centre undergoing reactions observed in their respective mononuclear compounds. In certain instances, the nature of the bridging ligand may allow for new modes of reactivity in the heterobimetallic complex. Also, heterobimetallic complexes have unusual electronic, electrochemical and magnetic properties due to the presence of different metal sites. ${ }^{234,235,236}$

The goal is to prepare heterobimetallic complexes of the $a$-diimine type ligands, in which the two metal centres are held in close proximity to explore potential cooperative effects between the two centres. A number of approaches have been adopted for the preparation of heterobimetallic complexes involving the 3,5-disubstituted pyrazolyl bridging moiety.

Akita and co-workers ${ }^{136}$ have described a method for the synthesis heterodinuclear complexes of a pyrazolate based ligand system. The method first involves the preparation of a mononuclear 1:1 adduct (XLV) by the addition of the metal reagent to an excess amount of the dinucleating ligand.

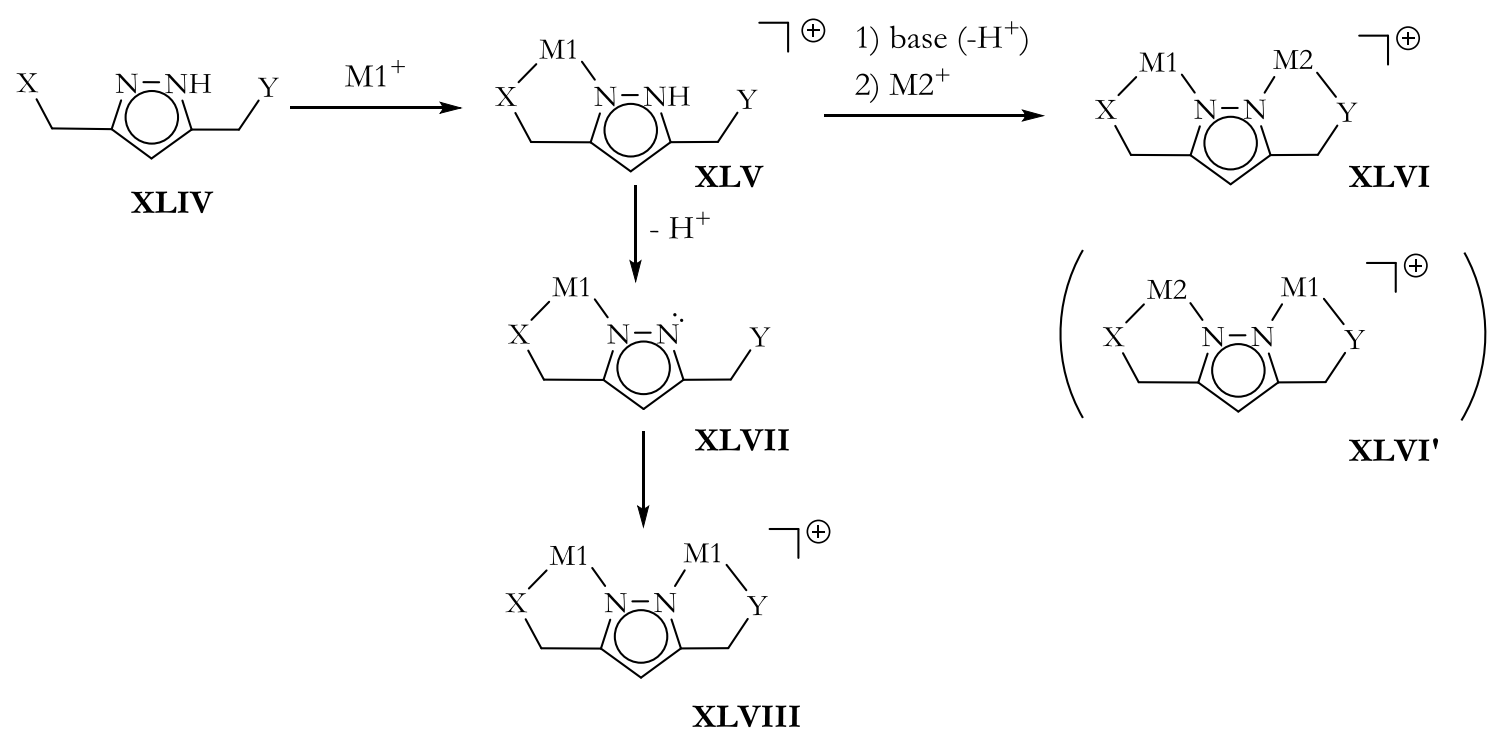

Scheme 6.3. 1: Scheme for the preparation of heterobimetallic complexes. ${ }^{136}$

This is followed by the treatment of the 1:1 educt with a base and a second metal reagent to furnish the heterobimetallic complex (XLVI). By changing the addition order, the 
regioisomer (XLVI') is also obtained. In addition, side products such as XLVIII are also formed from the spontaneous deprotonation of $\mathbf{X L V}$.

\subsection{Mononuclear palladium(II) complexes as templates to heterobimetallic complexes}

The target is to prepare mononuclear complexes of palladium(II) and nickel(II) as templates for the preparation of heterobimetallic complexes (Scheme 6.3.1. 1).

$$
\begin{aligned}
& \mathrm{HL}^{\mathrm{x}} \underset{\mathrm{ML}_{\mathrm{n}} \mathrm{X}_{\mathrm{n}} \longrightarrow}{\mathrm{KO}{ }^{\prime} \mathrm{Bu}} \\
& \begin{array}{l}
\mathbf{H L}^{1:} \mathbf{R}^{1}=\mathrm{H}, \mathrm{R}^{2}={ }^{i} \mathrm{Pr}, \mathrm{R}^{3}=\mathrm{H} \\
\mathbf{H L}^{2}: \mathrm{R}^{1}=\mathrm{Me}, \mathrm{R}^{2}={ }^{i} \mathrm{Pr}, \mathrm{R}^{3}=\mathrm{H} \\
\mathbf{H L}^{3}: \mathrm{R}^{1}=\mathrm{Me}, \mathrm{R}^{2}=\mathrm{Me}, \mathrm{R}^{3}=\mathrm{H} \\
\mathbf{H L}^{4}: \mathbf{R}^{1}=\mathrm{R}^{2}=\mathrm{R}^{3}=\mathrm{Me}
\end{array}
\end{aligned}
$$

Scheme 6.3.1. 1: Initial adopted scheme for the preparation of heterobimetallic complexes

To begin with, the treatment of the deprotonated ligand $\mathrm{L}^{1} / \mathrm{L}^{2}$ with 2 mol equivalent $\left[\mathrm{PdCl}\left(\mathrm{CH}_{3}\right)(\mathrm{COD})\right]$ results in the isolation of a homobimetallic complex of the type $\left[\mathrm{L}_{2}{ }_{2} \mathrm{Pd}_{2}\left(\mathrm{CH}_{3}\right) \mathrm{X}\right]\left(\mathrm{X}=\mathrm{Cl}, \mathrm{CH}_{3}\right)$ (Scheme 6.3.1. 2). The formation of this complex is not influenced by the ratio of ligand to metal precursor used. A 1:1 ratio of ligand to metal precursor gives the same type of complex.

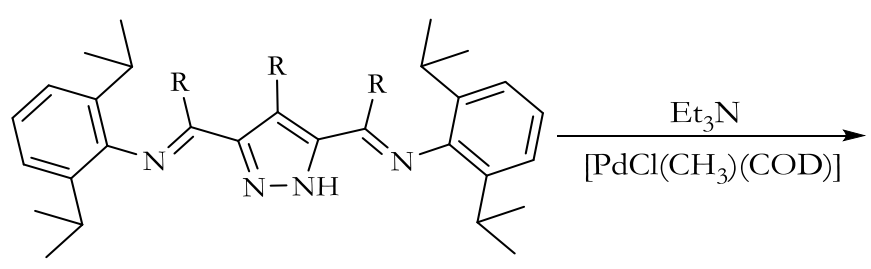

$$
\begin{aligned}
& \mathbf{H L}^{1}: \mathrm{R}=\mathrm{H} \\
& \mathbf{H L}^{2}: \mathrm{R}=\mathrm{Me}
\end{aligned}
$$

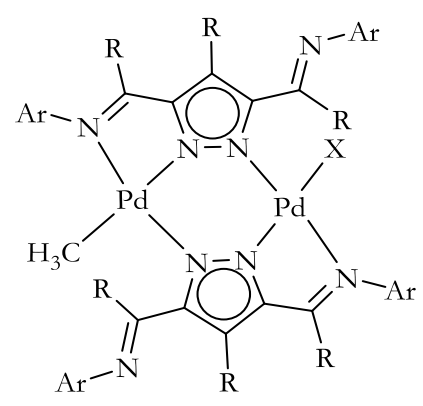

(3a) $: \mathrm{R}=\mathrm{Me}, \mathrm{X}=\mathrm{CH}_{3}$ (3b) $: \mathrm{R}=\mathrm{H}, \mathrm{X}=\mathrm{Cl}$

Scheme 6.3.1. 2:Synthetic scheme for the formation of $3 a$ and $3 b$ 
The ${ }^{1} \mathrm{H}$ NMR spectrum of $3 \mathrm{a}$ shows a $\mathrm{CH}_{3}{ }^{\mathrm{Pd}}$ resonance at $0.15 \mathrm{ppm}$, and the different $\mathrm{CH}_{3} \mathrm{C}=\mathrm{N}$ groups as singlets at 2.18 and 2.34 ppm respectively, as well as the $\mathrm{CH}_{3}{ }^{\mathrm{Pz} 4}$ group at 2.57 ppm (Fig. 6.3.1. 1).

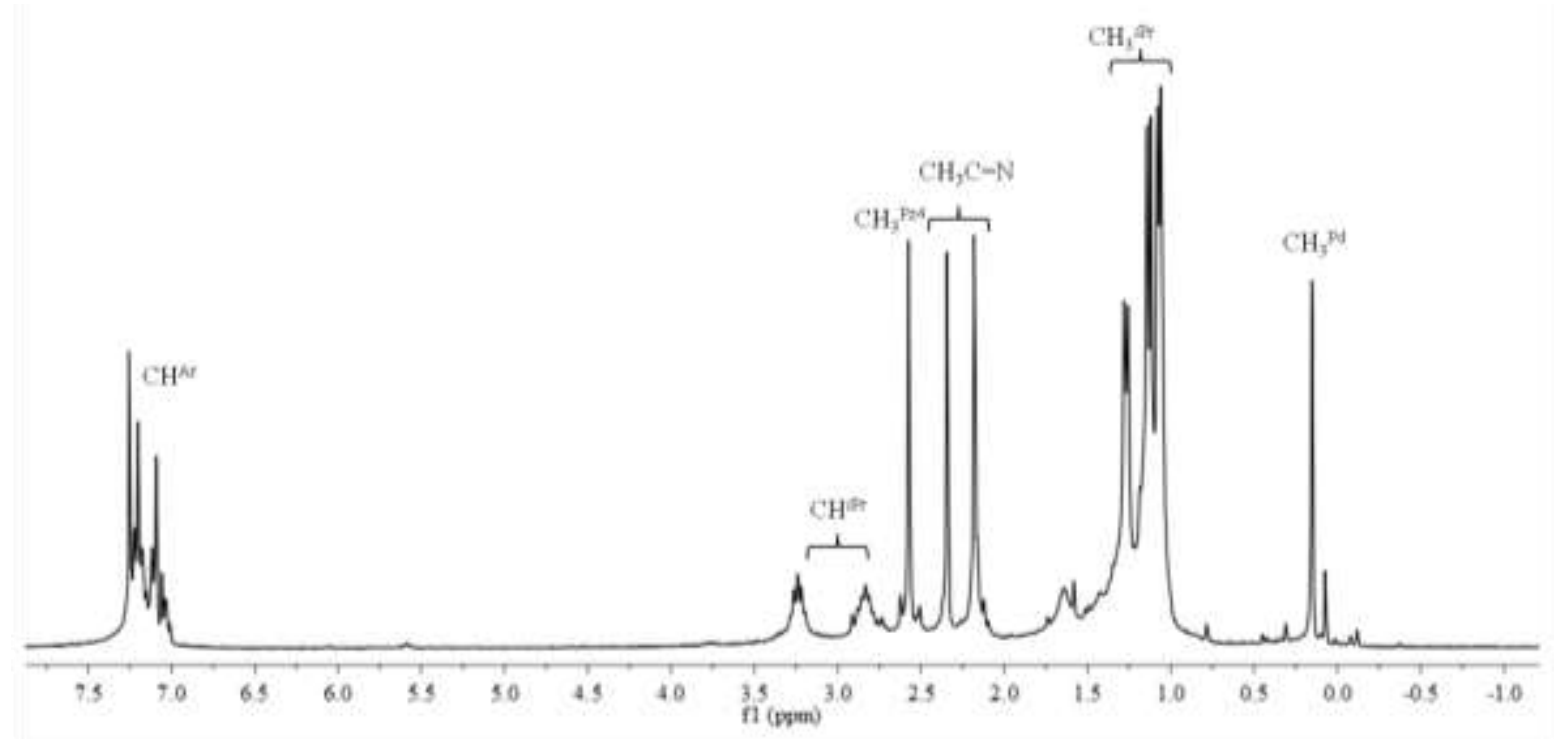

Fig. 6.3.1. 1: ${ }^{1} \mathrm{H}$ NMR spectrum of 3 a measured in $\mathrm{CDCl}_{3}$ at room temperature

The $\mathrm{CH}_{3}{ }^{2 \mathrm{Pr}}$ groups are observed as four doublets at 1.06, 1.12, 1.17, and $1.26 \mathrm{ppm}$ respectively. A HSQC NMR spectrum of 3a shows a ${ }^{13} \mathrm{C}$ correlation for the methyl group $\left(\mathrm{CH}_{3}{ }^{\mathrm{Pd}}\right)$ at $1.68 \mathrm{ppm}$, whiles the ${ }^{13} \mathrm{C}$ correlations for the two $\mathrm{CH}_{3} \mathrm{C}=\mathrm{N}$ are observed at 162.3 and $172.0 \mathrm{ppm}$ for the bound and unbound arms respectively. The ESI-MS of 3a shows a bis-chelate complex with $m /$ z peak at $1195(50 \%)$ assigned to $\left[\mathrm{M}-\mathrm{CH}_{3}\right]^{+}$.

When the experiment was repeated using a ratio of $\mathrm{HL}^{1}:\left[\mathrm{PdCl}\left(\mathrm{CH}_{3}\right)(\mathrm{COD})\right]$ of $1: 2$, the analogous complex $\mathbf{3} \mathbf{b}$ was isolated. In $\mathbf{3} \mathbf{b}$, the $\mathrm{CH}_{3}{ }^{\mathrm{Pd}}$ peak is observed as a doublet at 0.54 ppm in the ${ }^{1} \mathrm{H}$ NMR spectrum, possibly due to a mixture of isomers. In addition, the $\mathrm{CH}_{3}{ }^{\mathrm{Pd}}$ peak is deshielded compared to 3a. Examples of $\left[\mathrm{N}^{\wedge} \mathrm{NPd}\left(\mathrm{CH}_{3}\right) \mathrm{Cl}\right]\left(\mathrm{N}^{\wedge} \mathrm{N}\right.$ : a-diimine complexes have been reported with the $\mathrm{CH}_{3}{ }^{\mathrm{Pd}}$ signal shifted for complexes bearing electron withdrawing ligands and upfield for electron donating ligands. ${ }^{237}$

Crystals of $\mathbf{3} \mathbf{a}$ and $\mathbf{3} \mathbf{b}$ were grown by the slow evaporation of a $\mathrm{CH}_{2} \mathrm{Cl}_{2}$ of the complexes at room temperature. The molecular structures of the compounds are shown in (Fig. 6.3.1. 2) as well selected bond angles $\left[{ }^{\circ}\right]$ and bond lengths $[\AA]$ in Table 6.3.1. 1 and Table 6.3.1. 3 . 

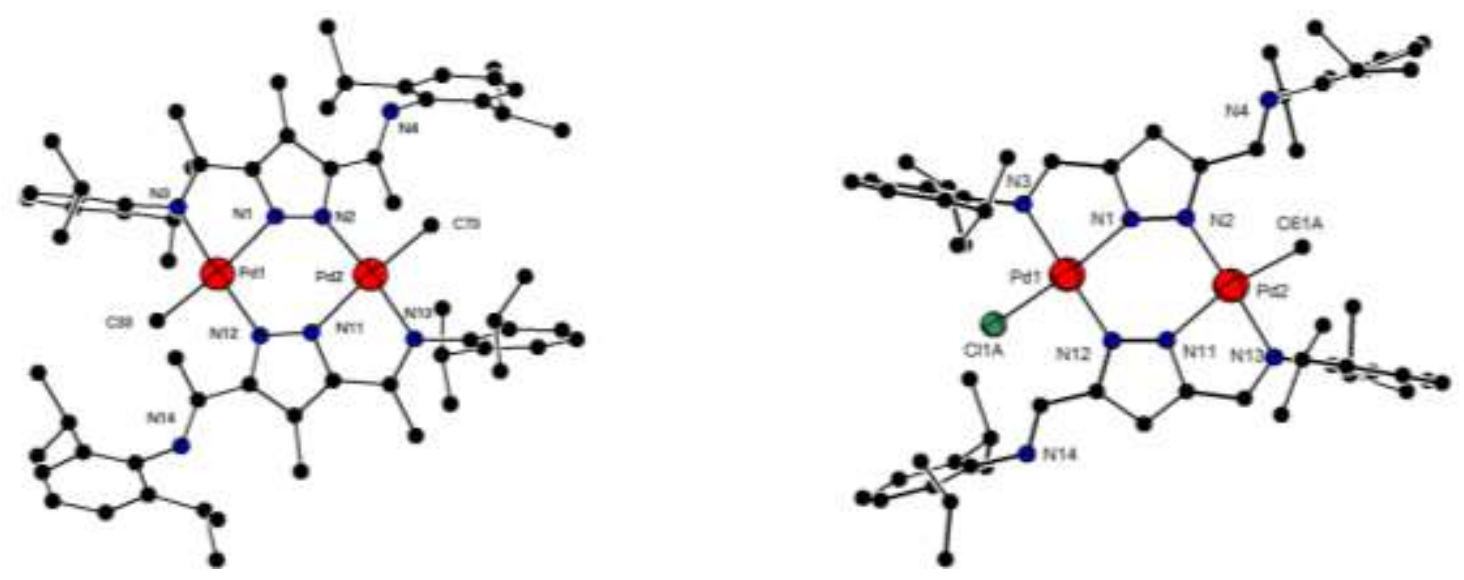

Fig. 6.3.1. 2: Molecular structures of 3a (left) and 3b (right) all $\mathrm{H}$ atoms omitted for clarity

The coordination geometry around the palladium centre in both complexes is square planar. The Pd-C bond length in $\left[\mathrm{L}_{2}^{2} \mathrm{Pd}_{2}\left(\mathrm{CH}_{3}\right)_{2}\right]$ 3a $(2.03 \AA)$ is significantly shorter than observed in $\left[\mathrm{L}_{2}{ }^{1} \mathrm{Pd}_{2}\left(\mathrm{CH}_{3}\right) \mathrm{Cl}\right] \mathbf{3 b}(2.13 \AA)$. The interplanar angle defined by the five atoms, which make up each pyrazole ring is twisted at $48.3^{\circ}$ in $\mathbf{3 a}$, compared to $\mathbf{3 b}$ where the twists is less at $28.9^{\circ}$. The $\operatorname{Pd}(1)-\mathrm{N}(1)$ bond length is slightly longer (2.12 $\AA$ ) compared to $\operatorname{Pd}(1)-\mathrm{N}(3)$ of $2.05 \AA$ in 3a, thus the palladium imine bond is slightly stronger than the palladium pyrazole bond.

In $\mathbf{3 b}$ there are no significant differences between the Pd-N bond lengths between the two palladium centres bearing the $\mathrm{Cl}$ or the $\mathrm{CH}_{3}$ ligand $(\operatorname{Pd}(1)-\mathrm{N}(1)=2.06 \AA ; \operatorname{Pd}(1)-\mathrm{N}(3)=2.04$ $\AA ; \operatorname{Pd}(2)-\mathrm{N}(11)=2.07 \AA ; \operatorname{Pd}(2)-\mathrm{N}(13)=2.05 \AA)$. The Pd-C and the Pd-Cl bond lengths in the two complexes however, fall in the range observed for other palladium(II) complexes. ${ }^{238,239}$

Table 6.3.1. 1: Selected bond lengths $[\AA]$ and bond angles $\left[{ }^{\circ}\right]$ for $3 a$

\begin{tabular}{llll}
\hline \multicolumn{1}{c}{ Bond lengths $[\AA \boldsymbol{\AA}]$} & \multicolumn{1}{c}{ Bond angles $\left[^{\circ}\right]^{\prime}$} \\
\hline $\operatorname{Pd}(1)-\mathrm{C}(33)$ & $2.030(9)$ & $\mathrm{C}(33)-\mathrm{Pd}(1)-\mathrm{N}(12)$ & $91.3(4)$ \\
$\operatorname{Pd}(1)-\mathrm{N}(12)$ & $2.044(8)$ & $\mathrm{C}(33)-\mathrm{Pd}(1)-\mathrm{N}(3)$ & $94.7(4)$ \\
$\operatorname{Pd}(1)-\mathrm{N}(3)$ & $2.057(8)$ & $\mathrm{N}(12)-\mathrm{Pd}(1)-\mathrm{N}(3)$ & $172.3(3)$ \\
$\operatorname{Pd}(1)-\mathrm{N}(1)$ & $2.122(8)$ & $\mathrm{C}(33)-\mathrm{Pd}(1)-\mathrm{N}(1)$ & $169.9(4)$ \\
$\operatorname{Pd}(2)-\mathrm{C}(73)$ & $2.033(9)$ & $\mathrm{N}(12)-\mathrm{Pd}(1)-\mathrm{N}(1)$ & $97.7(3)$ \\
\hline
\end{tabular}


Table 6.3.1. 2: Selected bond lengths $[\AA]$ and bond angles $\left[{ }^{\circ}\right]$ for $3 b$

\begin{tabular}{llll}
\hline \multicolumn{1}{c}{ Bond lengths $[\AA]$} & & \multicolumn{2}{c}{ Bond angles [ $\left.{ }^{\circ}\right]$} \\
\hline $\operatorname{Pd}(1)-\mathrm{N}(12)$ & $2.032(3)$ & $\mathrm{N}(12)-\mathrm{Pd}(1)-\mathrm{N}(3)$ & $169.07(16)$ \\
$\operatorname{Pd}(1)-\mathrm{N}(3)$ & $2.048(4)$ & $\mathrm{N}(12)-\mathrm{Pd}(1)-\mathrm{N}(1)$ & $97.08(15)$ \\
$\operatorname{Pd}(2)-\mathrm{C}(61 \mathrm{~A})$ & $2.130(2)$ & $\mathrm{N}(3)-\mathrm{Pd}(1)-\mathrm{N}(1)$ & $79.36(14)$ \\
$\operatorname{Pd}(1)-\mathrm{Cl}(1 \mathrm{~A})$ & $2.240(4)$ & $\mathrm{N}(3)-\mathrm{Pd}(1)-\mathrm{C}(61 \mathrm{~A})$ & $89.81(5)$ \\
$\operatorname{Pd}(2)-\mathrm{N}(2)$ & $2.039(4)$ & $\mathrm{N}(1)-\mathrm{Pd}(1)-\mathrm{C}(61 \mathrm{~A})$ & $160.62(5)$ \\
$\operatorname{Pd}(2)-\mathrm{N}(13)$ & $2.059(4)$ & $\mathrm{N}(12)-\mathrm{Pd}(1)-\mathrm{Cl}(1 \mathrm{~A})$ & $92.47(13)$ \\
\hline
\end{tabular}

To avoid the formation of $\left[\mathrm{L}_{2}^{\mathrm{x}} \mathrm{Pd}_{2}\left(\mathrm{CH}_{3}\right) \mathrm{X}\right]\left(\mathrm{X}=\mathrm{Cl}, \mathrm{CH}_{3}\right)$ type complexes, the deprotonated ligand was added to $\left[\mathrm{PdCl}\left(\mathrm{CH}_{3}\right)(\mathrm{COD})\right]$ in the presence of coligands such as $\mathrm{PPh}_{3}, \mathrm{PMe}_{3}$ or pyridine. Indeed, the formation of complexes of $\left[\mathrm{L}_{2}^{\mathrm{x}} \mathrm{Pd}_{2}\left(\mathrm{CH}_{3}\right) \mathrm{X}\right]\left(\mathrm{X}=\mathrm{Cl}, \mathrm{CH}_{3}\right)$ complexes were avoided, in place, mononuclear complexes of the type $\mathrm{L}^{\mathrm{x}} \mathrm{Pd}\left(\mathrm{L}^{\prime}\right)\left(\mathrm{CH}_{3}\right)\left(\mathrm{L}^{\prime}=\mathrm{PMe}_{3}, \mathrm{PPh}_{3}\right.$, pyridine) are formed (Scheme 6.3.1. 3).

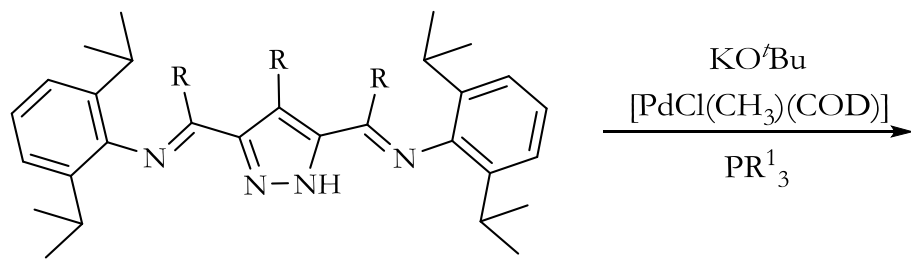

$\mathrm{HL}^{1}: \mathrm{R}=\mathrm{H}$

$\mathrm{HL}^{2}: \mathrm{R}=\mathrm{Me}$<smiles>[Y19]N=C([R])c1nn2c(c1[R])c([R])[n+]([Y8])[R]2([R17])C</smiles>

(3c): $\mathrm{R}=\mathrm{Me}, \mathrm{R}^{1}=\mathrm{Me}$

(3d): $\mathrm{R}=\mathrm{Me}, \mathrm{R}^{1}=\mathrm{Ph}$

Scheme 6.3.1. 3: Synthesis of $\left[\mathrm{Lxd}^{\times}\left(\mathrm{PR}_{3}{ }_{3}\right)\left(\mathrm{CH}_{3}\right)\right]$ complexes $(3 \mathrm{c}-3 \mathrm{~d})$

In one such experiment, treating $\mathrm{KL}^{2}$ with an equivalent $\left.\mathrm{PdCl}\left(\mathrm{CH}_{3}\right)(\mathrm{COD})\right]$ with $\mathrm{PR}_{3}^{1}\left(\mathrm{R}^{1}=\right.$ $\mathrm{Me}, \mathrm{Ph})$ results in the isolation of the neutral complexes $\mathbf{3} \mathbf{c}$ and $\mathbf{3 d}$. The ${ }^{1} \mathrm{H}$ NMR spectrum of $3 \mathbf{c}$ shows the $\mathrm{CH}_{3}{ }^{\mathrm{Pd}}$ resonance as a doublet at $-0.32 \mathrm{ppm}$ due to $\mathrm{P}-\mathrm{H}$ coupling. The ${ }^{13} \mathrm{C}\left\{{ }^{1} \mathrm{H}\right\}$ NMR spectrum of $3 \mathbf{c}$ shows a doublet at $\delta 15.9 \mathrm{ppm}$ for $\mathrm{PMe}_{3}\left(J_{\mathrm{P}-\mathrm{C}}=52.2 \mathrm{~Hz}\right)$, whiles the $\mathrm{CH}_{3}{ }^{\mathrm{Pd}}$ resonance is observed as a doublet at $0.76 \mathrm{ppm}\left(J_{\mathrm{PC}}=11.5 \mathrm{~Hz}\right)$ due to coupling with the phosphorous nucleus. Only broad and partially resolved signals are observed for the aromatic protons. Crystals of $\mathbf{3} \mathbf{c}$ were obtained by the slow diffusion of $\mathrm{Et}_{2} \mathrm{O}$ into a $\mathrm{CH}_{2} \mathrm{Cl}_{2}$ solution of the complex for several days. Selected bond lengths and bond angles for $\mathbf{3 c}$ are given in Table 6.3.1. 3 . 


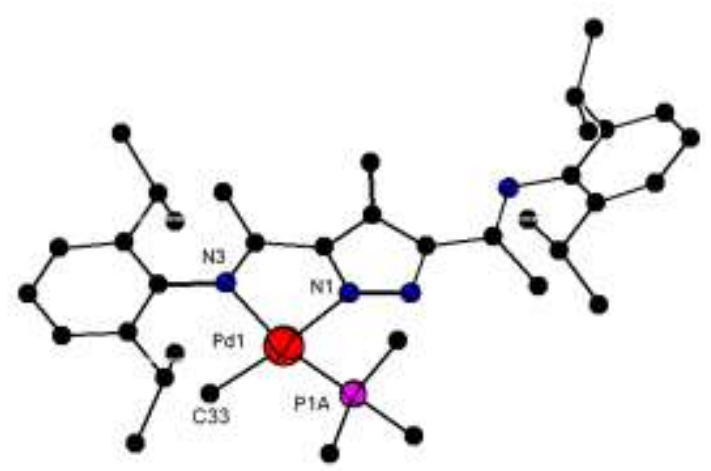

Fig. 6.3.1. 3: Molecular structure of 3c, all $\mathrm{H}$ atoms are omitted for clarity

The coordination about palladium(II) atom in $\mathbf{3 c}$ is defined by four ligand atoms N3, N1, C33, and P1A is essentially square planar. The $\operatorname{Pd}(1)-\mathrm{N}(1)$ bond length $(2.06 \AA)$ is smaller than the $\operatorname{Pd}(1)-\mathrm{N}(3)$ bond length $(2.10 \AA)$. This weakening of the $\operatorname{Pd}(1)-\mathrm{N}(3)$ bond is largely due to the trans influence of the $\mathrm{PMe}_{3}$ group. The palladium centre is part of a largely planar five-membered chelate ring involving $\mathrm{N}(1)-\mathrm{Pd}(1)-\mathrm{N}(3)$ with bond angles near $77^{\circ}$. The P-C bond length of 1.89 is longer than that of free $\mathrm{PMe}_{3}(1.84 \AA) .{ }^{240}$

Table 6.3.1. 3: Selected bond lengths $[\AA]]$ and bond angles $\left[{ }^{\circ}\right]$ for $3 c$

\begin{tabular}{llll}
\hline \multicolumn{3}{c}{ Bond lengths $[\AA]$} \\
\end{tabular}

On the other hand, neutral complexes of the type $\left[\mathrm{HL}^{x} \mathrm{Pd}\left(\mathrm{CH}_{3}\right) \mathrm{Cl}\right](\mathbf{3} \mathbf{e}, \mathbf{3} \mathbf{f}$ and $\mathbf{3 g}$ ) are formed when the ligands are treated with the metal precursor $\left[\mathrm{PdCl}\left(\mathrm{CH}_{3}\right)(\mathrm{COD})\right]$ without the use of a base. 


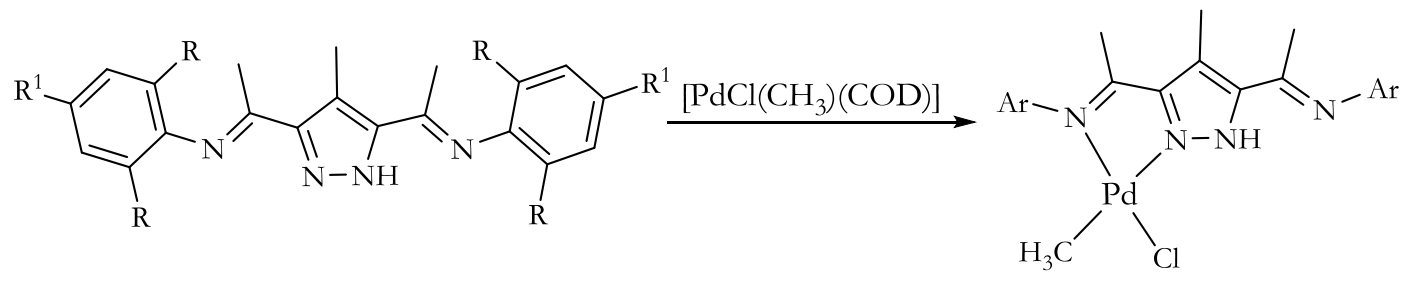

$$
\begin{aligned}
& \mathbf{H L}^{2}: \mathbf{R}={ }^{i} \operatorname{Pr}, \mathrm{R}^{1}=\mathrm{H} \\
& \mathrm{HL}^{3}: \mathbf{R}=\mathrm{Me}, \mathrm{R}^{1}=\mathrm{H} \\
& \mathbf{H L}^{4}: \mathbf{R}=\mathrm{Me}, \mathrm{R}^{1}=\mathrm{Me}
\end{aligned}
$$

\section{Scheme 6.3.1. 4: Synthesis of the neutral complexes $3 \mathrm{e}-3 \mathrm{~g}$}

In these complexes, the ligands remain protonated. The complexes, $\mathbf{3 e}, \mathbf{3} \mathbf{f}$, and $\mathbf{3 g}$ were characterized by ${ }^{1} \mathrm{H}$ and ${ }^{13} \mathrm{C}$ NMR, ESI-MS and in some instances elemental analysis, which confirmed the formation of such complexes. In all three complexes, the $\mathrm{CH}_{3}{ }^{\mathrm{Pd}}$ peaks in the ${ }^{1} \mathrm{H}$ NMR spectrum are observed at $\delta: 0.46,0.27$, and 0.32 for $\mathbf{3 e}, \mathbf{3} \mathbf{f}$, and $\mathbf{3} \mathbf{g}$ respectively. The ligands with the more bulky side arms usually show a lower field signal for the $\mathrm{CH}_{3}{ }^{\text {Pd }}$ group. Two ${ }^{1} \mathrm{H}$ NMR spectrum peaks are observed for the $\mathrm{CH}_{3} \mathrm{C}=\mathrm{N}$ group, reflecting the different $\mathrm{CH}_{3} \mathrm{C}=\mathrm{N}$ environments. The IR spectra of the complexes as expected also reflect the different $\mathrm{CH}_{3} \mathrm{C}=\mathrm{N}$ environments.

For instance in $\mathbf{3 f}$, the coordinated side arm shows a $\mathrm{C}=\mathrm{N}$ stretch at $1549 \mathrm{~cm}^{-1}$, compared to the free arm which shows a $\mathrm{C}=\mathrm{N}$ stretch at $1589 \mathrm{~cm}^{-1}$. The complexes $\mathbf{3 e}, \mathbf{3 f}$, and $\mathbf{3} \mathbf{g}$ are stable in the solid state but undergo reconstitution in solution. For instance, when $3 \mathrm{e}$ is left in solution at room temperature for several weeks, crystals obtained show the formation of $\left[\mathrm{L}_{2}^{2} \mathrm{Pd}\right]$ type complex $(\mathbf{3 h})$. Rearrangements reactions involving PdClMe complexes have been reported in literature. ${ }^{241}$
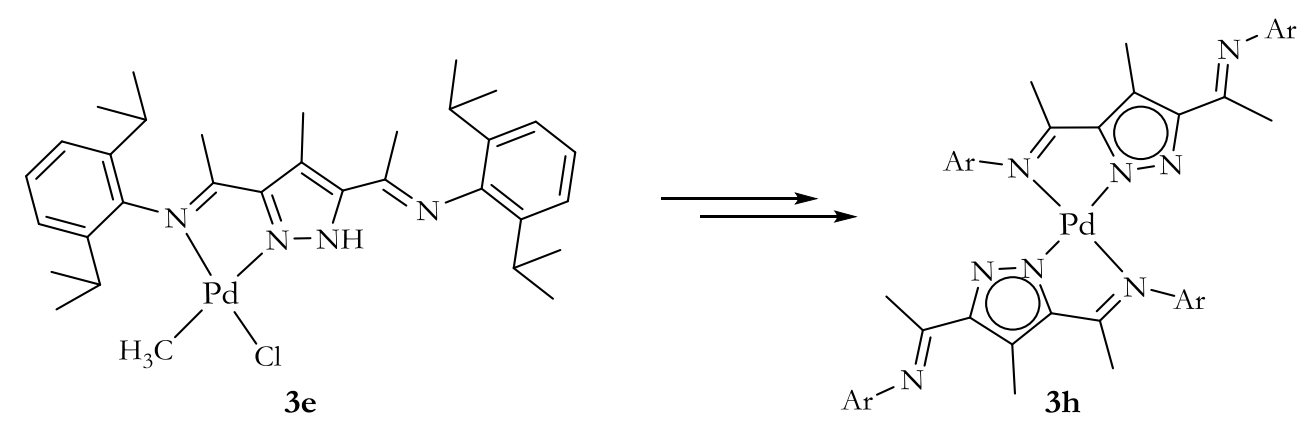

Scheme 6.3.1. 5: Formation of $3 \mathrm{~h}$ from rearrangement of $3 \mathrm{e}$ in solution at room temperature 
The complex $\mathbf{3 h}$ is also isolated as a side product in attempts at preparing a complex of the type $\left[\mathrm{L}^{2} \mathrm{Pd}(\mathrm{Pyr})\left(\mathrm{CH}_{3}\right)\right](\mathrm{Pyr}=$ pyridine $)$. The molecular structure of $\mathbf{3 h}$ is shown below.

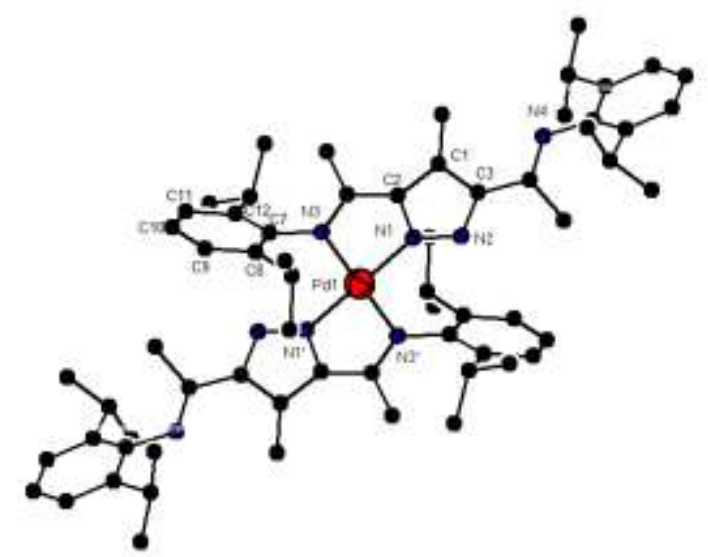

Fig. 6.3.1. 4: Molecular structure of $3 \mathrm{~h}, \mathrm{H}$ atoms, and counter ions omitted for clarity

In $3 \mathrm{~h}$, the coordination geometry around palladium centre is square planar, with the square plane defined by four atoms, $\mathrm{N}(3) / \mathrm{N}(1) / \mathrm{N}\left(3^{\prime}\right) / \mathrm{N}\left(1^{\prime}\right) / \mathrm{N}(3)$. The palladium-imine bond distance $\mathrm{Pd}(1)-\mathrm{N}(3)$ is slightly longer $2.03 \AA$ compared to the palladium-pyrazolyl nitrogen bond distance $\operatorname{Pd}(1)-\mathrm{N}(1)$ of $1.98 \AA$. The ligand bite angle is $\angle \mathrm{N}(1) \operatorname{Pd}(1) \mathrm{N}(3)=79.8^{\circ}$. In addition, the inter planar angle between the six carbon atoms $\mathrm{C}(7) / \mathrm{C}(8) / \mathrm{C}(9) / \mathrm{C}(10) / \mathrm{C}(11) / \mathrm{C}(12)$ which make up the coordinated aryl side arm and the five atoms which make the pyrazole ring $\mathrm{N}(1)-\mathrm{N}(2)-\mathrm{C}(3)-\mathrm{C}(1)-\mathrm{C}(2)$ is nearly perpendicular at $88.4^{\circ}$. The orientation of the non-coordinated $\mathrm{N}^{\wedge} \mathrm{N}$ sidearm is largely anti with a dihedral angle of $171.2^{\circ}(\mathrm{N}(2)-\mathrm{C}(3)-\mathrm{C}(19)-\mathrm{N}(4))$ compared to $-2.40^{\circ}$ for the coordinated $\mathrm{N}^{\wedge} \mathrm{N}$ side $\operatorname{arm}(\mathrm{N}(1)-\mathrm{C}(2)-\mathrm{C}(5)-\mathrm{N}(3))$. Selected bond lengths $[\AA]$ and bond angles $\left[{ }^{\circ}\right]$ given in Table 6.3.1. 4 .

Table 6.3.1. 4: Selected bond lengths $[\AA \AA]$ and bond angles $\left[{ }^{\circ}\right]$ for $3 \mathrm{~h}$

\begin{tabular}{llll}
\hline \multicolumn{3}{c}{ Bond lengths $[\AA]$} & \multicolumn{3}{c}{ Bond angles $\left[^{\circ}\right]^{\prime}$} \\
\hline $\operatorname{Pd}(1)-\mathrm{N}(1)$ & $1.989(4)$ & $\mathrm{N}(1)-\operatorname{Pd}(1)-\mathrm{N}(1)$ & $180.00(1)$ \\
$\operatorname{Pd}(1)-\mathrm{N}(1)$ & $1.989(4)$ & $\mathrm{N}(1)-\operatorname{Pd}(1)-\mathrm{N}(3)$ & $79.87(18)$ \\
$\operatorname{Pd}(1)-\mathrm{N}(3)$ & $2.034(5)$ & $\mathrm{N}(1)-\mathrm{Pd}(1)-\mathrm{N}(3)$ & $100.13(18)$ \\
$\operatorname{Pd}(1)-\mathrm{N}(3)$ & $2.034(5)$ & $\mathrm{N}(3)-\mathrm{Pd}(1)-\mathrm{N}(3)$ & $179.98(1)$ \\
\hline
\end{tabular}




\section{Results and Discussions}

In a brief attempt of mediating acrylate insertion reactions with $\mathbf{3 f}$, yellow crystalline blocks (3i) were isolated from the reaction medium after several days. However, there was not enough material available for thorough characterization. Single crystal X-ray structure of the crystalline blocks $3 \mathbf{i}$, showed it to be a $\left[\mathrm{L}_{2}^{3} \mathrm{Pd}_{2}\right]\left(\mathrm{BAr}_{4}^{\mathrm{F}}\right)_{2}$ type complex.

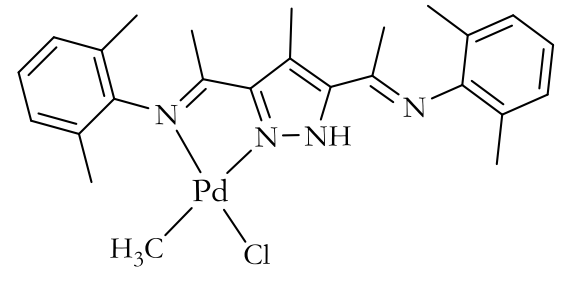

3f

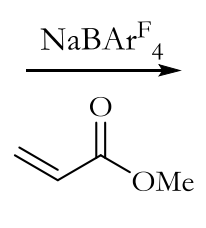

Scheme 6.3.1. 6: Formation of $3 \mathrm{i}$ from $3 \mathrm{f}$ at acrylate insertion reactions

The molecular structure of $\mathbf{3 i}$ is shown in Fig. 6.3.1. 5. The compound crystallizes in the $P-1$ space group. The two palladium atoms are bound by two pyrazolyl nitrogen atoms and two imine nitrogen atoms. The coordination around the palladium centre consists of four nitrogen donors, two each from the imine side arm and the pyrazolyl nitrogen atoms.

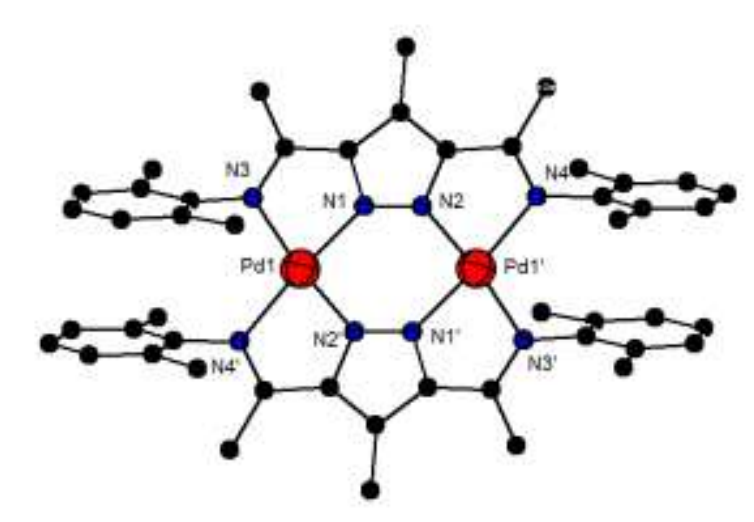

Fig. 6.3.1. 5: Molecular structure of 3i, $\mathrm{H}$ atoms, and counterions omitted for clarity

The shortest Pd-N bond is between the pyrazolyl nitrogen and the palladium(II) centre. The inter palladium distance is fixed by the $\mu$-pyrazolate framework at $3.94 \AA$. The torsional angle defined by $\operatorname{Pd}(1)-\mathrm{N}(1)-\mathrm{N}(2)-\mathrm{Pd}\left(1^{\prime}\right)$ is $0.68^{\circ}$, and the interplanar angle defined by two aromatic rings on opposite side of the palladium centre is $1.23^{\circ}$, thus the complex is largely planar. Selected bond lengths $[\AA]$ and bond angles $\left[{ }^{\circ}\right]$ also given in Table 6.3.1. 5 . 
Results and Discussions

Table 6.3.1. 5: :Selected bond lengths $[\AA]$ and bond angles $\left[{ }^{\circ}\right]$ for $3 \mathrm{i}$

\begin{tabular}{llll}
\hline \multicolumn{3}{c}{ Bond lengths $[\AA]$} & Bond angles $\left[^{\circ}\right]^{\circ}$ \\
\hline $\operatorname{Pd}(1)-\mathrm{N}(1)$ & $1.964(3)$ & $\mathrm{N}(1)-\mathrm{Pd}(1)-\mathrm{N}(4)$ & $173.37(12)$ \\
$\operatorname{Pd}(1)-\mathrm{N}(3)$ & $2.076(3)$ & $\mathrm{N}(3)-\mathrm{Pd}(1)-\mathrm{N}(4)$ & $108.72(12)$ \\
$\operatorname{Pd}(1)-\mathrm{N}(4)$ & $2.080(3)$ & $\mathrm{N}(2)-\mathrm{N}(1)-\mathrm{Pd}(1)$ & $131.7(2)$ \\
$\operatorname{Pd}(1)-\mathrm{Pd}(1)$ & $3.943(2)$ & $\mathrm{N}(1)-\mathrm{N}(2)-\mathrm{C}(3)$ & $108.6(3)$ \\
\hline
\end{tabular}

The Pd-N bond lengths are in the range of similar reported palladium complexes. ${ }^{155}$ 


\subsection{Mononuclear nickel(II) $\sigma$-aryl complexes as templates to heterobimetallic complexes}

A general synthetic route for the preparation of the nickel(II) $\sigma$-aryl complexes involved treating the deprotonated ligand with one mol equivalent of the precursor $\left[\mathrm{NiBr}(\mathrm{Ar})\left(\mathrm{PPh}_{3}\right)\right]$ in $\mathrm{CH}_{2} \mathrm{Cl}_{2}$ (Scheme 6.3.2. 1).

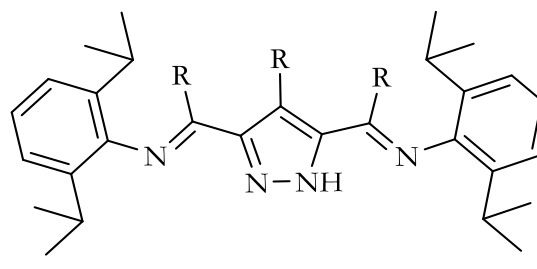

$\mathbf{H L}^{1}: \mathrm{R}=\mathrm{H}$

$\mathrm{HL}^{2}: \mathrm{R}=\mathrm{Me}$

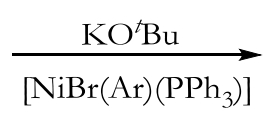

(3j): $\mathrm{R}=\mathrm{H}, \mathrm{Ar}=\mathrm{C}_{10} \mathrm{H}_{7}$

(3k): $\mathrm{R}=\mathrm{Me}, \mathrm{Ar}=\mathrm{C}_{10} \mathrm{H}_{7}$

(31): $\mathrm{R}=\mathrm{Me}, \mathrm{Ar}=\mathrm{C}_{6} \mathrm{H}_{5}$

Scheme 6.3.2. 1: Preparation of $\left[\mathrm{LxNi}(\mathrm{Ar})\left(\mathrm{PPh}_{3}\right)\right]$ complexes $(3 \mathrm{j}-31)$

The mononuclear nickel(II) complexes (3j-31) were generally isolated as orange-yellow powder in moderate yields (44-46\%). They are fairly air stable and soluble in toluene, halogenated solvents, hexanes, and ether. The complexes were characterized by ${ }^{1} \mathrm{H}$ and ${ }^{13} \mathrm{C}$ NMR, IR, ESI-MS, elemental analysis and in some instances single crystal X-ray structures.

For example, in a selected complex $\mathbf{3} \mathbf{j}$, the IR spectrum of $\mathbf{3} \mathbf{j}$ shows two $\mathrm{CH}=\mathrm{N}$ stretching vibrations at $1637 \mathrm{~cm}^{-1}$ and $1583 \mathrm{~cm}^{-1}$ for the unbound and metal bound side arms respectively, a shift to lower wavenumber due to coordination to the metal. The ${ }^{1} \mathrm{H}$ NMR spectrum confirms the asymmetric ligand environment, with the $\mathrm{CH}=\mathrm{N}$ peaks observed at 7.69 and $7.99 \mathrm{ppm}$ for the coordinated and uncoordinated side arms respectively. The complexes also assume a square planar geometry. The ${ }^{1} \mathrm{H}$ NMR spectrum of $3 \mathbf{k}$ (Fig. 6.3.2.1. 1) shows four different $\mathrm{CH}^{\mathrm{ipr}}$ environments $(\mathrm{h}, \mathrm{r}, \mathrm{s}$, and $\mathrm{l}$ ) which integrate in $1: 1: 1: 1$ ratio, due to the hindered rotation imposed by the presence of the bulky napthyl and triphenylphosphane groups. The ${ }^{1} \mathrm{H}$ NMR spectrum peaks for $\mathbf{3 k}$ were assigned from $1 \mathrm{D}$ and $2 \mathrm{D}$ experiments. Strong shielding of $\mathrm{CH}_{3}{ }^{\text {ipr }}$ by the naphthyl ring is observed in the ${ }^{1} \mathrm{H}$ NMR spectrum. The $\mathrm{CH}_{3}{ }^{\text {iPr }}$ group shielded by the napthyl ring is observed upfield as a doublet at $-0.52 \mathrm{ppm}$ due to coupling with the $\mathrm{CH}$ proton on the isopropyl group. The 
${ }^{31} \mathrm{P}\left\{{ }^{1} \mathrm{H}\right\}$ signal is observed at $30.3 \mathrm{ppm}$ as a singlet. The ${ }^{1} \mathrm{H}$ NMR spectrum assignments are shown in Fig. 6.3.2. 1. The ${ }^{1} \mathrm{H}-{ }^{1} \mathrm{H}$ COSY assignments for $3 \mathbf{k}$ is also shown in Fig. 6.3.2. 2.

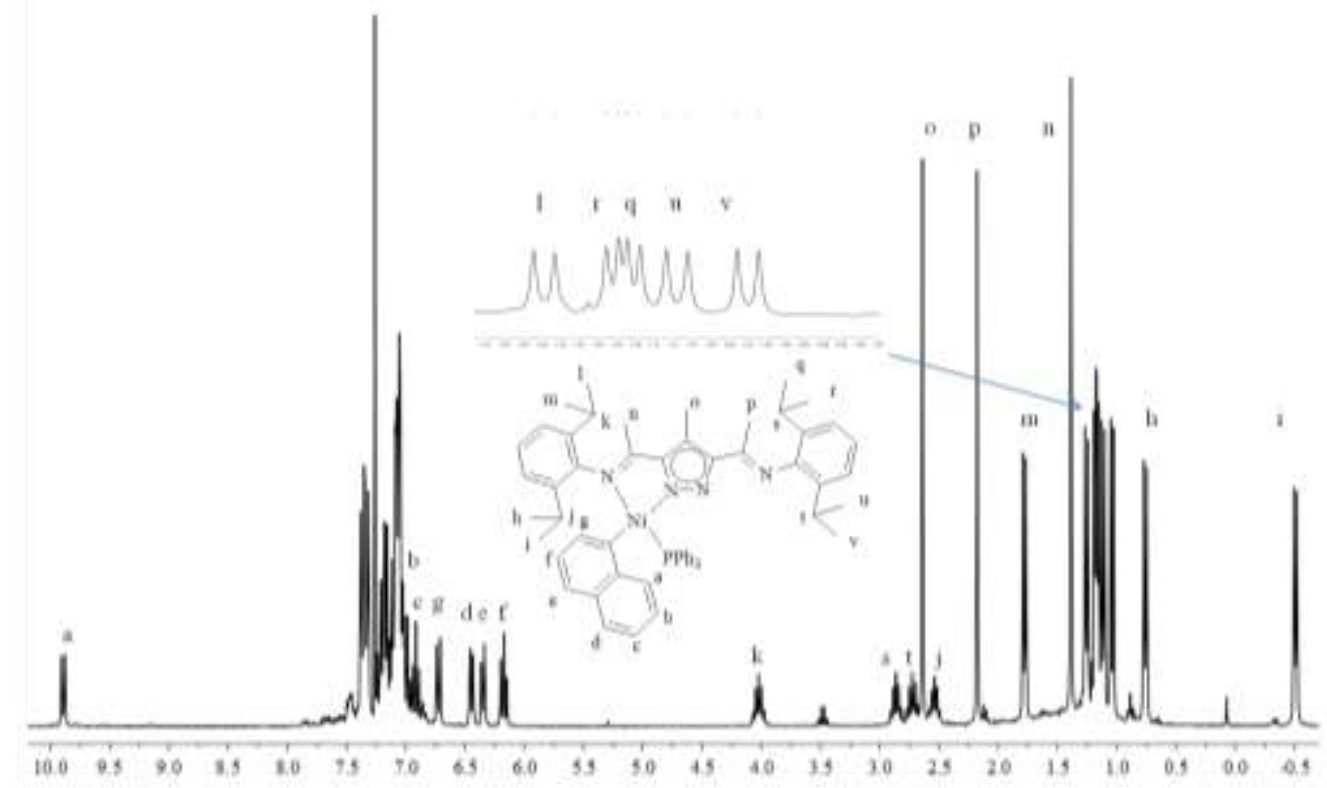

Fig. 6.3.2. 1: ${ }^{1} \mathrm{H}$ NMR spectrum of $3 \mathrm{k}$ measured in $\mathrm{CDCl}_{3}$ at room temperature

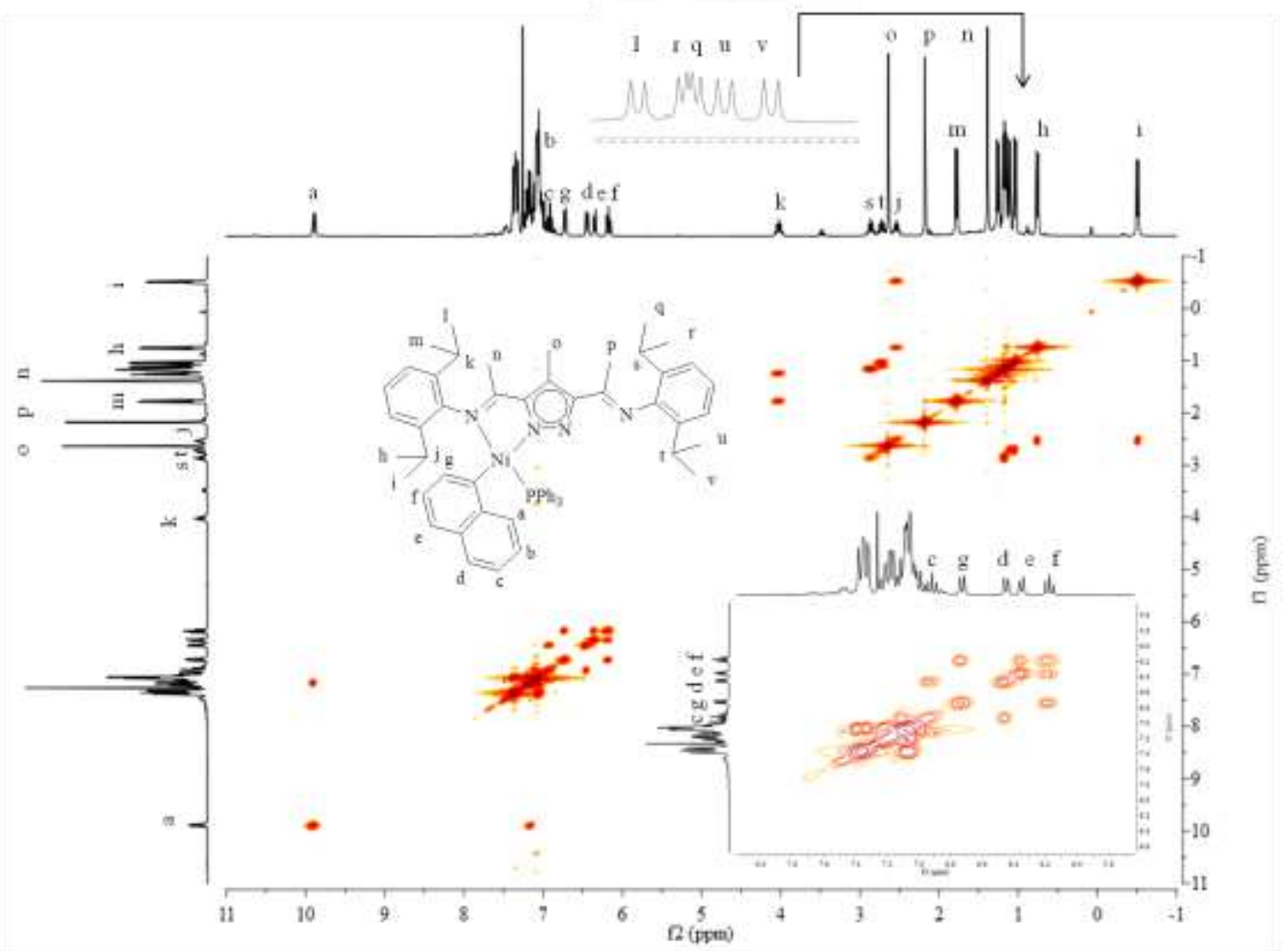

Fig. 6.3.2. 2: ${ }^{1} \mathrm{H}-1 \mathrm{H}$ COSY NMR spectrum of $3 \mathrm{k}$ measured in $\mathrm{CDCl}_{3}$ at room temperature 


\section{Results and Discussions}

A notable feature in the ${ }^{1} \mathrm{H}$ NMR spectrum of $\mathbf{3 k}$ is the presence of a downfield aromatic ${ }^{1} \mathrm{H}$ NMR spectrum signal at $9.89 \mathrm{ppm}$. This is also observed at $9.19 \mathrm{ppm}$ for the analogous compound $\mathbf{3} \mathbf{j}$, but not observed for $\mathbf{3 1}$, which has a $\sigma$-bonded phenyl ring.

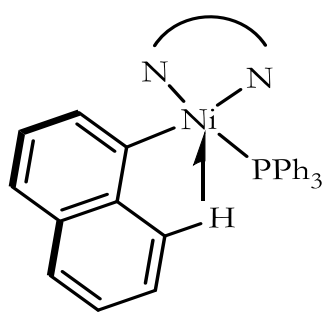

This is possibly, due to the close proximity of an aromatic $\mathrm{H}$ on the second ring of the naphthyl group to the metal centre. Single crystals of $\left[\mathrm{L}^{2} \mathrm{Ni}\left(\mathrm{C}_{10} \mathrm{H}_{7}\right)\left(\mathrm{PPh}_{3}\right)\right](\mathbf{3 k})$ were grown by the slow evaporation of a toluene solution of the complex over several days. The compound crystallizes in the $P 21 / \mathrm{c}$ space group. The structure consists of a mononuclear unit in which the metal binds to one pocket of the ligand whiles the other remains vacant. The geometry about the nickel(II) centre is a largely square planar. The nickel(II) centre is coordinated to the two nitrogen atoms $(\mathrm{N} 1, \mathrm{~N} 3)$, with the $\mathrm{PPh}_{3}$ ligand in a trans position to the imine nitrogen.

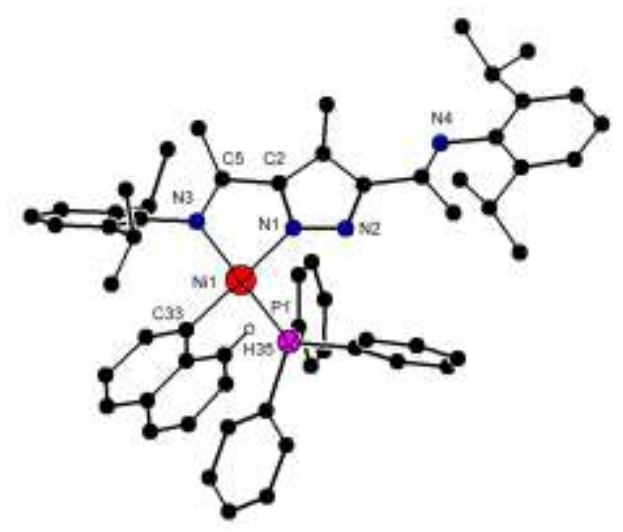

Fig. 6.3.2. 3: Molecular structure of 3k, most $\mathrm{H}$ atoms are omitted for clarity

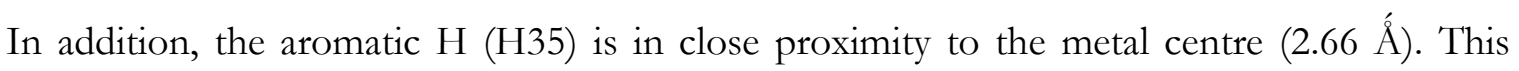
distance is substantially shorter than the sum of the van der Waals radii of $\mathrm{H}$ and $\mathrm{Ni}(1.20$ and $1.63 \AA$ respectively). The interplanar angle defined by Ni(1), N(3), C(5), C(2), N(1), and the naphthyl ring is $80.36^{\circ}$. The $\mathrm{Ni}(1)-\mathrm{N}(3)$ bond length is longer, $1.96 \AA$ compared to $\mathrm{Ni}(1)$ - 
$\mathrm{N}$ (1) $(1.90 \AA)$ due to the trans influence of the $\mathrm{PPh}_{3}$ group. The interplanar angle between the pyrazole ring and the napthyl ring is nearly perpendicular at $88.3^{\circ}$; this possibly is the only favourable orientation in order to avoid steric clash of the bulky aryl rings of $\mathrm{PPh}_{3}$, the napthyl ring and the 2,6-diisopropyl aryl ring. Selected bond lengths $[\AA]$ and angles $\left[{ }^{\circ}\right]$ are given in Table 6.3.2. 1.

Table 6.3.2. 1: Selected bond lengths $[\AA \AA]$ and bond angles $\left[{ }^{\circ}\right]$ for $3 \mathrm{k}$

\begin{tabular}{llll}
\hline \multicolumn{3}{c}{ Bond lengths $[\AA]$} & \multicolumn{1}{c}{ Bond angles $\left.{ }^{\circ}{ }^{\circ}\right]$} \\
\hline $\mathrm{Ni}(1)-\mathrm{C}(33)$ & $1.896(7)$ & $\mathrm{C}(33)-\mathrm{Ni}(1)-\mathrm{N}(1)$ & $169.6(3)$ \\
$\mathrm{Ni}(1)-\mathrm{N}(1)$ & $1.907(5)$ & $\mathrm{C}(33)-\mathrm{Ni}(1)-\mathrm{N}(3)$ & $93.2(3)$ \\
$\mathrm{Ni}(1)-\mathrm{N}(3)$ & $1.964(5)$ & $\mathrm{N}(1)-\mathrm{Ni}(1)-\mathrm{N}(3)$ & $81.5(2)$ \\
$\mathrm{Ni}(1)-\mathrm{P}(1)$ & $2.1754(19)$ & $\mathrm{C}(33)-\mathrm{Ni}(1)-\mathrm{N}(3)$ & $93.2(3)$ \\
\hline
\end{tabular}

Other compounds, which have the hydrogen of an aromatic group in close proximity with metals reported in literature, are shown below in XL and XLI. ${ }^{242,243}$

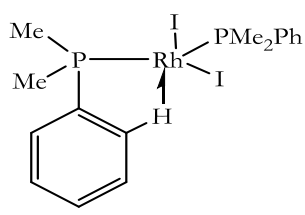

XL

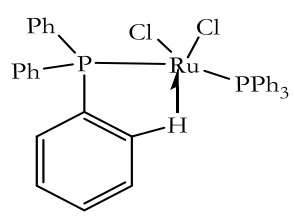

XLI

Studies have been conducted on the close contact between $\mathrm{d}^{8}$ metal ions such as palladium(II) and platinum(II) metal ions which have N-H or O-H bonds are located above or below the coordination sphere. ${ }^{244,245}$ In addition reports have also been made in close contacts which involve $\mathrm{sp}^{2}$ or $\mathrm{sp}^{3}$ hybridized C-H bonds. ${ }^{246,247,248}$ There are different schools of thought on the nature of these $\mathrm{C}-\mathrm{H}$ interactions. One school of thought is that these contacts are as a result of three-centre four electron $\mathrm{M} \cdots \mathrm{H}-\mathrm{C}$ bonds which involves the filled $\mathrm{d}_{\mathrm{z}^{2}}$ orbital (Scheme 6.3.2. 2). 
Results and Discussions
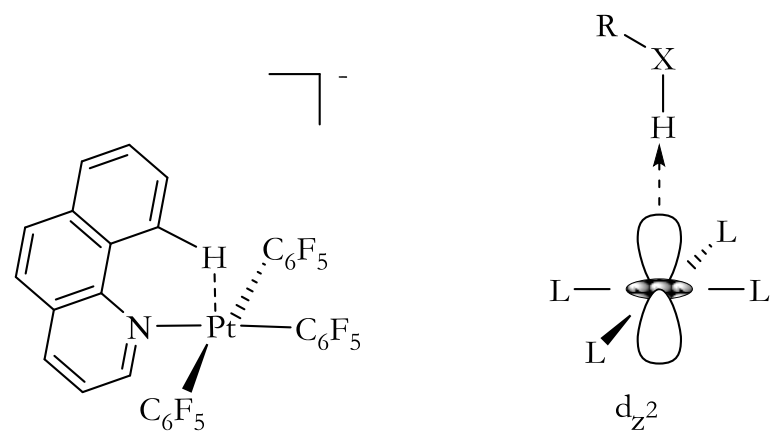

Scheme 6.3.2. 2: Three center four electron $\mathrm{M} \cdots \mathrm{H}-\mathrm{X}$ hydrogen bonds ${ }^{249}$

Some also argue it is as a result of agostic three-center two electron interactions. Whiles another school of thought is that, these close contacts are as a result of mainly repulsive interactions which are mainly due to geometric ligand caused by bulky ligand substituents. 250,155 These forces the $\mathrm{H}$ atoms to lie in close to the metal ions. The ESI-MS of $\mathbf{3 k}$ also shows the $\mathrm{m} /$ z peak at $931(100 \%)$ assigned to the molecular ion $[\mathrm{M}]^{+}$.

The analogous nickel(II) complex with a phenyl substituent $\left[\mathrm{L}^{2} \mathrm{Ni}(\mathrm{Ph})\left(\mathrm{PPh}_{3}\right)\right]$ (31) was prepared in like manner. The IR spectrum of this complex shows two absorption bands at $1626 \mathrm{~cm}^{-1}$ and $1566 \mathrm{~cm}^{-1}$ that can be attributed to the two different imine environments. The strong absorption band at $1435 v(\mathrm{P}-\mathrm{C})$ and $696 v(\mathrm{Ni}-\mathrm{P})$ confirms the binding of $\mathrm{PPh}_{3}$ to nickel. The ESI-MS shows fragmentation corresponding to the loss of a phenyl and $\mathrm{PPh}_{3}$ groups. Single crystals of $\mathbf{3 1}$ were grown by the slow evaporation of a $\mathrm{CH}_{2} \mathrm{Cl}_{2}$ solution of the complex at room temperature. The structure is of poor quality but unequivocally provides the atom connectivity (Fig. 6.3.2. 4).

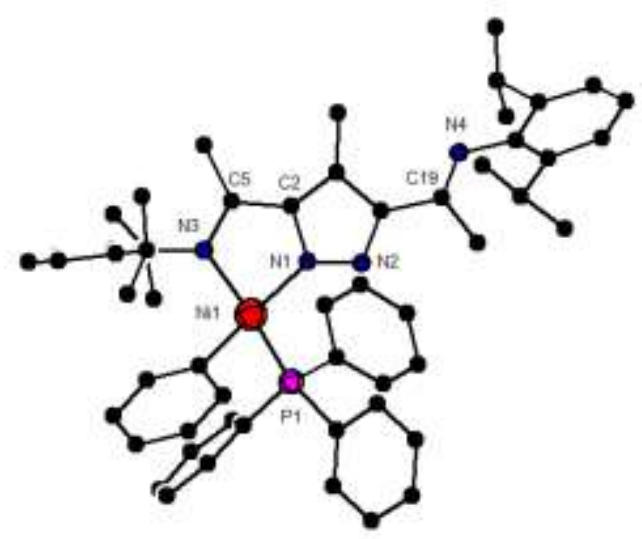

Fig. 6.3.2. 4: Molecular structure of 31, all $\mathrm{H}$ atoms are omitted for clarity 
The coordination around the nickel(II) is square planar with the $\mathrm{PPh}_{3}$ in a trans position to the imine nitrogen. Selected bond lengths and bond angles are given in Table 6.3.2. 2. The $\mathrm{C}(19)-\mathrm{N}(4)$ bond length of the imine group $(1.27 \AA)$ is consistent with the double bond character, and shorter than C(5)-N(3) (1.33 $\AA$ ) as expected. The Ni-P bond length of $2.16 \AA$ is shorter than that reported for the neutral phenoxyimine complex. ${ }^{40}$

Table 6.3.2. 2: Selected bond lengths $[\AA \AA]$ and bond angles $\left[{ }^{\circ}\right]$ for 31

\begin{tabular}{llll}
\hline \multicolumn{3}{c}{ Bond lengths $[\AA]$} & \multicolumn{3}{c}{ Bond angles $\left[^{\circ}\right]$} \\
\hline $\mathrm{Ni}(1)-\mathrm{N}(1)$ & $1.891(10)$ & $\mathrm{N}(1)-\mathrm{Ni}(1)-\mathrm{C}(34)$ & $161.0(5)$ \\
$\mathrm{Ni}(1)-\mathrm{C}(34)$ & $1.892(12)$ & $\mathrm{N}(1)-\mathrm{Ni}(1)-\mathrm{N}(3)$ & $82.4(5)$ \\
$\mathrm{Ni}(1)-\mathrm{N}(3)$ & $1.956(12)$ & $\mathrm{C}(34)-\mathrm{Ni}(1)-\mathrm{N}(3)$ & $95.4(6)$ \\
$\mathrm{Ni}(1)-\mathrm{P}(1)$ & $2.158(5)$ & $\mathrm{N}(1)-\mathrm{Ni}(1)-\mathrm{P}(1)$ & $99.0(4)$ \\
$\mathrm{C}(5)-\mathrm{N}(3)$ & $1.329(189)$ & & \\
$\mathrm{C}(19)-\mathrm{N}(4)$ & $1.269(185)$ & & \\
\hline
\end{tabular}

In the course of the experiments, crystal growth attempts yielded two unique systems, one of the crystals having two of the ligands coordinated to the nickel(II) centre $\left(\mathrm{L}_{2} \mathrm{Ni}\right)$ in a square planar environment. This dimer formed because of $\mathrm{PPh}_{3}$ dissociation. The formation of $\mathrm{L}_{2} \mathrm{Ni}$ types of complexes from $\mathrm{PPh}_{3}$ dissociation is documented in literature. ${ }^{251}$

Attempts at the use of the nickel $\sigma$-aryl complexes $(3 \mathbf{j}, \mathbf{3 k}$ and $3 \mathbf{1})$ in ethylene polymerization experiments failed. Addition of $\left[\mathrm{Ni}(\mathrm{COD})_{2}\right]$ as a $\mathrm{PPh}_{3}$ scavenger in the presence of ethylene (5 atm) did not yield any polymer nor oligomer product. Rather what was observed is the dimerization of the complex to $\mathrm{L}^{2} \mathrm{Ni}$. Computational work by Ziegler and co-workers indeed shows that the presence of bulky ortho substituent is primarily responsible for high catalytic activity by promoting the dissociation of phosphane from the nickel(II) centre. ${ }^{252}$ Attention was later focused on testing these nickel(II) $\sigma$-aryl complexes in radical polymerization experiments as other nickel aryl complexes have been employed in such reactions. 


\subsubsection{Nickel(II) $\sigma$-aryl catalyzed radical polymerization of styrene to polystyrene}

Controlled radical polymerization (CRP) has been one of the most utilized polymerization methods due to its high chemoselectivity, regioselectivity, and ability to obtain polymers with controlled molecular weight and structure. The work of Wang and Matyjaszewski on the living/controlled bulk polymerization of styrene in the presence of the 1phenylethylchloride/ $\mathrm{CuCl} / 2,2^{\prime}$-bipyridyl system ${ }^{253}$ has spurred more investigations into CRP. Sawamoto has reported on the use of commercially available $\mathrm{NiBr}_{2}\left(\mathrm{PPh}_{3}\right)_{2}$ (XLII) to induce the living radical polymerization of MMA in conjunction with $\mathrm{CCl}_{3} \mathrm{Br}$ initiator and a Lewis acid activator. ${ }^{254}$ Also, thermally more robust and highly soluble $\mathrm{NiBr}_{2}\left(\mathrm{PBu}_{3}\right)_{2}$ (XLIII) has been used for the ATRP polymerization of MMA and MA. Teyssie also reported the use of a homogeneous aryl nickel(II) complex, which with activated alkyl halides gives well-controlled radical polymerization of methacrylate monomers in organic solvents. ${ }^{255}$ The complex $\left[\mathrm{L}^{2} \mathrm{Ni}\left(\mathrm{C}_{10} \mathrm{H}_{7}\right)\left(\mathrm{PPh}_{3}\right)\right]$ 3k was tested as catalyst for the atom transfer radical polymerization of styrene.

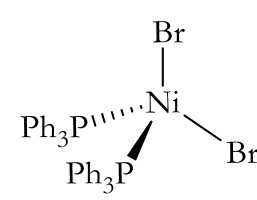

XLII

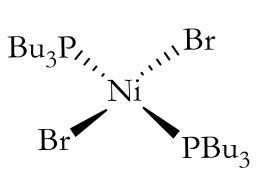

XLIII

It is worth stating that in atom transfer radical polymerization (ATRP), a halogen-capped polymer chain and a transition metal complex are in reversible equilibrium with a polymeric radical and the corresponding higher oxidation state metal halide 256,257 as shown in the simplified scheme below (Scheme 6.3.2.1. 1).

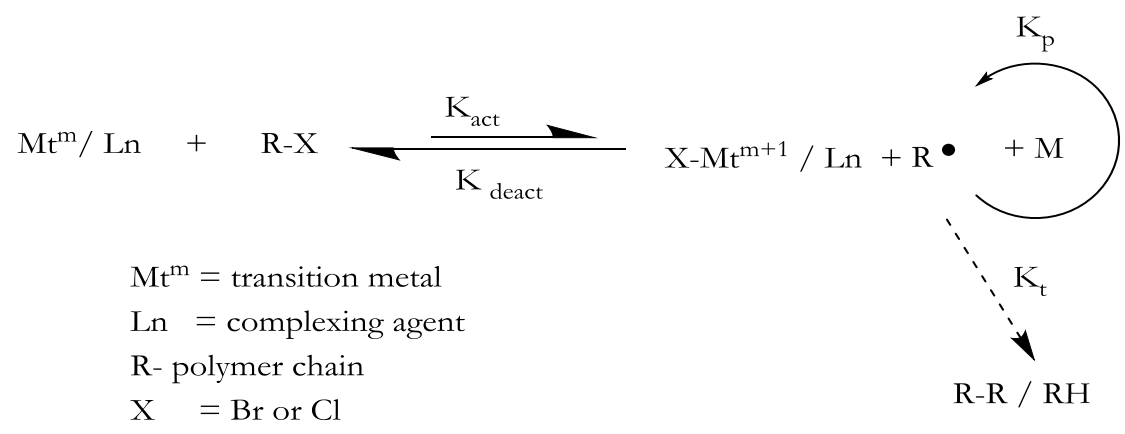

Scheme 6.3.2.1. 1: Mechanism of metal complex-mediated ATRP 
Organometallic mediated radical polymerization (OMRP), another controlled radical polymerization technique in contrast to ATRP, involves the reversible formation of a covalent bond between a transition metal and the polymer chain. It is also dependent on the lability of metal-carbon bonds under thermal or photolytic treatment. The complex $\mathbf{3 k}$ was screened for the radical polymerization of styrene to polystyrene. The linear time vs. conversion plot and the $\ln (1 /(1-$ conv. $))$ vs. $\mathrm{t}^{2 / 3}$ shows the characteristic plot for a persistent radical effect (Fig. 6.3.2.1. 1).
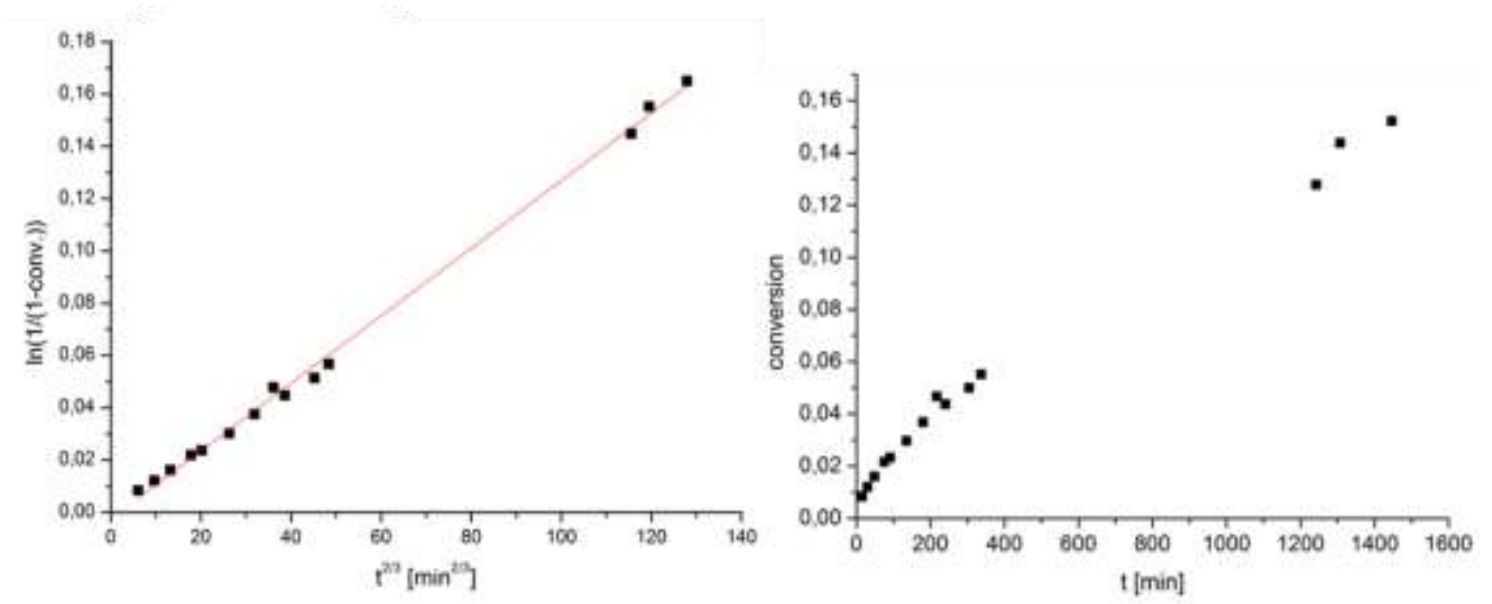

Fig. 6.3.2.1. 1: Kinetic plots for the radical polymerization of styrene using 3k

Usually, the linear first-order kinetic plot accompanied by the linear increase in polymer weight with conversion determines the "livingness "of the polymerization process. It can therefore be inferred that $\mathbf{3 k}$ is active in the living polymerization of polystyrene.
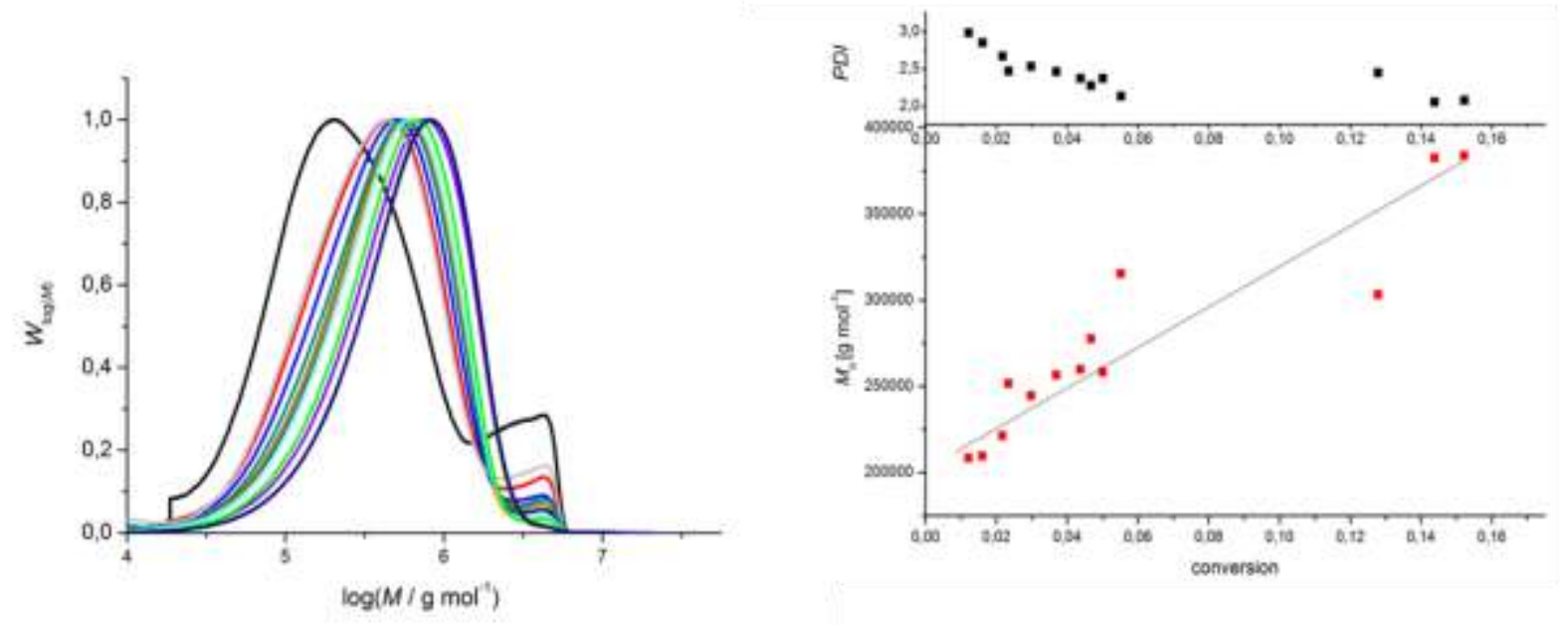

Fig. 6.3.2.1. 2: Molecular weight plots for the ATRP of styrene to polystyrene using $3 \mathrm{k}$ 


\section{Results and Discussions}

The PDI decreases with conversion but stays well above 2.0. Results also show that the catalyst has higher conversions with increasing reaction times (Fig. 6.3.2.1. 2). Conversions however are generally low, and $\mathrm{M}_{\mathrm{n}}$ of the polymers increases with monomer conversion. However, polymerization is uncontrolled with broad polydispersity $(>2.0)$ and molecular weight distributions. The complex $\mathbf{3 k}$ is therefore ineffective at controlling polymerization, and displays very low catalyst efficiency even at high catalyst loadings. Detailed discussions on the results will not be covered here. 


\subsection{Synthesis towards heterobimetallic palladium(II)-rhodium(I) complexes}

Having obtained mononuclear palladium(II) and nickel(II) complexes of the pyrazolebridged a-diimine type ligands (Scheme 6.3.3. 1), attempts were made at preparing heterobimetallic complexes by the addition of coordinatively unsaturated metal species to pre-existing mononuclear complexes (Scheme 6.3.3. 2), similar to the method adopted by Chen and co-workers ${ }^{152}$ and the approach adopted by Akita and co-workers. ${ }^{136}$

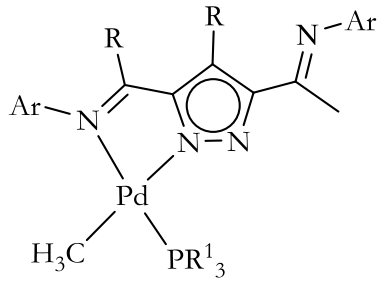

(3c): $\mathrm{R}=\mathrm{Me}, \mathrm{R}^{1}=\mathrm{Me}$

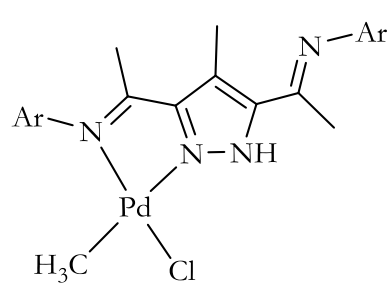

(3e): $\mathrm{R}=\mathrm{Me}$

$\mathrm{Ar}=2,6-{ }^{i} \mathrm{Pr}_{2}-\mathrm{C}_{6} \mathrm{H}_{3}$<smiles></smiles>

(3j) : $\mathrm{R}=\mathrm{H}, \mathrm{Ar}=\mathrm{C}_{10} \mathrm{H}_{7}$

(3k): $\mathrm{R}=\mathrm{Me}, \mathrm{Ar}=\mathrm{C}_{10} \mathrm{H}_{7}$

(31): $\mathrm{R}=\mathrm{Me}, \mathrm{Ar}=\mathrm{C}_{6} \mathrm{H}_{5}$

Scheme 6.3.3. 1: Scheme of mononuclear complexes used as templates for the preparation of heterobimetallic complexes

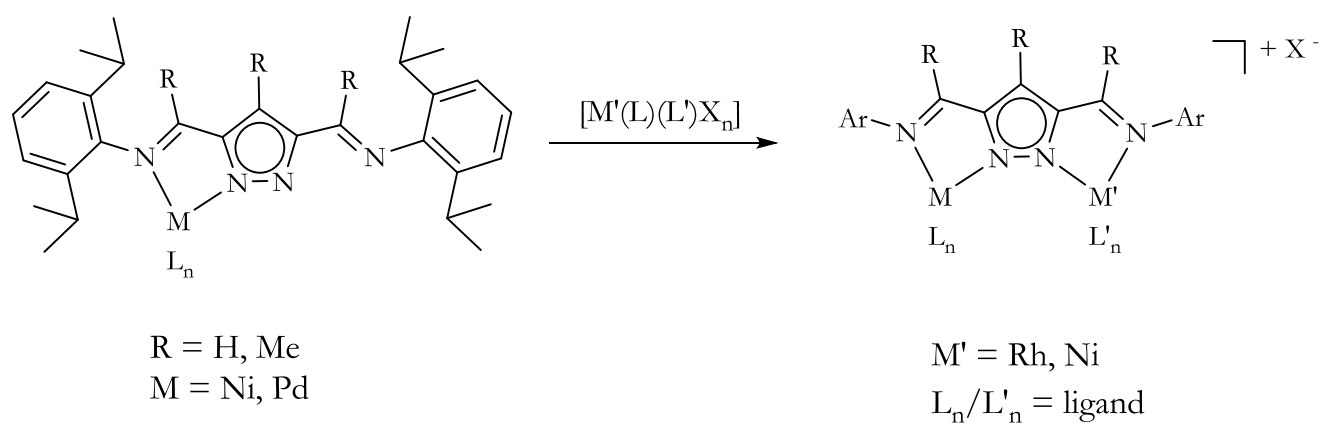

Scheme 6.3.3. 2: Attempted route to heterobimetallic complexes

Both approaches were however unsuccessful in this case. As an example, the addition of 1 mol equivalent of $\mathrm{NiBr}_{2}(\mathrm{dme})$ to $3 \mathbf{e}$ with and without a base results in the transmetallation of palladium(II) by nickel(II), to form a bis-chelate nickel(II) complex $\left[\mathrm{L}_{2}^{2} \mathrm{Ni}\right]$. This was confirmed by ${ }^{1} \mathrm{H}$ and ${ }^{13} \mathrm{C}\left\{{ }^{1} \mathrm{H}\right\}$ NMR spectrum of the resulting complex. 


\section{Results and Discussions}

Further confirmation was made by ESI-MS with $\mathrm{m} / \mathrm{z}$ value of $1072(100 \%)$ which can be assigned to $\left[\mathrm{L}_{2}^{2} \mathrm{Ni}\right]$ as well as single crystal X-ray structure of the resulting complex (already reported). ${ }^{221}$

In another example, $0.5 \mathrm{~mol}$ equivalent $[\mathrm{RhCl}(\mathrm{COD})]_{2}$ was added to a $\mathrm{CDCl}_{3}$ solution of $\mathbf{3 c}$ and the reaction mixture monitored for $24 \mathrm{~h}$ (Scheme 6.3.3. 3). After $15 \mathrm{~min}$, the ${ }^{1} \mathrm{H}$ NMR spectrum peak intensity at $-0.31 \mathrm{ppm}$ for $\mathrm{CH}_{3}{ }^{\text {Pd }}$ group decreases, as well as a decrease in ${ }^{31} \mathrm{P}\left\{{ }^{1} \mathrm{H}\right\}$ at $-3.30 \mathrm{ppm}\left(\mathrm{PMe}_{3}\right)$. In place of the diminishing ${ }^{31} \mathrm{P}\left\{{ }^{1} \mathrm{H}\right\}$ peak at $-3.30 \mathrm{ppm}$, a broadened peak at $-1.34 \mathrm{ppm}$ and a single ${ }^{31} \mathrm{P}\left\{{ }^{1} \mathrm{H}\right\}$ resonance at $-0.41 \mathrm{ppm}$ are observed with time (Fig. 6.3.3. 1).
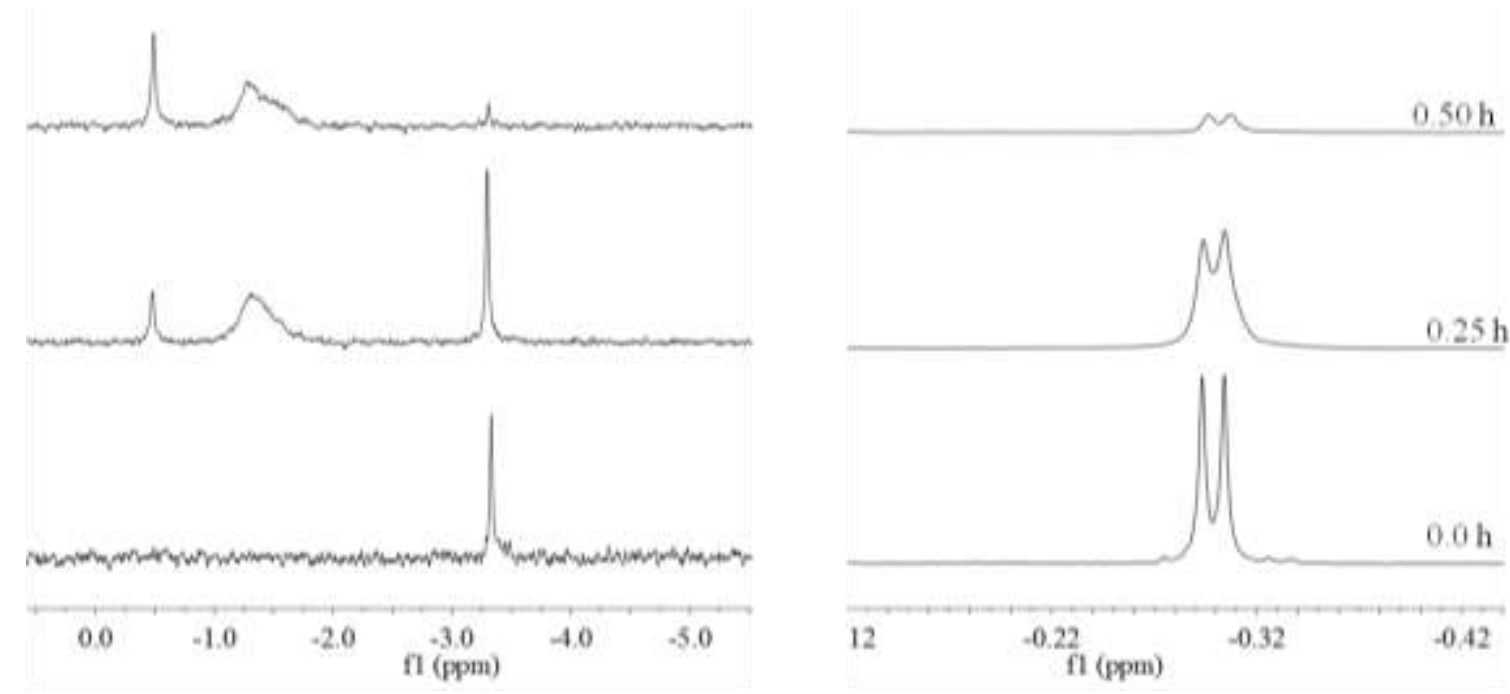

Fig. 6.3.3. 1: Changes in ${ }^{1} \mathrm{H}$ NMR (right) and ${ }^{31} \mathrm{P}\left\{{ }^{1} \mathrm{H}\right\}$ NMR spectra (left) of $\left[\mathrm{L}^{2} \mathrm{Pd}\left(\mathrm{CH}_{3}\right)\left(\mathrm{PMe}_{3}\right)\right]$ after addition of $[\mathrm{RhCl}(\mathrm{COD})]_{2}$ measured in $\mathrm{CDCl}_{3}$ at room temperature

Two batches of products were obtained after careful separation. The ${ }^{1} \mathrm{H}$ NMR spectrum of the first product points to the formation of $\left[\mathrm{PdCl}(\mathrm{Me})\left(\mathrm{PMe}_{3}\right)\right]_{2}$. After recrystallization of the filtrate, the ESI-MS data of the resulting complex shows $\mathrm{m} / \mathrm{z}$ values of 905 (60\%) which can be assigned to $\left[\mathrm{L}^{2} \mathrm{Rh}_{2}(\mathrm{COD})_{2}\right]^{+}$, and $695(30 \%)$ for $\left[\mathrm{L}^{2} \mathrm{Rh}(\mathrm{COD})\right]^{+}$, thus pointing to the formation of a mononuclear $\left[\mathrm{L}^{2} \mathrm{Rh}(\mathrm{COD})\right]$ and a binuclear $\left[\mathrm{L}^{2} \mathrm{Rh}_{2}(\mathrm{COD})_{2}\right]^{+}$complex. The exchange products were isolated and characterized by ${ }^{1} \mathrm{H}$ and ${ }^{13} \mathrm{C}$ NMR spectroscopy. 


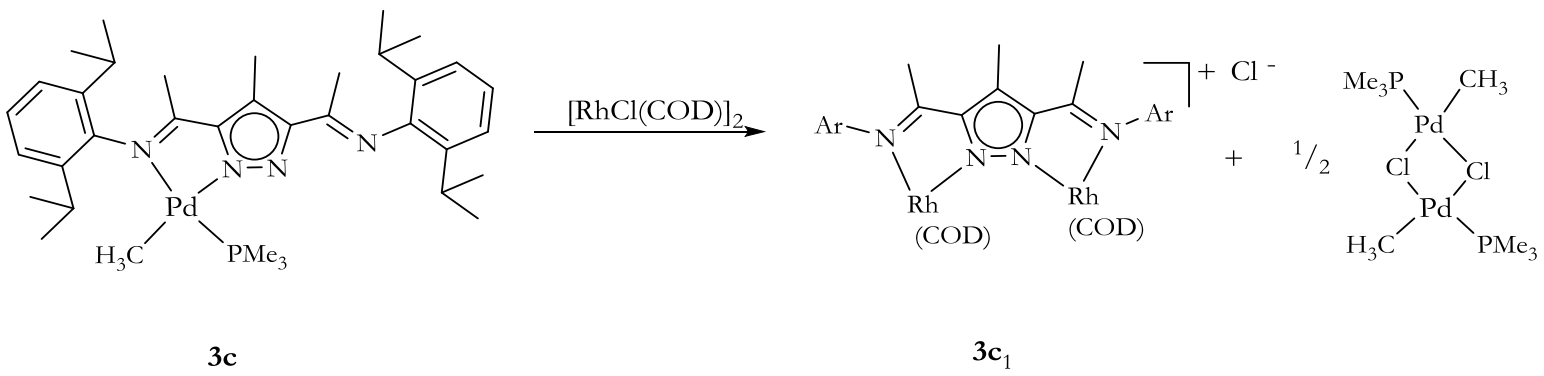

Scheme 6.3.3. 3: Transmetallation of $3 \mathrm{c}$ to form $3 \mathrm{c}_{1}$ and $\left[\mathrm{Pd}\left(\mathrm{CH}_{3}\right) \mathrm{Cl}\left(\mathrm{PMe}_{3}\right)\right]_{2}$

In view of the limited success achieved with this method, a second synthetic approach was explored having in mind that palladium(II) is easily displaced by rhodium(I) and nickel(II) salts.

\subsection{Homobimetallic palladium(II) $\eta^{3}$-allyl complex precursors}

The idea was therefore to first prepare homobimetallic complexes of palladium(II) and explore the possibility of a metal exchange in one of the binding pockets. To meet this end, the $\left[\mathrm{L}^{\mathrm{x}} \mathrm{Pd}_{2}\left(\eta^{3}-\mathrm{allyl}\right)_{2}\right] \mathrm{X}\left(\mathrm{X}=\mathrm{BF}_{4}, \mathrm{PF}_{6}\right)$ complexes were chosen for this purpose, due to their relative ease of synthesis (Scheme 6.3.4. 1).

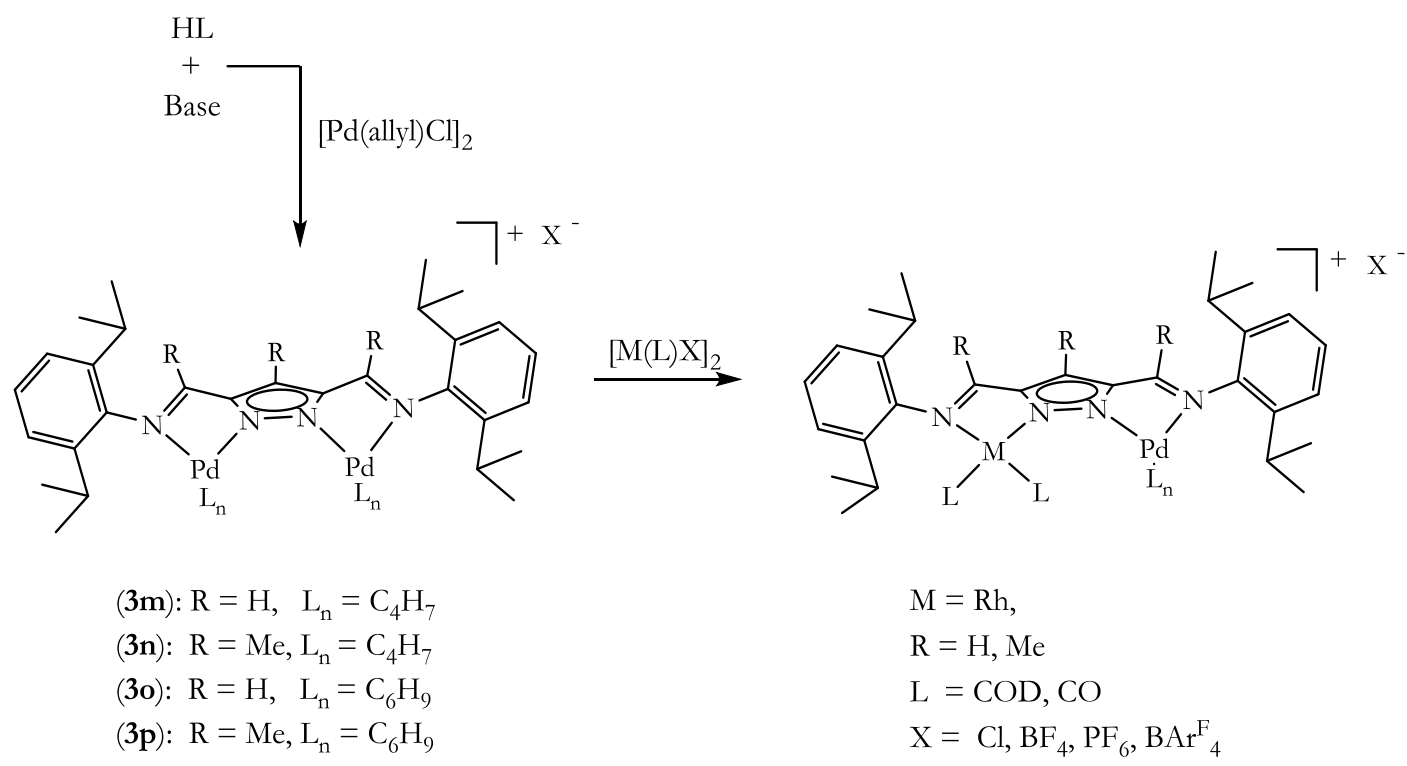

Scheme 6.3.4. 1: Metal exchange route to heterobimetallic complexes 


\section{Results and Discussions}

In general, the palladium(II)- $\eta^{3}$-allyl complexes $(3 \mathbf{m}-3 \mathbf{p})$ were prepared in good to moderate yields $(58-77 \%)$. The $\left[\mathrm{L}^{\mathrm{x}} \mathrm{Pd}_{2}\left(\eta^{3}-\mathrm{C}_{6} \mathrm{H}_{9}\right)_{2}\right] \mathrm{X}\left(\mathrm{X}=\mathrm{PF}_{6}\right)$ complexes 3o and $\mathbf{3 p}$ are generally not very stable in solution at room temperature for long hours. For instance, when $3 p$ is left in solution at room temperature for $48 \mathrm{~h}$, the formation of Pd "mirror" on the walls of the flask is observed (Scheme 6.3.4. 2). Colourless crystals (3q) were later harvested from the bottom of the flask.

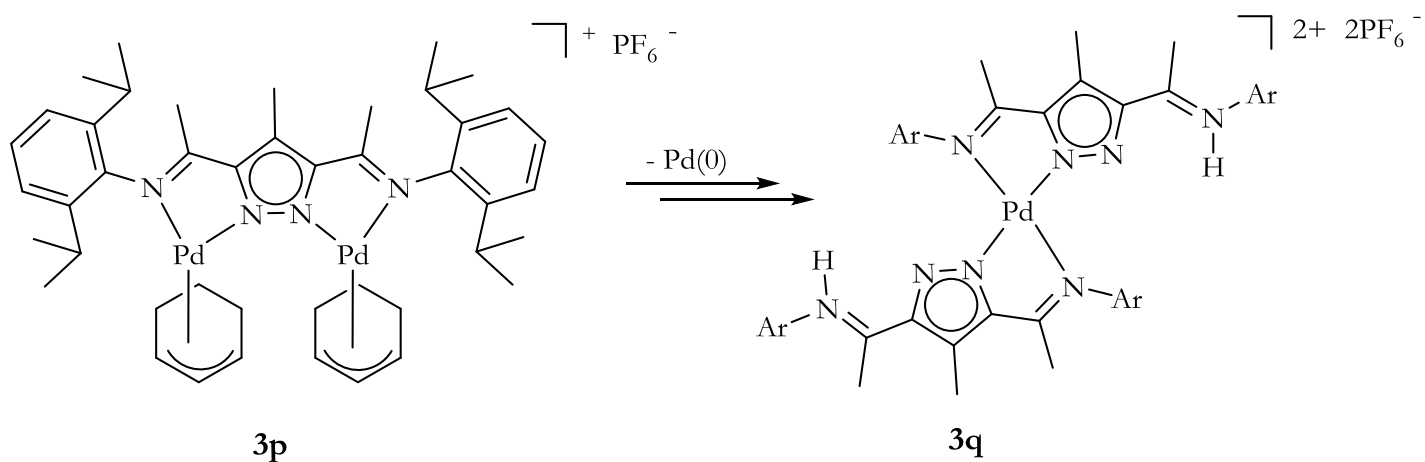

Scheme 6.3.4. 2: Dissociation and redistribution of $3 p$ to form $3 q$

Single crystal X-ray structure of the colourless crystals points to the formation of a complex of the type $\left[\left(\mathrm{HL}^{2}\right)_{2} \mathrm{Pd}\right]\left(\mathrm{PF}_{6}\right)_{2}$ (Fig. 6.3.4. 1). The compound crystallizes in the $P-1$ space group. The coordination around the palladium atom is square planar, with the plane around the palladium atom formed by $\mathrm{N}(1), \mathrm{N}(3), \mathrm{N}\left(1^{\prime}\right), \mathrm{N}\left(3^{\prime}\right)$. The two imine nitrogen atoms, $\mathrm{N}(4)$ and $\mathrm{N}\left(4^{\prime}\right)$ are protonated. The interplanar angle formed between the atoms of the pyrazolyl ring and the atoms that make up the aryl ring is nearly perpendicular at $85.0^{\circ}$.
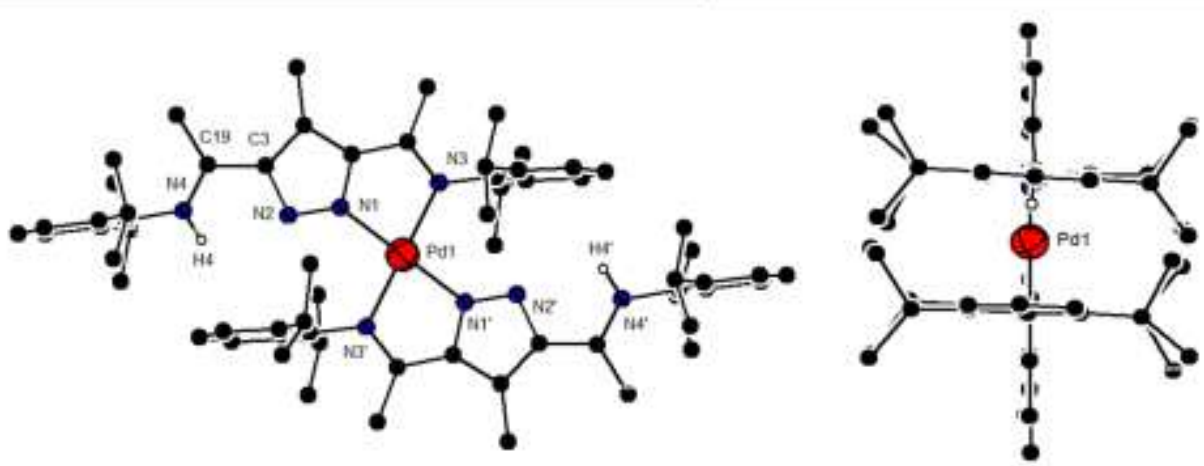

Fig. 6.3.4. 1: Molecular structure of 3q, most $\mathrm{H}$ atoms, and counterions omitted for clarity 
The interplanar angles between the aryl rings on opposite sides of the palladium centre are nearly planar at $6.27^{\circ}$. In addition, the torsional angle for the non coordinated side arm defined by $\mathrm{N}(2)-\mathrm{C}(3)-\mathrm{C}(19)-\mathrm{N}(4)$ is $-0.83^{\circ}$ compared to $171.2^{\circ}$ found in the analogous $\mathrm{L}_{2}^{2} \mathrm{Pd}$ complex (3h), thus the presence of the proton causes a change in orientation of the noncoordinating $\mathrm{N}^{\wedge} \mathrm{N}$ pocket. This may be due to some form of interaction between $\mathrm{H} 4 / \mathrm{H} 4$ ' with the $\pi$ cloud of the aromatic rings. Selected bond lengths $[\AA]$ and bond angles $\left[{ }^{\circ}\right]$ are given in Table 6.3.4. 1.

Table 6.3.4. 1: Selected bond lengths $[\AA \AA]$ and bond angles $\left[{ }^{\circ}\right]$ for $3 q$

\begin{tabular}{llll}
\hline \multicolumn{4}{c}{ Bond lengths $[\AA]$} \\
\\
\hline
\end{tabular}

However, $3 \mathbf{p}$ can be stored for several weeks at cold temperatures in the solid state. The $\left[\mathrm{L}^{\mathrm{x}} \mathrm{Pd}_{2}\left(\eta^{3}-\mathrm{C}_{4} \mathrm{H}_{7}\right)_{2}\right] \mathrm{X}\left(\mathrm{X}=\mathrm{BF}_{4}, \mathrm{BAr}_{4}^{\mathrm{F}}\right)$ complexes $(\mathbf{3 m}$ and $\mathbf{3 n})($ Scheme 6.3.4. 4) on the other hand are more stable in solution at room temperature. (NB: $3 \mathbf{n}$ with a $\mathrm{Cl}$ counterion has been reported ${ }^{221}$ ). In the ESI-MS of the complexes, the most pronounce fragmentation is the loss of the allyl moiety. The complexes were fully characterized by ${ }^{1} \mathrm{H},{ }^{13} \mathrm{C} \mathrm{NMR}$, IR, and ESI-MS and in some instances single crystal X-ray structures.
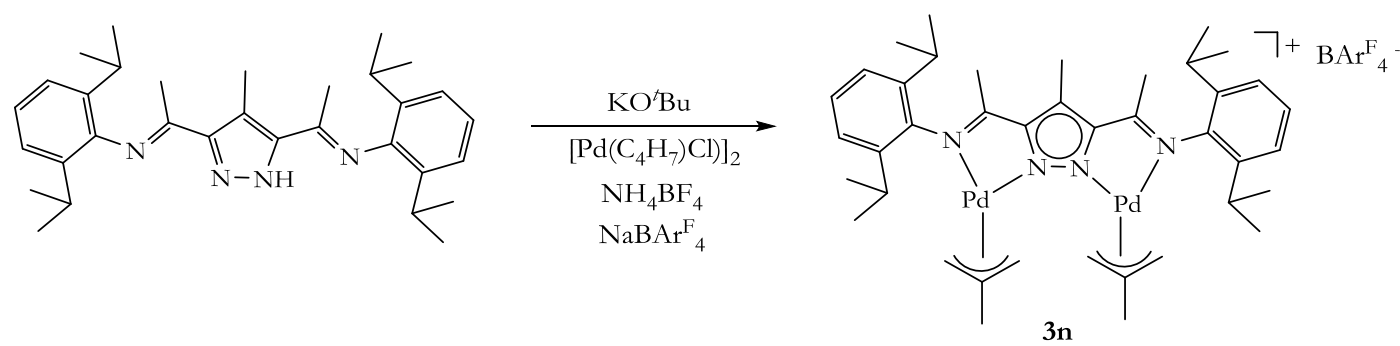

Scheme 6.3.4. 3: Synthetic scheme for the preparation of $3 \mathrm{n}$

For example, the IR spectrum of $\mathbf{3 n}$ shows a $\eta^{3}$-allyl palladium(II) complex; the absence of absorption in the region $1610 \mathrm{~cm}^{-1}$ (ATR) suggests the allyl groups are not $\sigma$-bonded. The NMR spectrum in $\mathrm{CDCl}_{3}$ is consistent with a $\eta^{3}$-allyl complex, although the spectrum at room temperature indicates a rapid exchange of the syn and anti protons, a feature common 


\section{Results and Discussions}

to palladium(II) allyl complexes. ${ }^{258}$ This broadening of the allylic $\mathrm{CH}_{2}$ is consistent with the $\eta^{3}-\eta^{1}$ opening of allylic ligands, usually followed by rotation around the C-C bond and subsequent isomerisation to $\eta^{1}-\eta^{3}$ to form the allyl ligand as depicted in Scheme 6.3.4. 4.

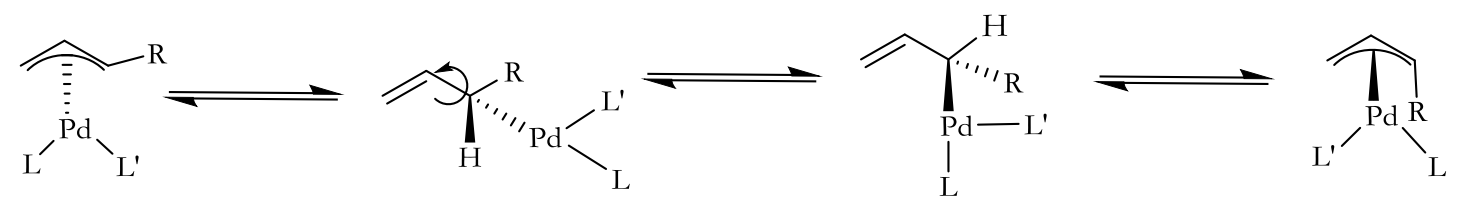

syn-isomer

anti-isomer

Scheme 6.3.4. 4: $\eta^{3}-\eta^{1}-\eta^{3}$ isomerization of palladium(II) allyl complexes

Apart from $\eta^{3}-\eta^{1}-\eta^{3}$ isomerization that occurs through the change in coordination of the palladium centre from $\eta^{3}-\eta^{1}$, and allows free rotation around the $\mathrm{C}-\mathrm{C}$ bond, with subsequent reformation to $\eta^{3}$ allyl complex; other dynamic processes in $\eta^{3}$-allyl palladium complexes also include: (i) Ligand exchange, which can proceed via either associative or dissociative processes (Scheme 6.3.4. 5).
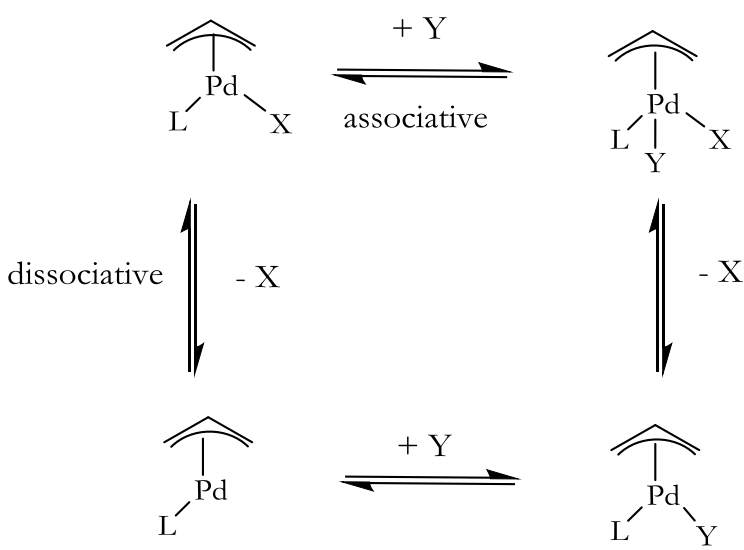

Scheme 6.3.4. 5: Ligand exchange through associative and dissociative pathways

(ii) Apparent rotation (syn-syn, anti-anti isomerisation); Two different mechanisms have been proposed since the direct rotations in $\eta^{3}$-allyl complexes seem unlikely in square planar complexes. These are the associative pseudo rotation ${ }^{259}$ and dissociative mechanism ${ }^{260,261}$ (Scheme 6.3.4. 6). 


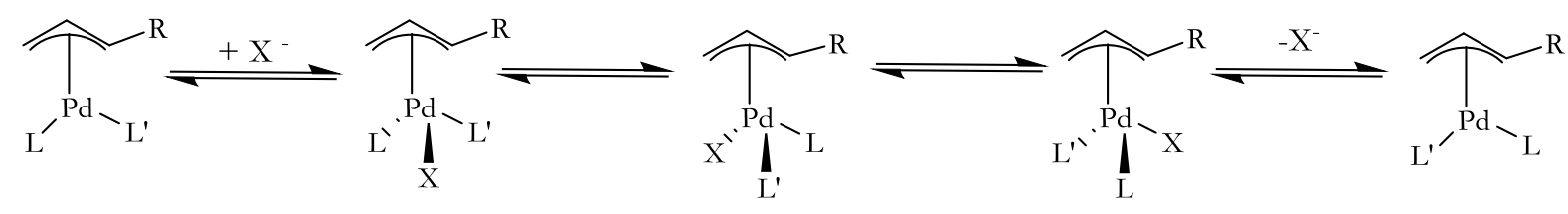

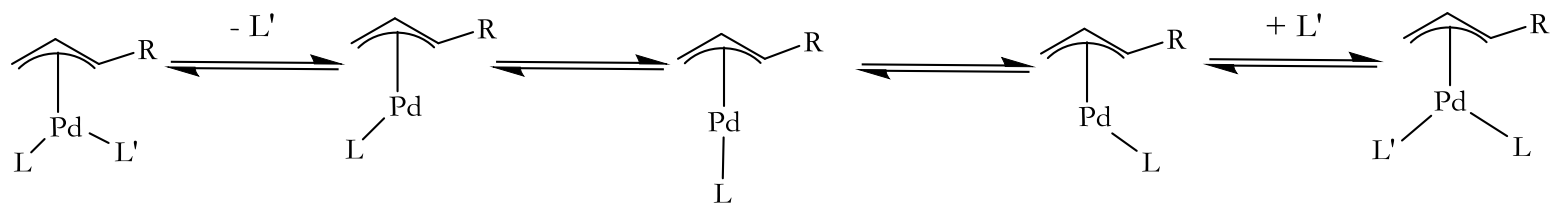

Scheme 6.3.4. 6: Apparent rotation through pseudo rotation (top) and apparent rotation by dissociative mechanism, through a T-shaped intermediate

Crystals of $3 \mathbf{n}$ were obtained by the slow diffusion of hexane into a $\mathrm{CH}_{2} \mathrm{Cl}_{2}$ solution of the complex at cold temperatures. Molecular structures of $\mathbf{3 n}$ and $\mathbf{3 p}$ complexes are shown in Fig. 6.3.4. 2 and Fig. 6.3.4. 3 respectively, as well as Tables showing selected bond lengths and bonds angles for these complexes.

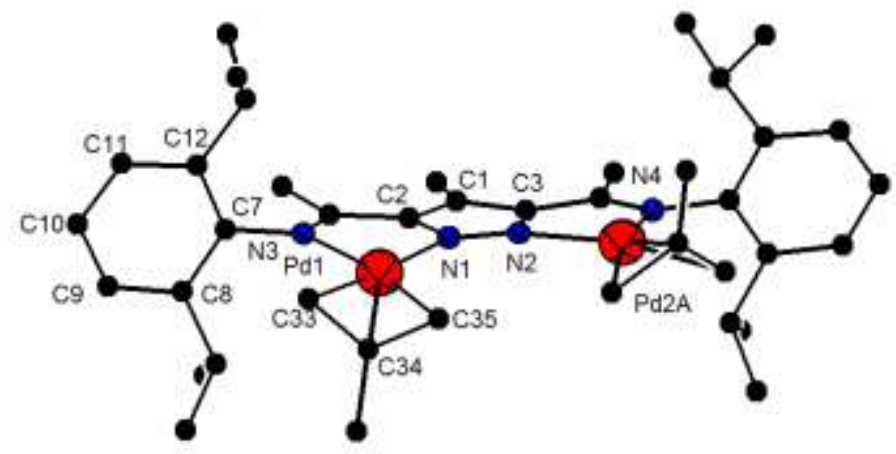

Fig. 6.3.4. 2: Molecular structure of $3 \mathrm{n}$, all $\mathrm{H}$ atoms and counterion omitted for clarity

In $3 \mathbf{n}$, the compound crystallizes in the $P 21 /$ c space group. The coordination geometry around the palladium(II) centre is square planar. The $\eta^{3}$-allyl bond lengths $\mathrm{C}(34)-\mathrm{C}(35)$ (1.40 $\AA)$ and $\mathrm{C}(33)-\mathrm{C}(34)(1.41 \AA)$ are almost equal. The dihedral angle defined by $\operatorname{Pd}(1)-\mathrm{N}(2)-$ $\mathrm{N}(1)-\mathrm{Pd}(2 \mathrm{~A})$ is $11.9^{\circ}$. The inter palladium distance is $4.57 \AA$. In addition, the angle between two planes described by six atoms in the aryl side arm $(\mathrm{C}(7) / \mathrm{C}(8) / \mathrm{C}(9) / \mathrm{C}(10) / \mathrm{C}(11) / \mathrm{C}(12))$ and five atoms of the pyrazole ring $(\mathrm{N}(2) / \mathrm{N}(1) / \mathrm{C}(3) / \mathrm{C}(1) / \mathrm{C}(2))$ is nearly perpendicular at 88.2 $2^{\circ}$. This orientation prevents steric interactions between the $\mathrm{CH}_{3}{ }^{\text {Pr }}$ and the $\eta^{3}-\mathrm{C}_{4} \mathrm{H}_{7}$ group. 


\section{Results and Discussions}

The Pd-C bond lengths are in the range of other palladium(II) allyl complexes. ${ }^{262,263,264}$ Selected bond lengths $[\AA]$ and bond angles $\left[^{\circ}\right]$ are given in Table 6.3.4. 2 .

Table 6.3.4. 2: Selected bond lengths $[\AA]$ and bond angles $\left[^{\circ}\right]$ for $3 n$

\begin{tabular}{|c|c|c|c|}
\hline Bond lengths [Å] & \multicolumn{3}{|c|}{ Bond angles $\left[{ }^{\circ}\right]$} \\
\hline $\operatorname{Pd}(1)-\mathrm{N}(3)$ & $2.092(4)$ & $\mathrm{N}(3)-\mathrm{Pd}(1)-\mathrm{N}(1)$ & $78.15(14)$ \\
\hline $\operatorname{Pd}(1)-C(35)$ & $2.141(6)$ & $\mathrm{N}(3)-\mathrm{Pd}(1)-\mathrm{C}(35)$ & $168.84(19)$ \\
\hline $\operatorname{Pd}(1)-C(34)$ & $2.171(6)$ & $\mathrm{N}(1)-\mathrm{Pd}(1)-\mathrm{C}(35)$ & 113.01(19) \\
\hline $\operatorname{Pd}(1)-\operatorname{Pd}(2 \mathrm{~A})$ & $4.576(21)$ & $\mathrm{N}(1)-\mathrm{Pd}(1)-\mathrm{C}(33)$ & $175.5(2)$ \\
\hline$C(33)-C(34)$ & $1.415(113)$ & $\mathrm{N}(3)-\mathrm{Pd}(1)-\mathrm{C}(33)$ & 105. 0(209) \\
\hline$C(34)-C(35)$ & $1.406(99)$ & $C(33)-C(34)-C(35)$ & $116.1(658)$ \\
\hline
\end{tabular}

Using $\left[\mathrm{Pd}\left(\eta^{3}-\mathrm{C}_{6} \mathrm{H}_{9}\right) \mathrm{Cl}\right]_{2}$, it was possible to isolate the analogous $\left[\mathrm{L}^{2} \mathrm{Pd}_{2}\left(\eta^{3}-\mathrm{C}_{6} \mathrm{H}_{9}\right)_{2}\right] \mathrm{PF}_{6}$ complex 3p under similar experimental conditions (Scheme 6.3.4. 7).

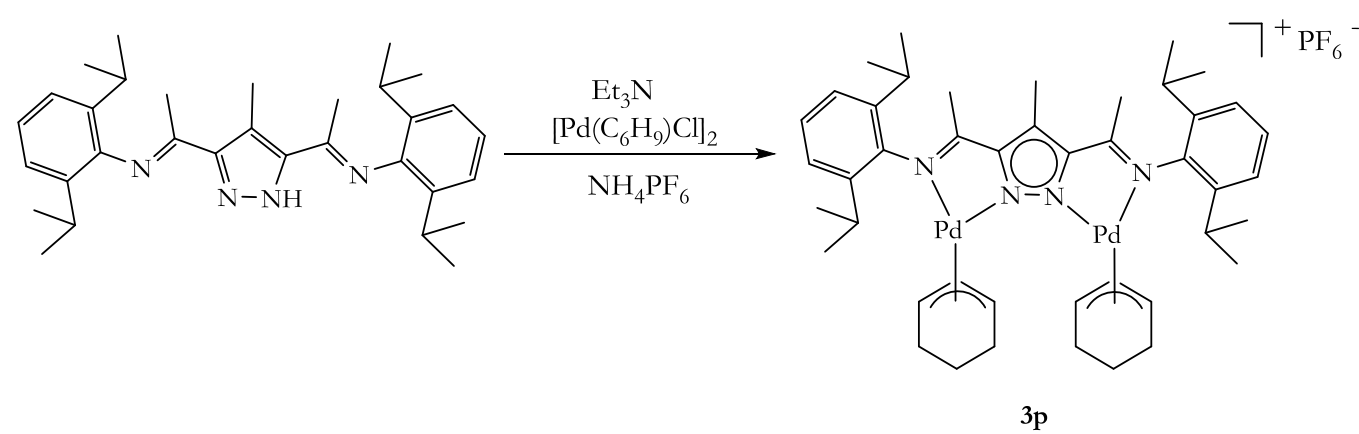

Scheme 6.3.4. 7: Synthetic scheme for the preparation of $3 p$

In the ${ }^{1} \mathrm{H}$ NMR spectrum of $3 \mathbf{p}$, the $\mathrm{CH}_{3}{ }^{\text {iPr }}$ groups at room temperature appear as overlapping sets of doublets between 1.09-1.29 ppm, possibly due to different orientations of the aryl ring with respect to the pyrazole plane. The methylene groups of the cyclohexenyl ring are also observed as broadened peaks in the ${ }^{1} \mathrm{H}$ NMR spectrum between 1.59-1.86 ppm. The peaks for the $\mathrm{CH}_{3} \mathrm{C}=\mathrm{N}$ and $\mathrm{CH}_{3}{ }^{\mathrm{P} 4}$ groups are observed at 2.29 and $2.62 \mathrm{ppm}$ and integrate for $6 \mathrm{H}$ and $3 \mathrm{H}$, respectively. The methine group on the other hand is observed as a triplet at 5.69 ppm (Fig. 6.3.4. 3). 


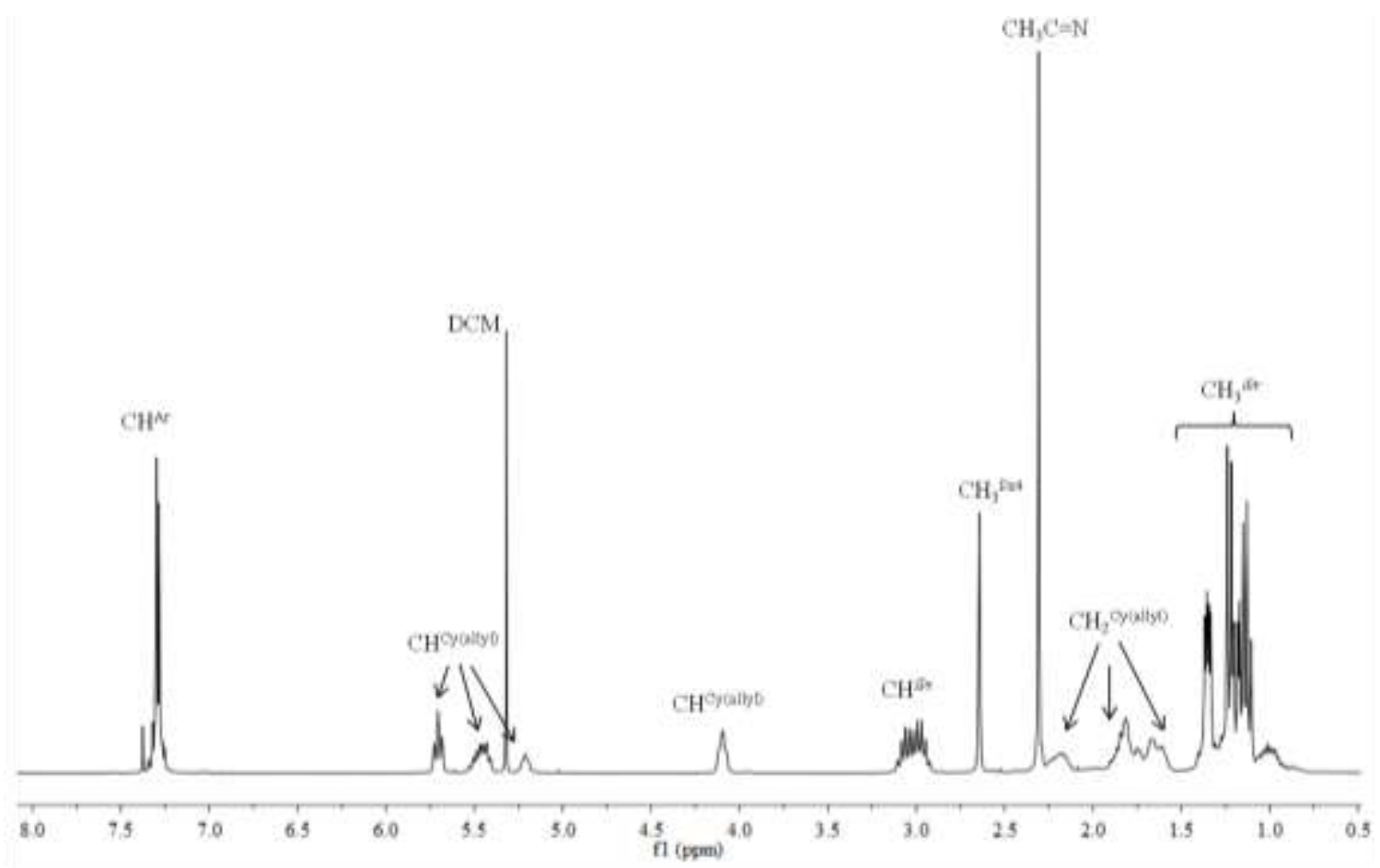

Fig. 6.3.4. 3: ${ }^{1} \mathrm{H}$ NMR spectrum of $3 \mathrm{p}$ measured in $\mathrm{CDCl}_{3}$ at room temperature

Single crystals of $3 \mathbf{p}$ were grown by the slow diffusion of $\mathrm{Et}_{2} \mathrm{O}$ into a $\mathrm{CH}_{2} \mathrm{Cl}_{2}$ solution of the complex. The molecular structure of $3 \mathrm{p}$ is shown in Fig. 6.3.4. 4.
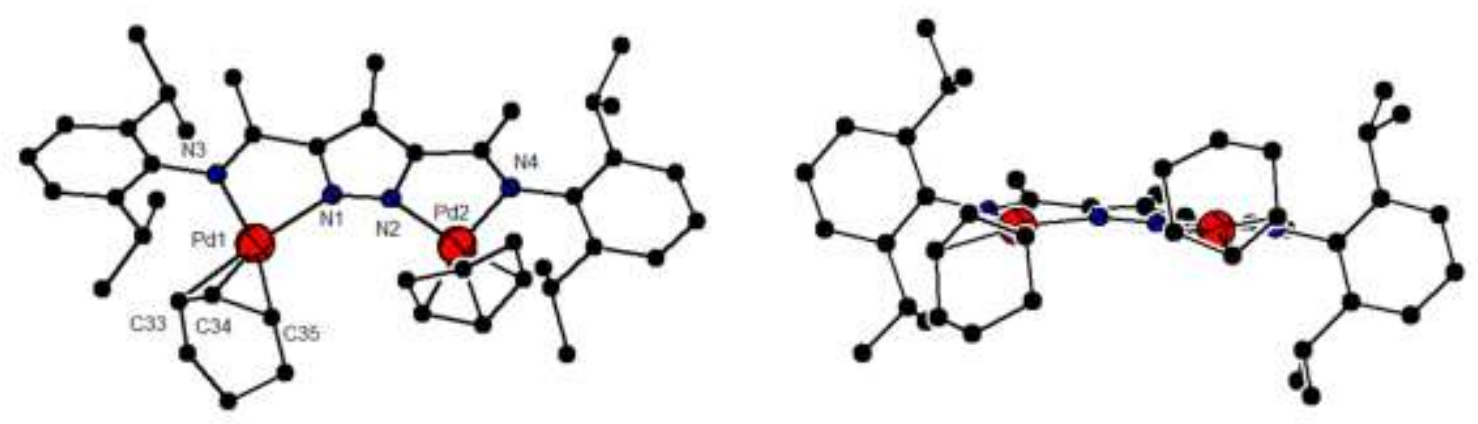

Fig. 6.3.4. 4: Molecular structure of 3p (different orientations) all $\mathrm{H}$ atoms and counterion omitted for clarity

The complex crystallizes with a $\mathrm{PF}_{6}$ counterion and one molecule of $\mathrm{CH}_{2} \mathrm{Cl}_{2}$. The coordination around the two palladium centres is square planar. The inter palladium distance in $3 \mathrm{p}$ is $4.53 \AA$ compared to $4.57 \AA$ in $3 \mathrm{n}$. The average Pd-N bond distance is $2.12 \AA$, and the ligand bite angle $\left(\angle \mathrm{N}(3) \operatorname{Pd}(1) \mathrm{N}(1)\right.$ is equal in both pockets at $77.1^{\circ}$. The dihedral angle defined by $\operatorname{Pd}(1)-\mathrm{N}(1)-\mathrm{N}(2)-\mathrm{Pd}(2)$ is $-16.0^{\circ}$ compared to $11.9^{\circ}$ in $3 \mathrm{n}$ due to limitations imposed by the cyclohexenyl ring. The $\eta^{3}$-allyl bond lengths C(34)-C(35) (1.40 $\AA$ ) and C(33)- 


\section{Results and Discussions}

C(34) (1.41 $\AA$ ) are almost equal and comparable to the $\eta^{3}$-allyl bond lengths observed for $\mathbf{3 n}$.

Selected bond lengths $[\AA]$ and bond angles $\left[{ }^{\circ}\right]$ are given in Table 6.3.4. 3.

Table 6.3.4. 3: Selected bond lengths $[\AA \AA]$ and bond angles $\left[^{\circ}\right]$ for $3 p$

\begin{tabular}{llll}
\hline \multicolumn{3}{c}{ Bond lengths $[\AA]$} & \multicolumn{1}{c}{ Bond Angles $\left[^{\circ}\right]$} \\
\hline $\operatorname{Pd}(1)-\mathrm{N}(1)$ & $2.125(3)$ & $\mathrm{N}(1)-\mathrm{Pd}(1)-\mathrm{N}(3)$ & $76.96(10)$ \\
$\operatorname{Pd}(1)-\mathrm{N}(3)$ & $2.113(37)$ & $\mathrm{C}(34)-\mathrm{Pd}(1)-\mathrm{C}(33)$ & $38.74(17)$ \\
$\operatorname{Pd}(1)-\operatorname{Pd}(2)$ & $4.529(4)$ & $\mathrm{N}(1)-\mathrm{Pd}(1)-\mathrm{C}(33)$ & $170.08(16)$ \\
$\mathrm{C}(33)-\mathrm{C}(34)$ & $1.404(73)$ & $\mathrm{N}(3)-\mathrm{Pd}(1)-\mathrm{C}(33)$ & $101.28(14)$ \\
$\mathrm{C}(34)-\mathrm{C}(35)$ & $1.413(83)$ & $\mathrm{N}(1)-\mathrm{Pd}(1)-\mathrm{C}(35)$ & $115.06(17)$ \\
\hline
\end{tabular}

With success in obtaining the homobimetallic palladium(II) $\eta^{3}$-allyl complexes ( $\left.3 \mathbf{m}-\mathbf{3} \mathbf{p}\right)$, the next step was to explore metal exchange in one of the palladium(II) pockets with rhodium(I). 


\subsection{Heterobimetallic palladium(II)-rhodium(I) complexes}

Having prepared the homobimetallic palladium(II) complexes, the synthetic route adopted involved treating the homobimetallic complexes with $\mathrm{Rh}(\mathrm{I})$ metal salts with the aim of obtaining the corresponding heteronuclear complex via a metal exchange process (Scheme 6.3.5. 1).
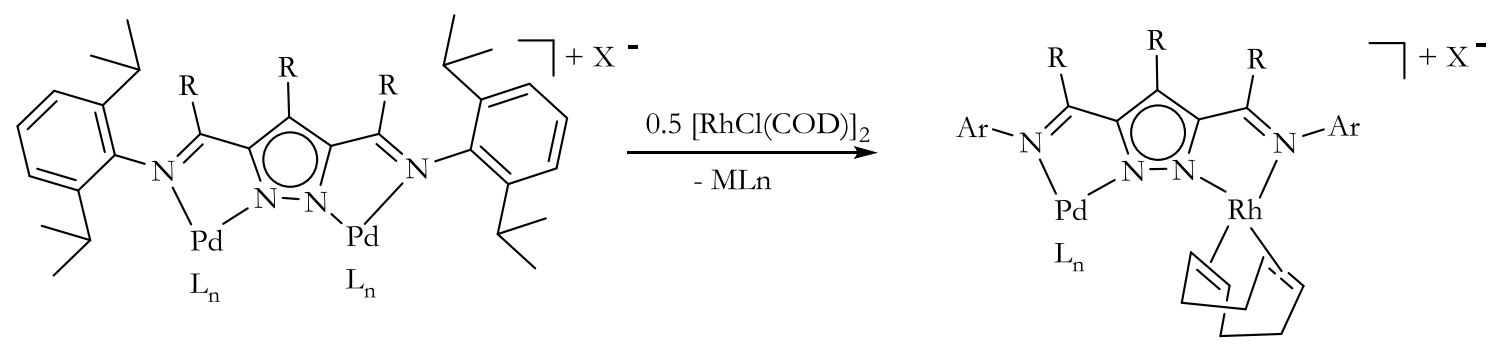

$$
\begin{aligned}
& \text { (3m): } \mathrm{R}=\mathrm{H}, \quad \mathrm{L}_{\mathrm{n}}=\mathrm{C}_{4} \mathrm{H}_{7}, \mathrm{X}=\mathrm{PF}_{6} \\
& \text { (3n): } \mathrm{R}=\mathrm{Me}, \mathrm{L}_{\mathrm{n}}=\mathrm{C}_{4} \mathrm{H}_{7}, \mathrm{X}=\mathrm{BAr}^{\mathrm{F}} \\
& \text { (3o): } \mathrm{R}=\mathrm{H}, \mathrm{L}_{\mathrm{n}}=\mathrm{C}_{6} \mathrm{H}_{9}, \mathrm{X}=\mathrm{PF}_{6} \\
& \text { (3p): } \mathrm{R}=\mathrm{Me}, \mathrm{L}_{\mathrm{n}}=\mathrm{C}_{6} \mathrm{H}_{9}, \mathrm{X}=\mathrm{PF}_{6}
\end{aligned}
$$

(3r): $\mathrm{R}=\mathrm{H}, \quad \mathrm{L}_{\mathrm{n}}=\mathrm{C}_{4} \mathrm{H}_{7}$

(3s): $\mathrm{R}=\mathrm{Me}, \mathrm{L}_{\mathrm{n}}=\mathrm{C}_{4} \mathrm{H}_{7}$

(3t): $\mathrm{R}=\mathrm{H}, \quad \mathrm{L}_{\mathrm{n}}=\mathrm{C}_{6} \mathrm{H}_{9}$

(3u): $\mathrm{R}=\mathrm{Me}, \mathrm{L}_{\mathrm{n}}=\mathrm{C}_{6} \mathrm{H}_{9}$

Scheme 6.3.5. 1:: Metal exchange route to heterobimetallic Pd-Rh complexes

This approach was largely successful, with the corresponding RhPd complexes obtained in moderate to good yields (34-94\%). The complexes were characterized by a combination of ${ }^{1} \mathrm{H}$ and ${ }^{13} \mathrm{C}$ NMR and IR spectroscopy, HRMS and in some instances single crystal X-ray structures. For instance, the treatment of the cationic $\left[\mathrm{L}^{2} \mathrm{Pd}_{2}\left(\eta^{3}-\mathrm{C}_{6} \mathrm{H}_{9}\right)_{2}\right] \mathrm{PF}_{6}$ complex $(\mathbf{3} \mathbf{p})$ with 0.5 mol equivalent of $[(\mathrm{Rh}(\mathrm{COD}) \mathrm{Cl})]_{2}$ in $\mathrm{CH}_{2} \mathrm{Cl}_{2}$ gives the corresponding heterobimetallic cationic complex $\left[\mathrm{L}^{2} \mathrm{Pd}\left(\eta^{3}-\mathrm{C}_{6} \mathrm{H}_{9}\right) \mathrm{Rh}(\mathrm{COD})\right] \mathrm{PF}_{6}(\mathbf{3 u})$. The HRMS data for $\mathbf{3 u}$ is in good agreement with calculated and observed isotopic mass (881.3232 amu). 


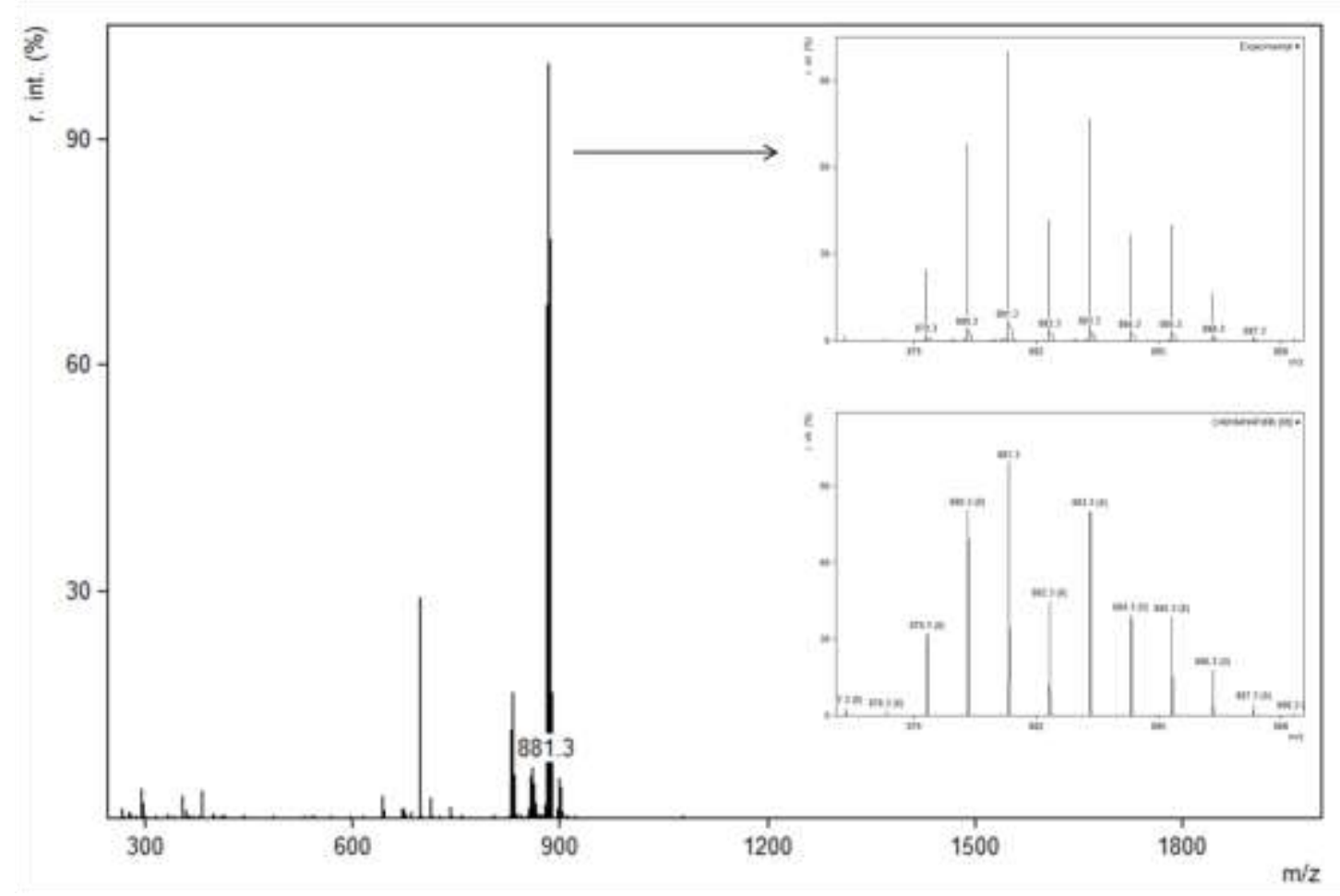

Fig. 6.3.5. 1: ESI mass spectrum of 3u Observed (top) and simulated (bottom) isotopic distribution pattern.

The formation of the heterobimetallic complex $3 \mathbf{u}$ was also observed in ${ }^{1} \mathrm{H}$ and ${ }^{13} \mathrm{C} \mathrm{NMR}$ spectra. However, attempts to grow single crystals of $\mathbf{3 u}$ suitable for X-ray crystallography always turn up a homobimetallic rhodium(I) complex $\left[\mathrm{L}^{2} \mathrm{Rh}_{2}(\mathrm{COD})_{2}\right] \mathrm{PF}_{6}(3 \mathbf{v})($ Scheme 6.3.5. 2). The use of metal exchange processes is known to lead to precipitation of homodinuclear or mononuclear complex species. ${ }^{265}$

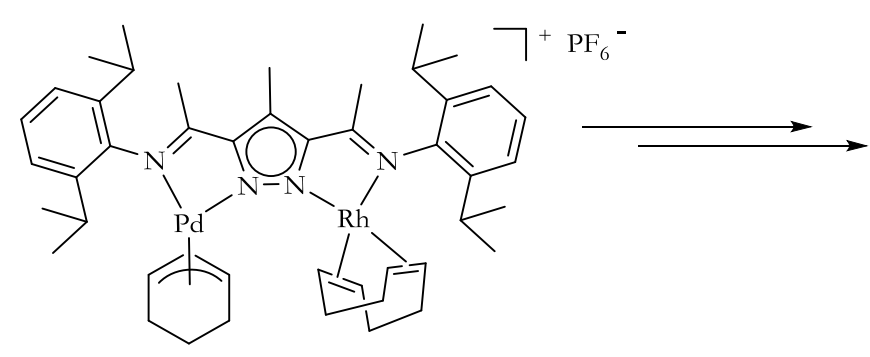

$3 \mathbf{u}$

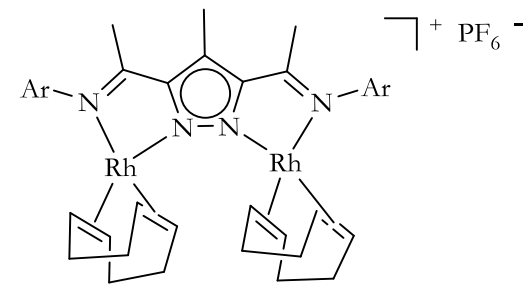

$3 \mathbf{v}$

Scheme 6.3.5. 2: Scheme showing the rearrangement of $3 u$ to form $3 v$

The mechanism leading to the formation of $\mathbf{3 v}$ is not well understood, but may be largely influenced by the instability of the palladium(II) cyclohexenyl allyl moiety, which easily undergoes homolysis to form $\operatorname{Pd}(0)$. The single crystal X-ray structure of $\mathbf{3} \mathbf{v}$ is shown below 
in Fig. 6.3.5. 2. Although the X-ray data is not good, the molecular structure invariably shows the atom connectivity.

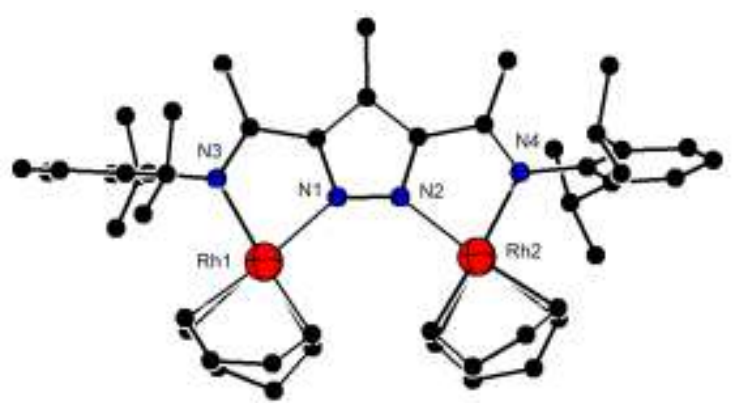

Fig. 6.3.5. 2: Molecular structure of $3 \mathrm{v}$ with all $\mathrm{H}$ atoms and counterion omitted for clarity

In the crystal structure of $\mathbf{3 v}$, the coordination around the two rhodium(I) centres is square planar. The $R h \cdots R h$ separation is $4.60 \AA$ which is significantly longer than the sum of the covalent radii (2.68 $\AA$ ). The torsional angle formed by $\mathrm{Rh}(1)-\mathrm{N}(1)-\mathrm{N}(2)-\mathrm{Rh}(2)$ is $-12.5^{\circ}$. The interplanar angle formed between the phenyl rings of the two peripheral aryl rings is $15.8^{\circ}$. The interplanar angle between the six carbons of the aromatic and the five atoms, which make up the pyrazolyl ring is nearly perpendicular at $84.6^{\circ}$. Selected bond lengths and bond angles are given in Table 6.3.5. 1.

Table 6.3.5. 1: Selected bond lengths $[\AA]$ and bond angles $\left[^{\circ}\right]$ for $3 \mathrm{v}$

\begin{tabular}{llll}
\hline \multicolumn{3}{c}{ bond lengths $[\AA]$} & \multicolumn{3}{c}{ bond angles $\left[^{\circ}\right]$} \\
\hline $\operatorname{Rh}(1)-\mathrm{N}(1)$ & $2.120(110)$ & $\operatorname{Rh}(1)-\mathrm{C}(38)-\mathrm{N}(3)$ & 160.0 \\
$\operatorname{Rh}(1)-\mathrm{N}(3)$ & $2.079(118)$ & $\operatorname{Rh}(2)-\mathrm{C}(34)-\mathrm{N}(4)$ & 165.2 \\
$\operatorname{Rh}(2)-\mathrm{N}(2)$ & $2.101(110)$ & $\operatorname{Rh}(1)-\mathrm{N}(3)-\mathrm{N}(1)$ & 77.3 \\
$\operatorname{Rh}(2)-\mathrm{N}(4)$ & $2.077(117)$ & $\operatorname{Rh}(2)-\mathrm{N}(4)-\mathrm{N}(2)$ & 78.0 \\
$\operatorname{Rh}(1)-\operatorname{Rh}(2)$ & $4.603(20)$ & $\operatorname{Rh}(1)-\mathrm{N}(1)-\mathrm{N}(2)$ & 138.2 \\
& & & \\
\hline
\end{tabular}

Efforts were made to overcome the formation of the dirhodium complex $\mathbf{3 v}$ in solution by replacing the $\mathrm{PF}_{6}{ }_{6}^{-}$counter ion with the more bulky $\left[\mathrm{BAr}_{4}^{\mathrm{F}}\right]^{-}$counterion. This technique was largely successful, MS data showed the required molecular ion $m / z, 882(100 \%)$ which can be assigned to $\left[\mathrm{M}-\mathrm{BAr}{ }_{4}^{\mathrm{F}}\right]^{+}$. A single crystal X-ray structure of the resulting heterobimetallic complex $\mathbf{3 u}$ is shown in Fig. 6.3.5. 3. This was obtained by the evaporation of cyclohexane $/ \mathrm{CH}_{2} \mathrm{Cl}_{2}$ solution of the complex at room temperature. 


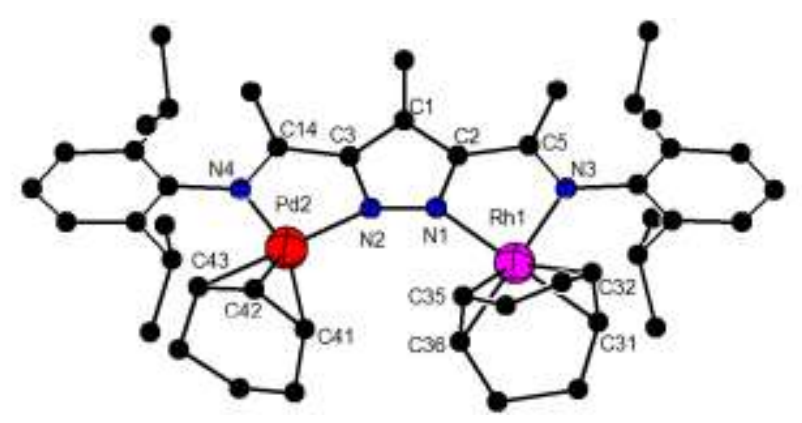

Fig. 6.3.5. 3: Molecular structure of $3 \mathrm{u}$ with solvent molecules, $\mathrm{H}$ atoms and counterion omitted for clarity

The compound $\mathbf{3 u}$ crystallizes in the $P-1$ space group, with a $\left[\mathrm{BAr}_{4}^{\mathrm{F}}\right]^{-}$counterion and two molecules of cyclohexane. The intermetallic distance $(\mathrm{Pd} \cdots \mathrm{Rh})$ is $4.65 \AA$. The dihedral angle formed by $\operatorname{Pd}(2)-\mathrm{N}(2)-\mathrm{N}(1)-\mathrm{Rh}(1)$ is $23.5^{\circ}$. The $\mathrm{Pd}(2)-\mathrm{N}(4)$ distance is $2.13 \AA$ compared to $\operatorname{Pd}(2)-\mathrm{N}(2)$ bond distance of $2.21 \AA$. Thus, the bond between the imine nitrogen and the palladium atom is stronger compared to the pyrazolyl nitrogen. The Rh-N bond distance is the same $(2.08 \AA)$ for both pyrazole $\mathrm{N}(1)$ and imine nitrogen $\mathrm{N}(3)$.

The interplanar angle defined by six atoms that make the two aromatic rings is nearly planar at $3.83^{\circ}$. On the other hand, the interplanar angles between planes defined by six atoms of the aromatic rings either side of the pyrazolyl ring and the five atoms of the pyrazole ring $(\mathrm{N}(1) / \mathrm{N}(2) / \mathrm{C}(3) / \mathrm{C}(1) / \mathrm{C}(2))$ is perpendicular at $90^{\circ}$. This orientation keeps the isopropyl groups away for the coligands. The $\eta^{3}$-allyl bond for $\mathrm{C}(42)-\mathrm{C}(43)(1.43 \AA)$ is longer than $\mathrm{C}(42)-\mathrm{C}(41)(1.35 \AA)$ compared to $\eta^{3}$-allyl bond of 1.40 and $1.41 \AA$ in the homobimetallic complex. Thus, the double bond character lies more between $\mathrm{C}(42)-\mathrm{C}(41)$. The ligand bite angle is larger in the rhodium pocket $\left(\angle \mathrm{N}(1) \mathrm{Rh}(1) \mathrm{N}(3)=79.0^{\circ}\right)$ compared to the palladium pocket $\left(\angle \mathrm{N}(4) \operatorname{Pd}(2) \mathrm{N}(2)=75.7^{\circ}\right)$ in order to accommodate the larger $\mathrm{Rh}(\mathrm{I})$ atom. Selected bond lengths and bond angles are given in Table 6.3.5. 2 .

Table 6.3.5. 2: Selected bond lengths $[\AA]$ and bond angles $\left[{ }^{\circ}\right]$ for $3 u$

\begin{tabular}{|c|c|c|c|}
\hline \multicolumn{2}{|c|}{ Bond lengths $[\AA]$} & \multicolumn{2}{|c|}{ Bond angles $\left[{ }^{\circ}\right]$} \\
\hline $\mathrm{Pd}(2)-\mathrm{N}(4)$ & $2.130(4)$ & $\mathrm{C}(36)-\mathrm{Rh}(1)-\mathrm{N}(1)$ & $98.1(2)$ \\
\hline $\operatorname{Pd}(2)-\operatorname{Rh}(1)$ & $4.653(8)$ & $\mathrm{C}(36)-\mathrm{Rh}(1)-\mathrm{N}(3)$ & $172.9(3)$ \\
\hline $\operatorname{Pd}(2)-\mathrm{N}(2)$ & $2.213(3)$ & $\mathrm{N}(1)-\mathrm{Rh}(1)-\mathrm{N}(3)$ & $79.0(13)$ \\
\hline $\mathrm{Rh}(1)-\mathrm{N}(1)$ & $2.081(3)$ & $\mathrm{N}(1)-\mathrm{Rh}(1)-\mathrm{C}(31)$ & $174.7(3)$ \\
\hline$C(34)-C(35)$ & $1.356(164)$ & $\mathrm{N}(3)-\mathrm{Rh}(1)-\mathrm{C}(31)$ & $98.0(18)$ \\
\hline$C(41)-C(42)$ & $1.349(141)$ & $\mathrm{N}(1)-\mathrm{Rh}(1)-\mathrm{C}(35)$ & $96.6(2)$ \\
\hline$C(42)-C(43)$ & $1.431(126)$ & $\mathrm{C}(36)-\mathrm{Rh}(1)-\mathrm{Pd}(1)$ & $39.2(3)$ \\
\hline
\end{tabular}


The analogous molecular structure of the heterobimetallic complex $\left[\mathrm{L}^{1} \mathrm{Pd}\left(\eta^{3}-\right.\right.$ $\left.\left.\mathrm{C}_{6} \mathrm{H}_{9}\right) \mathrm{Rh}(\mathrm{COD})\right] \mathrm{PF}_{6} 3 \mathbf{t}$ is shown in Fig. 6.3.5. 4 .

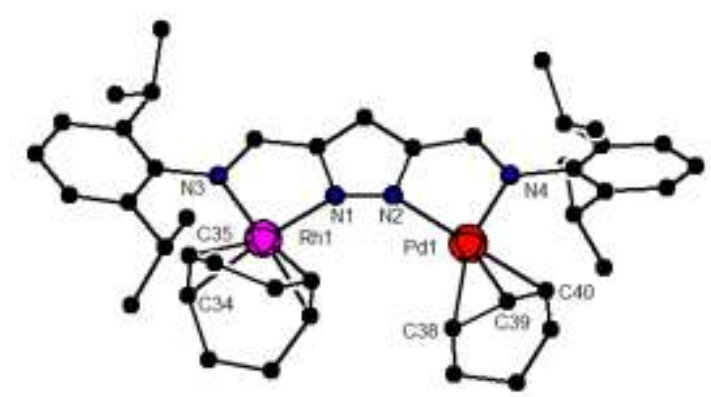

Fig. 6.3.5. 4: Molecular structure of $3 \mathrm{t}$ with $\mathrm{H}$ atoms and counterion omitted for clarity

Single crystals were obtained by the slow evaporation of a $\mathrm{CH}_{2} \mathrm{Cl}_{2}$ solution of the complex at room temperature. The compound $\mathbf{3 t}$ crystallizes in the $C_{c}$ space group with a $\mathrm{PF}_{6}^{-}$ counterion and a molecule of $\mathrm{CH}_{2} \mathrm{Cl}_{2}$. In $3 \mathbf{t}$, the intermetallic distance $(\mathrm{Pd} \cdots \mathrm{Rh}$ ) is $4.65 \AA$, compared to $4.63 \AA$ in $3 \mathbf{u}$. The dihedral angle formed by $\operatorname{Rh}(1)-\mathrm{N}(1)-\mathrm{N}(2)-\operatorname{Pd}(1)$ is $9.81^{\circ}$ compared to $23.5^{\circ}$ in $\mathbf{3 u}$. The ligand bite angles in the rhodium and palladium pockets are $\left(\angle \mathrm{N}(1) \mathrm{Rh}(1) \mathrm{N}(3)=79.9^{\circ}\right)$ and $\left(\angle \mathrm{N}(2) \operatorname{Pd}(1) \mathrm{N}(4)=78.19^{\circ}\right)$ respectively. The $\operatorname{Pd}(1)-\mathrm{N}(2)$ and $\operatorname{Pd}(1)-\mathrm{N}(4)$ bond lengths are 2.16 and $2.11 \AA$ respectively, whiles the $\operatorname{Rh}(1)-\mathrm{N}(3)$ (2.10 $\AA$ ) is slightly longer compared to $\mathrm{Rh}(1)-\mathrm{N}(2)$ bond lengths of $2.08 \AA$ respectively. The allyl group is again unsymmetrical with $\mathrm{C}(38)-\mathrm{C}(39)$ and $\mathrm{C}(39)-\mathrm{C}(40)$ bond lengths of $1.43 \AA$ and $1.37 \AA$ respectively, similar to allyl bond lengths observed in $\mathbf{3} \mathbf{u}$. The presence of the $\mathrm{Rh}(\mathrm{I})$ centre therefore seems to electronically influence the $\eta^{3}$-allyl bond lengths on the palladium(II) centre. Heterobimetallic complexes are known to have unusual electronic, electrochemical and magnetic properties due to the presence of two different metal sites. ${ }^{266,267}$ Some selected bond lengths and bond lengths in Table 6.3.5. 3.

Table 6.3.5. 3: Selected bond lengths $[\AA]]$ and bond angles $\left[{ }^{\circ}\right]$ for $3 t$

\begin{tabular}{llll}
\hline \multicolumn{3}{c}{ Bond lengths $[\AA \AA \mathbf{}]$} \\
\end{tabular}




\section{Results and Discussions}

The formation of the heterobimetallic complex was also evident from the ${ }^{1} \mathrm{H}$ and ${ }^{13} \mathrm{C}$ NMR spectra. The figure below (Fig. 6.3.5. 5) shows the ${ }^{1} \mathrm{H}$ NMR spectra of both the homobimetallic (above) and the heterobimetallic complex (below).

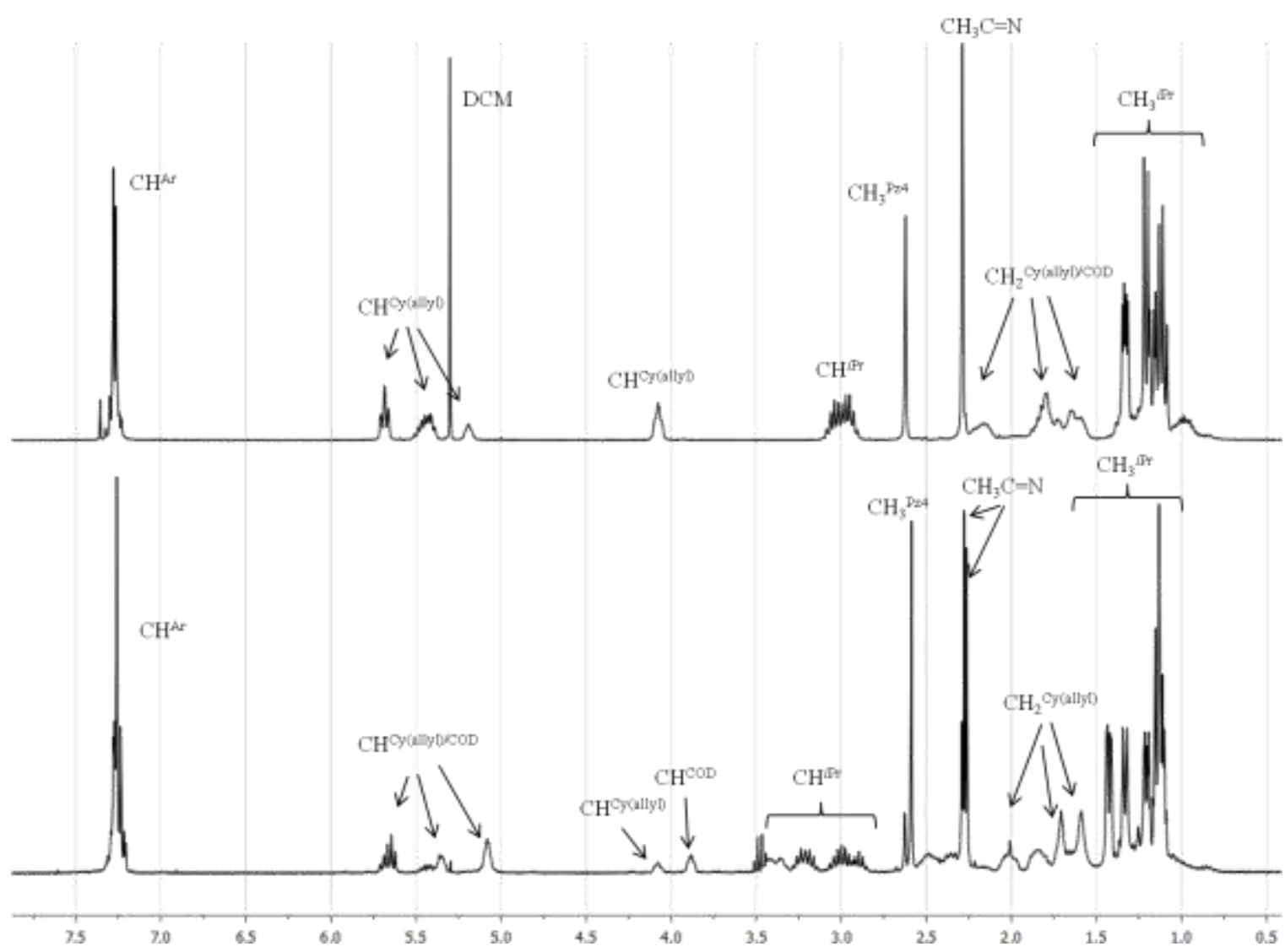

Fig. 6.3.5. 5: ${ }^{1} \mathrm{H}$ NMR spectra of homobimetallic palladium complex $3 \mathrm{p}$ (top) and the heterobimetallic palladiumrhodium complex $3 \mathrm{u}$ (bottom) measured in $\mathrm{CDCl}_{3}$ at room temperature

As earlier stated, the ${ }^{1} \mathrm{H}$ NMR spectrum of the $\left[\mathrm{L}^{2} \mathrm{Pd}_{2}\left(\eta^{3}-\mathrm{C}_{6} \mathrm{H}_{9}\right)_{2}\right] \mathrm{PF}_{6}(\mathbf{3} \mathbf{p})$ complex shows $\mathrm{CH}_{3} \mathrm{C}=\mathrm{N}$ and $\mathrm{CH}_{3}{ }^{\mathrm{P}} 4$ resonance peaks at 2.29 and $2.62 \mathrm{ppm}$ which integrate for $6 \mathrm{H}$ and $3 \mathrm{H}$ respectively, showing the symmetric ligand environment. In the heterobimetallic complex $\mathbf{3 u}$, the $\mathrm{CH}_{3} \mathrm{C}=\mathrm{N}$ splits into two singlets at 2.26 and $2.28 \mathrm{ppm}$ and integrates for $3 \mathrm{H}$ each. These signals have ${ }^{13} \mathrm{C}$ NMR correlation with the $\mathrm{CH}_{3} \mathrm{C}=\mathrm{N}$ at ca $170.6 \mathrm{ppm}$ for the imine side arm bearing palladium whiles $\mathrm{CH}_{3} \mathrm{C}=\mathrm{N}$ correlation of $c a 173.6 \mathrm{ppm}$ for the side arm bearing the rhodium(I) centre. The $\mathrm{CH}_{3}{ }^{\mathrm{P}} 4$ peak however remains unchanged.

${ }^{1} \mathrm{H}$ NMR spectrum peaks at 4.08, 5.08 and $5.62 \mathrm{ppm}$ are assigned to the vinylic protons in COD and allylic protons, while the $\mathrm{CH}_{2}{ }^{\mathrm{COD} / \mathrm{Cy}}$ protons are observed as multiplets between 
1.08-2.47 ppm. Compared to $3 \mathrm{n}$, the allyl species are locked in anti-anti conformation and hence no $s y n / a n t i$ isomerisation via $\pi-\sigma-\pi$ exchange is possible.

In the analogous complex $\left[\mathrm{L}^{1} \mathrm{Pd}\left(\eta^{3}-\mathrm{C}_{6} \mathrm{H}_{9}\right) \mathrm{Rh}(\mathrm{COD})\right] \mathrm{PF}_{6} 3 \mathbf{t}$, the $\mathrm{CH}=\mathrm{N}$ peaks $(\mathrm{H} 4$ and $\mathrm{H} 17)$ are observed as singlets at 7.97 and $8.22 \mathrm{ppm}$ for the arms bearing the rhodium(I) and palladium(II) atoms respectively.

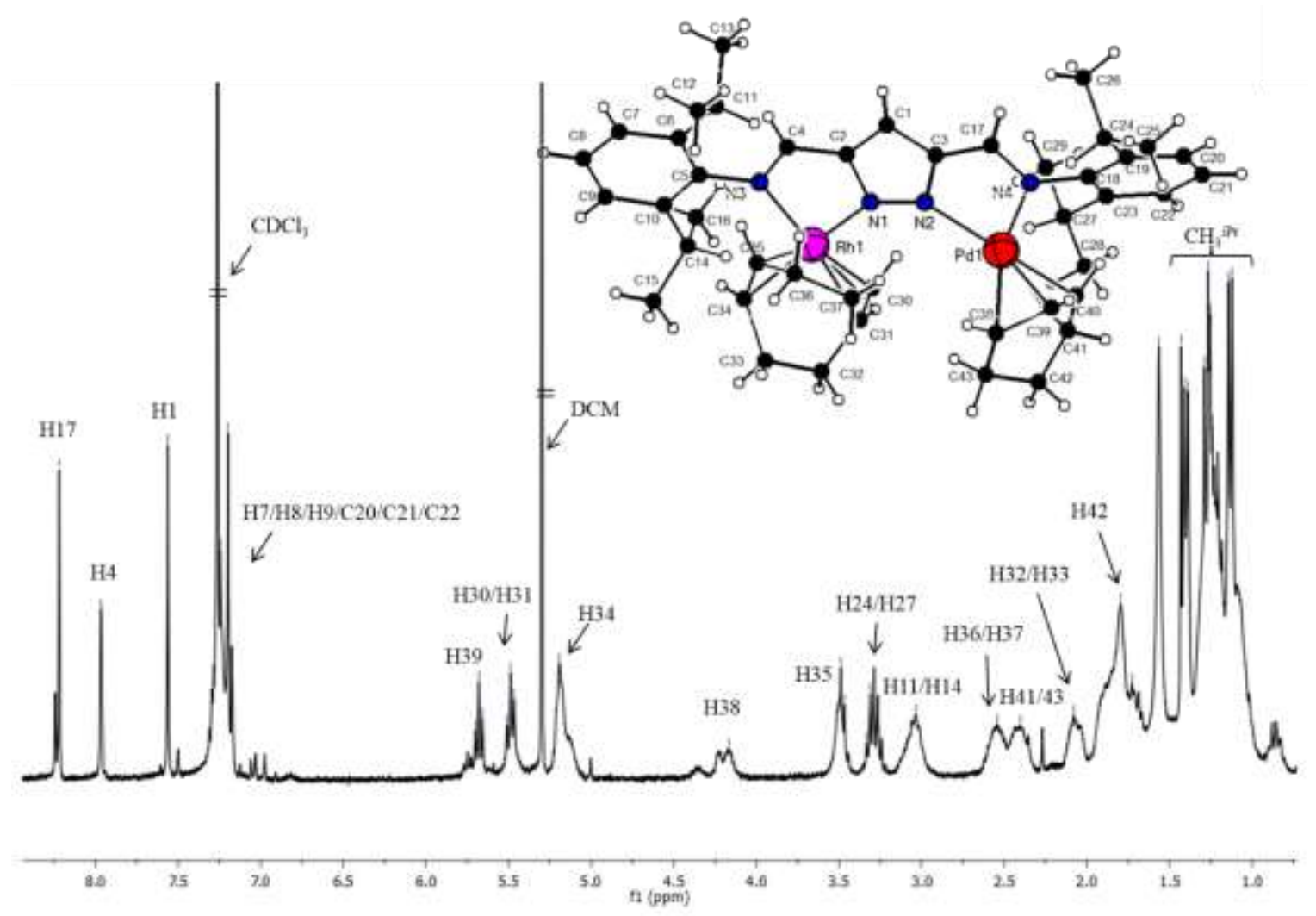

Fig. 6.3.5. 6: ${ }^{1} \mathrm{H}$ NMR spectrum assignments for 3t, $\mathrm{NMR}$ measured at room temperature in $\mathrm{CDCl}_{3}$

This is also observed in the IR spectrum where two different $\mathrm{CH}=\mathrm{N}$ stretching vibrations are observed at $1605 \mathrm{~cm}^{-1}$ and $1586 \mathrm{~cm}^{-1}$ for the sidearm bearing the palladium(II) and rhodium(I) centres respectively. Compared to the homobimetallic complex $\left[\mathrm{L}^{1} \mathrm{Pd}_{2}\left(\eta^{3}-\right.\right.$ $\left.\left.\mathrm{C}_{6} \mathrm{H}_{9}\right)_{2}\right] \mathrm{PF}_{6}(3 \mathbf{o})$ where only one $\mathrm{CH}=\mathrm{N}$ environment is observed at $1613 \mathrm{~cm}^{-1}$. Thus the presence of the rhodium centre causes the $\mathrm{CH}=\mathrm{N}$ stretching vibrations to shift to a lower wavenumber likely due to the more effective $\pi$-bonding between $\mathrm{Rh}(\mathrm{I})$ and COD coligands.

The signals for the allyl ligands are observed at 4.16, 5.49, 5.68 and $5.75 \mathrm{ppm}$. The methylene groups of the cyclohexenyl ring and COD ligands are observed as slightly broadened signals between 1.08 - $2.54 \mathrm{ppm}$ room temperature. The ${ }^{1} \mathrm{H}$ and ${ }^{13} \mathrm{C}$ NMR spectra assignment of the peaks of $3 \mathbf{t}$ were established by a combination of $1 \mathrm{D}$ and $2 \mathrm{D}\left({ }^{1} \mathrm{H}-{ }^{1} \mathrm{H}\right.$ COSY,${ }^{1} \mathrm{H}^{-13} \mathrm{C}$ HSQC, 
${ }^{1} \mathrm{H}-{ }^{13} \mathrm{C}$ HSQC) experiments. ${ }^{1} \mathrm{H}$ NMR spectral peaks were assigned (Fig. 6.3.5. 6) based on ${ }^{1} \mathrm{H}-{ }^{1} \mathrm{H}$ COSY and ${ }^{1} \mathrm{H}-{ }^{13} \mathrm{C}$ HSQC experiments. COSY correlations between $\mathrm{H} 34$ and $\mathrm{H} 33$, H38 and H39, H41 and H42 are observed.
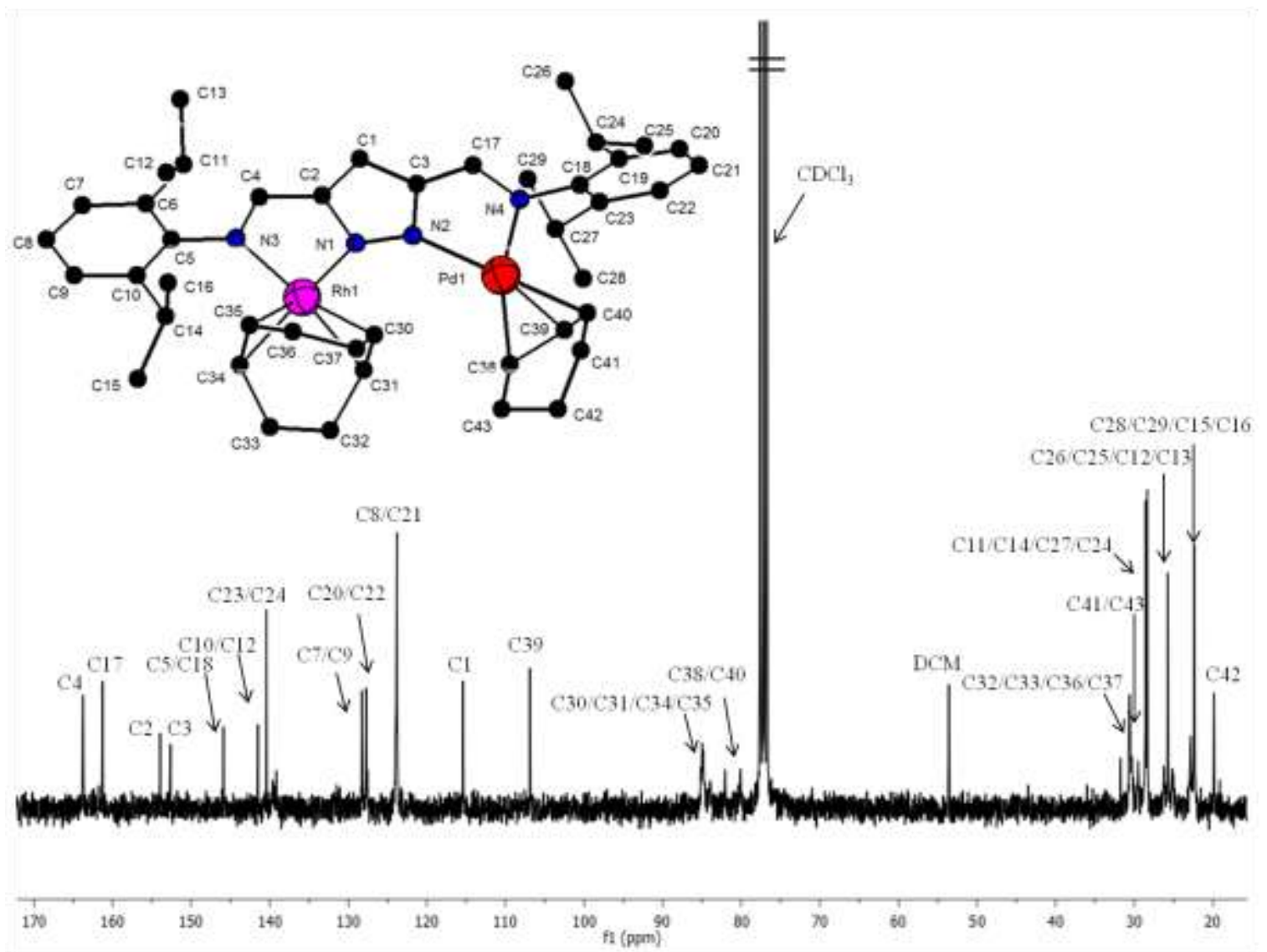

Fig. 6.3.5. 7: ${ }^{13} \mathrm{C}$ NMR spectrum assignments for 3t, $\mathrm{NMR}$ measured at room temperature in $\mathrm{CDCl}_{3}$

In the ${ }^{1} \mathrm{H}-{ }^{13} \mathrm{C}$ HSQC NMR spectrum, correlations are observed for the $\mathrm{CH}=\mathrm{N}$ group at 7.97 and $8.22 \mathrm{ppm}$ in ${ }^{1} \mathrm{H}$ NMR spectrum with ${ }^{13} \mathrm{C}$ NMR resonances at $163.7 \mathrm{ppm}$ and $161.2 \mathrm{ppm}$ for the side arms bearing the rhodium(I) (C4) and palladium(II) centres (C17) respectively. In the ${ }^{1} \mathrm{H}-{ }^{13} \mathrm{C}$ HMBC spectrum, $\mathrm{C} 1$ is identified by its cross peaks with $\mathrm{C} 2$ and $\mathrm{C} 3$. In addition, C15 is assigned from its cross peaks with C14 and C10. The quaternary carbons C10, C6, C23 and C19 are assigned from their strong peaks with the methyl protons of the isopropyl group. The complete ${ }^{13} \mathrm{C}$ NMR assignments are shown in Fig. 6.3.5. 7. The $\mathrm{CH}_{2}$ carbons of the COD (C32/C33/C36/C37) and cyclohexenyl (C41/C42/C43) are identified as negative peaks in a DEPT-135 experiment. In addition, a NOESY correlation is observed between the $\mathrm{CH}^{\mathrm{COD}}$ protons $\mathrm{H} 30$ and $\mathrm{H} 35$. 
The preparation of heterobimetallic complexes of the type $\left[\mathrm{L}^{\mathrm{x}} \mathrm{Pd}\left(\eta^{3}\right.\right.$-allyl $\left.) \mathrm{Rh}(\mathrm{CO})_{2}\right] \mathrm{X}(\mathrm{X}=$ $\left.\mathrm{PF}_{6}, \mathrm{BAr}_{4}^{\mathrm{F}}\right)(\mathbf{3} \mathbf{w}, \mathbf{3} \mathbf{x}, \mathbf{3} \mathbf{z})$ was achieved in $41-81 \%$ yield. Two synthetic routes were adopted, the first route involved transmetallation of $\left[\mathrm{L}^{\mathrm{x}} \mathrm{Pd}_{2}\left(\eta^{3} \text {-allyl }\right)_{2}\right] \mathrm{X}$ complexes with $0.5 \mathrm{~mol}$ equivalent $\left[\mathrm{RhCl}(\mathrm{CO})_{2}\right]_{2}$. The second synthetic route involved the carbonylation of the heterobimetallic $\left[\mathrm{L}^{\mathrm{x}} \mathrm{Pd}\left(\eta^{3}\right.\right.$-allyl $\left.) \mathrm{Rh}(\mathrm{COD})\right] \mathrm{X}$ complexes as shown in Scheme 6.3.5. 3.

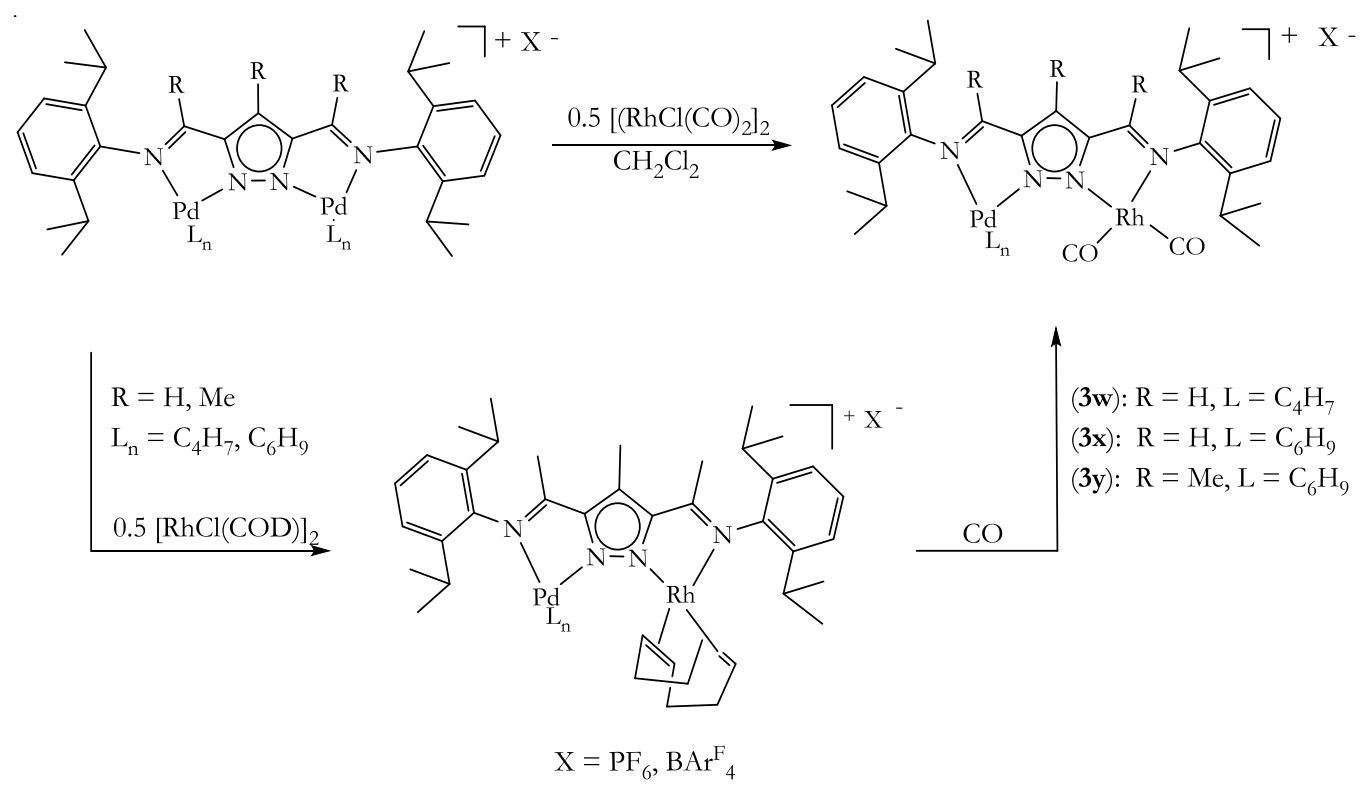

Scheme 6.3.5. 3: Reaction paths to the formation of complexes (3w-3y)

Both synthetic paths lead to the formation of the required product, although the carbonylation path sometimes leads to the formation of homobimetallic $\left[\mathrm{LRh}_{2}(\mathrm{CO})_{2}\right] \mathrm{X}$ in some instances. In the second synthetic route, which involves carbonylation of the COD complexes, generally, the $\mathrm{CO}$ complexes had to be kept under an atmosphere of $\mathrm{CO}$, to prevent the reversible binding of COD. The complexes were characterized by ${ }^{1} \mathrm{H}$ and ${ }^{13} \mathrm{C}$ NMR and IR spectroscopy, ESI-MS and HRMS analysis. Attempts at obtaining single crystals were unsuccessful.

Treating a $\mathrm{CH}_{2} \mathrm{Cl}_{2}$ solution of $3 \mathbf{p}$ with 0.5 mol equivalent $\left[\mathrm{RhCl}(\mathrm{CO})_{2}\right]_{2}$ results in the isolation of the heterobimetallic complex $\left[\mathrm{L}^{1} \mathrm{Pd}\left(\eta^{3}-\mathrm{C}_{6} \mathrm{H}_{9}\right) \mathrm{Rh}(\mathrm{CO})_{2}\right] \mathrm{PF}_{6}(\mathbf{3} \mathbf{x})$ in $41 \%$ yield (Scheme 6.3.5. 4). 


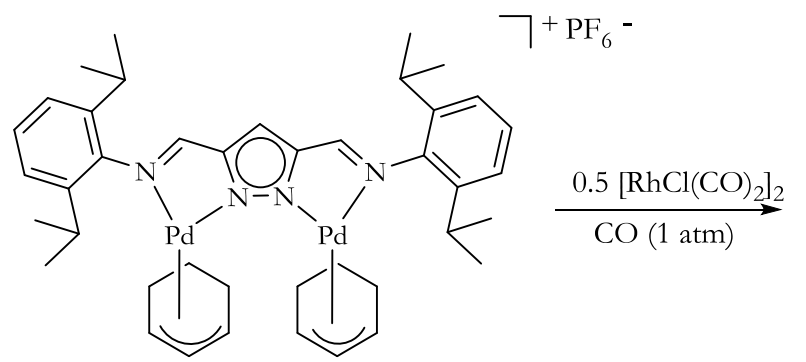

$3 \mathrm{p}$

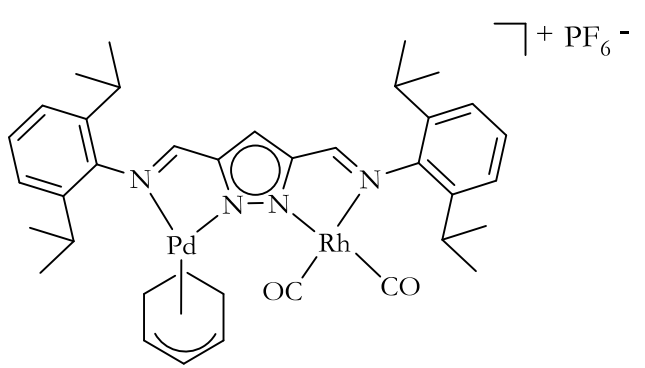

$3 \mathbf{x}$

Scheme 6.3.5. 4: Reaction path to the formation of $3 x$ from rhodium(I) exchange of $3 p$

The ESI mass spectrum of $\mathbf{3 x}$ shows $m / z$ peaks at $817(10 \%)$ and $787(100 \%)$ assigned to $\left[\mathrm{M}+\mathrm{CO}-\mathrm{PF}_{6}\right]^{+}$and $\left[\mathrm{M}-\mathrm{PF}_{6}\right]^{+}$respectively. The IR spectrum of the heterobimetallic complex 3x shows two different and intense CO stretching vibrations at 2098 and $2039 \mathrm{~cm}^{-1}$, consistent with a terminal CO environment (Fig. 6.3.5. 8). These are lower than the stretching frequency for free CO $\left(2143 \mathrm{~cm}^{-1}\right)$ due to back bonding from the d-orbitals of the metal to the $\pi^{*}$ antibonding orbitals of $\mathrm{CO}$. In addition, different $\mathrm{CH}=\mathrm{N}$ imine environments are also observed at $1610 \mathrm{~cm}^{-1}$ and $1577 \mathrm{~cm}^{-1}$ (Fig. 6.3.5. 8) for the side arms bearing the palladium(II) and rhodium(I) centres, respectively. The lower stretching frequency of the $\mathrm{CH}_{3} \mathrm{C}=\mathrm{N}$ side bearing the rhodium(I) centre due to lower bond strength compared to the palladium(II) centre.

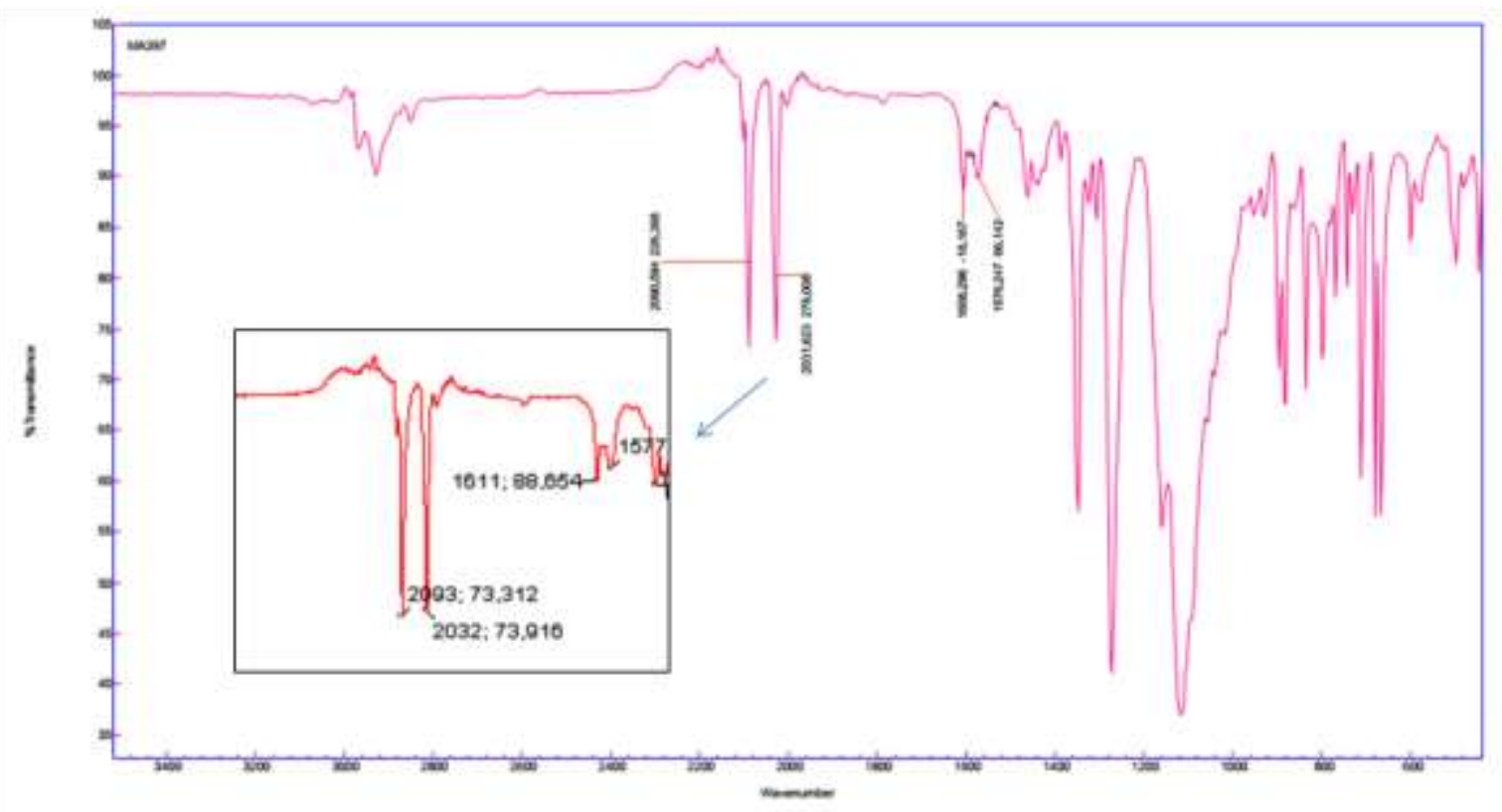

Fig. 6.3.5. 8: IR spectrum of $3 \mathrm{x}$ measured at room temperature (ATR) 
The ${ }^{1} \mathrm{H}$ NMR spectrum of $\mathbf{3} \mathbf{x}$ also reflects the asymmetric ligand environment. The $\mathrm{CH}=\mathrm{N}$ groups are observed at 7.93 and $8.31 \mathrm{ppm}$ for side arms bearing the rhodium(I) and palladium(II) centres respectively. Whiles the $\mathrm{CH}^{\mathrm{Pz}}$ group is observed at $7.80 \mathrm{ppm}$. The methylene groups of the cyclohexenyl ring are observed at $1.04 \mathrm{ppm}(2 \mathrm{H})$ and $1.81 \mathrm{ppm}$ $(4 \mathrm{H})$ respectively. The $\mathrm{CH}$ allyl groups are also observed at 5.24 (br s), 5.52 (br s) and 5.72 (m), which is consistent with $\eta^{3}$-coordination. The $\mathrm{CH}_{3}{ }^{\mathrm{Pr}}$ group on the other hand is observed as three doublets at 1.08, 1.22, $1.36 \mathrm{ppm}$ and integrate for 12:6:6 protons respectively, due to one of the aryl rings adopting a different orientation in relation to the pyrazole plane.

The ${ }^{13} \mathrm{C}$ NMR spectra of the heterobimetallic $\left[\mathrm{L}^{\mathrm{x}} \mathrm{Pd}\left(\eta^{3}\right.\right.$-allyl $\left.) \mathrm{Rh}(\mathrm{CO})_{2}\right] \mathrm{X}$ complexes on the other hand shows more pronounced downfield shift of the imine carbons in relation to the $\mathrm{L}^{\mathrm{x}} \mathrm{Pd}\left(\eta^{3}\right.$-allyl $\left.) \mathrm{Rh}(\mathrm{COD})_{2}\right] \mathrm{X}$ complexes. For instance the imine carbon environments for $\mathbf{3} \mathbf{x}$ are observed at 161.7 and $166.3 \mathrm{ppm}$ for the side arms bearing the palladium(II) and rhodium(I) centres compared to $\left[\mathrm{L}^{1} \mathrm{Pd}\left(\eta^{3}-\mathrm{C}_{6} \mathrm{H}_{9}\right) \mathrm{Rh}(\mathrm{COD})\right] \mathrm{PF}_{6}(\mathbf{3 t})$ where they are observed at 161.2 and $163.7 \mathrm{ppm}$ respectively in the ${ }^{13} \mathrm{C}$ NMR spectrum. This is due to the CO ligands been a better $\pi$-acceptor compared to COD ligand. The differences in ${ }^{1} \mathrm{H},{ }^{13} \mathrm{C}$ NMR and IR shift frequencies are outlined in Table 6.3.5. 4.

Table 6.3.5. 4: Table showing the ${ }^{1} \mathrm{H},{ }^{13} \mathrm{C}$ NMR chemical shifts and IR absorptions for complexes $3 t, 3 x, 30$ and HL $^{1}$

\begin{tabular}{|c|c|c|c|c|c|}
\hline & $\begin{array}{c}{\left[\mathrm{L}^{1} \mathbf{P d}\left(\mathrm{C}_{6} \mathrm{H}_{9}\right) \mathrm{Rh}(\mathrm{COD})\right]^{+}} \\
(3 \mathrm{t})\end{array}$ & $\begin{array}{c}{\left[\mathrm{L}^{1} \mathbf{P d}\left(\mathrm{C}_{6} \mathrm{H}_{9}\right) \mathrm{Rh}(\mathrm{CO})_{2}\right]^{+}} \\
(3 \mathrm{x})\end{array}$ & $\begin{array}{c}{\left[\mathrm{L}^{1} \mathbf{P d}_{2}\left(\mathrm{C}_{6} \mathrm{H}_{9}\right)_{2}\right]^{+}} \\
(3 \mathrm{o})\end{array}$ & $\overline{H^{\prime} L^{1}}$ \\
\hline \multirow[t]{2}{*}{${ }^{1} \mathrm{H}$ NMR ( $(\delta)$} & $\mathrm{CH}=\mathrm{N}^{\mathrm{Pd}}$ & 8.22 & 8.31 & 8.24 & 8.29 \\
\hline & $\mathrm{CH}=\mathrm{N}^{\mathrm{Rh}}$ & 7.97 & 7.93 & - & - \\
\hline \multirow{2}{*}{$\begin{array}{l}{ }^{13} \mathrm{C} \text { NMR } \\
(\delta:)\end{array}$} & $\mathrm{CH}=\mathrm{N}^{\mathrm{Pd}}$ & 161.2 & 161.7 & 171.1 & $\mathrm{~N} / \mathrm{A}$ \\
\hline & $\mathrm{CH}=\mathrm{N}^{\mathrm{Rh}}$ & 163.7 & 166.3 & - & - \\
\hline \multirow[t]{2}{*}{$\mathrm{IR} / \mathrm{cm}^{-1}$} & $\mathrm{CH}=\mathrm{N}^{\mathrm{Pd}}$ & 1605 & 1611 & 1613 & 1625 \\
\hline & $\mathrm{CH}=\mathrm{N}^{\mathrm{Rh}}$ & 1586 & 1577 & - & - \\
\hline
\end{tabular}

Attempts at obtaining single crystals of the carbonylated complexes for X-ray crystallography failed. The synthetic protocols for the formation of the heterobimetallic complexes $\left[\operatorname{Lxd}^{\mathrm{x}} \operatorname{P} \eta^{3}-\right.$ allyl) $\operatorname{Rh}(\mathrm{COD})] \mathrm{X}$ and $\left[\mathrm{L}^{\mathrm{x}} \mathrm{Pd}\left(\eta^{3}\right.\right.$-allyl $\left.) \mathrm{Rh}(\mathrm{CO})_{2}\right] \mathrm{X}$ complexes $(\mathbf{3 r}-\mathbf{3 u})$ are not always without 
drawbacks. In some instances, the formation of other metal exchange side products $(\mathbf{3} \mathbf{v}, \mathbf{3} \mathbf{z}$, 3z1) was observed (Scheme 6.3.5. 5).

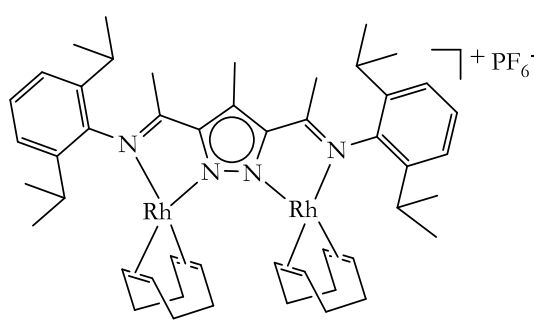

$3 \mathbf{v}$

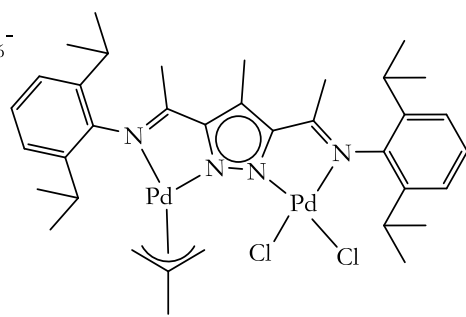

$3 z$

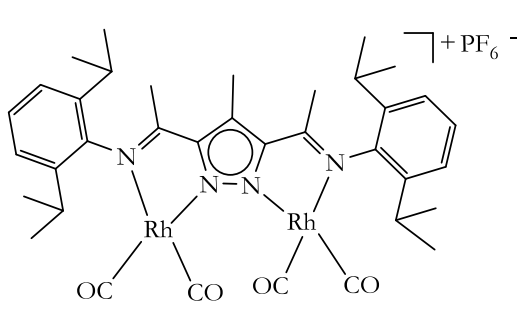

$3 z 1$

Scheme 6.3.5. 5: Side products obtained through metal exchange reactions

Akita et. al. ${ }^{268}$ also observed the formation of a statistical mixture of homo- and heterobimetallic complexes through metal exchange processes in the carbonylation reactions. The additional products such as $\left[\mathrm{L}^{2} \mathrm{Rh}_{2}(\mathrm{COD})_{2}\right] \quad(\mathbf{3 v}), \quad\left[\mathrm{L}^{2} \mathrm{Pd}_{2}\left(\eta^{3}-\mathrm{C}_{4} \mathrm{H}_{7}\right) \mathrm{Cl}_{2}\right] \quad(\mathbf{3} \mathbf{z})$ and $\left[\mathrm{L}^{2} \mathrm{Rh}_{2}(\mathrm{CO})_{2}\right]^{+}$(3z1) were characterized by NMR spectroscopy and single crystal X-ray crystallography. The mechanism leading to the formation of the observed side products is not well understood. Nevertheless, it may involve some associative and dissociative processes that occur in solution.
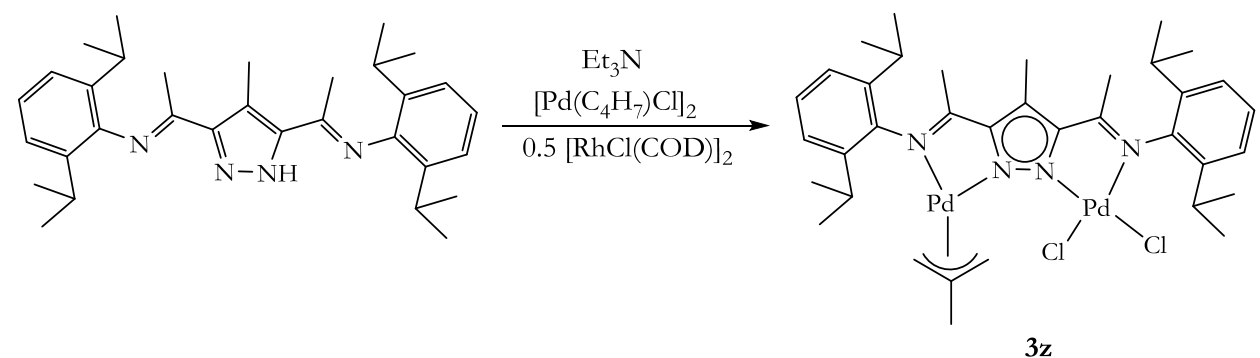

Scheme 6.3.5. 6: Formation of the unexpected side product $3 z$

The formation of $\mathbf{3} \mathbf{z}$ is possibly from the gradual association of chloride anions, which is followed by the dissociation of the $\eta^{3}-\mathrm{C}_{4} \mathrm{H}_{7}$ ligand. The molecular structure of $\mathbf{3} \mathbf{z}$ is shown (Fig. 6.3.5. 9). Single crystals were grown by the slow evaporation of a $\mathrm{CH}_{2} \mathrm{Cl}_{2} /$ ether solution of the complex at room temperature. The compound crystallizes in the $P 21$ /c space group. 


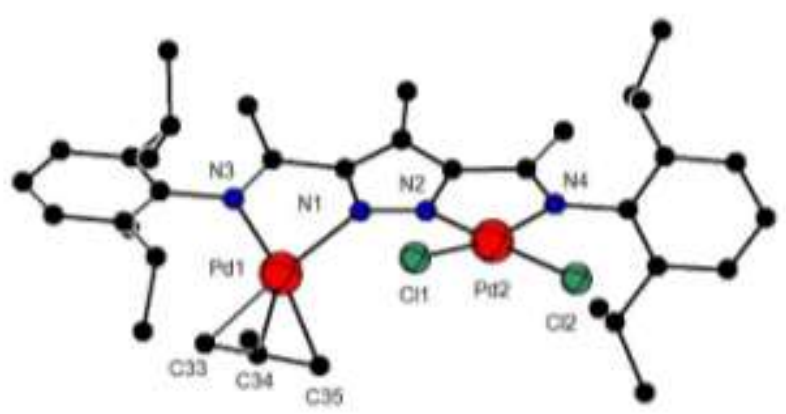

Fig. 6.3.5. 9: Molecular structure of $3 \mathrm{z}$ with all $\mathrm{H}$ atoms omitted for clarity

The interpalladium distance in $\mathbf{3 z}$ is significantly shorter (4.37 $\AA$ ) compared to $4.56 \AA$ found in the complex $\left[\mathrm{L}^{2} \mathrm{Pd}_{2}\left(\eta^{3}-\mathrm{C}_{4} \mathrm{H}_{7}\right)_{2}\right] \mathrm{BAr}_{4}^{\mathrm{F}}$. The coordination around both palladium(II) centres are square planar, as usually observed for 16 valence electron four-coordinate $\mathrm{d}^{8}$ complexes. The torsional angle defined by Pd1-N1-N2-Pd2 is larger $\left(-33.82^{\circ}\right)$ compared to $\left(-11.90^{\circ}\right)$ in $\left[\mathrm{L}^{2} \mathrm{Pd}_{2}\left(\eta^{3}-\mathrm{C}_{4} \mathrm{H}_{7}\right)_{2}\right] \mathrm{BAr}_{4}^{\mathrm{F}}{ }_{4}(\mathbf{3 n})$. Selected bond lengths $[\AA]$ and bond angles $\left[^{\circ}\right]$ are given in Table 6.3.5. 5 .

Table 6.3.5. 5: Selected bond lengths $[\AA \AA]$ and bond angles $\left[{ }^{\circ}\right]$ for $3 z$

\begin{tabular}{|c|c|c|c|}
\hline Bond lengths $[\AA ̊]$ & & Bond angles $\left[^{\circ}\right.$ & \\
\hline $\mathrm{Pd}(1)-\mathrm{N}(1)$ & $2.091(7)$ & $\mathrm{N}(1)-\mathrm{Pd}(1)-\mathrm{N}(3)$ & $76.6(3)$ \\
\hline $\operatorname{Pd}(1)-\mathrm{N}(3)$ & $2.095(7)$ & $\mathrm{N}(1)-\mathrm{Pd}(1)-\mathrm{C}(33)$ & $173.8(4)$ \\
\hline $\operatorname{Pd}(1)-C(33)$ & $2.094(9)$ & $\mathrm{N}(3)-\mathrm{Pd}(1)-\mathrm{C}(33)$ & $105.2(3)$ \\
\hline $\operatorname{Pd}(1)-C(35)$ & $2.132(9)$ & $\mathrm{N}(1)-\mathrm{Pd}(1)-\mathrm{C}(34)$ & $141.0(3)$ \\
\hline $\operatorname{Pd}(2)-\mathrm{N}(2)$ & $2.002(7)$ & $\mathrm{N}(3)-\mathrm{Pd}(1)-\mathrm{C}(34)$ & $140.9(3)$ \\
\hline $\operatorname{Pd}(2)-\mathrm{N}(4)$ & $2.028(8)$ & $\mathrm{C}(33)-\mathrm{Pd}(1)-\mathrm{C}(34)$ & $39.0(3)$ \\
\hline $\operatorname{Pd}(1)-\operatorname{Pd}(2)$ & $4.376(11)$ & $\mathrm{N}(1)-\mathrm{Pd}(1)-\mathrm{C}(35)$ & $109.7(3)$ \\
\hline
\end{tabular}

In the ${ }^{1} \mathrm{H}$ NMR spectrum of $\mathbf{3 z}$, the $\mathrm{CH}^{\mathrm{Pr}}$ are observed as multiplets between 1.10-1.48 ppm. The $\mathrm{CH}_{3}{ }^{\mathrm{Me}(a l l y)}$ is observed as a singlet at $2.14 \mathrm{ppm}$, whiles the $\mathrm{CH}_{3} \mathrm{C}=\mathrm{N}$ is observed as two close singlets at 2.18 and $2.20 \mathrm{ppm}$, reflecting the asymmetric ligand environment. The $\mathrm{CH}_{3}{ }^{\mathrm{Pz} 4}$ is also observed as a singlet at 2.57 ppm (Fig. 6.3.5. 10). 


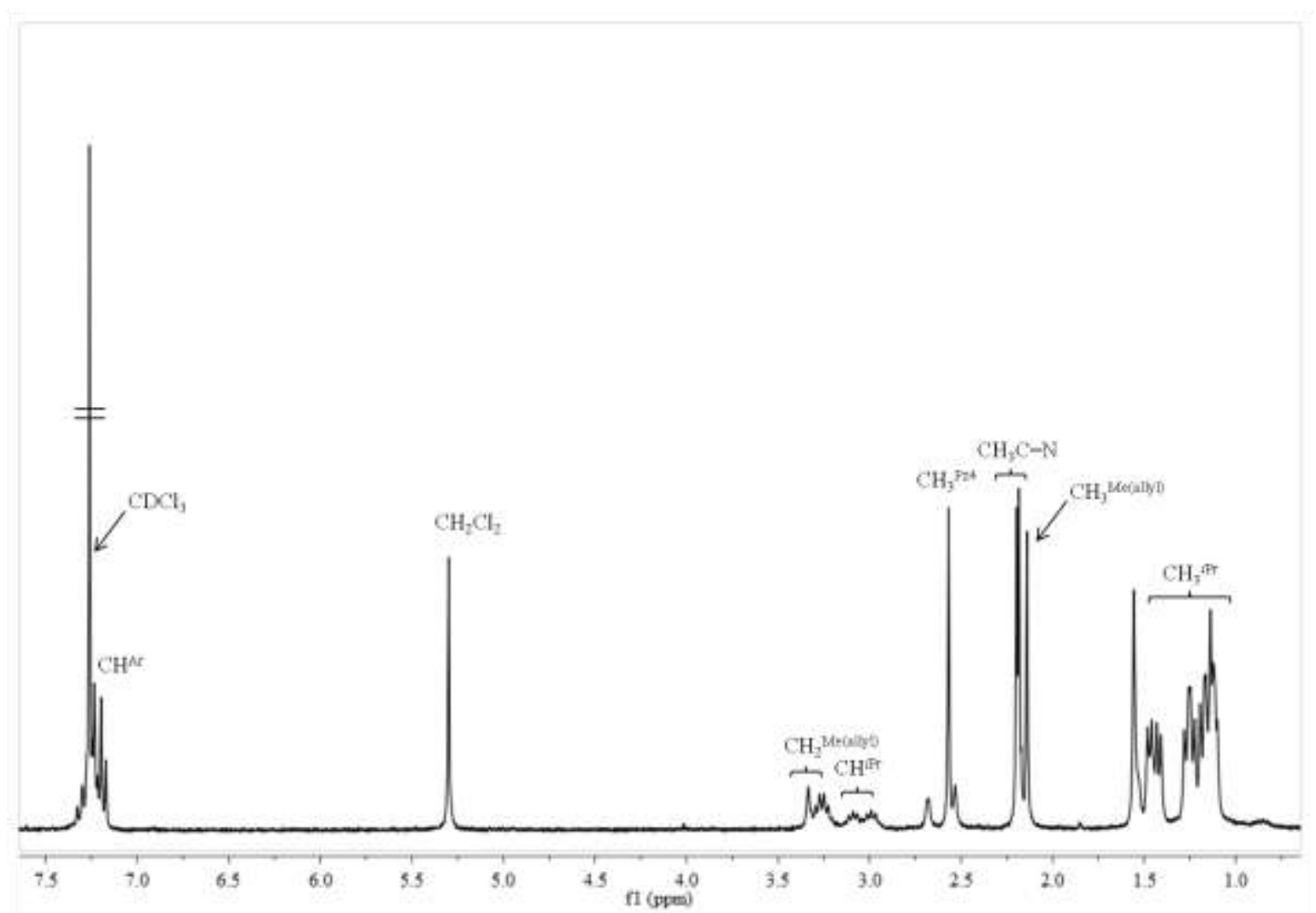

Fig. 6.3.5. 10: ${ }^{1} \mathrm{H}$ NMR spectrum of $3 \mathrm{z}$ measured in $\mathrm{CDCl}_{3}$ at room temperature

The ESI mass spectrum of $\mathbf{3} z$ shows $m / z$ fragments at $780(15 \%)$ and $749(100 \%)$ assigned to $[\mathrm{M}-\mathrm{Cl}]^{+}$and $[\mathrm{M}-2 \mathrm{Cl}]^{+}$respectively, a further confirmation of the formation of this side product.

After successful preparation and the heterobimetallic complexes, some selected complexes were screened towards some basic organometallic addition reactions. 


\subsubsection{Catalytic screening}

The aim was to investigate if the presence of the palladium(II) centre in any way influenced the activity and selectivity of the reaction profile. The complexes $\left[\mathrm{L}^{2} \mathrm{Pd}\left(\eta^{3}-\right.\right.$ $\left.\left.\mathrm{C}_{6} \mathrm{H}_{9}\right) \mathrm{Rh}(\mathrm{COD})\right] \mathrm{BAr}_{4}^{\mathrm{F}}(\mathbf{3 u}),\left[\mathrm{L}^{2} \mathrm{Rh}(\mathrm{COD})\right]^{221}$ and $\left[\mathrm{L}^{2} \mathrm{Pd}_{2}\left(\eta^{3}-\mathrm{C}_{6} \mathrm{H}_{9}\right)\right] \mathrm{PF}_{6}(\mathbf{3} \mathbf{p})$ complexes were screened in the rhodium catalyzed conjugate addition of organoboron reagents to alkenes and alkynes, ${ }^{269,270,271}$ as well as the rhodium catalyzed anti-Markovnikov intramolecular hydroalkoxylation of terminal acetylenes (Scheme 6.3.5.1. 1).

i.

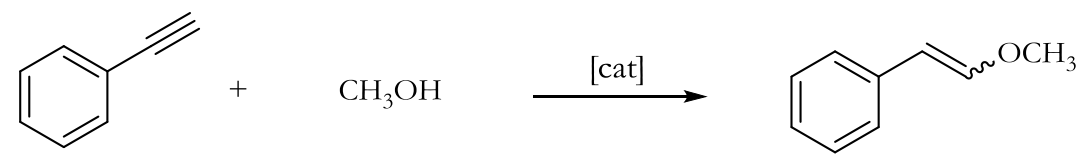

ii.

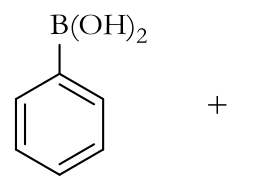<smiles>C=C(C)C(=O)OC</smiles><smiles>C=C1CC1[13CH3]</smiles><smiles>COC(=O)C(C)Cc1ccccc1</smiles>

iii.<smiles>O=C1C=CCCC1</smiles>

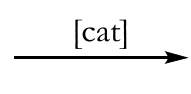<smiles>O=C1CCCC(P)C1</smiles><smiles>OC1(c2ccccc2)CCCC(P)C1</smiles>

Scheme 6.3.5.1. 1: Some screened organometallic transformation reactions

In the conjugate addition of organoboron reagents to 2-cyclohexenone (Scheme 6.3.5.1. 1iii) using $\mathbf{3} \mathbf{u}$, a white volatile crystalline solid with a pleasant aroma was obtained by column chromatography after workup. Analysis of the product by ${ }^{1} \mathrm{H}$ NMR spectroscopy showed the presence of a double bond, which was not consistent with the expected product and different from the ${ }^{1} \mathrm{H}$ NMR spectrum of cyclohexenone. An MS (EI) of the product on the other hand shows molecular peaks that can be assigned to an addition product. A look up in literature shows instances where palladium(II) complexes have been used for the oxidative Heck type addition of phenylboronic acids.

It seems though, that $\mathbf{3} \mathbf{u}$ fails to achieve the conjugative addition product reaction, but rather an oxidative Heck type addition reaction takes place. 


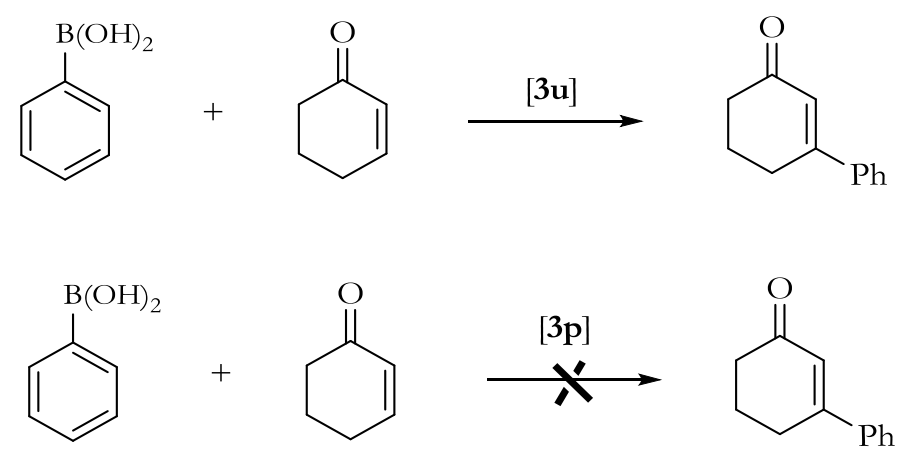

Scheme 6.3.5.1. 2: Oxidative Heck type addition product formed

What is of interest is the fact that the analogous homobimetallic palladium(II) complex $\mathbf{3 p}$ failed to achieve this transformation, the formation of a palladium $(0)$ is always observed. The interesting feature of $\mathbf{3 u}$ is that, the Heck type addition product was obtained up to $98 \%$ yield in an hour, compared to other traditional Heck type catalyst, which take up to $24 \mathrm{~h}$ to achieve such yields. Jones and James ${ }^{11}$ have also investigated the use of $\mathrm{Pd} / \mathrm{Pt}$ bimetallic complexes for Heck coupling reactions. They reported that the bimetallic catalysts were more active than the monometallic analogues.

Kondo et. al. ${ }^{272}$ reported the first transition-metal catalyzed anti-Markovnikov intermolecular hydroalkoxylation of terminal acetylenes to enol ethers in high yields (up to 92\%) without the use of a base. Using 8-quinolinolato rhodium complexes, arylacetylenes as well as alkenyland alkylacetylenes were coupled with aliphatic alcohols, and the products were obtained with high $Z$ selectivity in most cases. ${ }^{272}$ Attempts were therefore made at investigating the catalytic activity of $\left[\mathrm{L}^{2} \mathrm{Rh}(\mathrm{COD})\right]$ complex in the rhodium catalyzed anti-Markovnikov intramolecular hydroalkoxylation of terminal acetylenes (Scheme 6.3.5.1. 3), inspired by literature work in which rhodium(I) complexes have been used to achieve such transformations.

The reaction using $\left[\mathrm{L}^{2} \mathrm{Rh}(\mathrm{COD})\right]$ failed to yield the desired hydroxymethylated enol ether. Rather, it catalyzed the polymerization of acetylene to polyphenylacetylene, which under thermal conditions employed, undergoes scission of the polymer product, followed by cyclotrimerization to form 1,3,5-triphenyl benzene (TPB). The formation of 1,3,-5 TPB was observed from the ES-MS of the yellow crystalline solid which shows a peak at $m / z, 306$ $(100 \%)$. 
Results and Discussions

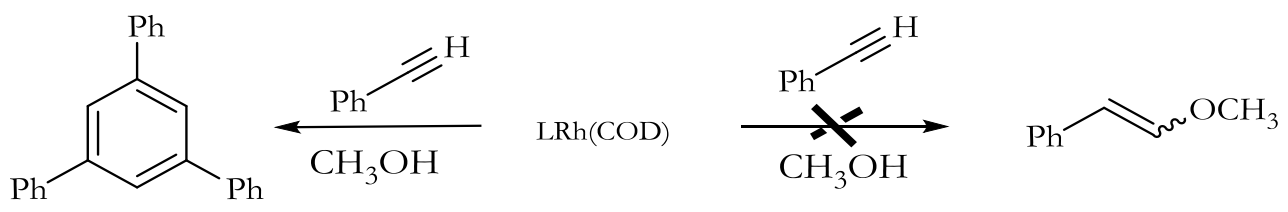

Scheme 6.3.5.1. 3: Thermal isomerisation of cis polyphenylacetylene

The thermal cis-trans isomerisation of cis-transoidal polyphenylacetylene has been studied in literature, and it has been suggested that, the thermal isomerisation of the polymer chain is accompanied by cyclization and scission of the polymer chain. ${ }^{273}$ Although cyclization reactions reported in literature are usually performed at temperatures above $120{ }^{\circ} \mathrm{C}$, tricyclization can also occur at lower temperatures $\left(78{ }^{\circ} \mathrm{C}\right)$ as observed with $\left[\mathrm{L}^{2} \mathrm{Rh}(\mathrm{COD})\right]$ given prolonged reaction times $(48 \mathrm{~h})$. No further investigations were carried out. 


\section{4 Tetranuclear zinc(II) complexes of $\alpha$-diimine type ligands as catalysts for polymerization of rac-D,L-lactide to poly $\mathrm{D}, \mathrm{L}-\mathrm{lactide}$, a bio-renewable polymer}

\subsection{Synthesis and characterization of tetranuclear zinc(II) complexes}

The complexes $\left[\mathrm{L}_{2}^{1} \mathrm{Zn}_{4}(\mu-\mathrm{OAc})_{6}\right](\mathbf{4 a}),\left[\mathrm{L}_{2}^{2} \mathrm{Zn}_{4}(\mu-\mathrm{OAc})_{6}\right](\mathbf{4 b}),\left[\mathrm{L}_{2}^{3} \mathrm{Zn}_{4}(\mu-\mathrm{OAc})_{6}\right](4 \mathbf{c})$ and $\left[\mathrm{L}_{2}^{4} \mathrm{Zn}_{4}(\mu \text {-OAc })_{6}\right]$ (4d) were prepared using a general synthetic route which involved the reaction of the appropriate ligand with $2 \mathrm{~mol}$ equivalent $\mathrm{Zn}(\mathrm{OAc})_{2} \cdot 2 \mathrm{H}_{2} \mathrm{O}$ in methanol with stirring under room temperature for $48 \mathrm{~h}$. The complexes were isolated as white crystalline solids, and purified by recrystallization from dichloromethane/methanol. The complexes were obtained in moderate to good yields (69-81\%). The complexes were fully characterized by ${ }^{1} \mathrm{H}$ and ${ }^{13} \mathrm{C}$ NMR spectroscopy, ESI-MS, IR spectroscopy, elemental analysis and in some instances single crystal diffraction studies.

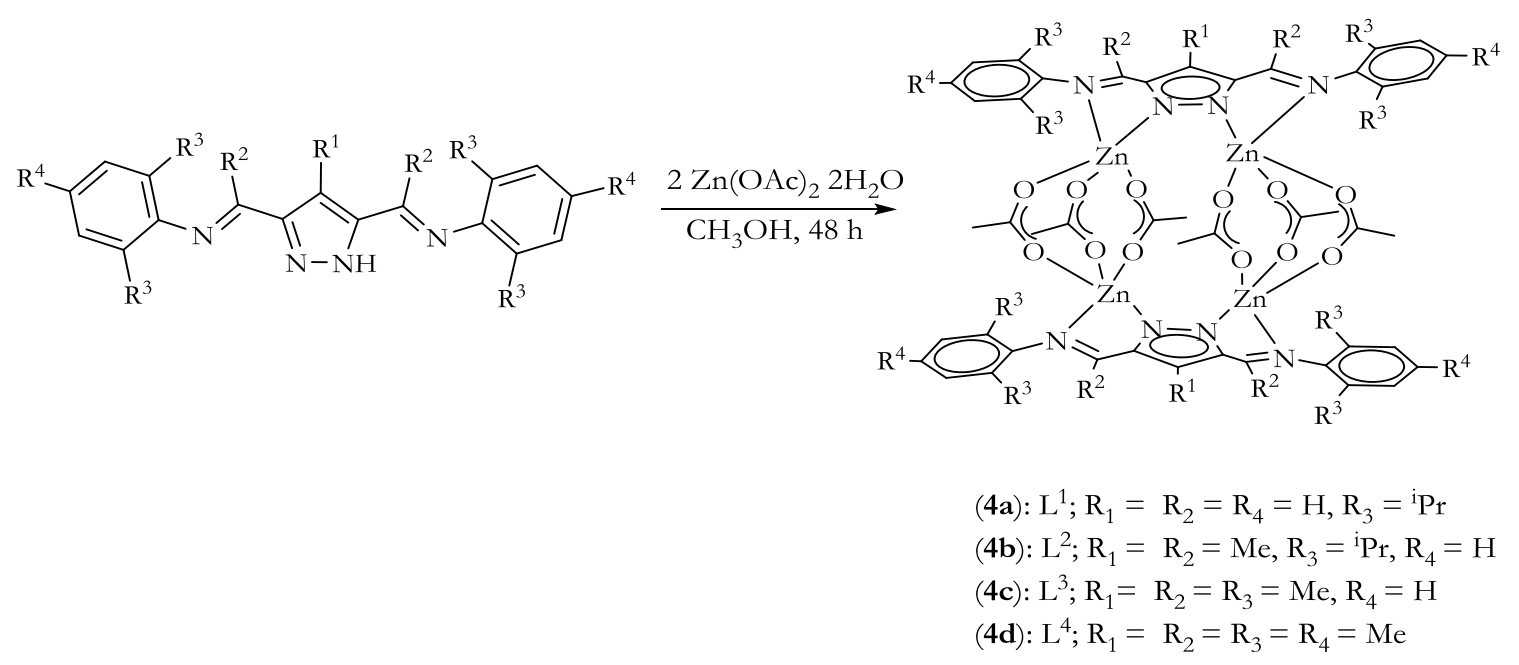

Scheme 6.4.1. 1: Synthetic scheme for the preparation of zinc(II) complexes 4a-4d

The ${ }^{1} \mathrm{H}$ NMR spectra of the complexes shows only one distinct acetate bridging and pyrazole environment, pointing to only one type of compound in solution, hence a dynamic process takes place at room temperature. The $\mathrm{CH}_{3}{ }^{\text {Pr }}$ group is broadened and only a single signal is observed for the $\mathrm{CH}_{3}{ }^{\mathrm{OAc}}$ protons. The ${ }^{13} \mathrm{C}$ NMR resonance for the bridging acetate groups of the complexes are observed between 179-180 ppm, although the imine carbons are not detected. The IR spectrum of the complexes also shows two distinct acetate bridging environments between 1585-1607 $\mathrm{cm}^{-1}$ for asymmetric stretching vibrations and 1417-1439 $\mathrm{cm}^{-1}$ for symmetric stretching vibrations. The $\mathrm{CH}_{3} \mathrm{C}=\mathrm{N}$ stretching vibrations also swamped 
under the broad acetate peak. Table 6.4.1. 1 summarizes the stretching vibrations for the acetate environment as observed in the various zinc(II) complexes. A carboxylate ion, $\mathrm{CO}_{2}$, can coordinate to metals in a number of ways, viz; as a unidentate ligand, as a chelating ligand, as a monatomic bridging ligand, or as a bridging bidentate ligand in a syn-syn, syn-anti or anti-anti configuration. These carboxylate binding modes are known to give rise to distinct frequencies for the asymmetric $\nu_{\text {as }}\left(\mathrm{CO}_{2}^{-}\right)$and symmetric $\nu_{\mathrm{sy}}\left(\mathrm{CO}_{2}^{-}\right)$vibrations. The difference between the separation of these vibrations $\Delta=\nu_{\text {as }}\left(\mathrm{CO}_{2}^{-}\right)-\nu_{\mathrm{sy}}\left(\mathrm{CO}_{2}^{-}\right)$is used as a criterion for distinguishing between the binding modes. The table below shows the $\Delta$ for the complexes 4a-4d. In 4a, $\Delta=146 \mathrm{~cm}^{-1}$ is smaller than the ionic acetate $\left(164-171 \mathrm{~cm}^{-1}\right)^{274}$ although the rest are in the range of chelating or bridging acetates.

Table 6.4.1. 1: Table showing the IR stretching frequencies of the acetate environment in complexes 4a-4d

\begin{tabular}{llll}
\hline Complex & $\nu_{\text {as }}\left(\mathbf{c m}^{-1}\right)$ & $\nu_{\text {sy }}\left(\mathbf{c m}^{-1}\right)$ & $\Delta\left(\mathbf{c m}^{-1}\right)$ \\
\hline $\mathrm{L}^{1}{ }_{2} \mathrm{Zn}_{4}(\mu-\mathrm{OAc})_{6}(\mathbf{4 a})$ & 1585 & 1439 & 146 \\
$\mathrm{~L}^{2}{ }_{2} \mathrm{Zn}_{4}(\mu-\mathrm{OAc})_{6}(\mathbf{4 b})$ & 1603 & 1430 & 173 \\
$\mathrm{~L}^{3}{ }_{2} \mathrm{Zn}_{4}(\mu-\mathrm{OAc})_{6}(\mathbf{4 c})$ & 1590 & 1423 & 167 \\
$\mathrm{~L}^{4}{ }_{2} \mathrm{Zn}_{4}(\mu-\mathrm{OAc})_{6}(\mathbf{4 d})$ & 1607 & 1417 & 190 \\
\hline
\end{tabular}

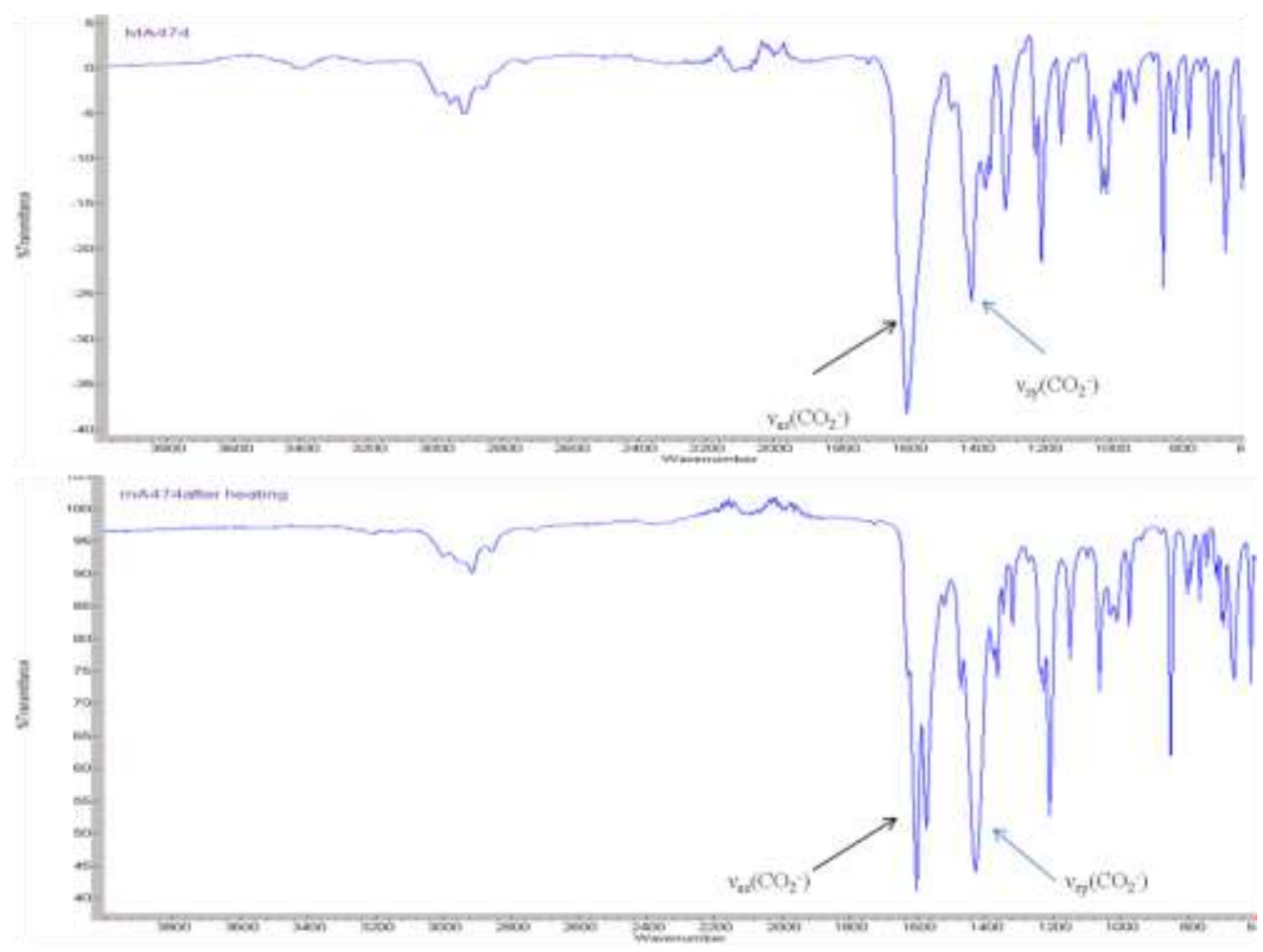

Fig. 6.4.1. 1: IR spectra of $4 \mathrm{~d}$ showing the acetate bridging environment before (upper) and after heating (lower) 
On heating 4d, the $\nu_{\text {as }}$ does not change $\left(1607 \mathrm{~cm}^{-1}\right)$, but a change in $\nu_{\mathrm{s}}\left(1432 \mathrm{~cm}^{-1}\right)$ is observed. The $\Delta$ before heating is $\left(190 \mathrm{~cm}^{-1}\right)$ and $\Delta$ after heating is $\left(175 \mathrm{~cm}^{-1}\right)$ (Fig. 6.4.1. 1).

The DSC/TG of $\mathbf{4 d}$ was performed in a dynamic inert atmosphere of nitrogen. The first peak in the curve indicates a melting temperature of $264^{\circ} \mathrm{C}$. Two consecutive weight loss points are observed, the first weight loss curve occurred between temperatures of $100^{\circ} \mathrm{C}$ and $164{ }^{\circ} \mathrm{C}$, representing a weight loss of $3.27 \%$, whiles between $164^{\circ} \mathrm{C}$ and $300^{\circ} \mathrm{C}$ only a $1.27 \%$ loss in weight is observed (Fig. 6.4.1. 2), the cause for the weight loss, not clear.

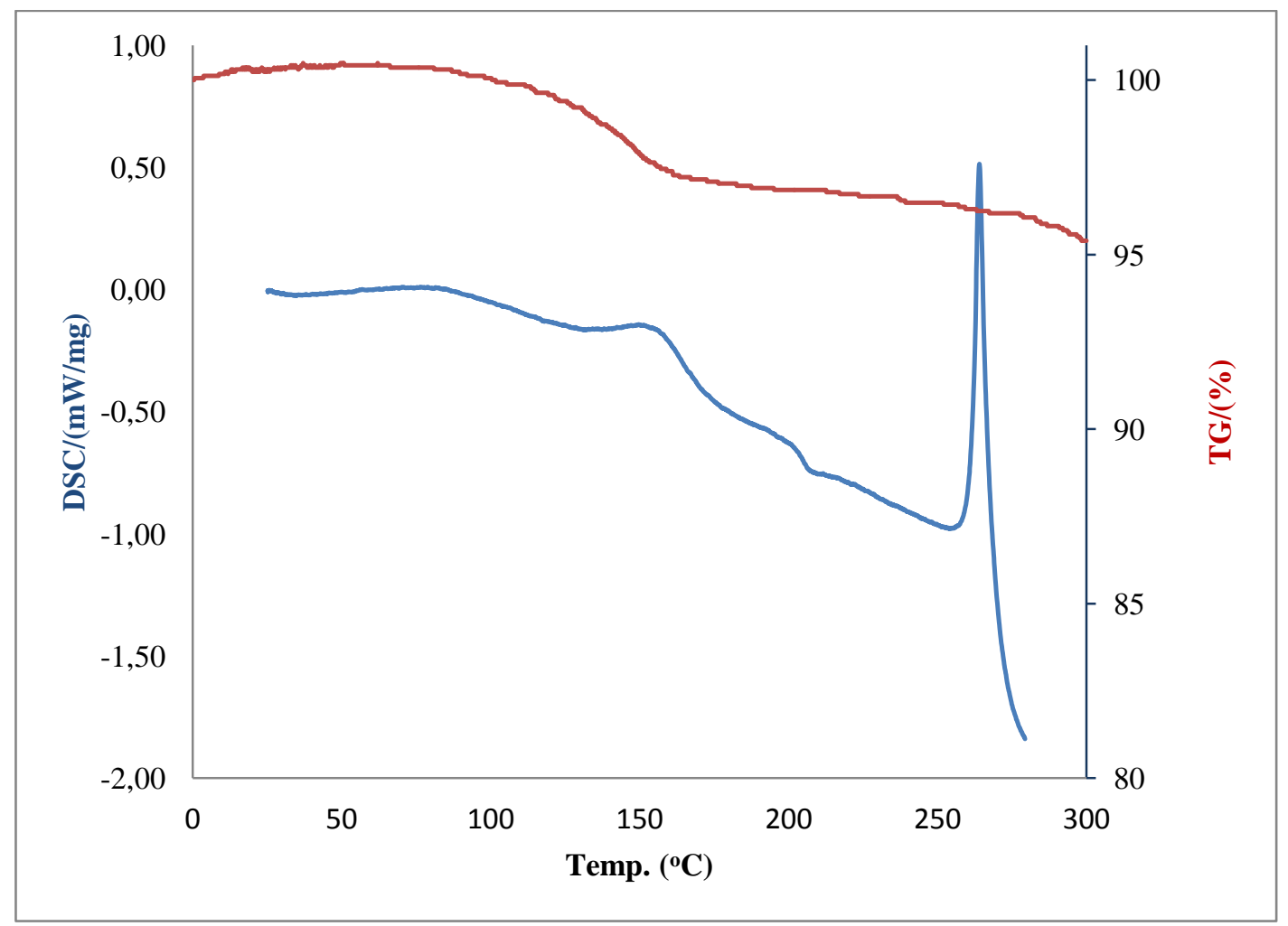

Fig. 6.4.1. 2: A DSC/TG curve for $4 \mathrm{~d}$ showing the metlting temperature and weight loss over a temperature range

ESI-MS data of the complexes supports a dimeric structure. Generally, the most intense peaks in the ESI-MS of complexes correspond to $\left[\mathrm{L}_{2} \mathrm{Zn}_{4}(\mathrm{OAc})_{\mathrm{x}}\right]^{+}$peaks. The dimeric nature of the complexes was confirmed by single crystal X-ray structures.

The molecular structure of $\mathbf{4 a}$ is shown in Fig. 6.4.1. 3. Crystals of the complex were obtained by the slow evaporation of a $\mathrm{CH}_{2} \mathrm{Cl}_{2}$ solution of the complex at room temperature. 


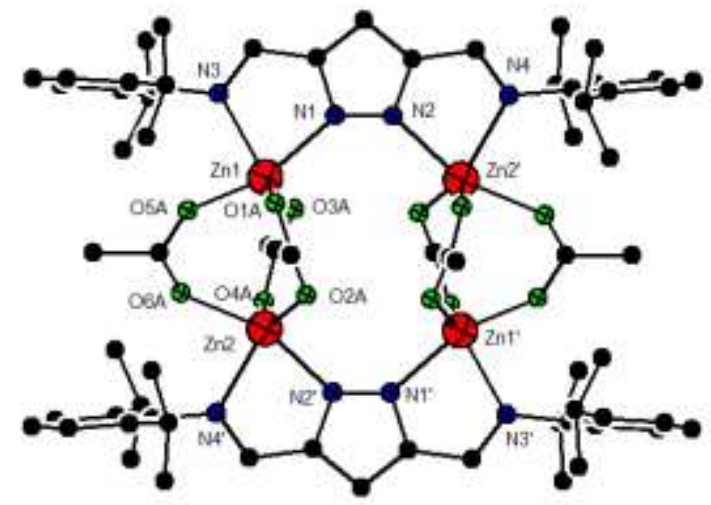

Fig. 6.4.1. 3: Molecular structure of 4a, $\mathrm{H}$ atoms, and solvents omitted for clarity

The complex $\mathbf{4 a}$ crystallizes in the $P$ 21/n space group and co-crystallizes with five molecules of dichloromethane. The complex has a dimeric structure in the solid state, with two different $\mathrm{LZn}_{2}$ units bridged together by six acetate units. The geometry about the $\mathrm{Zn}$ atom is octahedral. The inter-metallic distance between $\mathrm{Zn}$ centres linked by the acetate ligand $(\mathrm{Zn} \cdots \mathrm{Zn})$ distance is $3.45 \AA$. The $\mathrm{Zn}-\mathrm{O}$ distances are in the range of $1.86 \AA$ and $2.08 \AA$. The $\mathrm{Zn}-\mathrm{N}^{\mathrm{Pz}}$ bond distance in this complex is $2.10 \AA$, whiles that of the $\mathrm{Zn}$ imine nitrogen is slightly longer at $2.16 \AA$. The peripheral 2,6-diisopropyl groups are oriented perpendicular to the pyrazolyl plane to avoid steric interactions between isopropyl and acetate groups. Selected bond lengths $[\AA]$ and angles $\left[^{\circ}\right]$ are also given (Table 6.4.1. 2).

Table 6.4.1. 2: Selected bond lengths $[\AA \AA]$ and bond angles $\left[^{\circ}\right]$ for $4 \mathrm{a}$

\begin{tabular}{llll}
\hline \multicolumn{3}{c}{ Bond lengths $[\AA]$} \\
& & \multicolumn{1}{c}{ Bond Angles [0] } \\
\hline $\mathrm{Zn}(1)-\mathrm{O}(1 \mathrm{~A})$ & $1.860(3)$ & $\mathrm{O}(1 \mathrm{~A})-\mathrm{Zn}(1)-\mathrm{O}(3 \mathrm{~B})$ & $145.1(2)$ \\
$\mathrm{Zn}(1)-\mathrm{O}(3 \mathrm{~A})$ & $2.072(11)$ & $\mathrm{O}(1 \mathrm{~A})-\mathrm{Zn}(1)-\mathrm{O}(5 \mathrm{~A})$ & $68.02(18)$ \\
$\mathrm{Zn}(1)-\mathrm{N}(1)$ & $2.109(15)$ & $\mathrm{O}(3 \mathrm{~B})-\mathrm{Zn}(1)-\mathrm{O}(3 \mathrm{~A})$ & $18.89(11)$ \\
$\mathrm{Zn}(1)-\mathrm{N}(3)$ & $2.168(16)$ & $\mathrm{O}(3 \mathrm{~B})-\mathrm{Zn}(1)-\mathrm{N}(3)$ & $107.62(15)$ \\
$\mathrm{Zn}(2)-\mathrm{O}(6 \mathrm{~A})$ & $2.0648(31)$ & & \\
$\mathrm{Zn}(1)-\mathrm{Zn}(2)$ & $3.449(3)$ & & \\
$\mathrm{Zn}(1)-\mathrm{Zn}(2)$ & $4.493(3)$ & & \\
\hline
\end{tabular}

The analogous complex $\mathbf{4} \mathbf{c}$ crystallizes in the $P-1$ space group and similar to $4 \mathbf{a}$ in geometry. In $4 \mathbf{c}$, the intermetallic distance between $\mathrm{Zn}$ centres linked by the acetate ligand $\mathrm{Zn} \cdots \mathrm{Zn}$ distance is significantly shorter $3.30 \AA$. Whiles the $\mathrm{Zn}-\mathrm{O}$ distances are in the range of 1.97 to $2.68 \AA$. The $\mathrm{Zn}-\mathrm{N}$ bond distance is in the range of 2.03 to $2.23 \AA$. The $\mathrm{Zn}-\mathrm{N}^{\mathrm{Pz}}$ bond distance 
in this complex is short mainly $2.03 \AA$ compared to $2.11 \AA$ in $4 \mathbf{a}$. Selected bond lengths and angles for $\mathbf{4 c}$ are given in Table 6.4.1. 3 .

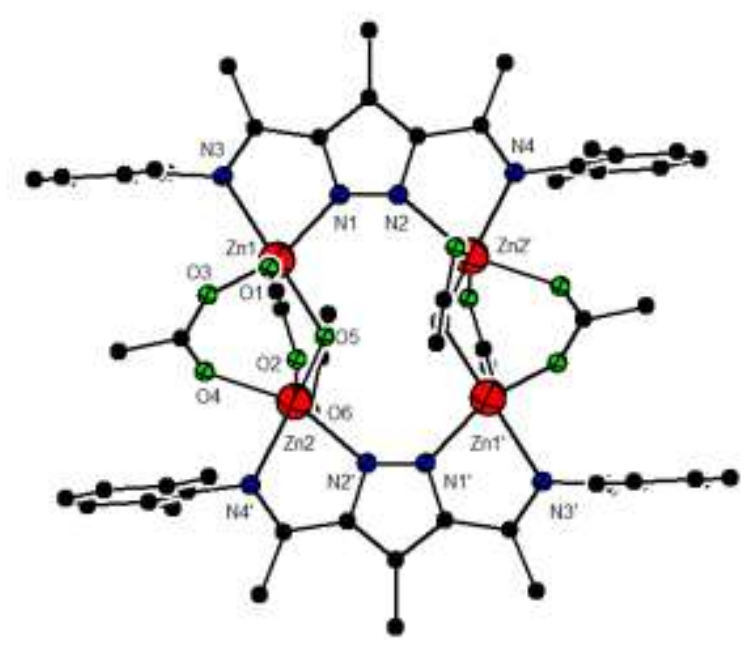

Fig. 6.4.1. 4: Molecular structure of $4 \mathrm{c}$ with solvents and $\mathrm{H}$ atoms omitted for clarity

Table 6.4.1. 3: Selected bond lengths and bond angles for $4 \mathrm{c}$

\begin{tabular}{llll}
\hline \multicolumn{2}{c}{ Bond lengths $[\AA \mathbf{\AA}]$} & \multicolumn{1}{c}{ Bond Angles [0] } \\
\hline $\mathrm{Zn}(1)-\mathrm{O}(1)$ & $1.978(2)$ & $\mathrm{O}(1)-\mathrm{Zn}(1)-\mathrm{O}(3)$ & $113.99(8)$ \\
$\mathrm{Zn}(1)-\mathrm{O}(3)$ & $2.007(2)$ & $\mathrm{O}(1)-\mathrm{Zn}(1)-\mathrm{N}(3)$ & $102.80(9)$ \\
$\mathrm{Zn}(2)-\mathrm{O}(2)$ & $1.996(19)$ & $\mathrm{O}(3)-\mathrm{Zn}(1)-\mathrm{O}(5)$ & $101.36(8)$ \\
$\mathrm{Zn}(1)-\mathrm{N}(1)$ & $\mathrm{O}(3)-\mathrm{Zn}(1)-\mathrm{N}(3)$ & $83.59(8)$ \\
$\mathrm{Zn}(1)-\mathrm{N}(3)$ & $\mathrm{N}(1)-\mathrm{Zn}(1)-\mathrm{N}(3)$ & $76.31(9)$ \\
$\mathrm{Zn}(1)-\mathrm{Zn}(2)$ & $2.233(2)$ & & \\
$\mathrm{Zn}(1)-\mathrm{Zn}(2)$ & $3.302(5)$ & & \\
\hline
\end{tabular}

A similar compound with four zinc atoms bridged by 3 acetate-groups has been published by Lewiński et al. ${ }^{275}$ Here the $\mathrm{Zn} \cdots \mathrm{Zn}$ distance is $3.38 \AA$, the $\mathrm{Zn}-\mathrm{N}$ bond lengths are in the range of $2.02 \AA$ to $2.09 \AA$, and the $\mathrm{Zn}-\mathrm{O}$ bond lengths are in the range of $1.94 \AA$ to $2.08 \AA$.

Pyrazolyl bearing complexes of the chiral and the enantiopure bis(pyrazol-1-yl)methanebased NNO-donor scorpionate zinc(II) alkyl complexes has been reported by Otero et. al. ${ }^{276}$ The zinc(II) complexes were screened towards ability to polymerize rac-lactides, the results of which are discussed in the following sections. 


\subsection{Polymerization of D,L-lactide to heteroatactic polylactide}

Heterotactic PLA is obtained from rac-lactide when there is the selective insertion of lactide isomer with opposite configuration to the previous inserted monomer. Amorphous polymers on the other hand are formed from rac-lactide when there is the lack of stereochemical control. The target usually is to prepare catalysts capable of generating isotactic PLA from rac-lactide, since the mixture of isotactic L-PLA and D-PLA have different bulk properties compared to pure PLA. ${ }^{277}$ PLA is a rigid transparent thermoplastic with a glass transition temperature $\left(\mathrm{T}_{\mathrm{g}}\right)$ and melting temperature $\left(\mathrm{T}_{\mathrm{m}}\right)$ of about $60^{\circ} \mathrm{C}$ and $170^{\circ} \mathrm{C}$ respectively. Carothers et. al. ${ }^{278}$ as far back as 1952 reported the synthesis of high molecular weight PLA.<smiles>C[C@@H]1OC(=O)[C@@H](C)OC1=O</smiles>

rac-lactide<smiles>[Z][C@@H]1OC(=O)[C@H](C)OC1=O</smiles>

rac-lactide<smiles>C[C@@H]1OC(=O)[C@H](C)OC1=O</smiles>

rac-lactide<smiles>C[C@H](OC(=O)[C@H](C)OC(=O)[C@H](C)OC(C)(C)C)C(=O)O[C@@H](C)C(=O)O[C@@H](C)C(=O)C(C)(C)C</smiles>

Atactic PLA

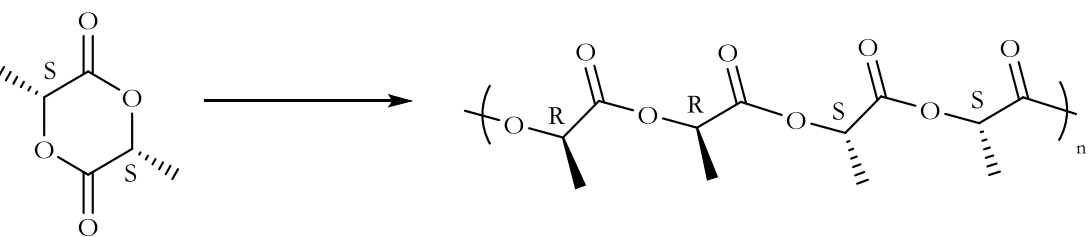
Heteroatactic PLA<smiles>C[C@@H]1OC(=O)[C@@H](C)OC1=O</smiles>

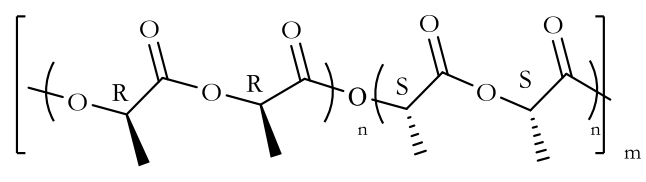

Stereoblock isotactic PLA

Scheme 6.4.2. 1: Examples of PLA microstructures that can be achieved through polymerization of rac-lactide

The catalysts failed to initiate polymerization in solvents such as $\mathrm{CH}_{2} \mathrm{Cl}_{2}$ and THF at room temperature. Polymerization of lactides is only initiated in the melt at temperatures exceeding $170{ }^{\circ} \mathrm{C}$, about the same temperature range where the second weight loss is observed in the DSC/TG of the complex. Generally, the formation of polymer required $\sim 15$ minutes for initiation. The slow initiation of the polymerization process can be attributed to the possible 


\section{Results and Discussions}

stable nature of the dimeric complex and trans esterification reactions that takes place during initiation. $^{205}$

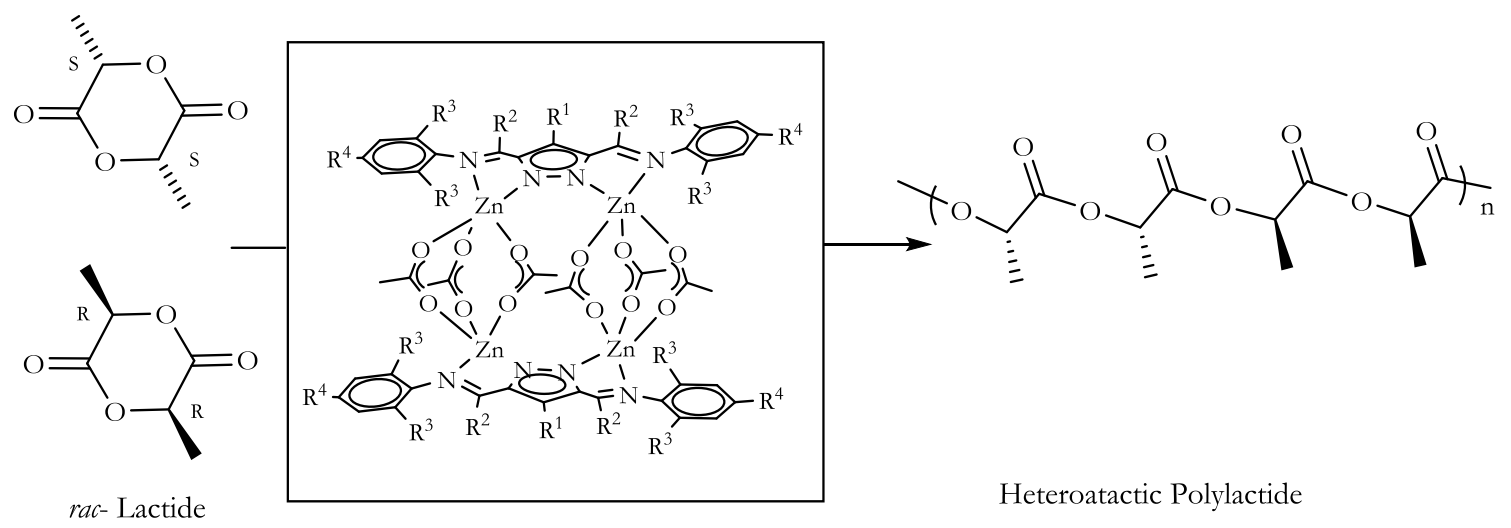

Scheme 6.4.2. 2: Synthetic scheme for the polymerization of $\operatorname{rac}$ D,L-lactide

Generally, increased polymerization times and monomer to initiator ratio also leads to an increase in the molecular weight of the polymer obtained, but with no further improvement in yields. Oxidation of the polymer is observed at reaction temperatures exceeding $200^{\circ} \mathrm{C}$, with the formation of a brown polymer sample. Generally, polymer conversion does not exceed $60 \%$, pointing to the possible inaccessibility of the monomer to the catalyst surface primarily due to the increased viscosity in the reaction media. The results of the polymerization experiment using the various catalysts are summarized in Table 6.4.2. 1.

Table 6.4.2. 1: ROP of rac-lactide promoted by zinc(II) complexes $4 \mathrm{a}-4 \mathrm{c}$

\begin{tabular}{|c|c|c|c|c|c|c|c|c|c|c|}
\hline Entry & Catalyst & {$[\mathrm{M}] /[\mathrm{cat}]$} & $\begin{array}{c}\text { Time } \\
\text { (h) }\end{array}$ & $\begin{array}{c}\text { Yield } \\
\text { (g) }\end{array}$ & $\begin{array}{c}\text { Conv. } \\
(\%)\end{array}$ & $\begin{array}{c}\mathrm{T}_{\mathrm{m}} \\
\left({ }^{\circ} \mathrm{C}\right)\end{array}$ & $\begin{array}{c}\mathbf{M}_{\mathrm{w}} \\
\left(\mathrm{x} 10^{4}\right) \\
(\mathrm{g} / \mathrm{mol})\end{array}$ & $\begin{array}{c}M_{n} \\
\left(x 10^{3}\right) \\
(g / m o l)\end{array}$ & PDI & $\mathbf{P}_{\mathrm{r}}$ \\
\hline 1 & $4 a$ & 500 & 18 & 0.46 & 47 & 64.0 & 2.92 & 1.50 & 1.9 & 0.61 \\
\hline 2 & $4 a$ & 1000 & 0.5 & 0.57 & 59 & 57.0 & 5.93 & 2.65 & 2.2 & 0.71 \\
\hline 3 & $4 a$ & 500 & 0.5 & 0.70 & 58 & 57.0 & 3.30 & 1.92 & 1.7 & 0.73 \\
\hline 4 & $4 b$ & 300 & 0.5 & 0.27 & 45 & 54.5 & 2.60 & 1.28 & 2.0 & 0.71 \\
\hline 5 & $4 c$ & 300 & 0.5 & 0.35 & 58 & 55.0 & 2.48 & 1.23 & 2.0 & 0.69 \\
\hline 6 & $4 c$ & 300 & 0.5 & 0.35 & 50 & 48.0 & 2.30 & 1.29 & 1.8 & 0.61 \\
\hline
\end{tabular}

$\mathrm{P}_{\mathrm{r}}$ is the probability of racemic linkages between monomer units and is determined from the relative intensity in the tetrads obtained in the decoupled ${ }^{1} \mathrm{H}$ NMR by $\operatorname{Pr}=2 \mathrm{I} 1 /(\mathrm{I} 1+\mathrm{I} 2)$, with $\mathrm{I} 1=\delta 5.20-5.25 \mathrm{ppm}(\mathrm{mrm}, \mathrm{mrr} / \mathrm{rrm})$ and $\mathrm{I} 2=\delta 5.13-5.20 \mathrm{ppm}(\mathrm{rrm} / \mathrm{mrr}, \mathrm{rrr}, \mathrm{rmr})$. Experiments run in the melt at $180^{\circ} \mathrm{C}$. 
Although polymer conversions generally did not exceed $60 \%$ due to the increased viscosity of the reaction medium, the catalysts could achieve as much $85 \mathrm{kgmol}^{-1}$ in $30 \mathrm{~min}$ at $0.1 \%$ catalyst loadings. The most active catalyst reported to date are mononuclear zinc(II) complexes supported by a phenoxy ligand bearing single ethylenediamine tether reported by Hillmyer and Tolman. These catalysts achieve $96 \%$ conversion at catalyst loadings of $0.15 \%$ catalyst loadings and yields $130 \mathrm{~kg} \mathrm{~mol}^{-1}$ of PLA. ${ }^{200}$

The PLA's were characterized by ${ }^{1} \mathrm{H}$ and ${ }^{13} \mathrm{C}$ NMR spectroscopy, IR, GPC, as well as DSC measurements. The IR spectrum of the polymers shows the presence of $v(\mathrm{OH})$ stretching vibrations between 3650 and $3200 \mathrm{~cm}^{-1}$, which can be attributed to the presence of linear and not cyclic polymers. The ${ }^{1} \mathrm{H}$ NMR spectrum of PLA obtained using [300]: [1] of monomer to 4b is shown below and is consistent with an acid terminated chain end, which is also observed in the IR spectrum. The ${ }^{1} \mathrm{H}$ NMR spectrum of the precipitated PLA's also shows the isopropoxycarbonyl moiety as multiplets at $1.55 \mathrm{ppm}$ and a multiplet at $5.17 \mathrm{ppm}$ for the methine region as shown in Fig. 6.4.2. 1.

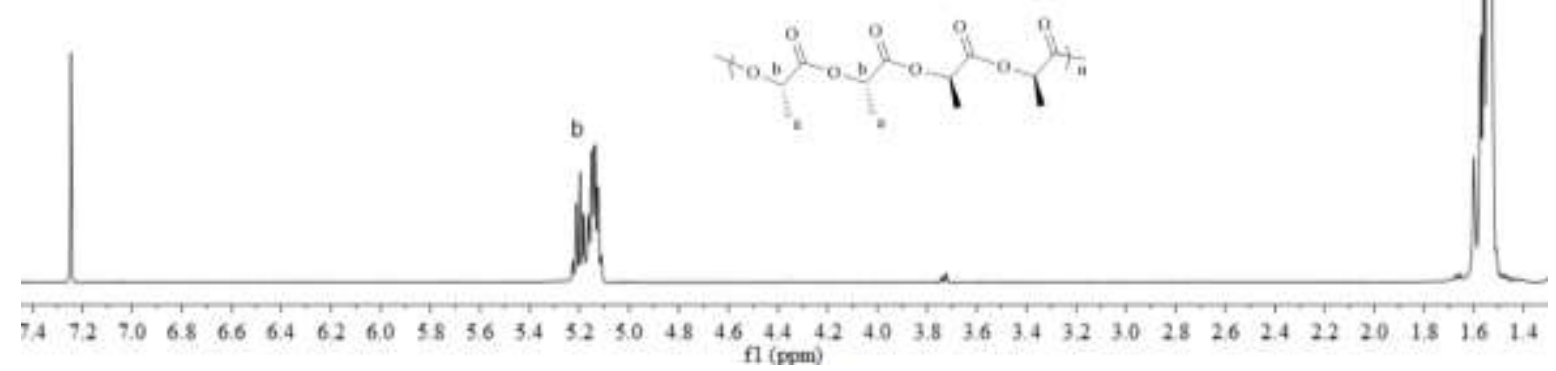

Fig. 6.4.2. 1: ${ }^{1} \mathrm{H}$ NMR spectrum of PLA obtained using $4 \mathrm{~b}$ measured in $\mathrm{CDCl}_{3}$ at room temperature

The microstructure of the prepared PLAs was determined by analyzing the homonuclear decoupled ${ }^{1} \mathrm{H}$ NMR spectrum of the methine region. The ${ }^{1} \mathrm{H}$ NMR spectrum reveals the formation of mostly heteroatactic microstructures. The homonuclear decoupled ${ }^{1} \mathrm{H}$ NMR spectrum of the methine region of PLA prepared with $4 \mathrm{c}$ is shown in Fig. 6.4.2. 2. 


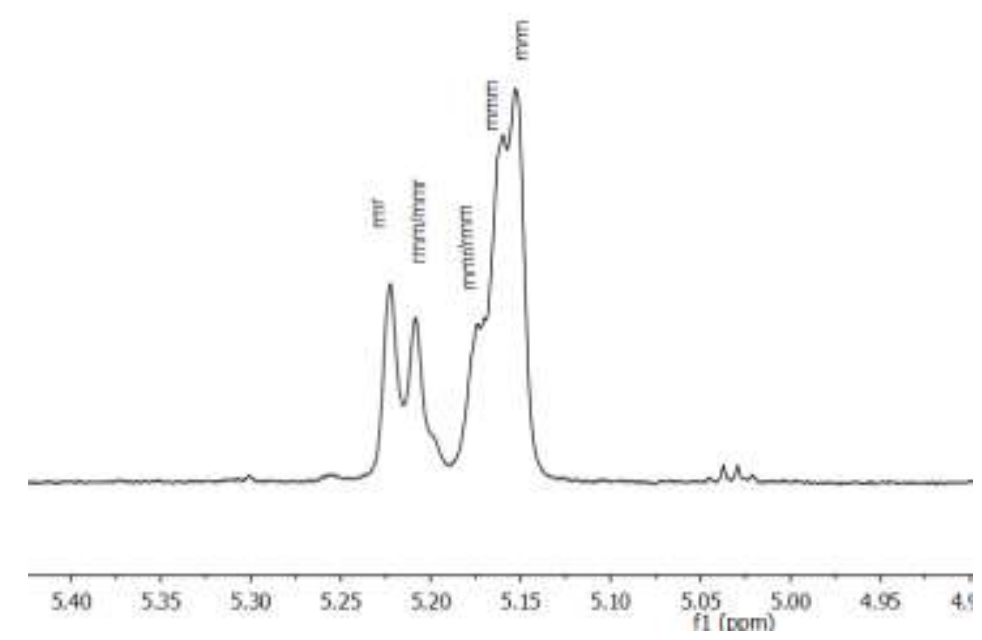

Fig. 6.4.2. 2: Homonuclear decoupled ${ }^{1} \mathrm{H}$ NMR spectrum of the methine region of heteroatactic PLA prepared with $4 \mathrm{c}$ measured in $\mathrm{CDCl}_{3}$ at room temperature.

The observed shifts at 5.22 and 5.14 can be assigned to heteroatactic $r m r$ and $m r m$ tetrads. ${ }^{279}$ The nature of ancillary ligand seems not to play any dominant role in the tacticity of the resulting PLA, with $\mathrm{P}_{\mathrm{r}}$ (probability of racemic enchainment) ${ }^{280,281}$ ranging between 0.61-0.73 for all complexes. That is $61-73 \%$ of the linkages are formed between lactides of opposite stereochemistry (heteroatactic junctions). The ${ }^{13} \mathrm{C}$ NMR spectrum shows the two enantiomer units of the lactide, the peak at $19.0 \mathrm{ppm}$ can be assigned to the methyl groups on the polymer chain whiles the peaks at 70.1 and 71.0 ppm can be assigned to the $\mathrm{CH}$ protons.

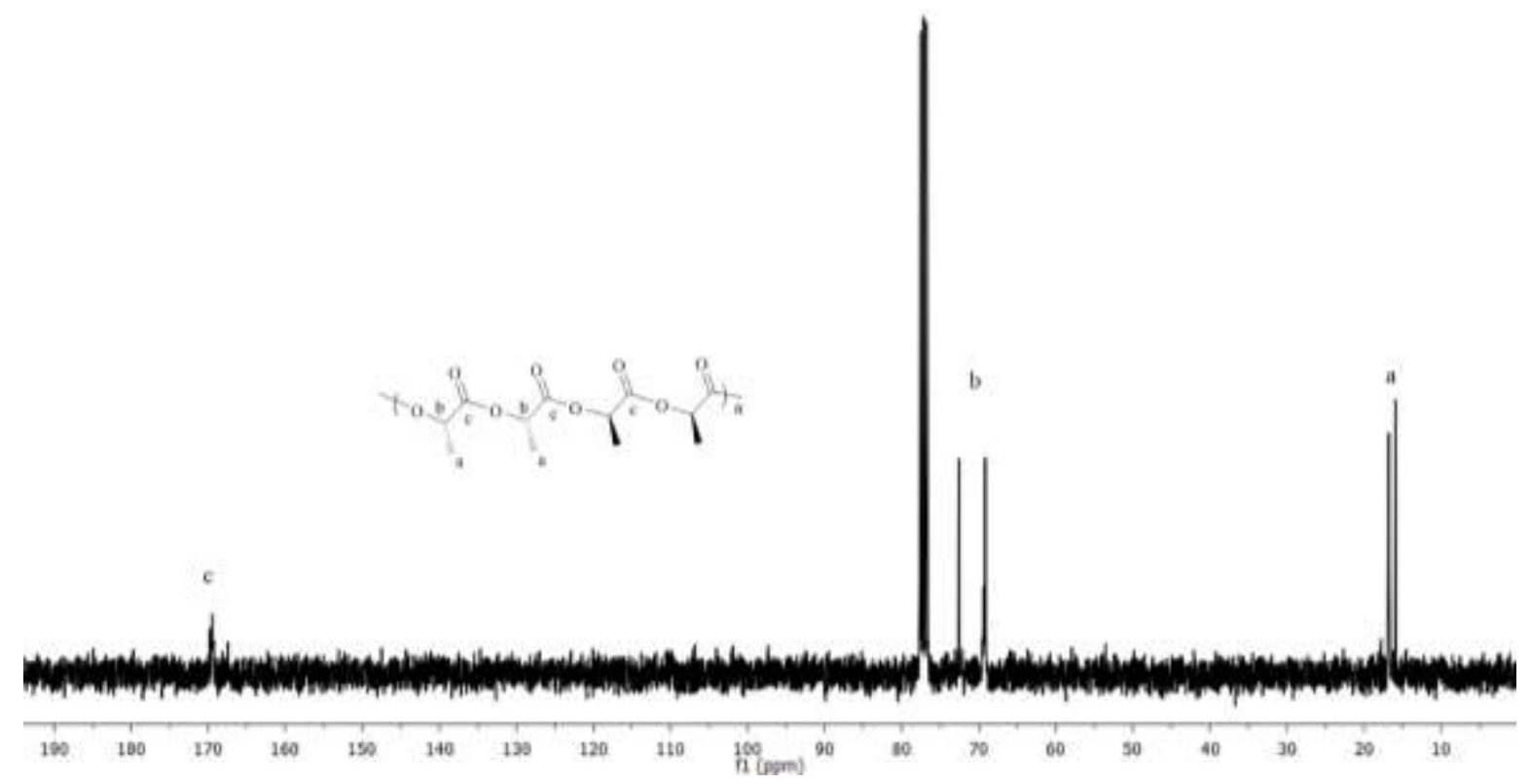

Fig. 6.4.2. 3: ${ }^{13} \mathrm{C}\left\{{ }^{1} \mathrm{H}\right\}$ NMR spectrum of PLA prepared with $4 \mathrm{c}$ measured in $\mathrm{CDCl}_{3}$ at room temperature 
The ${ }^{13} \mathrm{C}$ NMR spectrum signal for the carbonyl appears as a weak peak at $170 \mathrm{ppm}$. In addition, methoxy end groups were not observed in the ${ }^{13} \mathrm{C}$ NMR spectrum.

The molecular weight $\left(M_{n}\right)$ distributions of the polymers obtained are between 1200-1500 $\mathrm{g} / \mathrm{mol}$. (See Table 6.4.2. 1). The polymers from the zinc(II) complexes are generally of broad molecular weight distribution with polydispersities $\left(\mathrm{M}_{\mathrm{w}} / \mathrm{M}_{\mathrm{n}}\right)$ from 1.8-2.2, pointing to not well controlled reaction process, as observed in the GPC (Fig. 6.4.2. 4). The broadened molecular weights observed can be because of competing reactions such as intermolecular and intramolecular trans-esterification, as these competing reactions leads to the cleavage and reformation of the polymer chain. These competing side reactions are known to be significant at higher reaction temperatures. Further confirmation of the uncontrolled nature of this polymerization process comes from the disparities between the calculated and obtained average molecular weights.

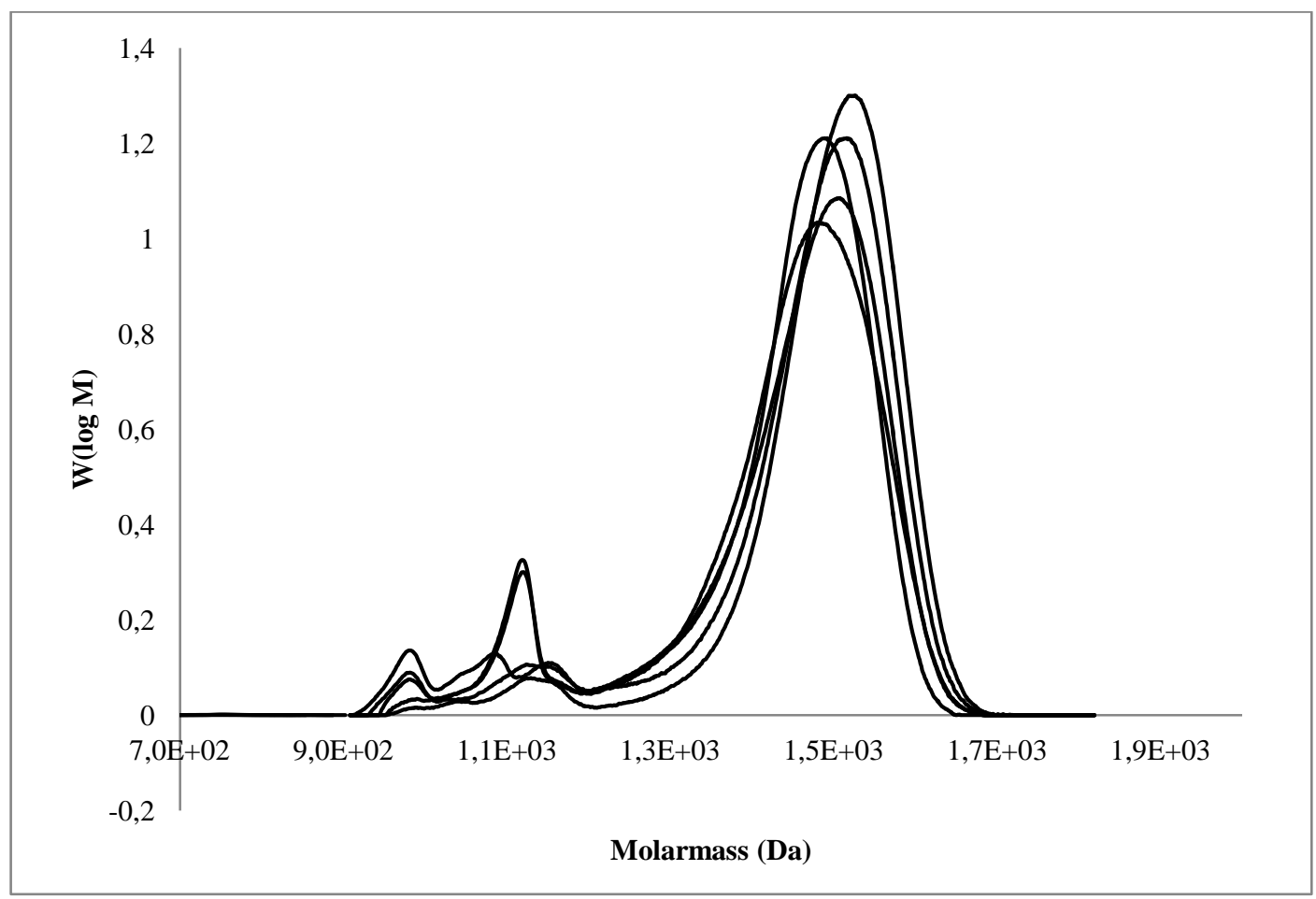

Fig. 6.4.2. 4: A GPC chromatograph of poly rac-lactides obtained using the zinc(II) catalysts 4a-4c

The GPC of the polymers shows in most cases bimodal molecular weight distributions with an average molecular weight of about $1530 \mathrm{~g} / \mathrm{mol}$. Regardless of the nature of the ligand used, all the molecular weight of the polymers obtained have similar molecular weight distributions. 


\section{Results and Discussions}

A careful look at the low-molecular-weight PLAs by MALDI-TOFMS shows the main distributions in the spectrum, indicating the existence of a single polymer chain with consecutive peaks separated by peak differences of $72 \mathrm{Da}$. In addition, a certain extension of undesirable intermolecular ester-exchange (trans esterification) reactions is detected since low intensity distributions are observed. The molecular weight of the polymer determined using MALDI-TOF technique, corroborates with GPC results, although it must be mentioned that this technique provides a direct access to the molecular weight rather than the average values that are compared with standard values (in the case of GPC). The MALDI-TOF spectrum is shown in Fig. 6.4.2. 5.

The nature of the lactide produced can be described as largely amorphous, as the melting temperatures of the lactide are between $48-65^{\circ} \mathrm{C}$. In the DSC measurement (Fig. 6.4.2. 6), the samples were first shock cooled in liquid nitrogen after heating for the first time in order to freeze any metastable states and then measured again.

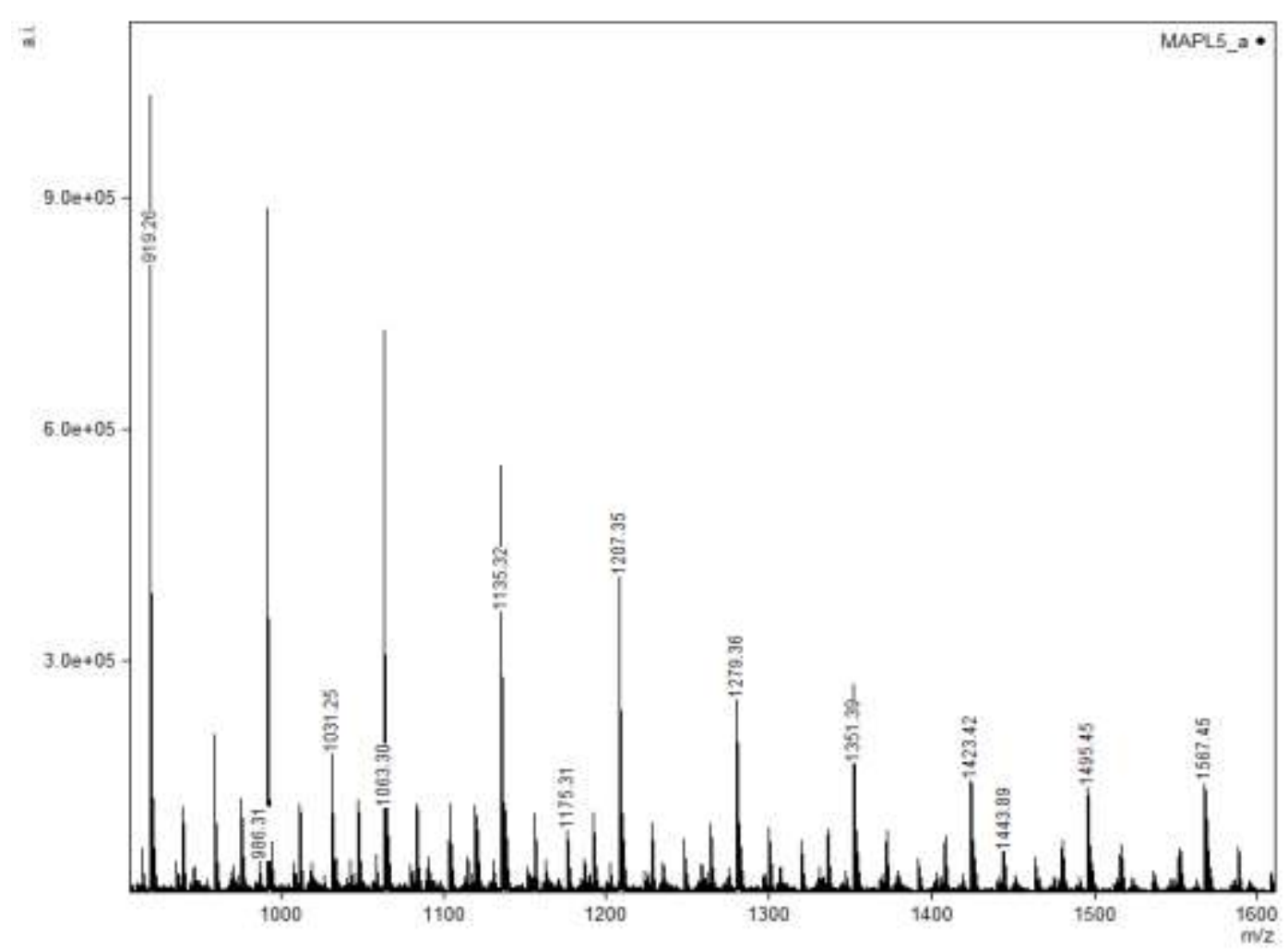

Fig. 6.4.2. 5: MALDI-TOF spectrum of rac-PLA prepared with 4c 


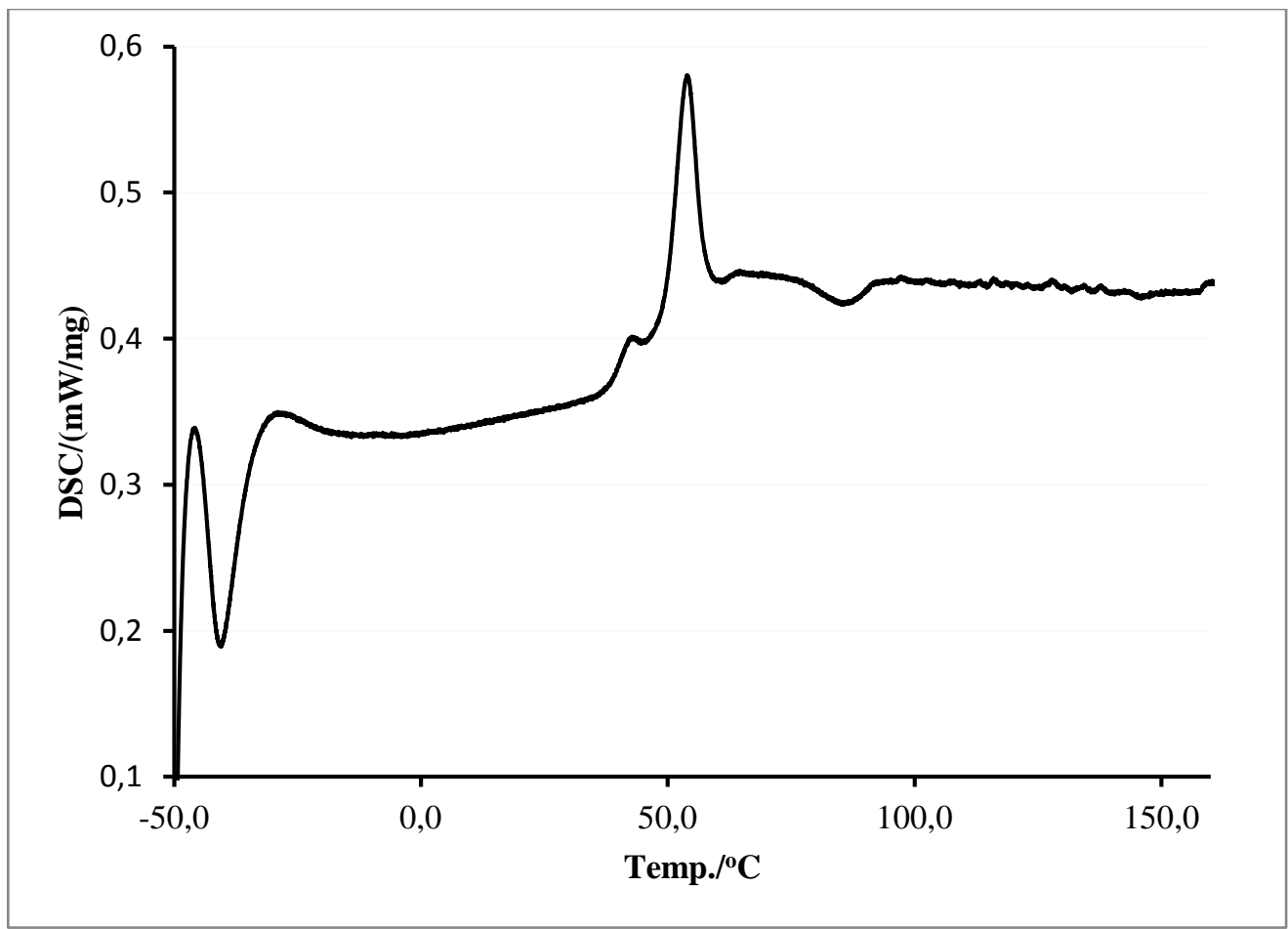

Fig. 6.4.2. 6: A DSC curve of heteroactactic PLA obtained using 4c

Because of the polymeric nature of the products, some of the melting curves, which are concave in shape, were characterized by the temperatures of their peak maxima. 


\section{5 Homobimetallic $\left[\mathrm{Rh}_{2}\left(\mathrm{O}_{2} \mathrm{CR}\right)_{4}\right]$ complexes of $\alpha$-diimine type ligands}

Complexes of the type $\left[\mathrm{M}_{2}\left(\mathrm{O}_{2} \mathrm{CR}\right)_{4}\right]$ (XLVIII) have generally been classified as the metalmetal multiply bonded paddlewheel compounds. They have proven usefulness in a number of catalytic applications and sometimes have very interesting electronic structures. ${ }^{282}$

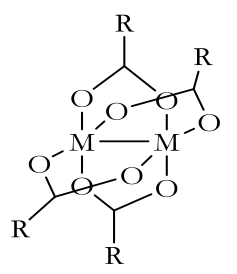

XLVIII

Notable among them is the isolation and characterization of dichromium compounds which sometimes feature quadruple and quintuple bonds in what is called "super short" metalmetal bonds ${ }^{283}$. Metals such as Mo, W, Re, Ru, Os and Rh are known to form paddle wheel complexes. Rh-Rh bonding interactions have been described by the ground state $\sigma^{2} \pi^{4} \delta^{2} \delta^{* 2} \pi^{* 4}$ for a net $\mathrm{Rh}-\mathrm{Rh}$ single bond. ${ }^{284}$ The first accurate $\mathrm{X}$-ray structure of the $\mathrm{Rh}$ paddle wheel complex has a Rh-Rh bond length of $2.39 \AA$. Rh paddle wheel complexes of the nature $\mathrm{Rh}_{2} \mathrm{~L}_{4}$ have interesting redox chemistry, and have the ability to undergo two redox steps involving reduction (a), oxidation (b) and a possible second one electron oxidation (c) (Scheme 6.5. 1). ${ }^{285}$

$$
\left[\mathrm{Rh}_{2} \mathrm{~L}_{4}\right]^{-} \stackrel{-\mathrm{e}^{-}}{\underset{+\mathrm{e}^{-}}{\rightleftharpoons}}\left[\mathrm{Rh}_{2} \mathrm{~L}_{4}\right] \stackrel{-\mathrm{e}^{-}}{\rightleftharpoons}\left[\mathrm{Rh}_{2} \mathrm{~L}_{4}\right]^{+} \stackrel{-\mathrm{e}^{-}}{\stackrel{\mathrm{e}^{-}}{\rightleftharpoons}}\left[\mathrm{Rh}_{2} \mathrm{~L}_{4}\right]^{2+}
$$

Scheme 6.5. 1: Redox steps of Rh-Rh paddle wheel complexes

The use of rhodiumdiacetate compounds as an important chemical transformation reagent in the generation of carbene diazocompounds has become very prominent. ${ }^{286,287,288,289}$ The past decades have seen efforts at changing the ligand environment around the $\mathrm{Rh}$ (II) core with the aim of influencing the chemical reactivity and selectivity of the products obtained. The treatment of $\mathrm{Rh}_{2}(\mathrm{OAc})_{4} \cdot 2 \mathrm{MeOH}$ with $\mathrm{HL}^{2}$ in methanol leads to the formation of a neutral metal-metal bonded paddlewheel complex which was characterized by ${ }^{1} \mathrm{H}$ and ${ }^{13} \mathrm{C}$ NMR spectroscopy as well as single crystal X-ray crystallography. 
Results and Discussions

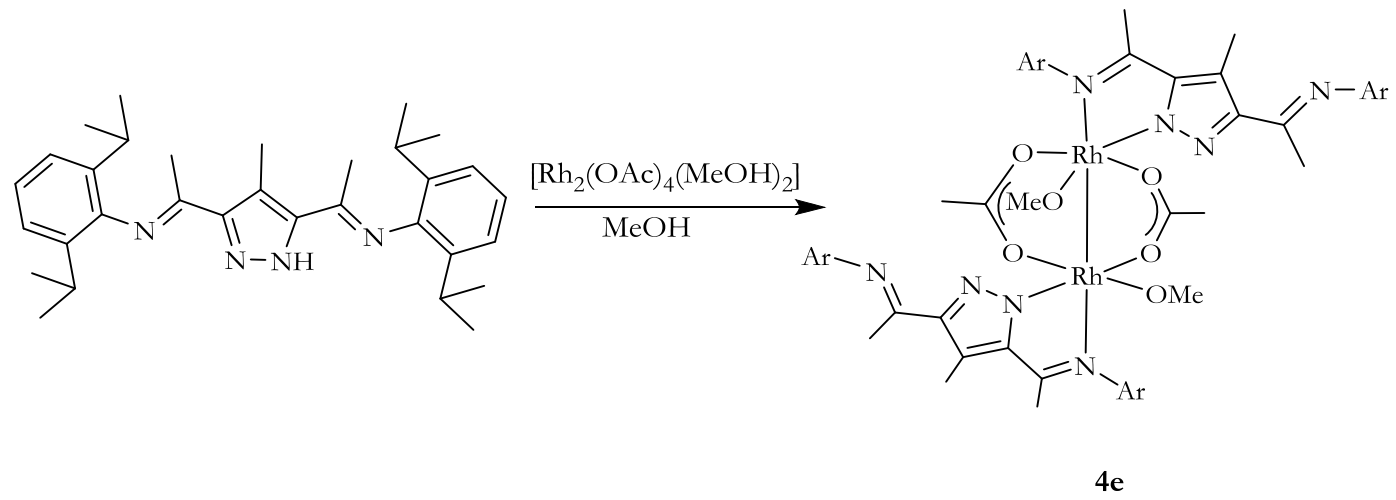

Scheme 6.5. 2: Preparation of rhodium-rhodium metal bridged complex 4e

The ${ }^{1} \mathrm{H}$ NMR spectrum of $4 \mathrm{e}$ shows two different $\mathrm{CH}_{3} \mathrm{C}=\mathrm{N}$ environments, thus pointing to an asymmetric ligand environment, also one group of aromatic protons appear shielded and moved further upfield to $7.0 \mathrm{ppm}$ and integrates for six protons whiles another set of six protons is further downfield at $7.24 \mathrm{ppm}$. Two different acetate environments are observed at 1.55 and $1.36 \mathrm{ppm}$ respectively, which correlates with ${ }^{13} \mathrm{C}$ NMR peaks at 191.6 and 186.1 ppm respectively. The ${ }^{1} \mathrm{H}$ NMR spectrum of $4 \mathrm{e}$ is shown in Fig. 6.5.1.

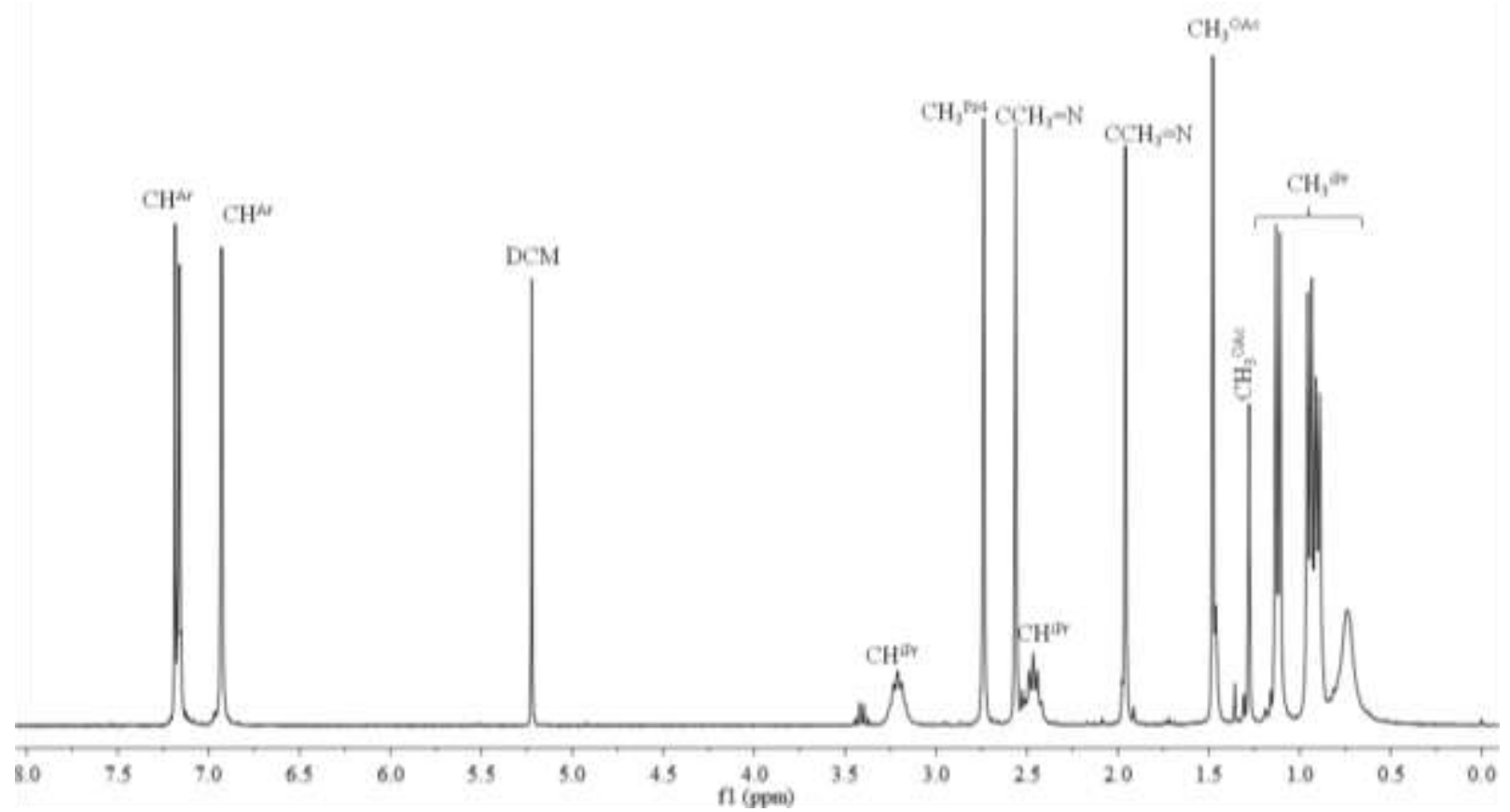

Fig. 6.5. 1: ${ }^{1} \mathrm{H}$ NMR spectrum of $4 \mathrm{e}$ measured in $\mathrm{CDCl}_{3}$ at room temperature 
Crystals of $4 \mathrm{e}$ were obtained by the slow evaporation of a methanolic solution of the complex. The compound crystallizes in the P 21/c space group. In the X-ray structure, one acetate bridge in $4 \mathrm{e}$ is replaced by two methanol molecules.

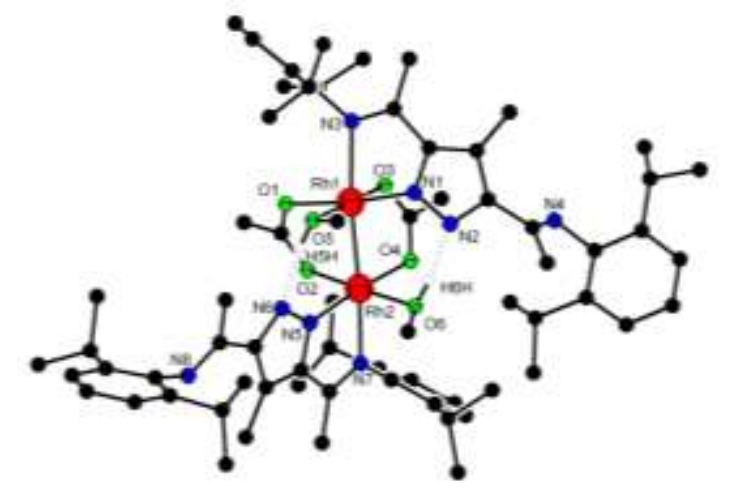

Fig. 6.5. 2: Molecular structure of $4 \mathrm{e}$, most $\mathrm{H}$ atoms, and counter ions omitted for clarity

The $\mathrm{Rh}-\mathrm{Rh}$ distance in this complex is $2.54 \AA$, a relative increase compared to $\mathrm{Rh}_{2}(\mathrm{OAc})_{4}$ due to the increased Lewis basicity of the ligand. The Rh-Rh bond distance of $2.54 \ddot{A}$ is longer than that of $\left[\mathrm{Rh}_{2}(\mathrm{OAc})_{2}\left(\mathrm{PPh}_{3}\right)_{2}\right]$ (2.4 $\left.\mathrm{A}\right)$. The dirhodium centre is coordinated by two of ligands with the imine nitrogen occupying the axial positions in the complex (Fig. 6.5. 2). The $\mathrm{Rh}$ atoms also lie in the middle of six coordinate geometry complex. Two intra-molecular N$\mathrm{H} \cdots \mathrm{O}$ hydrogen bonding interactions can be found in the molecule but are very weak due to the suboptimal $\mathrm{N}-\mathrm{H} \cdots \mathrm{O}$ bond angle of $119.5^{\circ}$. Selected lengths $[\AA]$ and bond angles $\left[{ }^{\circ}\right]$ are given in Table 6.5. 1.

Table 6.5. 1: Selected bond lengths $[\AA]$ and bond angles $\left[{ }^{\circ}\right]$ for $4 \mathrm{e}$

\begin{tabular}{llll}
\hline \multicolumn{3}{c}{ Bond lengths $[\AA]$} & \multicolumn{3}{c}{ Bond angles $\left[^{\circ}\right]$} \\
\hline $\mathrm{N}(1)-\mathrm{Rh}(1)$ & $1.978(2)$ & $\mathrm{N}(1)-\operatorname{Rh}(1)-\operatorname{Rh}(2)$ & $173.20(5)$ \\
$\mathrm{N}(3)-\mathrm{Rh}(1)$ & $2.344(2)$ & $\mathrm{N}(5)-\mathrm{Rh}(2)-\mathrm{O}(2)$ & $89.75(8)$ \\
$\mathrm{N}(5)-\mathrm{Rh}(2)$ & $1.986(2)$ & $\mathrm{N}(5)-\mathrm{Rh}(2)-\mathrm{O}(6)$ & $93.65(8)$ \\
$\mathrm{N}(7)-\mathrm{Rh}(2)$ & $2.244(2)$ & $\mathrm{N}(7)-\mathrm{Rh}(2)-\mathrm{Rh}(1)$ & $174.61(6)$ \\
$\mathrm{N}(2)-\mathrm{H}(6) \cdots \mathrm{O}(6)$ & $2.975(36)$ & $\mathrm{N}(2)-\mathrm{H}(6) \cdots \mathrm{O}(6)$ & $119.52(3)$ \\
\hline
\end{tabular}




\section{Trimethylsilyl cyclopentadienyl/indenyl/fluorenyl pyrazolyl tethered derivative ligands as precursors for the synthesis of group 4 metal complexes}

Different potential roles have been assigned to having side arms tethered to cyclopentadiene (Cp) ligands, roles such as acting as a hemi labile ligand, coordinating to a second metal site or providing improved solubility. ${ }^{290}$ Catalysts bearing $\mathrm{Cp}$ ligands with pendant amino or amido side chains have been used in olefin polymerization. ${ }^{291,292,293,294}$ Meyer et. al. ${ }^{141,145}$ have reported on tethered pyrazole derivatives on the 3,5-positions of the pyrazole which bear cyclopentadienyl $\left(\mathbf{H}_{3} \mathbf{L}^{\mathrm{A}}\right.$ - not isolated), indenyl $\left(\mathbf{H}_{3} \mathbf{L}^{\mathbf{B}}\right)$ and fluorenyl $\left(\mathbf{H}_{3} \mathbf{L}^{\mathbf{C}}\right)$ side arms in a symmetric ligand environment.

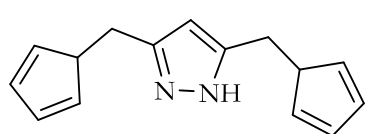

$\mathrm{H}_{3} \mathrm{~L}^{\mathrm{A}}$

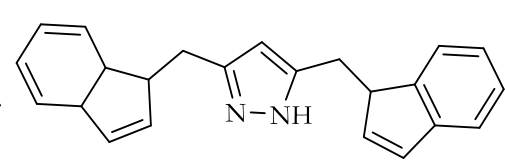

$\mathbf{H}_{3} \mathbf{L}^{B}$

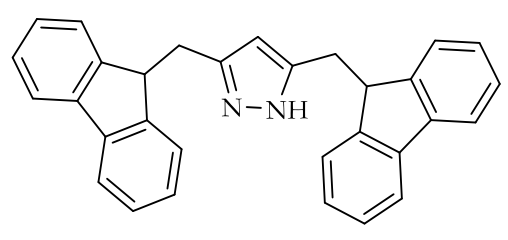

$\mathrm{H}_{3} \mathrm{~L}^{\mathrm{C}}$

Scheme 7. 1: Previously studied symmetric 3,5-substituted pyrazole bridged proligands

This section is a further study on this ligand system, with the aim of preparing ligands, which combine cyclopentadienyl, indenyl, and fluorenyl pyrazole derivatives in an asymmetric ligand environment $\left(\mathbf{H}_{3} \mathbf{L}^{5}\right.$ and $\left.\mathbf{H}_{3} \mathbf{L}^{6}\right)$.

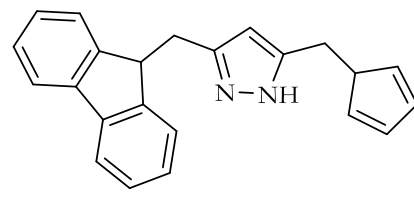

$\mathbf{H}_{3} \mathbf{L}^{5}$

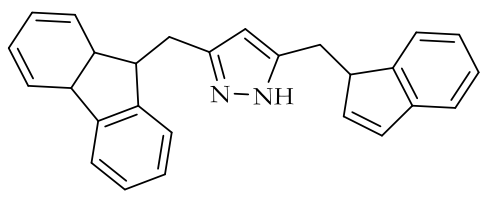

$\mathbf{H}_{\mathbf{3}} \mathbf{L}^{6}$

Scheme 7. 2: New asymmetric ligands investigated

Attempts would be made at preparing trimethylsilyl (TMS) derivatives of these new classes of ligands, as ligand precursors to the preparation of group 4 metal complexes for olefin polymerization. 


\section{1 Ligand synthesis}

Following already established synthetic procedures, it was possible to first prepare the single substituted sidearm product $(\mathbf{C})$, followed by a second substitution (D) from the bis(chloromethyl)pyrazole hydrochloride salt (A) prepared by Bosnich et. al. ${ }^{143}$ using the scheme below.

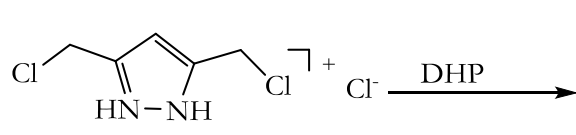

A<smiles>ClCc1cc(CCl)n([TlH])n1</smiles>

B

L $: X$ fluorenyl, $\mathrm{Y}=$ cyclopentadienyl

$\mathbf{H}_{3} \mathbf{L}^{6}: \mathrm{X}=$ fluorenyl, $\mathrm{Y}=$ indenyl

$\mathbf{H}_{3} \mathbf{L}^{\mathbf{B}}: \mathrm{X}=$ indenyl, $\quad \mathrm{Y}=$ indenyl

$\mathbf{H}_{3} \mathbf{L}^{\mathrm{C}}: \mathrm{X}=$ fluorenyl, $\mathrm{Y}=$ fluorenyl
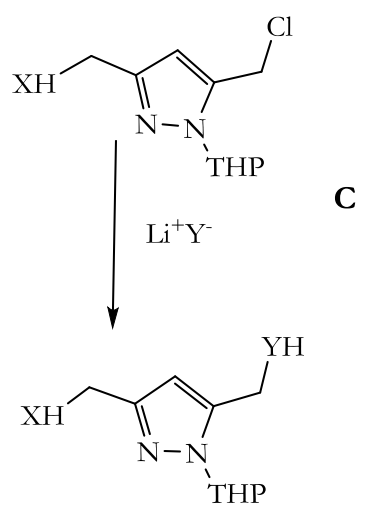

D

Scheme 7.1. 1: Synthetic scheme for the formation of heteroleptic tethered pyrazole ligands

The ${ }^{1} \mathrm{H}$ NMR spectrum of a singly substituted fluorenyl side arm $\mathbf{C}$ without THP is shown in Fig. 7.1. 1: The methylene protons $\mathrm{H}^{\mathrm{a}}$ are observed as a singlet at $4.50 \mathrm{ppm}$, whiles $\mathrm{H}^{\mathrm{c}}$ is a doublet at 3.29 ppm due coupling with $\mathrm{H}^{\mathrm{d}}$. The methine proton $\mathrm{H}^{\mathrm{d}}$ is observed as a triplet at 4.22 ppm due to coupling with $\mathrm{H}^{\mathrm{c}}$.

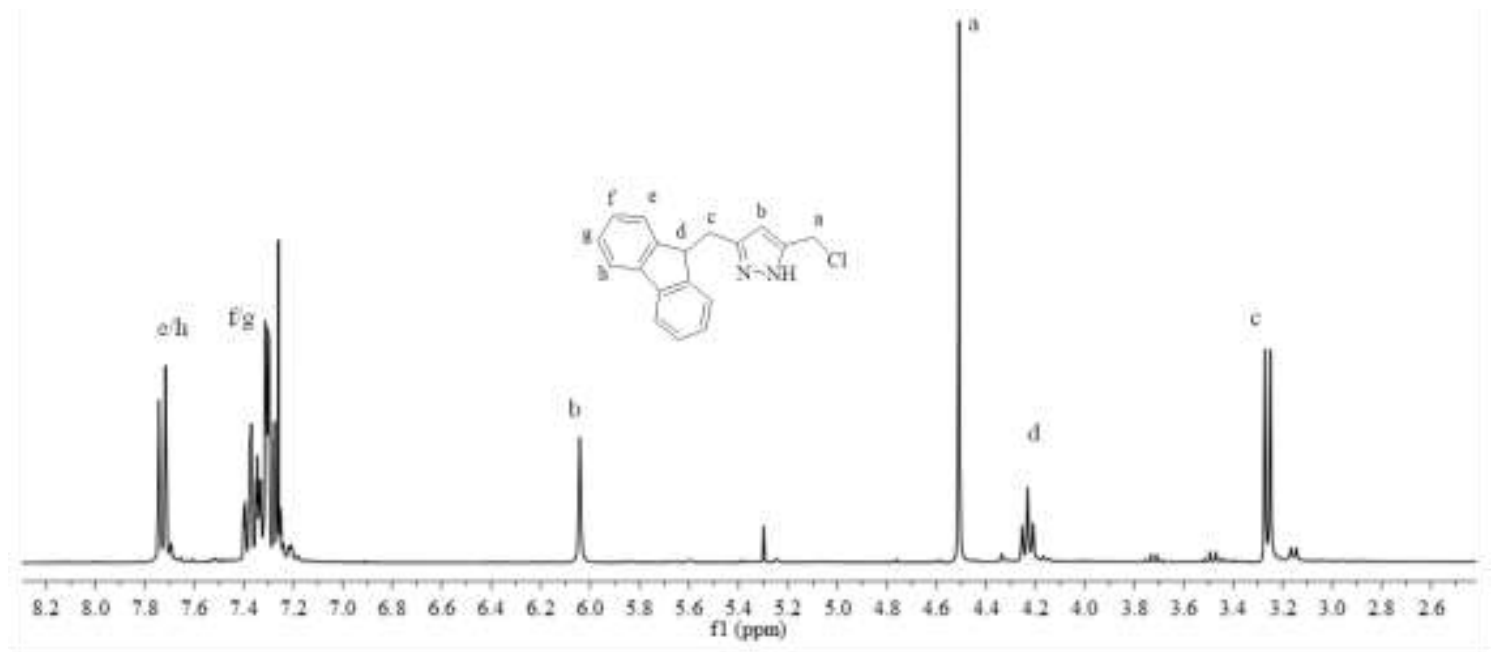

Fig. 7.1. 1: ${ }^{1} \mathrm{H}$ NMR spectrum of a single fluorenyl substituted sidearm (C) with THP removed measured in $\mathrm{CDCl}_{3}$ at room temperature 
After the substitution of both 3,5-sidearms, the THP protection was easily removed by treating $\mathbf{D}$ with an ethanolic $\mathrm{HCl}$ solution, to furnish the product $\mathbf{E}$ in $81-89 \%$ yield. The required ligands were obtained in moderate to good yields after recrystallization from a $\mathrm{CH}_{2} \mathrm{Cl}_{2} /$ hexane.

\subsection{Synthesis of trimethylsilyl derivatives}

The TMS-derivatives were obtained in moderate yields (33-42\%) using the reaction Scheme 7.1.1. 1 .

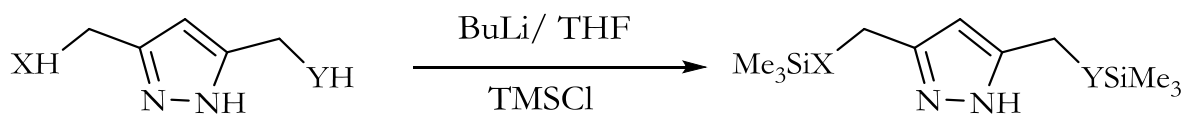
$\mathbf{H}_{3} \mathbf{L}^{5}: \mathrm{X}=$ fluorenyl, $\mathrm{Y}=$ cyclopentadienyl
HL': $\mathrm{X}=$ fluorenyl, $\mathrm{Y}=$ indenyl
$\mathbf{H}_{3} \mathbf{L}^{6}: \mathrm{X}=$ fluorenyl, $\mathrm{Y}=$ indenyl
$\mathbf{H L}^{10}$ : $\mathrm{X}=$ fluorenyl, $\mathrm{Y}=$ fluorenyl
$\mathbf{H}_{3} \mathbf{L}^{\mathbf{B}}: \mathrm{X}=$ indenyl, $\quad \mathrm{Y}=$ indenyl
$\mathbf{H L}^{11}: \mathrm{X}=$ indenyl,$\quad \mathrm{Y}=$ indenyl
$\mathbf{H}_{3} \mathbf{L}^{\mathrm{C}}: \mathrm{X}=$ fluorenyl, $\quad \mathrm{Y}=$ fluorenyl

Scheme 7.1.1. 1: Synthetic scheme for the formation of TMS derivatives

In a typical reaction procedure, $\mathbf{H}_{3} \mathbf{L}^{\mathbf{x}}$ is treated with 4 mol equivalent $n-\mathrm{BuLi}$ at $-78^{\circ} \mathrm{C}$, stirred for $14 \mathrm{~h}$, and warmed up to room temperature. The lithium salt solution is then treated with 3.0 mol equivalent TMSCl. The product was isolated as solids after appropriate workup. The proligands were obtained as air and moisture stable powders.

The ${ }^{1} \mathrm{H}$ NMR spectral analysis of the proligands $\mathbf{H L}^{9}-\mathbf{H L}^{11}$ show the formation of a mixture of double and triple TMS substitutions. For instance, The ${ }^{1} \mathrm{H}$ NMR of $\mathbf{L}^{9}$ shows three sets of signals for the TMS group at $-0.30,-0.16,-0.12 \mathrm{ppm}$ respectively. This corroborates with ESI-MS, which shows $m / z$ values at $590(65 \%)$ for $\left[\mathrm{L}^{6}\left(\mathrm{SiMe}_{3}\right)_{3}\right]^{+}$and $519(100 \%)$ for $\left[\mathrm{L}^{6}\left(\mathrm{SiMe}_{3}\right)_{2}\right]^{+}$fragments respectively. On the other hand, $\mathbf{H L}^{11}$ shows a singlet for the $\mathrm{SiMe}_{3}$ group at $-0.08 \mathrm{ppm}$ in the ${ }^{1} \mathrm{H}$ NMR spectrum and $m / z$ value at $468(100 \%)$ which can be assigned to $\left[\mathrm{L}^{\mathrm{c}}\left(\mathrm{SiMe}_{3}\right)_{2}\right]^{+}$in ESI-MS.

The ${ }^{1} \mathrm{H}$ NMR spectrum of the proligands shows the $\mathrm{CH}_{2}$ linkers as broadened signals at room temperature, pointing to a possible fluxional process involving different orientations 


\section{Results and Discussions}

(' $E$ ' and ' $Z$ ') of the aromatic groups with respect to the pyrazole plane. Variable temperature NMR analysis of these compounds shows the folded ("Z") conformations does not freeze out at lower temperatures. The ${ }^{13} \mathrm{C}$ NMR assignment of a selected ligand $\mathbf{L}^{10}$ is shown in Fig. 7.1.1.1.

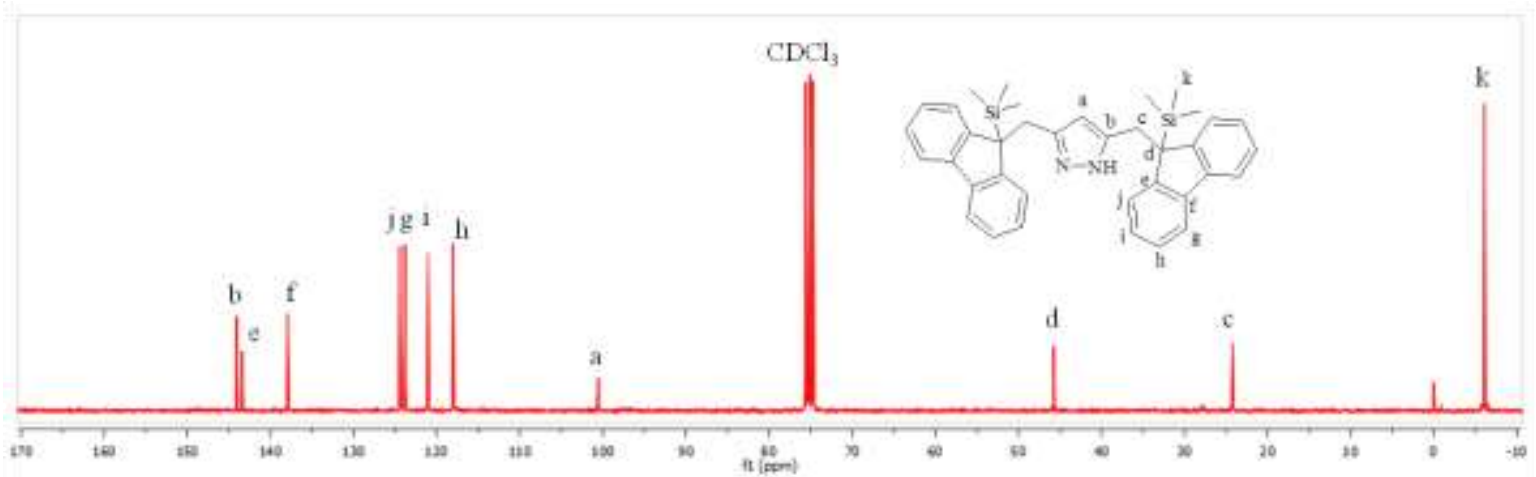

Fig. 7.1.1. 1: ${ }^{13} \mathrm{C}$ NMR spectrum of $\mathrm{HL}^{10}$ measured in $\mathrm{CDCl}_{3}$ at room temperature

\subsection{Complex synthesis}

Treating $\mathbf{H L}^{10}$ with $\mathrm{CrCl}_{3} \cdot 3 \mathrm{THF}$ under inert conditions results in the isolation of air stable colourless crystals, whiles the majority of the product remained green oil. The single crystal $\mathrm{X}$-ray structure of the crystals shows a hydrochloride salt of the nature $\left[\mathrm{H}_{2} \mathrm{~L}^{10}\right] \mathrm{Cl}$. The molecular structure (Fig. 7.1.2. 1) and selected bond lengths $[\AA]$ and angles $\left[{ }^{\circ}\right]$ are given in Table 7.1.2. 1. The molecule crystallizes in the $P-1(2)$ space group and has two molecules linked by hydrogen bonding in the unit cell.
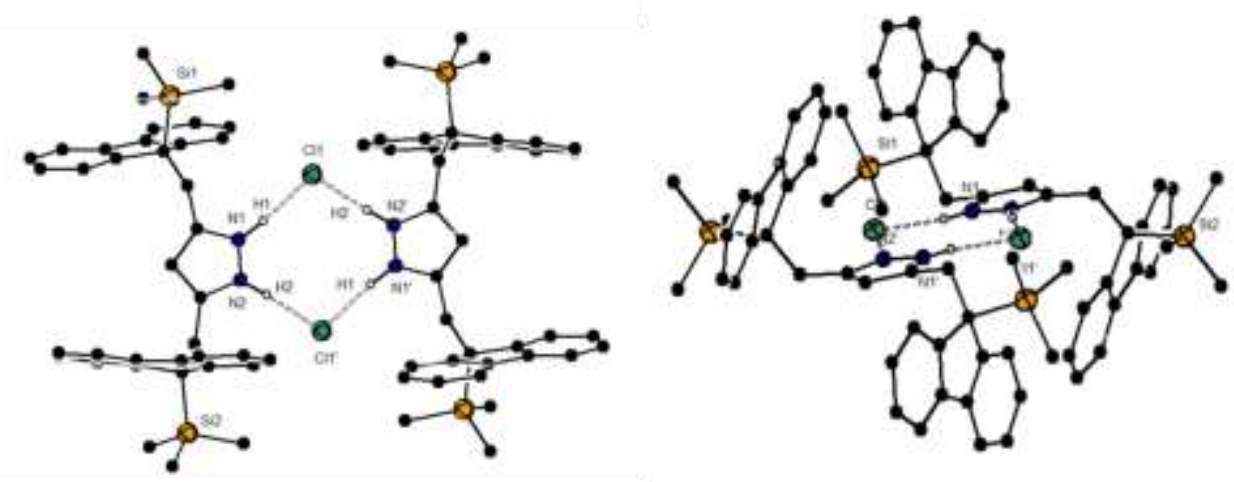

Fig. 7.1.2. 1: Molecular structure of $\left[\mathrm{H}_{2} \mathrm{~L}^{10}\right] \mathrm{Cl}$ showing different orientations, most $\mathrm{H}$ atoms omitted for clarity 


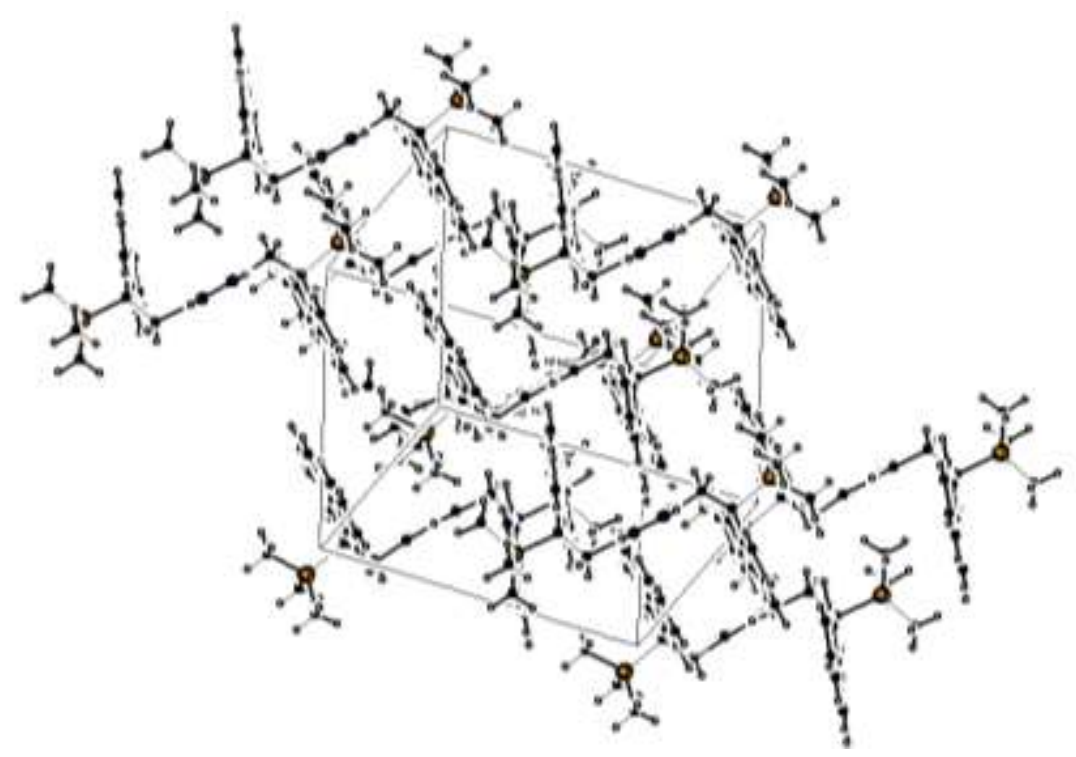

Fig. 7.1.2. 2: Molecular packing structure for $\mathrm{HL}^{10}$

The inter planar angle defined by the five atoms each which make up the two pyrazole rings is $0.00^{\circ}$. Thus, both pyrazole rings lie in the same plane. Two inter molecular $\mathrm{N}-\mathrm{H} \cdot \mathrm{Cl}$ bonding interactions can be found within the molecule. The hydrogen bonds are strong with $\mathrm{N}-\mathrm{H}{ }^{\cdots} \mathrm{Cl}$ angles between $172.5-172.7^{\circ}$. In the crystal structure, some degree of $\pi$-stacking is observed, as shown in Fig. 7.1.2. 2.

The molecule adopts an extended " $Z$ " conformation as a means of keeping the bulky $\mathrm{SiMe}_{3}$ groups away from each other for steric reasons, as opposed to the folded conformation " $E$ ".

Table 7.1.2. 1: Selected bond lengths $[\AA]$ and bond angles $\left[{ }^{\circ}\right]$ for $\left[\mathrm{H}_{2} \mathrm{~L}^{10}\right] \mathrm{Cl}$

\begin{tabular}{llll}
\hline \multicolumn{2}{c}{ Bond lengths $[\AA \AA]$} & & \multicolumn{2}{c}{ Bond Angles [ $\left.{ }^{\circ}\right]$} \\
\hline $\mathrm{Si}(1)-\mathrm{C}(20)$ & $1.859(3)$ & $\mathrm{C}(20)-\mathrm{Si}(1)-\mathrm{C}(18)$ & $108.74(14)$ \\
$\mathrm{N}(1)-\mathrm{H}(1) \cdots \mathrm{Cl} 1$ & $3.042(18)$ & $\mathrm{N}(1)-\mathrm{H}(1) \cdots \mathrm{Cl} 1$ & $172.56(32)$ \\
$\mathrm{N}(2)-\mathrm{H}(2) \cdots \mathrm{Cl1}{ }^{\prime}$ & $3.040(21)$ & $\mathrm{N}(2)-\mathrm{H}(2) \cdots \mathrm{Cl1}$ & $172.751(36)$ \\
\hline
\end{tabular}

Further reactions of the TMS derivatives with group 4 transition metals ( $\mathrm{Ti}, \mathrm{Zr}$ ) were not successful after several attempts. The ${ }^{1} \mathrm{H}$ NMR spectra of the products isolated showed an intact TMS group. 
Results and Discussions

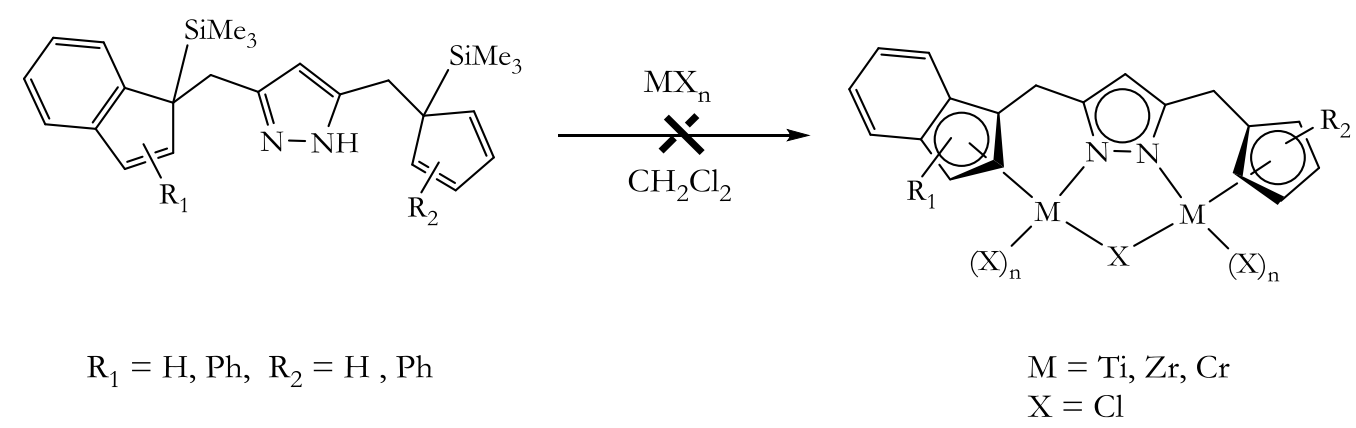

Scheme 7.1.2. 1: Attempted preparation of transition metal complexes with TMS precursors

Attention was therefore focused on the ability of the TMS derivative $\left[\mathbf{H}_{2} \mathbf{L}^{10}\right] \mathrm{Cl}$ to bind to silver cations, inspired by the work done on the conformationally adaptable ligand, 1,4-bis(9methyl-9H,fluoren-9-yl)methyl]benzene reported by Chebny et. al. ${ }^{295}$ The conformationally adaptable receptor undergoes a simple $\mathrm{C}-\mathrm{C}$ rotation in the presence of silver cations to give a $\pi$-prismand like receptor with a remarkable efficiency ( $K$ ca 15000). This ligand readily undergoes C-C bond rotation from the extended (“' $Z$ ") conformer to an isoenergetic (folded) conformer in the presence of $\mathrm{Ag}^{+}$, because of a cavity formed by the three aromatic walls in the " $\Delta$ " conformation (Scheme 7.1.2. 2).

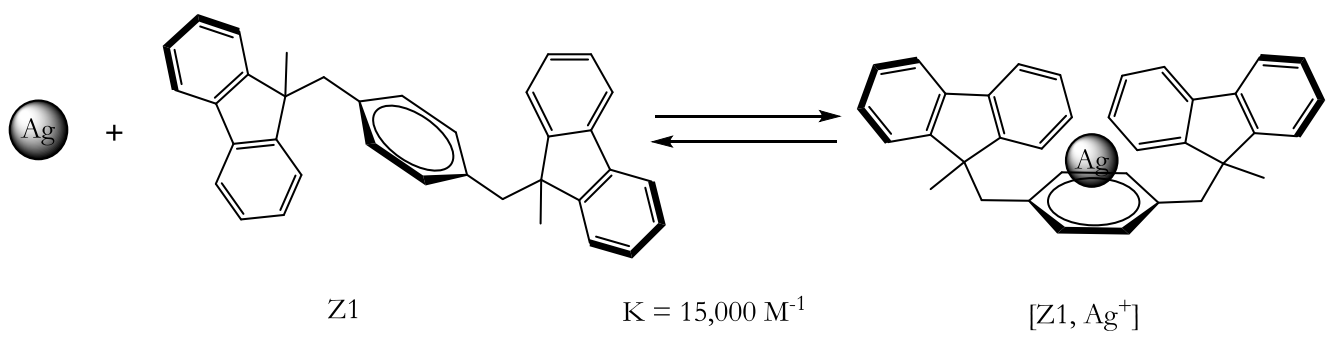

Scheme 7.1.2. 2: Binding of a single $\mathrm{Ag}^{+}$by the conformationally adaptable receptor $\mathrm{Z1}^{295}$

The reaction was monitored by ${ }^{1} \mathrm{H}$ NMR spectroscopy, by observing changes in the ${ }^{1} \mathrm{H}$ NMR spectrum upon the incremental addition of a solution of $\mathrm{Ag}(\mathrm{OTf})(14.1 \mathrm{mM})$ in a 1:1 chloroform-d/methanol- $\mathrm{d}_{4} .66 \mathrm{mM}$ of $\left[\mathrm{H}_{2} \mathrm{~L}^{10}\right] \mathrm{Cl}$. 


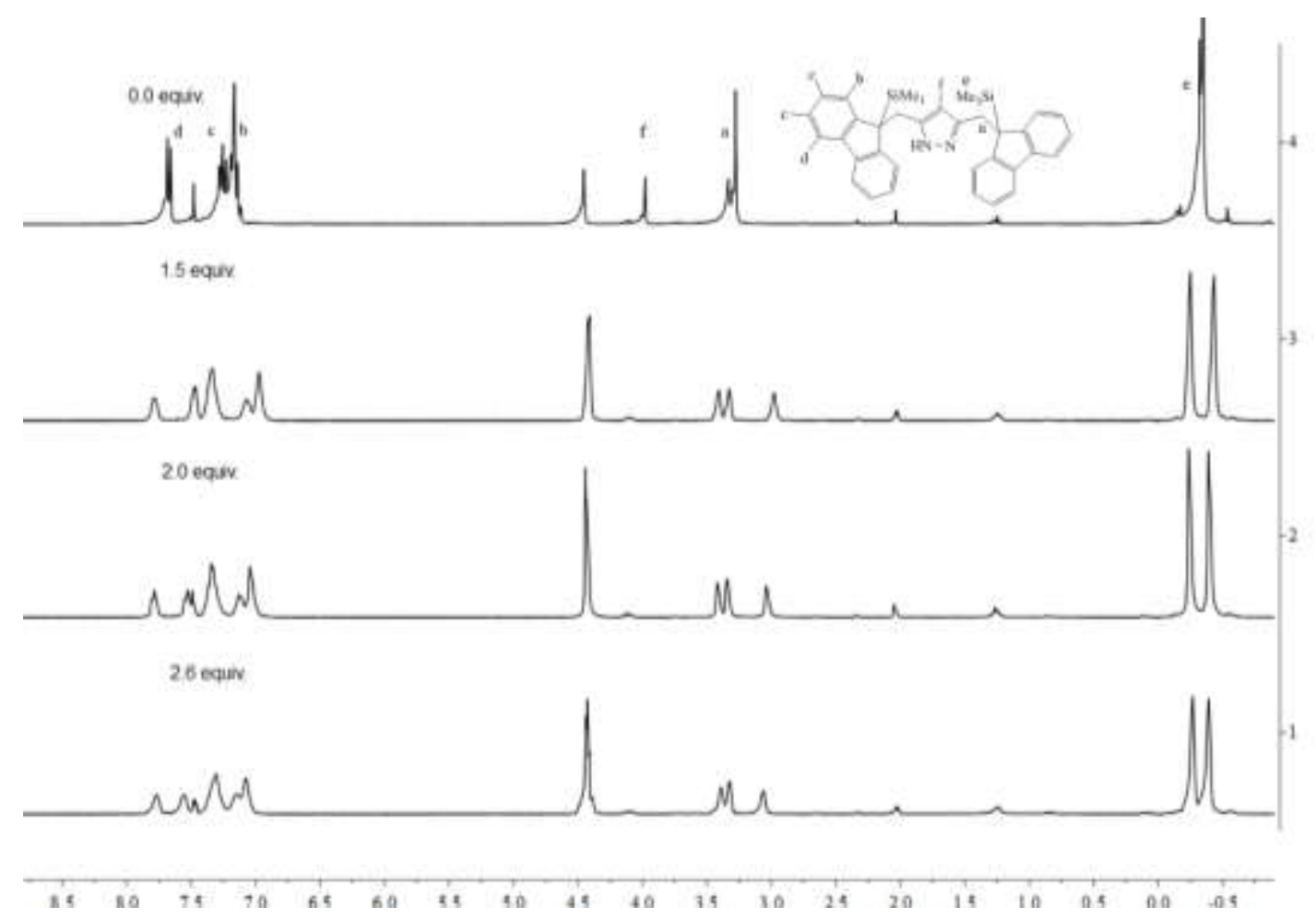

Fig. 7.1.2. 3: ${ }^{1} \mathrm{H}$ NMR spectra showing changes in the aromatic protons, with incremental addition of AgOTf to $\left[\mathrm{H}_{2} \mathrm{~L}^{10}\right] \mathrm{Cl}$ measured in $\mathrm{CDCl}_{3}$ at room temperature

Shifts in the ${ }^{1} \mathrm{H}$ NMR spectrum are observed with the addition of AgOTf solution. Notable changes in the spectrum include the upfield shift of the $\mathrm{CH}^{\mathrm{Pz} 4}$ and changes intensity and multiplicity of the aromatic protons (Fig. 7.1.2. 3). After the addition of 10 Eq. of AgOTf, the $\mathrm{SiMe}_{3}$ signal coalesce into a singlet, after which no further changes in the ${ }^{1} \mathrm{H}$ NMR spectrum is observed. From the ${ }^{1} \mathrm{H}$ NMR spectroscopic observations, titration with $\mathrm{Ag}^{+}$, causes $\left[\mathrm{H}_{2} \mathrm{~L}^{10}\right] \mathrm{Cl}$ possibly to undergoes folding into other structures in the presence of $\mathrm{Ag}^{+}$possibly as shown in XLIX. No further analysis were carried out since it was not part of the initially spelt out objectives.

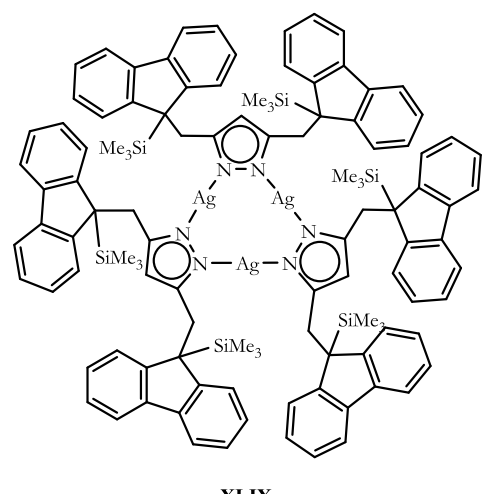

XLIX 


\section{$8 \mathrm{NHC}$ and cyclopentadienyl/indenyl/fluorenyl pyrazolyl tethered derivative ligands}

The first stable isolation of imidazole-2-ylidene by Arduengo et. al. ${ }^{296,297}$ has since broadened the chemistry of N-heterocyclic carbenes (NHCs) as very good $\sigma$-donors. They have been generally touted as more stable alternatives to tertiary phosphine ligands in relation to their stability and coordination behaviour. ${ }^{298}$ They generally form more stable complexes due to their strong $\sigma$-donating abilities, and are reported to be less susceptible to reductive elimination and degradative cleavage in catalytic reactions. ${ }^{299}$

$\mathrm{N}$-heterocyclic carbenes as Lewis base 2-electron donors have been applied extensively in coordination chemistry to a range of metals. Apart from their role as good ligands in metalbased catalytic reactions, their coordination chemistry has not only been limited to transition metals but with a range of other metals and periodic elements in the s block and $\mathrm{p}$ block (XLIX-LI). ${ }^{300,301302303,304}$
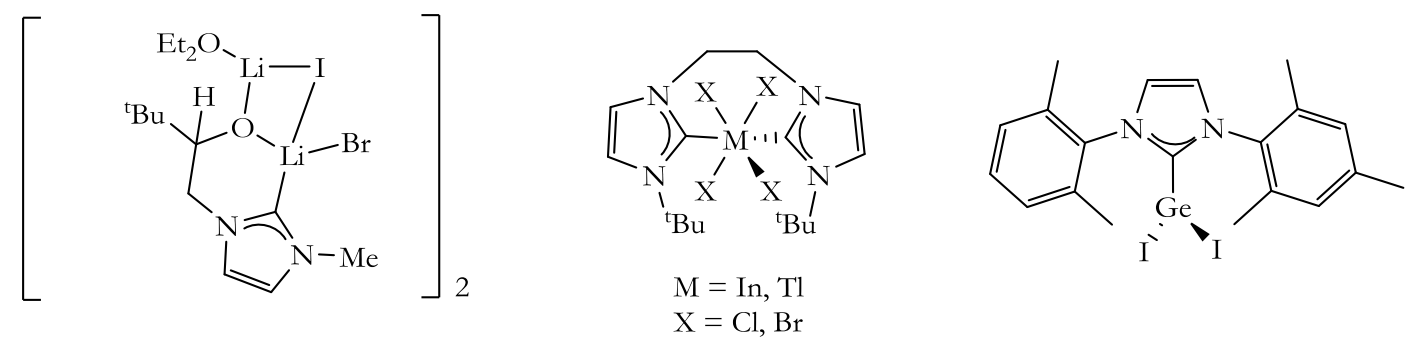

XLIX

$\mathbf{L}$

LI

They are also able to form different interactions ranging from ionic to covalent, and in the past few years' research have shown the ability of NHC ligands to react and stabilize elements across the periodic table. Meyer et. al. ${ }^{150}$ have reported on $\operatorname{Ag}_{4}(\mathrm{I})$ complexes of pyrazolate-bridged compartmental NHC ligands which provide two binding pockets and gives rise to unique multinuclear $\mathrm{Ag}(\mathrm{I})-\mathrm{NHC}$ complexes.

Combining polydentate anionic ligands with NHC's gives ligands with improved stability and the ability to stabilize metals in high oxidation states. Although attempts have been made at combining NHC's with other polydentate ligands with anionic functional groups, very few of have been reported to date. . $^{305,306,307,308,309}$

Danopoulos and co-workers have combined NHC carbenes with pendant indenyl (LII) and fluorenyl groups (LIII). ${ }^{310}$ In addition, rhodium(I) and iridium(I) complexes of this ligand 
system in catalytic studies are weakly active for the hydroformylation of 1-octene with poor selectivity. ${ }^{311}$
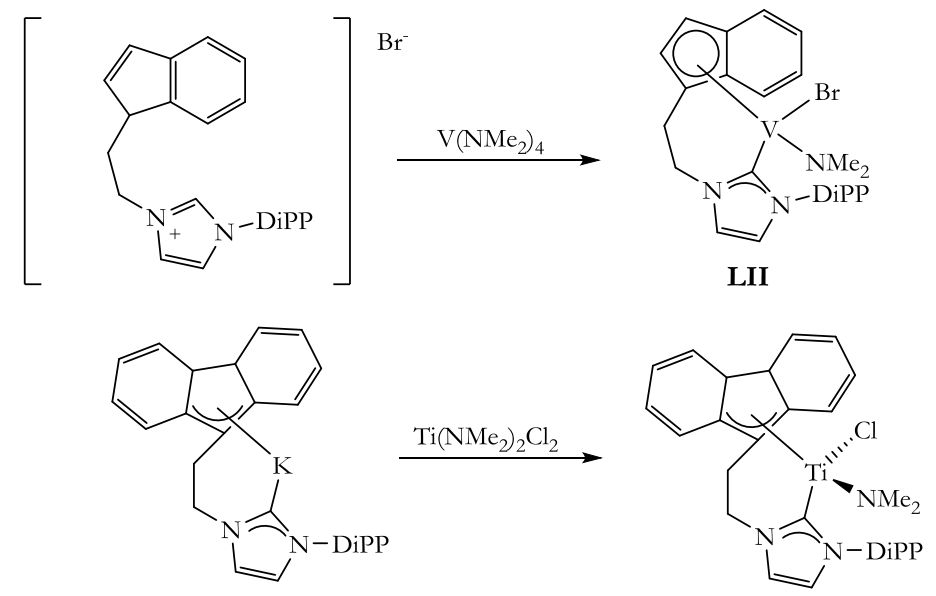

LIII

Scheme 8. 1: N-heterocyclic carbenes with pendant indenyl and fluorenyl groups. ${ }^{310}$

Yao et. al. ${ }^{305}$ have also reported on fluorenyl-NHC ligated rare earth (Ln) metal precursors which under mild conditions $\left(40^{\circ} \mathrm{C}\right.$ and normal ethylene pressure) with activation is highly active in the copolymerization of ethylene and 1-hexene (4120 $\left.\mathrm{kg} \mathrm{mol}_{\mathrm{sc}}{ }^{-1} \mathrm{~h}^{-1} \mathrm{~atm}^{-1}\right)$ with moderate 1-hexene insertion ratio $(20.2 \%)$.

The aim is to prepare a novel class of asymmetric 3,5-pyrazolyl bridging ligands, which have the potential of hosting two different organometallic fragments $\left(\mathbf{H}_{3} \mathbf{A}\right)$ in a single unit within cooperative distance.<smiles></smiles>

$\mathbf{H}_{3} \mathbf{B}$

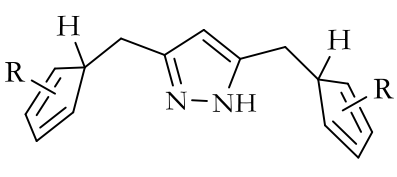

$\mathbf{H}_{3} \mathbf{C}$<smiles></smiles>

$\mathbf{H}_{3} \mathbf{A}$

$\mathrm{R}^{1}=$ alkyl, aryl<smiles>[R]c1cccc(C=CC(=O)OCC(=O)OCc2ccccc2)c1</smiles>

This new class of ligand $\left(\mathbf{H}_{3} \mathbf{A}\right)$ can be described as a combination of a ligand with an NHC side arm $\left(\mathbf{H}_{3} \mathbf{B}\right)$ and a $\mathrm{Cp}$ derivative side $\operatorname{arm}\left(\mathbf{H}_{3} \mathbf{C}\right)$. 


\section{Results and Discussions}

It is envisaged that this new class of ligands can be capable of hosting metals in different oxidation states.

\section{1 Ligand synthesis}

The syntheses of the ligands were achieved as outlined in Scheme 8.1. 1. The ligands were obtained in good to moderate yields $(60-90 \%)$ as moisture sensitive hygroscopic solids. Subsequent treatment of the chloride salts with excess $\mathrm{NH}_{4} \mathrm{PF}_{6}$ made possible the isolation of the corresponding hexafluorophosphate salts.
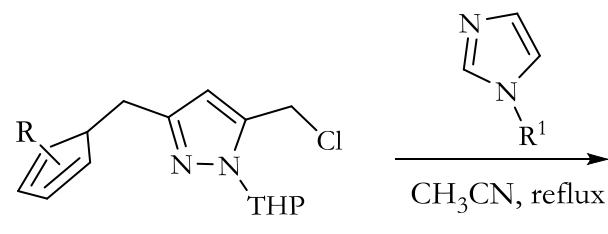

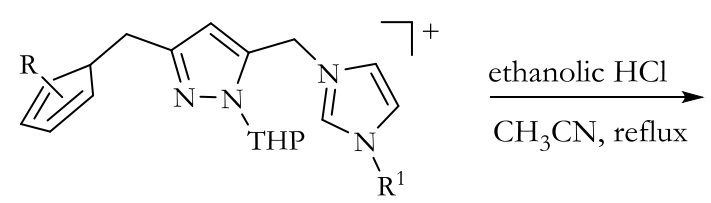<smiles></smiles>

Scheme 8.1. 1: Synthetic scheme for the preparation of $\mathrm{HL}^{12}-\mathrm{HL} \mathrm{L}^{18}$

$$
\begin{aligned}
& \mathbf{H}_{3} \mathbf{L}^{12}=\text { fluorenyl, } \mathrm{R}^{1}=\mathrm{Me} ; \mathbf{H}_{3} \mathbf{L}^{13}=\text { fluorenyl, } \mathrm{R}^{1}=n-\mathrm{Bu} \\
& \mathbf{H}_{3} \mathbf{L}^{14}=\text { fluorenyl, } \mathrm{R}^{1}={ }^{\circ} \mathrm{Bu} ; \mathbf{H}_{3} \mathbf{L}^{15}=\text { fluorenyl, } \mathrm{R}^{1}=2,4,6-{ }^{M e} \mathrm{C}_{6} \mathrm{H}_{2} \\
& \mathbf{H}_{3} \mathbf{L}^{16}=\text { fluorenyl, } \mathrm{R}^{1}=2,6-{ }^{-} \mathrm{Pr}_{2}-\mathrm{C}_{6} \mathrm{H}_{3} ; \mathbf{H}_{3} \mathbf{L}^{17}=\text { indenyl }, \mathrm{R}^{1}=2,4,6-\mathrm{MeC}_{6} \mathrm{H}_{2} \\
& \mathbf{H}_{3} \mathbf{L}^{18}=\text { indenyl, } \mathrm{R}^{1}=2,6={ }^{i}{ }^{i} \mathrm{Pr}_{2}-\mathrm{C}_{6} \mathrm{H}_{3}
\end{aligned}
$$

All the ligands, $\mathbf{H}_{3} \mathbf{L}^{12}-\mathbf{H}_{3} \mathbf{L}^{18}$ were characterized by ${ }^{1} \mathrm{H}$ and ${ }^{13} \mathrm{C}$ NMR spectroscopy, IR spectroscopy, ESI-MS and elemental analysis. All ligands are soluble in DMSO- $d_{6}$. The ${ }^{1} \mathrm{H}$ NMR spectrum of the ligands shows the characteristic imidazolium $\mathrm{CH}$ proton between 9.20-9.46 ppm. The $\mathrm{CH}_{2}$ linker between the imidazolium and pyrazolyl moiety is generally observed as a singlet between 5.35-5.85 ppm, whiles the $\mathrm{CH}$ of the fluorenyl moiety is observed as a triplet, due to coupling with the $\mathrm{CH}_{2}$ linker between 4.31-4.33 ppm. The $\mathrm{CH}$ pyrazole proton is observed between 5.94-5.97 ppm. The ${ }^{1} \mathrm{H}$ NMR spectrum of $\mathrm{H}_{3} \mathrm{~L}^{16}$ with assignments is shown in Fig. 8.1. 1. 


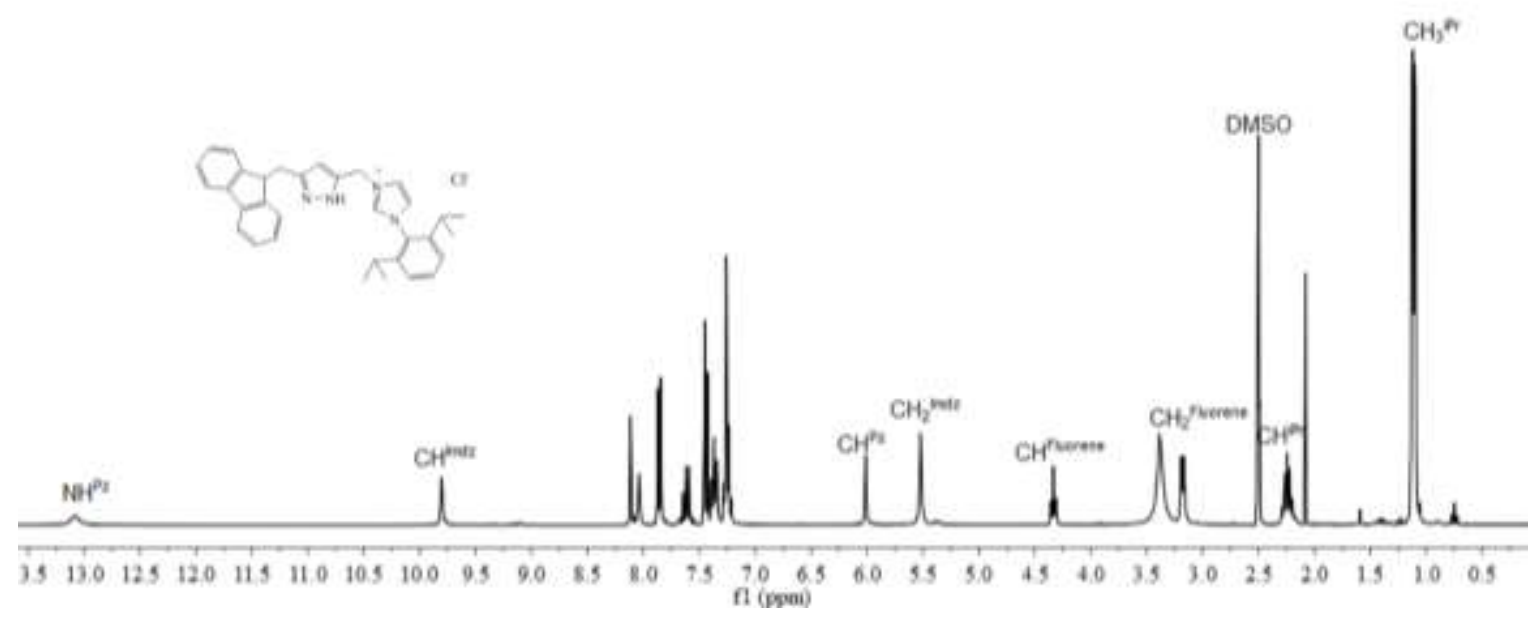

Fig. 8.1. 1: ${ }^{1} \mathrm{H}$ NMR spectrum of $\mathrm{H}_{3} \mathrm{~L}^{16}$ measured in DMSO- $d_{6}$ at room temperature

The ${ }^{13} \mathrm{C}$ NMR spectra assignments were made through a combination of $1 \mathrm{D}$ and $2 \mathrm{D}$ experiments (HSQC, HMBC, DETP-135, DEPT-90, and ${ }^{13} \mathrm{C}$ NMR). The Fig. 8.1. 2 show a partly assigned spectrum of $\mathrm{HL}^{13}$. Here, the $\mathrm{CH}_{2}$ group shows negative peaks in the DEPT135, whiles positive peaks are observed for $\mathrm{CH}$ groups in the DEPT-90 NMR spectrum.

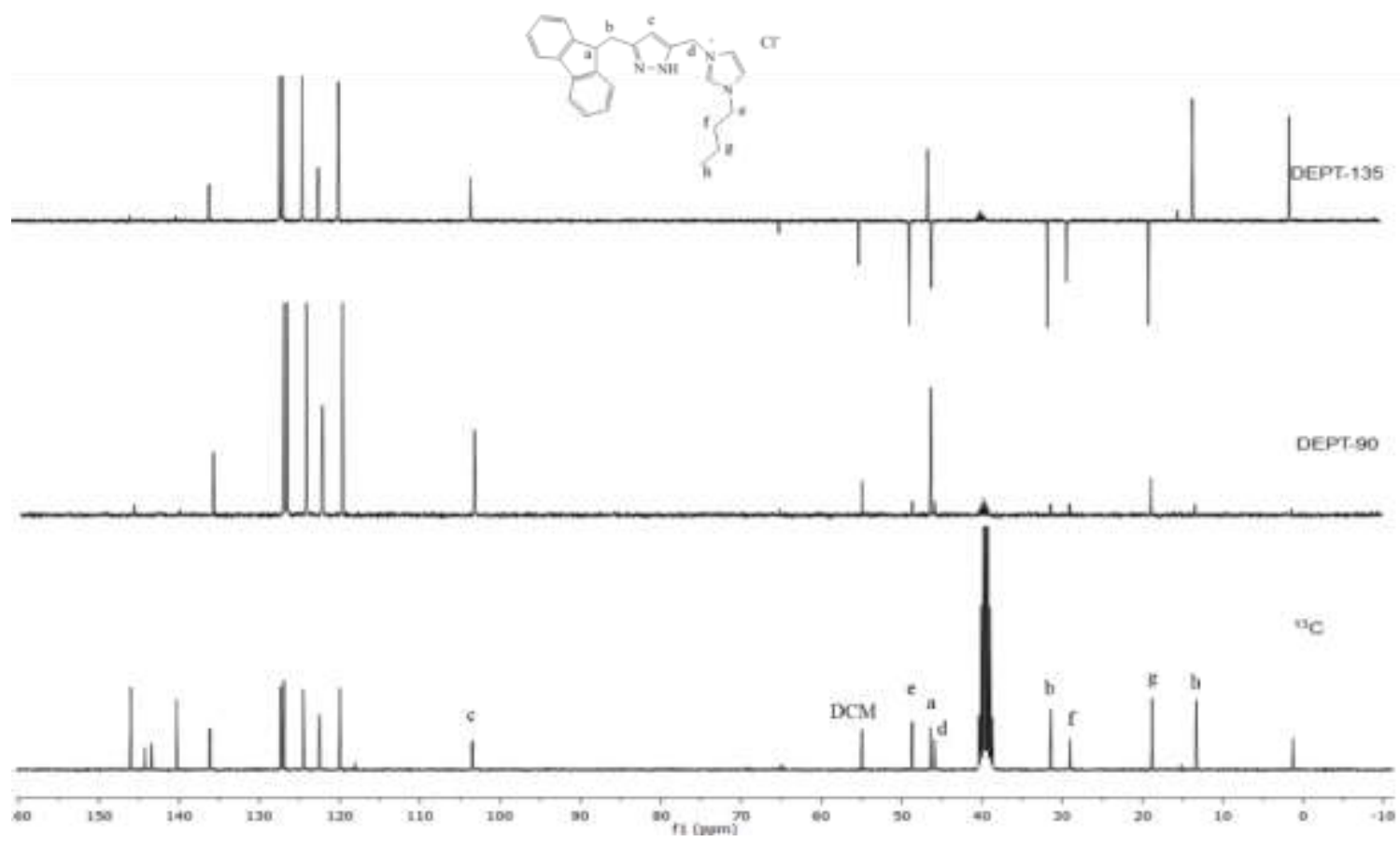

Fig. 8.1. 2: ${ }^{13} \mathrm{C}$, DEPT-90, and DEPT-135 stacked NMR spectra of $\mathrm{H}_{3} \mathrm{~L}^{13}$ measured in DMSO- $d_{6}$ at room temperature

The molecular structure of of $\mathbf{H}_{3} \mathbf{L}^{12}$ is shown in Fig. 8.1. 3. Single crystals were obtained by theslow diffusion of $\mathrm{Et}_{2} \mathrm{O}$ into a methanolic solution of the ligand. The compound 


\section{Results and Discussions}

crystallizes as a salt with two chloride counter ions due to protonation of the second $\mathrm{N}$ atom. Three hydrogen bonding interactions are observed between the protonated nitrogen atoms and the imidazolium protons with the chloride anions.

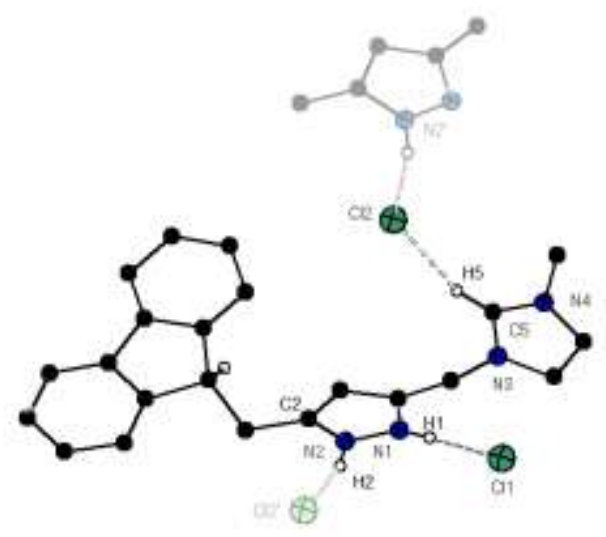

Fig. 8.1. 3: Molecular structure of $\mathrm{H}_{3} \mathrm{~L}^{12}$ with most $\mathrm{H}$ atoms omitted for clarity

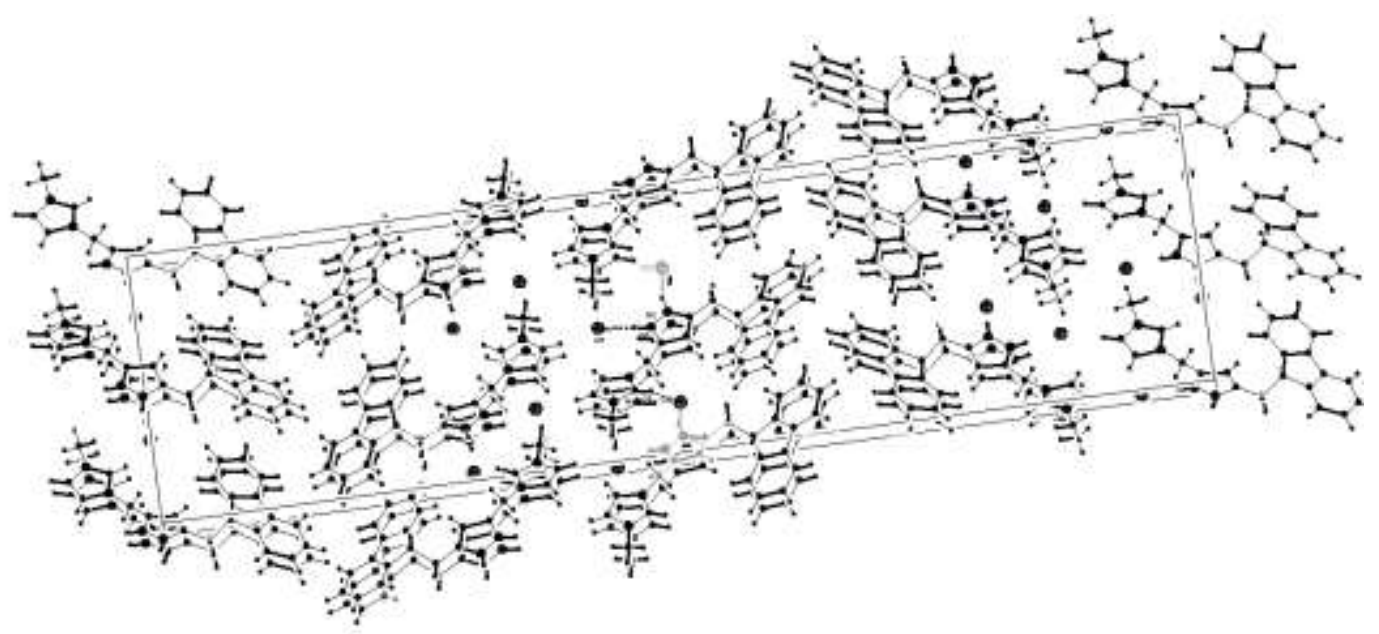

Fig. 8.1. 4: Molecular packing diagram of $\mathrm{H}_{4} \mathrm{~L}^{12}$

The $\mathrm{C}(5)-\mathrm{H}(5){ }^{\cdots} \mathrm{Cl}, \mathrm{N}(2)-\mathrm{H}(2){ }^{\cdots} \mathrm{Cl} 2^{\prime}$, and $\mathrm{N}(1)-\mathrm{H}(1){ }^{\cdots} \mathrm{Cl}(1)$ bond angles are $145.3^{\circ}, 162.3^{\circ}$ and $179.4^{\circ}$ respectively. The hydrogen bond in $\mathrm{N}(1)-\mathrm{H}(1) \cdots \mathrm{Cl}(1)$ is the strongest because of the optimal hydrogen bond angle of $179.4^{\circ}$. Nevertheless, in the case of $\mathrm{C}(5)-\mathrm{H}(5) \cdots \mathrm{Cl}$ and $\mathrm{N}(2)-\mathrm{H}(2) \cdots \mathrm{Cl} 2$ ', the hydrogen bonds are considered weaker because of the suboptimal X$\mathrm{H} \cdots \mathrm{Cl}$ angles of $145.3^{\circ}$ and $162.3^{\circ}$ respectively (Table 8.1. 1). It has been shown that $\mathrm{Cl}$ atoms may act as moderately strong hydrogen-bond acceptors. ${ }^{312}$ The hydrogen bond lengths found in $\mathbf{H}_{3} \mathbf{L}^{12}$ are $\mathrm{N}(1)-\mathrm{H}(1) \cdots \mathrm{Cl}(1)(2.99 \AA), \mathrm{N}(2)-\mathrm{H}(2) \cdots \mathrm{Cl}(2) \quad(3.00 \AA)$, and $\mathrm{C}(5)$ $\mathrm{H}(5) \cdots \mathrm{Cl}(2)(3.48 \AA)$. The $\mathrm{H} \cdots \mathrm{Cl}$ bond lengths in $\mathbf{H}_{3} \mathbf{L}^{12}$ are less than the sum of the van der 
Waals radii for $\mathrm{H}$ and $\mathrm{Cl}^{313}$ The $\mathrm{C}(5)-\mathrm{H}(5){ }^{\cdots} \mathrm{Cl}(2)$ length of $3.48 \AA$ is within the range of other reported $\mathrm{C}-\mathrm{H} \cdots \mathrm{Cl}$ bond lengths. ${ }^{314,315}$

Table 8.1. 1: Selected bond lengths $[\AA]$ and bond angles $\left[{ }^{\circ}\right]$ for $\mathrm{H}_{3} \mathrm{~L}^{12}$

\begin{tabular}{llll}
\hline \multicolumn{3}{c}{ Bond lengths $(\boldsymbol{\AA})$} & \multicolumn{1}{c}{ Bond Angles $\mathbf{(}^{\circ}$ ) } \\
\hline $\mathrm{N}(3)-\mathrm{C}(5)$ & $1.318(6)$ & $\mathrm{C}(5)-\mathrm{N}(3)-\mathrm{C}(6)$ & $109.3(3)$ \\
$\mathrm{N}(4)-\mathrm{C}(5)$ & $1.321(55)$ & $\mathrm{N}(3)-\mathrm{C}(5)-\mathrm{N}(4)$ & $108.3(4)$ \\
$\mathrm{N}(1)-\mathrm{H}(1) \cdots \mathrm{Cl}(1)$ & $2.995(35)$ & $\mathrm{N}(1)-\mathrm{H}(1) \cdots \mathrm{C}(1)$ & $162.3(4)$ \\
$\mathrm{N}(2)-\mathrm{H}(2) \cdots \mathrm{Cl}(2)$ & $3.001(31)$ & $\mathrm{N}(10)-\mathrm{H}(1) \cdots \mathrm{Cl}(1)$ & $179.4(3)$ \\
$\mathrm{C}(5)-\mathrm{H}(5) \cdots \mathrm{Cl}(2)$ & $3.483(44)$ & $\mathrm{C}(5)-\mathrm{H}(5) \cdots \mathrm{Cl}(2)$ & $145.3(2)$ \\
\hline
\end{tabular}

The ligand also shows extensive $\pi$-stacking with the molecules layered on top of each other as a means of limiting steric crowding (Fig. 8.1.4).

\section{2 Synthesis of rhodium(II) complex}

Attempts at obtaining $\operatorname{Ag}(\mathrm{I})$ complexes of this new ligand system failed, although a wide range of $\mathrm{Ag}(\mathrm{I})$ precursors were used. Complexation of $\mathbf{H}_{3} \mathbf{L}^{11}$ with $\mathrm{Rh}_{2}(\mathrm{OAc})_{4} \cdot 2 \mathrm{MeOH}$ leads to the formation of cationic complex $\left[\mathrm{HL}^{14}{ }_{2} \mathrm{Rh}_{2}(\mathrm{OAc})_{4}\right]\left(\mathrm{PF}_{6}\right)_{2}(\mathbf{4} \mathbf{f})$.

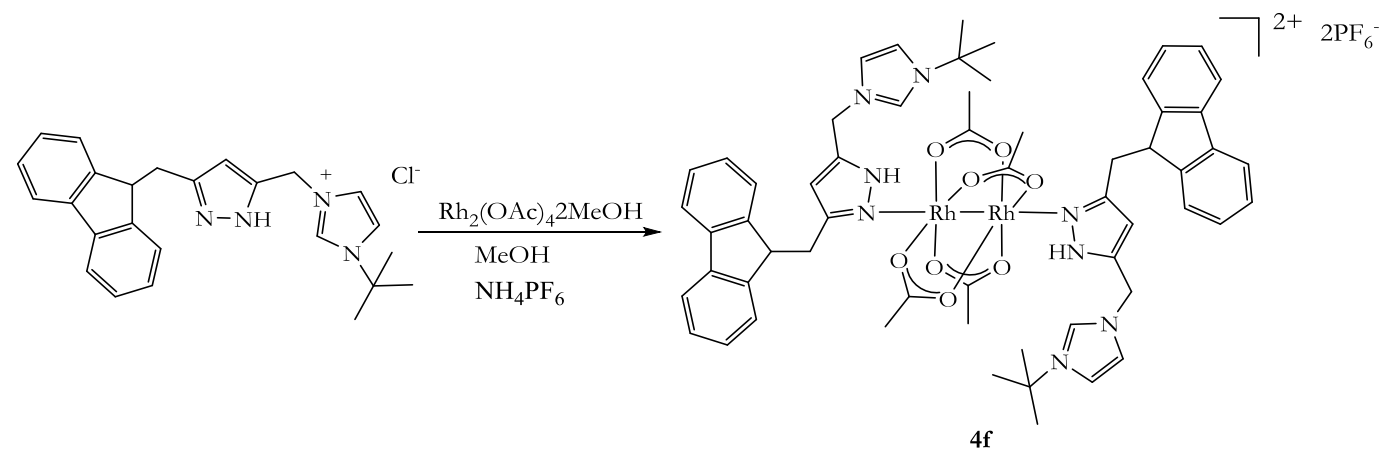

Scheme 8.2. 1: Synthetic scheme for the preparation of $4 \mathrm{f}$

The ${ }^{1} \mathrm{H}$ NMR spectrum of $4 \mathbf{f}$ shows the ${ }^{t} \mathrm{Bu}$ group is unchanged at $1.59 \mathrm{ppm}$, and the free carbene and $\mathrm{NH}^{\mathrm{Pz}}$ are observed at 9.34 and $12.78 \mathrm{ppm}$ compared to 9.56 and $15.08 \mathrm{ppm}$ in the free ligand respectively. The IR spectrum of $\mathbf{4} \mathbf{f}$ shows two strong asymmetric acetate bridging environments at 1572 and $1588 \mathrm{~cm}^{-1}$. Dark red single crystals of $\mathbf{4 f}$ were obtained 


\section{Results and Discussions}

by the slow evaporation of a $50: 50$ methanolic $/ \mathrm{CH}_{2} \mathrm{Cl}_{2}$ solution of the complex at room temperature. The complex crystallizes in the $P 21 / \mathrm{c}$ space group. The molecular structure of 4f is shown in Fig. 8.2. 1.

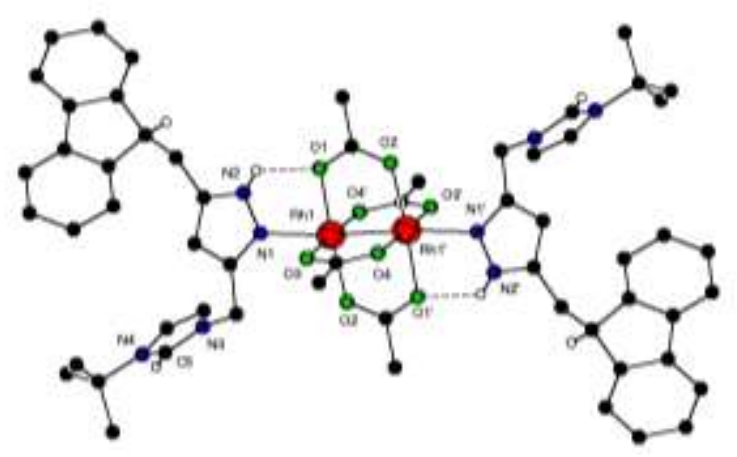

Fig. 8.2. 1: Molecular structure of $4 \mathrm{f}$ with counter ions and most $\mathrm{H}$ atoms omitted for clarity

The $\mathrm{Rh}(\mathrm{II})$ dimer $4 \mathrm{f}$ has two $\mathrm{PF}_{6}^{-}$counterions and cocrystalizes with a half molecule of methanol. Each $\mathrm{Rh}(\mathrm{II})$ centre is lying in the centre of a six coordinate octahedral geometry. The $\mathrm{Rh} \cdots \mathrm{Rh}$ bond distance in this complex $2.39 \AA$, which is significantly shorter than that observed in analogues rhodium-rhodium paddlewheel complexes. Intramolecular hydrogen bonding interactions are observed between an oxygen atom of an acetate molecule $\mathrm{O}(1)$ and a proton on the pyrazolyl nitrogen $\mathrm{N}(2)$. Selected bond lengths and bond angles for $\mathbf{4} \mathbf{f}$ are given in Table 8.2. 1.

Table 8.2. 1: Selected bond lengths $[\AA \AA]$ and bond angles $\left[{ }^{\circ}\right]$ for $4 f$

\begin{tabular}{llll}
\hline \multicolumn{1}{c}{ Bond lengths $(\boldsymbol{\AA} \mathbf{)}$} & & \multicolumn{1}{c}{ Bond Angles (o) } \\
\hline $\mathrm{Rh}(1)-\mathrm{Rh}\left(1^{\prime}\right)$ & $2.3961(5)$ & $\mathrm{N}(1)-\operatorname{Rh}(1)-\mathrm{Rh}(1)$ & $175.26(8)$ \\
$\mathrm{Rh}(1)-\mathrm{O}(3)$ & $2.045(2)$ & $\mathrm{O}(1)-\mathrm{Rh}(1)-\mathrm{O}(4)$ & $88.91(10)$ \\
$\mathrm{Rh}(1)-\mathrm{N}(1)$ & $2.224(3)$ & $\mathrm{O}(1)-\mathrm{Rh}(1)-\mathrm{N}(1)$ & $86.66(10)$ \\
$\mathrm{Rh}(1)-\mathrm{O}(4)$ & $2.035(2)$ & $\mathrm{O}(1)-\mathrm{Rh}(1)-\mathrm{O}(2)$ & $175.90(9)$ \\
\hline
\end{tabular}

The ESI mass spectrum of $\mathbf{4} \mathbf{f}$ showed the ligand as the prominent $\mathrm{m} / \mathrm{z}$ peak, $382(100 \%)$ assigned to $[\mathrm{L}]^{+}$. No further reactions were carried out on these new class of ligand system. 


\section{Conclusion}

\section{a). Mechanistic insights into the formation of the unusual tetrapalladium complex}

i. Further mechanistic studies have been conducted into the formation of the unusual tetrapalladium complex $\left(\mathbf{X X I}^{\circ}\right)$. The proposed mechanism leading to the formation of $\mathbf{X X I}^{\mathbf{c}}$ has been verified with a series of experiments. The proposed $C_{\mathrm{s}}(\mathbf{1})$ and $C_{2 \mathrm{v}}(\mathbf{2})$ intermediates have all been identified, and in some instances, characterized using ${ }^{1} \mathrm{H}$ and ${ }^{13} \mathrm{C}$ NMR spectroscopy, ESI-MS and elemental analysis. The analogous tetrapalladium complex of $\mathrm{HL}^{1} \mathbf{2 k}$ was also isolated, and characterized.
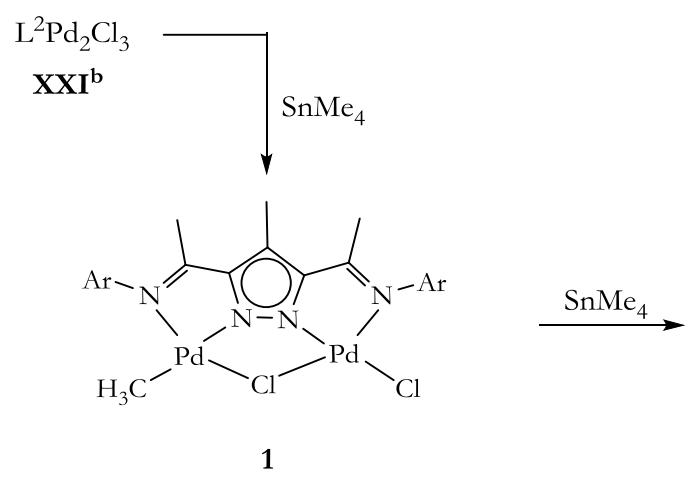

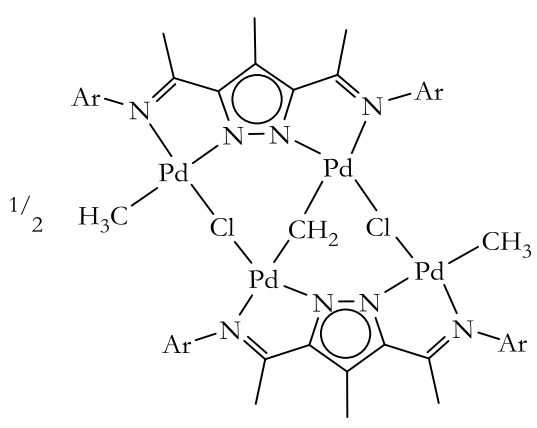

$\mathrm{XXI}^{\mathrm{c}}$

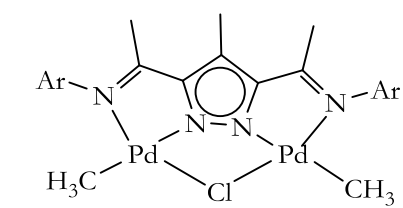

2

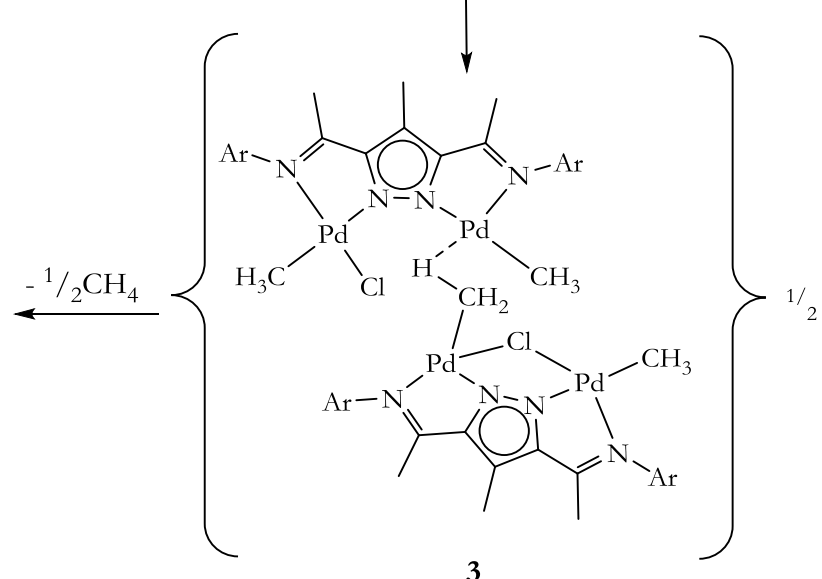

3

$$
\mathrm{Ar}=2,6-{ }^{-} \mathrm{Pr}_{2}-\mathrm{C}_{6} \mathrm{H}_{3}
$$

Scheme 9. 1: Proposed scheme to the formation of the unusual tetrapalladium complex XXIc 


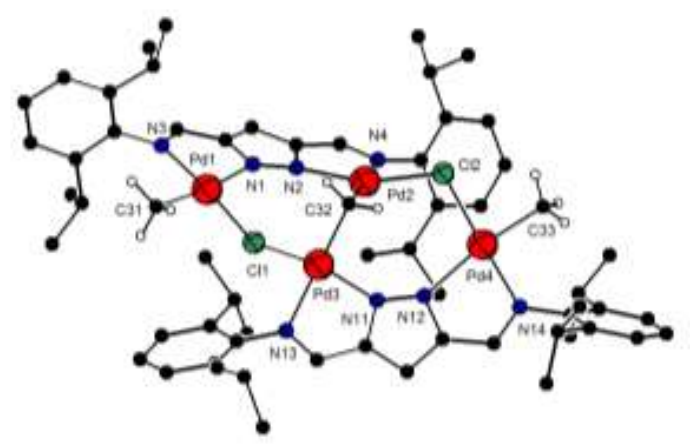

Fig. 9. 1: Molecular structure of the analogous imine complex 2k

ii. The identity of the second observed product, which was formed in the presence of excess $\mathrm{SnMe}_{4}$ and with longer reaction time, has been established as a new tripalladate complex $\mathbf{2} \mathbf{h}$. This complex is formed as a competing side product to the formation of the tetrapalladium complex. The identity of this complex has been established by ${ }^{1} \mathrm{H},{ }^{13} \mathrm{C}$ NMR, and elemental analysis and by single crystal Xray crystallography.

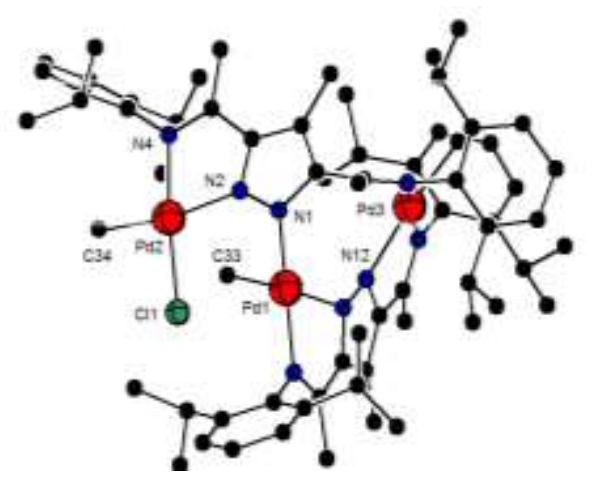

Fig. 9. 2: Molecular diagram of the new tripalladate complex $2 \mathrm{~h}$ formed as a competing side product

iii. The origin of the unlabeled carbon in olefin coupling reactions with ${ }^{13} \mathrm{C}$ labelled

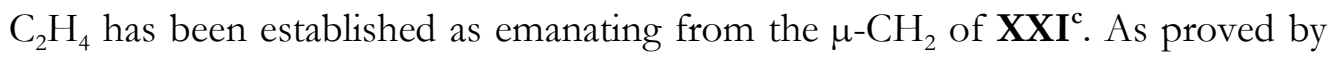
the series of reactions of the activated complex with normal styrene and styrene$d_{8 .}$

$$
{ }^{13} \mathrm{C}_{2} \mathrm{H}_{4} \stackrel{\left[\mathrm{XXI}^{\mathrm{C}}\right]}{\longrightarrow} \quad \begin{gathered}
\mathrm{CH}_{4} \\
\text { (traces) }
\end{gathered}{ }^{+{ }^{13} \mathrm{C}_{2} \mathrm{H}_{6}}+\overbrace{13}^{13}+\overbrace{13}^{13}+\overbrace{13}^{13} \overbrace{13}^{13}+\overbrace{13}^{13}+\overbrace{13}^{13}
$$




\section{Conclusion}

iv. This unusual tetrapalladium complex is also able couple olefins such as styrene, methylacrylate, acrylonitrile, and cyclohexenone in addition to ethylene in moderate to good yields, but only after chloride abstraction.

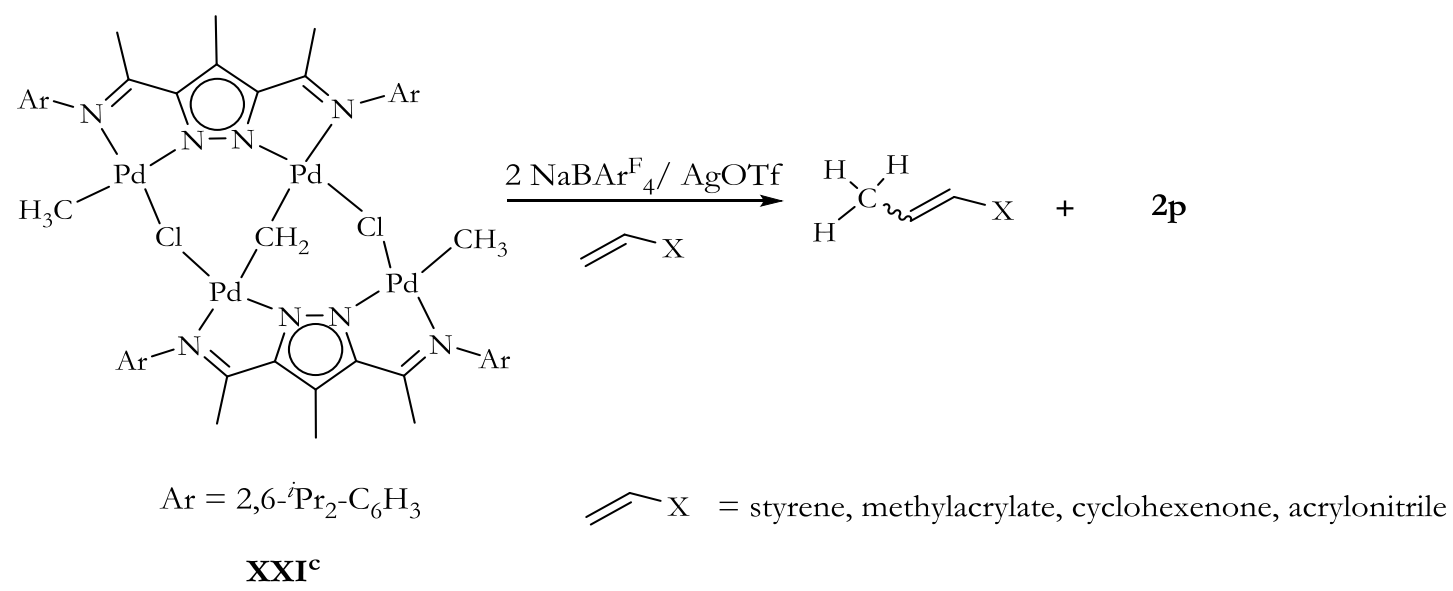

Scheme 9. 2:Olefin coupling ability of $\mathrm{XXI}^{\mathrm{c}}$ after activation with $\mathrm{NaBAr}_{4} \mathrm{or} \mathrm{AgOTf}$

v. A new tetrapalladium compound $2 \mathrm{p}$, with two $\mu-\mathrm{Cl}$, a $\mu-\mathrm{OH}$ and a $\mu-\mathrm{O}$ group has been identified and isolated. The complex $2 \mathrm{p}$ has been characterized by ${ }^{1} \mathrm{H}$, ${ }^{13} \mathrm{C}$ NMR and IR spectroscopy, ESI-MS, elemental analysis, and a single crystal X-ray crystallography. This complex is formed as the final product after activation of the tetrapalladium complex $\mathbf{X X I}^{\mathbf{c}}$ with a chloride abstracting agent $\left(\mathrm{AgOTf} / \mathrm{NaBAr}^{\mathrm{F}}{ }_{4}\right)$ with or without added olefin. It is formed as the final stable product after a series of complex rearrangements in solution.

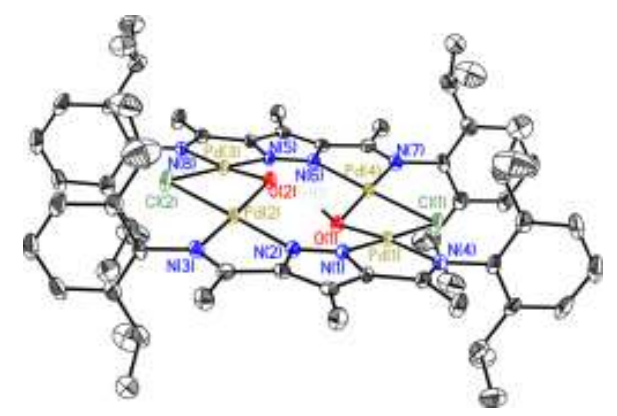

Fig. 9. 3: Molecular structure of final rearrangement product $2 \mathrm{p}$, most $\mathrm{H}$ atoms and one $\left[\mathrm{BAr} \mathrm{F}_{4}\right]^{-}$counterion, omitted for clarity

vi. A new class of palladium(II) $a$-diimine complexes with bromides and iodides (1b, 1c, 2c, 2g) have been prepared and fully characterized by ${ }^{1} \mathrm{H},{ }^{13} \mathrm{C}$ NMR, ES-MS, 


\section{Conclusion}

and elemental analysis. Attempts to obtain single crystals suitable for X-ray crystallography proved futile.

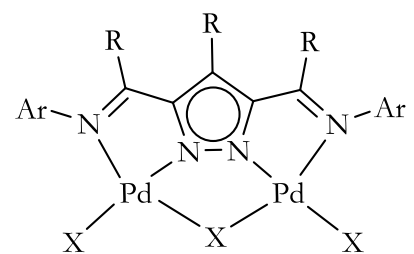

(1b): $\mathrm{R}=\mathrm{H}, \mathrm{X}=\mathrm{Br}$

(1c): $\mathrm{R}=\mathrm{H}, \mathrm{X}=\mathrm{I}$

(2b): $\mathrm{R}=\mathrm{Me}, \mathrm{X}=\mathrm{Br}$

(2c): $\mathrm{R}=\mathrm{Me}, \mathrm{X}=\mathrm{I}$

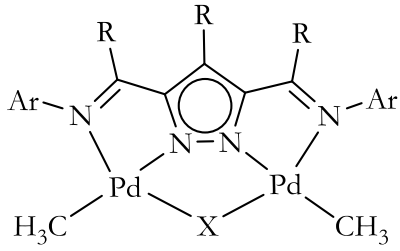

(2g): $\mathrm{R}=\mathrm{Me}, \mathrm{X}=\mathrm{Br}$ $\mathrm{Ar}=2,6-{ }^{i} \mathrm{Pr}_{2}-\mathrm{C}_{6} \mathrm{H}_{3}$

Scheme 9. 3: Scheme of new complexes prepared

b). Preparation of heterobimetallic complexes of palladium(II)-rhodium(I) with $\alpha$ diimine type ligands

i) Although the initial route adopted for the preparation of heterobimetallic complexes by addition of a second metal to pre-existing mononuclear complexes failed, a number of monoanionic complexes (3a, 3b, 3c, 3d, 3j, 3k, 31) were isolated and fully characterized. The nickel complex $\mathbf{3 k}$ is active in ATRP reaction, although the polymerization is not well controlled.

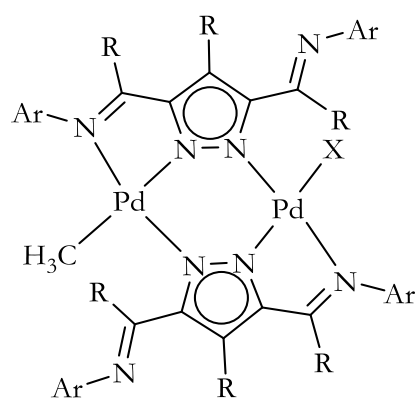

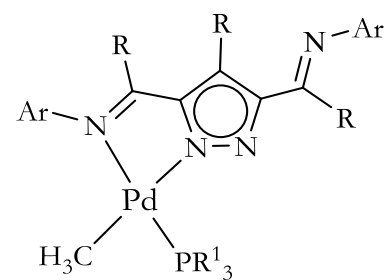

(3c): $\mathrm{R}=\mathrm{Me}, \mathrm{R}^{1}=\mathrm{Me}$

(3d): $\mathrm{R}=\mathrm{Me}, \mathrm{R}^{1}=\mathrm{Ph}$<smiles></smiles>

(3j) : $\mathrm{R}=\mathrm{H}, \mathrm{Ar}=\mathrm{C}_{10} \mathrm{H}_{7}$ (3k): $\mathrm{R}=\mathrm{Me}, \mathrm{Ar}=\mathrm{C}_{10} \mathrm{H}_{7}$ (31): $\mathrm{R}=\mathrm{Me}, \mathrm{Ar}=\mathrm{C}_{6} \mathrm{H}_{5}$

Scheme 9. 4: Scheme of new mononuclear and homobimetallic palladium(II) and nickel(II) complexes prepared

ii) The preparation of a new class of heterobimetallic complexes of the a-diimine type ligands (3r, 3s, 3t, 3u ) has been achieved using a more favourable metal 


\section{Conclusion}

exchange route, which involves the addition of coordinatively unsaturated rhodium(I) complexes to homobimetallic palladium(II) $\eta^{3}$-allyl complexes (3m$3 p)$.<smiles>[R]C1=C([R])N([Y])N2[Y]=NN([Y19])C([R])=C12</smiles>

$$
\mathrm{M}=\mathrm{Pd}
$$

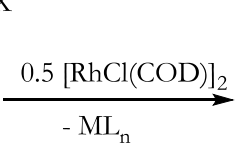

$$
\mathrm{Ar}=2,6-{ }^{i} \operatorname{Pr}_{2}-\mathrm{C}_{6} \mathrm{H}_{3}
$$

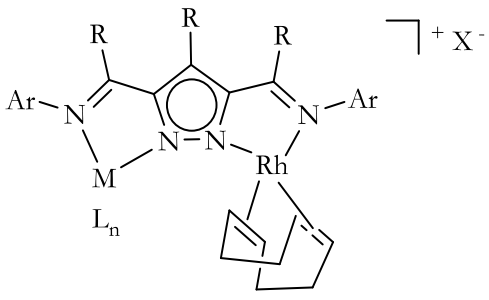

(3r): $\mathrm{R}=\mathrm{H}, \quad \mathrm{L}_{\mathrm{n}}=\mathrm{C}_{4} \mathrm{H}_{7}$

(3s): $\mathrm{R}=\mathrm{Me}, \mathrm{L}_{\mathrm{n}}=\mathrm{C}_{4} \mathrm{H}_{7}$

(3t): $\mathrm{R}=\mathrm{H}, \quad \mathrm{L}_{\mathrm{n}}=\mathrm{C}_{6} \mathrm{H}_{9}$

(3u): $\mathrm{R}=\mathrm{Me}, \mathrm{L}_{\mathrm{n}}=\mathrm{C}_{6} \mathrm{H}_{9}$

Scheme 9. 5: Scheme of new homobimetallic palladium(II) allyl and heterobimetallic palladium(II)-rhodium(I) complexes prepared

The complexes $(\mathbf{3 m}-\mathbf{3} \mathbf{p})$ have been fully characterized by ${ }^{1} \mathrm{H},{ }^{13} \mathrm{C}$ NMR, ES-MS, HRMS and single crystal X-ray crystallography.

iii) Palladium(II) and rhodium(I) complexes (3v, 3z, 3z1) were also isolated as byproducts in the preparation of heterobimetallic complexes.

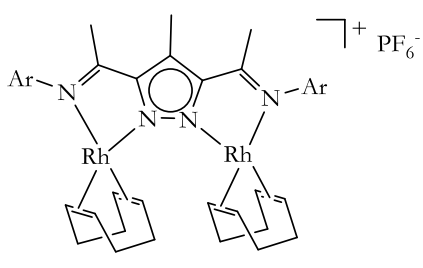

$3 \mathbf{v}$

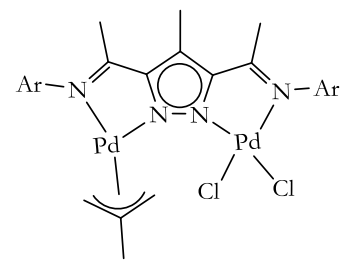

$3 z$

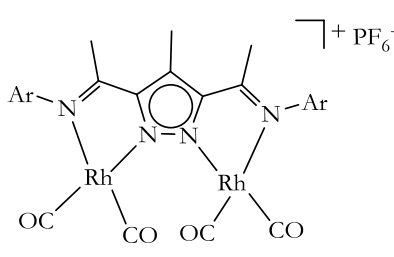

$3 z 1$

$$
\mathrm{Ar}=2,6-{ }^{i} \mathrm{Pr}_{2}-\mathrm{C}_{6} \mathrm{H}_{3}
$$

Scheme 9. 6: By-products from synthesis of heterobimetallic complexes 


\section{Conclusion}

c). Preparation of zinc(II) complexes of the $\alpha$-diimine like pyrazolyl scaffolds as catalyst precursors for the polymerization of rac-lactide to polylactide

New tetranuclear zinc(II) complexes) of the $a$-diimine type ligands have been prepared and characterized (4a, 4b, 4c, 4d).

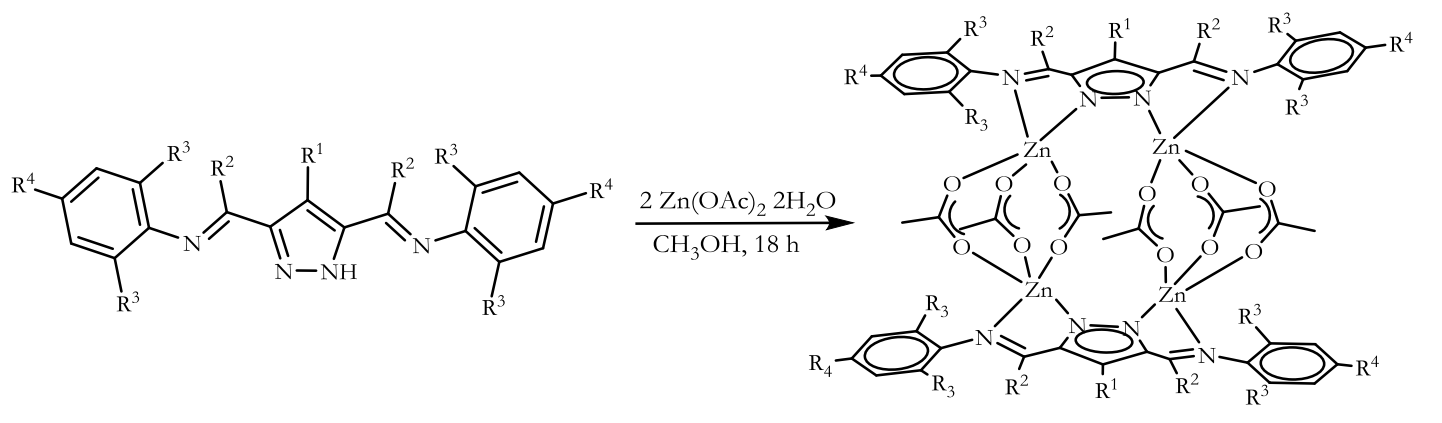

(4a): $\mathrm{L}^{1} ; \mathrm{R}^{1}=\mathrm{R}^{2}=\mathrm{R}^{4}=\mathrm{H}, \mathrm{R}^{3}={ }^{i} \operatorname{Pr}$
(4b): $\mathrm{L}^{2} ; \mathrm{R}^{1}=\mathrm{R}^{2}=\mathrm{Me}, \mathrm{R}^{3}={ }^{i} \operatorname{Pr}, \mathrm{R}^{4}=\mathrm{H}$
(4c): $\mathrm{L}^{3} ; \mathrm{R}^{1}=\mathrm{R}^{2}=\mathrm{R}^{3}=\mathrm{Me}, \mathrm{R}^{4}=\mathrm{H}$
(4d): $\mathrm{L}^{4} ; \mathrm{R}^{1}=\mathrm{R}^{2}=\mathrm{R}^{3}=\mathrm{R}^{4}=\mathrm{Me}$

Scheme 9. 7: New zinc(II) complexes (4a-4d) of $\alpha$-diimine type ligands prepared

The ability of these complexes $(\mathbf{4 a - 4 d})$ to catalyze the ring opening polymerization of raclactide has been evaluated. These catalysts were found to be moderately active, and catalyzes the conversion of rac-lactide to mostly amorphous heteroatactic polylactide with broad polydispersities $(>1.7)$ with up to $60 \%$ conversions in the melt. Although polymer conversions do not exceed $60 \%$ due to increased viscosity of the reaction media, the catalysts achieves productivities of up to $85 \mathrm{kgmol}^{-1}$ in $30 \mathrm{~min}$ at $0.1 \%$ catalyst loadings.

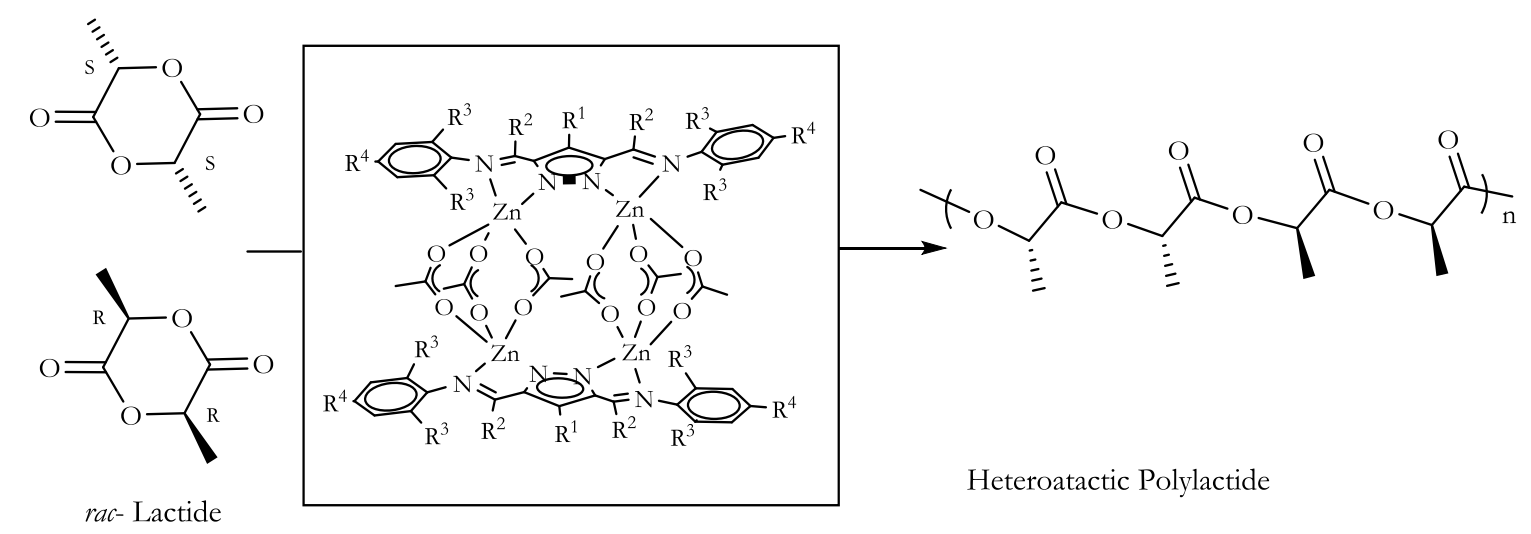

Scheme 9. 8: Lactide polymerization using tetranuclear zinc(II) complexes of $\alpha$-diimine type ligands 
d). Preparation of unsymmetric 3,5-indenyl/fluorenyl substituted pyrazole bridging ligand

The synthesis of unsymmetric 3,5-indenyl/fluorenyl substituted pyrazolyl ligands as well as their TMS derivatives has been successfully achieved. The ligands have been characterized, but attempts at preparing bimetallic group 4 metal complexes with this ligand system did not yield the desired results.

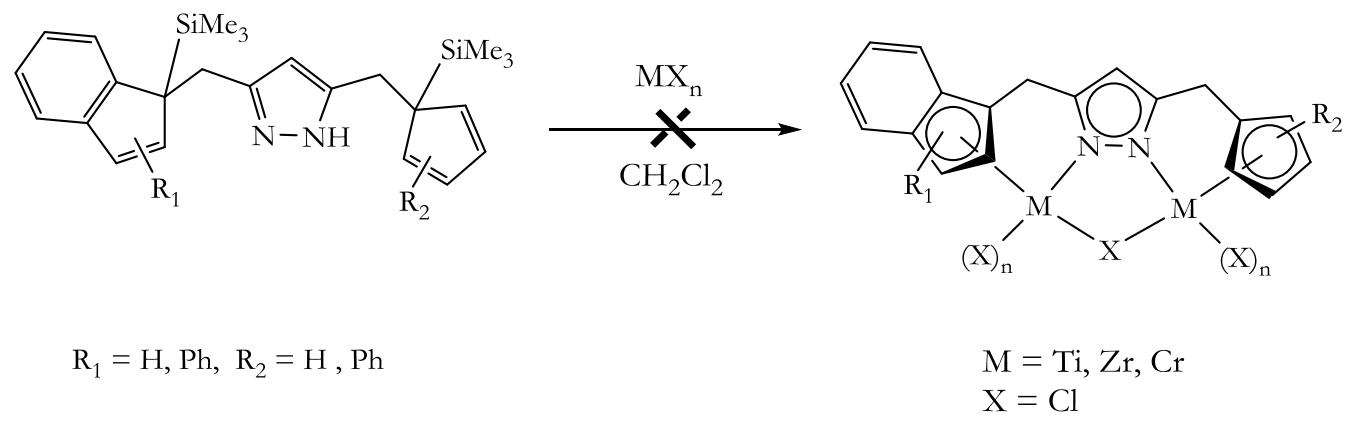

Scheme 9. 9: Unsuccessful attempts at preparation of group 4 metal complexes using a new class of unsymmetrical 3,5 substituted pyrazole ligands

e). Preparation of a novel class of unsymmetric 3,5-NHC and indenyl/fluorenyl substituted bridging ligands

A novel class of unsymmetric 3,5-NHC and indenyl/fluorenyl substituted pyrazolyl ligands $\left(\mathbf{H L}^{12}-\mathbf{H L}^{18}\right)$ potentially capable of hosting two different types of organometallic fragments have been prepared and characterized.

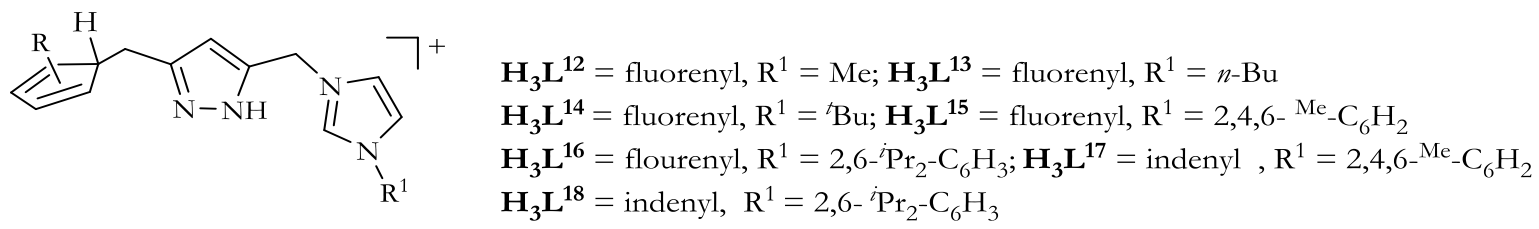

This new class of ligand can be likened to a combination of $\mathrm{NH}$ carbene ligands $\left(\mathrm{H}_{3} \mathbf{B}\right)$ and the cyclopentadienyl/cyclopentadienyl ligands $\left(\mathrm{H}_{3} \mathbf{C}\right)$ tethered to a pyrazole in the 3,5positions. 


\section{Conclusion}

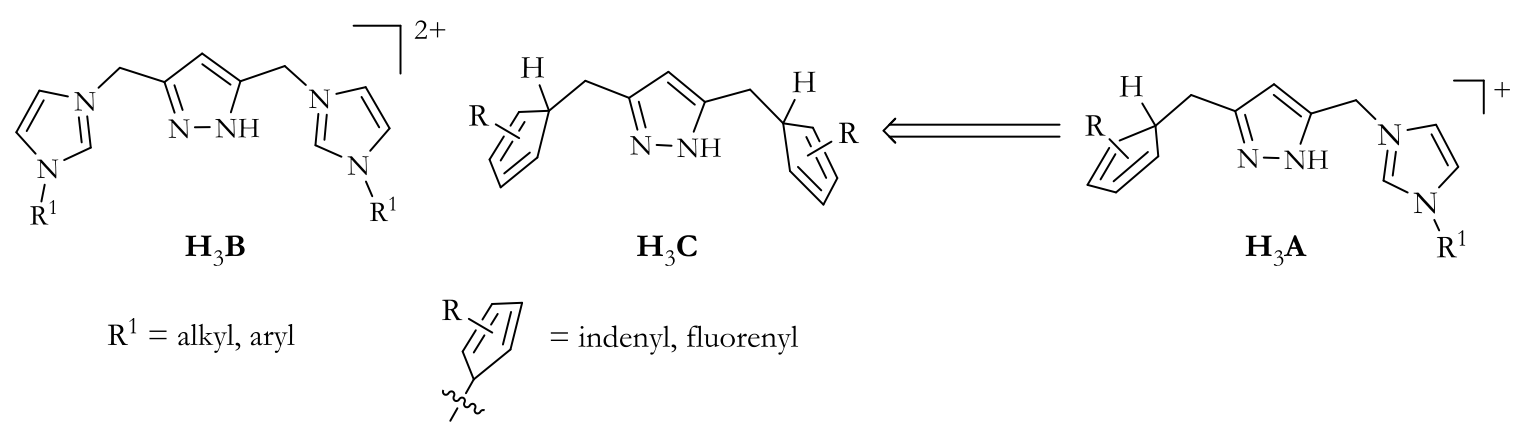

These classes of ligands have been characterized by ${ }^{1} \mathrm{H}$ and ${ }^{13} \mathrm{C}$ NMR, ESI-MS, elemental analysis and in some instances single crystal X-ray crystallography. These ligands in the future can serve as are very good candidates as ligands capable of hosting two different organometallic fragments with metals in different oxidation states in a highly compartmentalized pyrazolyl bridging environment. 


\section{Perspective}

\section{Perspective}

The incorporation of polar monomers such as acrylates into olefins such as ethylene is known to influence important properties such as toughness, surface as well as barrier properties. ${ }^{316}$ The challenge now remains in the development of well defined catalysts capable of copolymerizing a-olefins with polar monomers under mild conditions. Some catalysts reported to date capable of achieving such feat are the $a$-diimine palladium(II) catalysts reported by Brookhart and co-workers ${ }^{317318}$ that copolymerize ethylene and methylmethacrylate to yield highly branched copolymers. Other investigators such as Grubbs $^{319}$ and Gibson ${ }^{320}$ have also reported metal complexes capable of producing MMA terminated polyethylenes. However, very few reports of bimetallic complexes with enhanced $a$-olefin enchainment have been reported to date. ${ }^{321,322}$ The homobimetallic palladium(II) complex $\left[\mathrm{L}^{2}\left(\mathrm{CH}_{3}\right)_{2} \mathrm{Pd} \mathrm{B}_{2} \mathrm{Br}\right](\mathbf{2 g})$ would be an ideal candidate for exploring the polymerization of ethylene with polar comonomers. Preliminary investigations have shown that this complex after halide abstraction is able to mediate the polymerization of MA to PMMA.

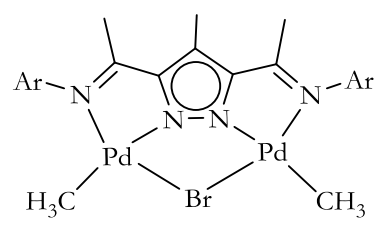
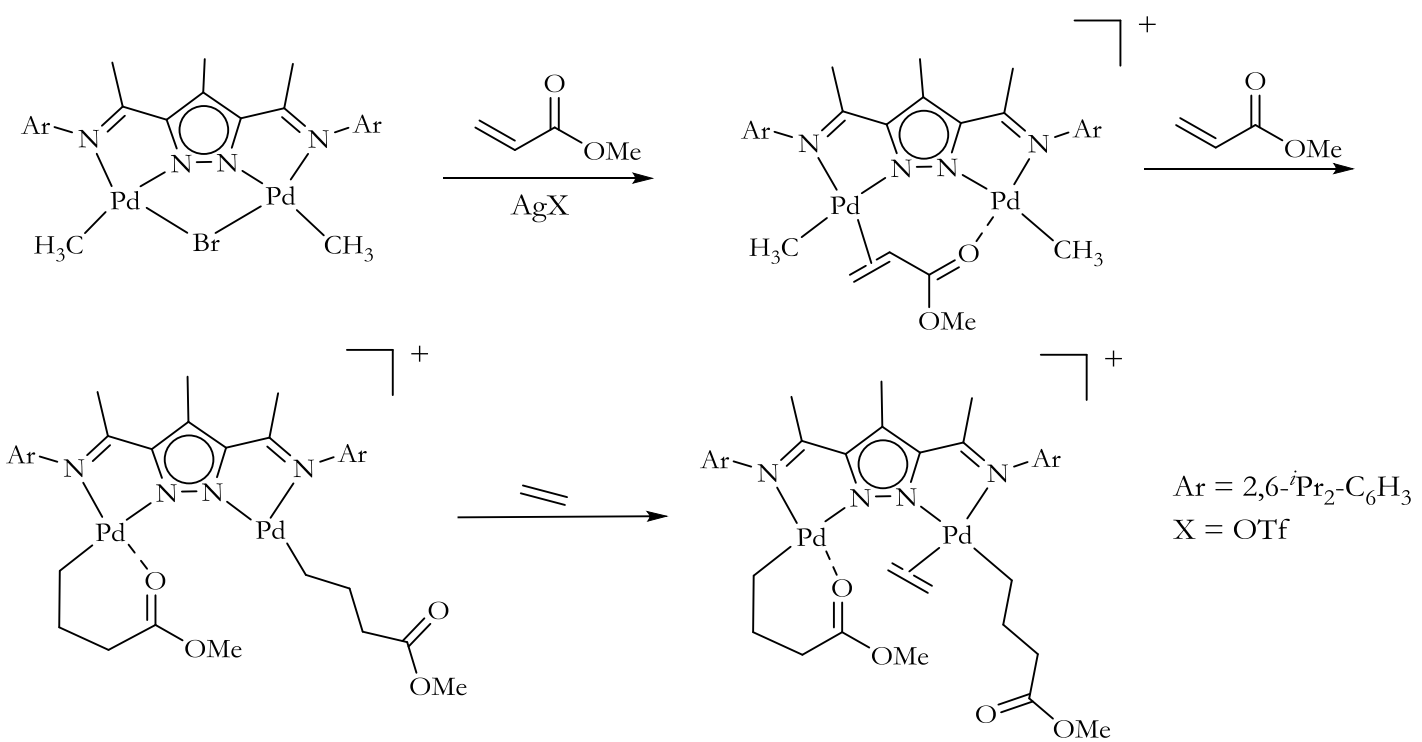

Scheme 10. 1: Proposed catalyst resting stages for ethylene/polar commoner insertion reactions in $2 \mathrm{~g}$

This homobimetallic palladium complex would also be a very attractive option for exploring $a$-olefin enchainment with the potential to bind to the two metal centres within a cooperative distance. It would also allow for the study of clear mechanistic insights into potential synergetic effects in multi-centre olefin/polar comonomer copolymerization reactions (Scheme 10. 1). 


\section{Experimental Section}

General methods: All reactions were carried out under dry and oxygen-free nitrogen atmosphere unless otherwise stated. All solvents were dried and distilled prior to use, diethyl ether, THF and toluene were dried and distilled over sodium, whiles $\mathrm{CH}_{2} \mathrm{Cl}_{2}$ was dried and distilled over calcium hydride.

Reagents:

General reagents were obtained from the chemical store of the Institute of Inorganic Chemistry.

The following reagents and chemicals were obtained from the following sources:

Celite

Deuterated solvents

Dichloromethane

2,6-di-isopropylaniline

$\mathrm{NiBr}_{2}(\mathrm{dme})$

Palladium(II)chloride

Phenylacetylene

Rhodium(III)chloride monohydrate

Tetramethyltin
ABCR

MERCK, SIGMA-ALDRICH

FLUKA

FLUKA

ALDRICH

UMICORE

MERCK

UMICORE

ALDRICH

The following ligands and metal precursors were prepared using established literature procedures:

3,5-Bis-chloromethyl-1-(tetrahydro-pyran-2-yl)-1H-pyrazole ${ }^{218}$

$1 H$-pyrazole-3,5-dicarbaldehyde ${ }^{219}$

Toluenesulfonylazide ${ }^{323}$

Diazoacetylacetone ${ }^{324}$

Chloro(1,5-cyclooctadiene)rhodium(I) dimer ${ }^{325}$

$\left(\eta^{3}\right.$-methylallyl)palladium chloride dimer ${ }^{326}$

$\left(\eta^{3}\right.$-cyclohexenyl)palladium chloride dimer ${ }^{327}$ 
$\mathbf{X X I}^{\mathrm{b} 151}$

$\mathbf{X X I}^{\mathrm{c} 154}$

$\left[\mathrm{L}^{2} \mathrm{RhCl}(\mathrm{COD})\right],\left[\mathrm{L}^{2} \mathrm{Pd}_{2}\left(\eta^{3}-\mathrm{C}_{4} \mathrm{H}_{7}\right)_{2}\right] \mathrm{Cl}^{221}$

\section{NMR:}

NMR experiments were performed at $25^{\circ} \mathrm{C}$ on a Bruker Avance 300 or $500 \mathrm{MHz}$ spectrometer using standard parameters. ${ }^{1} \mathrm{H}$ and ${ }^{13} \mathrm{C}$ NMR chemical shifts were calibrated with internal solvent signals $\left(\delta=5.32\right.$ and $53.8 \mathrm{ppm}$ for $\mathrm{CD}_{2} \mathrm{Cl}_{2}, \delta=7.26$ and 77.16 for $\mathrm{CDCl}_{3}$ ) and peaks were assigned using 2D experiments: COSY, NOESY (500 ms mixing), CH-COSY/HSQC, and HMBC (optimized for $J_{\mathrm{C}-\mathrm{H}}=7 \mathrm{~Hz}$ ). DOSY spectrum were recorded with $2 \mathrm{~ms}$ bipolar z-gradient pulses ramped linearly from 1 to $50 \mathrm{Gcm}^{-1}$ and a diffusion delay of $70 \mathrm{~ms} .{ }^{1} \mathrm{H}\left\{{ }^{1} \mathrm{H}\right\}(2.5 \mathrm{kHz}$ decoupling).

\section{Elemental analysis:}

Elemental analyses were carried out with a Heraeus CHN-O-RAPID instrument and were performed at the analytical laboratory in the Institute for Inorganic Chemistry, University of Göttingen.

\section{GPC-SEC:}

This was performed in THF on a GPC-SEC Analysis Systems 1260 Infinity, at the Institute of Physical Chemistry (IPC), University of Göttingen.

\section{DSC-TG:}

Differential scanning calorimetry with thermogravimetry was performed on a Netzsch STA409PC instrument in the analytical laboratory of the Institute of Inorganic Chemistry, University of Göttingen.

IR:

IR was performed on a Cary 630 FTIR spectrometer equipped with a Diamond ATR accessory.

\section{Mass spectrometry:}

Mass spectrometry was performed on a Finnigan MAT 8200 (EI, 70 eV), Finnigan MAT 95 (FAB, 3-Nitrobenzyl alcohol), Applied Biosystems API 2000 (ESI), or Finnigan MAT LCQ (HR-ESI) instruments in the Institute of Inorganic Chemistry and the Institute for Organic and 


\section{Experimetal}

Biomolecular chemistry, University of Göttingen. Isotopic distributions and exact masses were calculated with Mmass data miner. ${ }^{328,329}$

\section{X-ray:}

X-ray data were collected on a STOE IPDS II diffractometer (graphite monochromated Mo-K $\alpha$ radiation, $\lambda=0.71073 \AA$, $\omega$ scans) at $133 \mathrm{~K}$ and corrected for Lorentz and polarization ${ }^{330}$ and absorptions $^{331}$ the structures were solved by direct methods and refined on $\mathrm{F}^{2}$ using all reflections with SHELXS-97 and SHELXL-97. 332,333

\section{ATRP Polymerization:}

Conditions: Styrene (20 mL, distilled and stored under argon), a degassed solution of Ethyl- $\alpha-$ bromostyrene in toluene $(0.16 \mathrm{~mL}, 0.23 \mathrm{mmol}$, dried and stored under argon) and the nickel catalyst (21 $\mathrm{mg}, 0.23 \mathrm{mmol}$ ) were combined under argon and the reactor placed in an oil bath at $70^{\circ} \mathrm{C}$. Aliquots were taken via syringe at specified time intervals, cooled to $-20^{\circ} \mathrm{C}$ for at least 10 min, and placed in aluminium bowls. The conversions were determined by gravimetric analysis.

\section{Typical rac-polymerization procedure:}

Polymerization of rac-lactide was performed on a Schlenk line with a flame dried Schlenk flask equipped with a magnetic stirrer. The Schlenk flask was charged with the required amount of lactide and initiator and attached to the vacuum line. After at least three vacuum-nitrogen purge cycles, the flask was immersed in an oil bath heated to the required reaction temperature. Polymerization was stopped by injecting methanol. The polymers were precipitated in hexane, filtered off, reddisolved in $\mathrm{CH}_{2} \mathrm{Cl}_{2}$ and precipitated again in hexane, and dried in vacuum to a constant weight. 


\section{1. $1 \mathrm{Bi}$ - and oligonuclear palladium(II) complexes}

\subsection{Synthesis of $\left[\mathrm{L}^{1} \mathrm{Pd}_{2} \mathrm{Br}_{3}\right](1 \mathrm{~b})$}<smiles>CCc1cccc(C(C)(C)C)c1/N=C/c1cc(/C=N/c2c(C(C)C)cccc2C(C)(C)C)[nH]n1</smiles>

$\mathrm{HL}^{1}$

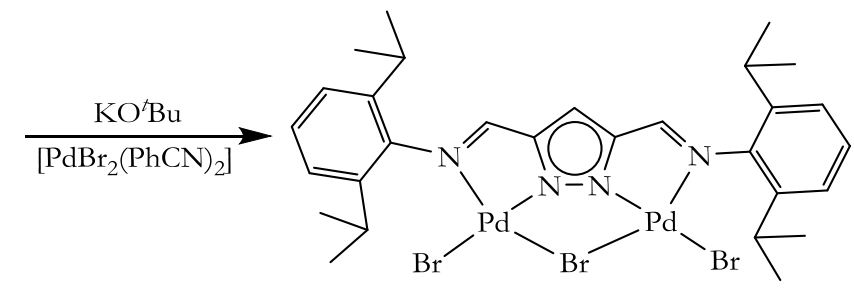

$1 \mathbf{b}$

To a $\mathrm{CH}_{2} \mathrm{Cl}_{2}$ solution $(10 \mathrm{~mL})$ of $\mathbf{H L}^{1}(45 \mathrm{mg}, 0.10 \mathrm{mmol})$ was added 1.2 equivalent $\mathrm{KO}^{\prime} \mathrm{Bu}(11.5$ $\mathrm{mg}, 0.12 \mathrm{mmol}$ ) with stirring for $30 \mathrm{~min}$. After this, the salt solution of the ligand was added to a stirring suspension of $\mathrm{PdBr}_{2}\left(\mathrm{PhCN}_{2}\right]\left(96 \mathrm{mg}, 0.20 \mathrm{mmol}, 2.0 \mathrm{~mol} \mathrm{Eq}\right.$.) in $\mathrm{CH}_{2} \mathrm{Cl}_{2}$ dropwise via a syringe over a 30 min period. A dark red solution was formed which was further stirred under room temperature for $18 \mathrm{~h}$. The suspension was filtered using a filter paper, and the solvent evaporated to obtain a dark red powder. This powder was redissolved in $\mathrm{CH}_{2} \mathrm{Cl}_{2}(20 \mathrm{~mL})$ and 30 $\mathrm{ml}$ of $\mathrm{Et}_{2} \mathrm{O}$ added, forming a suspension. Filtration of the suspension on a filter paper leaves a dark green hygroscopic solid on the filter paper, whiles a bright orange filtrate was obtained. Evaporation of the filtrate gives the product as a dull brown solid.

Yield:

Molecular formula:

Molecular weight:

MS (ESI, $\left.\mathrm{CH}_{2} \mathrm{Cl}_{2}\right) m / z(\%)$ :

IR $\left(\right.$ ATR, $\left.\mathrm{cm}^{-1}\right)$ :

${ }^{1} \mathrm{H}-\mathrm{NMR}\left(\mathrm{CDCl}_{3}\right) \delta$ :

${ }^{13} \mathrm{C}\left\{{ }^{1} \mathrm{H}\right\}\left(\mathrm{CDCl}_{3}\right) \delta$ :

Elemental analysis:
$53 \mathrm{mg}, 59 \%$

$\mathrm{C}_{29} \mathrm{H}_{37} \mathrm{Br}_{3} \mathrm{~N}_{4} \mathrm{Pd}_{2}$ $894.2 \mathrm{~g} / \mathrm{mol}$.

$1708(50 \%) \quad\left[\begin{array}{lllll}\left.\mathrm{L}_{2} \mathrm{Pd}_{4} \mathrm{Br}_{5}\right]^{+} ; & 1072(60 \%) & {\left[\mathrm{L}_{2} \mathrm{Pd}\right]^{+} ; 932(30 \%)}\end{array}\right.$ $[\mathrm{M}+\mathrm{K}]^{+} ; 814(20 \%)[\mathrm{M}-\mathrm{Br}]^{+}$.

2057 (m); 2924 (m); 2808 (m); 1547 (vs); 1450 (s); 1305 (vs); 1259 (m); 1138 (vs); 1095 (vs); 1058 (S); 927 (vs); 772 (m); 745 (vs); $668(\mathrm{~m}) ; 579(\mathrm{~m})$.

$1.18\left(\mathrm{~d},{ }^{3} J_{\mathrm{HH}}=6.9 \mathrm{~Hz}, 12 \mathrm{H}, \mathrm{CH}_{3}^{\mathrm{iPr}}\right) ; 1.41\left(\mathrm{~d},{ }^{3} J_{\mathrm{HH}}=6.9 \mathrm{~Hz}\right.$, $\left.12 \mathrm{H}, \mathrm{CH}_{3}{ }^{i \mathrm{Pr}}\right) ; 3.33\left(\mathrm{~m}, 4 \mathrm{H}, \mathrm{CH}^{\mathrm{iPr}}\right) ; 7.01\left(\mathrm{~s}, 1 \mathrm{H}, \mathrm{CH}^{\mathrm{P}_{\mathrm{P}}}\right) ; 7.21-7.36$ $\left(\mathrm{m}, 6 \mathrm{H}, \mathrm{CH}^{\mathrm{Ar}}\right) ; 7.73(\mathrm{~s}, 2 \mathrm{H}, \mathrm{CH}=\mathrm{N})$.

$22.8\left(\mathrm{CH}_{3}{ }^{2 \mathrm{PP}}\right) ; 24.5\left(\mathrm{CH}_{3}{ }^{i \mathrm{Pr}}\right) ; 29.3\left(\mathrm{CH}^{\mathrm{iPr}}\right) ; 110.7\left(\mathrm{CH}^{\mathrm{Pz}}\right) ; 123.8$ $\left(\mathrm{CH}^{\mathrm{Ar}}\right) ; 129.4\left(\mathrm{CH}^{\mathrm{Ar}}\right) ; 141.4\left(\mathrm{C}^{\mathrm{Ar}}\right) ; 146.1\left(\mathrm{C}^{\mathrm{Ar}}\right) ; 147.8\left(\mathrm{C}^{\mathrm{P}}\right) ; 165.0$ $(\mathrm{CH}=\mathrm{N})$.

Calcd. For $\mathrm{C}_{29} \mathrm{H}_{37} \mathrm{Br}_{3} \mathrm{~N}_{4} \mathrm{Pd}_{2}$ : (C) 38.95 (H) 4.17 (N) 6.27; Found: (C) $39.02(\mathrm{H}) 4.32(\mathrm{~N}) 5.82$. 


\subsection{Synthesis of $\left[\mathrm{L}^{1} \mathrm{Pd}_{2} \mathrm{I}_{3}\right](1 \mathrm{c})$}

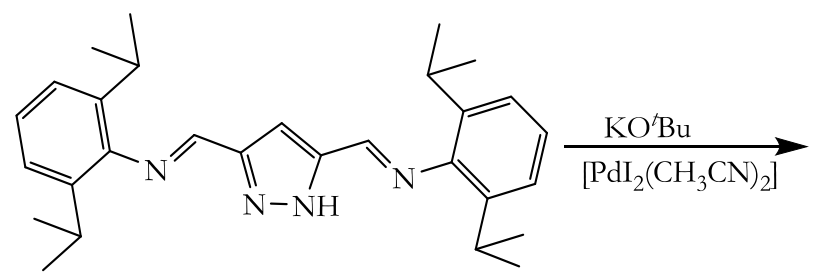

$\mathrm{HL}^{1}$

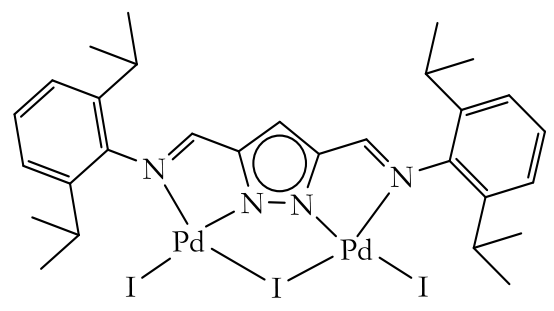

$1 \mathrm{c}$

A similar experimental procedure was followed as done for $\left[\mathrm{L}^{1} \mathrm{Pd}_{2} \mathrm{Br}_{3}\right]$. To a $\mathrm{CH}_{2} \mathrm{Cl}_{2}$ solution $(15 \mathrm{~mL})$ of the ligand $(40 \mathrm{mg}, 0.9 \mu \mathrm{mol})$ was added 1.1 equivalent $\mathrm{KO}^{\prime} \mathrm{Bu}(10 \mathrm{mg}, 0.92 \mu \mathrm{mol})$ with stirring for $30 \mathrm{~min}$. After this, the salt solution of the ligand was added to a stirring suspension of $\left[\mathrm{PdI}_{2}\left(\mathrm{CH}_{3} \mathrm{CN}\right)_{2}\right](63 \mathrm{mg}, 0.18 \mathrm{mmol}, 2 \mathrm{~mol} \mathrm{Eq}$. $)$ in $\mathrm{CH}_{2} \mathrm{Cl}_{2}$ dropwise via a syringe over a $30 \mathrm{~min}$ period. A red solution was formed which was further stirred at room temperature for $18 \mathrm{~h}$. The suspension was filtered and the solvent evaporated to obtain a dark-red powder. This powder was redissolved in $\mathrm{CH}_{2} \mathrm{Cl}_{2}(20 \mathrm{~mL})$ and $30 \mathrm{ml}$ of $\mathrm{Et}_{2} \mathrm{O}$ added, a suspension was formed. Filtration of the suspension on a filter paper leaves a brown solid on the filter paper, whiles a dark red filtrate was obtained. Slow evaporation of the filtrate at room temperature gave the product as fine brown needles.

Yield:

Molecular formula:

Molecular weight:

MS (ESI, $\left.\mathrm{CH}_{2} \mathrm{Cl}_{2}\right) m / z(\%)$ :

IR $\left(\right.$ ATR, $\left.\mathrm{cm}^{-1}\right)$ :

${ }^{1} \mathrm{H}-\mathrm{NMR}\left(\mathrm{CDCl}_{3}\right) \delta$ :

${ }^{13} \mathrm{C}\left\{{ }^{1} \mathrm{H}\right\}\left(\mathrm{CDCl}_{3}\right) \delta:$

Elemental analysis:
$34 \mathrm{mg}, 36 \%$

$\mathrm{C}_{29} \mathrm{H}_{37} \mathrm{I}_{3} \mathrm{~N}_{4} \mathrm{Pd}_{2}$

$1035.2 \mathrm{~g} / \mathrm{mol}$.

$1943(10 \%)\left[\mathrm{L}_{2} \mathrm{Pd}_{4} \mathrm{I}_{5}\right]^{+} ; 908(5 \%)\left[\mathrm{M}-\mathrm{I}^{+}\right.$.

2924 (m); 2955 (m); 2868 (m) ; 1551 (vs); 1468 (vs); 1361 (vs); 1352 (m); 1136 (vs); 1091 (vs); 921 (vs); 802 (vs); 666 (s); 599 (s).

$1.18\left(\mathrm{~d},{ }^{3} J_{\mathrm{HH}}=6.9 \mathrm{~Hz}, 12 \mathrm{H}, \mathrm{CH}_{3}^{2 \mathrm{PP}}\right) ; 1.41\left(\mathrm{~d},{ }^{3} J_{\mathrm{HH}}=6.9 \mathrm{~Hz}, 12 \mathrm{H}\right.$, $\left.\mathrm{CH}_{3}{ }^{i \mathrm{Pr}}\right) ; 3.30\left(\mathrm{~m}, 4 \mathrm{H}, \mathrm{CH}^{\mathrm{iPr}}\right) ; 6.91\left(\mathrm{~s}, 1 \mathrm{H}, \mathrm{CH}^{\mathrm{Pz}}\right) ; 7.19-7.36(\mathrm{~m}, 6 \mathrm{H}$, $\left.\mathrm{CH}^{\mathrm{Ar}}\right) ; 7.72(\mathrm{~s}, 2 \mathrm{H}, \mathrm{CH}=\mathrm{N})$.

$22.6\left(\mathrm{CH}_{3}^{2{ }^{2 \mathrm{Pr}}}\right) ; 24.8\left(\mathrm{CH}_{3}{ }^{2 \mathrm{Pr}}\right) ; 29.3\left(\mathrm{CH}^{\mathrm{IPr}}\right) ; 109.8\left(\mathrm{CH}^{\mathrm{Pz}}\right) ; 118.5$ $\left(\mathrm{CH}^{\mathrm{P}_{2}}\right) ; 123.7\left(\mathrm{CH}^{\mathrm{Ar}}\right) ; 128.9\left(\mathrm{CH}^{\mathrm{Ar}}\right) ; 141.0\left(\mathrm{C}^{\mathrm{Ar}}\right) ; 146.1\left(\mathrm{C}^{\mathrm{Ar}}\right) ; 149.3$ $\left(\mathrm{C}^{\mathrm{Pz}}\right) ; 164.9(\mathrm{CH}=\mathrm{N})$.

Calcd. For $\mathrm{C}_{29} \mathrm{H}_{37} \mathrm{I}_{3} \mathrm{~N}_{4} \mathrm{Pd}_{2} \cdot 2 \mathrm{CH}_{2} \mathrm{Cl}_{2}:$ (C) $30.90(\mathrm{H}) 3.43$ (N) 4.65; Found: (C) $30.18(\mathrm{H}) 3.17(\mathrm{~N}) 4.58$. 


\subsection{Synthesis of $\left[\mathrm{L}^{2} \mathrm{Pd}_{2} \mathrm{Br}_{3}\right](2 b)$}

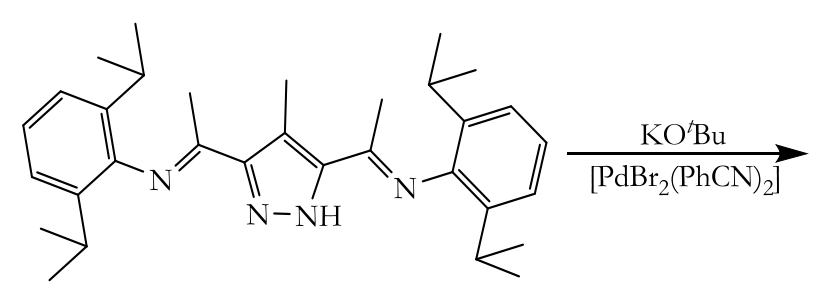

$\mathrm{HL}^{2}$

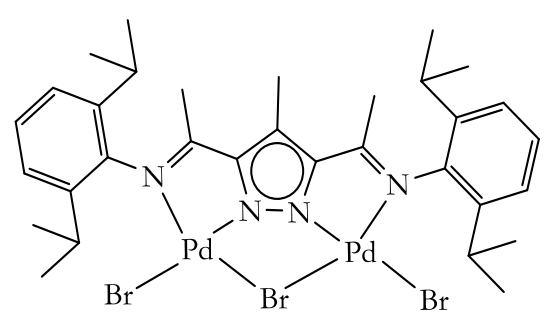

$2 b$

To a $\mathrm{CH}_{2} \mathrm{Cl}_{2}$ solution $(15 \mathrm{~mL})$ of $\mathbf{H L}^{2}(125 \mathrm{mg}, 0.26 \mathrm{mmol})$ was added $1.2 \mathrm{~mol}$ equivalent $\mathrm{KO} \mathrm{Bu}^{\prime}(35 \mathrm{mg}, 0.31 \mathrm{mmol})$ with stirring for 30 minutes. The salt solution of the ligand was added dropwise via syringe to a $\mathrm{CH}_{2} \mathrm{Cl}_{2}$ suspension of $\left[\mathrm{PdBr}_{2}\left(\mathrm{PhCN}_{2}\right](240 \mathrm{mg}, 0.52 \mathrm{mmol})\right.$ with stirring for $18 \mathrm{~h}$. A dark red suspension formed with time. This was filtered over celite to remove traces of $\mathrm{KBr}$ and unreacted $\mathrm{PdBr}_{2}$. The bright red solution was evaporated to obtain a dull yellow powder. Recrystallization from $\mathrm{CH}_{2} \mathrm{Cl}_{2}$ gives the product as a yellow solid.

Yield:

Molecular formula:

Molecular weight:

MS (ESI, $\left.\mathrm{CH}_{2} \mathrm{Cl}_{2}\right) m / z(\%)$ :

IR (ATR, $\left.\mathrm{cm}^{-1}\right)$ :

${ }^{1} \mathrm{H}-\mathrm{NMR}\left(\mathrm{CD}_{2} \mathrm{Cl}_{2}\right) \delta$ :

${ }^{13} \mathrm{C}\left\{{ }^{1} \mathrm{H}\right\}\left(\mathrm{CD}_{2} \mathrm{Cl}_{2}\right) \delta$ :

Elemental analysis:
$170 \mathrm{mg}, 71 \%$

$\mathrm{C}_{32} \mathrm{H}_{43} \mathrm{Br}_{3} \mathrm{~N}_{4} \mathrm{Pd}_{2}$

$936.3 \mathrm{~g} / \mathrm{mol}$.

$852(10 \%)[\mathrm{M}-\mathrm{Br}]^{+} ; 696(40 \%)\left[\mathrm{M}-\mathrm{Br}_{3}\right]^{+}$;

2963 (m); 2924 (m); 2864 (m); 1559 (m); 1477 (s); 1490 (s); 1441 (m); 1385 (s); 1367 (s); 1350 (m); 1264 (m); 1184 (m); 1059 (m); 806 (vs); 782 (vs).

$1.19\left(\mathrm{~d},{ }^{3} J_{\mathrm{HH}}=6.9 \mathrm{~Hz}, 12 \mathrm{H}, \mathrm{CH}_{3}^{i \mathrm{PP}}\right) ; 1.44\left(\mathrm{~d},{ }^{3} J_{\mathrm{HH}}=6.7 \mathrm{~Hz}, 12 \mathrm{H}\right.$, $\left.\mathrm{CH}_{3}{ }^{2 \mathrm{Pr}}\right) ; 2.18\left(\mathrm{~s}, 6 \mathrm{H}, \mathrm{CH}_{3} \mathrm{C}=\mathrm{N}\right) ; 2.50\left(\mathrm{~s}, 3 \mathrm{H}, \mathrm{CH}_{3}{ }^{\mathrm{Pz} 4}\right) ; 3.19\left(\mathrm{p},{ }^{3} J_{\mathrm{HH}}\right.$ $\left.=6.8 \mathrm{~Hz}, 4 \mathrm{H}, \mathrm{CH}^{\mathrm{IPr}}\right) ; 7.22-7.35\left(\mathrm{~m}, 6 \mathrm{H}, \mathrm{CH}^{\mathrm{Ar}}\right)$.

$10.6\left(\mathrm{CH}_{3}{ }^{\mathrm{P} z}\right) ; 19.5\left(\mathrm{CH}_{3} \mathrm{C}=\mathrm{N}\right) ; 23.2\left(\mathrm{CH}_{3}{ }^{\mathrm{PPr}}\right) ; 23.4\left(\mathrm{CH}_{3}{ }^{i \mathrm{Pr}}\right) ; 24.0$ $\left(\mathrm{CH}^{\mathrm{iPr}}\right) ; 29.3\left(\mathrm{CH}^{\mathrm{iPr}}\right) ; 116.9\left(\mathrm{CH}^{\mathrm{Ar}}\right) ; 123.0\left(\mathrm{C}^{\mathrm{Pz}}\right) ; 124.1\left(\mathrm{CH}^{\mathrm{Ar}}\right)$; $128.9 \quad\left(\mathrm{CH}^{\mathrm{An}}\right) ; 140.9 \quad\left(\mathrm{C}^{\mathrm{A \eta}}\right) ; 141.1 \quad\left(\mathrm{C}^{\mathrm{A \eta}}\right) ; 146.8 \quad\left(\mathrm{C}^{\mathrm{P}_{\mathrm{z}}}\right) ; 175.1$ $\left(\mathrm{CH}_{3} \mathrm{C}=\mathrm{N}\right)$.

Calcd. For $\mathrm{C}_{32} \mathrm{H}_{43} \mathrm{Br}_{3} \mathrm{~N}_{8} \mathrm{Pd}_{2} \cdot \mathrm{CH}_{2} \mathrm{Cl}_{2}$ : (C) $38.81(\mathrm{H}) 4.44(\mathrm{~N})$ 5.49; Found: (C) $39.31(\mathrm{H}) 4.58(\mathrm{~N}) 5.36$. 


\subsection{Synthesis of $\left[\mathrm{L}^{2} \mathbf{P d}_{2} \mathrm{I}_{3}\right](2 \mathrm{c})$}

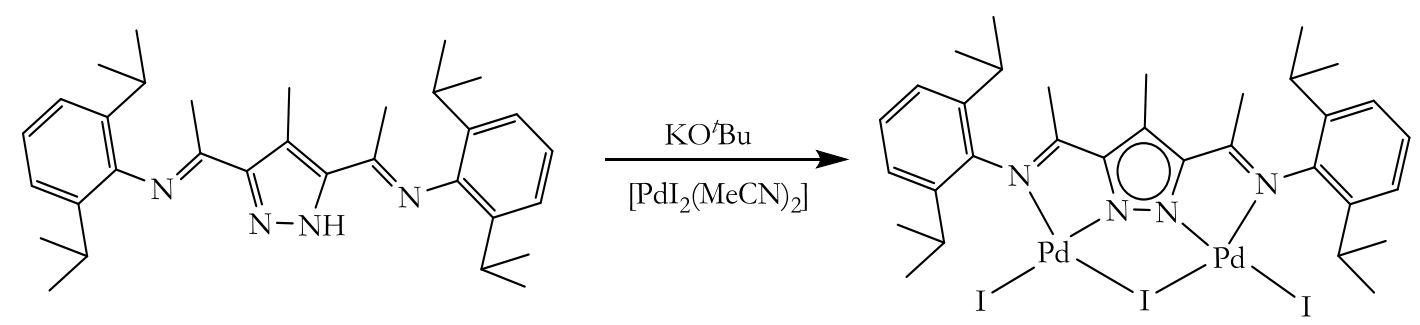

$\mathrm{HL}^{2}$

2c

To a $\mathrm{CH}_{2} \mathrm{Cl}_{2}$ solution $(10 \mathrm{~mL})$ of $\mathbf{H L}^{2}(150 \mathrm{mg}, 0.31 \mathrm{mmol})$ in $\mathrm{CH}_{2} \mathrm{Cl}_{2}(15 \mathrm{~mL})$ was added 1.8 mol equivalent $\mathrm{KO} \mathrm{Bu}^{\prime}\left(70 \mathrm{mg}, 0.57 \mathrm{mmol}\right.$ ) with stirring for 30 minutes. The $\mathrm{CH}_{2} \mathrm{Cl}_{2}$ salt solution of the ligand was then added dropwise via a syring to a $\mathrm{CH}_{2} \mathrm{Cl}_{2}$ suspension of $\left[\mathrm{PdI}_{2}\left(\mathrm{CH}_{3} \mathrm{CN}\right)_{2}\right]$ (290 mg, $0.61 \mathrm{mmol}$ ) with stirring for $18 \mathrm{~h}$. A dark brown suspension formed, the reaction mixture was filtered over celite to remove traces of KI to obtain a dark red solution. The dark red solution was evaporated to obtain a brown powder. The powder was reddisolved in $\mathrm{CH}_{2} \mathrm{Cl}_{2}$, and allowed to slowly evaporate at room temperature. The product was isolated as brown fluffy solid.

Yield:

Molecular Formula:

Molecular weight:

MS (ESI, $\left.\mathrm{CH}_{2} \mathrm{Cl}_{2}\right) m / z(\%)$ :

IR (ATR, $\mathrm{cm}^{-1}$ ):

${ }^{1} \mathrm{H}-\mathrm{NMR}\left(\mathrm{CDCl}_{3}\right) \delta$ :

$\left.{ }^{13} \mathrm{C}\left\{{ }^{1} \mathrm{H}\right\}\left(\mathrm{CD}_{2} \mathrm{Cl}\right)_{3}\right)$ :

CHN Analysis:
$110 \mathrm{mg}, 33 \%$

$\mathrm{C}_{32} \mathrm{H}_{43} \mathrm{I}_{3} \mathrm{~N}_{4} \mathrm{Pd}_{2}$ $1077.3 \mathrm{~g} / \mathrm{mol}$.

$2026(100 \%)\left[\mathrm{L}_{2} \mathrm{Pd}_{4} \mathrm{I}_{5}\right]^{+} ; 950$ (20\%) [M-I].

3005 (m); 2961 (s); 2924 (m); 2855 (m); 1546 (vs); 1462 (s); 1441 (m); $1424(\mathrm{~s}) ; 1367$ (s); 1385 (s); 1341 (m); 12579 (m); 1059 (s); $1026(\mathrm{~m}) ; 776(\mathrm{~s})$.

$1.15\left(\mathrm{~d},{ }^{3} J_{\mathrm{HH}}=6.9 \mathrm{~Hz}, 12 \mathrm{H}, \mathrm{CH}_{3}{ }^{\mathrm{iPr}}\right) ; 1.45\left(\mathrm{~d},{ }^{3} J_{\mathrm{HH}}=6.9 \mathrm{~Hz}, 12 \mathrm{H}\right.$, $\left.\mathrm{CH}_{3}{ }^{i \mathrm{Pr}}\right) ; 2.17\left(\mathrm{~s}, 6 \mathrm{H}, \mathrm{CH}_{3} \mathrm{C}=\mathrm{N}\right) ; 2.52\left(\mathrm{~s}, 3 \mathrm{H}, \mathrm{CH}_{3}{ }^{\mathrm{P} z 4}\right) ; 3.15(\mathrm{~m}, 4 \mathrm{H}$, $\left.\mathrm{CH}^{\mathrm{iPr}}\right) ; 6.91-7.24\left(\mathrm{~m}, 6 \mathrm{H}, \mathrm{CH}^{\mathrm{Ar}}\right)$.

$11.2\left(\mathrm{CH}_{3}{ }^{\mathrm{P} z}\right) ; 19.4\left(\mathrm{CH}_{3} \mathrm{C}=\mathrm{N}\right) 23.1\left(\mathrm{CH}_{3}{ }^{i \mathrm{PP}}\right) ; 23.3\left(\mathrm{CH}_{3}{ }^{i \mathrm{Pr}}\right) ; 23.8$ $\left(\mathrm{CH}_{3}{ }^{i \mathrm{PP}}\right) ; 23.6\left(\mathrm{CH}_{3}{ }^{\mathrm{iPr}}\right) ; 23.8\left(\mathrm{CH}_{3}{ }^{i \mathrm{Pr}}\right) ; 28.4\left(\mathrm{CH}^{i \mathrm{PP}}\right) ; 28.9\left(\mathrm{CH}^{i \mathrm{Pr}}\right)$; $123.0\left(\mathrm{CH}^{\mathrm{Ar}}\right) ; 124.0\left(\mathrm{CH}^{\mathrm{Ar}}\right) ; 128.1\left(\mathrm{CH}^{\mathrm{Ar}}\right) ; 128.5\left(\mathrm{CH}^{\mathrm{Ar}}\right) ; 136.5$; $140.6\left(\mathrm{C}^{\mathrm{Ar}}\right) ; 142.5\left(\mathrm{C}^{\mathrm{Ar}}\right) ; 164.9\left(\mathrm{CH}_{3} \mathrm{C}=\mathrm{N}\right) ; 175.1\left(\mathrm{CH}_{3} \mathrm{C}=\mathrm{N}\right)$

Calcd. For $\mathrm{C}_{32} \mathrm{H}_{43} \mathrm{I}_{3} \mathrm{~N}_{4} \mathrm{Pd}_{2}$ : (C) $35.68(\mathrm{H}) 4.02$ (N) 5.20; Found: (C) $39.39(\mathrm{H}) 4.58(\mathrm{~N}) 5.36$. 


\subsection{Synthesis of $\left[\mathrm{L}^{2} \mathrm{Pd}_{2}(\mu-\mathrm{Cl})\left(\mathrm{CH}_{3}\right)_{2}\right](2 \mathrm{f})$}

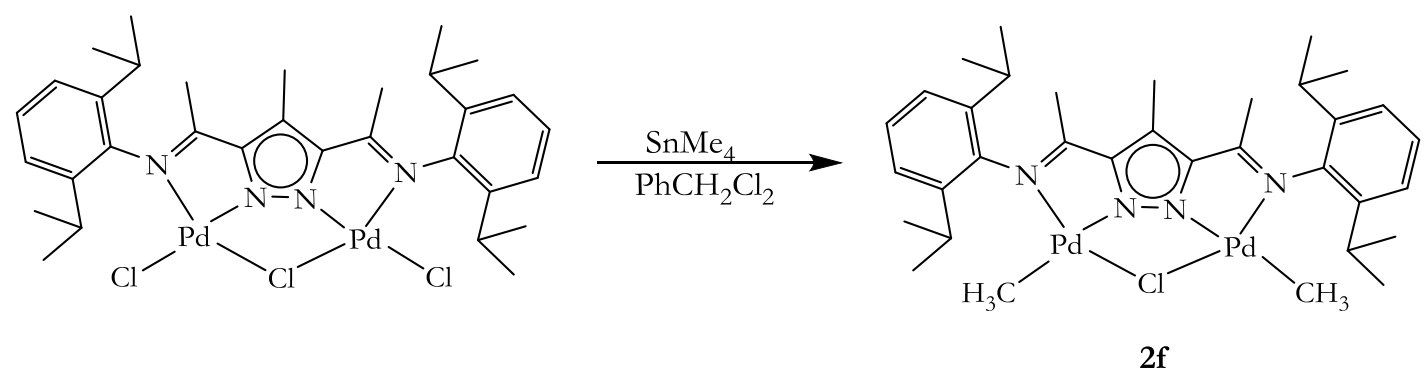

To a benzylchloride solution $(10 \mathrm{~mL})$ of $\left[\mathrm{L}^{2} \mathrm{Pd}_{2} \mathrm{Cl}_{3}\right](200 \mathrm{mg}, 0.25 \mathrm{mmol})$ was added $4.0 \mathrm{~mol}$ equivalent of $\mathrm{SnMe}_{4}(0.1 \mathrm{~mL}, 1.0 \mathrm{mmol})$ with stirring at room temperature. After $8 \mathrm{~h}$, a dark red solution was formed with traces of $\operatorname{Pd}(0)$. The mixture was filtered over celite to obtain an orange solution. The solution was evaporated to obtain a bright orange powder. The powder was re-dissolved in $\mathrm{CH}_{2} \mathrm{Cl}_{2}(5 \mathrm{~mL})$ and slowly layered with $\mathrm{Et}_{2} \mathrm{O}(15 \mathrm{ml})$, which results in the precipitation of an orange solid. The suspension was filtered and the solid washed with $\mathrm{Et}_{2} \mathrm{O}$ $(3 \times 3 \mathrm{~mL})$ and the product dried in air. Slow evaporation of a $\mathrm{CH}_{2} \mathrm{Cl}_{2}$ solution of the complex gives the complex as a yellow crystalline solid. This solid was contaminated with traces of $\mathrm{L}_{2} \mathrm{Pd}$ side product $(15 \%)$.

Yield:

Molecular formula:

Molecular weight:

MS (ESI, $\left.\mathrm{CH}_{2} \mathrm{Cl}_{2}\right) m / \%(\%)$ :

IR $\left(\right.$ ATR, $\left.\mathrm{cm}^{-1}\right)$ :

${ }^{1} \mathrm{H}-\mathrm{NMR}\left(\mathrm{CDCl}_{3}\right) \delta$ :

${ }^{13} \mathrm{C}\left\{{ }^{1} \mathrm{H}\right\}\left(\mathrm{CDCl}_{3}\right) \delta$ :
$120 \mathrm{mg}, 63 \%$

$\mathrm{C}_{34} \mathrm{H}_{49} \mathrm{ClN}_{4} \mathrm{Pd}_{2}$

$762.1 \mathrm{~g} / \mathrm{mol}$.

$1073(30 \%)\left[\mathrm{L}_{2} \mathrm{Pd}\right]^{+} ; 801(50 \%)[\mathrm{M}+\mathrm{K}]^{+} ; 762(10 \%)[\mathrm{M}]^{+} ; 725$ $(40 \%)[\mathrm{M}-\mathrm{Cl}]^{+}$.

2963 (m); 2870 (m); 1465 (s); 1439 (s); 1385 (vs); 1367 (vs); 1255 (m); 1147 (vs). 1059 (m); 979 (m); 936 (m); 778 (vs).

$-0.03\left(\mathrm{~s}, 6 \mathrm{H}, \mathrm{CH}_{3}^{\mathrm{Pd}}\right) ; 1.15\left(\mathrm{~d},{ }^{3} \mathrm{JHH}_{\mathrm{HH}}=6.7 \mathrm{~Hz}, 12 \mathrm{H}, \mathrm{CH}_{3}{ }^{i \mathrm{Pr}}\right) ; 1.30(\mathrm{~d}$, $\left.{ }^{3} J_{\mathrm{HH}}=6.9 \mathrm{~Hz}, 12 \mathrm{H}, \mathrm{CH}_{3}{ }^{i \mathrm{Pr}}\right) ; 2.13\left(\mathrm{~s}, 6 \mathrm{H}, \mathrm{CH}_{3} \mathrm{C}=\mathrm{N}\right) ; 2.47$ (s, 3H, $\left.\mathrm{CH}_{3}{ }^{\mathrm{Pz}}\right) ; 3.23\left(\mathrm{~m}, 4 \mathrm{H}, \mathrm{CH}^{\mathrm{Pr}}\right) ; 6.78-7.90\left(\mathrm{~m}, 6 \mathrm{H}, \mathrm{CH}^{\mathrm{Ar}}\right)$.

-1.99 $\left(\mathrm{CH}_{3}{ }^{\mathrm{Pd}}\right) ; 18.1\left(\mathrm{CH}_{3} \mathrm{C}=\mathrm{N}\right) ; 23.4\left(\mathrm{CH}_{3}{ }^{2 \mathrm{Pr}}\right) ; 23.4\left(\mathrm{CH}_{3}{ }^{1 \mathrm{PP}}\right) ; 28.1$ $\left(\mathrm{CH}^{\mathrm{IPr}}\right) ; 28.2\left(\mathrm{CH}^{\mathrm{iPr}}\right) ; 123.5\left(\mathrm{CH}^{\mathrm{Ar}}\right) ; 126.7\left(\mathrm{CH}^{\mathrm{Ar}}\right) ; 140.8\left(\mathrm{C}^{\mathrm{Ar}}\right) ; 141.0$ $\left(\mathrm{C}^{\mathrm{Ar}}\right) ; 145.5\left(\mathrm{C}^{\mathrm{Ar}}\right) ; 171.3\left(\mathrm{CH}_{3} \mathrm{C}=\mathrm{N}\right)$. 


\subsection{Synthesis of $\left[\mathrm{L}^{2} \mathrm{Pd}_{2}(\mu-\mathrm{Br})\left(\mathrm{CH}_{3}\right)_{2}\right](2 \mathrm{~g})$}

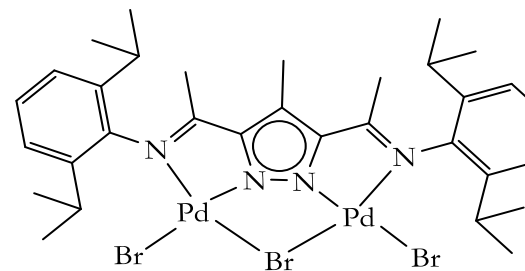

$2 \mathrm{~b}$

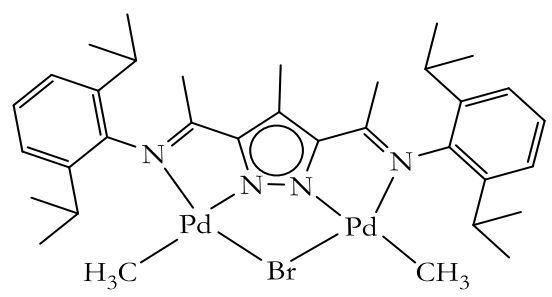

$2 \mathrm{~g}$

To a $\mathrm{CH}_{2} \mathrm{Cl}_{2}$ solution $(10 \mathrm{~mL})$ of $\mathbf{2 b}(100 \mathrm{mg}, 0.11 \mathrm{mmol})$ was added 90 equivalents of $\mathrm{SnMe}_{4}(1$ $\mathrm{mL}, 9.70 \mathrm{mmol}$ ) with stirring at room temperature. After $24 \mathrm{~h}$ no visible colour change in the bright red solution was observed. Compared to the chloro analogue of the complex where the formation of $\operatorname{Pd}(0)$ species can be observed after $18 \mathrm{~h}$. The reaction was stirred for 3 weeks and constantly monitored by ${ }^{1} \mathrm{H}$ NMR spectroscopy. After 3 weeks, the bright red colour was dischared with the formation of a bright yellow solution with trace amounts of $\operatorname{Pd}(0)$ species formed. The reaction was filtered over celite to obtain a bright yellow solution. The solution was concentrated to about $5 \mathrm{~mL}$ and layered with ether, which results in the precipitation of a bright yellow powder. The solid was filtered and washed with $\mathrm{Et}_{2} \mathrm{O}(3 \times 3 \mathrm{~mL})$ and the product dried in air.

Yield:

$70 \mathrm{mg}, 81 \%$

Molecular formula:

$\mathrm{C}_{34} \mathrm{H}_{49} \mathrm{BrN}_{4} \mathrm{Pd}_{2}$

Molecular weight:

$806.5 \mathrm{~g} / \mathrm{mol}$.

MS (ESI, $\left.\mathrm{CH}_{2} \mathrm{Cl}_{2}\right) m / z(\%)$ :

$807(2 \%)[\mathrm{M}+\mathrm{H}]^{+} ; 725(22 \%)[\mathrm{M}-\mathrm{Br}-\mathrm{H}]^{+}$.

IR $\left(\right.$ ATR, $\left.\mathrm{cm}^{-1}\right)$ :

2961 (m); 2926 (s); 1532 (vs); 1485 (s); 1439 (vs); 1255 (vs); 1147

(s); 1059 (m); 979 (m); 806 (s); 778 (vs); 594 (m); 547 (m).

${ }^{1} \mathrm{H}-\mathrm{NMR}\left(\mathrm{CDCl}_{3}\right) \delta$ :

$-0.03\left(\mathrm{~s}, 6 \mathrm{H}, \mathrm{CH}_{3}{ }^{\mathrm{Pd}}\right) ; 1.14\left(\mathrm{~d}, 12 \mathrm{H},{ }^{3} J_{\mathrm{HH}}=6.8 \mathrm{~Hz}, 12 \mathrm{H}, \mathrm{CH}_{3}{ }^{2 \mathrm{Pr}}\right)$;

$1.30\left(\mathrm{~d},{ }^{3} J_{\mathrm{HH}}=6.8 \mathrm{~Hz}, 12 \mathrm{H}, \mathrm{CH}_{3}{ }^{i \mathrm{Pr}}\right) ; 2.13\left(\mathrm{~s}, 6 \mathrm{H}, \mathrm{CH}_{3} \mathrm{C}=\mathrm{N}\right) ; 2.47$

$\left(\mathrm{s}, 3 \mathrm{H}, \mathrm{CH}_{3}{ }^{\mathrm{Pz}}\right) ; 3.22$ (sept, $\left.4 \mathrm{H},{ }^{3} J_{\mathrm{HH}}=6.8 \mathrm{~Hz}, \mathrm{CH}^{\mathrm{PP}}\right) ; 7.21-7.26(\mathrm{~m}$, $\left.6 \mathrm{H}, \mathrm{CH}^{\mathrm{Ar}}\right)$.

${ }^{13} \mathrm{C}\left\{{ }^{1} \mathrm{H}\right\}\left(\mathrm{CDCl}_{3}\right) \delta:$

$1.96\left(\mathrm{CH}_{3}{ }^{\mathrm{Pd}}\right) ; 10.4\left(\mathrm{CH}_{3}{ }^{\mathrm{P} 4}\right) ; 19.4\left(\mathrm{CH}_{3} \mathrm{C}=\mathrm{N}\right) ; 23.5\left(\mathrm{CH}_{3}{ }^{\text {PP }}\right) ; 24.0$ $\left(\mathrm{CH}_{3}{ }^{i \mathrm{Pr}}\right) ; 28.2\left(\mathrm{CH}^{i \mathrm{Pr}}\right) ; 119.6\left(\mathrm{C}^{\mathrm{P} z 3}\right) ; 123.7\left(\mathrm{CH}^{\mathrm{Ar}}\right) ; 123.9\left(\mathrm{CH}^{\mathrm{Ar}}\right)$; $127.0\left(\mathrm{CH}^{\mathrm{Ar}}\right) ; 140.2\left(\mathrm{C}^{\mathrm{Ar}}\right) ; 141.3\left(\mathrm{C}^{\mathrm{Ar}}\right) ; 146.5\left(\mathrm{C}^{\mathrm{Ar}}\right) ; 172.2$ $\left(\mathrm{CH}_{3} \mathrm{C}=\mathrm{N}\right)$.

Elemental analysis:

Calcd. For $\mathrm{C}_{34} \mathrm{H}_{49} \mathrm{Cl}_{4} \mathrm{~N}_{4} \mathrm{Pd}_{2} \cdot 1.5 \mathrm{CH}_{2} \mathrm{Cl}_{2}$ : (C) 45.65 (H) 5.61 6.00; Found: (C) $45.56(\mathrm{H}) 5.88$ (N) 6.05. 


\subsection{Synthesis of $\left[\mathrm{L}_{2}^{2}\left\{\mathrm{CH}_{3} \mathrm{Pd}\right\}_{2}\left\{\mathrm{CH}_{3} \mathrm{PdCl}\right\}\left(\mathrm{Sn}\left(\mathrm{CH}_{3}\right)_{3} \mathrm{Cl}\right)\right](2 \mathrm{~h})$}
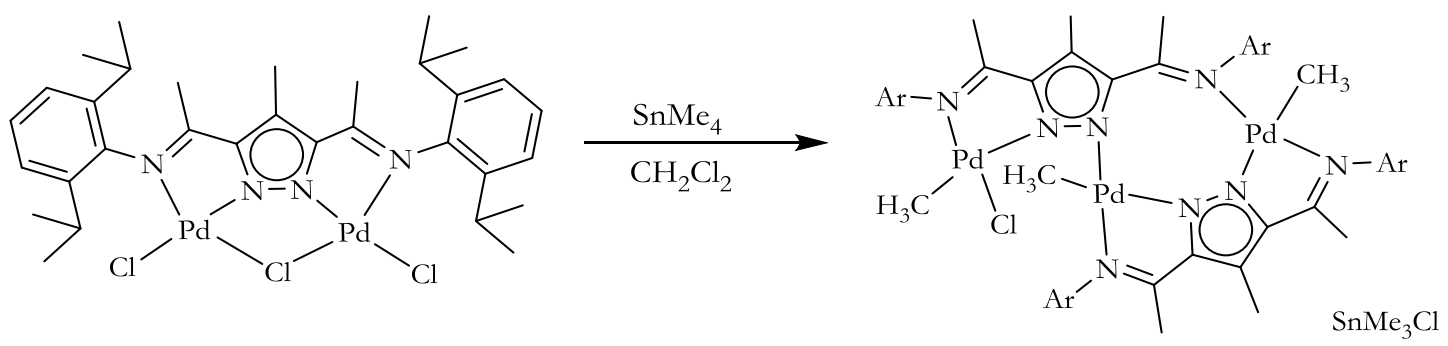

$2 \mathrm{~h}$

To a $\mathrm{CH}_{2} \mathrm{Cl}_{2}$ solution $(15 \mathrm{~mL})$ of $\left[\mathrm{L}^{2} \mathrm{Pd}_{2} \mathrm{Cl}_{3}\right](100 \mathrm{mg}, 0.13 \mathrm{mmol})$ was added 40 equivalents of $\mathrm{SnMe}_{4}(0.52 \mathrm{~mL}, 1.72 \mathrm{mmol})$ with stirring for $48 \mathrm{~h}$. The reaction mixture was filtered over celite to remove $\operatorname{Pd}(0)$. The bright yellow solution obtained was concentrated on a rotary evaporator to about $5 \mathrm{~mL}$ and $15 \mathrm{~mL}$ of hexane added. Bright yellow crystalline blocks were harvested from the bottom of the beaker after slow evaporation of the $\mathrm{CH}_{2} \mathrm{Cl}_{2} /$ hexane solution of the complex. The NMR of the yellow crystals was different from the rest of the yellow powdery material, which was left at the bottom of the beaker. In a separate but repeated experiment, the same product was obtained by recrystallization of the crude reaction mixture from toluene at a temperature of $-30^{\circ} \mathrm{C}$.

Yield:

Molecular formula:

Molecular weight:

MS (ESI, $\left.\mathrm{CH}_{2} \mathrm{Cl}_{2}\right) m / z(\%)$ :

IR $\left(\right.$ ATR, $\left.\mathrm{cm}^{-1}\right)$ :

${ }^{1} \mathrm{H}-\mathrm{NMR}\left(\mathrm{CDCl}_{3}\right) \delta:$
$68 \mathrm{mg}, 38 \%$

$\mathrm{C}_{70} \mathrm{H}_{104} \mathrm{Cl}_{2} \mathrm{~N}_{8} \mathrm{Pd}_{3} \mathrm{Sn}$

$1566.5 \mathrm{~g} / \mathrm{mol}$.

$1329(55 \%)\left[\mathrm{L}_{2} \mathrm{Pd}_{3}(\mathrm{Me})_{3}\right]^{+} ; 1314(20 \%)\left[\mathrm{L}_{2} \mathrm{Pd}_{3}(\mathrm{Me})_{2}\right]^{+} ; 1299$ (100\%) $\left[\mathrm{L}_{2} \mathrm{Pd}_{3}(\mathrm{Me})\right]^{+} ; 589(100 \%)[\mathrm{LPd}]^{+}$.

2959 (m); 2926 (m); 2868 (m); 1601 (vs); 1586 (vs); 1462 (s); 1444 (m); 1366 (m); 1346 (m); 1320 (m); 1059 (m); 1044 (m); 1100 (w); 908 (s); 802 (m); 780 (m); 746 (vs).

(mixture of isomers); -0.12 (s, $\left.3 \mathrm{H}, \mathrm{CH}_{3}{ }^{\mathrm{Pd}}\right) ;-0.08$ (s, $3 \mathrm{H}, \mathrm{CH}_{3}{ }^{\mathrm{Pd}}$ ); 0.31 (s, 3H, $\left.\mathrm{CH}_{3}{ }^{\mathrm{Pd}}\right) ; 0.45$ (s, 3H, $\left.\mathrm{CH}_{3}{ }^{\mathrm{Pd}}\right) ; 0.79$ (s, 9H, $\mathrm{CH}_{3}{ }^{\mathrm{SnMe}}$ ); 1.02-1.54 (m, 24H, $\left.\mathrm{CH}_{3}{ }^{\mathrm{PP}}\right) ; 2.01\left(\mathrm{~s}, 3 \mathrm{H}, \mathrm{CH}_{3} \mathrm{C}=\mathrm{N}\right) ; 2.12$ (s, 3H, $\left.\mathrm{CH}_{3} \mathrm{C}=\mathrm{N}\right) ; 2.16\left(\mathrm{~s}, 3 \mathrm{H}, \mathrm{CH}_{3} \mathrm{C}=\mathrm{N}\right) ; 2.17\left(\mathrm{~s}, 3 \mathrm{H}, \mathrm{CH}_{3} \mathrm{C}=\mathrm{N}\right) ; 2.19$ (s, $\left.3 \mathrm{H}, \mathrm{CH}_{3} \mathrm{C}=\mathrm{N}\right) ; 2.20\left(\mathrm{~s}, 3 \mathrm{H}, \mathrm{CH}_{3} \mathrm{C}=\mathrm{N}\right) ; 2.36\left(\mathrm{~s}, 3 \mathrm{H}, \mathrm{CH}_{3} \mathrm{C}=\mathrm{N}\right)$; $2.51\left(\mathrm{~s}, 3 \mathrm{H}, \mathrm{CH}_{3} \mathrm{C}=\mathrm{N}\right) ; 2.56\left(\mathrm{~s}, 3 \mathrm{H}, \mathrm{CH}_{3} \mathrm{C}=\mathrm{N}\right) ; 2.57$ (s, 3H, $\left.\mathrm{CH}_{3} \mathrm{C}=\mathrm{N}\right) ; 2.58\left(\mathrm{~s}, 3 \mathrm{H}, \mathrm{CH}_{3} \mathrm{C}=\mathrm{N}\right) ; 2.88\left(\mathrm{~s}, 3 \mathrm{H}, \mathrm{CH}_{3}{ }^{\mathrm{P} 4}\right) ; 2.91(\mathrm{~s}$, 


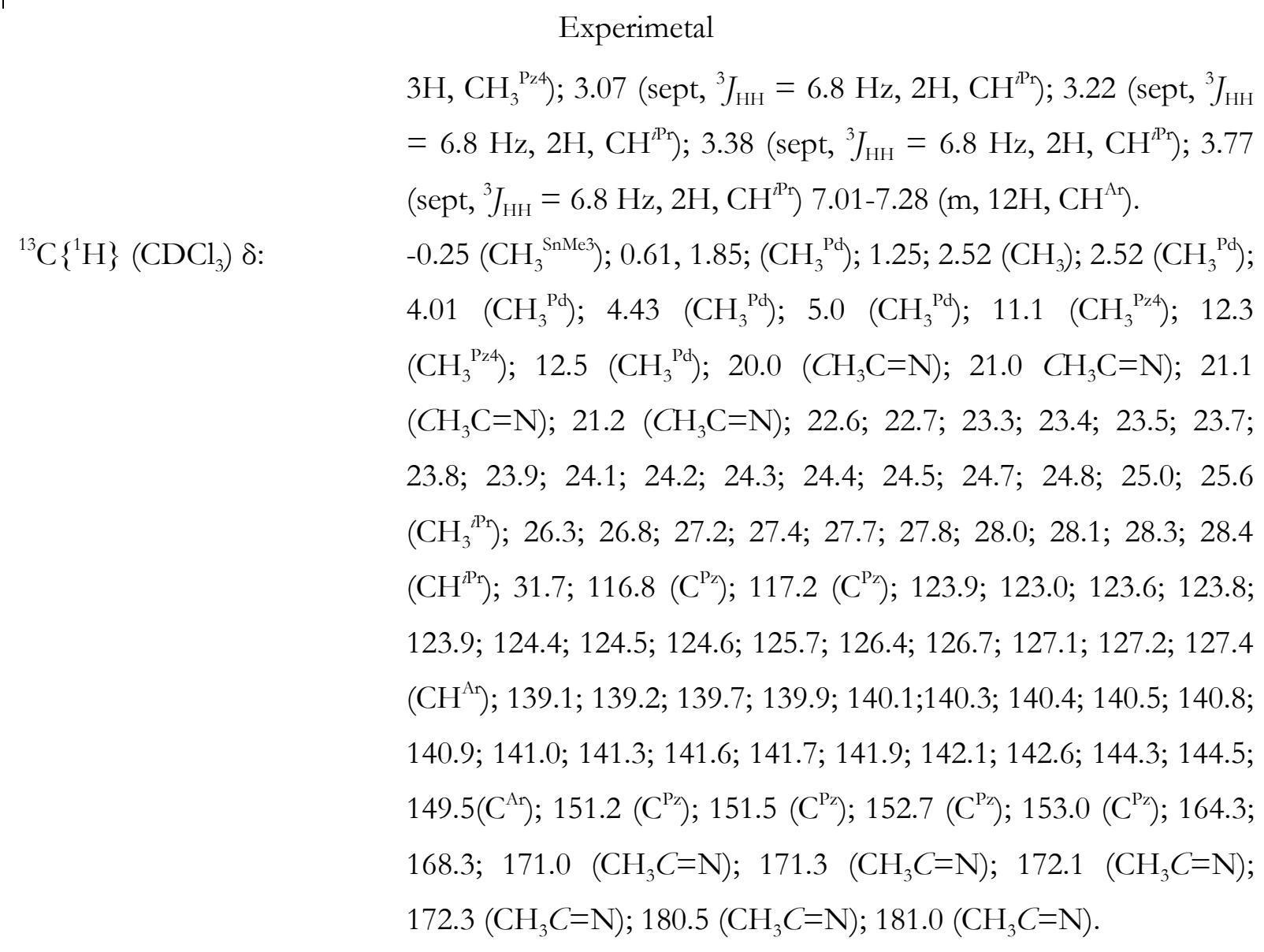

Elemental analysis: Found: (C) $53.94(\mathrm{H}) 6.64(\mathrm{~N}) 7.38$.

\subsection{Synthesis of $\left[\mathrm{L}_{2}^{1} \mathrm{Pd}_{4}\left(\mu-\mathrm{CH}_{2}\right)(\mu-\mathrm{Cl})_{2}\left(\mathrm{CH}_{3}\right)_{2}\right](2 \mathrm{k})$}
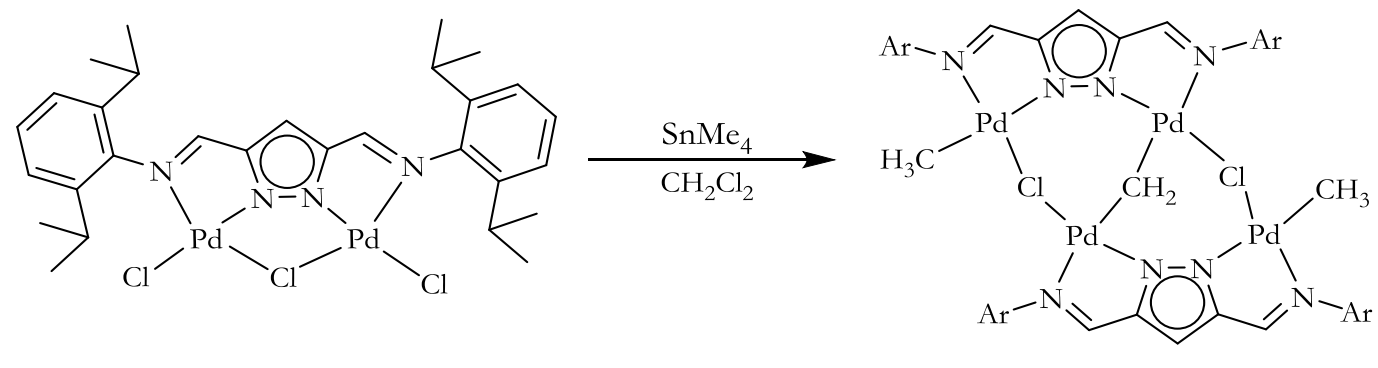

$2 k$

To a $\mathrm{CH}_{2} \mathrm{Cl}_{2}$ solution $(10 \mathrm{~mL})$ of $\left[\mathrm{L}^{1} \mathrm{Pd}_{2} \mathrm{Cl}_{3}\right](260 \mathrm{mg}, 0.34 \mathrm{mmol})$ was added $8 \mathrm{~mol}$ equivalent $\mathrm{SnMe}_{4}(0.27 \mathrm{~mL}, 2.72 \mathrm{mmol})$ with stirring under room temperature for $48 \mathrm{~h}$. After this period, a dark green suspension was formed. The reaction was filtered over celite to remove $\operatorname{Pd}(0)$, and a $\mathrm{CH}_{2} \mathrm{Cl}_{2}$ solution of the complex was concentrated and layered with hexane, which results in the precipitation of $\mathrm{SnMe}_{3} \mathrm{Cl}$. The yellow filterate was evaporated on a vacuum pump to obtain the 


\section{Experimetal}

crude product as a yellow solid. The product was redissolved in $\mathrm{CH}_{2} \mathrm{Cl}_{2}$ and layered with hexane. The required product was isolated as a bright yellow crystalline solids after several days from a $\mathrm{CH}_{2} \mathrm{Cl}_{2}$ solution at $-10^{\circ} \mathrm{C}$ to give a combined yield of $0.19 \mathrm{~g}$. However, a second crop of yet to be identified side product which is devoid of the $\mu-\mathrm{CH}_{2}$ bridge was quantitatively present in solution $(38 \%)$.

Yield:

Molecular formula:

Molecular weight:

MS (ESI, $\left.\mathrm{CH}_{2} \mathrm{Cl}_{2}\right) m / z(\%)$ :

IR $\left(\right.$ ATR, $\left.\mathrm{cm}^{-1}\right)$ :

${ }^{1} \mathrm{H}-\mathrm{NMR}\left(\mathrm{CDCl}_{3}\right) \delta:$

${ }^{13} \mathrm{C}\left\{{ }^{1} \mathrm{H}\right\}\left(\mathrm{CDCl}_{3}\right) \delta:$

Elemental analysis:
$190 \mathrm{mg}, 39 \%$

$\mathrm{C}_{61} \mathrm{H}_{82} \mathrm{Cl}_{2} \mathrm{~N}_{8} \mathrm{Pd}_{4}$ $1423.9 \mathrm{~g} / \mathrm{mol}$.

$1463(100 \%)[\mathrm{M}+\mathrm{K}]^{+}$.

2959 (vs); 2868 (s); 1687 (m); 1603 (vs); 1586 (vs); 1441 (s); 1365 (m); 1344 (m); 1275 (m); 1132 (s); 1110 (m); 1024 (S); 907 (s); 800 (vs); 745 (vs).

$-0.03\left(\mathrm{~s}, 6 \mathrm{H}, \mathrm{CH}_{3}{ }^{\mathrm{Pd}}\right) ; 1.05-1.28\left(\mathrm{~m}, 48 \mathrm{H}, \mathrm{CH}_{3}{ }^{\mathrm{iP}}\right) ; 3.01$ (sept, ${ }^{3} \mathrm{JHH}_{\mathrm{HH}}=$ $\left.6.8 \mathrm{~Hz}, 4 \mathrm{H}, \mathrm{CH}^{\mathrm{PP}}\right) ; 3.34$ (sept, $\left.{ }^{3} J_{\mathrm{HH}}=6.8 \mathrm{~Hz}, 2 \mathrm{H}, \mathrm{CH}^{\mathrm{PP}}\right) ; 3.54$ (sept, ${ }^{3} J_{\mathrm{HH}}=6.8 \mathrm{~Hz}, 2 \mathrm{H}, \mathrm{CH}^{\mathrm{PP}}$ ); 4.23 (s, 2H, $\left.\mu-\mathrm{CH}_{2}\right) ; 6.98$ (s, $2 \mathrm{H}$, $\left.\mathrm{CH}^{\mathrm{Pz} 4}\right)$; 7.13-7.26 (m, 12H, $\left.\mathrm{CH}^{\mathrm{Ar}}\right) ; 7.91$ (s, 2H, CH=N); 8.04 (s, $2 \mathrm{H}, \mathrm{CH}=\mathrm{N})$.

$1.45\left(\mathrm{CH}_{3}^{\mathrm{Pd}}\right) ; 21.6\left(\mathrm{CH}_{3}^{i \mathrm{PP}}\right) ; 22.7\left(\mathrm{CH}^{\mathrm{iPr}}\right) ; 22.8\left(\mathrm{CH}_{3}^{i \mathrm{Pr}}\right) ; 24.4\left(\mathrm{CH}_{3}^{i \mathrm{Pr}}\right)$; $24.6\left(\mathrm{CH}_{3}{ }^{i \mathrm{Pr}}\right) ; 25.0\left(\mathrm{CH}_{3}{ }^{i \mathrm{Pr}}\right) ; 25.4\left(\mathrm{CH}_{3}{ }^{i \mathrm{Pr}}\right) ; 27.9\left(\mathrm{CH}^{i \mathrm{Pr}}\right) ; 28.0\left(\mathrm{CH}^{i \mathrm{Pr}}\right)$; $28.2\left(\mathrm{CH}^{\mathrm{PP}}\right) ; 28.7\left(\mathrm{CH}^{\mathrm{iPr}}\right) ; 50.2\left(\mathrm{CH}_{2}\right) ; 111.3\left(\mathrm{CH}^{\mathrm{Pz}}\right) ; 122.3\left(\mathrm{CH}^{\mathrm{Ar}}\right)$; $123.1\left(\mathrm{CH}^{\mathrm{Ar}}\right) ; 123.2\left(\mathrm{CH}^{\mathrm{Ar}}\right) ; 123.5\left(\mathrm{CH}^{\mathrm{Ar}}\right) ; 125.4\left(\mathrm{CH}^{\mathrm{Ar}}\right) ; 125.9$ $\left(\mathrm{CH}^{\mathrm{Ar}}\right) ; 127.3\left(\mathrm{CH}^{\mathrm{Ar}}\right) ; 128.3\left(\mathrm{CH}^{\mathrm{Ar}}\right) ; 129.1\left(\mathrm{CH}^{\mathrm{Ar}}\right) ; 139.7\left(\mathrm{C}^{\mathrm{Ar}}\right) ; 140.3$ $\left(C^{A r}\right) ; 140.5\left(C^{A r}\right) ; 143.9\left(C^{A r}\right) ; 145.0\left(C^{A r}\right) ; 148.5\left(C^{P_{z}}\right) ; 152.4\left(C^{P_{z}}\right)$; $156.0(\mathrm{CH}=\mathrm{N}) ; 160.4(\mathrm{CH}=\mathrm{N})$.

Calcd. For $\mathrm{C}_{62} \mathrm{H}_{84} \mathrm{Cl}_{4} \mathrm{~N}_{8} \mathrm{Pd}_{4}$ : (C) 49.35 (H) 5.65 (N) 7.43; Found: (C) $49.97(\mathrm{H}) 5.67(\mathrm{~N}) 7.53$. 


\subsection{Synthesis of $\left[\mathrm{L}_{2}^{2} \mathrm{Pd}_{4}(\mu-\mathrm{Cl})_{3}\left(\mathrm{CH}_{3}\right)_{2}\right] \mathrm{Cl}\left(2 \mathrm{~d}_{2}\right)$}
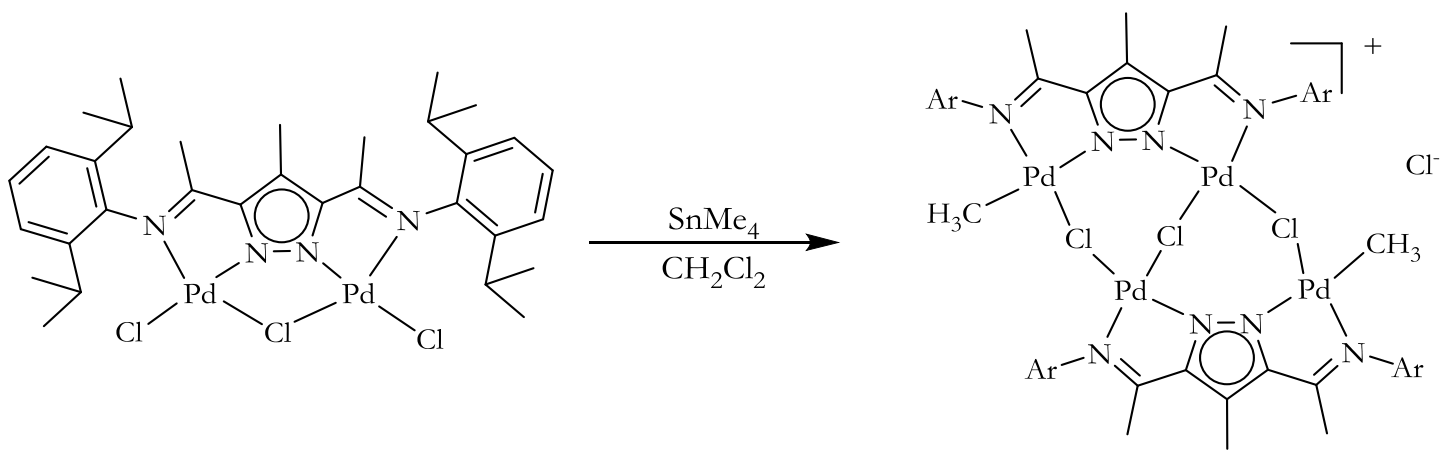

$2 d_{2}$

To a $\mathrm{CH}_{2} \mathrm{Cl}_{2}$ solution $(10 \mathrm{~mL})$ of $\left[\mathrm{L}^{2} \mathrm{Pd}_{2} \mathrm{Cl}_{3}\right](100 \mathrm{mg}, 0.12 \mathrm{mmol})$ was added $\mathrm{SnMe}_{4}(0.01 \mathrm{~mL}$, $0.09 \mathrm{mmol}, 0.75 \mathrm{~mol}$ Eq.) with stirring at room temperature conditions. After stirring for $18 \mathrm{~h}$, a dark red solution was obtained. Evaporation of the solution leads to the isolation of an orange solid. The solid was dissolved in $3 \mathrm{~mL} \mathrm{CH}_{2} \mathrm{Cl}_{2}$ and slowly layered with hexane to precipitate an orange powder. The powder is partially soluble in $\mathrm{CHCl}_{3}$, soluble in $\mathrm{CH}_{2} \mathrm{Cl}_{2}$ and sparingly soluble in methanol, acetonitrile, ether and hexane. This solid was washed several times with $\mathrm{Et}_{2} \mathrm{O}$ to obtain the product as an orange powder.

Yield:

$74 \mathrm{mg}, 39 \%$

Molecular formula:

$\mathrm{C}_{66} \mathrm{H}_{92} \mathrm{Cl}_{4} \mathrm{~N}_{8} \mathrm{Pd}_{4}$

Molecular weight:

$1564.9 \mathrm{~g} / \mathrm{mol}$.

MS (ESI, $\left.\mathrm{CH}_{2} \mathrm{Cl}_{2}\right) m / z(\%)$ :

1529 (50\%) [M-Cl ${ }^{+} ; 1410$ (25\%) $\left[\mathrm{L}_{2} \mathrm{Pd}_{4}\left(\mathrm{CH}_{3}\right)\right]^{+} ; 1373$ (20\%) [M-

$\left.\operatorname{Pd}\left(\mathrm{CH}_{3}\right) \mathrm{Cl}\right]^{+} ; 589(20 \%)[\mathrm{LPd}]^{+}$.

IR $\left(\right.$ ATR, $\left.\mathrm{cm}^{-1}\right)$ :

2963 (s); 2962 (m); 2866 (m); 1542 (vs); 1524 (s); 1490 (s); 1477

(s); 1184 (m); 1102 (m); 1059 (s); 1035 (m); 998 (s); 806 (vs); 782 (vs); $711(\mathrm{~m})$.

${ }^{1} \mathrm{H}-\mathrm{NMR}\left(\mathrm{CDCl}_{3}\right) \delta$ :

0.10 (br s, 6H, $\left.\mathrm{CH}_{3}{ }^{\mathrm{Pd}}\right) ; 1.12-1.21\left(\mathrm{~m}, 24 \mathrm{H}, \mathrm{CH}_{3}{ }^{\mathrm{iP}}\right) ; 1.31\left(\mathrm{~d},{ }^{3} \mathrm{HH}_{\mathrm{HH}}=\right.$ $\left.6.8 \mathrm{~Hz}, 12 \mathrm{H}, \mathrm{CH}_{3}{ }^{i \mathrm{Pr}}\right) ; 1.46\left(\mathrm{~d},{ }^{3} J_{\mathrm{HH}}=6.8 \mathrm{~Hz}, 12 \mathrm{H}, \mathrm{CH}_{3}{ }^{\text {PPr }}\right) ; 2.14(\mathrm{~s}$, $\left.6 \mathrm{H}, \mathrm{CH}_{3} \mathrm{C}=\mathrm{N}\right) ; 2.17\left(\mathrm{~s}, 6 \mathrm{H}, \mathrm{CH}_{3} \mathrm{C}=\mathrm{N}\right) ; 2.52\left(\mathrm{~s}, 6 \mathrm{H}, \mathrm{CH}_{3}{ }^{\mathrm{Pz}}\right) ; 3.20$ $\left(\mathrm{m}, 8 \mathrm{H}, \mathrm{CH}^{\mathrm{iP}}\right) ; 7.18-7.35\left(\mathrm{~m}, 12 \mathrm{H}, \mathrm{CH}^{\mathrm{Ar}}\right)$.

${ }^{13} \mathrm{C}\left\{{ }^{1} \mathrm{H}\right\}\left(\mathrm{CDCl}_{3}\right) \delta$ : $-1.31\left(\mathrm{CH}_{3}{ }^{\mathrm{Pd}}\right) ; 14.2\left(\mathrm{CH}_{3}{ }^{\mathrm{P}} 4\right) ; 23.4\left(\mathrm{CH}_{3} \mathrm{C}=\mathrm{N}\right) ; 23.7\left(\mathrm{CH}_{3} \mathrm{C}=\mathrm{N}\right)$; $24.0\left(\mathrm{CH}_{3}{ }^{\mathrm{iPr}}\right) ; 24.1\left(\mathrm{CH}_{3}{ }^{\mathrm{iPr}}\right) ; 28.3\left(\mathrm{CH}^{\mathrm{iPr}}\right) ; 29.0\left(\mathrm{CH}^{\mathrm{iPr}}\right) ; 123.8\left(\mathrm{CH}^{\mathrm{Ar}}\right)$; $123.9\left(\mathrm{CH}^{\mathrm{Ar}}\right) ; 127.5\left(\mathrm{CH}^{\mathrm{Ar}}\right) ; 128.7\left(\mathrm{C}^{\mathrm{Ar}}\right) ; 139.8\left(\mathrm{CH}^{\mathrm{Ar}}\right) ; 140.1\left(\mathrm{C}^{\mathrm{Ar}}\right)$; $140.9\left(\mathrm{C}^{\mathrm{Ar}}\right) ; 141.1\left(\mathrm{C}^{\mathrm{Ar}}\right) ; 174.0\left(\mathrm{CH}_{3} \mathrm{C}=\mathrm{N}\right)$. 
Elemental analysis:

Calcd. For $\mathrm{C}_{66} \mathrm{H}_{92} \mathrm{Cl}_{4} \mathrm{~N}_{8} \mathrm{Pd}_{4} \cdot \mathrm{CH}_{2} \mathrm{Cl}_{2}:(\mathrm{C}) 48.77(\mathrm{H}) 5.74$ (N) 6.79;

Found: (C) $48.60(\mathrm{H}) 5.55(\mathrm{~N}) 6.85$.

\subsection{Synthesis of $\left[\mathrm{L}_{2}^{2} \mathrm{Pd}_{4}\left(\mu-\mathrm{CH}_{2}\right)\left(\mu-\mathrm{CH}_{3}\right)_{2}\right](\mathrm{OTf})_{2}(21)$}

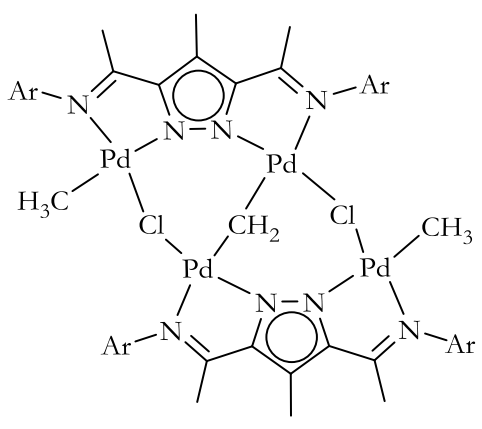

$\mathbf{X X I}^{\mathrm{c}}$

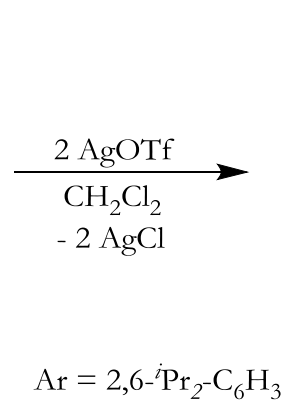

$\mathrm{Ar}=2,6-{ }^{-} \mathrm{Pr}_{2}-\mathrm{C}_{6} \mathrm{H}_{3}$

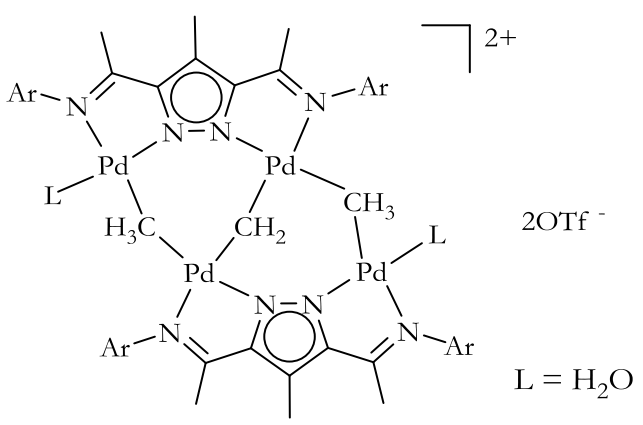

21

To a $\mathrm{CH}_{2} \mathrm{Cl}_{2}$ solution $(2 \mathrm{~mL})$ of $\mathbf{X X I}^{\mathbf{c}}(14 \mathrm{mg}, 9.3 \mu \mathrm{mol})$ was added $2 \mathrm{~mol}$ equivalent of $\mathrm{Ag}(\mathrm{OTf})$ with stirring at $10{ }^{\circ} \mathrm{C}$. After stirring at this temperature for $30 \mathrm{~min}$, the formation of an off-white precipitate was observed. The mixture was filtered over celite to obtain a bright yellow solution. Evaporation of the solution gives the product as a yellow solid which was highly unstable at room temperature. With time there is a gradual darkening of the yellow solid to $\operatorname{Pd}(0)$.

Yield:

Molecular formula:

Molecular weight:

MS (ESI, $\left.\mathrm{CH}_{2} \mathrm{Cl}_{2}\right) m / z(\%)$ :

${ }^{1} \mathrm{H}-\mathrm{NMR}\left(\mathrm{CDCl}_{3}\right) \delta$ :

${ }^{13} \mathrm{C}\left\{{ }^{1} \mathrm{H}\right\}\left(\mathrm{CDCl}_{3}\right) \delta$ :
$14.7 \mathrm{mg}, 89 \%$

$\mathrm{C}_{69} \mathrm{H}_{98} \mathrm{~F}_{6} \mathrm{~N}_{8} \mathrm{O}_{8} \mathrm{Pd}_{4} \mathrm{~S}_{2}$

$1768.3 \mathrm{~g} / \mathrm{mol}$.

$1474(100 \%)[\mathrm{M}-2 \mathrm{OTf}]^{+}$.

$0.03\left(\mathrm{~s}, 6 \mathrm{H}, \mu-\mathrm{CH}_{3}{ }^{\mathrm{Pd}}\right) ; 1.02-1.54\left(\mathrm{~m}, 48 \mathrm{H}, \mathrm{CH}_{3}{ }^{\mathrm{iP}}\right) ; 2.18(\mathrm{~s}, 12 \mathrm{H}$, $\left.\mathrm{CH}_{3} \mathrm{C}=\mathrm{N}\right) ; 2.53\left(\mathrm{~s}, 6 \mathrm{H}, \mathrm{CH}_{3}^{\mathrm{P}_{\mathrm{z}}}\right) ; 3.19\left(\mathrm{~m}, 8 \mathrm{H}, \mathrm{CH}^{\mathrm{PP}}\right) ; 4.15$ (s, 2H, $\mu-$ $\left.\mathrm{CH}_{2}\right) ; 7.01-7.32\left(\mathrm{~m}, 12 \mathrm{H}, \mathrm{CH}^{\mathrm{Ar}}\right)$.

$7.37\left(\mathrm{CH}_{3}^{\mathrm{Pd}}\right) ; 11.4\left(\mathrm{CH}_{3}^{\mathrm{Pz} 4}\right) ; 20.0\left(\mathrm{CH}_{3}^{i \mathrm{Pr}}\right) ; 20.4\left(\mathrm{CH}_{3}{ }^{i \mathrm{Pr}}\right) ; 23.2$ $\left(\mathrm{CH}_{3}{ }^{i \mathrm{PP}}\right) ; 23.6\left(\mathrm{CH}_{3}{ }^{i \mathrm{PP}}\right) ; 23.7 \quad\left(\mathrm{CH}_{3}{ }^{i \mathrm{PP}}\right) ; 24.0\left(\mathrm{CH}_{3} \mathrm{C}=\mathrm{N}\right) ; 24.2$ $\left(\mathrm{CH}_{3} \mathrm{C}=\mathrm{N}\right) ; 27.9\left(\mathrm{CH}^{\mathrm{PP}}\right) ; 28.5\left(\mathrm{CH}^{\mathrm{PP}}\right) 45.4\left(\mu-\mathrm{CH}_{2}\right) ; 120.7\left(\mathrm{C}^{\mathrm{Pz} 4}\right)$; $123.6\left(\mathrm{CH}^{\mathrm{Ar}}\right) ; 123.7\left(\mathrm{CH}^{\mathrm{Ar}}\right) ; 123.9\left(\mathrm{CH}^{\mathrm{Ar}}\right) ; 125.0 ; 127.3\left(\mathrm{CH}^{\mathrm{Ar}}\right)$; $129.6\left(\mathrm{CH}^{\mathrm{Ar}}\right) ; 139.9\left(\mathrm{C}^{\mathrm{Ar}}\right) ; 140.3\left(\mathrm{C}^{\mathrm{Ar}}\right) ; 147.7 ; \quad\left(\mathrm{C}^{\mathrm{Pz}}\right) ; 171.4$ $\left(\mathrm{CH}_{3} \mathrm{C}=\mathrm{N}\right)$. 


\subsection{Synthesis of $\left[\mathrm{L}_{2}^{2} \mathrm{Pd}_{4}(\mu-\mathrm{Cl})_{2}(\mu-\mathrm{O})(\mu-\mathrm{OH})\right] \mathrm{BAr}_{4}^{\mathrm{F}}(2 \mathrm{p})$}

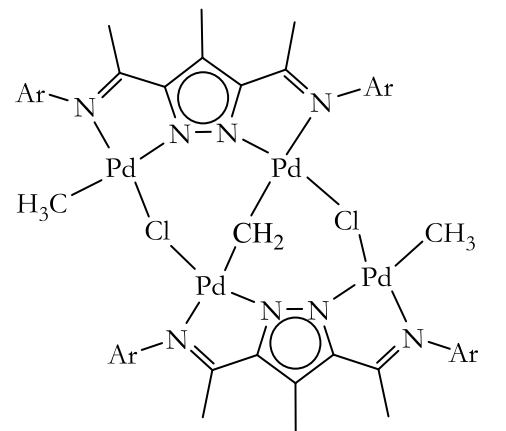

$\mathrm{Ar}=2,6-{ }^{i} \operatorname{Pr}_{2}-\mathrm{C}_{6} \mathrm{H}_{3}$

XXI $^{\mathrm{c}}$

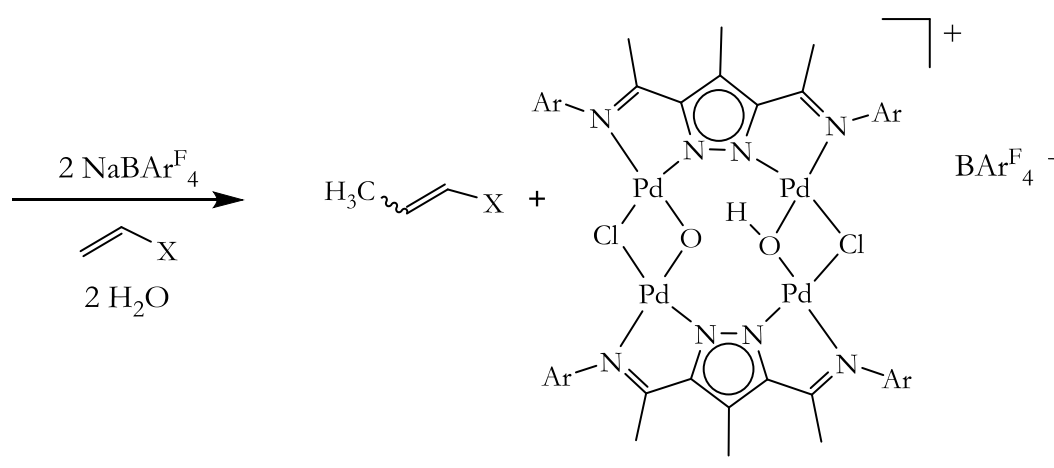

$2 p$

To a $\mathrm{CH}_{2} \mathrm{Cl}_{2}$ solution $(1 \mathrm{~mL})$ of $\mathbf{X X I}^{\mathbf{c}}(14 \mathrm{mg}, 9.3 \mathrm{mmol})$ cooled to $0^{\circ} \mathrm{C}$ was added excess styrene $(0.05 \mathrm{~mL})$ and $2 \mathrm{~mol}$ equivalent of $\mathrm{NaBAr}_{4}^{\mathrm{F}}(17 \mathrm{mg}, 19 \mathrm{mmol})$, the mixture was stirred over ice for $15 \mathrm{~min}$. The reaction mixture was filtered over celite, after which the gradual formation of $\operatorname{Pd}(0)$ was observed when gradually warmed up to room temperature. The bright yellow solution obtained after filteration was dried under vacuum for several hours to obtain a yellow powder. A micro-column of the yellow powder, first with ether, followed by methanol. Analysis of the ether fraction showed the formation of $\mathrm{L}_{2}^{2} \mathrm{Pd}$ The methanol fraction was evaporated in vacuo. The yellow powder obtained was again dissolved in $\mathrm{CH}_{2} \mathrm{Cl}_{2}$. Crystals were grown by slow evaporation of a $\mathrm{CH}_{2} \mathrm{Cl}_{2}$ of the complex at $-30^{\circ} \mathrm{C}$ for several weeks.

Yield:

Molecular formula:

Molecular weight:

HRMS (TOF-ESI):

MS (ESI, $\left.\mathrm{CH}_{2} \mathrm{Cl}_{2}\right) m / z(\%)$ :

IR $\left(\right.$ ATR, $\left.\mathrm{cm}^{-1}\right)$ :

${ }^{1} \mathrm{H}-\mathrm{NMR}\left(\mathrm{CDCl}_{3}\right) \delta$ :
$7 \mathrm{mg}, 50 \%$

$\mathrm{C}_{96} \mathrm{H}_{99} \mathrm{BCl}_{2} \mathrm{~F}_{24} \mathrm{~N}_{8} \mathrm{O}_{2} \mathrm{Pd}_{4}$ $2356.4 \mathrm{~g} / \mathrm{mol}$.

Calcd. For : $\mathrm{C}_{64} \mathrm{H}_{87} \mathrm{Cl}_{2} \mathrm{~N}_{8} \mathrm{O}_{2} \mathrm{Pd}_{4}$ (1497.2500); Found: (1497.2490). $1497(100 \%)\left[\mathrm{M}+\mathrm{H}-\mathrm{BAr}{ }_{4}^{\mathrm{F}}\right]^{+} ; 749(70 \%)\left[\mathrm{M}+2 \mathrm{H}-\mathrm{BAr}_{4}^{\mathrm{F}}\right]^{2+}$. 2967 (m); 2931 (m); 2874 (m); 1575 (s); 1467 (s); 1432 (s); 1354 (s); 1275 (vs); 1166 (s); 1121 (vs); 1099 (s); 888 (s); 842 (vs); 735 (s); $715(\mathrm{~s}) ; 684(\mathrm{~m}) ; 674(\mathrm{~m})$.

$1.08\left(\mathrm{~d},{ }^{3} J_{\mathrm{HH}}=6.8 \mathrm{~Hz}, 24 \mathrm{H}, \mathrm{CH}_{3}{ }^{i P r}\right) ; 1.32\left(\mathrm{~d},{ }^{3} J_{\mathrm{HH}}=6.8 \mathrm{~Hz}, 24 \mathrm{H}\right.$, $\left.\mathrm{CH}_{3}{ }^{2 \mathrm{PP}}\right) ; 2.00\left(\mathrm{~s}, 12 \mathrm{H}, \mathrm{CH}_{3} \mathrm{C}=\mathrm{N}\right) ; 2.45\left(\mathrm{~s}, 6 \mathrm{H}, \mathrm{CH}_{3}{ }^{\mathrm{z} z}\right) ; 3.04(\mathrm{~m}, 4 \mathrm{H}$, $\left.\mathrm{CH}^{\mathrm{PPr}}\right) ; 7.12\left(\mathrm{~d},{ }^{3} \mathrm{HH}_{\mathrm{HH}}=7.7 \mathrm{~Hz}, 8 \mathrm{H}, \mathrm{CH}^{\mathrm{Ar}}\right) ; 7.27\left(\mathrm{dd},{ }^{3} \mathrm{HH}_{\mathrm{HH}}=8.4,7.1\right.$ 


\section{Experimetal}

$\left.\mathrm{Hz}, 4 \mathrm{H}, \mathrm{CH}^{\mathrm{Ar}}\right) ; 7.55\left(\mathrm{~s}, 4 \mathrm{H}, \mathrm{CH}^{\mathrm{BArF} 4}\right) ; 7.71(\mathrm{dt}, J=5.0 \mathrm{~Hz}, 2.3 \mathrm{~Hz}$, $\left.8 \mathrm{H}, \mathrm{CH}^{\mathrm{BArF} 4}\right) \cdot 14.4(\mathrm{~s}, 1 \mathrm{H}, \mathrm{OH})$

${ }^{13} \mathrm{C}\left\{{ }^{1} \mathrm{H}\right\}\left(\mathrm{CD}_{2} \mathrm{Cl}_{2}\right) \delta: \quad 10.6\left(\mathrm{CH}_{3}{ }^{\mathrm{zz} 4}\right) ; 19.7\left(\mathrm{CH}_{3} \mathrm{C}=\mathrm{N}\right) ; 23.6\left(\mathrm{CH}_{3}{ }^{i \mathrm{Pr}}\right) ; 23.7\left(\mathrm{CH}_{3}^{i \mathrm{Pr}}\right) ; 23.9$ $\left(\mathrm{CH}_{3}{ }^{i \mathrm{Pr}}\right) ; 29.1\left(\mathrm{CH}^{\mathrm{PP}}\right) ; 117.8\left(\mathrm{C}^{\mathrm{Pz}}\right) ; 123.2\left(\mathrm{CH}^{\mathrm{Ar}}\right) ; 124.4\left(\mathrm{CH}^{\mathrm{Ar}}\right)$; $126.8\left(\mathrm{CH}^{\mathrm{Ar}}\right) ; 128.9\left(\mathrm{C}^{\mathrm{Ar}}\right) ; 129.0\left(\mathrm{C}^{\mathrm{Ar}}\right) ; 129.4\left(\mathrm{C}^{\mathrm{Ar}}\right) ; 135.2\left(\mathrm{C}^{\mathrm{Ar}}\right)$; $138.4\left(\mathrm{C}^{\mathrm{An}}\right) ; 140.9\left(\mathrm{C}^{\mathrm{An}}\right) ; 150.2\left(\mathrm{C}^{\mathrm{Pz}}\right) ; 161.4\left(\mathrm{~d}, J_{\mathrm{B}-\mathrm{C}}=50.4\right) 171.2$ $\left(\mathrm{CH}_{3} \mathrm{C}=\mathrm{N}\right)$.

Elemental analysis:

Calcd. For $\mathrm{C}_{96} \mathrm{H}_{99} \mathrm{BCl}_{2} \mathrm{~F}_{24} \mathrm{~N}_{8} \mathrm{O}_{2} \mathrm{Pd}_{4}$ : (C) 48.85 (H) 4.23 (N) 4.75; Found: (C) $48.70(\mathrm{H}) 4.44(\mathrm{~N}) 4.52$. 


\subsection{Synthesis of $\left[\mathrm{L}_{2}^{2} \mathrm{Pd}_{2}\left(\mathrm{CH}_{3}\right)_{2}\right]$ (3a)}

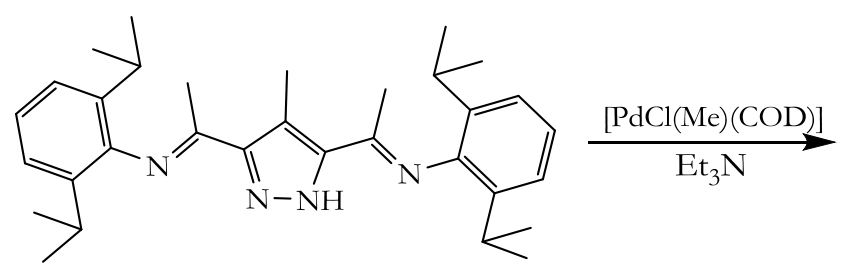

$\mathrm{HL}^{2}$

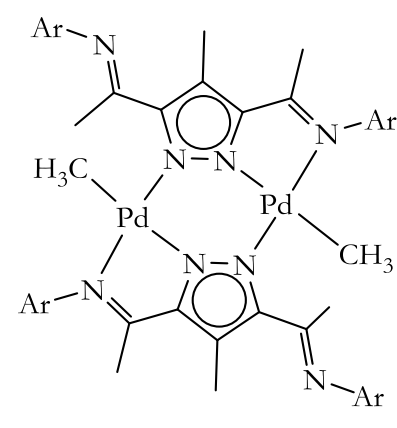

$3 a$

To a toluene solution $(15 \mathrm{~mL})$ of $\mathbf{H L}^{2}(990 \mathrm{mg}, 2.1 \mathrm{mmol})$ was added an equivalent of PdCl(Me)(COD)] (450 mg, $2.1 \mathrm{mmol})$ and an equivalent of $\mathrm{Et}_{3} \mathrm{~N}$ as base. A pale yellow solution was formed which was stirred for $18 \mathrm{~h}$. The product was filtered over celite to remove traces of $\operatorname{Pd}(0)$. The solution was worked up by concentrating the solution to $3 \mathrm{~mL}$ and adding hexane dropwise. The product was precipitated as a yellow powder, was filtered and washed with hexane $(1 \times 3 \mathrm{~mL})$ and dried in air. Crystals of the complex were grown by the slow evaporation of a $\mathrm{CH}_{2} \mathrm{Cl}_{2}$ solution of the complex at room temperature.

Yield:

Molecular formula:

Molecular weight:

MS (ESI, $\left.\mathrm{CH}_{2} \mathrm{Cl}_{2}\right) m / z(\%)$ :

IR $\left(\right.$ ATR, $\left.\mathrm{cm}^{-1}\right)$ :

${ }^{1} \mathrm{H}-\mathrm{NMR}\left(\mathrm{CDCl}_{3}\right) \delta$ :

${ }^{13} \mathrm{C}\left\{{ }^{1} \mathrm{H}\right\}\left(\mathrm{CDCl}_{3}\right) \delta:$

Elemental analysis:
$730 \mathrm{mg}, 29 \%$

$\mathrm{C}_{66} \mathrm{H}_{92} \mathrm{~N}_{8} \mathrm{Pd}_{2}$ $1210.5 \mathrm{~g} / \mathrm{mol}$.

$1195(50 \%)\left[\mathrm{M}-\mathrm{CH}_{3}\right]^{+}$

2959 (m); 1627 (m); 1562 (m); 1436 (s); 1385 (s); 1227 (vs); 780 (vs); $730(\mathrm{vs}) ; 581$ (m).

$0.15\left(\mathrm{~s}, 6 \mathrm{H}, \mathrm{CH}_{3}{ }^{\mathrm{Pd}}\right) ; 1.06\left(\mathrm{~d}, 3_{\mathrm{HH}}=6.7 \mathrm{~Hz}, 12 \mathrm{H}, \mathrm{CH}_{3}{ }^{2 \mathrm{Pr}}\right) ; 1.12(\mathrm{~d}$, $\left.{ }^{3} J_{\mathrm{HH}}=6.7 \mathrm{~Hz}, 12 \mathrm{H}, \mathrm{CH}_{3}{ }^{2 \mathrm{Pr}}\right) ; 1.17\left(\mathrm{~d},{ }^{3} J_{\mathrm{HH}}=6.8 \mathrm{~Hz}, 12 \mathrm{H}, \mathrm{CH}_{3}{ }^{2 \mathrm{Pr}}\right)$;

$1.26\left(\mathrm{~d},{ }^{3} \mathrm{~J}_{\mathrm{HH}}=6 \mathrm{~Hz}, 12 \mathrm{H}, \mathrm{CH}_{3}{ }^{\mathrm{iPr}}\right) ; 2.18\left(\mathrm{~s}, 6 \mathrm{H}, \mathrm{CH}_{3} \mathrm{C}=\mathrm{N}\right) ; 2.34(\mathrm{~s}$, $\left.6 \mathrm{H}, \mathrm{CH}_{3} \mathrm{C}=\mathrm{N}\right) ; 2.57\left(\mathrm{~s}, 6 \mathrm{H}, \mathrm{CH}_{3}^{\mathrm{P}_{\mathrm{z}} 4}\right) ; 2.56-3.20\left(\mathrm{~m}, 8 \mathrm{H}, \mathrm{CH}^{\mathrm{PP}}\right) ; 7.09-$ $7.26\left(\mathrm{~m}, 12 \mathrm{H}, \mathrm{CH}^{\mathrm{Ar}}\right)$.

$1.68\left(\mathrm{CH}_{3}{ }^{\mathrm{Pd}}\right) ; 11.0\left(\mathrm{CH}_{3}{ }^{\mathrm{P} z 4}\right) ; 20.9\left(\mathrm{CH}_{3} \mathrm{C}=\mathrm{N}\right) ; 22.3\left(\mathrm{CH}_{3} \mathrm{C}=\mathrm{N}\right) ; 23.4$ $\left(\mathrm{CH}_{3}{ }^{i \mathrm{PP}}\right) ; 23.6\left(\mathrm{CH}_{3}{ }^{\mathrm{PP}}\right) ; 24.5\left(\mathrm{CH}_{3}{ }^{i \mathrm{PP}}\right) ; 27.7\left(\mathrm{CH}^{i \mathrm{PP}}\right) ; 28.0\left(\mathrm{CH}^{i \mathrm{PP}}\right)$; $119.8 ; 120.8\left(\mathrm{CH}^{\mathrm{Ar}}\right) ; 123.2\left(\mathrm{CH}^{\mathrm{Ar}}\right) ; 123.6\left(\mathrm{CH}^{\mathrm{Ar}}\right) ; 126.9\left(\mathrm{CH}^{\mathrm{Ar}}\right)$; $140.6\left(C^{A_{r}}\right) ; 141.2\left(C^{A \eta}\right) ; 146.0\left(C^{A \eta}\right) ; 149.3\left(C^{P_{z}}\right) ; 153.5\left(C^{P_{z}}\right) ; 162.3$ $\left(\mathrm{CH}_{3} \mathrm{C}=\mathrm{N}\right) ; 172.0\left(\mathrm{CH}_{3} \mathrm{C}=\mathrm{N}\right)$.

Calcd. For $\mathrm{C}_{66} \mathrm{H}_{92} \mathrm{~N}_{8} \mathrm{Pd}_{2}$ : (C) $65.50(\mathrm{H}) 7.66$ (N) 9.26; Found: (C) $65.53(\mathrm{H}) 7.65(\mathrm{~N}) 9.12$. 


\subsection{Synthesis of $\left[\mathrm{L}_{2}^{1} \mathrm{Pd}_{2}\left(\mathrm{CH}_{3}\right) \mathrm{Cl}\right](3 \mathrm{~b})$}<smiles>CCc1cccc(C(C)(C)C)c1/N=C/c1cc(/C=N/c2c(C(C)(C)C)cccc2C(C)(C)C)[nH]n1</smiles>

$\mathrm{HL}^{1}$

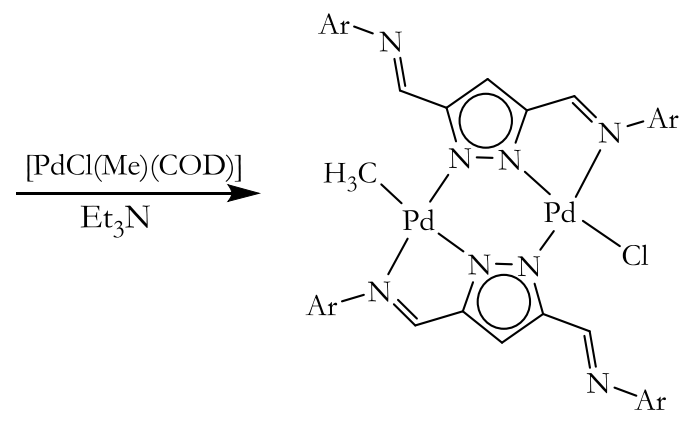

$3 b$

To a toluene solution $(10 \mathrm{~mL})$ of $\mathbf{H L}^{1}(150 \mathrm{mg}, 0.34 \mathrm{mmol})$ was added 2 mol equivalent PdCl(Me)(COD) $(180 \mathrm{mg}, 0.68 \mathrm{mmol})$ with stirring at room temperature. This was followed with the addition of a mol equivalent of $\mathrm{Et}_{3} \mathrm{~N}$. A bright yellow solution was formed which was allowed to stir for $18 \mathrm{~h}$. A white crystalline salt of $\mathrm{Et}_{3} \mathrm{~N} \cdot \mathrm{HCl}$ was filtered and the yellow solution evaporated. Attempts at recrystallization, by the slow evaporation of $\mathrm{CH}_{2} \mathrm{Cl}_{2}$ solution in a test tube yield the product as a yellow crystal on the walls of the tube, which was not the bulk of the reaction product.

Yield:

$27 \mathrm{mg}, 7 \%$

Molecular formula:

$\mathrm{C}_{59} \mathrm{H}_{77} \mathrm{ClN}_{8} \mathrm{Pd}_{2}$

Molecular weight:

$1146.6 \mathrm{~g} / \mathrm{mol}$.

MS (ESI, $\left.\mathrm{CH}_{2} \mathrm{Cl}_{2}\right) m / ₹(\%)$ :

$1145(30 \%)[\mathrm{M}-2 \mathrm{H}]^{+} ; 1111(100 \%)[\mathrm{M}-\mathrm{Cl}]^{+}$.

IR $\left(\right.$ ATR, $\left.\mathrm{cm}^{-1}\right)$ :

2959 (m); 2926 (m); 1575 (m); 1430 (m); 1367 (m); 938 (m); 808 (vs); 778 (vs); $753(\mathrm{~m})$.

${ }^{1} \mathrm{H}-\mathrm{NMR}\left(\mathrm{CDCl}_{3}\right) \delta$ :

$0.54\left(\mathrm{~d}, J=\mathrm{Hz}, 3 \mathrm{H}, \mathrm{CH}_{3}{ }^{\mathrm{Pd}}\right) ; 1.28-1.44$ (m, 48H, $\mathrm{CH}_{3}{ }^{2 \mathrm{P}}$ ); 3.10 (sept, $\left.{ }^{3} J_{\mathrm{HH}}=6.8 \mathrm{~Hz}, 4 \mathrm{H}, \mathrm{CH}^{\mathrm{iPr}}\right) ; 3.56\left(\mathrm{sept},{ }^{3} \mathrm{HH}_{\mathrm{HH}}=6.8 \mathrm{~Hz}, 4 \mathrm{H}, \mathrm{CH}^{\mathrm{iPr}}\right)$; 7.24-7.36 (m, 12H, $\left.\mathrm{CH}^{\mathrm{Ar}}\right) ; 7.58\left(\mathrm{~s}, 2 \mathrm{H}, \mathrm{CH}^{\mathrm{Pz}}\right) ; 8.15(\mathrm{~s}, 2 \mathrm{H}, \mathrm{CH}=\mathrm{N})$;

$8.27(\mathrm{~s}, 2 \mathrm{H}, \mathrm{CH}=\mathrm{N})$.

${ }^{13} \mathrm{C}\left\{{ }^{1} \mathrm{H}\right\}\left(\mathrm{CDCl}_{3}\right) \delta:$

$1.61\left(\mathrm{CH}_{3}{ }^{\mathrm{Pd}}\right) ; 22.6\left(\mathrm{CH}_{3}{ }^{\mathrm{PP}}\right) ; 23.7\left(\mathrm{CH}_{3}{ }^{\mathrm{iP}}\right) ; 25.1\left(\mathrm{CH}_{3}{ }^{2 \mathrm{PP}}\right) ; 25.2$ $\left(\mathrm{CH}_{3}{ }^{i \mathrm{Pr}}\right) ; 27.8\left(\mathrm{CH}^{\mathrm{iPr}}\right) ; 28.0\left(\mathrm{CH}^{i \mathrm{PP}}\right) ; 109.8\left(\mathrm{CH}^{\mathrm{Pz}}\right) ; 123.0\left(\mathrm{CH}^{\mathrm{Ar}}\right)$; $123.5\left(\mathrm{CH}^{\mathrm{Ar}}\right) ; 127.8\left(\mathrm{CH}^{\mathrm{Ar}}\right) ; 137.7\left(\mathrm{C}^{\mathrm{Ar}}\right) ; 141.4\left(\mathrm{C}^{\mathrm{Ar}}\right) ; 143.4\left(\mathrm{C}^{\mathrm{Ar}}\right)$; $148.4\left(\mathrm{C}^{\mathrm{Ar}}\right) ; 154.4\left(\mathrm{C}^{\mathrm{pz}}\right) ; 155.2\left(\mathrm{C}^{\mathrm{P}}\right) ; 162.8(\mathrm{CH}=\mathrm{N})$. 


\section{2 Mononuclear palladium(II) complexes}

\subsection{Synthesis of $\left[\mathrm{L}^{2} \mathrm{Pd}\left(\mathrm{CH}_{3}\right)\left(\mathrm{PMe}_{3}\right)\right](3 \mathrm{c})$}<smiles>CCc1cccc(C(C)(C)C)c1/N=C(\C)c1[nH]nc(/C(C)=N/c2c(C(C)(C)C)cccc2C(C)(C)C)c1C</smiles>

$\mathrm{HL}^{2}$

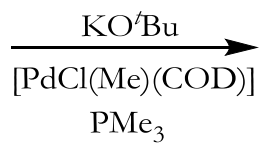

$\mathrm{PMe}_{3}$

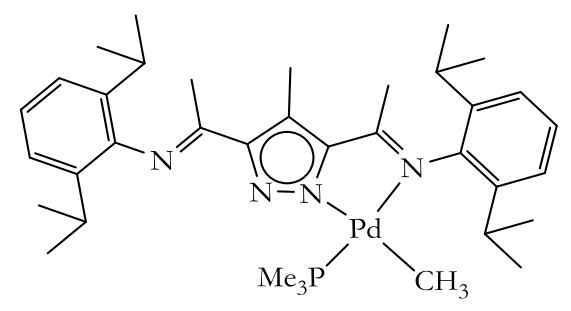

$3 c$

A THF solution $(10 \mathrm{~mL})$ of the deprotonated ligand $\mathbf{L}^{2}(300 \mathrm{mg}, 0.62 \mathrm{mmol})$ was added dropwise to a mol equivalent $[\mathrm{PdCl}(\mathrm{Me})(\mathrm{COD})](160 \mathrm{mg}, 0.62 \mathrm{mmol})$ in the presence of $\mathrm{PMe}_{3}$ (0.6 mL, $1 \mathrm{~mol} \mathrm{Eq.)} \mathrm{with} \mathrm{stirring.} \mathrm{The} \mathrm{reaction} \mathrm{was} \mathrm{stirred} \mathrm{overnight} \mathrm{at} \mathrm{room} \mathrm{temperature.} \mathrm{The}$ solvent was evaporated to obtain an off-white solid. The solid was washed with $\mathrm{Et}_{2} \mathrm{O}(3 \times 3 \mathrm{~mL})$ and the product dried in vacuum to give a pure off-white solid. Colourless crystals of $\mathbf{3 c}$ were obtained by the slow diffusion of $\mathrm{Et}_{2} \mathrm{O}$ into a $\mathrm{CH}_{2} \mathrm{Cl}_{2}$ solution of the complex at room temperature.

Yield:

Molecular formula:

Molecular weight:

MS (ESI, $\left.\mathrm{CH}_{2} \mathrm{Cl}_{2}\right) m / z(\%)$ :

IR $\left(\right.$ ATR, $\left.\mathrm{cm}^{-1}\right)$ :

${ }^{1} \mathrm{H}-\mathrm{NMR}\left(\mathrm{CDCl}_{3}\right) \delta$ :

${ }^{13} \mathrm{C}\left\{{ }^{1} \mathrm{H}\right\}\left(\mathrm{CDCl}_{3}\right) \delta$
$250 \mathrm{mg}, 59 \%$

$\mathrm{C}_{36} \mathrm{H}_{55} \mathrm{~N}_{4} \mathrm{Pd}$

$681.2 \mathrm{~g} / \mathrm{mol}$.

$681(100 \%)[\mathrm{M}]^{+}$.

2959 (vs); 2924 (vs); 2868 (vs); 1631 (vs); 1570 (vs); 1436 (vs); 1328 (s); 1229 (vs); 1097 (s); 1057 (s); 961 (vs); 863 (m); 810 (m); 780 (vs); 724 (m); 419 (m).

$-0.32\left(\mathrm{~d}, J=3.2 \mathrm{~Hz}, 3 \mathrm{H}, \mathrm{CH}_{3}^{\mathrm{Pd}}\right) ; 1.12-1.22\left(\mathrm{~m}, 21 \mathrm{H}, \mathrm{CH}_{3}{ }^{i \mathrm{PP}}\right) ; 1.62$ $\left(\mathrm{d},{ }^{3} \mathrm{~J}_{\mathrm{P}-\mathrm{H}}=10.8 \mathrm{~Hz}, 9 \mathrm{H}, \mathrm{CH}_{3}{ }^{\mathrm{PMe} 3}\right) ; 1.65\left(\mathrm{~s}, 3 \mathrm{H}, \mathrm{CH}_{3}{ }^{1 \mathrm{PP}}\right) ; 2.24(\mathrm{~s}, 6 \mathrm{H}$, $\left.\mathrm{CH}_{3} \mathrm{C}=\mathrm{N}\right) ; 2.77\left(\mathrm{~s}, 3 \mathrm{H}, \mathrm{CH}_{3}{ }^{\mathrm{P} z 4}\right) ; 2.95\left(\mathrm{sept},{ }^{3} J_{\mathrm{HH}}=6.8 \mathrm{~Hz}, 2 \mathrm{H}\right.$, $\left.\left.\mathrm{CH}^{\mathrm{iPr}}\right) ; 3.09\left(\mathrm{sept}^{3}\right]_{\mathrm{HH}}=6.8 \mathrm{~Hz}, 2 \mathrm{H}, \mathrm{CH}^{\mathrm{iPf}}\right) ; 7.02-7.26(\mathrm{~m}, 6 \mathrm{H}$, $\left.\mathrm{CH}^{\mathrm{Ar}}\right)$.

$0.76\left(\mathrm{~d}, J_{\mathrm{P}-\mathrm{C}}=11.5 \mathrm{~Hz}, \mathrm{CH}_{3}{ }^{\mathrm{Pd}}\right) ; 11.8\left(\mathrm{CH}_{3}{ }^{\mathrm{P} 4}\right) ; 15.1\left(\mathrm{CH}_{3}^{\mathrm{PMe} 3}\right) ; 15.9$ $\left(\mathrm{CH}_{3}{ }^{\mathrm{PMe}}\right) ; 19.0\left(\mathrm{CH}_{3} \mathrm{C}=\mathrm{N}\right) ; 19.6\left(\mathrm{CH}_{3} \mathrm{C}=\mathrm{N}\right) ; 22.9\left(\mathrm{CH}_{3}{ }^{2 \mathrm{PP}}\right) ; 23.3$ $\left(\mathrm{CH}_{3}{ }^{\mathrm{iPr}}\right) ; 23.5\left(\mathrm{CH}_{3}{ }^{\mathrm{iP}}\right) ; 24.0\left(\mathrm{CH}_{3}^{i \mathrm{PP}}\right) ; 28.1\left(\mathrm{CH}^{\mathrm{PP}}\right) ; 28.2\left(\mathrm{CH}^{\mathrm{iPr}}\right)$; $120.3\left(\mathrm{C}^{\mathrm{P} z 4}\right) ; 122.4\left(\mathrm{CH}^{\mathrm{An}}\right) ; 122.8\left(\mathrm{CH}^{\mathrm{Ar}}\right) ; 123.5\left(\mathrm{CH}^{\mathrm{An}}\right) ; 126.3$; 
136.2; 140.7; $141.3\left(\mathrm{CH}^{\mathrm{Ar}}\right) ; 147.6\left(\mathrm{CH}^{\mathrm{Ar}}\right) ; 150.6\left(\mathrm{C}^{\mathrm{Pz} 3 / 5}\right) ; 150.8$ $\left(\mathrm{C}^{\mathrm{Pz} 3 / 5}\right) ; 164.0\left(\mathrm{CH}_{3} \mathrm{C}=\mathrm{N}\right) ; 170.9\left(\mathrm{CH}_{3} \mathrm{C}=\mathrm{N}\right)$.

${ }^{31} \mathrm{P}\{1 \mathrm{H}\} \delta:$

\subsection{Synthesis of $\left[\mathrm{L}^{2} \mathbf{P d}\left(\mathrm{CH}_{3}\right)\left(\mathrm{PPh}_{3}\right)\right](3 \mathrm{~d})$}

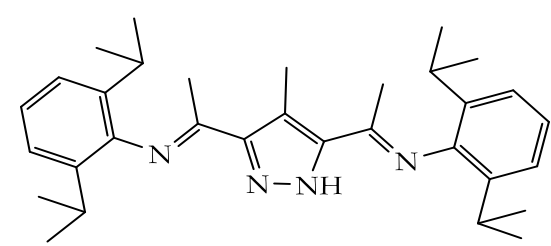

$\mathrm{HL}^{2}$

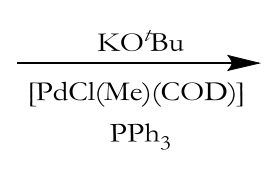

$\mathrm{PPh}_{3}$

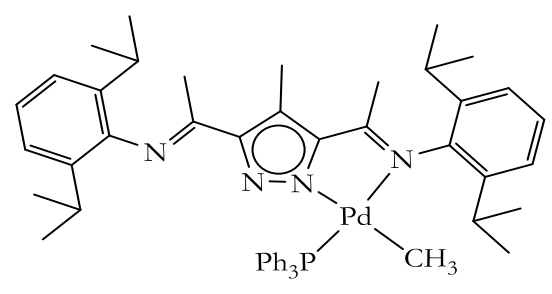

$3 d$

A $\mathrm{CH}_{2} \mathrm{Cl}_{2}$ solution $(5 \mathrm{~mL})$ of the deprotonated ligand $\mathbf{L}^{2}(30 \mathrm{mg}, 0.062 \mathrm{mmol})$ was added to a mol equivalent of $[\mathrm{PdCl}(\mathrm{Me})(\mathrm{COD})](16.4 \mathrm{mg}, 0.62 \mathrm{mmol})$ in the presence of $\mathrm{PPh}_{3}(16.0 \mathrm{mg}, 1$ mol Eq.) with stirring. The reaction was stirred overnight at room temperature. The solution was concentrated to $3 \mathrm{~mL}$ on a rotary evaporator and $\mathrm{Et}_{2} \mathrm{O}(10 \mathrm{~mL})$ added. There was the gradual precipitation of a white crystalline solid, the solid was filtered and washed with cold $\mathrm{Et}_{2} \mathrm{O}(3 \times 3$ $\mathrm{mL}$ ) and the product dried in air.

Yield:

Molecular formula:

Molecular weight:

MS (ESI, $\left.\mathrm{CH}_{2} \mathrm{Cl}_{2}\right) m / z(\%)$ :

IR $\left(\mathrm{ATR}, \mathrm{cm}^{-1}\right)$ :

${ }^{1} \mathrm{H}-\mathrm{NMR}\left(\mathrm{CDCl}_{3}\right) \delta$ :

$12 \mathrm{mg}, 23 \%$

$\mathrm{C}_{51} \mathrm{H}_{61} \mathrm{~N}_{4} \mathrm{PPd}$

$868.5 \mathrm{~g} / \mathrm{mol}$.

$867(100 \%)[\mathrm{M}]^{+}$.

2959 (s); 1564 (vs); 1437 (s); 1383 (vs); 1329 (s); 775 (vs).

$-0.31\left(\mathrm{~d},{ }^{3} \mathrm{~J}_{\mathrm{Pd}-\mathrm{P}}=3.1 \mathrm{~Hz}, 3 \mathrm{H}, \mathrm{CH}_{3}{ }^{\mathrm{Pd}}\right) ; 1.08\left(\mathrm{~d},{ }^{3} \mathrm{~J}_{\mathrm{HH}}=4.5 \mathrm{~Hz}, 6 \mathrm{H}\right.$, $\left.\mathrm{CH}_{3}{ }^{\mathrm{PP}}\right) ; 1.10\left(\mathrm{~d},{ }^{3} J_{\mathrm{HH}}=4.4 \mathrm{~Hz}, 6 \mathrm{H}, \mathrm{CH}_{3}{ }^{\mathrm{iP}}\right) ; 1.16\left(\mathrm{~d},{ }^{3} J_{\mathrm{HH}}=6.9 \mathrm{~Hz}\right.$, $\left.6 \mathrm{H}, \mathrm{CH}_{3}{ }^{i \mathrm{PP}}\right) ; 1.26\left(\mathrm{~m}, 6 \mathrm{H}, \mathrm{CH}_{3}{ }^{i \mathrm{PP}}\right) ; 1.64\left(\mathrm{~s}, 3 \mathrm{H}, \mathrm{CH}_{3} \mathrm{C}=\mathrm{N}\right) ; 2.26(\mathrm{~s}$, $\left.3 \mathrm{H}, \mathrm{CH}_{3} \mathrm{C}=\mathrm{N}\right) ; 2.70\left(\mathrm{~s}, 3 \mathrm{H}, \mathrm{CH}_{3}^{\mathrm{Pz} 4}\right) ; 2.82\left(\mathrm{sept},{ }^{3} \mathrm{JH}_{\mathrm{HH}}=6.8 \mathrm{~Hz}, 2 \mathrm{H}\right.$, $\left.\mathrm{CH}^{\mathrm{iPr}}\right) ; 3.28\left(\mathrm{sept},{ }^{3} J_{\mathrm{HH}}=6.8 \mathrm{~Hz}, 2 \mathrm{H}, \mathrm{CH}^{\mathrm{iPr}}\right) ; 6.96-7.24(\mathrm{~m}, 21 \mathrm{H}$, $\left.\mathrm{CH}^{\mathrm{Ar}}\right)$.

${ }^{13} \mathrm{C}\left\{{ }^{1} \mathrm{H}\right\}\left(\mathrm{CDCl}_{3}\right) \delta: \quad 6.37 \quad\left(\mathrm{CH}_{3}{ }^{\mathrm{Pd}}\right) ; 11.8 \quad\left(\mathrm{CH}_{3}{ }^{\mathrm{P} \mathrm{z}}\right) ; 14.2 ; 19.3 \quad\left(\mathrm{CH}_{3} \mathrm{C}=\mathrm{N}\right) ; 19.4$ $\left(\mathrm{CH}_{3} \mathrm{C}=\mathrm{N}\right) ; 19.8\left(\mathrm{CH}_{3} \mathrm{C}=\mathrm{N}\right) ; 22.8\left(\mathrm{CH}_{3}^{\mathrm{iPr}}\right) ; 23.0\left(\mathrm{CH}_{3}{ }^{i \mathrm{PP}}\right) ; 23.4$ 
$\left(\mathrm{CH}_{3}{ }^{\mathrm{iP}}\right) ; 23.6\left(\mathrm{CH}_{3}{ }^{\mathrm{PP}}\right) ; 24.3\left(\mathrm{CH}_{3}{ }^{i \mathrm{PP}}\right) ; 28.0\left(\mathrm{CH}^{\mathrm{iP}}\right) ; 28.2\left(\mathrm{CH}^{\mathrm{iP}}\right) ; 28.3$

$\left(\mathrm{CH}^{\mathrm{iPr}}\right) ; 28.4\left(\mathrm{CH}^{\mathrm{iPr}}\right) ; 117.6 ; 119.9 ; 122.3 ; 122.7 ; 123.0\left(\mathrm{CH}^{\mathrm{Ar}}\right) ; 123.2$

$\left(\mathrm{CH}^{\mathrm{A \eta}}\right) ; 123.5\left(\mathrm{CH}^{\mathrm{A \eta}}\right) ; 124.2 ; 126.4 ; 127.9\left(\mathrm{CH}^{\mathrm{A \eta}}\right) ; 128.1 ; 130.2$

$\left(\mathrm{CH}^{\mathrm{An}}\right) ; 131.4 ; 132.1 ; 134.8\left(\mathrm{CH}^{\mathrm{An}}\right) ; 135.0 ; 135.8 ; 136.3\left(\mathrm{C}^{\mathrm{An}}\right)$;

136.6(C $\left.\mathrm{C}^{\mathrm{Ar}}\right)$; 140.9 $\left(\mathrm{C}^{\mathrm{Ar}}\right) ; 141.2\left(\mathrm{C}^{\mathrm{Ar}}\right) ; 147.7\left(\mathrm{C}^{\mathrm{Pz}}\right) ; 150.6\left(\mathrm{C}^{\mathrm{Pz}}\right) ; 150.7$;

164.6 $\left(\mathrm{CH}_{3} \mathrm{C}=\mathrm{N}\right) ; 171.2\left(\mathrm{CH}_{3} \mathrm{C}=\mathrm{N}\right)$.

${ }^{31} \mathrm{P}\{1 \mathrm{H}\} \delta:$

40.8 .

\subsection{Synthesis of $\left[\mathrm{HL}^{2} \mathrm{Pd}\left(\mathrm{CH}_{3}\right) \mathrm{Cl}\right](3 \mathrm{e})$}

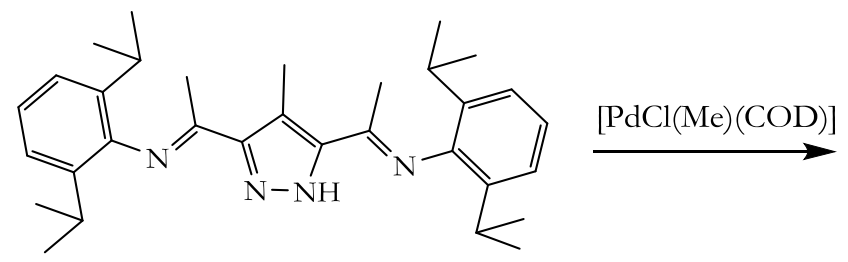

$\mathrm{HL}^{2}$

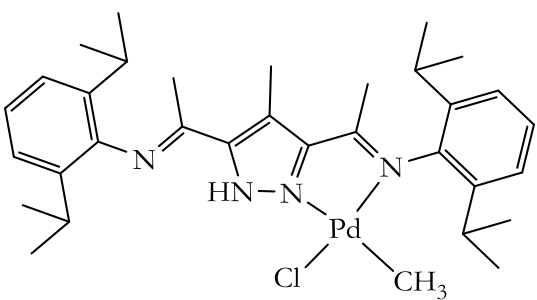

$3 \mathbf{e}$

To a toluene solution $(10 \mathrm{~mL})$ of $\mathbf{H L}^{2}(220 \mathrm{mg}, 0.45 \mathrm{mmol})$ was added a mol equivalent of [PdCl(Me)(COD)] (120 mg, $0.46 \mathrm{mmol}$ ) with stirring. A bright yellow solution was formed instantly. The reaction was stirred further at room temperature for $8 \mathrm{~h}$. The solution was concentrated on a rotary evaporator to $c a .3 \mathrm{~mL}$ and the solution allowed to stand for some time, after which an off-white precipitate began to form. The precipitate was filtered, and the solid washed several times with cold ether $(3 \times 3 \mathrm{~mL})$ and dried in air. The product was obtained as an off-white solid. Recrystallization from $\mathrm{CH}_{2} \mathrm{Cl}_{2}$ gives the product as an off-white crystalline solid.

Yield:

Molecular formula:

Molecular weight:

MS (ESI, $\left.\mathrm{CH}_{2} \mathrm{Cl}_{2}\right) m / z(\%)$ :

IR $\left(\right.$ ATR, $\left.\mathrm{cm}^{-1}\right)$ :
$100 \mathrm{mg}, 34 \%$

$\mathrm{C}_{33} \mathrm{H}_{47} \mathrm{ClN}_{4} \mathrm{Pd}$

$641.6 \mathrm{~g} / \mathrm{mol}$.

$646(80 \%)[\mathrm{M}+4 \mathrm{H}]^{+} ; 628(25 \%)[\mathrm{M}-\mathrm{Cl}+\mathrm{Na}]^{+}$.

2959 (m); 2926 (m); 2868 (m); 1564 (s); 1462 (s); 1437 (vs); 1229

(s); 775 (vs); 730 (s). 
${ }^{1} \mathrm{H}-\mathrm{NMR}\left(\mathrm{CDCl}_{3}\right) \delta$ :

CHN Analysis:

${ }^{13} \mathrm{C}\left\{{ }^{1} \mathrm{H}\right\}\left(\mathrm{CDCl}_{3}\right) \delta:$ $0.46\left(\mathrm{~s}, 3 \mathrm{H}, \mathrm{CH}_{3}{ }^{\mathrm{Pd}}\right) ; 1.16\left(\mathrm{~d},{ }^{3} J_{\mathrm{HH}}=6.8 \mathrm{~Hz}, 12 \mathrm{H}, \mathrm{CH}_{3}{ }^{\mathrm{PP}}\right) ; 1.31(\mathrm{~d}$, $\left.{ }^{3} J_{\mathrm{HH}}=6.8 \mathrm{~Hz}, 12 \mathrm{H}, \mathrm{CH}_{3}^{i \mathrm{PP}}\right) ; 2.13\left(\mathrm{~s}, 3 \mathrm{H}, \mathrm{CH}_{3} \mathrm{C}=\mathrm{N}\right) ; 2.24(\mathrm{~s}, 3 \mathrm{H}$, $\left.\mathrm{CH}_{3} \mathrm{C}=\mathrm{N}\right) ; 2.66\left(\mathrm{sept},{ }^{3} \mathrm{HH}_{\mathrm{HH}}=6.8 \mathrm{~Hz}, 2 \mathrm{H}, \mathrm{CH}^{\mathrm{iP}}\right) ; 2.70\left(\mathrm{~s}, \mathrm{CH}_{3}, 3 \mathrm{H}\right.$, $\mathrm{CH}_{3}{ }^{\mathrm{Pz}}$ ); 3.12 (sept, $\left.{ }^{3} \mathrm{H}_{\mathrm{HH}}=6.8 \mathrm{~Hz}, 2 \mathrm{H}, \mathrm{CH}^{\mathrm{iPp}}\right) ; 7.15-7.27(\mathrm{~m}, 6 \mathrm{H}$, $\left.\mathrm{CH}^{\mathrm{Ar}}\right)$.

$2.8\left(\mathrm{CH}_{3}^{\mathrm{Pd}}\right) ; 11.0\left(\mathrm{CH}_{3}{ }^{\mathrm{Pz} 4}\right) ; 19.3\left(\mathrm{CH}_{3}{ }^{\mathrm{iPr}}\right) ; 21.0\left(\mathrm{CH}_{3}{ }^{i \mathrm{Pr}}\right) ; 22.9\left(\mathrm{CH}_{3}{ }^{i \mathrm{Pr}}\right)$; $23.3\left(\mathrm{CH}_{3}{ }^{i \mathrm{PP}}\right) ; 23.4\left(\mathrm{CH}_{3}{ }^{i \mathrm{PP}}\right) ; 24.0\left(\mathrm{CH}^{i \mathrm{PP}}\right) ; 28.1\left(\mathrm{CH}^{\mathrm{iPr}}\right) ; 28.3\left(\mathrm{CH}^{i \mathrm{Pr}}\right)$; $123.1\left(\mathrm{C}^{\mathrm{P} z 4}\right) ; 123.8\left(\mathrm{CH}^{\mathrm{Ar}}\right) ; 124.4\left(\mathrm{CH}^{\mathrm{Ar}}\right) ; 129.0\left(\mathrm{C}^{\mathrm{Ar}}\right) ; 135.9\left(\mathrm{C}^{\mathrm{Ar}}\right)$; $136.0\left(\mathrm{C}^{\mathrm{Ar}}\right) ; 139.6\left(\mathrm{C}^{\mathrm{Ar}}\right) ; 140.3\left(\mathrm{C}^{\mathrm{Ar}}\right) ;\left(\mathrm{CH}_{3} \mathrm{C}=\mathrm{N}\right)$-not observed.

Calcd. For $\mathrm{C}_{33} \mathrm{H}_{46} \mathrm{ClN}_{4} \mathrm{Pd} \cdot \mathrm{CH}_{2} \mathrm{Cl}_{2}$ (C) 56.28 (H) 6.67 (N) 7.72; Found: (C) $55.00(\mathrm{H}) 6.63(\mathrm{~N}) 7.36$.

\subsection{Synthesis of $\left[\mathrm{HL}^{3} \mathrm{Pd}\left(\mathrm{CH}_{3}\right) \mathrm{Cl}\right](3 \mathrm{f})$}

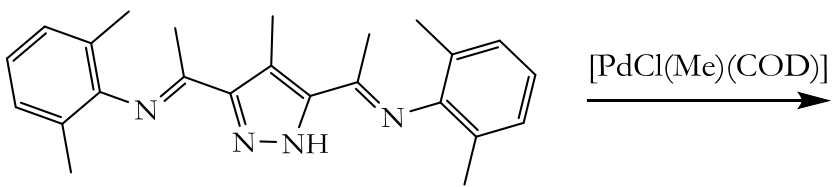

$\mathrm{HL}^{3}$

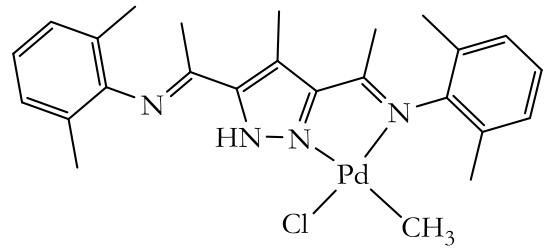

$3 \mathbf{f}$

To a toluene solution $(10 \mathrm{~mL})$ of $\mathbf{H L}^{3}(300 \mathrm{mg}, 0.8 \mathrm{mmol})$ was added a mol equivalent [PdCl(Me)(COD)] (210 mg, $0.8 \mathrm{mmol})$. The solution was stirred overnight, forming a bright yellow suspension. The suspension was filtered to obtain an offwhite powder which was washed with cold $\mathrm{Et}_{2} \mathrm{O}(3 \times 3 \mathrm{~mL})$ and the product dried in air. Recrystalization from a 50:50 mixture of $\mathrm{CH}_{2} \mathrm{Cl}_{2}$ and hexane gave an offwhite powder.

Yield:

Molecular formula:

Molecular weight:

MS (ESI, $\left.\mathrm{CH}_{2} \mathrm{Cl}_{2}\right) m / z(\%)$ :

IR (ATR, $\left.\mathrm{cm}^{-1}\right)$ :
$280 \mathrm{mg}, 66 \%$

$\mathrm{C}_{25} \mathrm{H}_{30} \mathrm{ClN}_{4} \mathrm{Pd}$

$528.4 \mathrm{~g} / \mathrm{mol}$.

$534(35 \%)\left[\mathrm{M}^{+}-\mathrm{Me}+\mathrm{Na}\right]^{+} ; 477(100 \%)[\mathrm{LPd}]^{+}$.

2998 (vs); 2901 (s); 1631 (vs); 1589 (m); 1549 (m); 1465 (m); 1370

(w); 1270 (s); 1233 (s); 1199 (m); 764 (s). 
${ }^{1} \mathrm{H}-\mathrm{NMR}\left(\mathrm{CDCl}_{3}\right) \delta$ :

${ }^{13} \mathrm{C}\left\{{ }^{1} \mathrm{H}\right\}\left(\mathrm{CDCl}_{3}\right) \delta:$
0.27 (s, 3H, $\left.\mathrm{CH}_{3}{ }^{\mathrm{Pd}}\right) ; 1.98$ (s, 6H, $\left.\mathrm{CH}_{3}{ }^{\mathrm{Mes}}\right) ; 2.13\left(\mathrm{~s}, 6 \mathrm{H}, \mathrm{CH}_{3}{ }^{\mathrm{Mes}}\right) ; 2.16$ (s, $\left.3 \mathrm{H}, \mathrm{CH}_{3} \mathrm{C}=\mathrm{N}\right) ; 2.53$ (s, $\left.3 \mathrm{H}, \mathrm{CH}_{3} \mathrm{C}=\mathrm{N}\right) ; 2.66$ (s, $\left.3 \mathrm{H}, \mathrm{CH}_{3}{ }^{\mathrm{P}_{24}}\right)$; 6.90-7.26 (m, 6H, $\left.\mathrm{CH}^{\mathrm{A}}\right)$; NH-not observed.

$-0.31\left(\mathrm{CH}_{3}{ }^{\mathrm{Pd}}\right) ; 10.0\left(\mathrm{CH}_{3}{ }^{\mathrm{P} z}\right) ; 10.2\left(\mathrm{CH}_{3}{ }^{{ }_{\mathrm{z}} 4}\right) ; 17.0\left(\mathrm{CH}_{3}{ }^{\mathrm{Mes}}\right) ; 17.1$ $\left(\mathrm{CH}_{3}{ }^{\mathrm{Mes}}\right) ; 17.3\left(\mathrm{CH}_{3}{ }^{\mathrm{Mes}}\right) ; 17.7\left(\mathrm{CH}_{3}{ }^{\mathrm{Mes}}\right) ; 17.9\left(\mathrm{CH}_{3}{ }^{\mathrm{Mes}}\right) ; 18.0$ $\left(\mathrm{CH}_{3} \mathrm{C}=\mathrm{N}\right) ; 18.2\left(\mathrm{CH}_{3} \mathrm{C}=\mathrm{N}\right) ; 18.3\left(\mathrm{CH}_{3} \mathrm{C}=\mathrm{N}\right) ; 117.8\left(\mathrm{C}^{\mathrm{Pz} 4}\right) ; 122.5$; $\left(\mathrm{CH}^{\mathrm{Ar}}\right) 124.2\left(\mathrm{CH}^{\mathrm{Ar}}\right) ; 124.3\left(\mathrm{CH}^{\mathrm{Ar}}\right) ; 125.4\left(\mathrm{CH}^{\mathrm{Ar}}\right) ; 127.0\left(\mathrm{CH}^{\mathrm{Ar}}\right)$; 127.2 $\left(\mathrm{CH}^{\mathrm{Mes}}\right) ; 128.1\left(\mathrm{C}^{\mathrm{Ar}}\right) ; 128.2\left(\mathrm{C}^{\mathrm{A \eta}}\right) ; 128.8\left(\mathrm{C}^{\mathrm{Ar}}\right)$; $\left(\mathrm{CH}_{3} \mathrm{C}=\mathrm{N}\right)$-not observed.

\subsection{Synthesis of $\left[\mathrm{HL}^{4} \mathrm{Pd}\left(\mathrm{CH}_{3}\right) \mathrm{Cl}\right](3 \mathrm{~g})$}

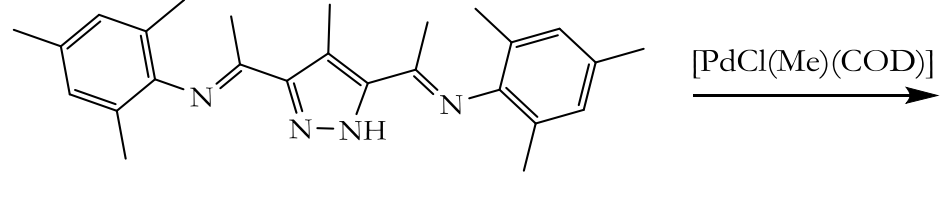

$\mathrm{HL}^{4}$

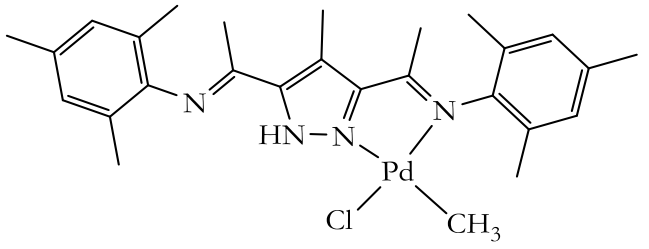

$3 g$

To a toluene solution $(15 \mathrm{~mL})$ of $\mathbf{H L}^{4}(300 \mathrm{mg}, 0.57 \mathrm{mmol})$ was added a mol equivalent [PdCl(Me)(COD)] (190 mg, $0.57 \mathrm{mmol})$. The reaction was stirred for $18 \mathrm{~h}$. The suspension was filtered and the product washed with $\mathrm{Et}_{2} \mathrm{O}(3 \times 3 \mathrm{~mL})$ and dried in air. Product was obtained as an off-white powder.

Yield:

Molecular formula:

Molecular weight:

MS (ESI, $\left.\mathrm{CH}_{2} \mathrm{Cl}_{2}\right) m / z(\%)$ :

IR $\left(\right.$ ATR, $\left.\mathrm{cm}^{-1}\right)$ :

${ }^{1} \mathrm{H}-\mathrm{NMR}\left(\mathrm{CDCl}_{3}\right) \delta$ :
$200 \mathrm{mg}, 32 \%$

$\mathrm{C}_{27} \mathrm{H}_{34} \mathrm{ClN}_{4} \mathrm{Pd}$

$556.5 \mathrm{~g} / \mathrm{mol}$.

$562(85 \%)[\mathrm{M}-\mathrm{Cl}+\mathrm{K}]^{+} ; 505(100 \%)[\mathrm{M}-\mathrm{Cl}(\mathrm{Me})]^{+}$.

2916 (br); 1633 (vs); 1583 (s); 1462 (w); 1373 (m); 1268 (s); 1222

(m); 1153 (s); 1002 (m); $964(\mathrm{~m}) ; 852$ (s); 766 (m).

$0.32\left(\mathrm{~s}, 3 \mathrm{H}, \mathrm{CH}_{3}{ }^{\mathrm{Pd}}\right) ; 1.96$ (s, 6H, $\left.\mathrm{CH}_{3}^{\mathrm{Mes}}\right) ; 2.11$ (s, 3H, $\left.\mathrm{CH}_{3}^{\text {Mes }}\right) ; 2.13$

(s, 6H, $\left.\mathrm{CH}_{3}{ }^{\mathrm{Mes}}\right) ; 2.16$ (s, 3H, $\left.\mathrm{CH}_{3} \mathrm{C}=\mathrm{N}\right) ; 2.28$ (s, 3H, $\left.\mathrm{CH}_{3} \mathrm{C}=\mathrm{N}\right)$;

$2.30\left(\mathrm{~s}, 3 \mathrm{H}, \mathrm{CH}_{3}{ }^{\mathrm{Mes}}\right) ; 2.66\left(\mathrm{~s}, 3 \mathrm{H}, \mathrm{CH}_{3}{ }^{\mathrm{Pz} 4}\right)$ 6.98-7.22 (m, 6H, $\left.\mathrm{CH}^{\mathrm{Mes}}\right)$. 


\section{Experimetal}

\begin{tabular}{|c|c|}
\hline${ }^{3} \mathrm{C}\left\{{ }^{1} \mathrm{H}\right\}\left(\mathrm{CDCl}_{3}\right) \delta:$ & 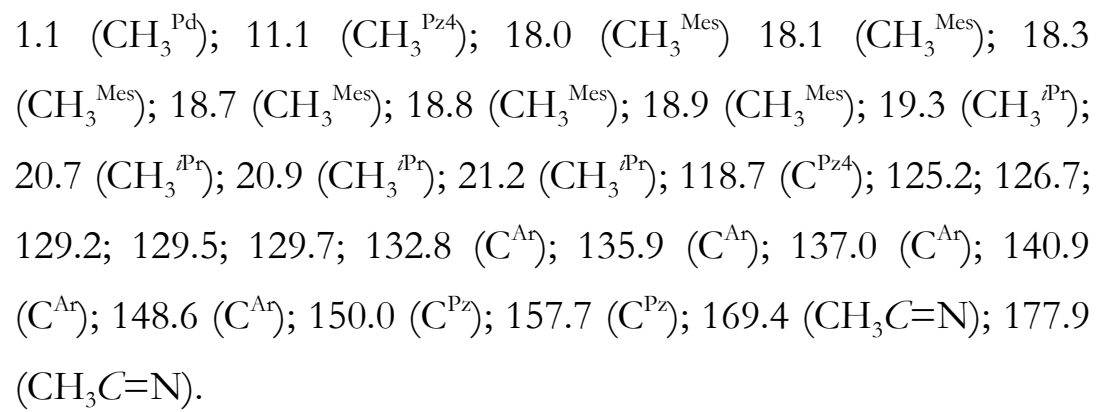 \\
\hline
\end{tabular}

\subsection{Synthesis of $\left[\mathrm{L}_{2}^{2} \mathrm{Pd}\right](3 \mathrm{~h})$}

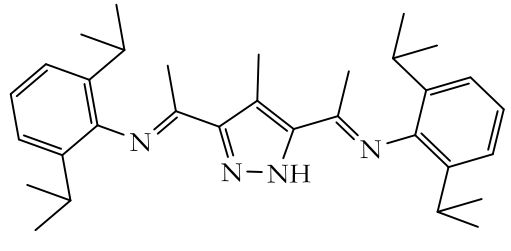

$\mathrm{HL}^{2}$

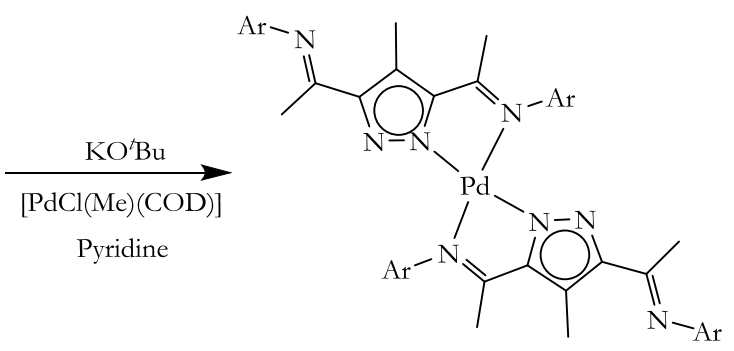

$3 \mathrm{~h}$

To a $\mathrm{CH}_{2} \mathrm{Cl}_{2}$ solution $(15 \mathrm{~mL})$ of $\mathbf{H L}^{2}(50 \mathrm{mg}, 0.13 \mathrm{mmol})$ was added a mol equivalent of $\mathrm{KO}^{\prime} \mathrm{Bu}$ (11.6 mg, $0.13 \mathrm{mmol})$. To the stirring solution were added [PdCl(Me)(COD)] (34 mg, $0.13 \mathrm{mmol}$ ) and an equivalent pyridine. A bright yellow solution was formed, which was allowed to stir at room temperature for $18 \mathrm{~h}$. The reaction was filtered and filtrate evaporated to obtain a bright yellow solid. The solid was redissolved in $\mathrm{CH}_{2} \mathrm{Cl}_{2}(5 \mathrm{~mL})$ and layered with hexane, which again results in the precipitation of a bright yellow solid. The solid was filtered, washed with cold $\mathrm{Et}_{2} \mathrm{O}$ $(3 \times 3 \mathrm{~mL})$ and dried in air. Yellow crystals of the complex were grown by the slow evaporation of a $\mathrm{CH}_{2} \mathrm{Cl}_{2}$ solution of the complex at room temperature.

Yield:

$13 \mathrm{mg}, 10 \%$

Molecular formula:

$\mathrm{C}_{64} \mathrm{H}_{86} \mathrm{~N}_{8} \mathrm{Pd}$

Molecular weight:

$1072.6 \mathrm{~g} / \mathrm{mol}$.

MS (ESI, $\left.\mathrm{CH}_{2} \mathrm{Cl}_{2}\right)$ m/ ₹ (\%): $1073(100 \%)[\mathrm{M}+\mathrm{H}]^{+}$.

IR $\left(\right.$ ATR, $\left.\mathrm{cm}^{-1}\right)$ : 2926 (m); 2808 (m); 1631 (s); 1564 (s); 1437 (s); 1326 (m); 1227 (vs); 1097 (s); 1059 (s). 
${ }^{1} \mathrm{H}-\mathrm{NMR}\left(\mathrm{CDCl}_{3}\right) \delta:$

${ }^{13} \mathrm{C}\left\{{ }^{1} \mathrm{H}\right\}\left(\mathrm{CDCl}_{3}\right) \delta:$

CHN Analysis:

\section{Experimetal}

1.11-1.19 (m, $\left.48 \mathrm{H}, \mathrm{CH}_{3}{ }^{2 \mathrm{Pr}}\right) ; 1.59\left(\mathrm{~s}, 6 \mathrm{H}, \mathrm{CH}_{3} \mathrm{C}=\mathrm{N}\right) ; 2.16(\mathrm{~s}, 6 \mathrm{H}$, $\mathrm{CH}_{3} \mathrm{C}=\mathrm{N}$ ); $2.63\left(\mathrm{~s}, 6 \mathrm{H}, \mathrm{CH}_{3}{ }^{\mathrm{P}_{z} 4}\right) ; 2.74$ (sept, ${ }^{3} \mathrm{~J}_{\mathrm{HH}}=6.8 \mathrm{~Hz}, 4 \mathrm{H}$, $\left.\mathrm{CH}^{\mathrm{iPr}}\right) ; 3.35\left(\mathrm{sept},{ }^{3} \mathrm{HH}_{\mathrm{HH}}=6.8 \mathrm{~Hz}, 4 \mathrm{H}, \mathrm{CH}^{\mathrm{iPr}}\right) ; 7.00-7.26(\mathrm{~m}, 12 \mathrm{H}$, $\left.\mathrm{CH}^{\mathrm{An}}\right)$.

$11.2\left(\mathrm{CH}_{3}{ }^{\mathrm{Pz} 4}\right) ; 18.1\left(\mathrm{CH}_{3} \mathrm{C}=\mathrm{N}\right) ; 19.5\left(\mathrm{CH}_{3} \mathrm{C}=\mathrm{N}\right) ; 22.9\left(\mathrm{CH}_{3}{ }^{i \mathrm{Pr}}\right) ; 23.1$ $\left(\mathrm{CH}_{3}{ }^{i \mathrm{PP}}\right) ; 23.4\left(\mathrm{CH}_{3}{ }^{i \mathrm{PP}}\right) ; 23.7\left(\mathrm{CH}_{3}{ }^{i \mathrm{PP}}\right) ; 28.0\left(\mathrm{CH}_{3}{ }^{i \mathrm{PP}}\right) ; 28.5 ; 120.4$ $\left(\mathrm{C}^{\mathrm{Pz} 4}\right) ; 122.5\left(\mathrm{CH}^{\mathrm{Ar}}\right) ; 122.6\left(\mathrm{CH}^{\mathrm{Ar}}\right) ; 123.4\left(\mathrm{CH}^{\mathrm{Ar}}\right) ; 127.6\left(\mathrm{CH}^{\mathrm{Ar}}\right)$; 136.1 $\left(\mathrm{C}^{\mathrm{Ar} 1}\right) ; 140.7 \quad\left(\mathrm{C}^{\mathrm{Ar} 2 / 6}\right) ; 147.3\left(\mathrm{C}^{\mathrm{P} z 3 / 5}\right) ; 148.8 \quad\left(\mathrm{C}^{\mathrm{P} z 3 / 5}\right) ; 164.3$ $\left(\mathrm{CH}_{3} \mathrm{C}=\mathrm{N}\right) ; 172.1\left(\mathrm{CH}_{3} \mathrm{C}=\mathrm{N}\right)$.

Calcd. For $\mathrm{C}_{64} \mathrm{H}_{86} \mathrm{ClN}_{8} \mathrm{Pd} \cdot 0.5 \mathrm{CH}_{2} \mathrm{Cl}_{2}$ : (C) 69.23, (H) 7.90, (N) 10.09; Found: (C) $70.16(\mathrm{H}) 7.77$ (N) 10.03. 


\section{3 Mononuclear nickel(II) complexes}

\subsection{Synthesis of $\left[\mathrm{L}^{1} \mathrm{Ni}\left(\mathrm{C}_{10} \mathrm{H}_{7}\right)\left(\mathrm{PPh}_{3}\right)\right](3 \mathrm{j})$}<smiles>CCc1cccc(/C=N/c2cc(/C=N/c3c(C(C)C)cccc3C(C)(C)C)[nH]n2)c1CC</smiles>

$\mathbf{H L}^{1}$
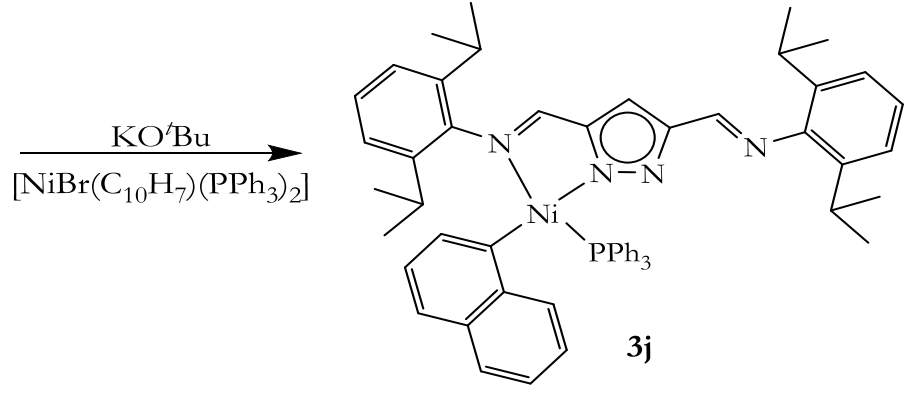

A $\mathrm{CH}_{2} \mathrm{Cl}_{2}$ solution $(15 \mathrm{~mL})$ of the deprotonated ligand $\mathbf{L}^{1}(150 \mathrm{mg}, 0.34 \mathrm{mmol})$ was added dropwise to a $\mathrm{CH}_{2} \mathrm{Cl}_{2}$ solution of $\left[\mathrm{NiBr}\left(\mathrm{C}_{10} \mathrm{H}_{7}\right)\left(\mathrm{PPh}_{3}\right)_{2}\right](270 \mathrm{mg}, 0.34 \mathrm{mmol})$ with stirring for 18 $\mathrm{h}$, forming a bright yellow solution. The bright yellow solution was filtered over celite to remove traces of $\mathrm{KBr}$. Slow evaporation of the $\mathrm{CH}_{2} \mathrm{Cl}_{2}$ solution of the complex precipates the product as a bright orange powder.

Yield:

Molecular formula:

Molecular weight:

MS (ESI, $\left.\mathrm{CH}_{2} \mathrm{Cl}_{2}\right) m / z(\%)$ :

IR $\left(\right.$ ATR, $\left.\mathrm{cm}^{-1}\right)$ :

${ }^{1} \mathrm{H}-\mathrm{NMR}\left(\mathrm{CDCl}_{3}\right) \delta$ :
$130 \mathrm{mg}, 44 \%$

$\mathrm{C}_{57} \mathrm{H}_{59} \mathrm{~N}_{4} \mathrm{NiP}$

$889.8 \mathrm{~g} / \mathrm{mol}$.

$889(100 \%)[\mathrm{M}]^{+}$.

3052 (m); 2959 (m); 2926 (m); 1637 (vs); 1583 (vs); 1375 (s); 1365

(s); 1436 (vs); 1383 (s); 1184 (s); 1097 (vs); 692 (vs); 510 (s); 497 (vs).

$0.14\left(\mathrm{~d},{ }^{3} J_{\mathrm{HH}}=6.7 \mathrm{~Hz}, 3 \mathrm{H}, \mathrm{CH}_{3}{ }^{2 \mathrm{Pr}}\right) ; 0.87\left(\mathrm{~d},{ }^{3} J_{\mathrm{HH}}=6.8 \mathrm{~Hz}, 3 \mathrm{H}\right.$, $\left.\mathrm{CH}_{3}{ }^{\mathrm{PPr}}\right) ; 1.02-1.44\left(\mathrm{~m}, 15 \mathrm{H}, \mathrm{CH}_{3}^{i \mathrm{Pr}}\right) ; 1.65\left(\mathrm{~d},{ }^{3} J_{\mathrm{HH}}=6.8 \mathrm{~Hz}, 3 \mathrm{H}\right.$, $\left.\mathrm{CH}_{3}{ }^{\mathrm{PP}}\right) ; 2.74\left(\mathrm{~m},{ }^{3} J_{\mathrm{HH}}=6.8 \mathrm{~Hz}, 1 \mathrm{H}, \mathrm{CH}^{\mathrm{IPr}}\right) ; 3.00\left(\mathrm{sept},{ }^{3} J_{\mathrm{HH}}=6.8\right.$ $\left.\mathrm{Hz}, 2 \mathrm{H} ; \mathrm{CH}^{\mathrm{PP}}\right) ; 4.20$ (sept, $\left.{ }^{3} \mathrm{H}_{\mathrm{HH}}=6.8 \mathrm{~Hz}, 1 \mathrm{H} ; \mathrm{CH}^{\mathrm{PP}}\right) ; 6.29(\mathrm{t}, J=$ $\left.7.5 \mathrm{~Hz}, 1 \mathrm{H}, \mathrm{CH}^{\mathrm{Ar}}\right) ; 6.42-6.51\left(\mathrm{~m}, 2 \mathrm{H}, \mathrm{CH}^{\mathrm{Ar}}\right) ; 6.68(\mathrm{~d}, J=7.0 \mathrm{~Hz}$, $\left.1 \mathrm{H}, \mathrm{CH}^{\mathrm{Ar}}\right) ; 6.74\left(\mathrm{~d}, J=8.7 \mathrm{~Hz}, 2 \mathrm{H}, \mathrm{CH}^{\mathrm{A}}\right) 6.87(\mathrm{t}, J=7.7 \mathrm{~Hz}, 1 \mathrm{H}$, $\left.\mathrm{CH}^{\mathrm{Ar}}\right) ; 7.18\left(\mathrm{~s}, 1 \mathrm{H}, \mathrm{CH}^{\mathrm{Pz}}\right) ; 7.69(\mathrm{~s}, 1 \mathrm{H}, \mathrm{CH}=\mathrm{N}) ; 6.98-7.55(\mathrm{~m}, 21 \mathrm{H}$, $\left.\mathrm{CH}^{\mathrm{Ar}, \mathrm{Pph} 3}\right) ; 7.99(\mathrm{~d}, J=5.8 \mathrm{~Hz}, 1 \mathrm{H}, \mathrm{CH}=\mathrm{N}) ; 9.19\left(\mathrm{~d}, 3_{\mathrm{HH}}=5.9\right.$ $\left.\mathrm{Hz}, 1 \mathrm{H}, \mathrm{CH}^{\mathrm{Napth}}\right)$. 


\begin{tabular}{|c|c|}
\hline${ }^{13} \mathrm{C}\left\{{ }^{1} \mathrm{H}\right\}\left(\mathrm{CDCl}_{3}\right) \delta:$ & 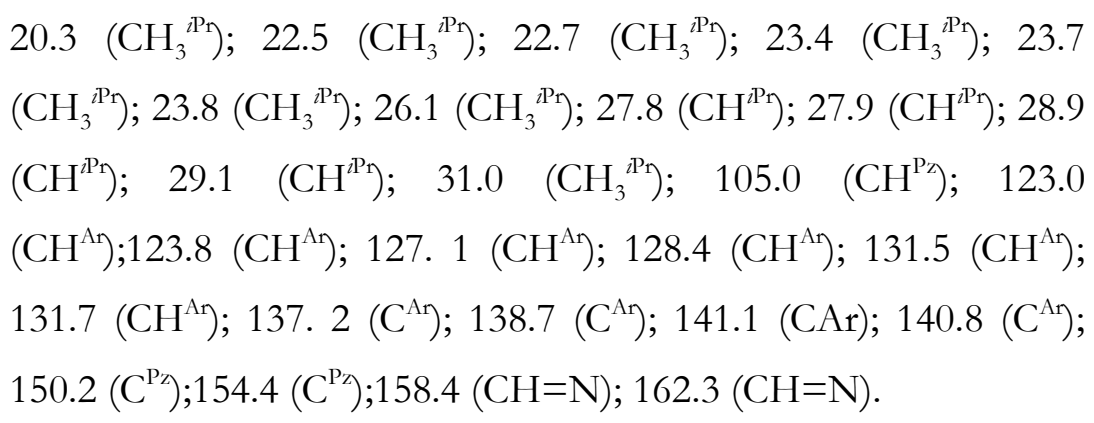 \\
\hline${ }^{31} \mathrm{P}\left\{{ }^{1} \mathrm{H}\right\}:$ & 30.75 . \\
\hline
\end{tabular}

\subsection{Synthesis of $\left[\mathrm{L}^{2} \mathrm{Ni}\left(\mathrm{C}_{10} \mathrm{H}_{7}\right)\left(\mathrm{PPh}_{3}\right)\right](3 \mathrm{k})$}
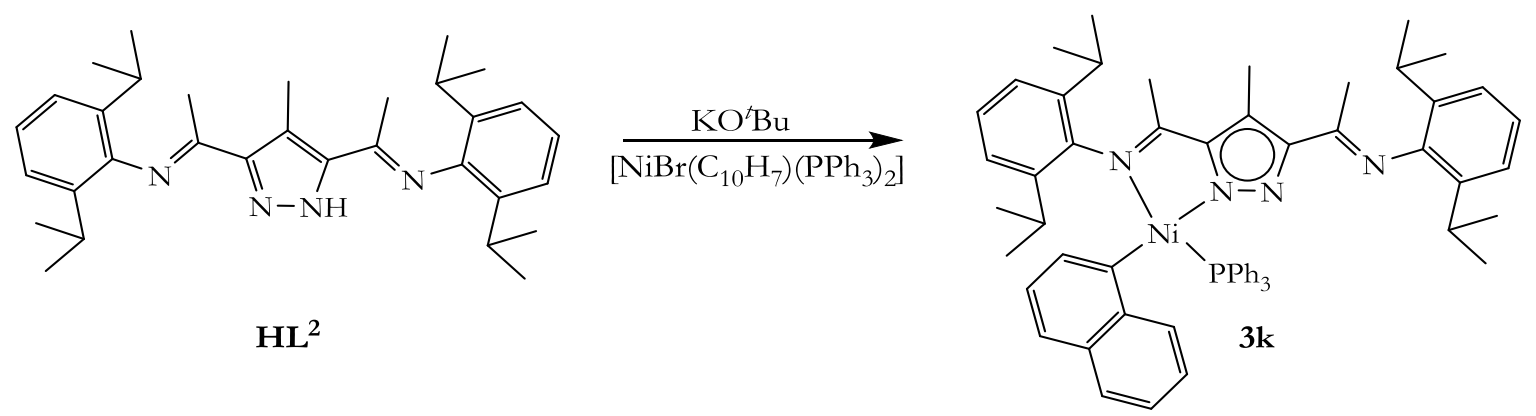

A $\mathrm{CH}_{2} \mathrm{Cl}_{2}$ solution $(10 \mathrm{~mL})$ of the deprotonated ligand, $\mathbf{L}^{2}(110 \mathrm{mg}, 0.23 \mathrm{mmol})$ was added dropwise to a $\mathrm{CH}_{2} \mathrm{Cl}_{2}$ solution of $\left[\mathrm{NiBr}\left(\mathrm{C}_{10} \mathrm{H}_{7}\right)\left(\mathrm{PPh}_{3}\right)_{2}\right](180 \mathrm{mg}, 0.22 \mathrm{mmol})$ with stirring for 18 $\mathrm{h}$, forming a yellow solution. The bright yellow solution was filtered over celite to remove traces of $\mathrm{KBr}$. Slow evaporation of the $\mathrm{CH}_{2} \mathrm{Cl}_{2}$ solution of the complex precipates the product as a bright orange powder. Crystals were grown by the slow evaporation of a toluene solution of the complex at room temperature.

Yield:

$97 \mathrm{mg}, 46 \%$

Molecular formula:

$\mathrm{C}_{60} \mathrm{H}_{65} \mathrm{~N}_{4} \mathrm{NiP}$

Molecular weight:

$931.9 \mathrm{~g} / \mathrm{mol}$.

MS (ESI, $\left.\mathrm{CH}_{2} \mathrm{Cl}_{2}\right) m / z(\%)$ :

$931(100 \%)[\mathrm{M}]^{+}$.

IR $\left(\right.$ ATR, $\left.\mathrm{cm}^{-1}\right)$ :

2969 (m); 2928 (m); 1620 (vs); 1578 (vs); 1385 (vs); 1311 (m); 1222 (vs); 1059 (m); 756 (vs).

${ }^{1} \mathrm{H}-\mathrm{NMR}\left(\mathrm{CDCl}_{3}\right) \delta$ : $-0.52\left(\mathrm{~d},{ }^{3} J_{\mathrm{HH}}=6.6 \mathrm{~Hz}, 3 \mathrm{H}, \mathrm{CH}_{3}{ }^{\mathrm{PPr}}\right) ; 0.75\left(\mathrm{~d},{ }^{3} \mathrm{HH}_{\mathrm{HH}}=6.8 \mathrm{~Hz}, 3 \mathrm{H}\right.$, $\left.\mathrm{CH}_{3}^{i \mathrm{Pr}}\right) ; 1.04\left(\mathrm{~d}, J_{\mathrm{HH}}=6.9 \mathrm{~Hz}, 3 \mathrm{H}, \mathrm{CH}_{3}{ }^{\mathrm{PPr}}\right) ; 1.12\left(\mathrm{~d}, 3_{\mathrm{HH}}^{3}=6.9 \mathrm{~Hz}\right.$, 


\begin{abstract}
Experimetal
$\left.3 \mathrm{H}, \mathrm{CH}_{3}^{i \mathrm{Pr}}\right) ; 1.16\left(\mathrm{~d},{ }^{3} J_{\mathrm{HH}}=4.1 \mathrm{~Hz}, 3 \mathrm{H}, \mathrm{CH}_{3}^{i \mathrm{Pr}}\right) ; 1.18\left(\mathrm{~d},{ }^{3} J_{\mathrm{HH}}=4.0\right.$ $\left.\mathrm{Hz}, 3 \mathrm{H}, \mathrm{CH}_{3}{ }^{\mathrm{PPr}}\right) ; 1.26\left(\mathrm{~d},{ }^{3} \mathrm{HH}_{\mathrm{HH}}=6.8 \mathrm{~Hz}, 3 \mathrm{H}, \mathrm{CH}_{3}{ }^{\mathrm{PP}}\right) ; 1.39(\mathrm{~s}, 3 \mathrm{H}$, $\left.\mathrm{CCH}_{3}=\mathrm{N}\right) ; 1.77\left(\mathrm{~d},{ }^{3} J_{\mathrm{HH}}=6.8 \mathrm{~Hz}, 3 \mathrm{H}, \mathrm{CH}_{3}{ }^{\mathrm{PP}}\right) ; 2.18(\mathrm{~s}, 3 \mathrm{H}$, $\mathrm{CCH}_{3}=\mathrm{N}$ ); 2.54 (sept, $\left.{ }^{3} J_{\mathrm{HH}}=6.8 \mathrm{~Hz}, 1 \mathrm{H}, \mathrm{CH}^{\mathrm{PP}}\right) ; 2.64(\mathrm{~s}, 3 \mathrm{H}$, $\mathrm{CH}_{3}{ }^{\mathrm{Pz}}$ ) $; 2.73$ (sept, $\left.J_{\mathrm{HH}}=6.8 \mathrm{~Hz}, 1 \mathrm{H}, \mathrm{CH}^{\mathrm{iPr}}\right) ; 2.86$ (sept, ${ }^{3} \mathrm{H}_{\mathrm{HH}}=6.8$ $\left.\mathrm{Hz}, 1 \mathrm{H}, \mathrm{CH}^{\mathrm{iP}}\right) ; 4.02$ (sept, $\left.{ }^{3} \mathrm{HH}_{\mathrm{HH}}=6.8 \mathrm{~Hz}, 1 \mathrm{H}, \mathrm{CH}^{\mathrm{iP}}\right) ; 6.17\left(\mathrm{t}, 3_{\mathrm{HH}}\right.$ $\left.=7.5 \mathrm{~Hz}, 2 \mathrm{H}, \mathrm{CH}^{\mathrm{Ar}}\right) ; 6.35\left(\mathrm{~d}, 3_{\mathrm{HH}}=7.0 \mathrm{~Hz}, 1 \mathrm{H}, \mathrm{CH}^{\mathrm{Ar}}\right) ; 6.45(\mathrm{~d}$, $\left.{ }^{3} J_{\mathrm{HH}}=7.3 \mathrm{~Hz}, 1 \mathrm{H}, \mathrm{CH}^{\mathrm{Ar}}\right) ; 6.72\left(\mathrm{~d},{ }^{3} J_{\mathrm{HH}}=8.0 \mathrm{~Hz}, 2 \mathrm{H}, \mathrm{CH}^{\mathrm{Ar}}\right)$; 6.86$7.50\left(\mathrm{~m}, 21 \mathrm{H}, \mathrm{CH}^{\mathrm{Ar}}\right) ; 9.89\left(\mathrm{~d},{ }^{3} \mathrm{HH}_{\mathrm{H}}=8.1 \mathrm{~Hz}, 1 \mathrm{H}, \mathrm{CH}^{\mathrm{Ar}}\right)$.

${ }^{13} \mathrm{C}\left\{{ }^{1} \mathrm{H}\right\}\left(\mathrm{CDCl}_{3}\right) \delta:$

$11.4\left(\mathrm{CH}_{3}{ }^{\mathrm{P} z 4}\right) ; 18.7\left(\mathrm{CH}_{3} \mathrm{C}=\mathrm{N}\right) ; 20.4\left(\mathrm{CH}_{3} \mathrm{C}=\mathrm{N}\right) ; 21.1\left(\mathrm{CH}_{3}{ }^{i \mathrm{Pr}}\right)$; 23.0; 23.2; 23.7; $24.5\left(\mathrm{CH}_{3}{ }^{\mathrm{iP}}\right) ; 25.0 ; 28.1\left(\mathrm{CH}^{\mathrm{iPr}}\right) ; 28.5\left(\mathrm{CH}^{\mathrm{iPr}}\right) ; 28.6$ $\left(\mathrm{CH}^{\mathrm{iPr}}\right) ; 121.2\left(\mathrm{CH}^{\mathrm{Ar}}\right) ; 123.0 ; 123.6 ; 125.8 ; 127.1 ; 127.3 ; 129.3$; 132.0; $132.6\left(\mathrm{CH}^{\mathrm{Ar}}\right) ; 134.2\left(\mathrm{CH}^{\mathrm{Ar}}\right) ; 134.3 ; 134.8 ; 136.3 ; 140.5\left(\mathrm{C}^{\mathrm{Ar}}\right)$; $142.0\left(\mathrm{C}^{\mathrm{A}}\right) ; 164.7\left(\mathrm{CH}_{3} \mathrm{C}=\mathrm{N}\right) ; 172.0\left(\mathrm{CH}_{3} \mathrm{C}=\mathrm{N}\right)$.

${ }^{31} \mathrm{P}\{1 \mathrm{H}\} \delta:$

30.3 .
\end{abstract}

Elemental analysis:

Calcd. For $\mathrm{C}_{60} \mathrm{H}_{65} \mathrm{~N}_{4} \mathrm{NiP}$ : (C) $77.33(\mathrm{H}) 7.03 \mathrm{~N}$ (6.01); Found: $\mathrm{C}$ (76.46) H (6.85) (N) (5.90).

\subsection{Synthesis of $\left[\mathrm{L}^{2} \mathrm{Ni}\left(\mathrm{C}_{6} \mathrm{H}_{5}\right)\left(\mathrm{PPh}_{3}\right)\right](31)$}

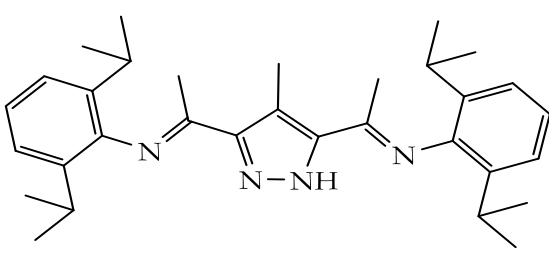

$\mathbf{H L}^{2}$
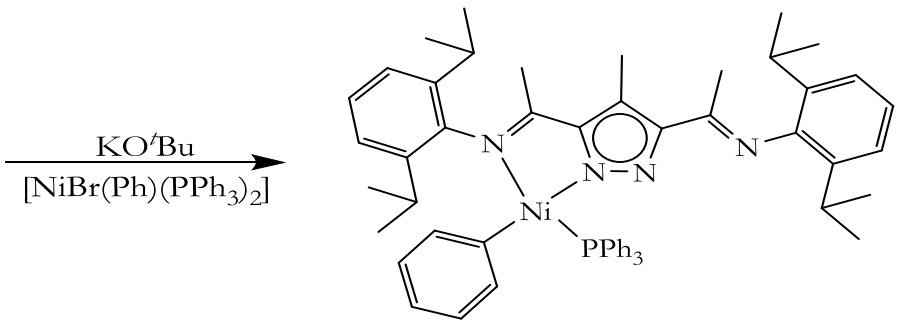

31

Following a similar procedure as done for $3 \mathbf{k}$, using $\mathbf{L}^{2}(120 \mathrm{mg}, 0.25 \mathrm{mmol})$ and $\left[\mathrm{NiBr}(\mathrm{Ph})\left(\mathrm{PPh}_{3}\right)_{2}\right](120 \mathrm{mg}, 0.25 \mathrm{mmol})$. The product was obtained as an orange powder. Single crystals were obtained by the slow evaporation of a $\mathrm{CH}_{2} \mathrm{Cl}_{2}$ solution of the complex at room temperature.

Yield:

$98 \mathrm{mg}, 45 \%$

Molecular formula:

$\mathrm{C}_{56} \mathrm{H}_{63} \mathrm{~N}_{4} \mathrm{NiP}$ 
Molecular weight:

MS (ESI, $\left.\mathrm{CH}_{2} \mathrm{Cl}_{2}\right) m / z(\%)$ :

IR (ATR, $\left.\mathrm{cm}^{-1}\right)$ :

${ }^{1} \mathrm{H}-\mathrm{NMR}\left(\mathrm{CDCl}_{3}\right) \delta$ :

${ }^{13} \mathrm{C}\left\{{ }^{1} \mathrm{H}\right\}\left(\mathrm{CDCl}_{3}\right) \delta:$
$881.8 \mathrm{~g} / \mathrm{mol}$.

$539(100 \%)$ [M-Ph- $\left.\mathrm{PPh}_{3}\right]^{+}$.

2959 (m); 2918 (m); 1626 (vs); 1566 (vs); 1385 (vs); 1324 (m); 1229 (vs); 1059 (m); 730 (vs); 696 (vs).

1.08-1.15 (m, 24H, $\left.\mathrm{CH}_{3}^{i \mathrm{Pr}}\right) ; 1.49$ (s, $\left.3 \mathrm{H}, \mathrm{CH}_{3} \mathrm{C}=\mathrm{N}\right) ; 2.20$ (s, $3 \mathrm{H}$, $\left.\mathrm{CH}_{3} \mathrm{C}=\mathrm{N}\right) ; 2.53\left(\mathrm{~s}, 3 \mathrm{H}, \mathrm{CH}_{3}{ }^{\mathrm{Pz} 4}\right) ; 2.78\left(\mathrm{sept},{ }^{3} J_{\mathrm{HH}}=6.6 \mathrm{~Hz}, 2 \mathrm{H}\right.$, $\mathrm{CH}^{\mathrm{iPr}}$ ); 3.33 (sept, ${ }^{3} J_{\mathrm{HH}}=6.6 \mathrm{~Hz}, 2 \mathrm{H}, \mathrm{CH}^{\mathrm{iPr}}$ ); 4.01 (sept, ${ }^{3} J_{\mathrm{HH}}=6.6$ $\left.\mathrm{Hz}, 1 \mathrm{H}, \mathrm{CH}^{\mathrm{iPr}}\right) ; 6.17\left(\mathrm{t}, J_{\mathrm{HH}}=6.0 \mathrm{~Hz}, 2 \mathrm{H}, \mathrm{CH}^{\mathrm{An}}\right) ; 6.32\left(\mathrm{t}, J_{\mathrm{HH}}=6.0\right.$ $\left.\mathrm{Hz}, 1 \mathrm{H}, \mathrm{CH}^{\mathrm{Ar}}\right) ; 6.56\left(\mathrm{~d},{ }^{2} J_{\mathrm{HH}}=7 \mathrm{~Hz}, 1 \mathrm{H}, \mathrm{CH}^{\mathrm{Ar}}\right) ; 7.07-7.67(\mathrm{~m}$, $\left.21 \mathrm{H}, \mathrm{CH}^{\mathrm{An}}\right)$.

$11.1\left(\mathrm{CH}_{3}{ }^{\mathrm{Pz} 4}\right) ; 18.2\left(\mathrm{CH}_{3} \mathrm{C}=\mathrm{N}\right) ; 19.2\left(\mathrm{CH}_{3} \mathrm{C}=\mathrm{N}\right) ; 21.5\left(\mathrm{CH}_{3}{ }^{\mathrm{iP}}\right) ; 22.9$ $\left(\mathrm{CH}_{3}{ }^{\mathrm{iPr}}\right) ; 23.0\left(\mathrm{CH}_{3}{ }^{i \mathrm{PP}}\right) ; 23.1\left(\mathrm{CH}_{3}{ }^{\mathrm{iPr}}\right) ; 23.3\left(\mathrm{CH}_{3}{ }^{i \mathrm{PP}}\right) ; 23.5\left(\mathrm{CH}_{3}{ }^{i \mathrm{PP}}\right)$; $24.0\left(\mathrm{CH}_{3}^{i \mathrm{PP}}\right) ; 24.5\left(\mathrm{CH}_{3}{ }^{\mathrm{iP}}\right) ; 28.0\left(\mathrm{CH}^{\mathrm{IPr}}\right) ; 28.1\left(\mathrm{CH}^{\mathrm{PP}}\right) ; 28.6\left(\mathrm{CH}^{\mathrm{IPr}}\right)$; $29.2\left(\mathrm{CH}^{\mathrm{Pr}}\right) ; 120.2\left(\mathrm{C}^{\mathrm{P} z}\right) ; 122.6\left(\mathrm{CH}^{\mathrm{Ar}}\right) ; 122.9\left(\mathrm{CH}^{\mathrm{Ar}}\right) ; 123.3\left(\mathrm{CH}^{\mathrm{Ar}}\right)$; $125.1\left(\mathrm{CH}^{\mathrm{An}}\right) ; 125.3\left(\mathrm{CH}^{\mathrm{An}}\right) ; 127.2\left(\mathrm{CH}^{\mathrm{An}}\right) ; 127.4\left(\mathrm{CH}^{\mathrm{Ar}}\right) ; 127.5$ $\left(\mathrm{CH}^{\mathrm{Ar}}\right) ; 128.2\left(\mathrm{CH}^{\mathrm{Ar}}\right) ; 128.4\left(\mathrm{CH}^{\mathrm{Ar}}\right) ; 128.5\left(\mathrm{CH}^{\mathrm{Ar}}\right) ; 128.6\left(\mathrm{CH}^{\mathrm{Ar}}\right)$; $128.7\left(\mathrm{CH}^{\mathrm{Ar}}\right) ; 129.1\left(\mathrm{CH}^{\mathrm{Ar}}\right) ; 129.4\left(\mathrm{CH}^{\mathrm{Ar}}\right) ; 132.0\left(\mathrm{CH}^{\mathrm{Ar}}\right) ; 132.1$ $\left(\mathrm{CH}^{\mathrm{Ar}}\right) ; 132.3\left(\mathrm{CH}^{\mathrm{Ar}}\right) ; 132.4\left(\mathrm{CH}^{\mathrm{Ar}}\right) ; 134.3\left(\mathrm{CH}^{\mathrm{Ar}}\right) ; 134.4\left(\mathrm{CH}^{\mathrm{Ar}}\right)$; $135.2\left(\mathrm{CH}^{\mathrm{Ar}}\right) ; 135.3\left(\mathrm{CH}^{\mathrm{Ar}}\right) ; 136.9\left(\mathrm{CH}^{\mathrm{Ar}}\right) ; 136.5\left(\mathrm{CH}^{\mathrm{A \eta}}\right) ; 137.1$ $\left(\mathrm{CH}^{\mathrm{Ar}}\right) ; 141.1\left(\mathrm{CH}^{\mathrm{Ar}}\right) ; 141.2\left(\mathrm{CH}^{\mathrm{Ar}}\right) ; 142.4\left(\mathrm{C}^{\mathrm{Pz} 3 / 5}\right) ; 147.3\left(\mathrm{C}^{\mathrm{Pz} 3 / 5}\right)$; $149.2\left(\mathrm{C}^{\mathrm{Ar}}\right) ; 150.4\left(\mathrm{C}^{\mathrm{Ar}}\right) ; 164.1\left(\mathrm{CH}_{3} \mathrm{C}=\mathrm{N}\right) ; 172.6\left(\mathrm{CH}_{3} \mathrm{C}=\mathrm{N}\right)$. 


\section{4 Homobimetallic palladium(II) $\eta^{3}$-allyl complexes}

\subsection{Synthesis of $\left[\mathrm{L}^{1} \mathrm{Pd}_{2}\left(\eta^{3}-\mathrm{C}_{4} \mathrm{H}_{7}\right)_{2}\right] \mathrm{PF}_{6}(3 \mathrm{~m})$}

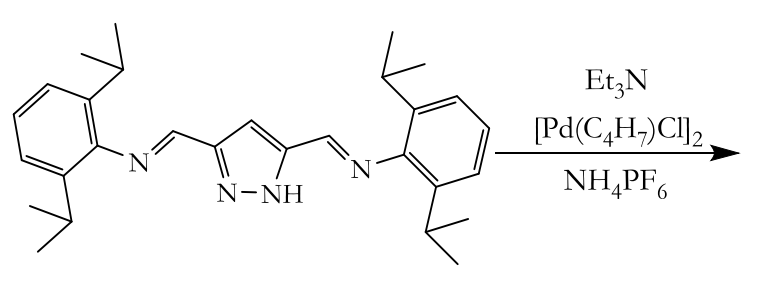

$\mathbf{H L}^{1}$

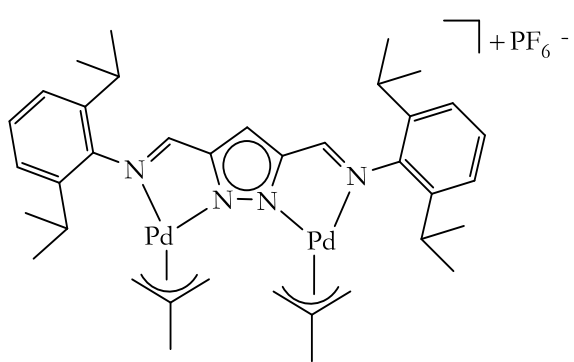

$3 \mathrm{~m}$

To a $\mathrm{CH}_{2} \mathrm{Cl}_{2}$ solution $(10 \mathrm{~mL})$ of $\mathbf{H L}^{1}(91.7 \mathrm{mg}, 0.21 \mathrm{mmol})$ was added an equivalent $\mathrm{Et}_{3} \mathrm{~N}$ as base with stirring for $10 \mathrm{~min}$. To this solution was added $\left[\mathrm{Pd}\left(\mathrm{C}_{4} \mathrm{H}_{7}\right) \mathrm{Cl}\right]_{2}(81 \mathrm{mg}, 0.21 \mathrm{mmol})$ and $\mathrm{NH}_{4} \mathrm{PF}_{6}(20 \mathrm{mg}, 0.12 \mathrm{mmol})$, and the reaction mixture stirred further for $18 \mathrm{~h}$. The reaction was filtered and the mixture washed with water $(3 \times 5 \mathrm{~mL})$. The organic phase was combined and dried over $\mathrm{MgSO}_{4}$. The solution was evaporated to remove all volatiles, giving an off-white crystalline solid. The product was recrystallized from a $\mathrm{CH}_{2} \mathrm{Cl}_{2} /$ hexane mixture at room temperature. The product was obtained as a light yellow solid.

Yield:

$110 \mathrm{mg}, 58 \%$

Molecular formula:

$\mathrm{C}_{37} \mathrm{H}_{51} \mathrm{BF}_{4} \mathrm{~N}_{4} \mathrm{Pd}_{2}$

Molecular weight:

$909.7 \mathrm{~g} / \mathrm{mol}$.

HRMS (TOF-ESI):

Calcd. For: $\mathrm{C}_{37} \mathrm{H}_{51} \mathrm{~N}_{4} \mathrm{Pd}_{2}$ (765.2199); Found: 765.2187.

MS (ESI, $\left.\mathrm{CH}_{2} \mathrm{Cl}_{2}\right) \mathrm{m} / \mathrm{z}(\%): \quad 764(100 \%)\left[\mathrm{M}-\mathrm{PF}_{6}\right]^{+}$.

IR (ATR, $\left.\mathrm{cm}^{-1}\right)$ :

2959 (m); 2924 (m); 2868 (m); 1605 (vs); 1588 (vs); 1489 (m); 1462 (m); 1389 (m); 1365 (m); 1343 (m); 1300 (m); 1070 (vs); 1043 (vs); 1028 (vs); 927 (m); 802 (m); 756 (m); 745 (m).

${ }^{1} \mathrm{H}-\mathrm{NMR}\left(\mathrm{CDCl}_{3}\right) \delta$ : 1.22-1.29 (m, 24H, $\left.\mathrm{CH}_{3}{ }^{\text {iPr }}\right) ; 2.13$ (s, $6 \mathrm{H}, \mathrm{CH}_{3}{ }^{\mathrm{Me}(\mathrm{allyl})}$ ); 3.07 (br s, $12 \mathrm{H}$, $\left.\mathrm{CH}^{\mathrm{iPr}}, \mathrm{CH}_{2}^{\mathrm{Me}(\mathrm{allyl})}\right) ; 7.19-7.30\left(\mathrm{~m}, 6 \mathrm{H}, \mathrm{CH}^{\mathrm{Ar}}\right) ; 7.70$ (s, $\left.1 \mathrm{H}, \mathrm{CH}^{\mathrm{Pz} 4}\right)$; $8.32(\mathrm{~s}, 2 \mathrm{H}, \mathrm{CH}=\mathrm{N})$.

${ }^{13} \mathrm{C}\left\{{ }^{1} \mathrm{H}\right\}\left(\mathrm{CDCl}_{3}\right)$ :

$23.3\left(\mathrm{CH}_{3}^{\mathrm{Me}(\mathrm{allyl})}\right) ; 28.2\left(\mathrm{CH}^{\mathrm{iPf}}\right) ; 46.3\left(\mathrm{CH}_{2}^{\mathrm{Me}(\mathrm{allyl})}\right) ; 114.5\left(\mathrm{CH}^{\mathrm{Pz}}\right) ; 123.7$ $\left(\mathrm{CH}^{\mathrm{Ar} 3 / 5}\right) ; 127.5\left(\mathrm{CH}^{\mathrm{Ar} 4}\right) ; 134.4\left(\mathrm{C}^{\mathrm{Me}(\mathrm{allyl})}\right) ; 139.2\left(\mathrm{C}^{\mathrm{Ar} 2 / 6}\right) ; 146.7\left(\mathrm{C}^{\mathrm{Arl}}\right)$; $153.0\left(\mathrm{C}^{\mathrm{P} z 3 / 5}\right) ; 162.6(\mathrm{CH}=\mathrm{N})$. 


\subsection{Synthesis of $\left[\mathrm{L}^{1} \mathrm{Pd}_{2}\left(\eta^{3}-\mathrm{C}_{6} \mathrm{H}_{9}\right)_{2}\right] \mathrm{PF}_{6}(3 \mathrm{o})$}

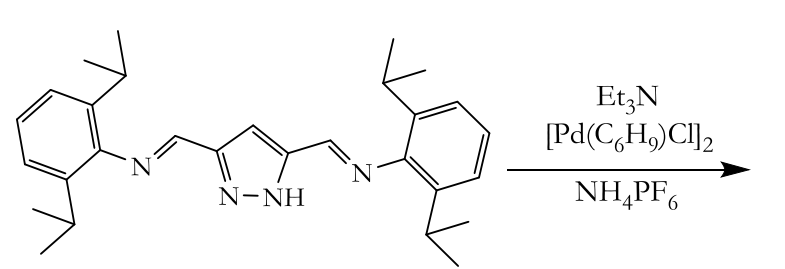

$\mathrm{HL}^{1}$

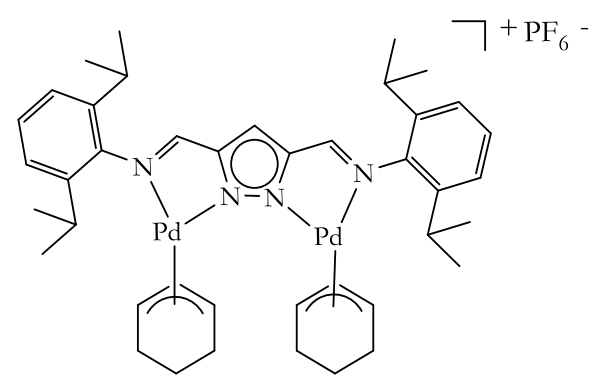

30

To a $\mathrm{CH}_{2} \mathrm{Cl}_{2}$ solution $(15 \mathrm{~mL})$ of $\mathbf{H L}^{1}(55.0 \mathrm{mg}, 0.12 \mathrm{mmol})$ was added an equivalent of $\mathrm{Et}_{3} \mathrm{~N}$ and stirred for $10 \mathrm{~min}$. To this solution was added $\left[\mathrm{Pd}\left(\eta^{3}-\mathrm{C}_{6} \mathrm{H}_{9}\right) \mathrm{Cl}\right]_{2}(56 \mathrm{mg}, 0.12 \mathrm{mmol})$. The initial bright yellow colour was discharged to a colourless solution with time after addition of $\mathrm{NH}_{4} \mathrm{PF}_{6}(65 \mathrm{mg}, 0.40 \mathrm{mmol})$. After $2 \mathrm{~h}$, the formation of $\mathrm{Pd}(0)$ species was observed. The reaction mixture was filtered over celite and the solution washed with water $(3 \times 5 \mathrm{~mL})$. The organic phase was combined and dried over $\mathrm{MgSO}_{4}$. Evaporation of all the volatiles gives an offwhite crystalline solid.

Yield:

Molecular formula:

Molecular weight:

HRMS (TOF-ESI):

MS (ESI, $\left.\mathrm{CH}_{2} \mathrm{Cl}_{2}\right) m / z(\%)$ :

IR $\left(\right.$ ATR, $\left.\mathrm{cm}^{-1}\right)$ :

${ }^{1} \mathrm{H}-\mathrm{NMR}\left(\mathrm{CDCl}_{3}\right) \delta$ :
$92 \mathrm{mg}, 77 \%$

$\mathrm{C}_{41} \mathrm{H}_{55} \mathrm{~F}_{6} \mathrm{~N}_{4} \mathrm{PPd}_{2}$

$961.7 \mathrm{~g} / \mathrm{mol}$.

Calcd. For: $\mathrm{C}_{41} \mathrm{H}_{55} \mathrm{~N}_{4} \mathrm{Pd}_{2}+\mathrm{H}$ (816.7345); Found: 816.2510.

$817(100 \%)\left[\mathrm{M}-\mathrm{PF}_{6}\right]^{+}$.

2957 (m); 2870 (m); 1613 (vs); 1465 (m); 1450 (s); 1441 (vs); 1346 (m); 1301 (s); 1141 (m); 1072 (m); 1057 (m); 840 (vs); 804 (vs); 748 (m); 558 (vs).

1.09-1.33 (m, 16H, $\left.\mathrm{CH}_{3}{ }^{i \mathrm{Pr}}, \mathrm{CH}_{2}^{\text {Cy(allyl) }}\right) ; 1.25\left(\mathrm{~d}, 3_{\mathrm{HH}}=6.9 \mathrm{~Hz}, 12 \mathrm{H}\right.$,

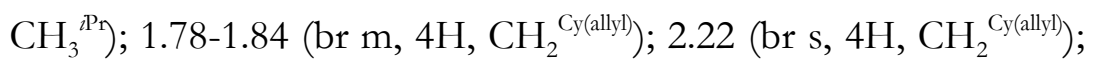
3.11 (m, 4H, $\mathrm{CH}^{\mathrm{PP}}$ ); 4.36 (br t, 1H, $\mathrm{CH}^{\mathrm{Cy}(\mathrm{allyl})}$ ); 5.22 (br t, $2 \mathrm{H}$, $\left.\mathrm{CH}^{\text {Cy(allyl) }}\right) ; 5.53-5.62\left(\mathrm{~m}, 2 \mathrm{H}, \mathrm{CH}^{\text {Cy(allyl })}\right) ; 5.77\left(\mathrm{t},{ }^{3} J_{\mathrm{HH}}=6.4 \mathrm{~Hz}, 1 \mathrm{H}\right.$, $\left.\mathrm{CH}^{\text {Cy(allyl })}\right) ; 7.24-7.36\left(\mathrm{~m}, 6 \mathrm{H}, \mathrm{CH}^{\mathrm{Ar}}\right) ; 7.56\left(\mathrm{~s}, 1 \mathrm{H}, \mathrm{CH}^{\mathrm{P}_{z}}\right) 8.24(\mathrm{~s}, 2 \mathrm{H}$, $\mathrm{CH}=\mathrm{N})$. 


\section{Experimetal}

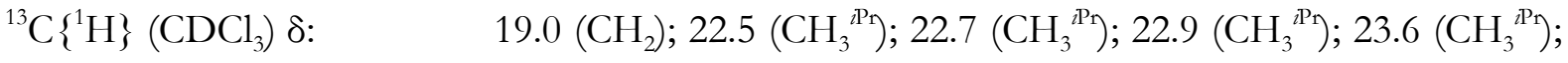

$$
\begin{aligned}
& 24.9\left(\mathrm{CH}_{3}^{i P \mathrm{IP}}\right) ; 25.2\left(\mathrm{CH}_{3}^{i \mathrm{PP}}\right) ; 24.9\left(\mathrm{CH}_{3}^{i \mathrm{PP}}\right) ; 25.9\left(\mathrm{CH}_{3}{ }^{\mathrm{PPr}}\right) ; 26.0
\end{aligned}
$$

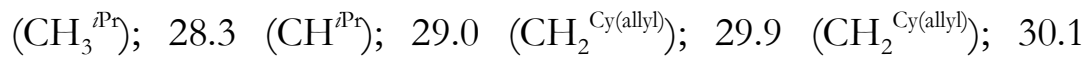

$$
\begin{aligned}
& \left(\mathrm{CH}_{2}{ }^{\text {Cy(allyl) }}\right) ; 74.1\left(\mathrm{CH}^{\mathrm{Cy}(a l l y l)}\right) ; 75.4\left(\mathrm{CH}^{\text {Cy(allyl) }}\right) ; 81.0\left(\mathrm{CH}^{\mathrm{Cy}(a \text { ally })}\right) ; 81.9 \\
& \left(\mathrm{CH}^{\mathrm{Cy}(a l l y l)}\right) ; 114.3\left(\mathrm{CH}^{\mathrm{Cy}(a l l y l}\right) ; 123.8\left(\mathrm{CH}^{\mathrm{Ar}}\right) ; 123.9\left(\mathrm{CH}^{\mathrm{Ar3} / 5}\right) ; 127.5 \\
& \left(\mathrm{CH}^{\mathrm{Ar}}\right) ; 128.4\left(\mathrm{C}^{\mathrm{Ar}}\right) ; 139.1\left(\mathrm{C}^{\mathrm{Ar}}\right) ; 139.5\left(\mathrm{C}^{\mathrm{Ar} 2 / 6}\right) ; 139.6\left(\mathrm{C}^{\mathrm{Ar}}\right) ; 146.0 \\
& \left(\mathrm{C}^{\mathrm{An}}\right) ; 152.8\left(\mathrm{C}^{\mathrm{Pz} 3 / 5}\right) ; 161.6(\mathrm{CH}=\mathrm{N}) \text {. }
\end{aligned}
$$

Following similar reaction procedures, other homobimetallic palladium(II) $\eta^{3}$-allyl complexes were prepared.

\subsection{Synthesis of $\left[\mathrm{L}^{2} \mathrm{Pd}_{2}\left(\eta^{3}-\mathrm{C}_{6} \mathrm{H}_{9}\right)_{2}\right] \mathrm{PF}_{6}(3 \mathrm{p})$}

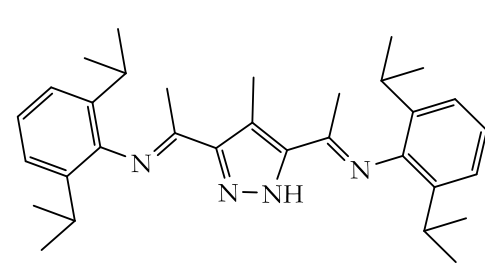

$\mathrm{HL}^{2}$

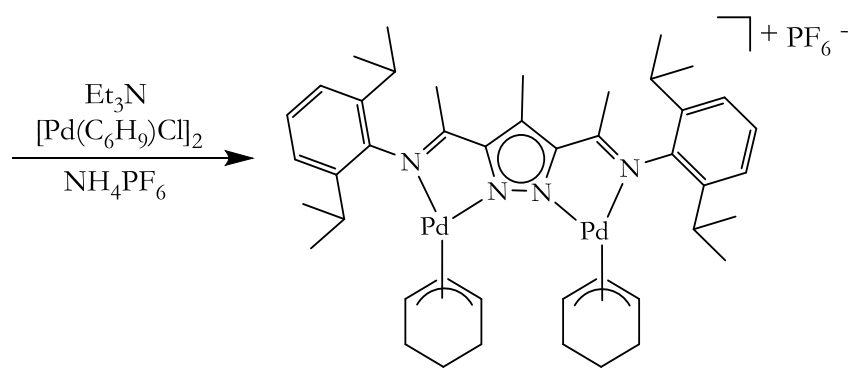

$3 p$

Using $\mathbf{H L}^{2}$ (270 mg, $\left.0.56 \mathrm{mmol}\right),\left[\mathrm{Pd}\left(\eta^{3}-\mathrm{C}_{6} \mathrm{H}_{9}\right) \mathrm{Cl}_{2}(250 \mathrm{mg}, 0.55 \mathrm{mmol}, 1.0 \mathrm{Eq}), \mathrm{NH}_{4} \mathrm{PF}_{6}(500\right.$ $\mathrm{mg}, 3.1 \mathrm{mmol}, 5.5 \mathrm{Eq}$ ) and an equivalent $\mathrm{Et}_{3} \mathrm{~N}$. The product was obtained as an offwhite solid, after all volatiles were removed. This solid is unstable at room temperature, but can be kept for several weeks at cold temperatures. Single crystals were grown by the slow diffusion of $\mathrm{Et}_{2} \mathrm{O}$ inot a $\mathrm{CH}_{2} \mathrm{Cl}_{2}$ solution of the complex at low temperature.

Yield:

Molecular formula:

Molecular weight:

HRMS (TOF-ESI):

MS (ESI, $\left.\mathrm{CH}_{2} \mathrm{Cl}_{2}\right) m /$ z $(\%)$ :
$270 \mathrm{mg}, 48 \%$

$\mathrm{C}_{44} \mathrm{H}_{61} \mathrm{~F}_{6} \mathrm{~N}_{4} \mathrm{PPd}_{2}$

$1003.8 \mathrm{~g} / \mathrm{mol}$.

Calcd. For $\mathrm{C}_{44} \mathrm{H}_{61} \mathrm{~N}_{4} \mathrm{Pd}_{2}$ (859.2991); Found: 859.2976

$859(100 \%)\left[\mathrm{M}-\mathrm{PF}_{6}\right]^{+}$. 


\section{Experimetal}

\begin{tabular}{|c|c|}
\hline IR $\left(\right.$ ATR, $\left.\mathrm{cm}^{-1}\right)$ : & $\begin{array}{l}2933(\mathrm{~m}) ; 2959(\mathrm{~m}) ; 2874(\mathrm{~m}) ; 1598(\mathrm{~s}) ; 1585(\mathrm{~s}) ; 1452(\mathrm{~s}) ; 1432 \\
(\mathrm{~m}) ; 1326(\mathrm{~m}) ; 1309(\mathrm{~m}) ; 838(\mathrm{vs}) ; 780(\mathrm{~m}) 558(\mathrm{~s}) .\end{array}$ \\
\hline${ }^{1} \mathrm{H}-\mathrm{NMR}\left(\mathrm{CDCl}_{3}\right) \delta:$ & 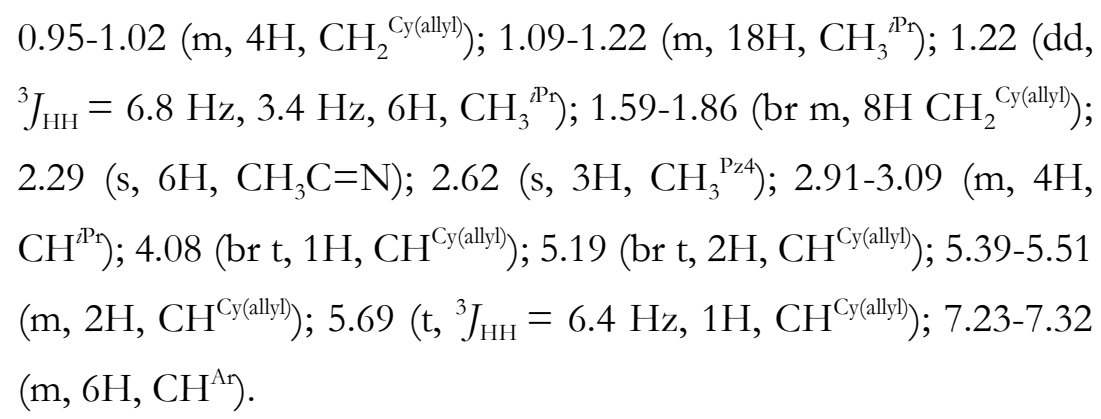 \\
\hline${ }^{13} \mathrm{C}\left\{{ }^{1} \mathrm{H}\right\}\left(\mathrm{CDCl}_{3}\right) \delta:$ & 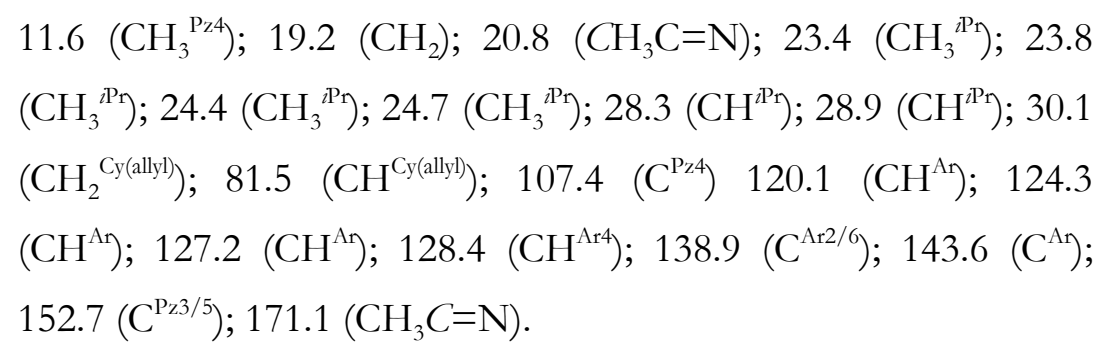 \\
\hline
\end{tabular}

\subsection{Synthesis of $\left[\mathrm{L}^{2} \mathrm{Pd}_{2}\left(\eta^{3}-\mathrm{C}_{4} \mathrm{H}_{7}\right) \mathrm{Cl}_{2}\right](3 \mathrm{z})$}

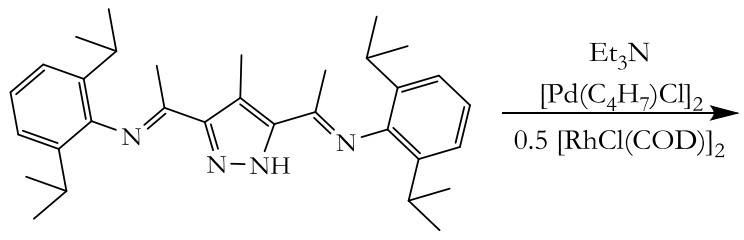

$\mathrm{HL}^{2}$

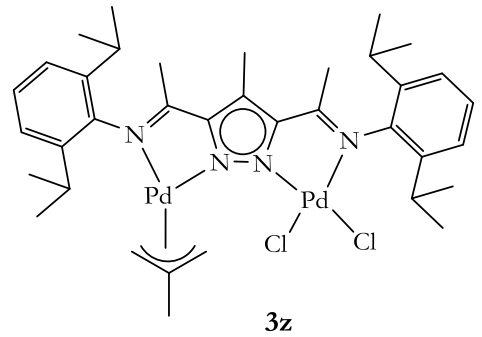

$3 z$

To a $\mathrm{CH}_{2} \mathrm{Cl}_{2}$ solution $(10 \mathrm{~mL})$ of $\mathbf{H L}^{2}(100 \mathrm{mg}, 0.21 \mathrm{mmol})$ was added with stirring an equivalent $\mathrm{Et}_{3} \mathrm{~N}$. After 30 minutes $\left[\left(\mathrm{Pd}\left(\eta^{3}-\mathrm{C}_{4} \mathrm{H}_{7}\right) \mathrm{Cl}\right]_{2}(90 \mathrm{mg}, 0.23 \mathrm{mmol})\right.$ and $\mathrm{NH}_{4} \mathrm{PF}_{6}(300 \mathrm{mg}, 1.8 \mathrm{mmol})$ were added and the mixture stirred for $6 \mathrm{~h}$. A bright yellow solution was formed. After $6 \mathrm{~h}, 0.5$ mol equivalent of $[\mathrm{RhCl}(\mathrm{COD})]_{2}(50 \mathrm{mg}, 0.11 \mathrm{mmol})$ was added to the reaction mixture and stirred overnight. The reaction was filtered to remove excess $\mathrm{NH}_{4} \mathrm{PF}_{6}$. The filtrate was washed with water $(3 \times 3 \mathrm{~mL})$ and the organic phase was combined and dried over $\mathrm{MgSO}_{4} \cdot \mathrm{A} \mathrm{CH}_{2} \mathrm{Cl}_{2}$ solution of the complex was layered with ether and allowed to slowly evaporate at room temperature. $23 \mathrm{mg}$ of yellow crystalline solid was havested from the sides of the test tube, and colourless solid (14 mg), was later harvested from the buttom of the test tube. The colourless solid was later identified by ESI-MS as $\left[\left(\mathrm{Pd}\left(\eta^{3}-\mathrm{C}_{4} \mathrm{H}_{7}\right) \mathrm{Cl}\right]_{2}\right.$. 
Yield:

Molecular formula:

Molecular weight:

MS (ESI, $\left.\mathrm{CH}_{2} \mathrm{Cl}_{2}\right) m / z(\%)$ :

IR (ATR, $\left.\mathrm{cm}^{-1}\right)$ :

${ }^{1} \mathrm{H}-\mathrm{NMR}\left(\mathrm{CDCl}_{3}\right) \delta$ :

${ }^{13} \mathrm{C}\left\{{ }^{1} \mathrm{H}\right\}\left(\mathrm{CDCl}_{3}\right) \delta:$
$23 \mathrm{mg}, 34 \%$

$\mathrm{C}_{36} \mathrm{H}_{50} \mathrm{Cl}_{2} \mathrm{~N}_{4} \mathrm{Pd}_{2}$

$822.6 \mathrm{~g} / \mathrm{mol}$.

$786(15 \%)[\mathrm{M}-\mathrm{Cl}]^{+} ; 749(100 \%)[\mathrm{M}-2 \mathrm{Cl}]^{+}$.

2983 (vs); 2967 (vs); 2872 (vs); 2857 (vs); 1575 (m); 1385 (m); 1326 (m); 1244 (m); 1087 (vs); 923 (m); 806 (m); 778 (m); 733 (m).

1.10-1.48 (m, 24H, $\left.\mathrm{CH}_{3}{ }^{i \mathrm{PP}}\right) ; 2.14$ (s, 3H, $\left.\mathrm{CH}_{3}{ }^{\mathrm{Me}(\mathrm{ally})}\right) ; 2.18$ (s, 3H, $\left.\mathrm{CH}_{3} \mathrm{C}=\mathrm{N}\right) ; 2.20\left(\mathrm{~s}, 3 \mathrm{H}, \mathrm{CH}_{3} \mathrm{C}=\mathrm{N}\right) ; 2.57\left(\mathrm{~s}, 3 \mathrm{H}, \mathrm{CH}_{3}{ }^{\mathrm{Pz} 4}\right) ; 2.97-3.12$ $\left(\mathrm{m}, 2 \mathrm{H}, \mathrm{CH}_{2}^{\mathrm{Me}(a l l y)}\right) ; 3.27-3.30\left(\mathrm{~m}, 4 \mathrm{H}, \mathrm{CH}^{\mathrm{iPr}}\right) ; 3.30$ (br s, $2 \mathrm{H}$, $\left.\mathrm{CH}_{2}{ }^{\mathrm{Me}(a l l y l)}\right) ; 7.17-7.34\left(\mathrm{~m}, 6 \mathrm{H}, \mathrm{CH}^{\mathrm{Ar}}\right)$.

10.6 $\left(\mathrm{CH}_{3}{ }^{\mathrm{Pz} 4}\right) ; 19.7\left(\mathrm{CH}_{3} \mathrm{C}=\mathrm{N}\right) ; 22.3\left(\mathrm{CH}_{3}{ }^{\text {PP }}\right) ; 23.7\left(\mathrm{CH}_{3}^{\text {Me(ally) })}\right) ; 24.1$ $\left(\mathrm{CH}_{3}{ }^{\mathrm{PP}}\right) ; 28.3\left(\mathrm{CH}^{\mathrm{iPr}}\right) ; 28.5\left(\mathrm{CH}^{\mathrm{iPr}}\right) ; 121.0\left(\mathrm{C}^{\mathrm{P} \mathrm{Z} 4}\right) ; 123.6\left(\mathrm{CH}^{\mathrm{Ar} 3 / 5}\right)$; $124.0\left(\mathrm{CH}^{\mathrm{Ar} 3 / 5}\right) ; 127.1\left(\mathrm{C}^{\mathrm{Ar} 4}\right) ; 128.0\left(\mathrm{C}^{\mathrm{Ar} 4}\right) ; 140.6\left(\mathrm{C}^{\mathrm{Ar} 2 / 6}\right) ; 141.2$ $\left(\mathrm{C}^{\mathrm{Ar} 2 / 6}\right) ; 144.2\left(\mathrm{C}^{\mathrm{Ar}}\right) ; 150.8\left(\mathrm{C}^{\mathrm{Pz} 3 / 5}\right) ; 169.4\left(\mathrm{CH}_{3} \mathrm{C}=\mathrm{N}\right)$. 


\section{5 Heterobimetallic palladium(II)-rhodium(I) complexes}

\subsection{Synthesis of $\left[\mathrm{L}^{1} \mathrm{Pd}\left(\eta^{3}-\mathrm{C}_{4} \mathrm{H}_{7}\right) \operatorname{Rh}(\mathrm{COD})\right] \mathrm{BAr}^{\mathrm{F}}{ }_{4}(3 r)$}

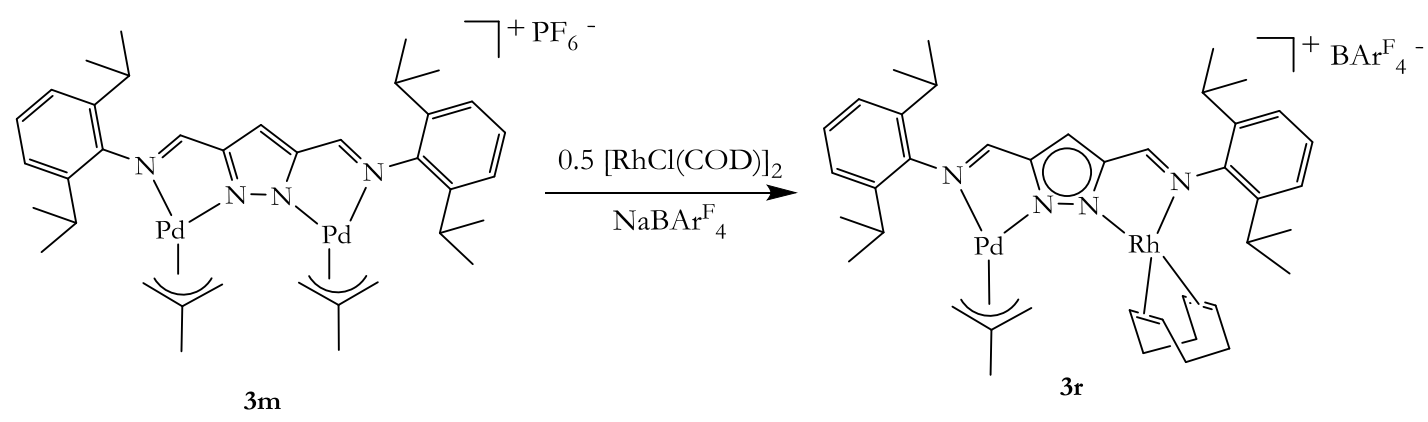

To a $\mathrm{CH}_{2} \mathrm{Cl}_{2}$ solution $(15 \mathrm{~mL})$ of $3 \mathrm{~m}(30.0 \mathrm{mg}, 0.033 \mathrm{mmol})$ was added 0.5 mol equivalent $[\mathrm{RhCl}(\mathrm{COD})]_{2}(8.6 \mathrm{mg}, 0.017 \mathrm{mmol})$ with stirring for $30 \mathrm{~min}$. A red/orange solution was formed. The formation of $\operatorname{Pd}(0)$ species was not observed in this instance. The reaction mixture was filtered over celite to obtain a bright orange solution. Hexane was added drop wise to the $\mathrm{CH}_{2} \mathrm{Cl}_{2}$ solution of the complex, resulting in the precipitation of a bright orange powder. This was filtered and dried in vacuum for several minutes. Yield: $17 \mathrm{mg}, 63 \%\left(\mathrm{PF}_{6}\right)$. The $\mathrm{PF}_{6}$ counter ion was exchanged to $\left[\mathrm{BAr}_{4}^{\mathrm{F}}\right]^{-}$by stirring the complex over a mol $\mathrm{NaBAr}_{4}{ }_{4}$ for 2 hours.

Yield:

$17 \mathrm{mg}, 63 \%$

Molecular formula:

$\mathrm{C}_{73} \mathrm{H}_{68} \mathrm{BF}_{24} \mathrm{~N}_{4} \mathrm{PdRh}$

Molecular weight:

$814.3 \mathrm{~g} / \mathrm{mol}$.

HRMS (TOF-ESI):

Calcd. For: $\mathrm{C}_{41} \mathrm{H}_{56} \mathrm{~N}_{4} \mathrm{PdRh}$ (813.2605); Found: 813.2604.

MS (ESI, $\left.\mathrm{CH}_{2} \mathrm{Cl}_{2}\right) \mathrm{m} / \mathrm{z}(\%)$ :

$813(100 \%)\left[\mathrm{M}-\mathrm{BAr}_{4}{ }^{-} \mathrm{H}\right]^{+} ; 764(45 \%)\left[\mathrm{LPd}_{2}\left(\mathrm{C}_{4} \mathrm{H}_{7}\right)_{2}\right]^{+}$.

IR $\left(\right.$ ATR, $\left.\mathrm{cm}^{-1}\right)$ :

2928 (m); 2959 (m); 2872 (m); 1609 (vs); 1588 (s); 1463 (s); 1414 (m); 1365 (m); 1387 (m); 1352 (m); 1303 (m); 1139 (s); 1056 (vs); 1031 (vs); 804 (m); 746 (m); 679 (m).

${ }^{1} \mathrm{H}-\mathrm{NMR}\left(\mathrm{CDCl}_{3}\right)$ 8: $\quad$ (Isomer 1); $1.17\left(\mathrm{~d},{ }^{3} \mathrm{~J}_{\mathrm{HH}}=6.8 \mathrm{~Hz}, 8 \mathrm{H}, \mathrm{CH}_{3}{ }^{i \mathrm{Pr}}\right) ; 1.26\left(\mathrm{~d},{ }^{3} \mathrm{~J}_{\mathrm{HH}}=6.8\right.$ $\left.\mathrm{Hz}, 8 \mathrm{H}, \mathrm{CH}_{3}{ }^{i \mathrm{PP}}\right) ; 1.39\left(\mathrm{~d},{ }^{3} \mathrm{HH}_{\mathrm{HH}}=6.9 \mathrm{~Hz}, 8 \mathrm{H}, \mathrm{CH}_{3}{ }^{\mathrm{iPp}}\right) ; 1.86-2.09(\mathrm{~m}$, $5 \mathrm{H}, \mathrm{CH}_{2}{ }^{\mathrm{COD}}, \mathrm{CH}_{3}{ }^{\mathrm{Me}(\mathrm{allyl})}$ ); 2.39-2.52 (br m, $2 \mathrm{H}, \mathrm{CH}_{2}{ }^{\mathrm{COD}}$ ); 2.92-3.29 $\left(\mathrm{m}, 12 \mathrm{H}, \mathrm{CH}_{2}{ }^{\mathrm{COD}}, \mathrm{CH}_{2}^{\mathrm{Me}(\mathrm{allyl})}, \mathrm{CH}^{\mathrm{IP}}\right) ; 3.55$ (br s, $\left.1 \mathrm{H}, \mathrm{CH}^{\mathrm{COD}}\right) ; 4.00-$ 4.15 (m, 1H, $\mathrm{CH}^{\mathrm{COD}}$ ); 4.24 (br s, $1 \mathrm{H}, \mathrm{CH}^{\mathrm{COD}}$ ); 5.07 (br s, $1 \mathrm{H}$, $\left.\mathrm{CH}^{\mathrm{COD}}\right) ; 7.21-7.27\left(\mathrm{~m}, 6 \mathrm{H}, \mathrm{CH}^{\mathrm{Ar}}\right) ; 7.50\left(\mathrm{~s}, 4 \mathrm{H}, \mathrm{CH}^{\mathrm{BArF4}}\right)$; $7.69(\mathrm{~s}$, 
$\left.8 \mathrm{H}, \mathrm{CH}^{\mathrm{BArF} 4}\right) ; 7.81\left(\mathrm{~s}, 1 \mathrm{H}, \mathrm{CH}^{\mathrm{P}}\right) ; 8.09\left(\mathrm{~s}, 1 \mathrm{H}, \mathrm{CH}=\mathrm{N}^{\mathrm{Rh}}\right) ; 8.32(\mathrm{~s}$, $\left.1 \mathrm{H}, \mathrm{CH}=\mathrm{N}^{\mathrm{Pd}}\right)$.

${ }^{13} \mathrm{C}\left\{{ }^{1} \mathrm{H}\right\}\left(\mathrm{CDCl}_{3}\right) \delta:$

$22.2\left(\mathrm{CH}_{3}{ }^{\mathrm{iPr}}\right) ; 22.4\left(\mathrm{CH}_{3}{ }^{i \mathrm{PP}}\right) ; 22.6\left(\mathrm{CH}_{3}{ }^{i \mathrm{Pr}}\right) ; 22.8\left(\mathrm{CH}_{3}{ }^{\mathrm{Me}(\mathrm{allyl})}\right) ; 23.2$ $\left(\mathrm{CH}_{3}{ }^{i \mathrm{PP}}\right) ; 24.5\left(\mathrm{CH}_{3}{ }^{i \mathrm{Pr}}\right) ; 24.8\left(\mathrm{CH}_{3}{ }^{\mathrm{iPr}}\right) ; 24.9\left(\mathrm{CH}_{3}{ }^{i \mathrm{Pr}}\right) ; 25.6\left(\mathrm{CH}_{3}{ }^{i \mathrm{Pr}}\right)$; $27.0\left(\mathrm{C}^{\mathrm{BArF} 4}\right) ; 28.3\left(\mathrm{CH}^{\mathrm{iPr}}\right) ; 28.6\left(\mathrm{CH}^{\mathrm{iPr}}\right) ; 30.4\left(\mathrm{CH}_{2}^{\mathrm{COD}}\right) ; 30.5$ $\left(\mathrm{CH}_{2}{ }^{\mathrm{COD}}\right) ; 62.6\left(\mathrm{CH}_{2}^{\mathrm{Me}(\mathrm{allyl})}\right) ; 64.8\left(\mathrm{CH}_{2}^{\mathrm{Me}(\mathrm{allyl})}\right) ; 65.7\left(\mathrm{CH}_{2}^{\mathrm{Me}(\mathrm{allyl})}\right) ; 85.4$ $\left(\mathrm{CH}^{\mathrm{COD}}\right) ; 113.1\left(\mathrm{CH}^{\mathrm{Pz} 4}\right) ; 117.5 ; 122.8 ;\left(\mathrm{C}^{\mathrm{Ar}}\right) ; 124.0\left(\mathrm{CH}^{\mathrm{Ar}}\right) ; 126.5$ $\left(\mathrm{CH}^{\mathrm{Ar}}\right) ; 128.3\left(\mathrm{CH}^{\mathrm{An}}\right) ; 128.7\left(\mathrm{CH}^{\mathrm{An}}\right) ; 129.2\left(\mathrm{CH}^{\mathrm{Ar}}\right) ; 134.6\left(\mathrm{C}^{\mathrm{Me}(a l l y)}\right) ;$ $134.9\left(\mathrm{C}^{\mathrm{BArF} 4}\right) ; 138.7\left(\mathrm{C}^{2 / \mathrm{g}}\right) ; 139.1\left(\mathrm{C}^{2 / 6}\right) ; 140.1\left(\mathrm{C}^{\mathrm{Ar}}\right) ; 146.2\left(\mathrm{C}^{\mathrm{Ar}}\right)$; $152.6\left(\mathrm{C}^{\mathrm{P} z 3 / 5}\right) ; 153.4\left(\mathrm{C}^{\mathrm{P} z 3 / 5}\right) ; 160.4\left(\mathrm{CH}=\mathrm{N}^{\mathrm{Pd}}\right) ; 160.8\left(\mathrm{CH}=\mathrm{N}^{\mathrm{Rh}}\right)$; $162.8\left(\mathrm{CH}=\mathrm{N}^{\mathrm{Rh}}\right)$.

\subsection{Synthesis of $\left[\mathrm{L}^{2} \mathrm{Pd}\left(\eta^{3}-\mathrm{C}_{4} \mathrm{H}_{7}\right) \mathrm{Rh}(\mathrm{COD})\right] \mathrm{PF}_{6}(3 \mathrm{~s})$}
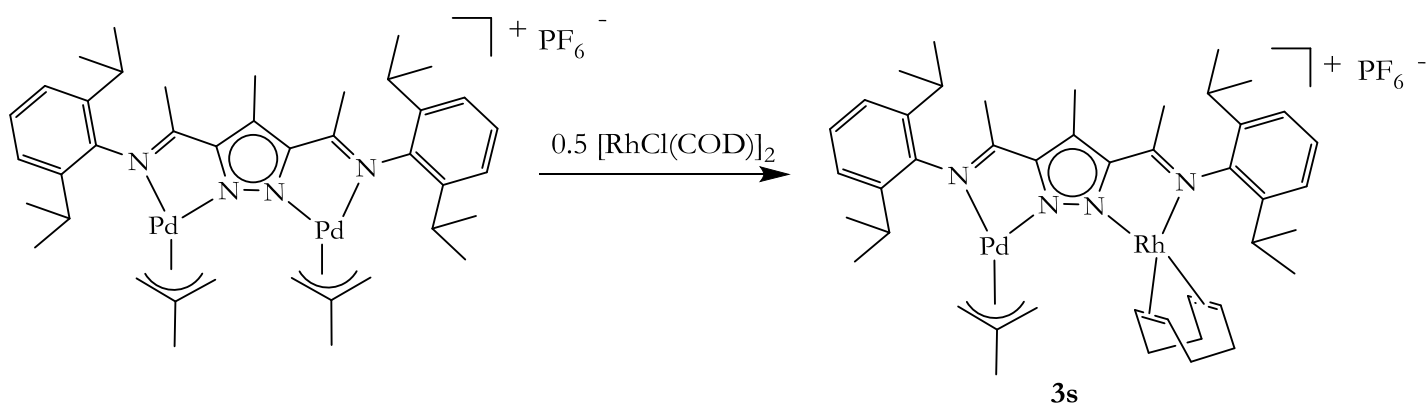

To a $\mathrm{CH}_{2} \mathrm{Cl}_{2}$ solution $(10 \mathrm{~mL})$ of $\left[\mathrm{L}^{2} \mathrm{Pd}_{2}\left(\eta^{3}-\mathrm{C}_{4} \mathrm{H}_{7}\right) 2\right] \mathrm{PF}_{6}(20.0 \mathrm{mg}, 21.0 \mu \mathrm{mol})$ was added $0.5 \mathrm{~mol}$ equivalent $[\mathrm{RhCl}(\mathrm{COD})]_{2}(5.10 \mathrm{mg}, 10.5 \mu \mathrm{mol})$ with stirring. The formation of a yellow suspension was observed. After $18 \mathrm{~h}$, the reaction mixture was filtered over celite to obtain a bright yellow-orange solution. $\mathrm{A} \mathrm{CH}_{2} \mathrm{Cl}_{2}$ solution $(5 \mathrm{~mL})$ of the complex was layered with ether and kept in the fridge at $-20{ }^{\circ} \mathrm{C}$. A yellow powdery material was harvested from the solution after several days.

Yield:

$9 \mathrm{mg}, 43 \%$

Molecular formula:

$\mathrm{C}_{44} \mathrm{H}_{62} \mathrm{~F}_{6} \mathrm{~N}_{4} \mathrm{PPdRh}$

Molecular weight: $1001.3 \mathrm{~g} / \mathrm{mol}$.

HRMS (TOF-ESI):

Calcd. For: $\mathrm{C}_{44} \mathrm{H}_{62} \mathrm{~N}_{4} \mathrm{PdRh}+\mathrm{H}$ (855.3074); Found: 855.3076. 
MS (ESI, $\left.\mathrm{CH}_{2} \mathrm{Cl}_{2}\right) \mathrm{m} / \mathrm{z}(\%): \quad 855(100 \%)\left[\mathrm{M}-\mathrm{H}-\mathrm{PF}_{6}\right]^{+} ; 804(35 \%)\left[\mathrm{LPd}_{2}\left(\mathrm{C}_{4} \mathrm{H}_{7}\right)_{2}\right]^{+}$.

IR (ATR, $\left.\mathrm{cm}^{-1}\right)$ :

${ }^{1} \mathrm{H}-\mathrm{NMR}\left(\mathrm{CDCl}_{3}\right) \delta:$

${ }^{13} \mathrm{C}\left\{{ }^{1} \mathrm{H}\right\}\left(\mathrm{CDCl}_{3}\right) \delta:$
2959 (m); 2928 (m); 2870 (m); 1626 (s); 1564 (s);1462 (m); 1434 (m); 1413 (s) 1385 (s); 1326 (m); 1313 (m); 1059 (m); 838 (vs); 778 (vs); 558 (s).

$1.13\left(\mathrm{~d},{ }^{3} J_{\mathrm{HH}}=6.8 \mathrm{~Hz}, 6 \mathrm{H}, \mathrm{CH}_{3}{ }^{i P r}\right) ; 1.18\left(\mathrm{~d}, 3_{\mathrm{HH}}=6.8 \mathrm{~Hz}, 6 \mathrm{H}\right.$, $\left.\mathrm{CH}_{3}{ }^{i \mathrm{Pr}}\right) ; 1.27\left(\mathrm{~d}, J_{\mathrm{HH}}=6.8 \mathrm{~Hz}, 6 \mathrm{H}, \mathrm{CH}_{3}{ }^{2 \mathrm{PP}}\right) ; 1.42\left(\mathrm{~d},{ }^{3} J_{\mathrm{HH}}=6.8 \mathrm{~Hz}\right.$, $\left.3 \mathrm{H}, \mathrm{CH}_{3}{ }^{i \mathrm{PP}}\right) ; 1.44\left(\mathrm{~d},{ }^{3} \mathrm{HH}_{\mathrm{HH}}=6.8 \mathrm{~Hz}, 3 \mathrm{H}, \mathrm{CH}_{3}{ }^{\mathrm{PP}}\right) ; 1.79-1.89(\mathrm{~m}, 2 \mathrm{H}$, $\mathrm{CH}_{2}{ }^{\mathrm{COD}}$ ); 2.03 (s, 3H, $\left.\mathrm{CH}_{3}{ }^{\text {Me(allyl) }}\right) ; 2.26$ (s, 3H, $\left.\mathrm{CH}_{3} \mathrm{C}=\mathrm{N}\right) ; 2.27$ (s, $\left.3 \mathrm{H}, \mathrm{CH}_{3} \mathrm{C}=\mathrm{N}\right) ; 2.33-2.52\left(\mathrm{~m}, 4 \mathrm{H}, \mathrm{CH}_{2}{ }^{\mathrm{COD}}\right) ; 2.60\left(\mathrm{~s}, 3 \mathrm{H}, \mathrm{CH}_{3}{ }^{{ }_{\mathrm{z}} 4}\right)$; 2.63-3.12 (m, 2H, $\mathrm{CH}_{2}^{\mathrm{COD}}$ ); $3.07\left(\mathrm{sept},{ }^{3} \mathrm{HH}_{\mathrm{HH}}=6.8 \mathrm{~Hz}, 2 \mathrm{H}, \mathrm{CH}^{\mathrm{iPr}}\right.$ ); 3.19 (sept, ${ }^{3} J_{\mathrm{HH}}=6.8 \mathrm{~Hz}, 2 \mathrm{H}, \mathrm{CH}^{\mathrm{PPr}}$ ); 3.40 (br s, $2 \mathrm{H}, \mathrm{CH}_{2}{ }^{\mathrm{Me}(a l l y l)}$ ); 4.15 (br s, $\left.2 \mathrm{H}, \mathrm{CH}_{2}^{\mathrm{Me}(\mathrm{allyl})}\right)$; 4.91-5.03 (m, 4H, $\mathrm{CH}^{\mathrm{COD}}$ ); 7.22-7.32 (m, $\left.6 \mathrm{H}, \mathrm{CH}^{\mathrm{Ar}}\right)$.

$11.6\left(\mathrm{CH}_{3}{ }^{\mathrm{zz} 4}\right) ; 19.9\left(\mathrm{CH}_{3} \mathrm{C}=\mathrm{N}\right) ; 20.6\left(\mathrm{CH}_{3} \mathrm{C}=\mathrm{N}\right) ; 21.6 ; 22.6$ $\left(\mathrm{CH}_{3}{ }^{\mathrm{Me}(\mathrm{allyl})}\right) ; 23.2\left(\mathrm{CH}_{3}{ }^{i \mathrm{Pr}}\right) ; 23.4\left(\mathrm{CH}_{3}{ }^{i \mathrm{Pr}}\right) ; 23.6\left(\mathrm{CH}_{3}{ }^{i \mathrm{Pr}}\right) ; 23.6\left(\mathrm{CH}_{3}{ }^{i \mathrm{PP}}\right)$; $24.0\left(\mathrm{CH}_{3}^{i \mathrm{Pr}}\right) ; 24.3\left(\mathrm{CH}_{3}{ }^{\mathrm{iPr}}\right) ; 25.0\left(\mathrm{CH}_{3}{ }^{\mathrm{iPr}}\right) ; 28.4\left(\mathrm{CH}^{\mathrm{iPr}}\right) ; 28.5\left(\mathrm{CH}^{\mathrm{iPr}}\right)$; $28.6\left(\mathrm{CH}^{\mathrm{PPr}}\right) ; 30.2\left(\mathrm{CH}_{2}{ }^{\mathrm{COD}}\right) ; 30.4\left(\mathrm{CH}_{2}{ }^{\mathrm{COD}}\right) ; 30.5\left(\mathrm{CH}_{2}{ }^{\mathrm{COD}}\right) ; 53.5$ $\left.\left(\mathrm{CH}_{2}{ }^{\mathrm{Me}(a l l y l}\right) ; 63.8\left(\mathrm{CH}_{2}{ }^{\text {Me(allyl) }}\right) ; 64.5\left(\mathrm{CH}_{2}{ }^{\mathrm{Me}(a l l y l}\right) ; 65.4\left(\mathrm{CH}_{2}{ }^{\mathrm{Me}(a l l y l}\right)\right)$; 77.3; $83.3\left(\mathrm{CH}^{\mathrm{COD}}\right) ; 83.5\left(\mathrm{CH}^{\mathrm{COD}}\right) ; 83.7 ; 85.0 ; 85.1\left(\mathrm{CH}^{\mathrm{COD}}\right) ; 123.9$ $\left(\mathrm{C}^{\mathrm{Pz} 4}\right) ; 124.0\left(\mathrm{CH}^{\mathrm{Ar}}\right) ; 124.1\left(\mathrm{CH}^{\mathrm{Ar}}\right) ; 124.3\left(\mathrm{CH}^{\mathrm{Ar}}\right) ; 124.4\left(\mathrm{CH}^{\mathrm{Ar}}\right)$; $127.4\left(\mathrm{CH}^{\mathrm{Ar}}\right) ; 127.5\left(\mathrm{CH}^{\mathrm{Ar}}\right) ; 128.0\left(\mathrm{CH}^{\mathrm{Ar}}\right) ; 133.8\left(\mathrm{C}^{\mathrm{Me}(\mathrm{allyl})}\right) ; 134.7$ $\left(C^{\text {Me(allyl })}\right) ; 138.6 ; 138.7 ; 138.9\left(\mathrm{C}^{\mathrm{Ar} 2 / 6}\right) ; 139.0\left(\mathrm{CAr}^{2 / 6}\right) ; 140.2\left(\mathrm{C}^{\mathrm{Ar}-\mathrm{Rh}}\right)$; $144.5\left(C^{\mathrm{Ar}-\mathrm{Pd}}\right) ; 152.9\left(\mathrm{C}^{\mathrm{P} z 3 / 5}\right) ; 154.5\left(\mathrm{C}^{\mathrm{Pz} 3 / 5}\right) ; 170.9\left(\mathrm{CH}_{3} C=\mathrm{N}^{\mathrm{Pd}}\right)$; $173.6\left(\mathrm{CH}_{3} C=\mathrm{N}^{\mathrm{Rh}}\right)$. 


\subsection{Synthesis of $\left[\mathrm{L}^{1} \mathrm{Pd}\left(\eta^{3}-\mathrm{C}_{6} \mathrm{H}_{9}\right) \mathrm{Rh}(\mathrm{COD})\right] \mathrm{PF}_{6}(3 t)$}

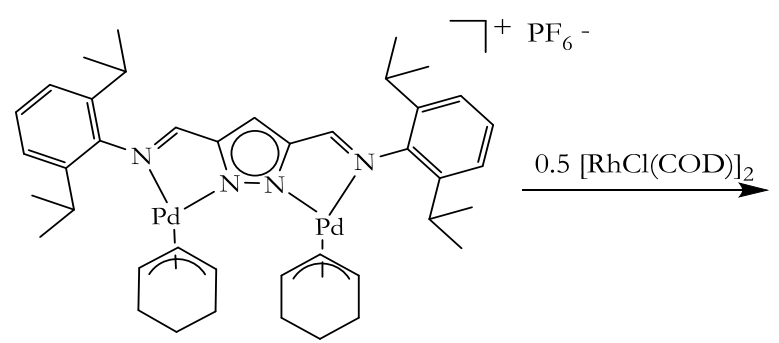

30

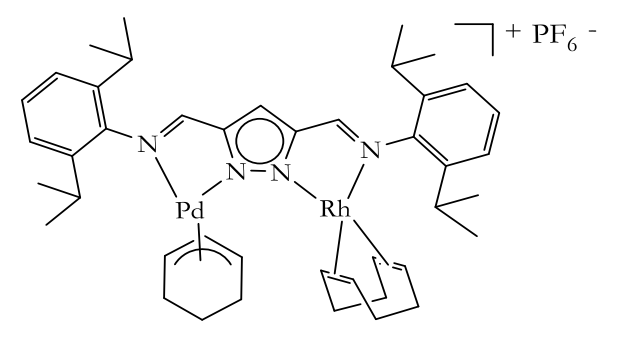

$3 \mathbf{t}$

To a $\mathrm{CH}_{2} \mathrm{Cl}_{2}$ solution $(15 \mathrm{~mL})$ of $\mathbf{3 o}(150 \mathrm{mg}, 0.15 \mathrm{mmol})$ was added with stirring $\sim 0.5 \mathrm{~mol}$ equivalent) of $[\mathrm{RhCl}(\mathrm{COD})]_{2}(30 \mathrm{mg}, 0.06 \mathrm{mmol})$. After stirring overnight, what appears to be the formation of $\operatorname{Pd}(0)$ species was observed. The reaction mixture was filtered over celite to obtain a bright yellow-orange solution. Addition of hexane dropwise to the $\mathrm{CH}_{2} \mathrm{Cl}_{2}$ solution results in the precipitation of a bright orange solid. The solid was filtered and dried in vacuum for several minutes. Very fine needles were recrystallized from a $\mathrm{CH}_{2} \mathrm{Cl}_{2}$ solution of the complex by slow evaporation of the $\mathrm{CH}_{2} \mathrm{Cl}_{2}$ solution for several days.

Yield:

Molecular formula:

Molecular weight:

HRMS (TOF-ESI):

MS (ESI, $\left.\mathrm{CH}_{2} \mathrm{Cl}_{2}\right) m / z(\%)$ :

IR (ATR, $\mathrm{cm}^{-1}$ ):

${ }^{1} \mathrm{H}-\mathrm{NMR}\left(\mathrm{CDCl}_{3}\right) \delta$ :
$54.3 \mathrm{mg}, 37 \%$

$\mathrm{C}_{43} \mathrm{H}_{58} \mathrm{~F}_{6} \mathrm{~N}_{4} \mathrm{PPdRh}$

$985.3 \mathrm{~g} / \mathrm{mol}$.

Calcd. For: $\mathrm{C}_{43} \mathrm{H}_{58} \mathrm{~N}_{4} \mathrm{PdRh}$ (839.2762); Found: 839.2764.

$839(100 \%)\left[\mathrm{M}-\mathrm{PF}_{6}\right]^{+}$.

2957 (m); 1605 (s); 1586 (s); 1460 (m); 1439 (m); 1346 (m); 1300 (m); $1141(\mathrm{~m}) ; 836(\mathrm{vs}) ; 558(\mathrm{~s})$.

$1.13\left(\mathrm{~d}, J_{\mathrm{HH}}=6.8 \mathrm{~Hz}, 6 \mathrm{H}, \mathrm{CH}_{3}{ }^{2 \mathrm{Pr}}\right) ; 1.19\left(\mathrm{~d}, 3_{\mathrm{HH}}=6.8 \mathrm{~Hz}, 6 \mathrm{H}\right.$, $\left.\mathrm{CH}_{3}{ }^{i \mathrm{Pr}}\right) ; 1.22\left(\mathrm{~d},{ }^{3} J_{\mathrm{HH}}=6.8 \mathrm{~Hz}, 6 \mathrm{H}, \mathrm{CH}_{3}{ }^{\mathrm{iP}}\right) ; 1.26\left(\mathrm{~d},{ }^{3} J_{\mathrm{HH}}=6.8 \mathrm{~Hz}\right.$, $\left.3 \mathrm{H}, \mathrm{CH}_{3}{ }^{\mathrm{iPr}}\right) ; 1.40\left(\mathrm{~d},{ }^{3} \mathrm{JHH}_{\mathrm{HH}}=6.8 \mathrm{~Hz}, 3 \mathrm{H}, \mathrm{CH}_{3}{ }^{\mathrm{PP}}\right) ; 1.74-1.92(\mathrm{~m}, 2 \mathrm{H}$, $\left.\mathrm{CH}_{2}{ }^{\text {Cy(allyl) }}\right) ; 1.80$ (br s, $2 \mathrm{H}, \mathrm{CH}_{2}{ }^{\text {Cy(allyl) })} ; 2.08$ (br s, 4H, $\mathrm{CH}_{2}{ }^{\mathrm{COD}}$ ); 2.40 (br s, $2 \mathrm{H}, \mathrm{CH}_{2}{ }^{\text {Cy(allyl) })} ; 2.54$ (br s, 4H, $\mathrm{CH}_{2}{ }^{\mathrm{COD}}$ ); 3.04 (sept, ${ }^{3} \mathrm{JHH}_{\mathrm{HH}}=6.8$ $\mathrm{Hz}, 2 \mathrm{H}, \mathrm{CH}^{\mathrm{iPr}}$ ); 3.29 (sept, $J_{\mathrm{HH}}=6.8 \mathrm{~Hz}, 2 \mathrm{H}, \mathrm{CH}^{\mathrm{PP}}$ ); 3.49 (br s, 2H, $\mathrm{CH}^{\mathrm{COD}}$ ); 4.16 (br s, 1H, $\mathrm{CH}^{\mathrm{Cy}(\text { allyl) }}$ ); 5.17 (br s, 2H, $\mathrm{CH}^{\mathrm{COD}}$ ); 5.49 $\left(\mathrm{m}, 1 \mathrm{H}, \mathrm{CH}^{\text {Cy(allyl) })} ; 5.68\left(\mathrm{t}, 1 \mathrm{H}, \mathrm{CH}^{\text {Cy(allyl })}\right) ; 5.75\left(\mathrm{~m}, 1 \mathrm{H}, \mathrm{CH}^{\text {Cy(allyl) }}\right)\right.$; 7.13-7.36 (m, 6H, $\left.\mathrm{CH}^{\mathrm{Ar}}\right) ; 7.57\left(\mathrm{~s}, 1 \mathrm{H}, \mathrm{CH}^{\mathrm{Pz} 4}\right) ; 7.97$ (s, $\left.1 \mathrm{H}, \mathrm{CH}=\mathrm{N}\right)$; $8.22(\mathrm{~s}, 1 \mathrm{H}, \mathrm{CH}=\mathrm{N})$. 
${ }^{13} \mathrm{C}\left\{{ }^{1} \mathrm{H}\right\}\left(\mathrm{CDCl}_{3}\right) \delta$ :

$19.8\left(\mathrm{CH}_{2}{ }^{\mathrm{Cy}(\mathrm{allyl})}\right) ; 22.3\left(\mathrm{CH}_{3}{ }^{\mathrm{PP}}\right) ; 22.7\left(\mathrm{CH}_{3}{ }^{{ }^{\mathrm{PP}}}\right) ; 25.7\left(\mathrm{CH}_{3}{ }^{\mathrm{PP}}\right) ; 28.3$ $\left(\mathrm{CH}^{\mathrm{PP}}\right) ; 28.5\left(\mathrm{CH}_{3}{ }^{\mathrm{PP}}\right) ; 29.49\left(\mathrm{CH}_{2}{ }^{\mathrm{Cy}(\mathrm{allyl})}\right) ; 30.1\left(\mathrm{CH}_{2}{ }^{\mathrm{COD}}\right) 30.5$ $\left(\mathrm{CH}_{2}{ }^{\mathrm{COD}}\right) ; 80.0\left(\mathrm{CH}^{\mathrm{Cy}(\mathrm{ally} \mathrm{l})}\right) ; 82.0\left(\mathrm{CH}^{\mathrm{COD}}\right) ; 84.9\left(\mathrm{CH}^{\mathrm{COD}}\right) ; 106.9$ $\left(\mathrm{CH}^{\mathrm{Cy}(\text { allyly })}\right) ; 115.3\left(\mathrm{CH}^{\mathrm{Pz}}\right) ; 120.1 ; 123.8\left(\mathrm{CH}^{\mathrm{Ar}}\right) ; 127.7\left(\mathrm{CH}^{\mathrm{Ar}}\right) ; 128$ $\left(\mathrm{CH}^{\mathrm{Ar}}\right) ; 140.3\left(\mathrm{C}^{\mathrm{Ar} 2 / \sigma}\right) ; 141.5\left(\mathrm{C}^{\mathrm{Ar} 2 / \sigma}\right) ; 145.8\left(\mathrm{C}^{\mathrm{Ar}}\right) ; 152.6\left(\mathrm{C}^{\mathrm{Pz} 3 / 5}\right)$; $153.9\left(\mathrm{C}^{\mathrm{Pz} 3 / 5}\right) ; 161.2\left(\mathrm{CH}=\mathrm{N}^{\mathrm{Pd}}\right) ; 163.7\left(\mathrm{CH}=\mathrm{N}^{\mathrm{Rh}}\right)$.

Elemental analysis:

Calcd. For $\mathrm{C}_{44} \mathrm{H}_{60} \mathrm{Cl}_{2} \mathrm{~F}_{6} \mathrm{~N}_{4} \mathrm{PPdRh} \cdot \mathrm{CH}_{2} \mathrm{Cl}_{2}:(\mathrm{C}) 49.38(\mathrm{H}) 5.65(\mathrm{~N})$ 5.24; Found: C (49.17) (H) 5.73 (N) 5.17.

\subsection{Synthesis of $\left[\mathrm{L}^{2} \operatorname{Pd}\left(\eta^{3}-\mathrm{C}_{6} \mathrm{H}_{9}\right) \mathrm{Rh}(\mathrm{COD})\right] \mathrm{BAr}_{4}^{\mathrm{F}}(3 \mathrm{u})$}

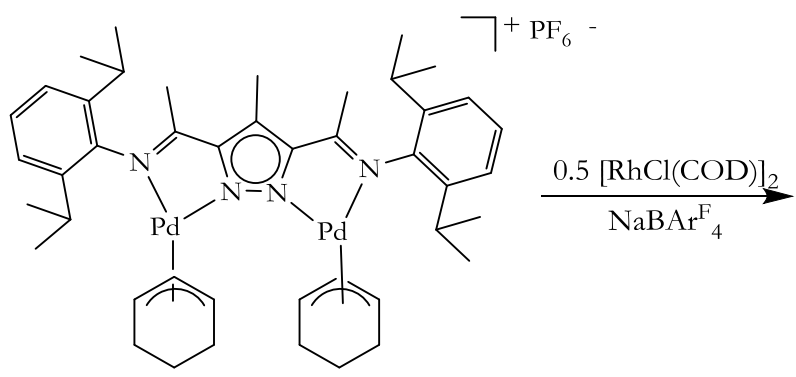

$3 \mathbf{p}$

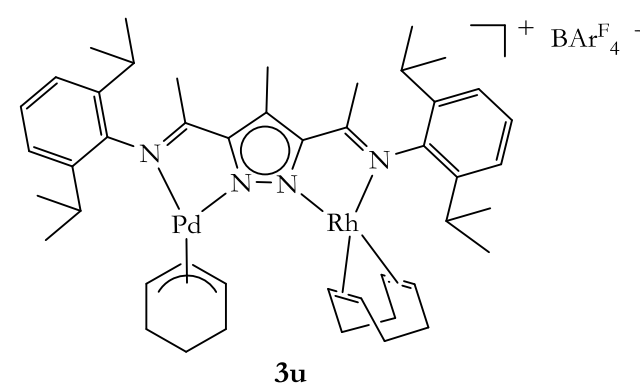

$3 \mathbf{u}$

To a $\mathrm{CH}_{2} \mathrm{Cl}_{2}$ solution $(15 \mathrm{~mL})$ of $3 \mathbf{p}(78.8 \mathrm{mg}, 0.079 \mathrm{mmol})$ was added $0.5 \mathrm{~mol}$ equivalent of $[\mathrm{RhCl}(\mathrm{COD})]_{2}(19.3 \mathrm{mg}, 0.039 \mathrm{mmol})$ with stirring. After $2 \mathrm{~h}$, a dark red solution was formed, accompanied by the formation of traces of $\operatorname{Pd}(0)$. The reaction was filtered over celite to obtain a bright red solution. A bright orange powder $(74.0 \mathrm{mg})$ was obtained after evaporating the solution. The powder was divided into two fractions; the first fraction was dissolved in $\mathrm{CH}_{2} \mathrm{Cl}_{2}$, stirred over a mol equivalent $\mathrm{NaBAr}_{4}^{\mathrm{F}}$, and again filtered. The slow evaporation of a $\mathrm{CH}_{2} \mathrm{Cl}_{2} /$ cyclohexane (10:1) solution (fraction 1) of the complex at room temperature gave the complex as bright orange prisms.

Yield:

Molecular formula:

Molecular weight:

HRMS (TOF-ESI):

MS (ESI, $\left.\mathrm{CH}_{2} \mathrm{Cl}_{2}\right) m / z(\%)$ :
$74.0 \mathrm{mg}, 94 \%$

$\mathrm{C}_{46} \mathrm{H}_{64} \mathrm{~F}_{6} \mathrm{~N}_{4} \mathrm{PPdRh}$

$1027.3 \mathrm{~g} / \mathrm{mol}$.

Calcd. For $\mathrm{C}_{46} \mathrm{H}_{64} \mathrm{~N}_{4} \mathrm{PdRh}$ (881.3232); Found: 881.3232.

881.9 (100) $\left[\mathrm{M}-\mathrm{PF}_{6}\right]^{+}$. 
IR $\left(\right.$ ATR, $\left.\mathrm{cm}^{-1}\right)$ :

H-NMR $\left(\mathrm{CDCl}_{3}\right) \delta$ :

${ }^{13} \mathrm{C}\left\{{ }^{1} \mathrm{H}\right\}\left(\mathrm{CDCl}_{3}\right) \delta:$
2967 (m); 2928 (m); 1613 (m); 1581 (m); 1456 (m); 1465 (m); 1345

(s); 1275 (vs); 1158 (vs); 1121 (vs); 888 (s); 841 (m); 717 (s); 450 (m).

1.14-1.33 (m, 24H, $\left.\mathrm{CH}_{3}{ }^{\mathrm{PP}}\right)$; $1.55-1.63$ (br s, $\left.2 \mathrm{H}, \mathrm{CH}_{2}{ }^{\text {Cyallyly })}\right) ; 1.80$ (br s, $2 \mathrm{H}, \mathrm{CH}_{2}{ }^{\text {Cy(allyl) }}$ ); 2.08 (br s, 4H, $\mathrm{CH}_{2}{ }^{\mathrm{COD}}$ ); 2.47 (br s, $2 \mathrm{H}$,

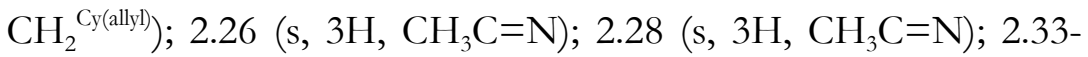
$2.47\left(\mathrm{~m}, 4 \mathrm{H}, \mathrm{CH}_{2}{ }^{\mathrm{COD}}\right) ; 2.59$ (s, $\left.3 \mathrm{H}, \mathrm{CH}_{3}{ }^{\mathrm{Pz}_{4}}\right) ; 2.90-3.36(\mathrm{~m}, 4 \mathrm{H}$, $\mathrm{CH}^{\mathrm{iPr}}$ ); 4.08 (br t, 2H, CH ${ }^{\mathrm{COD}}$ ); 5.08 (br t, $2 \mathrm{H}, \mathrm{CH}^{\mathrm{COD}}$ ); 5.35-5.43 $\left(\mathrm{m}, 2 \mathrm{H}, \mathrm{CH}^{\text {Cy(allyl) })}\right.$; $5.62\left(\mathrm{~m}, 1 \mathrm{H}, \mathrm{CH}^{\text {Cy(allyl })}\right) ; 7.10-7.36(\mathrm{~m}, 6 \mathrm{H}$, $\left.\mathrm{CH}^{\mathrm{Ar}}\right)$.

$11.7\left(\mathrm{CH}_{3}{ }^{\mathrm{P} 4}\right) ; 20.4\left(\mathrm{CH}_{2}{ }^{\text {Cy(allyl }}\right) ; 20.9\left(\mathrm{CH}_{3} \mathrm{C}=\mathrm{N}\right) ; 21.5\left(\mathrm{CH}_{3} \mathrm{C}=\mathrm{N}\right)$; $21.6\left(\mathrm{CH}_{3}{ }^{2 \mathrm{Pr}}\right) ; 23.5\left(\mathrm{CH}_{3}{ }^{\mathrm{PPr}}\right) ; 23.7\left(\mathrm{CH}_{3}{ }^{i \mathrm{Pr}}\right) ; 23.9\left(\mathrm{CH}_{3}{ }^{2 \mathrm{Pr}}\right) ; 24.5$ $\left(\mathrm{CH}_{3}^{i \mathrm{PP}}\right) ; 24.8\left(\mathrm{CH}_{3}^{\mathrm{iPr}}\right) ; 25.0 ; 28.2\left(\mathrm{CH}^{\mathrm{IP}}\right) ; 28.4\left(\mathrm{CH}^{\mathrm{PP}}\right) ; 28.5\left(\mathrm{CH}^{\mathrm{PP}}\right)$; $29.5\left(\mathrm{CH}_{2}{ }^{\mathrm{Cy}(\mathrm{allyl})}\right) ; 30.1\left(\mathrm{CH}_{2}{ }^{\mathrm{COD}}\right) ; 30.2\left(\mathrm{CH}_{2}^{\mathrm{COD}}\right) ; 79.4\left(\mathrm{CH}^{\mathrm{Cy}(a l l y l)}\right)$; $82.8\left(\mathrm{CH}^{\mathrm{COD}}\right) ; 83.5\left(\mathrm{CH}^{\mathrm{COD}}\right) ; 106.6\left(\mathrm{CH}^{\mathrm{Cy}(a l l y l}\right) ; 124.0\left(\mathrm{C}^{\mathrm{Pz}}\right) ; 124.3$ $\left(\mathrm{CH}^{\mathrm{Ar}}\right) ; 127.4\left(\mathrm{CH}^{\mathrm{Ar}}\right) ; 127.9\left(\mathrm{CH}^{\mathrm{Ar}}\right) ; 138.8\left(\mathrm{C}^{\mathrm{Cy}(a l l y l}\right) ; 139.0\left(\mathrm{C}^{\mathrm{Ar} 1}\right)$; $140.3\left(\mathrm{C}^{\mathrm{Ar} 2 / \mathrm{g}}\right) ; 143.8\left(\mathrm{C}^{\mathrm{Ar}}\right) ; 152.7\left(\mathrm{C}^{\mathrm{Pz} 3 / 5}\right) ; 170.6\left(\mathrm{CH}_{3} C=\mathrm{N}^{\mathrm{Pd}}\right) ; 173.6$ $\left(\mathrm{CH}_{3} \mathrm{C}=\mathrm{N}^{\mathrm{Rh}}\right)$.

\subsection{Synthesis of $\left[\mathrm{L}^{1} \mathrm{Pd}\left(\eta^{3}-\mathrm{C}_{4} \mathrm{H}_{7}\right) \mathrm{Rh}(\mathrm{CO})_{2}\right] \mathrm{PF}_{6}(3 \mathrm{w})$}

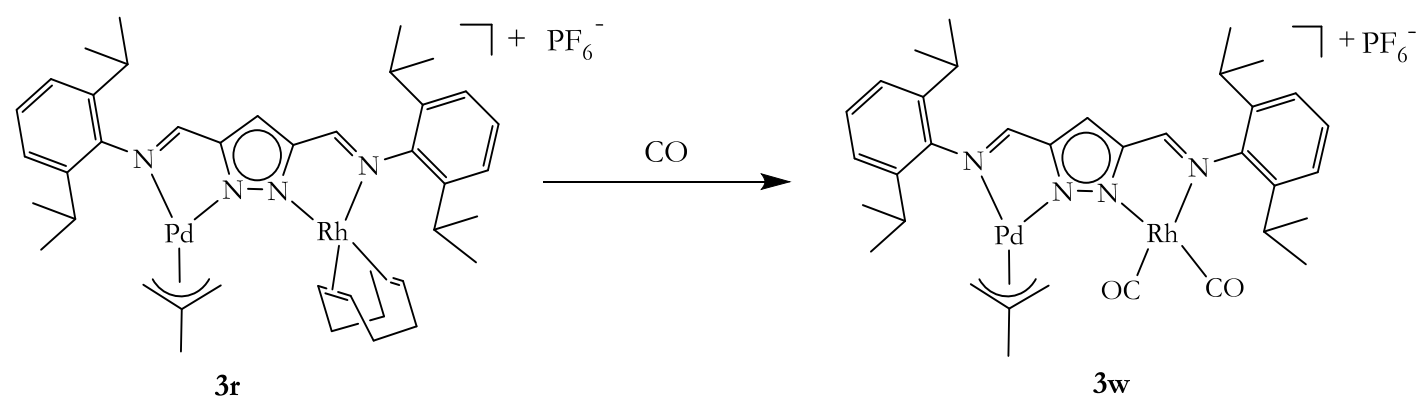

Carbon monoxide (CO, $1 \mathrm{~atm})$ was continuesly bubled through a $\mathrm{CH}_{2} \mathrm{Cl}_{2}$ solution $(15 \mathrm{~mL})$ of $\mathbf{3 r}$ (30.0 mg, $0.035 \mathrm{mmol}$ ) for $30 \mathrm{~min}$. This was followed by a change in colour of the solution from yellow to lemon green. The $\mathrm{CH}_{2} \mathrm{Cl}_{2}$ solution of the complex was kept in the fridge at $-20{ }^{\circ} \mathrm{C}$ under an atmosphere of CO. Lemon green powdery material was harvested from the solution after several days. 
Yield:

Molecular formula:

Molecular weight:

MS (ESI, $\left.\mathrm{CH}_{2} \mathrm{Cl}_{2}\right) m / z(\%)$ :

${ }^{1} \mathrm{H}-\mathrm{NMR}\left(\mathrm{CDCl}_{3}\right) \delta$ :

${ }^{13} \mathrm{C}\left\{{ }^{1} \mathrm{H}\right\}\left(\mathrm{CDCl}_{3}\right) \delta$ :
$24.1 \mathrm{mg}, 81 \%$

$\mathrm{C}_{35} \mathrm{H}_{44} \mathrm{~F}_{6} \mathrm{~N}_{4} \mathrm{O}_{2} \mathrm{PPdRh}$

$863.9 \mathrm{~g} / \mathrm{mol}$.

$764.1(100 \%)\left[\mathrm{M}+\mathrm{H}-\mathrm{PF}_{6}\right]^{+}$.

0.98-1.40 (m, 24H, $\left.\mathrm{CH}_{3}^{\text {iPr }}\right) ; 2.08\left(\mathrm{~s}, 3 \mathrm{H}, \mathrm{CH}_{3}{ }^{\mathrm{Me}(\mathrm{allyl})}\right) ; 2.67-3.27$ (m, $\left.4 \mathrm{H}, \mathrm{CH}^{\text {PP }}\right) ; 4.02\left(\mathrm{~m}, 2 \mathrm{H}, \mathrm{CH}_{2}^{\text {Me(allyl })}\right) ; 4.28\left(\mathrm{~m}, 2 \mathrm{H}, \mathrm{CH}_{2}\right.$, $\left.{ }^{\mathrm{Me}(a l l y l)}\right) 7.10-$ $7.40\left(\mathrm{~m}, 6 \mathrm{H}, \mathrm{CH}^{\mathrm{An}}\right) ; 8.05\left(\mathrm{~s}, 1 \mathrm{H}, \mathrm{CH}^{\mathrm{Pz} 4}\right) ; 8.15(\mathrm{~s}, 1 \mathrm{H}, \mathrm{CH}=\mathrm{N}) ; 8.16$ (s, $1 \mathrm{H}, \mathrm{CH}=\mathrm{N})$.

$22.8\left(\mathrm{CH}_{3}^{\text {PPr }}\right) ; 23.0\left(\mathrm{CH}_{3}^{\mathrm{Me}(\mathrm{allyl})}\right) ; 24.6\left(\mathrm{CH}_{3}^{\text {PPr }}\right) ; 27.0\left(\mathrm{CH}^{\mathrm{TP}}\right) ; 28.6$ $\left(\mathrm{CH}^{\text {Prr }}\right) ; 62.4\left(\mathrm{CH}_{2}^{\mathrm{Me}(a l l y l}\right) ; 108.0117 .5\left(\mathrm{CH}^{\mathrm{Pz}}\right) ; 120.1\left(\mathrm{CH}^{\mathrm{Pz}}\right) ; 122.8$; $124.1\left(\mathrm{CH}^{\mathrm{Ar}}\right) ; 126.5\left(\mathrm{CH}^{\mathrm{Ar}}\right) ; 129.6\left(\mathrm{CH}^{\mathrm{Ar}}\right) ; 134.5\left(\mathrm{C}^{\mathrm{Me}(a l l y l}\right) ; 134.9$; $139.1\left(\mathrm{C}^{\mathrm{Ar} 2 / 6}\right) ; 139.6\left(\mathrm{C}^{\mathrm{Ar} 2 / \mathrm{g}}\right) ; 146.4\left(\mathrm{C}^{\mathrm{Ar}}\right) ; 146.7\left(\mathrm{C}^{\mathrm{Ar}}\right) ; 153.0$ $\left(\mathrm{CC}=\mathrm{N}^{\mathrm{Pd}}\right) ; 154.7\left(\mathrm{CC}=\mathrm{N}^{\mathrm{Rh}}\right) ; 164.2\left(\mathrm{CH}=\mathrm{N}^{\mathrm{Pd}}\right) ; 164.4\left(\mathrm{CH}=\mathrm{N}^{\mathrm{Rh}}\right)$; CO-not observed.

\subsection{Synthesis of $\left[\mathrm{L}^{1} \mathrm{Pd}\left(\eta^{3}-\mathrm{C}_{6} \mathrm{H}_{9}\right) \mathrm{Rh}(\mathrm{CO})_{2}\right] \mathrm{PF}_{6}(3 \mathrm{x})$}

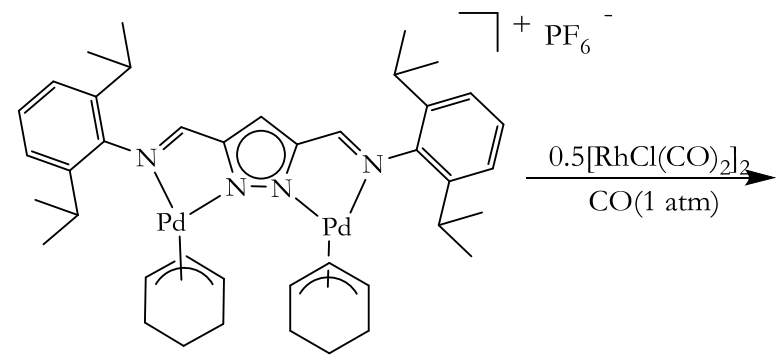

3o

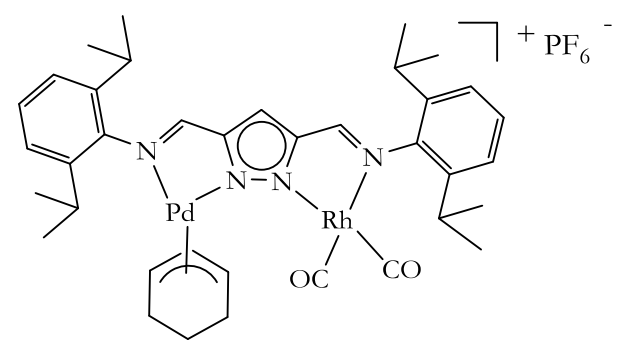

$3 \mathbf{x}$

To a $\mathrm{CH}_{2} \mathrm{Cl}_{2}$ solution $(10 \mathrm{~mL})$ of $\mathbf{3 o}(34.0 \mathrm{mg}, 0.035 \mathrm{mmol})$ was added $0.5 \mathrm{~mol}$ equivalent $\left[\mathrm{RhCl}(\mathrm{CO})_{2}\right]_{2}(6.80 \mathrm{mg}, 0.017 \mathrm{mmol})$ and the mixture stirred for $30 \mathrm{~min}$ under $1 \mathrm{~atm} \mathrm{CO}$ atmosphere. After this period, what appears to be the formation of $\operatorname{Pd}(0)$ species was observed. The reaction mixture was filtered over celite to obtain a bright yellowish-orange solution. Addition of hexane dropwise to the $\mathrm{CH}_{2} \mathrm{Cl}_{2}$ solution results in the precipitation of a bright yellow solid. This was filtered and dried in vacuum for several hours.

Yield: $16 \mathrm{mg}, 41 \%$

Molecular formula: $\mathrm{C}_{37} \mathrm{H}_{46} \mathrm{~F}_{6} \mathrm{~N}_{4} \mathrm{O}_{2} \mathrm{PPdRh}$ 
Molecular weight:

HRMS (TOF-ESI):

MS (ESI, $\left.\mathrm{CH}_{2} \mathrm{Cl}_{2}\right) m / z(\%)$ :

IR $\left(\right.$ ATR, $\left.\mathrm{cm}^{-1}\right)$ :

${ }^{1} \mathrm{H}-\mathrm{NMR}\left(\mathrm{CDCl}_{3}\right) \delta$ :

${ }^{13} \mathrm{C}\left\{{ }^{1} \mathrm{H}\right\}\left(\mathrm{CDCl}_{3}\right) \delta$ :
$933.1 \mathrm{~g} / \mathrm{mol}$.

Calcd. For $\mathrm{C}_{37} \mathrm{H}_{46} \mathrm{~N}_{4} \mathrm{O}_{2} \mathrm{PdRh}$ (787.1718); Found: 787.1718.

$817(10 \%)\left[\mathrm{M}+\mathrm{CO}-\mathrm{PF}_{6}\right]^{+} ; 787(100 \%)\left[\mathrm{M}-\mathrm{PF}_{6}\right]^{+}$.

2970 (m); 2933 (m); 2877 (m); 2098 (vs); 2039 (vs); 1611 (m); 1577 (m); 1495 (m); 1357 (vs); 1275 (vs); 1050 (vs); 936 (m); 777 (m); 888 (m); 843 (m); 806 (m); $672(\mathrm{~m}) ; 612(\mathrm{~m})$.

$1.04\left(\mathrm{~m}, 2 \mathrm{H}, \mathrm{CH}_{2}{ }^{\mathrm{Cy}(\mathrm{allyl})}\right) ; 1.08\left(\mathrm{~d},{ }^{3} J_{\mathrm{HH}}=6.8 \mathrm{~Hz}, 12 \mathrm{H}, \mathrm{CH}_{3}^{i \mathrm{PP}}\right) ; 1.22$ $\left(\mathrm{d},{ }^{3} J_{\mathrm{HH}}=6.8 \mathrm{~Hz}, 6 \mathrm{H}, \mathrm{CH}_{3}{ }^{i \mathrm{PP}}\right) ; 1.36\left(\mathrm{~d},{ }^{3} \mathrm{JH}_{\mathrm{HH}}=6.8 \mathrm{~Hz}, 6 \mathrm{H}, \mathrm{CH}_{3}{ }^{i \mathrm{PP}}\right)$; 1.81 (br s, 4H, $\mathrm{CH}_{2}^{\text {Cy(allyl) }}$ ); 3.19 (m, 4H, $\mathrm{CH}^{\text {iPf }}$ ); 5.24 (br s, $1 \mathrm{H}$, $\mathrm{CH}^{\text {Cy(allyl) }) ; 5.52(b r ~ s, ~} 1 \mathrm{H}, \mathrm{CH}^{\text {Cy(allyl })}$ ); 5.70-5.73 (m, 1H, $\mathrm{CH}^{\text {Cy(allyl })}$; 7.24-7.40 (m, 6H, $\left.\mathrm{CH}^{\mathrm{Ar}}\right) ; 7.80\left(\mathrm{~s}, 1 \mathrm{H}, \mathrm{CH}^{\mathrm{Pz} 4}\right) ; 7.93(\mathrm{~s}, 1 \mathrm{H}, \mathrm{CH}=\mathrm{N})$; $8.31(\mathrm{~s}, 1 \mathrm{H}, \mathrm{CH}=\mathrm{N})$.

$19.1\left(\mathrm{CH}_{2}^{\text {Cy(allyl) }}\right) ; 22.7\left(\mathrm{CH}_{3}^{\text {iPr }}\right) ; 24.4\left(\mathrm{CH}_{3}^{\text {iP }}\right) ; 28.4\left(\mathrm{CH}^{\mathrm{PP}}\right) 28.7$ $\left(\mathrm{CH}^{\mathrm{PP}}\right) ; 28.9\left(\mathrm{CH}^{\mathrm{PP}}\right) ; 79.8(\mathrm{CH}) ; 102.3\left(\mathrm{CH}^{\mathrm{Cy}(\mathrm{allyl})}\right) ; 107.4\left(\mathrm{CH}^{\mathrm{Cy}(a l l y l)}\right)$; $116.0(\mathrm{CH}) ; 116.5(\mathrm{CH}) ; 124.2\left(\mathrm{CH}^{\mathrm{Ar} 3 / 5}\right) ; 124.4\left(\mathrm{CH}^{\mathrm{Ar} 3 / 5}\right) ; 127.8$ $\left(\mathrm{CH}^{\mathrm{Ar} 3 / 5}\right) ; 128.3\left(\mathrm{CH}^{\mathrm{Ar} 3 / 5}\right) ; 128.4\left(\mathrm{CH}^{\mathrm{Ar} 3 / 5}\right) ; 129.1\left(\mathrm{CH}^{\mathrm{Ar} 4}\right) ; 129.4$ $\left(\mathrm{CH}^{\mathrm{Ar} 4}\right) ; 139.3\left(\mathrm{C}^{\mathrm{Ar} 2 / 6}\right) ; 139.5\left(\mathrm{C}^{\mathrm{Ar} 2 / 6}\right) ; 146.1\left(\mathrm{C}^{\mathrm{Ar}}\right) ; 155.3\left(\mathrm{CC}=\mathrm{N}^{\mathrm{Rh}}\right)$; $161.7\left(\mathrm{CH}=\mathrm{N}^{\mathrm{Pd}}\right) ; 166.3\left(\mathrm{CH}=\mathrm{N}^{\mathrm{Rh}}\right) ; 179.5(\mathrm{CO})$.

\subsection{Synthesis of $\left[\mathrm{L}^{2} \operatorname{Pd}\left(\eta^{3}-\mathrm{C}_{6} \mathrm{H}_{9}\right) \mathrm{Rh}(\mathrm{CO})_{2}\right] \mathrm{BAr}^{\mathrm{F}}{ }_{4}(3 \mathrm{y})$}

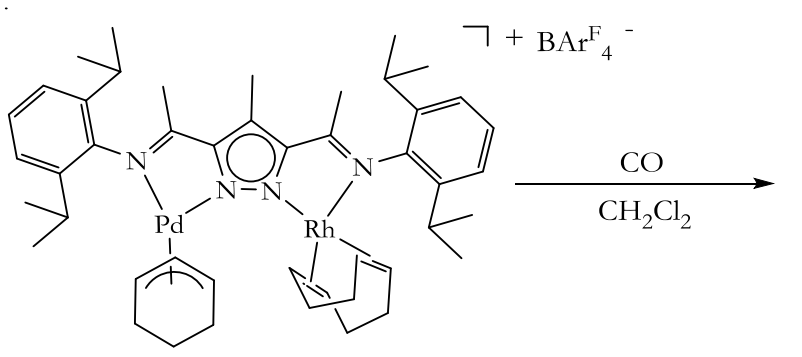

$3 \mathbf{u}$

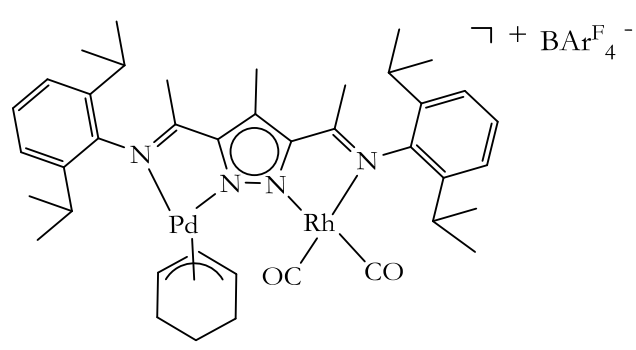

$3 y$

Carbon monoxide (CO, $1 \mathrm{~atm})$, was continuously bubbled through a $\mathrm{CH}_{2} \mathrm{Cl}_{2}$ solution $(10 \mathrm{~mL})$ of 3u $(14.0 \mathrm{mg}, 8.0 \mu \mathrm{mol})$ in a schlenk flask for 20 minutes. The initial orange solution, gradually changed with time to a lemon green solution. This solution, however when exposed to the atmosphere, gradually reverts to orange. However, when kept under an atmosphere of CO, the 
lemon green colour was persistent. A solution of the complex was kept in the referigerator for several days at $-20{ }^{\circ} \mathrm{C}$. After this period, yellow crystalline solid material was isolated.

Yield:

Molecular formula:

Molecular weight:

HRMS (TOF-ESI):

MS (ESI, $\left.\mathrm{CH}_{2} \mathrm{Cl}_{2}\right) m / z(\%)$ :

IR $\left(\right.$ ATR, $\left.\mathrm{cm}^{-1}\right)$ :

${ }^{1} \mathrm{H}-\mathrm{NMR}(\mathrm{CDCl} 3) \delta$ :

${ }^{13} \mathrm{C}\left\{{ }^{1} \mathrm{H}\right\}\left(\mathrm{CDCl}_{3}\right) \delta:$
$6 \mathrm{mg}, 44 \%$

$\mathrm{C}_{72} \mathrm{H}_{64} \mathrm{BF}_{24} \mathrm{~N}_{4} \mathrm{O}_{2} \mathrm{RhPd}$

$1693.4 \mathrm{~g} / \mathrm{mol}$.

Calcd. For $\mathrm{C}_{40} \mathrm{H}_{52} \mathrm{~N}_{4} \mathrm{O}_{2} \mathrm{PdRh}$ (829.2189); Found: 829.2194.

$829(55 \%)\left[\mathrm{M}-\mathrm{BAr}_{4}^{\mathrm{F}}\right]^{+} ; 800(5 \%)\left[\mathrm{M}-\mathrm{CO}-\mathrm{BAr}_{4}{ }_{4}^{\mathrm{F}}\right]^{+}$.

2931 (m); 2970 (m); 2093 (vs); 2032 (vs); 1611 (m); 1577 (m); 1465 (m); 1448 (m); 1354 (m); 1277 (vs); 1121 (vs); 901 (m); 840 (m); 685 (s); 670 (s).

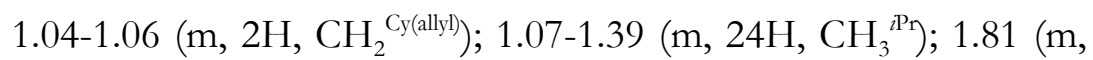
$\left.4 \mathrm{H}, \mathrm{CH}_{2}{ }^{\text {Cy(allyl) }}\right) ; 2.24\left(\mathrm{~s}, 3 \mathrm{H}, \mathrm{CH}_{3} \mathrm{C}=\mathrm{N}\right) ; 2.49\left(\mathrm{~s}, 3 \mathrm{H}, \mathrm{CH}_{3}{ }^{{ }_{\mathrm{z}} 4}\right) ; 2.55$ (s, $\left.3 \mathrm{H}, \mathrm{CH}_{3} \mathrm{C}=\mathrm{N}\right) ; 2.87-3.04\left(\mathrm{~m}, 4 \mathrm{H}, \mathrm{CH}^{\mathrm{PP}}\right) ; 4.30(\mathrm{~m}, 2 \mathrm{H}$, $\mathrm{CH}^{\text {Cy(allyl) })} ; 5.62\left(\mathrm{~m}, 1 \mathrm{H}, \mathrm{CH}^{\text {Cy(allyl) }}\right) ; 7.27-7.31\left(\mathrm{~m}, 6 \mathrm{H}, \mathrm{CH}^{\mathrm{Ar}}\right) ; 7.51$ (s, $\left.4 \mathrm{H}, \mathrm{CH}^{\mathrm{BArF4}}\right) ; 7.69$ (s, 8H, $\left.\mathrm{CH}^{\mathrm{BArF4}}\right)$.

$10.3\left(\mathrm{CH}_{3}{ }^{\mathrm{P} 4}\right) ; 18.9\left(\mathrm{CH}_{2}{ }^{\mathrm{Cy}(\mathrm{allly})}\right) ; 19.0\left(\mathrm{CH}_{3} \mathrm{C}=\mathrm{N}\right) ; 20.7\left(\mathrm{CH}_{3} \mathrm{C}=\mathrm{N}\right)$; $23.3\left(\mathrm{CH}_{3}{ }^{\mathrm{PP}}\right) ; 23.6\left(\mathrm{CH}_{3}{ }^{i \mathrm{Pr}}\right) ; 24.0\left(\mathrm{CH}_{3}{ }^{i \mathrm{PP}}\right) ; 24.1\left(\mathrm{C}^{\mathrm{CF} 3}\right) ; 24.6\left(\mathrm{CF}_{3}\right)$ $28.5\left(\mathrm{CH}^{i \mathrm{Pr}}\right) ; 28.6\left(\mathrm{CH}^{\mathrm{iPf}}\right) ; 28.7\left(\mathrm{CH}^{\mathrm{iPr}}\right) ; 28.8\left(\mathrm{CH}^{\mathrm{iP}}\right) ; 28.9\left(\mathrm{CH}^{i \mathrm{Pr}}\right)$; $29.8\left(\mathrm{CH}_{2}^{\mathrm{Cy}(\mathrm{allyl})}\right) ; 79.6\left(\mathrm{CH}^{\mathrm{Cy}(\mathrm{allyl})}\right) ; 80.0\left(\mathrm{CH}^{\mathrm{Cy}(\mathrm{allyl})}\right) ; 107.0\left(\mathrm{CH}^{\mathrm{Ar}}\right)$; $117.5\left(\mathrm{CH}^{\mathrm{BArF} 4}\right) ; 119.2 ; 122.7\left(\mathrm{CH}^{\mathrm{BArF} 4}\right) ; 122.8\left(\mathrm{C}^{\mathrm{Pz} 4}\right) ; 124.5\left(\mathrm{CH}^{\mathrm{Ar}}\right)$; 124.6 $\left(\mathrm{CH}^{\mathrm{Ar}}\right) ; 124.9\left(\mathrm{CH}^{\mathrm{Ar}}\right) ; 125.0\left(\mathrm{CH}^{\mathrm{Ar}}\right) ; 126.4\left(\mathrm{CH}^{\mathrm{BArF} 4}\right) ; 127.9$ $\left(\mathrm{CH}^{\mathrm{Ar}}\right) ; 128.7\left(\mathrm{CH}^{\mathrm{Ar}}\right) ; 129.2\left(\mathrm{CH}^{\mathrm{Ar}}\right) ; 134.9\left(\mathrm{CH}^{\mathrm{BArF} 4}\right) ; 138.5\left(\mathrm{C}^{\mathrm{Ar}}\right)$; 138.6 $\left(\mathrm{C}^{\mathrm{Ar}}\right) ; 138.7\left(\mathrm{C}^{\mathrm{A}}\right)$; $138.8\left(\mathrm{C}^{\mathrm{Ar}}\right) ; 138.9\left(\mathrm{C}^{\mathrm{Ar}}\right) ; 142.8\left(\mathrm{C}^{\mathrm{Ar}}\right) ; 143.7$ $\left(\mathrm{C}^{\mathrm{Ar}}\right) ; 160.8\left(\mathrm{C}^{\mathrm{Ar}}\right) ; 162.1\left(\mathrm{C}^{\mathrm{Ar}}\right) ; 162.8\left(\mathrm{C}^{\mathrm{Ar}}\right) ; 170.7\left(\mathrm{CH}_{3} \mathrm{C}=\mathrm{N}^{\mathrm{Pd}}\right)$; $175.5\left(\mathrm{CH}_{3} \mathrm{C}=\mathrm{N}^{\mathrm{Rh}}\right)$. 


\section{6 Homobimetallic rhodium complexes}

\subsection{Synthesis of $\left.\left[\mathrm{L}^{2} \mathrm{Rh}_{2}(\mathrm{CO})_{4}\right)\right] \mathrm{PF}_{6}(3 \mathrm{z} 1)$}
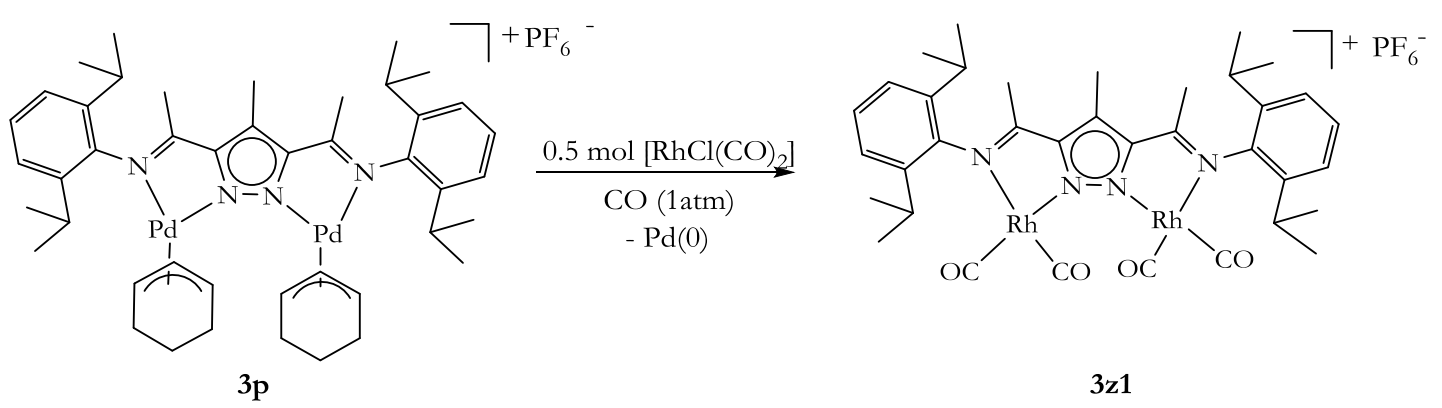

To a $\mathrm{CH}_{2} \mathrm{Cl}_{2}$ solution $(10 \mathrm{~mL})$ of $3 \mathbf{p}(10.0 \mathrm{mg}, 0.01 \mathrm{mmol})$ was added $0.5 \mathrm{~mol}$ equivalent $(1.90$ $\mathrm{mg}, 0.05 \mathrm{mmol})$ of $\left[\mathrm{RhCl}(\mathrm{CO})_{2}\right]_{2}$ with stirring under $1 \mathrm{~atm}$ of $\mathrm{CO}$. A lemon green solution was formed after a few minutes. The formation of $\operatorname{Pd}(0)$ species is observed after $2 \mathrm{~h}$. The reaction mixture was allowed to stir for $48 \mathrm{~h}$, after this period, a black suspension was observed. This suspension when filtered over celite to yield a lemon green solution, which when evaporated, gives a lemon green powder.

Yield:

$4.1 \mathrm{mg}, 43 \%$

Molecular formula:

$\mathrm{C}_{36} \mathrm{H}_{43} \mathrm{~F}_{6} \mathrm{~N}_{4} \mathrm{O}_{4} \mathrm{PRh}_{2}$

Molecular weight:

$946.10 \mathrm{~g} / \mathrm{mol}$.

HRMS (TOF-ESI):

Calcd. For $\mathrm{C}_{36} \mathrm{H}_{43} \mathrm{~N}_{4} \mathrm{O} 4 \mathrm{Rh}_{2}$ (801.1394); Found: 801.1409.

MS (ESI, $\left.\mathrm{CH}_{2} \mathrm{Cl}_{2}\right) m / z(\%)$ :

801(100\%) [M-PF $]^{+} ; 770(15 \%)\left[\mathrm{M}-\mathrm{CO}-\mathrm{PF}_{6}\right]^{+} ; 743$ (25\%) [M-2CO$\left.\mathrm{PF}_{6}\right] ; 712(35 \%)\left[\mathrm{M}-4 \mathrm{CO}+\mathrm{Na}-\mathrm{PF}_{6}\right]^{+}$.

IR $\left(\right.$ ATR, $\left.\mathrm{cm}^{-1}\right)$ : 2923 (s); 2963 (s); 2869 (s); 2475 (s); 1569 (vs); 1437 (vs); 1383 (m); 1365 (s); 1326 (s); 1254 (m); 1226 (m); 1098 (s); 1075 (s); 1038 (m); $803(\mathrm{~s}) ; 777$ (s).

${ }^{1} \mathrm{H}-\mathrm{NMR}\left(\mathrm{CDCl}_{3}\right)$ 8: $1.21\left(\mathrm{~d}, 3_{\mathrm{HH}}=6.8 \mathrm{~Hz}, 12 \mathrm{H}, \mathrm{CH}_{3}{ }^{\mathrm{iPr}}\right) ; 1.37\left(\mathrm{~d},{ }^{3} \mathrm{JHH}_{\mathrm{HH}}=6.8 \mathrm{~Hz}, 12 \mathrm{H}\right.$, $\left.\mathrm{CH}_{3}{ }^{\mathrm{PP}}\right) ; 2.36\left(\mathrm{~s}, 6 \mathrm{H}, \mathrm{CH}_{3} \mathrm{C}=\mathrm{N}\right) ; 2.65\left(\mathrm{~s}, 3 \mathrm{H}, \mathrm{CH}_{3}{ }^{\mathrm{P}_{\mathrm{z}}}\right) ; 3.08(\mathrm{~m}, 4 \mathrm{H}$, $\left.\mathrm{CH}^{\mathrm{iPr}}\right) ; 7.26-7.39\left(\mathrm{~m}, 6 \mathrm{H}, \mathrm{CH}^{\mathrm{Ar}}\right)$.

${ }^{13} \mathrm{C}\left\{{ }^{1} \mathrm{H}\right\}\left(\mathrm{CDCl}_{3}\right) \delta$ : $10.2\left(\mathrm{CH}_{3}{ }^{\mathrm{z} 4}\right) ; 22.7\left(\mathrm{CH}_{3} \mathrm{C}=\mathrm{N}\right) ; 23.4\left(\mathrm{CH}_{3} \mathrm{C}=\mathrm{N}\right) ; 23.9\left(\mathrm{CH}_{3}{ }^{2 \mathrm{Pr}}\right) ; 25.2$ $\left(\mathrm{CH}_{3}{ }^{\text {iPr }}\right) ; 28.8\left(\mathrm{CH}^{\text {iPr }}\right) ; 124.8\left(\mathrm{C}^{\mathrm{Ar}}\right) 126.4\left(\mathrm{C}^{\mathrm{Pz} 3 / 5}\right) ; 128.4\left(\mathrm{C}^{\mathrm{Ar}}\right) ; 129.0$ $\left(\mathrm{C}^{\mathrm{An}}\right) ; 139.3\left(\mathrm{C}^{\mathrm{An}}\right) ; 143.9\left(\mathrm{C}^{\mathrm{An}}\right) ; 154.7\left(\mathrm{CCH}_{3}\right) ; 176.7\left(\mathrm{CH}_{3} \mathrm{C}=\mathrm{N}\right)$. 


\subsection{Synthesis of $\left[\mathrm{L}^{2} \mathrm{Rh}_{2}(\mathrm{COD})_{2}\right] \mathrm{Cl}\left(3 \mathrm{c}_{1}\right)$}

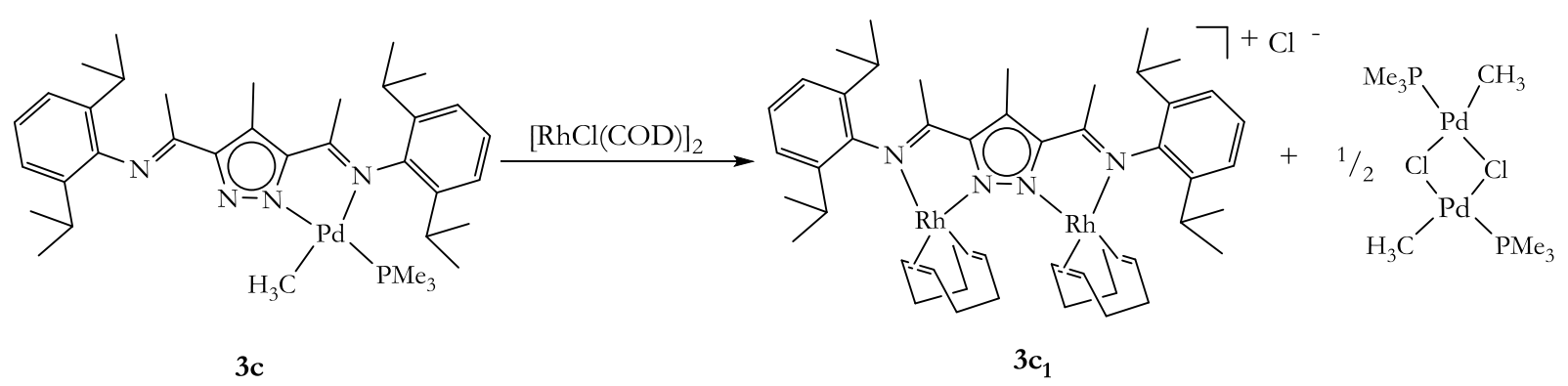

To a $\mathrm{CH}_{2} \mathrm{Cl}_{2}$ solution $(10 \mathrm{~mL})$ of $3 \mathbf{c}(100 \mathrm{mg}, 0.15 \mathrm{mmol})$ was added $1 \mathrm{~mol}$ equivalent $[\mathrm{RhCl}(\mathrm{COD})]_{2}(72.4 \mathrm{mg}, 0.15 \mathrm{mmol})$ with stirring for $72 \mathrm{~h}$. The bright yellow solution was filtered and the filtrate evaporated to obtain a yellow powder. The powder was washed with hexane $(3 \times 3 \mathrm{~mL})$, and the solid dried in air. The solid was again dissolved in $\mathrm{CH}_{2} \mathrm{Cl}_{2}(2 \mathrm{~mL})$ and slowly layered with hexane, precipitating a yellow solid in the process. The precipitate was filtered and dried in air.

Yield:

Molecular formula:

Molecular weight:

MS (ESI, $\left.\mathrm{CH}_{2} \mathrm{Cl}_{2}\right) m / z(\%)$ :

${ }^{1} \mathrm{H}-\mathrm{NMR}\left(\mathrm{CDCl}_{3}\right) \delta$ :

${ }^{13} \mathrm{C}\left\{{ }^{1} \mathrm{H}\right\}\left(\mathrm{CDCl}_{3}\right) \delta:$
$65 \mathrm{mg}, 46 \%$

$\mathrm{C}_{48} \mathrm{H}_{67} \mathrm{ClN}_{4} \mathrm{Rh}_{2}$

$942.4 \mathrm{~g} / \mathrm{mol}$.

905 (30\%) [M-Cl $]^{+} ; 695$ (30\%) [M-Rh(COD)-Cl $]^{+}$.

$1.23\left(\mathrm{~d},{ }^{3} J_{\mathrm{HH}}=6.8 \mathrm{~Hz}, 12 \mathrm{H}, \mathrm{CH}_{3}{ }^{\mathrm{PP}}\right) ; 1.32\left(\mathrm{~d},{ }^{3} J_{\mathrm{HH}}=6.8 \mathrm{~Hz}, 12 \mathrm{H}\right.$, $\left.\mathrm{CH}_{3}{ }^{i \mathrm{P}}\right) ; 2.36\left(\mathrm{~s}, 6 \mathrm{H}, \mathrm{CH}_{3} \mathrm{C}=\mathrm{N}\right) ; 2.65\left(\mathrm{~s}, 3 \mathrm{H}, \mathrm{CH}_{3}{ }^{\mathrm{zz} 4}\right) ; 2.33-2.52(\mathrm{~m}$, $8 \mathrm{H}, \mathrm{CH}_{2}{ }^{\mathrm{COD}}$ ); 3.10 (m, 4H, $\mathrm{CH}^{\mathrm{iP}}$ ); 3.91 (br s, $8 \mathrm{H}, \mathrm{CH}_{2}{ }^{\mathrm{COD}}$ ); 4.24 (br s, 4H, $\mathrm{CH}^{\mathrm{COD}}$ ); 5.07 (br s, 4H, $\mathrm{CH}^{\mathrm{COD}}$ ); 7.16-7.39 (m, 6H, $\left.\mathrm{CH}^{\mathrm{Ar}}\right)$.

$11.40\left(\mathrm{CH}_{3}{ }^{\mathrm{P} z}\right) ; 18.8\left(\mathrm{CH}_{3} \mathrm{C}=\mathrm{N}\right) ; 19.4\left(\mathrm{CH}_{3} \mathrm{C}=\mathrm{N}\right) ; 22.3\left(\mathrm{CH}_{3}{ }^{\text {IP }}\right)$; $23.4\left(\mathrm{CH}_{3}{ }^{i \mathrm{PP}}\right) ; 23.8\left(\mathrm{CH}_{3}{ }^{i \mathrm{Pr}}\right) ; 24.9\left(\mathrm{CH}_{3}{ }^{i \mathrm{PP}}\right) ; 28.0\left(\mathrm{CH}^{\mathrm{iPr}}\right) ; 28.1\left(\mathrm{CH}^{\mathrm{iPr}}\right)$; $30.0\left(\mathrm{CH}_{2}{ }^{\mathrm{COD}}\right) ; 30.6\left(\mathrm{CH}_{2}{ }^{\mathrm{COD}}\right) ; 81.7\left(\mathrm{CH}^{\mathrm{COD}}\right) ; 81.8\left(\mathrm{CH}^{\mathrm{COD}}\right) ; 83.5$ $\left(\mathrm{CH}^{\mathrm{COD}}\right) ; 83.6\left(\mathrm{CH}^{\mathrm{COD}}\right) ; 120.9\left(\mathrm{C}^{\mathrm{Pz}}\right) ; 122.6\left(\mathrm{CH}^{\mathrm{Ar}}\right) ; 122.7\left(\mathrm{CH}^{\mathrm{Ar}}\right)$; $123.7\left(\mathrm{CH}^{\mathrm{Ar}}\right) ; 126.7\left(\mathrm{CH}^{\mathrm{Ar}}\right) ; 128.7\left(\mathrm{C}^{\mathrm{Ar}}\right) ; 135.9\left(\mathrm{C}^{\mathrm{Ar}}\right) ; 140.4\left(\mathrm{C}^{\mathrm{Ar}}\right)$; $147.2\left(\mathrm{C}^{\mathrm{Ar}}\right) ; 163.8\left(\mathrm{C}^{\mathrm{P}}\right) ; 172.5\left(\mathrm{CH}_{3} \mathrm{C}=\mathrm{N}\right)$. 


\subsection{Synthesis of $\left[\mathrm{L}_{2}^{2} \mathrm{Rh}_{2}(\mathrm{OAc})_{2}(\mathrm{MeOH})_{2}\right]\left(\mathrm{PF}_{6}\right)_{2}(4 \mathrm{e})$}

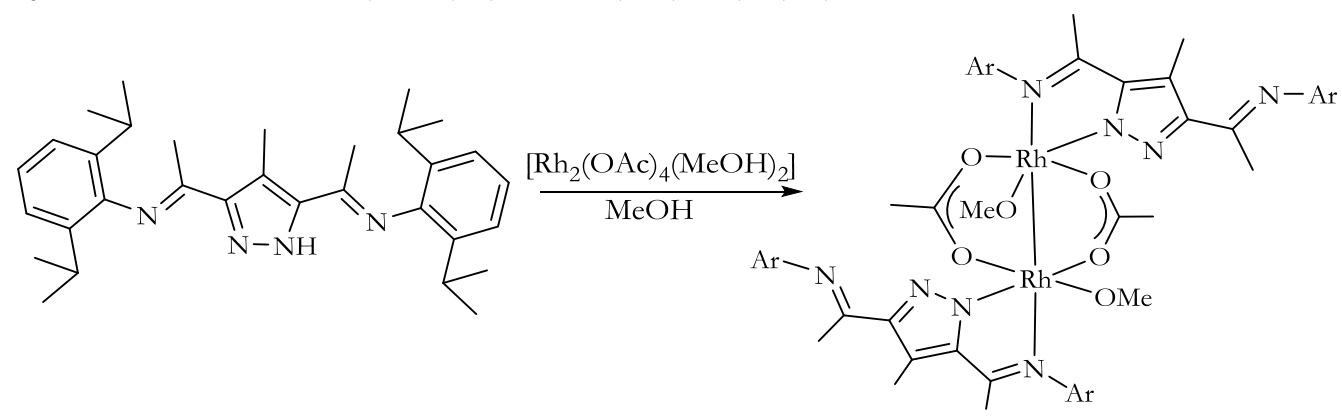

$4 \mathrm{e}$

To a methanolic solution $(10 \mathrm{~mL})$ of $\mathbf{H L}^{2}(20.0 \mathrm{mg}, 41.2 \mu \mathrm{mol})$ was added a $1.1 \mathrm{~mol}$ equivalent $\left[\mathrm{Rh}_{2}(\mathrm{OAc})_{4}(\mathrm{MeOH})_{2}\right](20.0 \mathrm{mg}, 43.7 \mu \mathrm{mol})$ with stirring for $18 \mathrm{~h}$ to form a dark red solution. The solution was filtered and allowed to slowly evaporate at room temperature for $48 \mathrm{~h}$, after which the product was isolated as dark red crystalline solids.

Yield:

Molecular formula:

Molecular weight:

MS (ESI, $\left.\mathrm{CH}_{2} \mathrm{Cl}_{2}\right) m / z(\%)$ :

IR $\left(\right.$ ATR, $\left.\mathrm{cm}^{-1}\right)$ :

${ }^{1} \mathrm{H}-\mathrm{NMR}\left(\mathrm{CDCl}_{3}\right) \delta$ :

${ }^{13} \mathrm{C}\left\{{ }^{1} \mathrm{H}\right\}\left(\mathrm{CDCl}_{3}\right) \delta$ :
$11 \mathrm{mg}, 16 \%$

$\mathrm{C}_{70} \mathrm{H}_{97} \mathrm{~F}_{12} \mathrm{~N}_{8} \mathrm{O}_{6} \mathrm{P}_{2} \mathrm{Rh}_{2}$

$1642.3 \mathrm{~g} / \mathrm{mol}$.

$484(100 \%)[\mathrm{L}]^{+}$

2959 (m); 2926 (m); 1637 (vs); 1583 (vs); 1375 (s); 1365 (s); 1436

(vs); 1383 (s); 1184 (s); 1097 (vs); 692 (vs); 510 (s); 497 (vs).

$0.98\left(\mathrm{~d},{ }^{3} J_{\mathrm{HH}}=6.8 \mathrm{~Hz}, 12 \mathrm{H}, \mathrm{CH}_{3}{ }^{2 \mathrm{PP}}\right) ; 1.02\left(\mathrm{~d},{ }^{3} J_{\mathrm{HH}}=6.8 \mathrm{~Hz}, 12 \mathrm{H}\right.$, $\left.\mathrm{CH}_{3}{ }^{i \mathrm{Pr}}\right) ; 1.19\left(\mathrm{~d},{ }^{3} J_{\mathrm{HH}}=6.8 \mathrm{~Hz}, 24 \mathrm{H}, \mathrm{CH}_{3}{ }^{\mathrm{iPr}}\right) ; 1.35$ (s, 3H, $\mathrm{CH}_{3}{ }^{\mathrm{OAg}}$ ); 1.55 (s, 6H, $\left.\mathrm{CH}_{3}{ }^{\mathrm{OAg}}\right) ; 2.03$ (s, 6H, $\left.\mathrm{CH}_{3} \mathrm{C}=\mathrm{N}\right) ; 2.52\left(\mathrm{~m}, 4 \mathrm{H}, \mathrm{CH}^{\mathrm{PPr}}\right)$; $2.56\left(\mathrm{~s}, 6 \mathrm{H}, \mathrm{CH}_{3} \mathrm{C}=\mathrm{N}\right) ; 2.81\left(\mathrm{~s}, 6 \mathrm{H}, \mathrm{CH}_{3}{ }^{\mathrm{Pz}}\right) ; 3.29\left(\mathrm{~m}, 4 \mathrm{H}, \mathrm{CH}^{\mathrm{iPr}}\right)$; $7.00\left(\mathrm{~s}, 6 \mathrm{H}, \mathrm{CH}^{\mathrm{Ar}}\right) ; 7.24\left(\mathrm{~s}, 6 \mathrm{H}, \mathrm{CH}^{\mathrm{Ar}}\right)$.

11.6 $\left(\mathrm{CH}_{3}{ }^{\mathrm{P} 4}\right) ; 20.2\left(\mathrm{CH}_{3} \mathrm{C}=\mathrm{N}\right): 21.2\left(\mathrm{CH}_{3} \mathrm{C}=\mathrm{N}\right) ; 23.8\left(\mathrm{CH}_{3}{ }^{\text {PPr }}\right) ; 24.4$ $\left(\mathrm{CH}_{3}^{i \mathrm{iP}}\right) ; 24.6\left(\mathrm{CH}_{3}^{i \mathrm{PP}}\right) ; 24.8\left(\mathrm{CH}_{3}^{i \mathrm{PP}}\right) ; 27.7\left(\mathrm{CH}^{\mathrm{PP}}\right) ; 28.1\left(\mathrm{CH}^{\mathrm{iPr}}\right)$; $121.4\left(\mathrm{C}^{\mathrm{P} z 4}\right) ; 122.9\left(\mathrm{CH}^{\mathrm{Ar}}\right) ; 123.4\left(\mathrm{CH}^{\mathrm{Ar}}\right) ; 123.7\left(\mathrm{CH}^{\mathrm{Ar}}\right) ; 125.3$ $\left(\mathrm{CH}^{\mathrm{Ar}}\right) ; 135.7\left(\mathrm{C}^{\mathrm{Ar}}\right) ; 141.2\left(\mathrm{C}^{\mathrm{Ar}}\right) ; 142.6\left(\mathrm{C}^{\mathrm{Ar}}\right) ; 145.1\left(\mathrm{CH}^{\mathrm{Ar}}\right) ; 148.4$ $\left(\mathrm{CH}^{\mathrm{Ar}}\right) ; 154.6\left(\mathrm{CH}^{\mathrm{Ar}}\right) ; 158.7\left(\mathrm{CH}^{\mathrm{Ar}}\right) ; 166.2\left(\mathrm{CH}_{3} \mathrm{C}=\mathrm{N}\right) ; 186.1$ $\left(\mathrm{C}^{\mathrm{OAg}}\right) ; 191.6\left(\mathrm{C}^{\mathrm{OAg}}\right)$. 


\section{7 Tetranuclear zinc(II) complexes}

\subsection{Synthesis of $\left[\mathrm{L}^{1} \mathrm{Zn}_{4}(\mu-\mathrm{OAc})_{6}\right]$ (4a)}

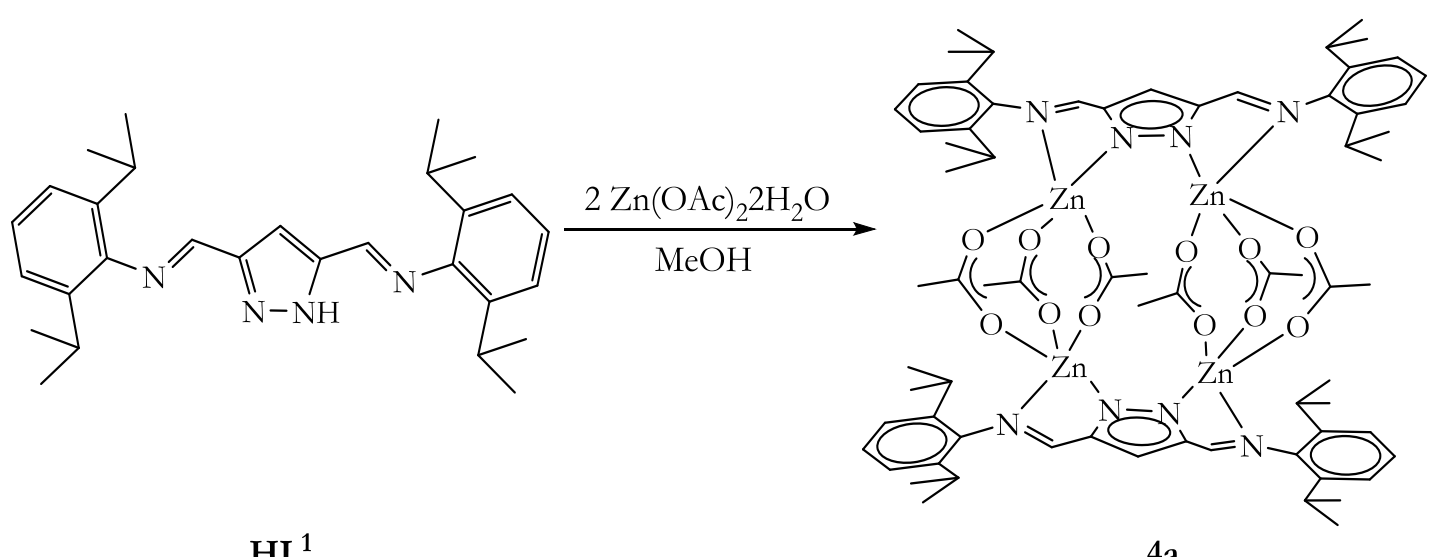

$\mathrm{HL}^{1}$

$4 a$

A Schlenk flask was equipped with a magnetic stirrer, evacuated, and filled with nitrogen. The flask was charged with $\mathrm{Zn}(\mathrm{OAc})_{2} \cdot 2 \mathrm{H}_{2} \mathrm{O}(200 \mathrm{mg}, 0.90 \mathrm{mmol})$ in $\mathrm{MeOH}(10 \mathrm{~mL})$. The ligand, $\mathbf{H L}^{1}$ (200 $\mathrm{mg}, 0.45 \mathrm{mmol}$ ) was added to the reaction mixture and the mixture stirred at room temperature for $48 \mathrm{~h}$. The solvent was evaporated, dissolved in $\mathrm{CH}_{2} \mathrm{Cl}_{2}$, and allowed to slowly evaporate at room temperature. The product was obtained as white crystalline solid. The solid was isolated and dried overnight in air.

Yield:

$230 \mathrm{mg}, 73 \%$

Molecular formula:

$\mathrm{C}_{70} \mathrm{H}_{92} \mathrm{~N}_{8} \mathrm{O}_{12} \mathrm{Zn}_{4}$

Molecular weight:

$1501.1 \mathrm{~g} / \mathrm{mol}$.

MS (ESI, $\left.\mathrm{CH}_{3} \mathrm{OH}\right) \mathrm{m} / \mathrm{z}(\%): 565(40 \%)[\mathrm{LZn}(\mathrm{OAc})]^{+} ; 688(60 \%)\left[\mathrm{LZn}_{2}(\mathrm{OAc})_{2}+2 \mathrm{H}\right]^{+} ; 947(15 \%)$ $\left[\mathrm{L}_{2} \mathrm{Zn}-\mathrm{H}\right]^{+} ; 1073(8 \%)\left[\mathrm{L}_{2} \mathrm{Zn}_{2}(\mathrm{OAc})\right]^{+}$.

IR (ATR, $\left.\mathrm{cm}^{-1}\right)$ : $\quad 2961$ (m); 2929 (m); 2870 (m); 1585 (vs); 1439 (vs); 1385 (m); 1257 (m); 1188 (m); 1118 (m); 1061 (m); 875 (m); 799 (s); 756 (s); 618 (m); 481 (m).

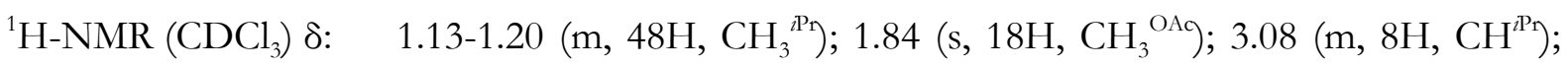
7.15-7.18 (m, 14H, $\left.\mathrm{CH}^{\mathrm{Pz}}, \mathrm{CH}^{\mathrm{Ar}}\right) ; 8.23(\mathrm{~d}, J=7.7 \mathrm{~Hz}, 4 \mathrm{H}, \mathrm{CH}=\mathrm{N})$.

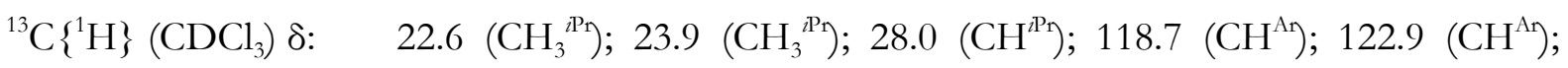
$123.1\left(\mathrm{CH}^{\mathrm{Ar}}\right) ; 124.6\left(\mathrm{CH}^{\mathrm{Ar}}\right) ; 125.3\left(\mathrm{CH}^{\mathrm{Ar}}\right) ; 132.6\left(\mathrm{C}^{\mathrm{Ar}}\right) ; 138.2\left(\mathrm{C}^{\mathrm{Ar}}\right) ; 140.3$ $\left(\mathrm{C}^{\mathrm{Ar}}\right) ; 153.8\left(\mathrm{C}^{\mathrm{P}_{\mathrm{z}}}\right)$; imine (not observed); $180.3\left(\mathrm{C}^{\mathrm{OAq}}\right)$.

Elemental analysis: Calcd. For $\mathrm{C}_{70} \mathrm{H}_{92} \mathrm{~N}_{8} \mathrm{O}_{12} \mathrm{Zn}_{4} \cdot 0.5 \mathrm{CH}_{2} \mathrm{Cl}_{2}:(\mathrm{C}) 54.93(\mathrm{H}) 6.08$ (N) 7.27: Found: (C) $54.51(\mathrm{H}) 6.03(\mathrm{~N}) 7.21$. 


\section{Experimetal}

Subsequent complexes were prepared in like manner.

\subsection{Synthesis of $\left[\mathrm{L}^{2} \mathrm{Zn}_{4}(\mu-\mathrm{OAc})_{6}\right](4 \mathrm{~b})$}

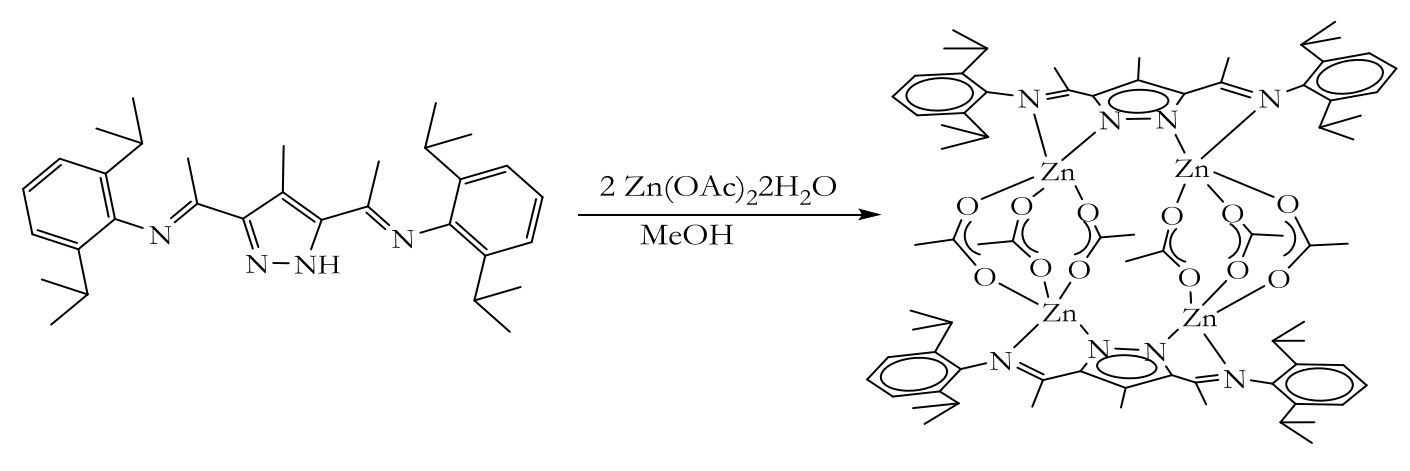

$\mathrm{HL}^{2}$

$4 b$

To a stirring methanolic solution $(15 \mathrm{~mL})$ of $\mathrm{Zn}(\mathrm{OAc})_{2} \cdot 2 \mathrm{H}_{2} \mathrm{O}(180 \mathrm{mg}, 0.83 \mathrm{mmol})$ was added $0.5 \mathrm{~mol}$ equivalent of the ligand, $\mathbf{H L}^{2}(200 \mathrm{mg}, 0.41 \mathrm{mmol})$ with stirring for $48 \mathrm{~h}$. The product was isolated as a white crystalline solid from the slow evaporation of dichloromethane solution of the complex.

Yield:

Molecular formula:

Molecular weight:

MS (ESI, $\left.\mathrm{CH}_{3} \mathrm{OH}\right) \mathrm{m} / \mathrm{z}(\%): 1496$

IR (ATR, $\left.\mathrm{cm}^{-1}\right)$ :

${ }^{1} \mathrm{H}-\mathrm{NMR}\left(\mathrm{CDCl}_{3}\right) \delta$ :

${ }^{13} \mathrm{C}\left\{{ }^{1} \mathrm{H}\right\}\left(\mathrm{CDCl}_{3}\right) \delta:$

Elemental analysis:
$\left[\mathrm{L}_{2} \mathrm{Zn}_{4}(\mathrm{OAc})_{3}(\mathrm{MeOH})_{2}\right]^{+} ; 731(20 \%)\left[\mathrm{LZn}_{2}(\mathrm{OAc})_{2}\right]^{+}$.

$230 \mathrm{mg}, 73 \%$

$\mathrm{C}_{76} \mathrm{H}_{104} \mathrm{~N}_{8} \mathrm{O}_{12} \mathrm{Zn}_{4}$ $1585.3 \mathrm{~g} / \mathrm{mol}$.

2963 (m); 2928 (m); 2870 (m); 1603 (vs); 1430 (vs); 1365 (m); 1231 (m); $1190(\mathrm{~m}) ; 1065$ (m); 618 (m); 774 (s); 670 (m); 558 (m).

1.06-1.14 (m, 48H, $\left.\mathrm{CH}_{3}{ }^{2 \mathrm{PP}}\right) ; 2.22\left(\mathrm{~s}, 30 \mathrm{H}, \mathrm{CH}_{3} \mathrm{C}=\mathrm{N}, \mathrm{CH}_{3} \mathrm{O}^{\mathrm{Ag}}\right) ; 2.63$ $\left(\mathrm{s}, 6 \mathrm{H}, \mathrm{CH}_{3}{ }^{\mathrm{P} 4}\right) ; 2.94\left(\mathrm{~m}, 8 \mathrm{H}, \mathrm{CH}^{\mathrm{PPr}}\right) ; 7.08-7.14\left(\mathrm{~m}, 12 \mathrm{H}, \mathrm{CH}^{\mathrm{Ar}}\right)$.

$12.1\left(\mathrm{CH}_{3}{ }^{\mathrm{Pz} 4}\right) ; 20.3 ; 22.6 ; 23.9 ; 24.2 ; 28.0 ; 123.4\left(\mathrm{C}^{\mathrm{OAg}}\right) ; 139.2$; $147.7 ; 165.7 ; 179.9\left(\mathrm{C}^{\mathrm{OAg}}\right)$.

Calcd. For $\mathrm{C}_{76} \mathrm{H}_{104} \mathrm{~N}_{8} \mathrm{O}_{12} \mathrm{Zn}_{4}$ : (C) $57.65(\mathrm{H}) 6.62$ (N) 7.08; Found: (C) $57.34(\mathrm{H}) 5.39(\mathrm{~N}) 7.35$. 
<smiles>C/C(=N\c1c(C)cccc1C)c1n[nH]c(/C(C)=N/c2c(C)cccc2C)c1C</smiles>

$\underset{\mathrm{MeOH}}{\stackrel{2 \mathrm{Zn}(\mathrm{OAc})_{2} 2 \mathrm{H}_{2} \mathrm{O}}{\longrightarrow}}$

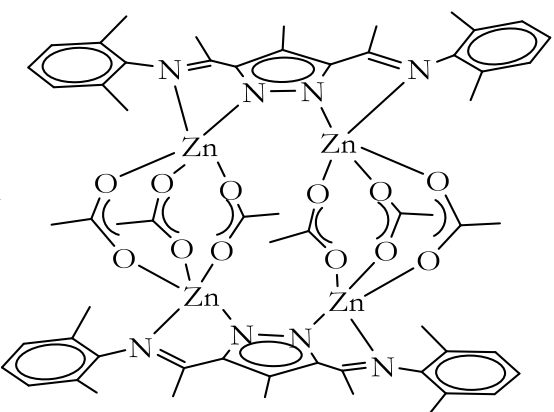

$4 \mathrm{c}$

$\mathrm{HL}^{3}$

To a stirring methanolic solution $(15 \mathrm{~mL})$ of $\mathrm{Zn}(\mathrm{OAc})_{2} \cdot 2 \mathrm{H}_{2} \mathrm{O}(270 \mathrm{mg}, 1.23 \mathrm{mmol})$ was added $0.5 \mathrm{~mol}$ equivalent $\mathbf{H L}^{3}$ (200 $\mathrm{mg}, 0.63 \mathrm{mmol}$ ) with stirring for $48 \mathrm{~h}$. The product was isolated as a white crystalline solid from the slow evaporation of a 50:50 mixture $\mathrm{CH}_{2} \mathrm{Cl}_{2} / \mathrm{CH}_{3} \mathrm{OH}$ solution of the complex.

Yield:

Molecular formula:

Molecular weight:

MS (ESI, $\left.\mathrm{CH}_{3} \mathrm{OH}\right) m / z(\%)$ :

IR (ATR, $\left.\mathrm{cm}^{-1}\right)$ :

${ }^{1} \mathrm{H}-\mathrm{NMR}\left(\mathrm{CDCl}_{3}\right) \delta$ :

${ }^{13} \mathrm{C}\left\{{ }^{1} \mathrm{H}\right\}\left(\mathrm{CDCl}_{3}\right) \delta:$

Elemental analysis:
$300 \mathrm{mg}, 72 \%$

$\mathrm{C}_{60} \mathrm{H}_{72} \mathrm{~N}_{8} \mathrm{O}_{12} \mathrm{Zn}_{4}$

$1358.8 \mathrm{~g} / \mathrm{mol}$.

$1299(10 \%)\left[\mathrm{L}_{2} \mathrm{Zn}_{4}(\mathrm{OAc})_{5}\right]^{+} ; 934(100 \%)\left[\mathrm{L}_{2} \mathrm{Zn}(\mathrm{OAc})\right]^{+}$.

2922 (br); 1590 (vs); 1423 (vs); 1320 (s); 1201 (s); 1095 (m); 1065 (m); 1024 (m); 970 (m); 784 (m);767 (s); 666 (s); 618 (s); 569 (m).

1.78 (s, $18 \mathrm{H}, \mathrm{CH}_{3}{ }^{\mathrm{OAg}}$; 2.12 (s, 24H, $\left.\mathrm{CH}_{3}{ }^{\mathrm{Ar}}\right) ; 2.20$ (s, $12 \mathrm{H}$; $\left.\mathrm{CH}_{3} \mathrm{C}=\mathrm{N}\right) ; 2.65\left(\mathrm{~s}, 6 \mathrm{H}, \mathrm{CH}_{3}^{\mathrm{Pz} 4}\right) ; 6.99-7.07\left(\mathrm{~m}, 12 \mathrm{H}, \mathrm{CH}^{\mathrm{Ar}}\right)$.

$12.0\left(\mathrm{CH}_{3}{ }^{\mathrm{z} z 4}\right) ; 18.0\left(\mathrm{CH}_{3}{ }^{\mathrm{Ar}}\right) ; 18.8\left(\mathrm{CH}_{3}{ }^{\mathrm{P} z 3 / 5}\right) ; 22.3 ; 118.6\left(\mathrm{C}^{\mathrm{Ar}}\right) ; 124.9$ $\left(\mathrm{C}^{\mathrm{Ar}}\right) ; 128.1\left(\mathrm{CH}^{\mathrm{Ar}}\right) ; 129.1\left(\mathrm{CH}^{\mathrm{Ar}}\right) ; 179.4\left(\mathrm{C}^{\mathrm{OAg}}\right)$.

Calcd. For $\mathrm{C}_{60} \mathrm{H}_{72} \mathrm{~N}_{8} \mathrm{O}_{12} \mathrm{Zn}_{4} \cdot \mathrm{CH}_{2} \mathrm{Cl}_{2}:(\mathrm{C}) 50.75(\mathrm{H}) 5.17$ (N) 7.76; Found: (C) $50.71(\mathrm{H}) 5.39$ (N) 7.92 . 


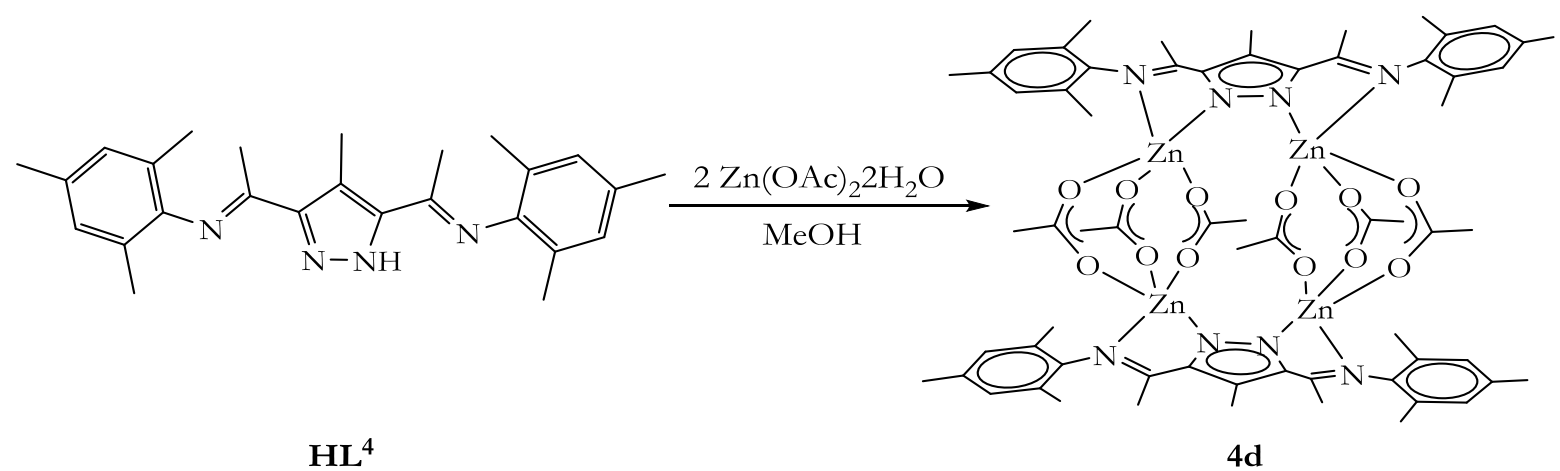

To a stirring methanolic solution $(10 \mathrm{~mL})$ of $\mathrm{Zn}(\mathrm{OAc})_{2} \cdot 2 \mathrm{H}_{2} \mathrm{O}$ [270 mg, $\left.1.23 \mathrm{mmol}\right]$ was added $0.5 \mathrm{~mol}$ equivalent of $\mathbf{H L}^{4}$ (200 mg, $0.63 \mathrm{mmol}$ ) with stirring for $48 \mathrm{~h}$. The product was isolated as a white crystalline solid from the slow evaporation of a methanolic solution of the complex.

Yield:

Molecular formula:

Molecular weight:

MS (ESI, $\left.\mathrm{CH}_{3} \mathrm{OH}\right) m / z(\%)$ :

IR $\left(\right.$ ATR, $\left.\mathrm{cm}^{-1}\right)$ :

${ }^{1} \mathrm{H}-\mathrm{NMR}\left(\mathrm{CDCl}_{3}\right) \delta$ :

${ }^{13} \mathrm{C}\left\{{ }^{1} \mathrm{H}\right\}\left(\mathrm{CDCl}_{3}\right) \delta:$

Elemental analysis:
$300 \mathrm{mg}, 69 \%$

$\mathrm{C}_{64} \mathrm{H}_{80} \mathrm{~N}_{8} \mathrm{O}_{12} \mathrm{Zn}_{4}$

$1414.9 \mathrm{~g} / \mathrm{mol}$.

$991.4(100 \%)\left[\mathrm{L}_{2} \mathrm{Zn}_{2}(\mathrm{MeOH})_{2}+\mathrm{H}\right]^{+}$.

2295 (br); 2916 (m); 1607 (vs); 1417 (vs); 1316 (s); 1210 (vs); 1031 (m); 851 (vs); 664 (vs).

1.69 (s, $\left.18 \mathrm{H}, \mathrm{CH}_{3}{ }^{\mathrm{OAg}}\right) ; 2.09\left(\mathrm{~s}, 24 \mathrm{H}, \mathrm{CH}_{3}{ }^{\mathrm{Ar}}\right) ; 2.18$ (s, $12 \mathrm{H}$; $\mathrm{CH}_{3} \mathrm{C}=\mathrm{N}$ ); 2.29 (s, $\left.12 \mathrm{H}, \mathrm{CH}_{3}{ }^{\mathrm{Ar}}\right) ; 2.62\left(\mathrm{~s}, 6 \mathrm{H}, \mathrm{CH}_{3}{ }^{\mathrm{P} z 4}\right) ; 6.87$ (br s, $\left.8 \mathrm{H}, \mathrm{CH}^{\mathrm{Ar}}\right)$.

$12.0\left(\mathrm{CH}_{3}{ }^{\mathrm{Pz} 4}\right) ; 17.9\left(\mathrm{CH}_{3}\right) ; 18.7\left(\mathrm{CH}_{3}\right) ; 20.8\left(\mathrm{CH}_{3}{ }^{\mathrm{Ar}}\right) ; 22.3\left(\mathrm{CH}_{3}{ }^{\mathrm{OAg}}\right)$; $118.7\left(\mathrm{CH}^{\mathrm{Ar}}\right) ; 128.7\left(\mathrm{C}^{\mathrm{Ar}}\right) ; 139.9\left(\mathrm{C}^{\mathrm{Ar}}\right) ; 165.8\left(\mathrm{CH}_{3} \mathrm{C}=\mathrm{N}\right) 179.5$ $\left(\mathrm{C}^{\mathrm{OAc}}\right)$.

Calcd. For $\mathrm{C}_{64} \mathrm{H}_{80} \mathrm{~N}_{8} \mathrm{O}_{12} \mathrm{Zn}_{4} \cdot \mathrm{CH}_{2} \mathrm{Cl}_{2}:(\mathrm{C}) 52.05$ (H) 5.51 (N) 7.47; Found: (C) $52.34(\mathrm{H}) 5.81(\mathrm{~N}) 7.67$. 


\section{8 Bis-cyclopentadienyl/indenyl/fluorenyl-tethered pyrazolyl ligands}

\subsection{Synthesis of $\mathrm{H}_{3} \mathrm{~L}^{5}$}

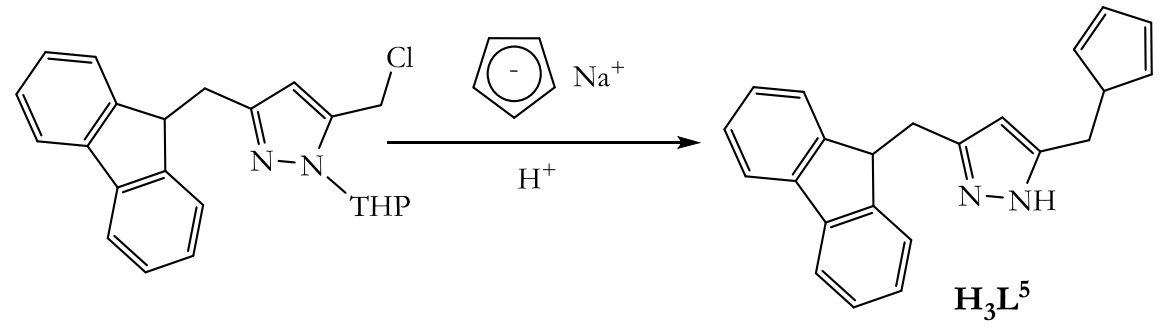

To a stirring THF solution $(15 \mathrm{~mL})$ of $\mathrm{NaCp}(0.17 \mathrm{~g}, 2.61 \mathrm{mmol})$ cooled to $-40^{\circ} \mathrm{C}$ was added via cannula, a THF solution of 3-((9H-fluoren-9-yl)methyl)-5-(chloromethyl)-1-(tetrahydro-2Hpyran-2-yl)-1H-pyrazole (1.02 g, $2.7 \mathrm{mmol})$. The reaction was warmed up to room temperature and stirred overnight. A dark brown solution was formed. The solvent was evaporated, redissolved in $\mathrm{CH}_{2} \mathrm{Cl}_{2}$, and washed with $\mathrm{H}_{2} \mathrm{O}(3 \times 5 \mathrm{~mL})$. The organic fraction was dried over $\mathrm{MgSO}_{4}$ and evaporated to dry. The orange solid obtained was re-dissolved in $\mathrm{C}_{2} \mathrm{H}_{5} \mathrm{OH}, 5 \mathrm{~mL}$ ethanolic $\mathrm{HCl}$ added and reflux for several days to complete THP deprotection. The product was obtained as an orange solid.

Yield

Molecular formula:

Molecular weight:

MS (EI) $m / z(\%)$ :

IR $\left(\right.$ ATR, $\left.\mathrm{cm}^{-1}\right)$ :

${ }^{1} \mathrm{H}-\mathrm{NMR}\left(\mathrm{CDCl}_{3}\right) \delta$ :

${ }^{13} \mathrm{C}\left\{{ }^{1} \mathrm{H}\right\}\left(\mathrm{CDCl}_{3}\right) \delta$ :
$890 \mathrm{mg}, 81 \%$

$\mathrm{C}_{23} \mathrm{H}_{20} \mathrm{~N}_{2}$

$324.5 \mathrm{~g} / \mathrm{mol}$.

$324(100 \%)[\mathrm{M}]^{+} ; 259(55 \%)[\mathrm{M}-\mathrm{Cp}]^{+}$.

2927 (br); 2949 (m); 1560 (w); 1533 (vs); 1419 (s);1255 (w); 1048

(m); $862(\mathrm{~s}) ; 750(\mathrm{~m})$.

$3.15\left(\mathrm{~d}, 3_{\mathrm{HH}}=6.9 \mathrm{~Hz}, 2 \mathrm{H}, \mathrm{CH}_{2}\right.$, pyrazol- $\left.\mathrm{CH}_{2}-\mathrm{Cp}\right) ; 3.27$ (d, $J=$ 6.8. $\mathrm{Hz}, 2 \mathrm{H}, \mathrm{CH}_{2}$, pyrazol- $\mathrm{CH}_{2}$-fluorene); 4.10 (t, ${ }^{3} \mathrm{~J}_{\mathrm{HH}}=6.8 \mathrm{~Hz}$, $1 \mathrm{H}, \mathrm{CH}, \mathrm{H}-1-\mathrm{Cp}) ; 4.30$ (t, ${ }^{3} J_{\mathrm{HH}}=6.9 \mathrm{~Hz}, 1 \mathrm{H}, \mathrm{CH}, \mathrm{H}-9$-fluorene); 5.96 (s, 1H, CH, H-4-pyrazol); 7.22-7.36 (m, 8H, CH, H-Ar); 7.707.74 ( $\mathrm{m}, 4 \mathrm{H}, \mathrm{CH}, \mathrm{H}-\mathrm{Cp}$ ); NH-not observed.

$30.8\left(\mathrm{CH}_{2}\right.$, pyrazol- $\mathrm{CH}_{2}$-fluorene $) ; 32.1\left(\mathrm{CH}_{2}\right.$, pyrazol- $\left.\mathrm{CH}_{2}-\mathrm{Cp}\right)$; 47.1 (CH, C-9-fluorene); 60.5, 61.0 (CH, C-1-Cp); 120.0 (CH, C4/C-5-fluorene); 124.1 (CH, C-1/C-8-fluorene); 127.2, 127.5 (CH, C-2/C-3/C-6/C-7-fluorene); 141.1 (C, C-4/fluorene); 146.3 (CH, C-2/C-3/C-4/C-5-Cp); 146.3 (C, C-3/C-5-pyrazol). 


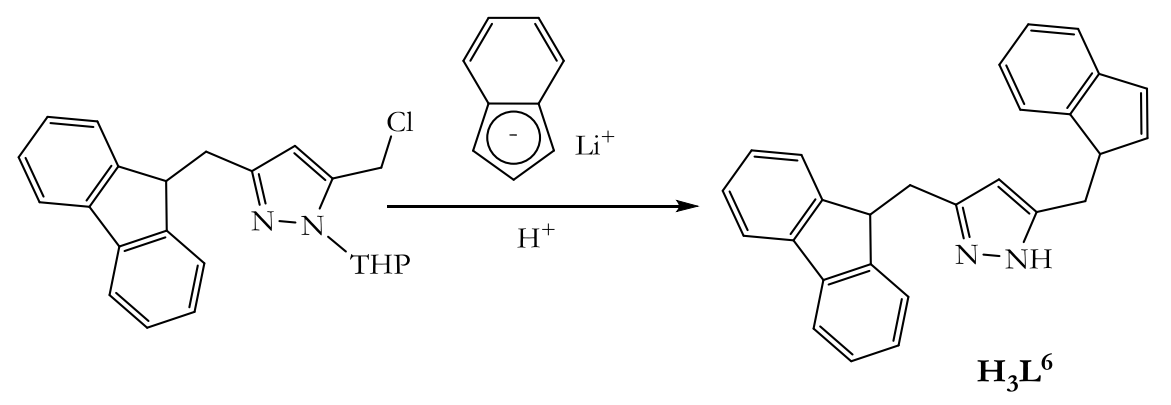

A lithium salt solution of indene was prepared by treating indene $(1 \mathrm{~mL}, 8.6 \mathrm{mmol})$ with $(3.4 \mathrm{~mL}$, $2.5 \mathrm{M} \mathrm{BuLi}, 8.5 \mathrm{mmol}$ ) at $-65^{\circ} \mathrm{C}$ and allowed to warm up to room temperature over $18 \mathrm{~h}$. To this red lithium salt solution was added dropwise 3-((9H-fluoren-9-yl)methyl)-5-(chloromethyl)-1(tetrahydro-2H-pyran-2-yl)-1H-pyrazole (3.2 g, $8.4 \mathrm{mmol}$ ) with stirring for $18 \mathrm{~h}$, after which the red colour was discharged. The reaction was quenched, followed by evaporation of all volatiles, which gave the THP protected product as a brown solid. This solid was dissolved in ethanol and $5 \mathrm{~mL}$ ethanolic $\mathrm{HCl}$ added. Complete deprotection was obtained after refluxing the ethanolic solution for several days. Addition of hexane to a concentrated $\mathrm{CH}_{2} \mathrm{Cl}_{2}$ solution of the ligand precipitates the ligand as an orange solid.

Yield:

Molecular formula:

Molecular weight:

MS (EI) $m / z(\%)$ :

IR (ATR, $\left.\mathrm{cm}^{-1}\right)$ :

${ }^{1} \mathrm{H}-\mathrm{NMR}\left(\mathrm{CDCl}_{3}\right) \delta$ :

${ }^{13} \mathrm{C}-\mathrm{NMR}\left(\mathrm{CDCl}_{3}\right) \delta$ :
$2.8 \mathrm{~g}, 89 \%$

$\mathrm{C}_{27} \mathrm{H}_{22} \mathrm{~N}_{2}$

$374.5 \mathrm{~g} / \mathrm{mol}$.

$374(100 \%)[\mathrm{M}]^{+}$.

2923 (br); 2957 (m); 1566 (w); 1533 (vs); 1424 (s);1255 (w); 1048 (m); $864(\mathrm{~s}) ; 756(\mathrm{~m})$.

$3.19\left(\mathrm{~d},{ }^{3} J_{\mathrm{HH}}=7.0 \mathrm{~Hz}, 2 \mathrm{H}, \mathrm{CH}_{2}, \mathrm{Pz}_{-} \mathrm{CH}_{2}\right.$-fluorene); 3.36 (s, $2 \mathrm{H}$, $\mathrm{CH}_{2}, \mathrm{H}-1$-indene); 3.87 (s, $2 \mathrm{H}, \mathrm{CH}_{2}$, pyrazol- $\mathrm{CH}_{2}$-indene); 4.27 (t, $1 \mathrm{H}, 3_{\mathrm{HH}}=6.9 \mathrm{~Hz}, \mathrm{CH}, \mathrm{H}-9$-fluorene); 5.84 (s, 1H, CH, H-4pyrazol); 6.17 (s, 1H, CH, H-2-indene); 7.13-7.42 (m, 12H, CH, $\left.\mathrm{CH}^{\mathrm{Ar}}\right) ; 7.47\left(\mathrm{~d},{ }^{3} J_{\mathrm{HH}}=6.9 \mathrm{~Hz}, 1 \mathrm{H}, \mathrm{CH}, \mathrm{H}-4\right.$-indene); 7.71 (d, $J_{\mathrm{HH}}$ $=7.6 \mathrm{~Hz}, 2 \mathrm{H}, \mathrm{CH}, \mathrm{H}-4 / \mathrm{H}-5$-fluorene).

$26.3\left(\mathrm{CH}_{2}\right.$, pyrazol- $\mathrm{CH}_{2}$-indene $) ; 30.9\left(\mathrm{CH}_{2}\right.$, pyrazol- $\mathrm{CH}_{2}{ }^{-}$ fluorene); 37.7 ( $\mathrm{CH}_{2}, \mathrm{C}-1$-indene); 47.3 (CH, C-9-fluorene); 104.4 (CH, C-4-pyrazol); 119.3 (CH, C-Ar); 120.0 (CH, C-4/C-5- 


\section{Experimetal}

fluorene); 123.7 (CH, C-4-indene); 124.5 (CH, C-Ar); 126.1 (CH, C-1/C-8-fluorene); 126.9 (CH, C-Ar); 127.0, 127.3 (CH, C-2/C3/C-6/C-7-fluorene); 130.0 (CH, C-2-indene); 140.9 (C, C-3indene); 141.4 (C, C-4-fluorene); 144.4, 144.7 (C, C-3/C-7indene); 146.3 (C, C-3/C-5-pyrazol).

The synthesis of $\mathbf{H L}^{7}$ and $\mathbf{H L}^{8}$ have already been reported and would not be covered here.

\section{9 Synthesis of trimethylsilyl derivatives}

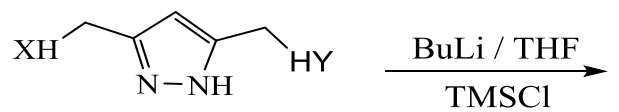

$\mathbf{H}_{3} \mathbf{L}^{\mathbf{5}}: \mathrm{X}=$ fluorenyl, $\mathrm{Y}=$ cyclopentadienyl

$\mathbf{H}_{3} \mathbf{L}^{6}: \mathrm{X}=$ fluorenyl, $\mathrm{Y}=$ indenyl

$\mathbf{H}_{3} L^{7}: X=$ fluorenyl, $Y=$ fluorenyl

$\mathbf{H}_{3} \mathbf{L}^{\mathbf{8}}: \mathrm{X}=$ indenyl,$\quad \mathrm{Y}=$ indenyl

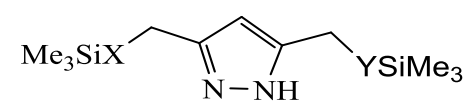

HL $^{9}: \mathrm{X}=$ fluorenyl, $\mathrm{Y}=$ indenyl
HL $^{\mathbf{1 0}}: \mathrm{X}=$ fluorenyl, $\mathrm{Y}=$ fluorenyl
HL $^{\mathbf{1 1}}: \mathrm{X}=$ indenyl, $\mathrm{Y}=$ indenyl

\section{General procedure for preparation of precursors}

A dry THF solution (20 mL) of 3-(fluoren-9-ylmethyl), 5-(inden-9-ylmethyl)-1H-pyrazol (HL') (0.59 g, $1.58 \mathrm{mmol}, 1.00 \mathrm{Eq}$.) was cooled to $-65^{\circ} \mathrm{C}$. To this was added $n$-BuLi (2.5 M, $1.9 \mathrm{~mL}, 4.7$ mmol, 3.0 Eq.), and the reaction gradually warmed to $0^{\circ} \mathrm{C}$. A dark red solution was formed which was allowed to stir further for $14 \mathrm{~h}$ at room temperature. To the dark red solution was added TMSCl (0.66 g, $4.7 \mathrm{mmol}, 3.0$ Eq.) dropwise. The red lithium salt solution was immediately discharged to a colourless solution. The reaction was allowed to stir at room temperature overnight. The solution was evaporated, redissolved in toluene and the off-white solid of $\mathrm{LiCl}$ filtered. The toluene solution was evaporated, to yield the product as an off-white crystalline solid. 


\subsection{Synthesis of $L^{9}$}

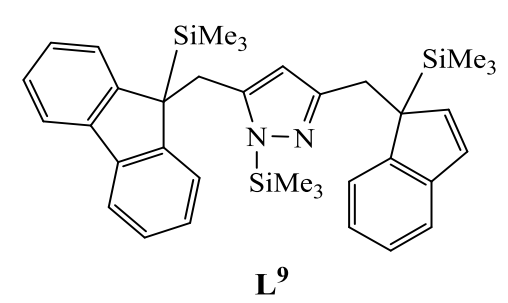

Using the general procedure, the product was obtained as an off-white crystalline solid.

Yield:

$250 \mathrm{mg}, 42 \%$

Molecular formula:

$\mathrm{C}_{36} \mathrm{H}_{40} \mathrm{~N}_{2} \mathrm{Si}_{3}$

Molecular weight:

$591.0 \mathrm{~g} / \mathrm{mol}$.

MS (EI) $m / z(\%)$ :

$590(65 \%)[\mathrm{M}]^{+} ; 519(100 \%)\left[\mathrm{M}-\mathrm{SiMe}_{3}\right]^{+}$.

IR $\left(\right.$ ATR, $\left.\mathrm{cm}^{-1}\right)$ :

3033 (br); 2959 (s); 1581 (s); 1436 (vs); 1444 (vs) 1249 (m); 1010 (m); 817 (m) 725 (vs); 622 (vs).

${ }^{1} \mathrm{H}-\mathrm{NMR}\left(\mathrm{CDCl}_{3}\right) \delta$ : -0.30 (s, 9H, $\left.\mathrm{SiMe}_{3}\right) ;-0.16$ (s, 9H, SiMe 3 ); -0.12 (s, 9H, $\mathrm{CH}_{3}$, $\mathrm{SiMe}_{3}$ ); 2.37 (s, $2 \mathrm{H}, \mathrm{CH}_{2}$, pyrazol- $\mathrm{CH}_{2}$-fluorene); 3.30 (s, $2 \mathrm{H}, \mathrm{CH}_{2}$, H-1-indene); 3.61 (s, $2 \mathrm{H}, \mathrm{CH}_{2}$, pyrazol- $\mathrm{CH}_{2}$-indene); $3.68(1 \mathrm{H}$, CH, H-9-fluorene); 6.02 (s, 1H, CH, H-2-indene); 7.00-7.85 (m, $\left.11 \mathrm{H}, \mathrm{CH}^{\mathrm{An}}\right)$.

${ }^{13} \mathrm{C}-\mathrm{NMR}\left(\mathrm{CDCl}_{3}\right) \delta$ :

-6.02 (C-SiMe 3$) ;-0.00\left(\mathrm{~N}_{3} \mathrm{SiMe}_{3}\right) ; 19.5\left(\mathrm{CH}_{2}\right.$, pyrazol- $\mathrm{CH}_{2}$-indene);

$24.2\left(\mathrm{CH}_{2}\right.$, pyrazol-CH${ }_{2}$-fluorene $) ; 26.2\left(\mathrm{CH}_{2}, \mathrm{C}-1\right.$-indene $) ; 42.6$ (C, C-9-fluorene); 102.0 (CH, C-4-pyrazol); 117.2-126.3 (CH, C ${ }^{\mathrm{Ar}}$ ); 127.0, 129.7 (CH, C-2/C-3/C-6/C-7-fluorene); 130.0 (CH, C-2indene); 138.4 (C, C-3-indene); 141.7 (C, C-4-fluorene); 144.0 (C, C-3/C-7-indene); 145.5 (C, C-3/C-5-pyrazole). 


\subsection{Synthesis of $L^{10}$}

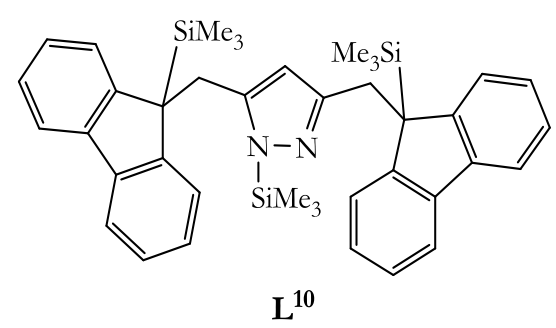

Following a similar synthetic procedure as done for the general procedure, using 3,5-Bis(fluoren9-ylmethyl)-1 $H$-pyrazol (HL $)$ (0.50 g, $1.2 \mathrm{mmol}, 1.00 \mathrm{Eq}$.) in dry THF (15 mL) with n-BuLi (2.5 M, $1.4 \mathrm{~mL}, 3.6 \mathrm{mmol}, 3.0 \mathrm{Eq}$.) and TMSCl (0.49 g, $3.6 \mathrm{mmol}, 3.0 \mathrm{Eq}$.$) . The product was obtained$ as a white crystalline solid.

Yield:

Molecular formula:

Molecular weight:

MS (EI) $m / z(\%)$ :

IR $\left(\right.$ ATR, $\left.\mathrm{cm}^{-1}\right)$ :

${ }^{1} \mathrm{H}-\mathrm{NMR}\left(\mathrm{CDCl}_{3}\right) \delta$ :

${ }^{13} \mathrm{C}\left\{{ }^{1} \mathrm{H}\right\}\left(\mathrm{CDCl}_{3}\right) \delta$ :
$310 \mathrm{mg}, 40 \%$

$\mathrm{C}_{40} \mathrm{H}_{48} \mathrm{~N}_{2} \mathrm{Si}_{3}$

$641.1 \mathrm{~g} / \mathrm{mol}$.

$640(100 \%)\left[\mathrm{M}^{+}\right] ; 568(40 \%)\left[\mathrm{M}-\mathrm{SiMe}_{3}\right]^{+}$.

3207 (m); 3039 (br); 3060 (s); 2955 (s); 1575 (s); 1437 (vs); 1447

(vs) 1249 (m); 1007 (m); 817 (m) 730 (vs); 623 (vs).

$-0.12,-0.28,-0.41$ (s, 27H, $\mathrm{CH}_{3}, \mathrm{SiMe}_{3}$ ); 3.25 (s, 4H, $\mathrm{CH}_{2}$, pyrazol$\mathrm{CH}_{2}$-fluorene); 3.35-3.90 (t, ${ }^{3} \mathrm{HH}_{\mathrm{HH}}=7 \mathrm{~Hz}, 2 \mathrm{H}, \mathrm{CH}, \mathrm{H}-9$-fluorene); $4.52\left(\mathrm{~s}, 1 \mathrm{H}, \mathrm{CH}^{\mathrm{Pz}}\right) ; 7.05-7.83\left(\mathrm{~m}, 14 \mathrm{H}, \mathrm{CH}^{\mathrm{Ar}}\right)$.

-2.04, -4.06 (C, $\left.\mathrm{SiMe}_{3}\right) ; 26.3\left(\mathrm{CH}_{2}\right.$, pyrazol- $\mathrm{CH}_{2}-$ fluorene); $47.7(\mathrm{C}$, C-9-fluorene); 102.6 (CH, C-4-pyrazol); 120.0 (CH, C-4/C-5fluorene); 123.0 (CH, C-1/C-8-fluorene); 125.8; 126.5 (CH, C2/C-3/C-6/C-7-fluorene); 139.9 (C, C-4a/C-4b-fluorene); 146.1 (C, C-3/C-5-pyrazol). 


\subsection{Synthesis of $\mathrm{HL}^{11}$}

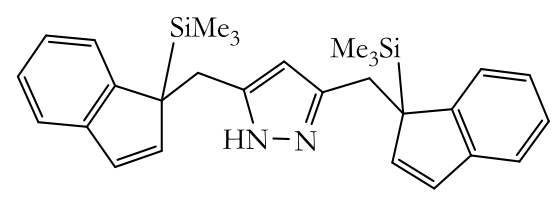

$\mathrm{HL}^{11}$

Following the general procedure a using a THF solution $(20 \mathrm{~mL})$ of 3,5-Bis(inden-9-ylmethyl)$1 H$-pyrazol $\left(\mathrm{HL}^{8}\right)$ (0.54 g, 1,7 mmol, 1.00 Eq.), with n-BuLi (2.5 M, 2.0 mL, 5.0 mmol, 3.0 Eq.) and TMSCl (0.70 g, $5.0 \mathrm{mmol}, 3.0 \mathrm{Eq}$.). The product was obtained as a light yellow powder

Yield:

Molecular formula:

Molecular weight:

EI (MS) $m / z(\%)$ :

IR $\left(\right.$ ATR, $\left.\mathrm{cm}^{-1}\right)$ :

${ }^{1} \mathrm{H}-\mathrm{NMR}\left(\mathrm{CDCl}_{3}\right) \delta$ :
$260 \mathrm{mg}, 33 \%$

$\mathrm{C}_{29} \mathrm{H}_{30} \mathrm{~N}_{2} \mathrm{Si}_{2}$

$468.8 \mathrm{~g} / \mathrm{mol}$.

$468(100 \%)[\mathrm{M}]^{+}$.

2929 (w); 2957 (m); 1566 (m); 1532 (s); 1424 (vs); 1255 (m); 1048 (m); 864 (vs); 756 (m).

-0.08 (s, 18H, SiMe 3 ); 3.41 (s, 4H, $\mathrm{CH}_{2}, \mathrm{H}-1$-indene); 3.57 (s, 4H, $\mathrm{CH}_{2}$, pyrazol- $\mathrm{CH}_{2}$-indene); 3.73 (s, $1 \mathrm{H}, \mathrm{CH}, \mathrm{H}-4$-pyrazol); 3.94 (s, 2H, CH, H-2-indene); 7.01-7.28 (m, 6H, $\left.\mathrm{CH}^{\mathrm{Ar}}\right) ; 7.51$ (s, 2H, CH, $\mathrm{H}$-4-indene). 


\section{10 Heteroleptic N-Heterocyclic carbene and fluorenyl/indenyl pyrazolyl tethered derivatives}

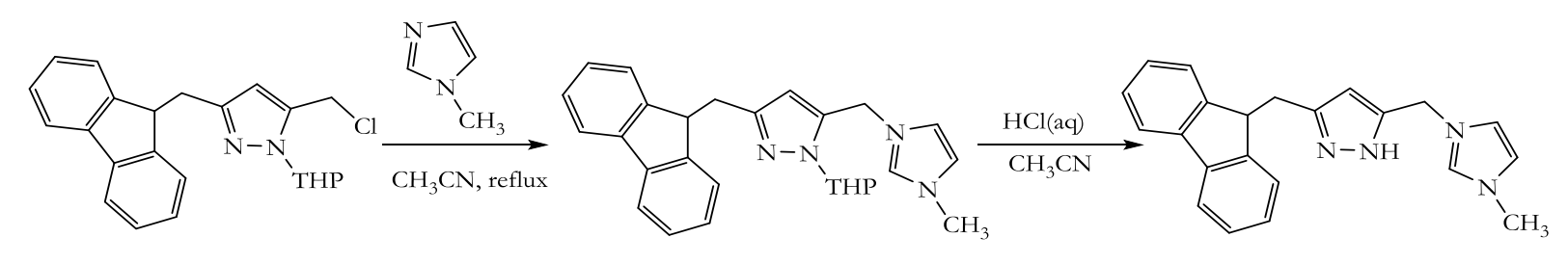

\section{General procedure:}

In a typical experiment, an acetonitrile solution $(40 \mathrm{~mL})$ of the mono substituted fluorenyl derivative 3-((9H-fluoren-9-yl)methyl)-5-(chloromethyl)-1-(tetrahydro-2H-pyran-2-yl)-1Hpyrazole $(0.75 \mathrm{~g}, 2.0 \mathrm{mmol})$ was added $0.50 \mathrm{~g}$ of $\mathrm{Na}_{2} \mathrm{CO}_{3}$. To this mixture was added methyl imidazole $(1 \mathrm{~mL}, 12.0 \mathrm{mmol})$ and the mixture was refluxed with stirring for $72 \mathrm{~h}$. After this period, the volatile components were removed under vacuum to obtain a yellow oil residue. This oil was dissolved in $5 \mathrm{~mL}$ of $\mathrm{CH}_{2} \mathrm{Cl}_{2}$ and $40 \mathrm{~mL}$ of petroleum ether added dropwise to precipitate a yellow oil once again. The petroleum ether was decanted and the yellow oil dried under vacuum to obtain a yellow solid. The resulting solid was dried azeotropically with toluene and isolated as a white powder, rapidly forming oil on exposure to air. The THP protection was removed by adding $5 \mathrm{~mL}$ of ethanolic $\mathrm{HCl}$ and refluxing the solution in $\mathrm{CH}_{3} \mathrm{CN}$ for $72 \mathrm{~h}$. The analytically pure THP free product precipitates out of solution, filtered and dried under vacuum for several hours.

\subsection{Synthesis of $\mathrm{H}_{3} \mathrm{~L}^{12}$}

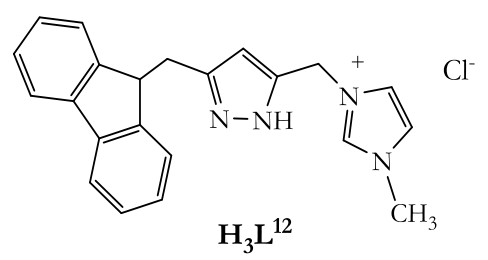

Using the general synthetic procedure, the product was obtained as a white hygroscopic solid.

Yield:

$150 \mathrm{mg}, 85 \%$

Molecular formula:

$\mathrm{C}_{22} \mathrm{H}_{21} \mathrm{~N}_{4} \mathrm{Cl}$ 


\section{Experimetal}

Molecular weight:

$376.9 \mathrm{~g} / \mathrm{mol}$.

MS (ESI, DMSO) $m / z(\%)$ :

EI:

$383(100 \%)[\mathrm{M}-\mathrm{Cl}+\mathrm{K}]^{+}$

IR $\left(\right.$ ATR, $\left.\mathrm{cm}^{-1}\right)$ :

$340(35 \%)[\mathrm{M}+\mathrm{H}-\mathrm{Cl}]^{+}, 326(100 \%)[\mathrm{M}-\mathrm{Me}-\mathrm{Cl}]^{+}$.

2922 (m); 1467 (m); 1344 (m); 1185(m); 1266 (s); 1003 (m); 751

(vs); $721(\mathrm{~m})$.

${ }^{1} \mathrm{H}\left(\mathrm{DMSO}-\mathrm{d}_{6}\right) \delta:$

$3.16\left(\mathrm{~d},{ }^{2} J_{\mathrm{HH}}=6 \mathrm{~Hz}, 2 \mathrm{H}, \mathrm{CH}_{2}\right) ; 3.87\left(\mathrm{~s}, 3 \mathrm{H}, \mathrm{CH}_{3}^{\text {Imdz }}\right) ; 4.33(\mathrm{t}, 1 \mathrm{H}$,

$\left.{ }^{3} J_{\mathrm{HH}}=6 \mathrm{~Hz}, \mathrm{CH}^{\text {Fluor }}\right) ; 5.35$ (s, 2H, Pz-CH$\left.-\mathrm{CH}_{2}-\mathrm{Imd}\right) ; 5.94$ (s, $1 \mathrm{H}$,

$\left.\mathrm{CH}^{\mathrm{P}_{\mathrm{z}}}\right) ; 7.2-7.87\left(\mathrm{~m}, 10 \mathrm{H}, \mathrm{CH}^{\mathrm{Ar}}\right) ; 9.20\left(\mathrm{~s}, 1 \mathrm{H}, \mathrm{CH}^{\mathrm{Imdz}}\right)$

${ }^{13} \mathrm{C}\left\{{ }^{1} \mathrm{H}\right\}\left(\mathrm{DMSO}-\mathrm{d}_{6}\right)$ 8: $28.9\left(\mathrm{Pz}_{-} \mathrm{CH}_{2}\right.$-fluorene) $34.1\left(\mathrm{~N}-\mathrm{CH}_{3}\right) ; 45.9\left(\mathrm{Pz}_{-}-\mathrm{CH}_{2}-\mathrm{Imdz}\right) ; 46.3$

$\left(\mathrm{CH}^{\text {Fluor }}\right) ; 103.3\left(\mathrm{CH}^{\mathrm{Pz} 4}\right) ; 124.5,126.9,127.3,136.5,140.3,143.2$, $144.5\left(C^{\mathrm{P}_{75}}\right), 146.0\left(\mathrm{C}^{\mathrm{P} 73}\right)$.

Elemental analysis : $\quad$ Calcd. For $\mathrm{C}_{22} \mathrm{H}_{21} \mathrm{ClN}_{4} \cdot \mathrm{HCl}$ (C) $63.93(\mathrm{H}) 5.36(\mathrm{~N})$ 13.55; Found: (C) $63.53(\mathrm{H}) 5.42(\mathrm{~N}) 13.46$.

\subsection{Synthesis of $\mathrm{H}_{3} \mathrm{~L}^{13}$}

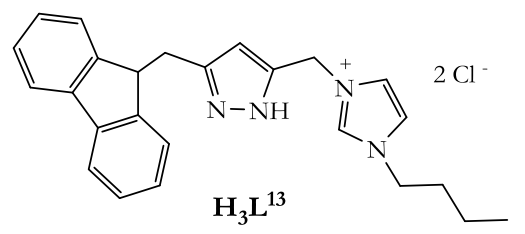

Using the general procedure, 3-((9H-fluoren-9-yl)methyl)-5-(chloromethyl)-1-(tetrahydro-2Hpyran-2-yl)-1H pyrazole $(3.0 \mathrm{~g}, 8.0 \mathrm{mmol})$ was treated with 1-butyl-1H-imidazole $(1.5 \mathrm{~g}, 12.0$ $\mathrm{mmol}$ ) in acetonitrile under refluxing conditions. The product obtained as a yellow hygroscopic oil.

Yield:

$2.1 \mathrm{~g}, 62 \%$

Molecular formula:

$\mathrm{C}_{25} \mathrm{H}_{28} \mathrm{~N}_{4} \mathrm{Cl}_{2}$

Molecular weight:

$455.3 \mathrm{~g} / \mathrm{mol}$.

MS (ESI, DMSO) $m / z(\%)$ :

$383(100 \%)[\mathrm{M}-\mathrm{Cl}]^{+}$.

IR $\left(\right.$ ATR, $\left.\mathrm{cm}^{-1}\right)$ :

3073 (m); 2933 (m); 2259 (m); 2251 (br); 1714 (br); 1594 (w); 1560

(s); 1447 (vs); 1287 (m); 1172 (s); 1158 (s); 1105 (m); 632 (m); 730 (vs); 754 (vs); 742 (s). 
${ }^{1} \mathrm{H}-\mathrm{NMR}\left(\mathrm{DMSO}-\mathrm{d}_{6}\right)$

${ }^{13} \mathrm{C}\left\{{ }^{1} \mathrm{H}\right\}\left(\mathrm{DMSO}-\mathrm{d}_{6}\right) \delta$

Elemental analysis :

\section{Experimetal}

$0.86\left(\mathrm{t}, 3_{\mathrm{HH}}=7.3 \mathrm{~Hz}, 3 \mathrm{H}, \mathrm{CH}_{3}\right) ; 1.13-1.39\left(\mathrm{~m}, 2 \mathrm{H}, \mathrm{CH}_{2}\right) ; 1.63-$ $1.88\left(\mathrm{~m}, 2 \mathrm{H}, \mathrm{CH}_{2}^{\mathrm{n}-\mathrm{Bu}}\right) ; 3.17\left(\mathrm{~d},{ }^{3} \mathrm{HH}_{\mathrm{HH}}=7.0 \mathrm{~Hz}, 2 \mathrm{H}, \mathrm{Pz}_{-} \mathrm{CH}_{2^{-}}\right.$ fluorene); $4.19\left(\mathrm{t}, J_{\mathrm{HH}}=7.1 \mathrm{~Hz}, 2 \mathrm{H}, \mathrm{CH}_{2}\right) ; 4.34\left(\mathrm{t}, 3_{\mathrm{HH}}=6.7 \mathrm{~Hz}\right.$, $1 \mathrm{H}, \mathrm{CH}^{\text {Fluor }}$ ); 5.37 (s, 2H, Pz-CH$-\mathrm{Imdz}$ ); 5.95 (s, 1H, $\left.\mathrm{CH}^{\mathrm{Pz} 4}\right) ; 7.02-$ $7.99\left(\mathrm{~m}, 10 \mathrm{H}, \mathrm{H}^{\mathrm{Imdz}}-\mathrm{Ar}^{\mathrm{H}}\right) ; 7.84\left(\mathrm{~d}, 3_{\mathrm{HH}}=7.6 \mathrm{~Hz}, 2 \mathrm{H}, \mathrm{CH}^{\text {Fluor }}\right)$; $9.41\left(\mathrm{~s}, 1 \mathrm{H}, \mathrm{CH}^{\mathrm{Imd}}\right)$.

:13.2 ( $\left.\left(\mathrm{CH}_{3} \mathrm{CH}_{2}\right)^{-}\right) ; 18.1\left(\mathrm{CH}_{2} \mathrm{CH}_{2} \mathrm{CH}_{3}\right) ; 29.0$ (fluorene- $\left.\mathrm{CH}_{2}-\mathrm{Pz}\right) ; 31.4$ $\left(-\mathrm{CH}_{2} \mathrm{CH}_{2} \mathrm{CH}_{2}-\right) ; 45.9\left(\mathrm{Pz}_{-} \mathrm{CH}_{2}-\mathrm{Imdz}\right) ; 46.3\left(\mathrm{CH}^{\text {Fluor }}\right) ; 48.6(\mathrm{~N}-$ $\left.\mathrm{CH}_{2} \mathrm{CH}_{2^{-}}\right) ; 103.4\left(\mathrm{CH}^{\mathrm{Pz} 4}\right) ; 120.0 ; 122.5\left(\mathrm{CH}^{\mathrm{Ar}}\right) ; 124.5\left(\mathrm{CH}^{\mathrm{Ar}}\right) ; 126.9$ $\left(\mathrm{CH}^{\mathrm{Ar}}\right) ; 127.3 ; 136.1\left(\mathrm{CH}^{\mathrm{Imd}}\right) ; 140.3 ; 143.4 ; 144.2\left(\mathrm{C}^{\mathrm{P} z 5}\right) ; 146.0$ $\left(\mathrm{C}^{\mathrm{Pz} 3}\right)$.

Calcd. For $\mathrm{C}_{25} \mathrm{H}_{27} \mathrm{ClN}_{4} \cdot \mathrm{H}_{2} \mathrm{O} \cdot \mathrm{HCl}$ : (C) $64.65(\mathrm{H}) 6.29$ (N) 12.06; Found: (C) $63.81(\mathrm{H}) 6.11(\mathrm{~N}) 12.66$.

\subsection{Synthesis of $\mathrm{H}_{3} \mathrm{~L}^{14}$}

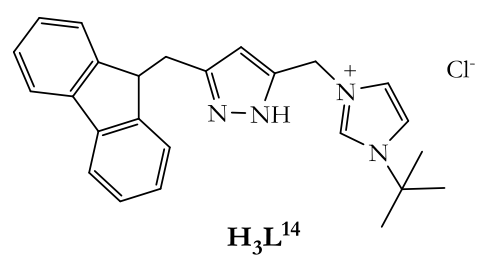

Using 3-((9H-fluoren-9-yl)methyl)-5-(chloromethyl)-1-(tetrahydro-2H-pyran-2-yl)-1H pyrazole (4.0 g, $10.0 \mathrm{mmol})$ with 1-tert butyl-1H-imidazole $(2.0 \mathrm{~g}, 15.0 \mathrm{mmol})$ in acetonitrile under refluxing for a week. The product obtained as a pale yellow solid.

Yield: $1.5 \mathrm{~g}, 30 \%$

Molecular formula: $\mathrm{C}_{25} \mathrm{H}_{27} \mathrm{~N}_{4} \mathrm{Cl}$

Molecular weight: $419.0 \mathrm{~g} / \mathrm{mol}$.

MS (ESI, DMSO) m/z (\%): $383(100 \%)\left[\mathrm{M}-\mathrm{Cl}^{+}, 327(27 \%)\left[\mathrm{M}-{ }^{\mathrm{t}} \mathrm{Bu}-\mathrm{Cl}\right]^{+}, 259(11 \%)[\mathrm{M}-\mathrm{Imdz}-\right.$ $\mathrm{Cl}]^{+}$.

IR $\left(\right.$ ATR, $\left.\mathrm{cm}^{-1}\right)$ :

3167 (br); 2983 (m); 1551 (m); 1449 (m); 1379 (s); 1232 (m); 1220 (s); 1127 (s); 829 (vs); 739 (vs) 557 (vs). 
${ }^{1} \mathrm{H}-\mathrm{NMR}\left(\mathrm{DMSO}_{-} \mathrm{d}_{6}\right)$ 8: $1.59\left(\mathrm{~s}, 9 \mathrm{H}, \mathrm{CH}_{3}{ }^{\mathrm{tBu}}\right) ; 3.18\left(\mathrm{~d},{ }^{3} \mathrm{~J}_{\mathrm{HH}}=6.9 \mathrm{~Hz}, 2 \mathrm{H}\right.$, fluorene- $\left.\mathrm{CH}_{2}-\mathrm{Pz}\right)$; $4.34\left(\mathrm{t}, 3_{\mathrm{HH}}=6.9 \mathrm{~Hz}, 1 \mathrm{H}\right.$, fluorene- $\left.\mathrm{CH}_{2}-\mathrm{Pz}\right) ; 5.34$ (s, 2H, Imdz$\left.\mathrm{CH}_{2}-\mathrm{Pz}\right) ; 5.94\left(\mathrm{~s}, 1 \mathrm{H}, \mathrm{CH}^{\mathrm{Pz}}\right) ; 7.20-7.40\left(\mathrm{~m}, 6 \mathrm{H}, \mathrm{CH}^{\text {Fluor }}\right) ; 7.67$ (t, $\left.1 \mathrm{H},{ }^{4} J_{\mathrm{HH}}=1.8 \mathrm{~Hz}, \mathrm{CH}^{\mathrm{Imdz}}\right) ; 7.85\left(\mathrm{~d},{ }^{3} J_{\mathrm{HH}}=7.5 \mathrm{~Hz}, 2 \mathrm{H}, \mathrm{CH}^{\text {Fluor }}\right.$; $8.06\left(\mathrm{t},{ }^{4} J_{\mathrm{HH}}=1.8 \mathrm{~Hz}, 1 \mathrm{H}, \mathrm{CH}^{\mathrm{Imdz}}\right) ; 9.56\left(\mathrm{t},{ }^{4} \mathrm{~J}_{\mathrm{HH}}=1.8 \mathrm{~Hz}, 1 \mathrm{H}\right.$, $\left.\mathrm{CH}^{\mathrm{Imd}}\right) ; 15.08\left(\mathrm{~s}, 1 \mathrm{H}, \mathrm{NH}^{\mathrm{p} z}\right)$.

${ }^{13} \mathrm{C}\left\{{ }^{1} \mathrm{H}\right\}\left(\mathrm{DMSO}-\mathrm{d}_{6}\right): \quad 29.0\left(\mathrm{CH}_{3}{ }^{\mathrm{tBu}}\right) ; 29.1$ (fluorene- $\left.\mathrm{CH}_{2}-\mathrm{Pz}\right) ; 46.0\left(\mathrm{Imdz}_{-} \mathrm{CH}_{2}-\mathrm{Pz}\right) ; 46.4$ (fluorene- $\left.\mathrm{CH}_{2}-\mathrm{Pz}\right) ; 54.9,103.3\left(\mathrm{CH}^{\mathrm{Pz}}\right) ; 120.0,120.4,122.5,124.5$, $\left.126.9,127.3,133.3,134.6\left(\mathrm{CH}^{\mathrm{Imd} z}\right) ; 140.3,143.2,144.4,145.3 \mathrm{C}^{\mathrm{P} z 5}\right)$, $146.1\left(C^{\mathrm{Pz} 3}\right)$.

\subsection{Synthesis of $\mathrm{H}_{3} \mathrm{~L}^{15}$}

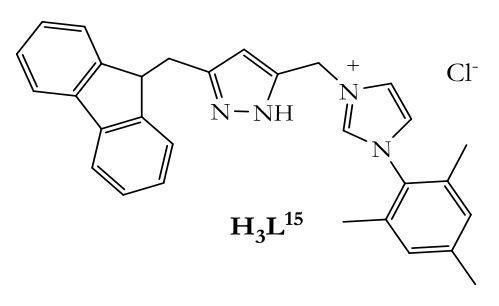

Using 3-((9H-fluoren-9-yl)methyl)-5-(chloromethyl)-1-(tetrahydro-2H-pyran-2-yl)-1H pyrazole $(2.0 \mathrm{~g}, 15.0 \mathrm{mmol})$ with 1-mesityl-1H-imidazole $(1.5 \mathrm{~g}, 12.0 \mathrm{mmol})$ in acetonitrile under refluxing conditions for several days. Product was obtained as a white solid.

Yield:

$4.81 \mathrm{~g}, 90 \%$

Molecular formula:

$\mathrm{C}_{30} \mathrm{H}_{30} \mathrm{~N}_{4} \mathrm{Cl}$

Molecular weight:

$482.1 \mathrm{~g} / \mathrm{mol}$.

MS (ESI, DMSO) $m / z(\%)$ :

$445.1(100 \%)[\mathrm{M}-\mathrm{Cl}]^{+}$.

IR $\left(\mathrm{ATR}, \mathrm{cm}^{-1}\right)$ :

3429 (m); 2955 (m); 1572 (m); 1549 (m); 1447 (s); 1205 (vs); 1158 (m); 1005 (m); 870 (vs); 774 (vs); 759 (vs); 745 (vs); 731 (m).

${ }^{1} \mathrm{H}-\mathrm{NMR}\left(\mathrm{DMSO}_{-} \mathrm{d}_{6}\right)$ 8: $2.01\left(\mathrm{~s}, 6 \mathrm{H}, \mathrm{CH}_{3}\right) ; 2.34\left(\mathrm{~s}, 3 \mathrm{H}, \mathrm{CH}_{3}\right) ; 3.20\left(\mathrm{~d},{ }^{3} \mathrm{HH}_{\mathrm{HH}}=6.9 \mathrm{~Hz}, 2 \mathrm{H}\right.$, fluorene- $\mathrm{CH}_{2}-\mathrm{pz}$ ); 4.34 (t, 1H, CH ${ }^{\mathrm{Fluor}}$ ); 5.47 (s, 2H, Imdz- $\mathrm{CH}_{2}-\mathrm{Pz}$ ); $5.97\left(\mathrm{~s}, 1 \mathrm{H}, \mathrm{CH}^{\mathrm{Pz} 4}\right) ; 7.16\left(\mathrm{~s}, 3 \mathrm{H}, \mathrm{CH}^{\mathrm{Ar}}\right) ; 7.25-7.39\left(\mathrm{~m}, 8 \mathrm{H}, \mathrm{CH}^{\mathrm{Ar}}\right)$; $7.83\left(\mathrm{~d},{ }^{3} J_{\mathrm{HH}}=1.9 \mathrm{~Hz}, 1 \mathrm{H}, \mathrm{CH}^{\mathrm{Imd}}\right) ; 7.95\left(\mathrm{~s}, 1 \mathrm{H}, \mathrm{CH}^{\mathrm{Imd}}\right) ; 9.56(\mathrm{~s}$, $\left.1 \mathrm{H}, \mathrm{CH}^{\mathrm{Imdz}}\right) ; 13.01$ (s, $\left.1 \mathrm{H}, \mathrm{NH}^{\mathrm{Pyz}}\right)$. 
${ }^{13} \mathrm{C}\left\{{ }^{1} \mathrm{H}\right\}\left(\mathrm{DMSO}-\mathrm{d}_{6}\right) \delta:$

Elemental analysis :
$16.7\left(\mathrm{o}-\mathrm{CH}_{3}{ }^{\mathrm{Mes}}\right) ; 20.4$ (p- $\left.\mathrm{CH}_{3}{ }^{\mathrm{Mes}}\right) ; 28.5$ (fluorene- $\left.\mathrm{CH}_{2}-\mathrm{Pz}\right) ; 46.2$ (fluorene- $\left.\mathrm{CH}_{2}-\mathrm{Pz}\right) ; 46.8$ (Imdz-CH$\left.-\mathrm{Pz}\right) ; 102.5\left(\mathrm{CH}^{\mathrm{pz}}\right) ; 120.0$, $123.2\left(\mathrm{CH}^{\mathrm{Ar}}\right), 123.9\left(\mathrm{CH}^{\mathrm{Ar}}\right), 124.5\left(\mathrm{CH}^{\mathrm{Ar}}\right), 126.9\left(\mathrm{CH}^{\mathrm{Ar}}\right), 127.3$ $\left(\mathrm{CH}^{\mathrm{Ar}}\right), 129.3\left(\mathrm{CH}^{\mathrm{Ar}}\right), 131.2,134.3,137.5\left(\mathrm{CH}^{\mathrm{Imd} z}\right) ; 140.3,140.4$, $145.4\left(\mathrm{C}^{\mathrm{Pz} 5}\right), 146.0\left(\mathrm{C}^{\mathrm{Pz} 3}\right)$.

Calcd. For $\mathrm{C}_{30} \mathrm{H}_{29} \mathrm{ClN}_{4}$ : (C) $74.91(\mathrm{H}) 6.23(\mathrm{~N})$ 11.65; Found: (C) 74.30; (H) $5.97(\mathrm{~N}) 11.66$.

\subsection{Synthesis of $\mathrm{H}_{3} \mathrm{~L}^{16}$}

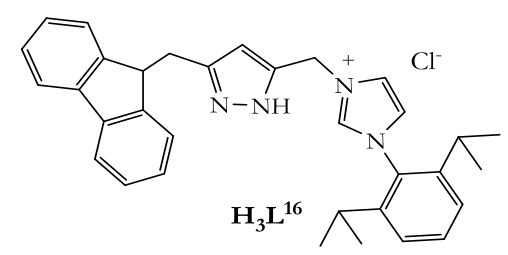

Using 3-((9H-fluoren-9-yl)methyl)-5-(chloromethyl)-1-(tetrahydro-2H-pyran-2-yl)-1H-pyrazole $(1.2 \mathrm{~g}, 3.1 \mathrm{mmol}, 1 \mathrm{eq})$ and 1-(2,6-diisopropylphenyl)-1H-imidazole (1.0 g, $4.1 \mathrm{mmol}, 1.3 \mathrm{eq})$ dissolved in acetonitrile $(15 \mathrm{~mL})$ and refluxed for 5 days. The solution was cooled to $90^{\circ} \mathrm{C}$ and ethanolic $\mathrm{HCl}$ added and refluxing continued. The reaction solution after cooling was added dropwide to diethyl ether in a beaker to precipitate the crude. The product was purified by the sublimation of unreacted imidazole precursor and obtained as a white solid.

Yield:

$$
0.48 \mathrm{~g}, 25 \%
$$

Molecular formula:

$\mathrm{C}_{33} \mathrm{H}_{35} \mathrm{~N}_{4} \mathrm{Cl}$

Molecular weight:

$523.2 \mathrm{~g} / \mathrm{mol}$.

MS (ESI, DMSO) $m / z(\%)$ :

$487(100 \%)[\mathrm{M}-\mathrm{Cl}]^{+}$.

IR $\left(\right.$ ATR, $\left.\mathrm{cm}^{-1}\right)$ :

3430 (s); 3173 (m); 1480 (m); 1462 (m); 1378 (m); 1199 (m); 1126 (m); 826 (vs); 737 (vs); 558 (vs).

${ }^{1} \mathrm{H}-\mathrm{NMR}\left(\mathrm{CDCl}_{3}\right) \delta$

$1.07\left(\mathrm{~d},{ }^{3} J_{\mathrm{HH}}=6.8 \mathrm{~Hz}, 6 \mathrm{H}, \mathrm{CH}_{3}{ }^{2 \mathrm{Pr}}\right) ; 1.12\left(\mathrm{~d},{ }^{3} J_{\mathrm{HH}}=6.8 \mathrm{~Hz}, 6 \mathrm{H}\right.$, $\left.\mathrm{CH}_{3}^{i \mathrm{Pr}}\right) ; 2.19\left(\mathrm{sept}, J_{\mathrm{HH}}=6.8 \mathrm{~Hz}, 2 \mathrm{H}, \mathrm{CH}^{i \mathrm{PP}}\right) ; 3.28\left(\mathrm{~d},{ }^{3} J_{\mathrm{HH}}=6.5\right.$ $\mathrm{Hz}, 2 \mathrm{H}$, fluorene- $\left.\mathrm{CH}_{2} \mathrm{Pz}\right) ; 4.31\left(\mathrm{t},{ }^{3} \mathrm{~J}_{\mathrm{HH}}=6.4 \mathrm{~Hz}, 2 \mathrm{H}\right.$, fluorene$\mathrm{CH}_{2}$-Imdz); 5.85 (s, 2H, Pz-CH$\left.-\mathrm{Imdz}\right) ; 5.96$ (s, 1H, $\mathrm{CH}^{\mathrm{Pz}}$ ); 7.05 (s, $\left.1 \mathrm{H}, \mathrm{CH}^{\mathrm{Ar}}\right)$; 7.16-7.77 (m, 12H, $\left.\mathrm{CH}^{\mathrm{Imdz}}, \mathrm{CH}^{\mathrm{Ar}}\right) ; 10.18$ (s, $1 \mathrm{H}$, $\left.\mathrm{CH}^{\mathrm{Imdz}}\right)$. 


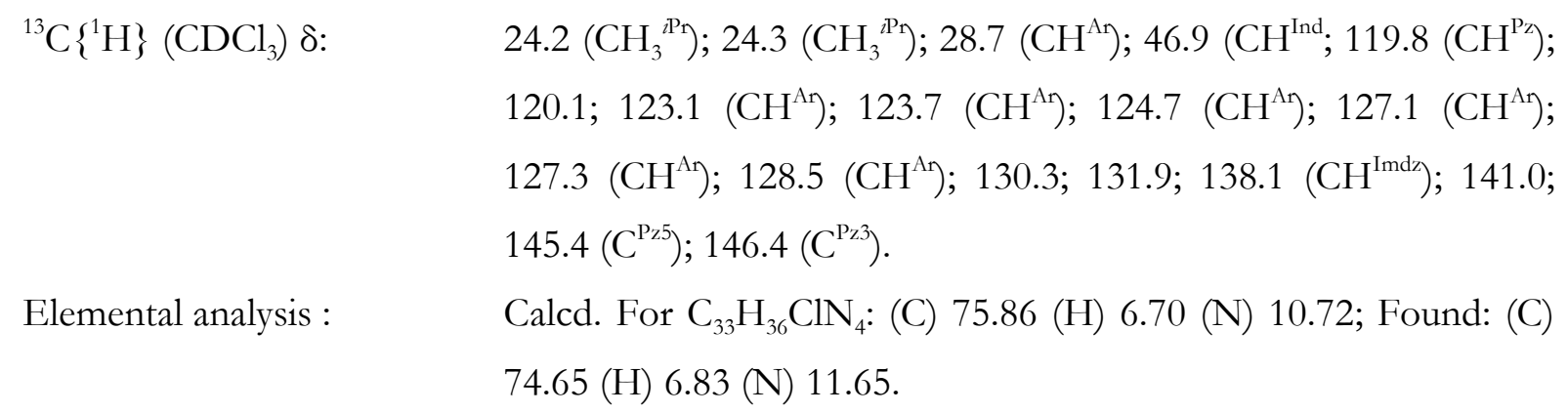

Elemental analysis : $\quad$ Calcd. For $\mathrm{C}_{33} \mathrm{H}_{36} \mathrm{ClN}_{4}$ : (C) $75.86(\mathrm{H}) 6.70(\mathrm{~N})$ 10.72; Found: (C) $74.65(\mathrm{H}) 6.83(\mathrm{~N}) 11.65$.

\subsection{Synthesis of $\mathrm{H}_{3} \mathrm{~L}^{17}$}

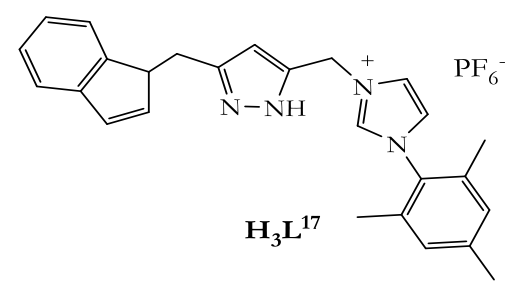

Using 3-((1H-inden-1-yl)methyl)-5-(chloromethyl)-1-(tetrahydro-2H-pyran-2-yl)-1H-pyrazole (1.2 g, $3.2 \mathrm{mmol}, 1 \mathrm{Eq}$ ) and 1-mesityl-1H-imidazole (0.6 g, $3.2 \mathrm{mmol}, 1.0 \mathrm{Eq}$.$) dissolved in$ acetonitrile $(10 \mathrm{~mL})$ under reflux for 5 days. A $28 \%$ aqueous ammonia solution $(2 \mathrm{~mL})$ was added and the mixture and the solution treated with $\mathrm{NH}_{4} \mathrm{PF}_{6}(0.6 \mathrm{~g}, 3.2 \mathrm{mmol}, 1 \mathrm{Eq}$.). The reaction mixture was washed with water $(3 \times 5 \mathrm{~mL})$ and the organic phase dried over $\mathrm{MgSO}_{4}$. This was added dropwise to $\mathrm{Et}_{2} \mathrm{O}$ to precipitate the solid. The precipitate was washed with $\mathrm{Et}_{2} \mathrm{O}(3 \times 3$ $\mathrm{mL}$ ) and dried in vacuum. The product was obtained as a colourless solid.

Yield:

$0.10 \mathrm{~g}, 6 \%$

Molecular formula:

$\mathrm{C}_{26} \mathrm{H}_{26} \mathrm{~N}_{4} \mathrm{PF}_{6}$

Molecular weight:

$539.5 \mathrm{~g} / \mathrm{mol}$.

MS (ESI, DMSO) m/z (\%): $395.1(100 \%) \quad\left[\mathrm{M}-\mathrm{PF}_{6}\right]^{+}, 233.2(7 \%) \quad[\mathrm{M}-\mathrm{Imdz}]^{+}, 187.1$ (13\%) $[\mathrm{Imd} z]^{+}$.

IR (ATR, $\left.\mathrm{cm}^{-1}\right)$ : $\quad 3139(\mathrm{~m}) ; 1551(\mathrm{~m}) ; 1447(\mathrm{~m}) ; 1162(\mathrm{~s}) ; 1203(\mathrm{~s}) ; 1030$ (s); 840 (vs); 559 (s).

${ }^{1} \mathrm{H}-\mathrm{NMR}\left(\mathrm{DMSO}-d_{6}\right) \delta: \quad 2.03\left(\mathrm{~s}, 6 \mathrm{H}, \mathrm{o}-\mathrm{CH}_{3}{ }^{\mathrm{Mes}}\right) ; 2.33\left(\mathrm{~s}, 3 \mathrm{H}, \mathrm{p}-\mathrm{CH}_{3}{ }^{\mathrm{Mes}}\right) ; 2.86-2.97$ (m, 2H, indene- $\left.\mathrm{CH}_{2}-\mathrm{pz}\right) ; 3.05-3.12(\mathrm{~m}, 2 \mathrm{H}, \mathrm{CH}) ; 5.56$ (s, 2H, Imdz-CH $2^{-}$ pz); 6.54 (s, 1H, Imdz-CH-pz); 6.93 (s, 1H, indene); 7.12-7.38 (m, $4 \mathrm{H})$; 7.56-7.64 (m, 1H, indene); $7.95\left(\mathrm{t},{ }^{4} J_{\mathrm{HH}}=1.8 \mathrm{~Hz}, 1 \mathrm{H}, \mathrm{CH}^{\mathrm{Imd} z}\right)$; $8.10\left(\mathrm{t},{ }^{4} J_{\mathrm{HH}}=1.8 \mathrm{~Hz}, 1 \mathrm{H}, \mathrm{CH}^{\mathrm{Imd} z}\right) ; 9.62\left(\mathrm{~s}, 1 \mathrm{H}, \mathrm{CH}^{\mathrm{Imd} z}\right) ; 13.10(\mathrm{~s}$, $1 \mathrm{H}, \mathrm{NH}^{\mathrm{p}}$ ). 
${ }^{13} \mathrm{C}\left\{{ }^{1} \mathrm{H}\right\}\left(\mathrm{DMSO}-d_{6}\right) \delta:$

Elemental analysis:
$16.9\left(\mathrm{o}-\mathrm{CH}_{3}{ }^{\mathrm{Mes}}\right) ; 20.6 \quad\left(\mathrm{p}-\mathrm{CH}_{3}{ }^{\mathrm{Mes}}\right) ; 29.9$ (indene- $\left.\mathrm{CH}_{2}-\mathrm{Pz}\right)$; 30.0 (indene-CH-Pz); 46.9 ( $\left.\mathrm{Imdz}_{-} \mathrm{CH}_{2}-\mathrm{Pz}\right) ; 102.6\left(\mathrm{CH}^{\text {ind }}\right) ; 105.2$ $\left(\mathrm{CH}^{\mathrm{P}_{2}}\right) ; 120.1,123.5\left(\mathrm{CH}^{\mathrm{An}}\right), 123.9\left(\mathrm{CH}^{\mathrm{An}}\right), 125.4\left(\mathrm{CH}^{\mathrm{An}}\right), 126.8$ $\left(\mathrm{CH}^{\mathrm{Ar}}\right), 128.7,129.2,131.2,134.2\left(\mathrm{CH}^{\mathrm{Imd}}\right) ; 137.82,140.2,140.7$, 141.9, $147.3\left(\mathrm{C}^{\mathrm{P} z 3}\right), 148.3,152.5\left(\mathrm{C}^{\mathrm{Ar}}\right) ; 155.8\left(\mathrm{C}^{\mathrm{Ar}}\right)$.

Calcd. For $\mathrm{C}_{33} \mathrm{H}_{36} \mathrm{ClN}_{4}$ : C (78.99) H (6.58) N (12.70); Found: C (70.65) H (6.43) N (26.01).

\subsection{Synthesis of $\mathrm{H}_{3} \mathrm{~L}^{18}$}

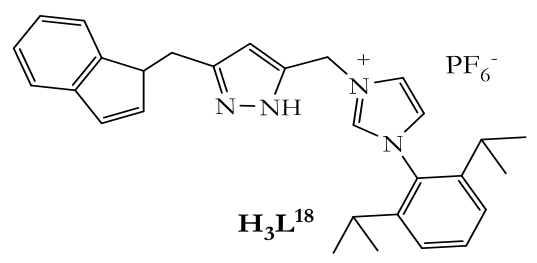

Using 3-((1H-inden-1-yl)methyl)-5-(chloromethyl)-1-(tetrahydro-2H-pyran-2-yl)-1H-pyrazole (1.2 g, $3.2 \mathrm{mmol}, 1 \mathrm{Eq}$.) and 1-(2,6-diisopropylphenyl)-1H-imidazole (0.6 g, $3.2 \mathrm{mmol}, 1.0$ Eq.) dissolved in acetonitrile $(10 \mathrm{~mL})$ with refluxing for 5 days. A $10 \%$ ammonia solution $(2 \mathrm{~mL})$ was added and the mixture treated with $\mathrm{NH}_{4} \mathrm{PF}_{6}(0.6 \mathrm{~g}, 3.2 \mathrm{mmol}, 1 \mathrm{Eq}$.). The organic phase was washed with water $(7 \mathrm{~mL})$ and dried over $\mathrm{MgSO}_{4}$. This solution was added dropwise to $\mathrm{Et}_{2} \mathrm{O}$. The product precipitated was filtered and dried in vacuum. The product was obtained as a colourless solid

Yield:

Molecular formula:

Molecular weight:

IR (ATR, $\left.\mathrm{cm}^{-1}\right)$ :

${ }^{1} \mathrm{H}-\mathrm{NMR}\left(\mathrm{DMSO}-d_{6}\right) \delta$ :
$0.54 \mathrm{~g}, 36 \%$

$\mathrm{C}_{29} \mathrm{H}_{33} \mathrm{~N}_{4} \mathrm{Cl}$

$473.1 \mathrm{~g} / \mathrm{mol}$.

2998 (s); 2962 (s); 1450 (vs); 1369 (m); 1108 (m); 1339 (m); 1186 (vs); 1003 (m); 730 (vs); 743 (vs).

1.05-1.02 (m, 12H, $\left.\mathrm{CH}_{3}{ }^{\mathrm{PP}}\right)$; 2.88-2.97 (m, 2H, $\left.\mathrm{CH}^{\mathrm{PPr}}\right)$; 3.07-3.14 (m, $2 \mathrm{H}$, Ind- $\mathrm{CH}_{2}-\mathrm{Pz}$ ); 3.93 (m, 1H, Ind-CH-Pz); 5.60 (s, 2H, Imdz$\left.\mathrm{CH}_{2}-\mathrm{Pz}\right) ; 6.53$ (s, $1 \mathrm{H}, \mathrm{CH}^{\mathrm{P}}$ ); 6.94 (m, 1H, $\left.\mathrm{CH}^{\mathrm{Imd}}\right) ; 7.20-7.70(\mathrm{~m}$, $\left.8 \mathrm{H}, \mathrm{CH}^{\mathrm{Imdz}}, \mathrm{CH}^{\mathrm{Ar}}\right)$; 8.03-8.13 (m, 2H, $\left.\mathrm{CH}^{\mathrm{Ar}}\right)$; $9.62\left(\mathrm{~s}, 1 \mathrm{H}, \mathrm{CH}^{\mathrm{Imd} z}\right)$; $13.03\left(\mathrm{~s}, 1 \mathrm{H}, \mathrm{NH}^{\mathrm{P}}\right)$.

${ }^{13} \mathrm{C}\left\{{ }^{1} \mathrm{H}\right\}\left(\mathrm{DMSO}-d_{6}\right) \delta: \quad 23.8\left(\mathrm{CH}_{3}{ }^{\mathrm{iPr}}\right) ; 28.1\left(\mathrm{CH}^{\mathrm{IPr}}\right) ; 29.9$ (Ind- $\left.\mathrm{CH}_{2}-\mathrm{pz}\right) ; 37.3$ (Ind-CH-pz); 47.0 (Imdz-CH $-\mathrm{Pz}) ; 104.86\left(\mathrm{CH}^{\mathrm{pz}}\right) ; 120.2,123.8\left(\mathrm{CH}^{\mathrm{An}}\right), 124.5$ 
Experimetal

$\left(\mathrm{CH}^{\mathrm{An}}\right), 125.1\left(\mathrm{CH}^{\mathrm{An}}\right), 125.5\left(\mathrm{CH}^{\mathrm{An}}\right), 126.9\left(\mathrm{CH}^{\mathrm{An}}\right), 130.5,130.6$, 131.5, $138.2\left(\mathrm{CH}^{\mathrm{Imdz}}\right) ; 145.1\left(\mathrm{C}^{\mathrm{Pz} 3}\right)$.

\subsection{Synthesis of $\left[\mathrm{H}_{3} \mathrm{~L}^{14}{ }_{2} \mathrm{Rh}_{2}(\mathrm{OAc})_{4}\right]\left(\mathrm{PF}_{6}\right)_{2}(4 \mathrm{f})$}

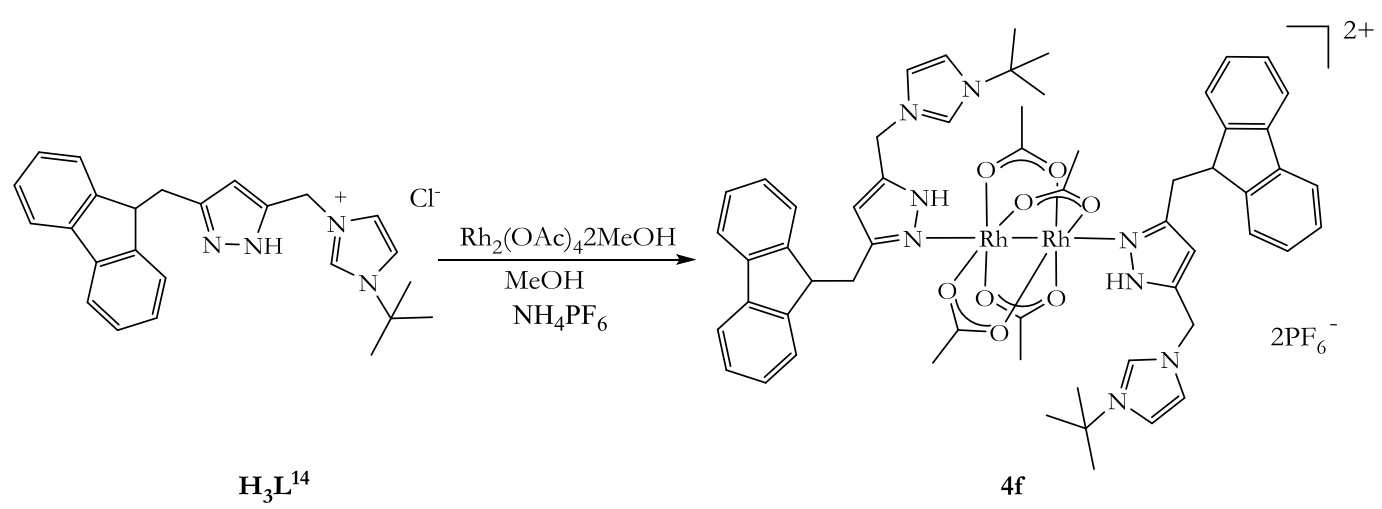

To a $\mathrm{MeOH}$ solution $(10 \mathrm{~mL})$ of $\mathbf{H}_{3} \mathbf{L}^{14}(50 \mathrm{mg}, 0.10 \mathrm{mmol})$ was added $0.5 \mathrm{~mol}$ equivalent of $\mathrm{Rh}_{2}(\mathrm{OAc})_{4} \cdot 2 \mathrm{MeOH}(26.5 \mathrm{mg}, 0.05 \mathrm{mmol})$ with stirring. A pale blue solution was formed in 5 min. 2.0 mol equivalent $\mathrm{NH}_{4} \mathrm{PF}_{6}$ was added and the reaction was allowed to stir overnight. A purple suspension was formed was overnight, the precipitate was filtered and washed several times with methanol $(3 \times 3 \mathrm{~mL})$ after which the product was dried in air to obtain the pure product. This product was sparingly soluble in both methanol and $\mathrm{CH}_{2} \mathrm{Cl}_{2}$ but dissolves in a 50:50 mixture of the two. Crystals of the product were obtained by the slow evaporation of 50:50 methanolic/ $\mathrm{CH}_{2} \mathrm{Cl}_{2}$ solution of the complex at room temperature.

Yield:

$40 \mathrm{mg}, 63 \%$

Molecular formula:

$\mathrm{C}_{58} \mathrm{H}_{66} \mathrm{~N}_{8} \mathrm{O}_{8} \mathrm{Rh}_{2}$

Molecular weight:

$1208.3 \mathrm{~g} / \mathrm{mol}$.

MS (ESI, $\mathrm{MeOH}) m / z(\%)$ :

$825(10 \%)\left[\mathrm{LRh}_{2}(\mathrm{OAc})_{4}\right]^{+} ; 382(100 \%)[\mathrm{L}]^{+}$.

IR $\left(\right.$ ATR, $\left.\mathrm{cm}^{-1}\right)$ :

3173 (m); 2555 (m); 1588 (vs); 1572 (s); 1436 (vs); 1415 (vs);

13809 (m); 1205(m); 1130 (m); 908 (m); 841 (vs); 819 (vs); 746 (m).

${ }^{1} \mathrm{H}-\mathrm{NMR}\left(\mathrm{CDCl}_{3}\right) \delta$ :

1.59 (s, $\left.18 \mathrm{H}, \mathrm{CH}_{3}{ }^{\mathrm{tBu}}\right) ; 1.80$ (s, $12 \mathrm{H}, \mathrm{CH}_{3}{ }^{\mathrm{OAq}}$ ); 4.30 (t, 2H, $\mathrm{CH}^{\mathrm{Imd} / z}$ );

$5.29\left(\mathrm{~s}, 8 \mathrm{H}, \mathrm{CH}_{2}\right) ; 5.91\left(\mathrm{~s}, 2 \mathrm{H}, \mathrm{CH}^{\mathrm{Pz}}\right) ; 7.25-7.37\left(\mathrm{~m}, 8 \mathrm{H}, \mathrm{CH}^{\mathrm{Ar}}\right)$;

$7.63\left(\mathrm{~s}, 2 \mathrm{H}, \mathrm{CH}^{\mathrm{Imdz}}\right) ; 7.83\left(\mathrm{~d},{ }^{4} J_{\mathrm{HH}}=1.2 \mathrm{~Hz}, 2 \mathrm{H}, \mathrm{CH}^{\mathrm{Imd}}\right) ; 8.01(\mathrm{~s}$, $\left.8 \mathrm{H}, \mathrm{CH}^{\mathrm{Ar}}\right) ; 9.34\left(\mathrm{~s}, 2 \mathrm{H}, \mathrm{CH}^{\mathrm{Imd} z}\right) ; 12.78\left(\mathrm{~s}, 2 \mathrm{H}, \mathrm{NH}^{\mathrm{P} z}\right)$. 
List of prepared complexes and ligands

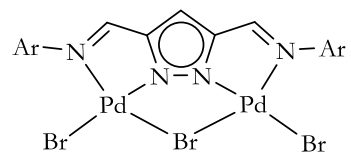

$1 b$

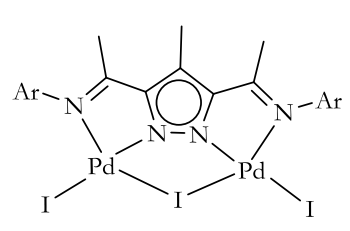

2c

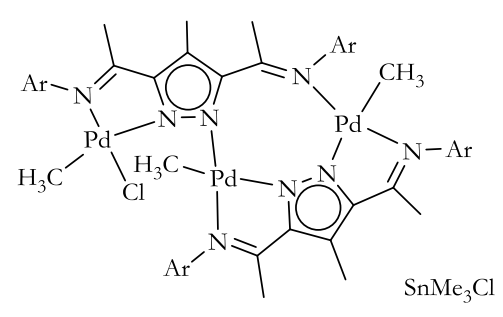

$2 \mathrm{~h}$

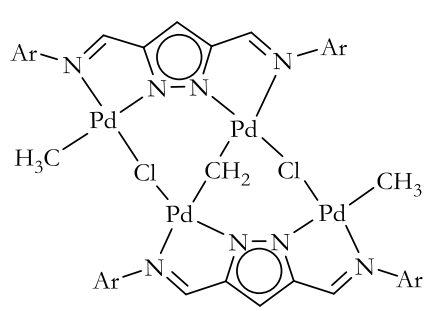

$2 \mathrm{k}$
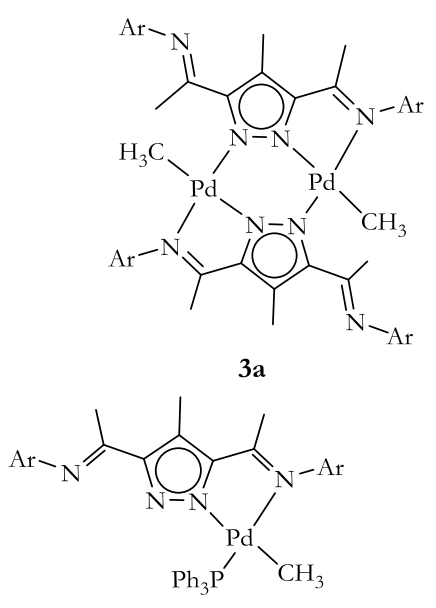

$3 d$

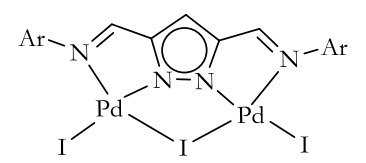

$1 \mathrm{c}$

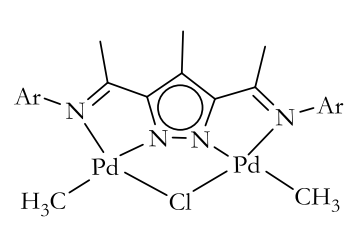

$2 \mathrm{f}$

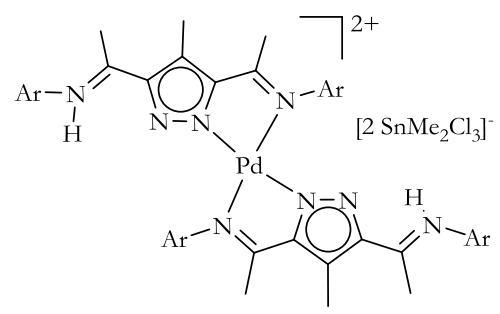

$2 \mathrm{i}$

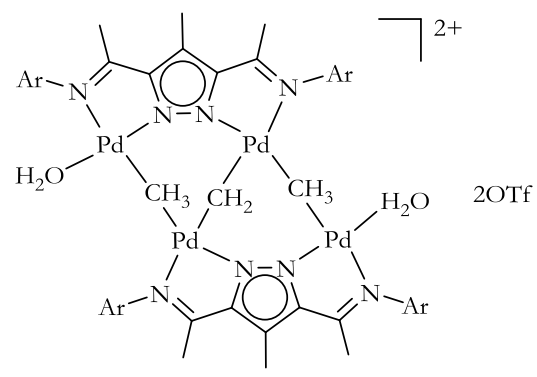

21
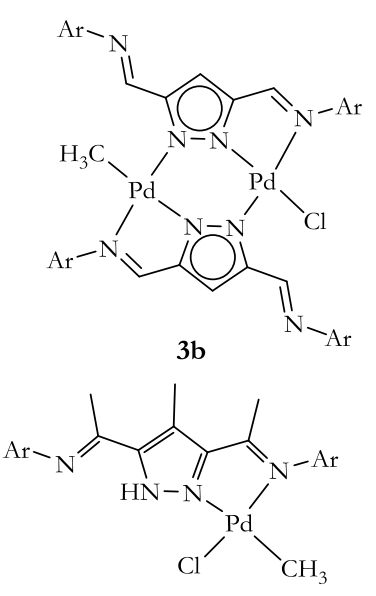

$3 \mathrm{e}$

$\mathrm{Ar}=2,6-{ }^{-} \mathrm{Pr}_{2}-\mathrm{C}_{6} \mathrm{H}_{3}$

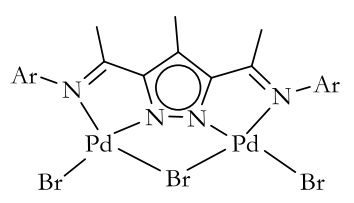

$2 b$

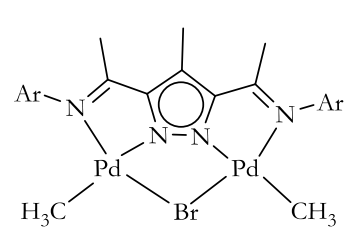

$2 \mathrm{~g}$

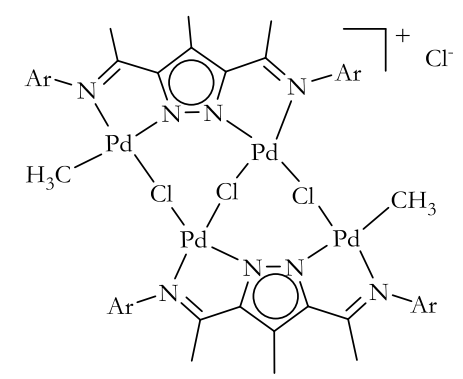

$2 d_{2}$

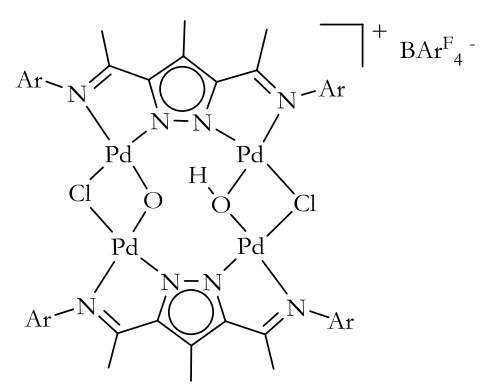

$2 p$
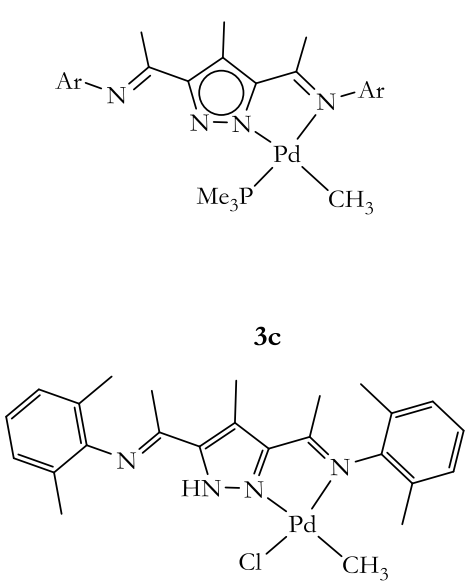

$3 f$ 
List of prepared complexes and ligands<smiles></smiles>

$3 g$
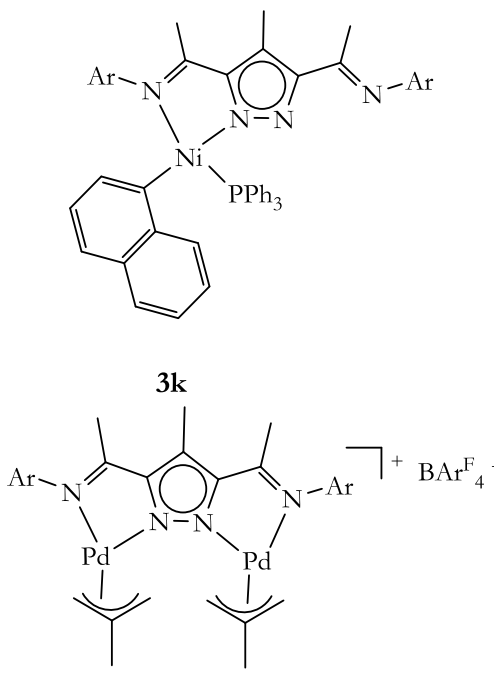

$3 n$

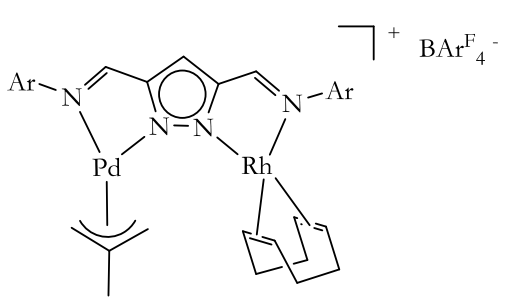

$3 \mathbf{r}$

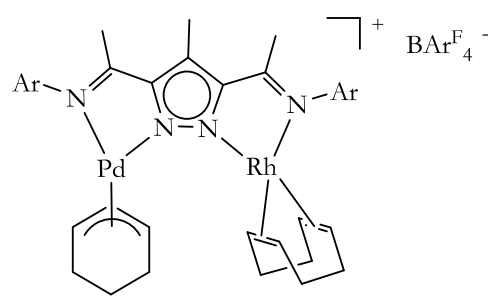

$3 \mathrm{u}$

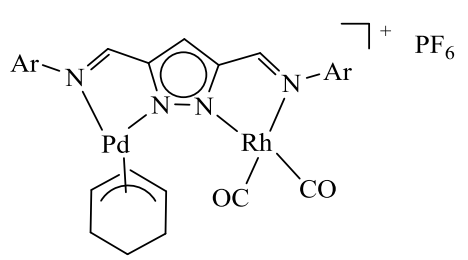

3x

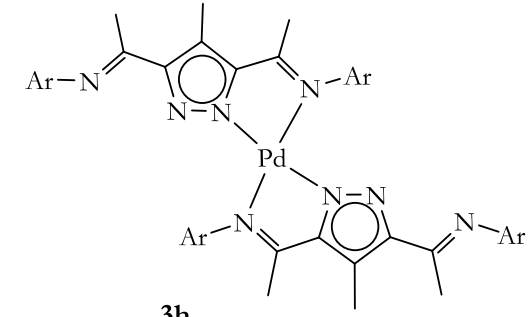

31

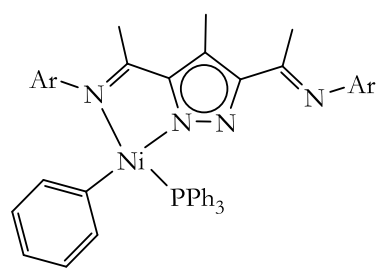

31

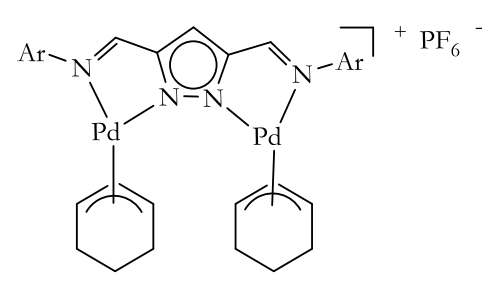

30

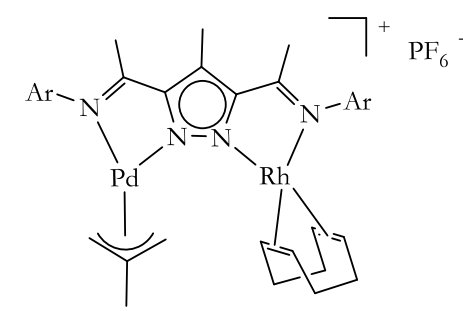

$3 s$

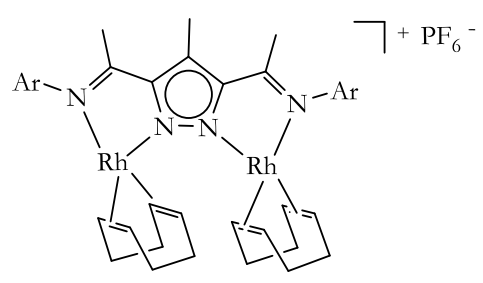

$3 v$

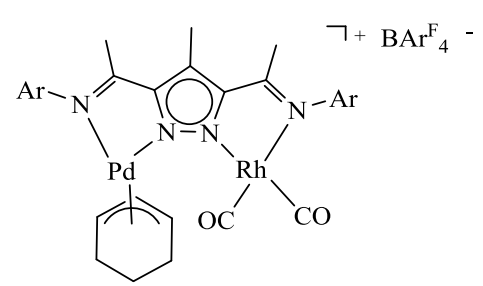

$3 \mathbf{y}$

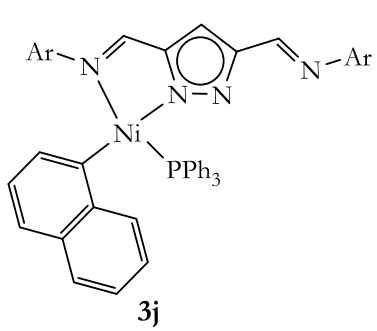

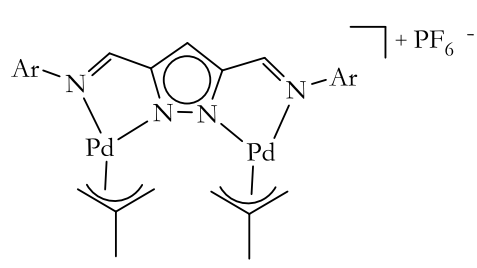

$3 m$

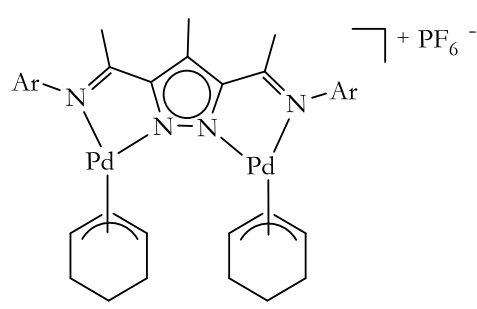

$3 p$

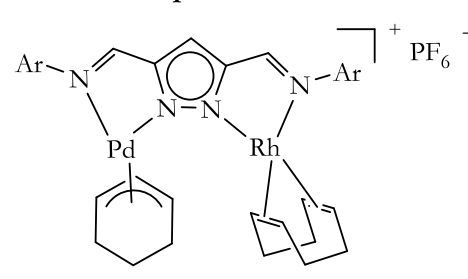

$3 t$

$3 w$

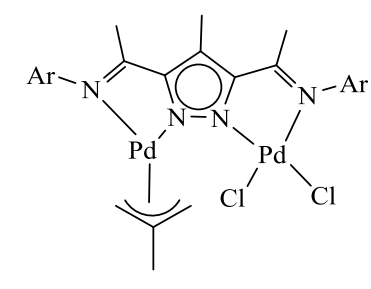

3z 
List of prepared complexes and ligands

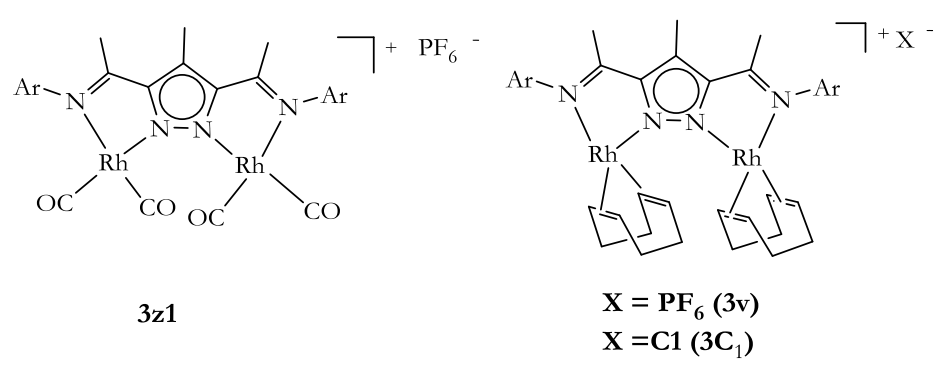

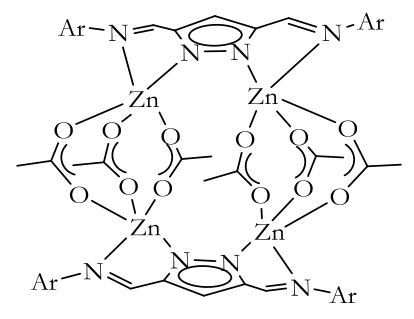

$4 a$
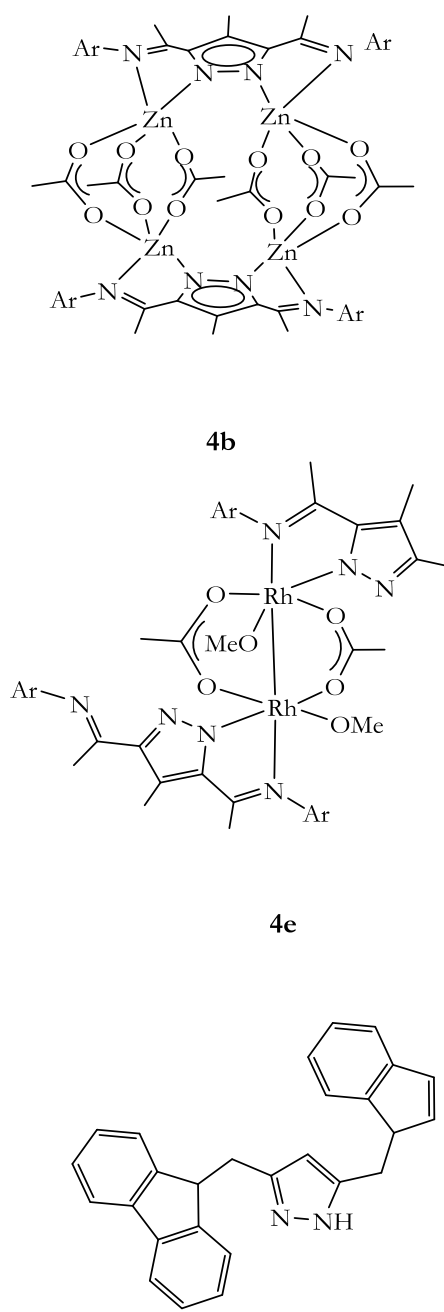

$\mathrm{H}_{3} \mathrm{~L}^{6}$

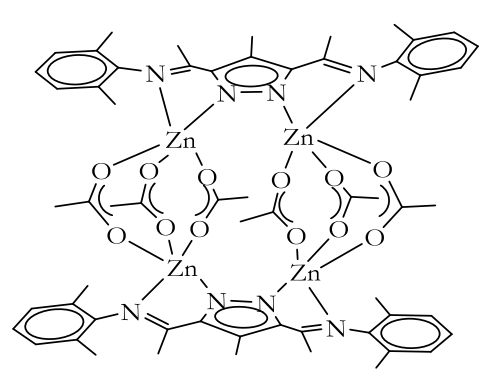

$4 c$

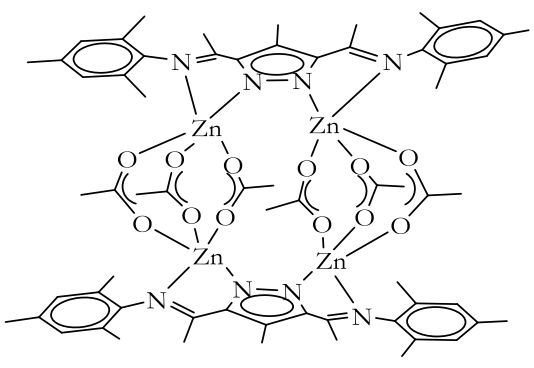

$4 d$

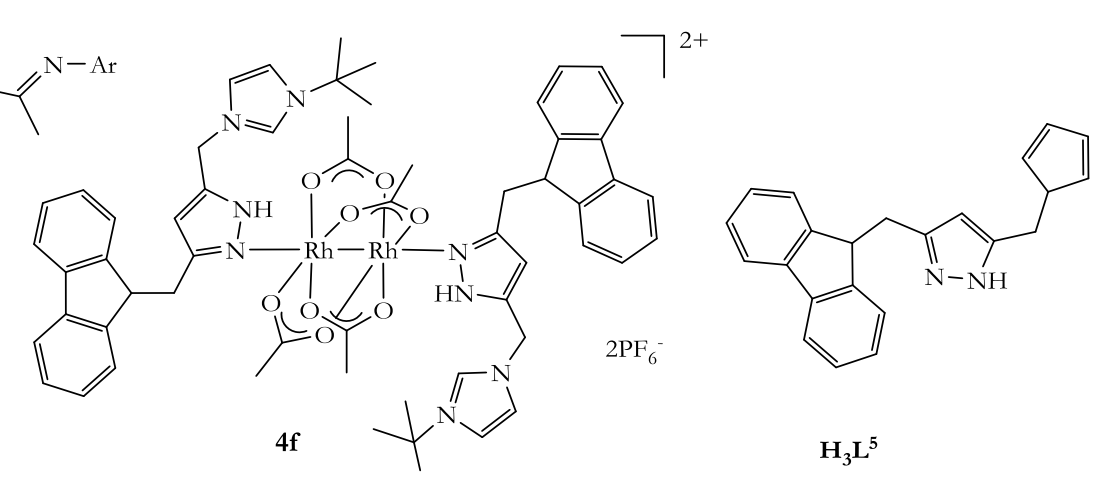

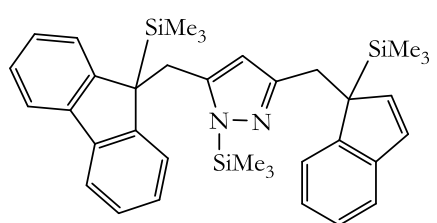

$\mathbf{L}^{9}$
$\mathrm{Ar}=2,6-{ }^{-} \mathrm{Pr}_{2}-\mathrm{C}_{6} \mathrm{H}_{3}$ 
List of prepared complexes and ligands

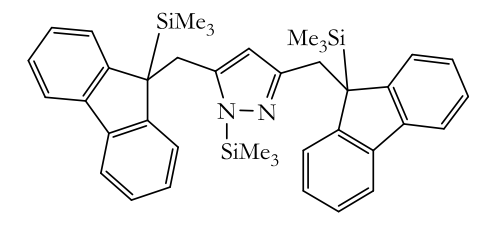

$\mathbf{L}^{10}$

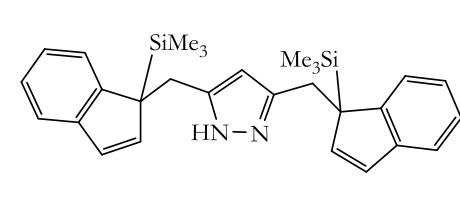

$\mathbf{H L}^{11}$

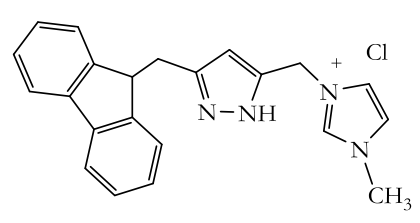

$\mathrm{H}_{3} \mathrm{~L}^{12}$
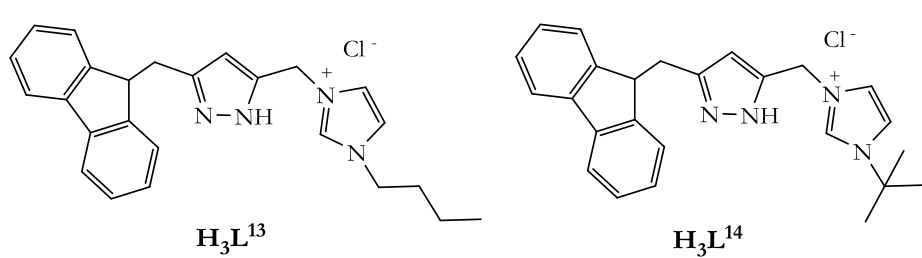

$\mathrm{H}_{3} \mathrm{~L}^{14}$

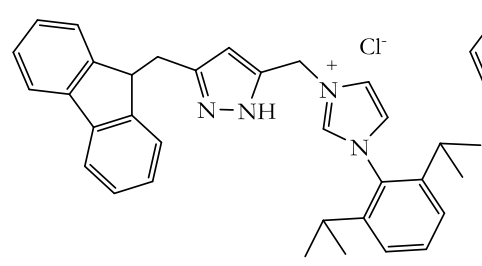

$\mathbf{H}_{3} \mathbf{L}^{16}$

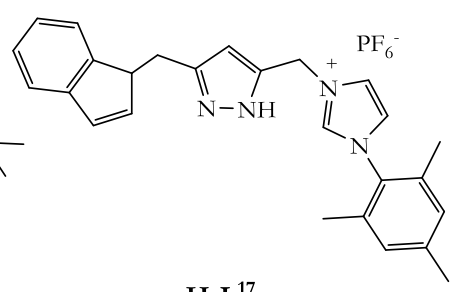

$\mathbf{H}_{3} \mathbf{L}^{17}$
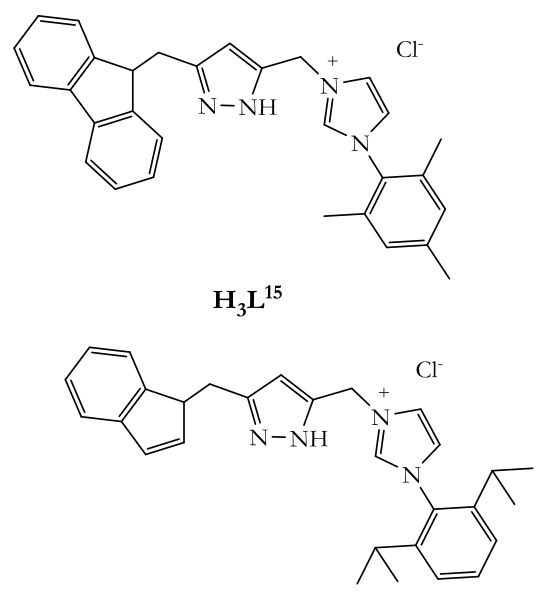

$\mathbf{H}_{3} \mathbf{L}^{18}$ 
11. 11: Crystallographic Data

\begin{tabular}{|c|c|c|c|c|}
\hline Label & \multicolumn{2}{|l|}{$2 \mathrm{~h}$} & \multicolumn{2}{|l|}{$2 \mathbf{i}$} \\
\hline Empirical formula & \multicolumn{2}{|c|}{$\mathrm{C}_{74} \mathrm{H}_{114} \mathrm{Cl}_{2} \mathrm{~N}_{8} \mathrm{OPd} \mathrm{O}_{3} \mathrm{Sn}$} & \multicolumn{2}{|c|}{$\mathrm{C}_{70} \mathrm{H}_{104} \mathrm{C}_{110} \mathrm{~N}_{8} \mathrm{PdSn}_{2}$} \\
\hline Formula weight & \multicolumn{2}{|l|}{1640.52} & \multicolumn{2}{|l|}{1755.89} \\
\hline Temperature & \multicolumn{2}{|l|}{$133(2) \mathrm{K}$} & \multicolumn{2}{|l|}{$133(2) \mathrm{K}$} \\
\hline Wavelength & \multicolumn{2}{|l|}{$0.71073 \AA$} & \multicolumn{2}{|l|}{$0.71073 \AA$} \\
\hline Crystal system & \multicolumn{2}{|l|}{ Triclinic } & \multicolumn{2}{|l|}{ Triclinic } \\
\hline Space group & $P-1$ & & $P-1$ & \\
\hline \multirow[t]{3}{*}{ Unit cell dimensions } & $\mathrm{a}=13.3849(9) \AA$ & $\alpha=93.101(5)^{\circ}$ & $\mathrm{a}=10.2900(4) \AA$ & $\alpha=111.722(3)^{\circ}$ \\
\hline & $\mathrm{b}=15.8627(10) \AA$ & $\beta=91.417(5)^{\circ}$ & $\mathrm{b}=13.8960(6) \AA$ & $\beta=93.324(3)^{\circ}$ \\
\hline & $c=19.8753(13) \AA$ & $\gamma=94.222(5)^{\circ}$ & $\mathrm{c}=15.4928(6) \AA$ & $\gamma=99.462(3)^{\circ}$ \\
\hline Volume & \multicolumn{2}{|l|}{$4200.6(5) \AA^{3}$} & \multicolumn{2}{|l|}{$2012.86(14) \AA^{3}$} \\
\hline Z & \multicolumn{2}{|l|}{2} & \multicolumn{2}{|l|}{1} \\
\hline Density (calculated) & \multicolumn{2}{|l|}{$1.297 \mathrm{Mg} / \mathrm{m}^{3}$} & \multicolumn{2}{|l|}{$1.449 \mathrm{Mg} / \mathrm{m}^{3}$} \\
\hline Absorption coefficient & \multicolumn{2}{|l|}{$1.031 \mathrm{~mm}^{-1}$} & \multicolumn{2}{|l|}{$1.212 \mathrm{~mm}^{-1}$} \\
\hline $\mathrm{F}(000)$ & \multicolumn{2}{|l|}{1688} & \multicolumn{2}{|l|}{896} \\
\hline Crystal size & \multicolumn{2}{|c|}{$0.29 \times 0.21 \times 0.11 \mathrm{~mm}^{3}$} & \multicolumn{2}{|c|}{$0.5 \times 0.5 \times 0.46 \mathrm{~mm}^{3}$} \\
\hline Theta range for data collection & \multicolumn{2}{|l|}{1.29 to $24.70^{\circ}$} & \multicolumn{2}{|l|}{1.61 to $26.76^{\circ}$} \\
\hline Index ranges & \multicolumn{2}{|c|}{$-13<=\mathrm{h}<=15,-18<=\mathrm{k}<=18,-23<=\mathrm{l}<=23$} & \multicolumn{2}{|c|}{$-13<=\mathrm{h}<=12,-17<=\mathrm{k}<=17,-19<=\mathrm{l}<=19$} \\
\hline Reflections collected & \multicolumn{2}{|l|}{44270} & \multicolumn{2}{|l|}{26484} \\
\hline Independent reflections & \multicolumn{2}{|c|}{$14097[\mathrm{R}(\mathrm{int})=0.1318]$} & $8535[\mathrm{R}$ (int) $=0.0$ & \\
\hline Completeness to theta $=$ & $98.5 \%$ & & $99.6 \%$ & \\
\hline Absorption correction & None & & Numerical & \\
\hline Max. and min. transmission & 0.9204 and 0.7503 & & 0.6268 and 0.539 & \\
\hline Refinement method & Full-matrix least-sc & ares on $\mathrm{F}^{2}$ & Full-matrix least-s & aares on $\mathrm{F}^{2}$ \\
\hline Data / restraints / parameters & $14097 / 0$ / 830 & & $8535 / 1 / 429$ & \\
\hline Goodness-of-fit on $\mathrm{F}^{2}$ & 1.043 & & 1.050 & \\
\hline Final $\mathrm{R}$ indices $[\mathrm{I}>2 \operatorname{sigma}(\mathrm{I})]$ & $\mathrm{R} 1=0.0583, \mathrm{wR} 2$ & 0.1437 & $\mathrm{R} 1=0.0400, \mathrm{w} \mathrm{R}^{2}$ & $=0.1048$ \\
\hline $\mathrm{R}$ indices (all data) & $\mathrm{R} 1=0.0722, \mathrm{wR} 2$ & 0.1507 & $\mathrm{R} 1=0.0432, \mathrm{wR} 2$ & $=0.1068$ \\
\hline Largest diff. peak and hole & 1.635 and $-1.019 \mathrm{e}$ & & 1.058 and -2.045 & \\
\hline
\end{tabular}




\begin{tabular}{|c|c|c|c|}
\hline Label & $2 \mathrm{k}$ & \multicolumn{2}{|l|}{$3 a$} \\
\hline Empirical formula & $\mathrm{C}_{67} \mathrm{H}_{96} \mathrm{Cl}_{2} \mathrm{~N}_{8} \mathrm{Pd}_{4}$ & \multicolumn{2}{|l|}{$\mathrm{C}_{66} \mathrm{H}_{92} \mathrm{~N}_{8} \mathrm{Pd}_{2}$} \\
\hline Formula weight & 1510.02 & \multicolumn{2}{|l|}{1210.28} \\
\hline Temperature & $133(2) \mathrm{K}$ & \multicolumn{2}{|l|}{$133(2) \mathrm{K}$} \\
\hline Wavelength & $0.71073 \AA$ & \multicolumn{2}{|l|}{$0.71073 \AA$} \\
\hline Crystal system & Monoclinic & \multicolumn{2}{|l|}{ Triclinic } \\
\hline Space group & $P 21 / \mathrm{c}$ & $P-1$ & \\
\hline \multirow[t]{3}{*}{ Unit cell dimensions } & $\mathrm{a}=12.9287(5) \AA \quad \alpha=90^{\circ}$ & $\mathrm{a}=13.5729(6) \AA$ & $\alpha=111.890(3)^{\circ}$ \\
\hline & $\mathrm{b}=19.8561(4) \AA \quad \beta=93.957(3)^{\circ}$ & $\mathrm{b}=22.2338(10) \AA$ & $\beta=92.033(3)^{\circ}$ \\
\hline & $\mathrm{c}=30.0916(10) \AA \quad \gamma=90^{\circ}$ & \multicolumn{2}{|c|}{$\mathrm{c}=23.2797(10) \AA \quad \gamma=90.035(4)^{\circ}$} \\
\hline Volume & $7706.5(4) \AA^{3}$ & \multicolumn{2}{|l|}{$6513.9(5) \AA^{3}$} \\
\hline $\mathrm{Z}$ & 4 & \multicolumn{2}{|l|}{4} \\
\hline Density (calculated) & $1.301 \mathrm{Mg} / \mathrm{m}^{3}$ & \multicolumn{2}{|l|}{$1.234 \mathrm{Mg} / \mathrm{m}^{3}$} \\
\hline Absorption coefficient & $1.027 \mathrm{~mm}^{-1}$ & \multicolumn{2}{|l|}{$0.595 \mathrm{~mm}^{-1}$} \\
\hline $\mathrm{F}(000)$ & 3088 & \multicolumn{2}{|l|}{2544} \\
\hline Crystal size & $0.19 \times 0.11 \times 0.10 \mathrm{~mm}^{3}$ & \multicolumn{2}{|c|}{$0.21 \times 0.07 \times 0.06 \mathrm{~mm}^{3}$} \\
\hline Theta range for data collection & 1.23 to $25.65^{\circ}$ & \multicolumn{2}{|l|}{1.60 to $25.73^{\circ}$} \\
\hline Index ranges & $-12<=\mathrm{h}<=15,-24<=\mathrm{k}<=24,-36<=\mathrm{l}<=36$ & \multicolumn{2}{|c|}{$-16<=\mathrm{h}<=14,-27<=\mathrm{k}<=26,-28<=\mathrm{l}<=28$} \\
\hline Reflections collected & 81720 & \multicolumn{2}{|l|}{68299} \\
\hline Independent reflections & $14535[\mathrm{R}$ (int) $=0.0660]$ & \multicolumn{2}{|c|}{$24564[\mathrm{R}$ (int) $=0.1776]$} \\
\hline Completeness to theta $=$ & $99.7 \%$ & \multicolumn{2}{|l|}{$98.8 \%$} \\
\hline Absorption correction & Numerical & \multicolumn{2}{|l|}{ Numerical } \\
\hline Max. and min. transmission & 0.9047 and 0.7670 & \multicolumn{2}{|l|}{0.9284 and 0.7513} \\
\hline Refinement method & Full-matrix least-squares on $\mathrm{F}^{2}$ & \multicolumn{2}{|c|}{ Full-matrix least-squares on $\mathrm{F}^{2}$} \\
\hline Data / restraints / parameters & $14535 / 31 / 751$ & \multicolumn{2}{|l|}{$24564 / 0 / 1417$} \\
\hline Goodness-of-fit on $\mathrm{F}^{2}$ & 1.001 & \multicolumn{2}{|l|}{1.041} \\
\hline Final $R$ indices $[I>2 \operatorname{sigma}(I)]$ & $\mathrm{R} 1=0.0408, \mathrm{wR} 2=0.0716$ & \multicolumn{2}{|c|}{$\mathrm{R} 1=0.0998, \mathrm{w} \mathrm{R} 2=0.1461$} \\
\hline $\mathrm{R}$ indices (all data) & $\mathrm{R} 1=0.0668, \mathrm{wR} 2=0.0780$ & $\mathrm{R} 1=0.1924, \mathrm{wR} 2$ & 0.1725 \\
\hline Largest diff. peak and hole & 0.532 and -0.515 e. $\AA^{-3}$ & 0.985 and $-0.900 \mathrm{e}$. & \\
\hline
\end{tabular}




\section{Crystallographic Data}

\begin{tabular}{|c|c|c|}
\hline Label & $3 b$ & $3 \mathrm{c}$ \\
\hline Empirical formula & $\mathrm{C}_{62} \mathrm{H}_{84.5} \mathrm{ClN}_{8} \mathrm{O}_{0.75} \mathrm{Pd}_{2}$ & $\mathrm{C}_{36.50} \mathrm{H}_{56} \mathrm{ClN}_{4} \mathrm{PPd}$ \\
\hline Formula weight & 1202.13 & 723.67 \\
\hline Temperature & $133(2) \mathrm{K}$ & $133(2) \mathrm{K}$ \\
\hline Wavelength & $0.71073 \AA$ & $0.71073 \AA$ \\
\hline Crystal system & Triclinic & Monoclinic \\
\hline Space group & $P-1$ & $P 21 / \mathrm{n}$ \\
\hline \multirow[t]{3}{*}{ Unit cell dimensions } & $\mathrm{a}=12.3368(5) \AA \quad \alpha=67.294(3)^{\circ}$ & $\mathrm{a}=18.0042(8) \AA \quad \alpha=90^{\circ}$ \\
\hline & $\mathrm{b}=16.8529(8) \AA \quad \beta=78.181(3)^{\circ}$ & $\mathrm{b}=8.5291(2) \AA$ \\
\hline & $\mathrm{c}=17.3280(7) \AA \quad \gamma=82.082(4)^{\circ}$ & $\mathrm{c}=24.7195(11) \AA \quad \gamma=90^{\circ}$ \\
\hline Volume & $3246.1(2) \AA^{3}$ & $3788.6(3) \AA^{3}$ \\
\hline Z & 2 & 4 \\
\hline Density (calculated) & $1.230 \mathrm{Mg} / \mathrm{m}^{3}$ & $1.269 \mathrm{Mg} / \mathrm{m}^{3}$ \\
\hline Absorption coefficient & $0.637 \mathrm{~mm}^{-1}$ & $0.631 \mathrm{~mm}^{-1}$ \\
\hline $\mathrm{F}(000)$ & 1255 & 1424 \\
\hline Crystal size & $0.44 \times 0.25 \times 0.18 \mathrm{~mm}^{3}$ & $0.5 \times 0.16 \times 0.12 \mathrm{~mm}^{3}$ \\
\hline Theta range for data collection & 1.29 to $25.63^{\circ}$ & 1.36 to $25.70^{\circ}$ \\
\hline Index ranges & $-14<=\mathrm{h}<=14,-20<=\mathrm{k}<=18,-21<=\mathrm{l}<=21$ & $21<=\mathrm{h}<=21,-9<=\mathrm{k}<=10,-30<=\mathrm{l}<=30$ \\
\hline Reflections collected & 34720 & 42713 \\
\hline Independent reflections & $12217[\mathrm{R}$ (int) $=0.0615]$ & $7178[\mathrm{R}$ (int) $=0.1011]$ \\
\hline Completeness to theta $=$ & $99.6 \%$ & $99.4 \%$ \\
\hline Absorption correction & Numerical & Numerical \\
\hline Max. and min. transmission & 0.9003 and 0.7906 & 0.8795 and 0.5859 \\
\hline Refinement method & Full-matrix least-squares on $\mathrm{F}^{2}$ & Full-matrix least-squares on $\mathrm{F}^{2}$ \\
\hline Data / restraints / parameters & $12217 / 66 / 694$ & $7178 / 0 / 427$ \\
\hline Goodness-of-fit on $\mathrm{F}^{2}$ & 1.057 & 1.039 \\
\hline Final R indices $[I>2 \operatorname{sigma}(I)]$ & $\mathrm{R} 1=0.0553, \mathrm{wR} 2=0.1538$ & $\mathrm{R} 1=0.0460, \mathrm{wR} 2=0.1181$ \\
\hline $\mathrm{R}$ indices (all data) & $\mathrm{R} 1=0.0704, \mathrm{wR} 2=0.1631$ & $\mathrm{R} 1=0.0580, \mathrm{wR} 2=0.1240$ \\
\hline Largest diff. peak and hole & 1.534 and -1.284 e. $\AA^{-3}$ & 1.036 and -0.793 e. $\AA^{-3}$ \\
\hline
\end{tabular}


Crystallographic Data

\begin{tabular}{|c|c|c|c|c|}
\hline Label & \multicolumn{2}{|l|}{$3 \mathrm{~h}$} & \multicolumn{2}{|l|}{$3 \mathbf{i}$} \\
\hline Empirical formula & \multicolumn{2}{|l|}{$\mathrm{C}_{64} \mathrm{H}_{86} \mathrm{~N}_{8} \mathrm{Pd}$} & \multicolumn{2}{|c|}{$\mathrm{C}_{112} \mathrm{H}_{78} \mathrm{~B}_{2} \mathrm{~F}_{48} \mathrm{~N}_{8} \mathrm{Pd}_{2}$} \\
\hline Formula weight & \multicolumn{2}{|l|}{1073.81} & \multicolumn{2}{|l|}{2682.24} \\
\hline Temperature & \multicolumn{2}{|l|}{$133(2) \mathrm{K}$} & \multicolumn{2}{|l|}{$133(2) \mathrm{K}$} \\
\hline Wavelength & \multicolumn{2}{|l|}{$0.71073 \AA$} & \multicolumn{2}{|l|}{$0.71073 \AA$} \\
\hline Crystal system & \multicolumn{2}{|l|}{ Monoclinic } & \multicolumn{2}{|l|}{ Triclinic } \\
\hline Space group & $P 21 / \mathrm{c}$ & & $P-1$ & \\
\hline \multirow[t]{3}{*}{ Unit cell dimensions } & $\mathrm{a}=8.7514(6) \AA$ & $\alpha=90^{\circ}$ & $\mathrm{a}=13.0997(4) \AA$ & $\alpha=73.881(3)^{\circ}$ \\
\hline & $\mathrm{b}=21.3165(16) \AA$ & $\beta=101.921(6)^{\circ}$ & $\mathrm{b}=13.1432(4) \AA$ & $\beta=83.613(3)^{\circ}$ \\
\hline & $\mathrm{c}=15.8556(12) \AA$ & $\gamma=90^{\circ}$ & $\mathrm{c}=17.5534(6) \AA$ & $\gamma=71.885(3)^{\circ}$ \\
\hline Volume & \multicolumn{2}{|l|}{ 2894.1(4) $\AA^{3}$} & \multicolumn{2}{|l|}{$2758.46(15) \AA^{3}$} \\
\hline Z & \multicolumn{2}{|l|}{2} & \multicolumn{2}{|l|}{1} \\
\hline Density (calculated) & \multicolumn{2}{|l|}{$1.232 \mathrm{Mg} / \mathrm{m}^{3}$} & \multicolumn{2}{|l|}{$1.615 \mathrm{Mg} / \mathrm{m}^{3}$} \\
\hline Absorption coefficient & \multicolumn{2}{|l|}{$0.367 \mathrm{~mm}^{-1}$} & \multicolumn{2}{|l|}{$0.460 \mathrm{~mm}^{-1}$} \\
\hline $\mathrm{F}(000)$ & \multicolumn{2}{|l|}{1144} & \multicolumn{2}{|l|}{1340} \\
\hline Crystal size & \multicolumn{2}{|c|}{$0.26 \times 0.09 \times 0.07 \mathrm{~mm}^{3}$} & \multicolumn{2}{|c|}{$0.5 \times 0.45 \times 0.35 \mathrm{~mm}^{3}$} \\
\hline Theta range for data collection & \multicolumn{2}{|l|}{1.62 to $25.00^{\circ}$} & \multicolumn{2}{|l|}{1.64 to $26.72^{\circ}$} \\
\hline Index ranges & \multicolumn{2}{|c|}{$-10<=\mathrm{h}<=9,-25<=\mathrm{k}<=25,-18<=\mathrm{l}<=18$} & \multicolumn{2}{|c|}{$-16<=\mathrm{h}<=16,-16<=\mathrm{k}<=16,-22<=\mathrm{l}<=22$} \\
\hline Reflections collected & \multicolumn{2}{|l|}{28514} & \multicolumn{2}{|l|}{35344} \\
\hline Independent reflections & \multicolumn{2}{|c|}{$5099[\mathrm{R}(\mathrm{int})=0.1933]$} & $11696[\mathrm{R}$ (int) $=0$ & \\
\hline Completeness to theta $=$ & $100.0 \%$ & & $99.8 \%$ & \\
\hline Absorption correction & Numerical & & Numerical & \\
\hline Max. and min. transmission & 0.8981 and 0.5965 & & 0.9166 and 0.7555 & \\
\hline Refinement method & Full-matrix least-sc & ares on $\mathrm{F}^{2}$ & Full-matrix least-s & $\mathrm{s}$ on $\mathrm{F}^{2}$ \\
\hline Data / restraints / parameters & $5099 / 0 / 342$ & & $11696 / 42 / 772$ & \\
\hline Goodness-of-fit on $\mathrm{F}^{2}$ & 1.073 & & 1.037 & \\
\hline Final $\mathrm{R}$ indices $[\mathrm{I}>2 \operatorname{sigma}(\mathrm{I})]$ & $\mathrm{R} 1=0.0739, \mathrm{wR} 2$ & 0.1108 & $\mathrm{R} 1=0.0522, \mathrm{wR} 2$ & 1367 \\
\hline $\mathrm{R}$ indices (all data) & $\mathrm{R} 1=0.1519, \mathrm{wR} 2$ & 0.1355 & $\mathrm{R} 1=0.0590, \mathrm{wR} 2$ & 403 \\
\hline Largest diff. peak and hole & 0.705 and -1.315 e. & & 2.314 and -1.313 & \\
\hline
\end{tabular}


Crystallographic Data

\begin{tabular}{|c|c|c|c|c|}
\hline Label & \multicolumn{2}{|l|}{$3 \mathrm{k}$} & \multicolumn{2}{|l|}{31} \\
\hline Empirical formula & \multicolumn{2}{|l|}{$\mathrm{C}_{60} \mathrm{H}_{65} \mathrm{~N}_{4} \mathrm{NiP}$} & \multicolumn{2}{|l|}{$\mathrm{C}_{59} \mathrm{H}_{66} \mathrm{~N}_{4} \mathrm{NiP}$} \\
\hline Formula weight & \multicolumn{2}{|l|}{931.84} & \multicolumn{2}{|l|}{920.84} \\
\hline Temperature & \multicolumn{2}{|l|}{$133(2) \mathrm{K}$} & \multicolumn{2}{|l|}{$133(2) \mathrm{K}$} \\
\hline Wavelength & \multicolumn{2}{|l|}{$0.71073 \AA$} & \multicolumn{2}{|l|}{$0.71073 \AA$} \\
\hline Crystal system & \multicolumn{2}{|l|}{ Monoclinic } & \multicolumn{2}{|l|}{ Triclinic } \\
\hline Space group & \multicolumn{2}{|l|}{$P 21 / \mathrm{c}$} & \multicolumn{2}{|l|}{$P-1$} \\
\hline \multirow[t]{3}{*}{ Unit cell dimensions } & $\mathrm{a}=17.5591(9) \AA$ & $\alpha=90^{\circ}$ & $\mathrm{a}=10.1233(10) \AA$ & $\alpha=75.101(8)^{\circ}$ \\
\hline & $\mathrm{b}=17.1847(6) \AA$ & $\beta=102.785(4)^{\circ}$ & $\mathrm{b}=12.8898(14) \AA$ & $\beta=88.306(8)^{\circ}$ \\
\hline & $c=17.4217(7) \AA$ & $\gamma=90^{\circ}$ & $\mathrm{c}=22.209(2) \AA$ & $\gamma=66.845(8)^{\circ}$ \\
\hline Volume & \multicolumn{2}{|l|}{$5126.6(4) \AA^{3}$} & \multicolumn{2}{|l|}{$2566.6(5) \AA^{3}$} \\
\hline Z & \multicolumn{2}{|l|}{4} & \multicolumn{2}{|l|}{2} \\
\hline Density (calculated) & \multicolumn{2}{|l|}{$1.207 \mathrm{Mg} / \mathrm{m}^{3}$} & \multicolumn{2}{|l|}{$1.192 \mathrm{Mg} / \mathrm{m}^{3}$} \\
\hline Absorption coefficient & \multicolumn{2}{|l|}{$0.452 \mathrm{~mm}^{-1}$} & \multicolumn{2}{|l|}{$0.450 \mathrm{~mm}^{-1}$} \\
\hline $\mathrm{F}(000)$ & \multicolumn{2}{|l|}{1984} & \multicolumn{2}{|l|}{982} \\
\hline Crystal size & \multicolumn{2}{|c|}{$0.21 \times 0.09 \times 0.05 \mathrm{~mm}^{3}$} & \multicolumn{2}{|c|}{$0.22 \times 0.06 \times 0.02 \mathrm{~mm}^{3}$} \\
\hline Theta range for data collection & \multicolumn{2}{|l|}{1.68 to $25.00^{\circ}$} & \multicolumn{2}{|l|}{1.78 to $26.82^{\circ}$} \\
\hline Index ranges & \multicolumn{2}{|c|}{$-20<=\mathrm{h}<=20,-20<=\mathrm{k}<=20,-20<=\mathrm{l}<=20$} & \multicolumn{2}{|c|}{$-12<=\mathrm{h}<=12,-15<=\mathrm{k}<=16,0<=\mathrm{l}<=28$} \\
\hline Reflections collected & \multicolumn{2}{|l|}{35756} & 10934 & \\
\hline Independent reflections & $8863[\mathrm{R}$ (int) $=0.1$ & & $10934[\mathrm{R}$ (int) $=0.0$ & \\
\hline Completeness to theta $=$ & $98.2 \%$ & & $99.2 \%$ & \\
\hline Absorption correction & Numerical & & Numerical & \\
\hline Max. and min. transmission & 0.9659 and 0.7675 & & 0.9201 and 0.6555 & \\
\hline Refinement method & Full-matrix least-s & es on $\mathrm{F}^{2}$ & Full-matrix least-sq & ares on $\mathrm{F}^{2}$ \\
\hline Data / restraints / parameters & $8863 / 1 / 604$ & & $10934 / 0$ / 575 & \\
\hline Goodness-of-fit on $\mathrm{F}^{2}$ & 1.130 & & 0.743 & \\
\hline Final $\mathrm{R}$ indices $[\mathrm{I}>2 \operatorname{sigma}(\mathrm{I})]$ & $\mathrm{R} 1=0.1061, \mathrm{w} \mathrm{R} 2$ & 1524 & $\mathrm{R} 1=0.1173, \mathrm{wR} 2=$ & 0.1768 \\
\hline $\mathrm{R}$ indices (all data) & $\mathrm{R} 1=0.1830, \mathrm{w} 22$ & 1755 & $\mathrm{R} 1=0.3334, \mathrm{wR} 2=$ & 0.2787 \\
\hline Largest diff. peak and hole & 0.542 and $-0.416 \mathrm{e}$ & & 0.595 and $-1.050 \mathrm{e}$. & \\
\hline
\end{tabular}




\section{Crystallographic Data}

\begin{tabular}{|c|c|c|c|}
\hline Label & $3 n$ & \multicolumn{2}{|l|}{$3 p$} \\
\hline Empirical formula & $\mathrm{C}_{84} \mathrm{H}_{93} \mathrm{BF}_{24} \mathrm{~N}_{4} \mathrm{Pd}_{2}$ & \multicolumn{2}{|c|}{$\mathrm{C}_{45} \mathrm{H}_{63} \mathrm{Cl}_{2} \mathrm{~F}_{6} \mathrm{~N}_{4} \mathrm{PPd}_{2}$} \\
\hline Formula weight & 1838.23 & \multicolumn{2}{|l|}{1088.6} \\
\hline Temperature & $133(2) \mathrm{K}$ & \multicolumn{2}{|l|}{$133(2) \mathrm{K}$} \\
\hline Wavelength & $0.71073 \AA$ & \multicolumn{2}{|l|}{$0.71073 \AA$} \\
\hline Crystal system & Monoclinic & \multicolumn{2}{|l|}{ Monoclinic } \\
\hline Space group & $P 21 / \mathrm{c}$ & \multicolumn{2}{|l|}{$P 21 / \mathrm{n}$} \\
\hline \multirow[t]{3}{*}{ Unit cell dimensions } & $\mathrm{a}=16.0445(3) \AA \quad \alpha=90^{\circ}$ & $\mathrm{a}=8.3238(2) \AA$ & $\alpha=90.0^{\circ}$ \\
\hline & $\mathrm{b}=16.9736(2) \AA \quad \beta=100.237(2)^{\circ}$ & $\mathrm{b}=25.4691 \AA$ & $\beta=94.485(2)^{\circ}$ \\
\hline & $\mathrm{c}=31.7612(6) \AA \quad \gamma=90^{\circ}$ & \multicolumn{2}{|c|}{$\mathrm{c}=22.4117(5) \AA \quad \gamma=90^{\circ}$} \\
\hline Volume & $8511.9(2) \AA^{3}$ & \multicolumn{2}{|l|}{$2758.46(15) \AA^{3}$} \\
\hline Z & 4 & \multicolumn{2}{|l|}{4} \\
\hline Density (calculated) & $1.434 \mathrm{Mg} / \mathrm{m}^{3}$ & \multicolumn{2}{|l|}{$1.527 \mathrm{Mg} / \mathrm{m}^{3}$} \\
\hline Absorption coefficient & $0.520 \mathrm{~mm}^{-1}$ & \multicolumn{2}{|l|}{$0.965 \mathrm{~mm}^{-1}$} \\
\hline $\mathrm{F}(000)$ & 3752 & \multicolumn{2}{|l|}{2224} \\
\hline Crystal size & $0.50 \times 0.48 \times 0.32 \mathrm{~mm}^{3}$ & \multicolumn{2}{|c|}{$0.5 \times 0.07 \times 0.03 \mathrm{~mm}^{3}$} \\
\hline Theta range for data collection & 1.29 to $25.64^{\circ}$ & \multicolumn{2}{|l|}{1.21 to $25.63^{\circ}$} \\
\hline Index ranges & $-19<=\mathrm{h}<=19,-18<=\mathrm{k}<=20,-38<=\mathrm{l}<=38$ & \multicolumn{2}{|c|}{$-9<=\mathrm{h}<=10,-30<=\mathrm{k}<=30,-27<=\mathrm{l}<=27$} \\
\hline Reflections collected & 97363 & \multicolumn{2}{|l|}{48499} \\
\hline Independent reflections & $16051[\mathrm{R}$ (int) $=0.0706]$ & \multicolumn{2}{|c|}{$8898[\mathrm{R}(\mathrm{int})=0.0874]$} \\
\hline Completeness to theta $=$ & $99.7 \%$ & \multicolumn{2}{|l|}{$99.6 \%$} \\
\hline Absorption correction & Numerical & \multicolumn{2}{|l|}{ Numerical } \\
\hline Max. and min. transmission & 0.8988 and 0.8084 & \multicolumn{2}{|l|}{0.9702 and 0.7656} \\
\hline Refinement method & Full-matrix least-squares on $\mathrm{F}^{2}$ & \multicolumn{2}{|c|}{ Full-matrix least-squares on $\mathrm{F}^{2}$} \\
\hline Data / restraints / parameters & $16051 / 152 / 1054$ & \multicolumn{2}{|l|}{$8898 / 6 / 569$} \\
\hline Goodness-of-fit on $\mathrm{F}^{2}$ & 1.034 & \multicolumn{2}{|l|}{1.010} \\
\hline Final $\mathrm{R}$ indices $[\mathrm{I}>2 \operatorname{sigma}(\mathrm{I})]$ & $\mathrm{R} 1=0.0642, \mathrm{wR} 2=0.1802$ & \multicolumn{2}{|c|}{$\mathrm{R} 1=0.0406, \mathrm{wR} 2=0.0713$} \\
\hline $\mathrm{R}$ indices (all data) & $\mathrm{R} 1=0.0753, \mathrm{wR} 2=0.1889$ & \multicolumn{2}{|c|}{$\mathrm{R} 1=0.0636, \mathrm{wR} 2=0.0766$} \\
\hline Largest diff. peak and hole & 2.571 and -1.101 e. $\AA^{-3}$ & \multicolumn{2}{|c|}{0.915 and -0.609 e. $\AA^{-3}$} \\
\hline
\end{tabular}


Crystallographic Data

\begin{tabular}{|c|c|c|c|c|}
\hline Label & \multicolumn{2}{|l|}{$3 q$} & \multicolumn{2}{|l|}{$3 t$} \\
\hline Empirical formula & \multicolumn{2}{|l|}{$\mathrm{C}_{86} \mathrm{H}_{96} \mathrm{Cl}_{8} \mathrm{~F}_{12} \mathrm{~N}_{8} \mathrm{P}_{2} \mathrm{Pd}$} & \multicolumn{2}{|c|}{$\mathrm{C}_{44} \mathrm{H}_{60} \mathrm{Cl}_{2} \mathrm{~F}_{6} \mathrm{~N}_{4} \mathrm{P}$ Pd Rh } \\
\hline Formula weight & \multicolumn{2}{|l|}{1705.47} & \multicolumn{2}{|l|}{1070.14} \\
\hline Temperature & \multicolumn{2}{|l|}{$133(2) \mathrm{K}$} & \multicolumn{2}{|l|}{$133(2) \mathrm{K}$} \\
\hline Wavelength & \multicolumn{2}{|l|}{$0.71073 \AA$} & \multicolumn{2}{|l|}{$0.71073 \AA$} \\
\hline Crystal system & \multicolumn{2}{|l|}{ Triclinic } & \multicolumn{2}{|l|}{ Monoclinic } \\
\hline Space group & \multicolumn{2}{|l|}{$P-1$} & \multicolumn{2}{|l|}{$\mathrm{C} \mathrm{c}$} \\
\hline \multirow[t]{3}{*}{ Unit cell dimensions } & $\mathrm{a}=12.6945(11) \AA$ & $\alpha=97.038(6)^{\circ}$ & $\mathrm{a}=22.5325(13) \AA$ & $\alpha=90^{\circ}$ \\
\hline & $\mathrm{b}=13.5645(11) \AA$ & $\beta=115.436(6)^{\circ}$ & $\mathrm{b}=13.2280(5) \AA$ & $\beta=110.444(4)^{\circ}$ \\
\hline & $\mathrm{c}=14.6984(14) \AA$ & $\gamma=110.504(6)^{\circ}$ & $c=16.6094(10) \AA$ & $\gamma=90^{\circ}$ \\
\hline Volume & \multicolumn{2}{|l|}{$1681.55(15) \AA^{3}$} & \multicolumn{2}{|l|}{$4638.8(4) \AA^{3}$} \\
\hline $\mathrm{Z}$ & \multicolumn{2}{|l|}{1} & \multicolumn{2}{|l|}{4} \\
\hline Density (calculated) & \multicolumn{2}{|l|}{$1.398 \mathrm{Mg} / \mathrm{m}^{3}$} & \multicolumn{2}{|l|}{$1.532 \mathrm{Mg} / \mathrm{m}^{3}$} \\
\hline Absorption coefficient & \multicolumn{2}{|l|}{$0.603 \mathrm{~mm}^{-1}$} & \multicolumn{2}{|l|}{$0.953 \mathrm{~mm}^{-1}$} \\
\hline $\mathrm{F}(000)$ & \multicolumn{2}{|l|}{880} & \multicolumn{2}{|l|}{2184} \\
\hline Crystal size & \multicolumn{2}{|c|}{$0.39 \times 0.32 \times 0.28 \mathrm{~mm}^{3}$} & \multicolumn{2}{|l|}{$0.5 \times 0.02 \times 0.02 \mathrm{~mm}^{3}$} \\
\hline Theta range for data collection & \multicolumn{2}{|l|}{1.62 to $26.92^{\circ}$} & \multicolumn{2}{|l|}{1.82 to 25.67} \\
\hline Index ranges & \multicolumn{2}{|c|}{$-16<=\mathrm{h}<=15,-17<=\mathrm{k}<=15,-18<=\mathrm{l}<=18$} & \multicolumn{2}{|c|}{$-27<=\mathrm{h}<=27,-16<=\mathrm{k}<=16,-18<=\mathrm{l}<=20$} \\
\hline Reflections collected & \multicolumn{2}{|l|}{25795} & 22020 & \\
\hline Independent reflections & $8671[\mathrm{R}$ (int) $=0.1243$ & & $8081[\mathrm{R}$ (int) $=0.0923$ & \\
\hline Completeness to theta $=$ & $100.0 \%$ & & $99.4 \%$ & \\
\hline Absorption correction & Numerical & & Numerical & \\
\hline Max. and min. transmission & 0.8693 and 0.5634 & & 0.9854 and 0.7946 & \\
\hline Refinement method & Full-matrix least-squ & on $\mathrm{F}^{2}$ & Full-matrix least-sq & res on $\mathrm{F}^{2}$ \\
\hline Data / restraints / parameters & $8671 / 14 / 472$ & & $8081 / 2 / 541$ & \\
\hline Goodness-of-fit on $\mathrm{F}^{2}$ & 1.004 & & 1.005 & \\
\hline Final $\mathrm{R}$ indices $[\mathrm{I}>2 \operatorname{sigma}(\mathrm{I})]$ & $\mathrm{R} 1=0.0567, \mathrm{wR} 2=$ & 3290 & $\mathrm{R} 1=0.0513, \mathrm{wR} 2=$ & 0826 \\
\hline $\mathrm{R}$ indices (all data) & $\mathrm{R} 1=0.0823, \mathrm{wR} 2=$ & 416 & $\mathrm{R} 1=0.0743, \mathrm{wR} 2=0$ & 894 \\
\hline Largest diff. peak and hole & 0.905 and -0.910 e. $\AA$ & & 0.632 and -0.771 e..$\AA$ & \\
\hline
\end{tabular}




\begin{tabular}{|c|c|c|c|c|}
\hline Label & \multicolumn{2}{|l|}{$3 u$} & \multicolumn{2}{|l|}{$3 z$} \\
\hline Empirical formula & \multicolumn{2}{|c|}{$\mathrm{C}_{90} \mathrm{H}_{100} \mathrm{BF}_{24} \mathrm{~N}_{4} \mathrm{Pd} \mathrm{Rh}$} & \multicolumn{2}{|l|}{$\mathrm{C}_{37} \mathrm{H}_{52} \mathrm{Cl}_{4} \mathrm{~N}_{4} \mathrm{Pd}_{2}$} \\
\hline Formula weight & \multicolumn{2}{|l|}{1913.86} & \multicolumn{2}{|l|}{907.43} \\
\hline Temperature & \multicolumn{2}{|l|}{$133(2) \mathrm{K}$} & \multicolumn{2}{|l|}{$133(2) \mathrm{K}$} \\
\hline Wavelength & \multicolumn{2}{|l|}{$0.71073 \AA$} & \multicolumn{2}{|l|}{$0.71073 \AA$} \\
\hline Crystal system & \multicolumn{2}{|l|}{ Triclinic } & \multicolumn{2}{|l|}{ Monoclinic } \\
\hline Space group & \multicolumn{2}{|l|}{$P-1$} & \multicolumn{2}{|l|}{$P 21 / \mathrm{c}$} \\
\hline \multirow[t]{3}{*}{ Unit cell dimensions } & $\mathrm{a}=12.6288(4) \AA$ & $\alpha=99.524(3)^{\circ}$ & $\mathrm{a}=19.3381(17) \AA$ & $\alpha=90^{\circ}$ \\
\hline & $\mathrm{b}=13.3336(4) \AA$ & $\beta=98.920(3)^{\circ}$ & $\mathrm{b}=12.5436(8) \AA$ & $\beta=96.192(7)^{\circ}$ \\
\hline & $c=26.6732(9) \AA$ & $\gamma=91.400(3)^{\circ}$ & $c=16.4910(14) \AA$ & $\gamma=90^{\circ}$ \\
\hline Volume & $4370.2(2) \AA^{3}$ & & $3976.9(5) \AA^{3}$ & \\
\hline Z & \multicolumn{2}{|l|}{2} & \multicolumn{2}{|l|}{4} \\
\hline Density (calculated) & \multicolumn{2}{|l|}{$1.454 \mathrm{Mg} / \mathrm{m}^{3}$} & \multicolumn{2}{|l|}{$1.516 \mathrm{M} / \mathrm{m}^{3}$} \\
\hline Absorption coefficient & \multicolumn{2}{|l|}{$0.493 \mathrm{~mm}^{-1}$} & \multicolumn{2}{|l|}{$1.204 \mathrm{~mm}^{-1}$} \\
\hline $\mathrm{F}(000)$ & \multicolumn{2}{|l|}{1960} & \multicolumn{2}{|l|}{1848} \\
\hline Crystal size & \multicolumn{2}{|c|}{$0.23 \times 0.19 \times 0.07 \mathrm{~mm}^{3}$} & \multicolumn{2}{|c|}{$0.18 \times 0.05 \times 0.04 \mathrm{~mm}^{3}$} \\
\hline Theta range for data collection & \multicolumn{2}{|l|}{1.55 to $25.68^{\circ}$} & \multicolumn{2}{|l|}{1.94 to $25.50^{\circ}$} \\
\hline Index ranges & \multicolumn{2}{|c|}{$-15<=\mathrm{h}<=15,-15<=\mathrm{k}<=16,-32<=\mathrm{l}<=32$} & \multicolumn{2}{|c|}{$-23<=\mathrm{h}<=23,-15<=\mathrm{k}<=15,-19<=\mathrm{l}<=18$} \\
\hline Reflections collected & \multicolumn{2}{|l|}{51040} & \multicolumn{2}{|l|}{35252} \\
\hline Independent reflections & \multicolumn{2}{|c|}{$16476[\mathrm{R}(\mathrm{int})=0.0790]$} & $7206[\mathrm{R}$ (int) $=0.20$ & \\
\hline Completeness to theta $=$ & $99.2 \%$ & & $97.6 \%$ & \\
\hline Absorption correction & Numerical & & Numerical & \\
\hline Max. and min. transmission & 0.9676 and 0.9006 & & 0.9120 and 0.7257 & \\
\hline Refinement method & Full-matrix least-sc & ares on $\mathrm{F}^{2}$ & Full-matrix least-sc & res on $\mathrm{F}^{2}$ \\
\hline Data / restraints / parameters & $16476 / 57 / 1111$ & & $7206 / 6 / 444$ & \\
\hline Goodness-of-fit on $\mathrm{F}^{2}$ & 1.035 & & 0.920 & \\
\hline Final $\mathrm{R}$ indices $[\mathrm{I}>2 \operatorname{sigma}(\mathrm{I})]$ & $\mathrm{R} 1=0.0774, \mathrm{wR} 2$ & 0.2030 & $\mathrm{R} 1=0.0719, \mathrm{w} \mathrm{R} 2$ & .0848 \\
\hline $\mathrm{R}$ indices (all data) & $\mathrm{R} 1=0.1099, \mathrm{wR} 2$ & 0.2241 & $\mathrm{R} 1=0.1597, \mathrm{wR} 2$ & 0.1017 \\
\hline Largest diff. peak and hole & 0.891 and $-1.991 \mathrm{e}$ & & 0.889 and $-0.637 \mathrm{e}$ & \\
\hline
\end{tabular}




\section{Crystallographic Data}

\begin{tabular}{|c|c|c|}
\hline Label & $4 a$ & $4 \mathrm{~b}$ \\
\hline Empirical formula & $\mathrm{C}_{75} \mathrm{H}_{102} \mathrm{Cl}_{10} \mathrm{~N}_{8} \mathrm{O}_{12} \mathrm{Zn}_{4}$ & $\mathrm{C}_{62} \mathrm{H}_{76} \mathrm{Cl}_{4} \mathrm{~N}_{8} \mathrm{O}_{12} \mathrm{Zn}_{4}$ \\
\hline Formula weight & 1923.6 & 1528.59 \\
\hline Temperature & $133(2) \mathrm{K}$ & $133(2) \mathrm{K}$ \\
\hline Wavelength & 0.71073 & $0.71073 \AA$ \\
\hline Crystal system & Monoclinic & Triclinic \\
\hline Space group & $P 21 / \mathrm{n}$ & $P-1$ \\
\hline \multirow[t]{3}{*}{ Unit cell dimensions } & $\mathrm{a}=20.0089(5) \AA$ & $\mathrm{a}=10.5775(5) \AA \quad \alpha=96.820(4)^{\circ}$ \\
\hline & $\mathrm{b}=11.1020(2) \AA$ & $\mathrm{b}=11.1996(5) \AA \quad \beta=105.941(3)^{\circ}$ \\
\hline & $\mathrm{c}=20.0964(2) \AA$ & $\mathrm{c}=16.0678(7) \AA \quad \gamma=107.980(3)^{\circ}$ \\
\hline Volume & $4415.35(19) \AA^{3}$ & $1697.22(13) \AA^{3}$ \\
\hline Z & 2 & 1 \\
\hline Density (calculated) & $1.447 \mathrm{Mg} / \mathrm{m}^{3}$ & $1.496 \mathrm{Mg} / \mathrm{m}^{3}$ \\
\hline Absorption coefficient & $1.436 \mathrm{~mm}^{-1}$ & $1.618 \mathrm{~mm}^{-1}$ \\
\hline $\mathrm{F}(000)$ & 1988 & 788 \\
\hline Crystal size & $0.50 \times 0.40 \times 0.17 \mathrm{~mm}^{3}$ & $0.50 \times 0.50 \times 0.20 \mathrm{~mm}^{3}$ \\
\hline Theta range for data collection & 1.34 to $26.77^{\circ}$ & 1.35 to $26.75^{\circ}$ \\
\hline Index ranges & $-25<=\mathrm{h}<=25,-14<=\mathrm{k}<=14,-25<=\mathrm{l}<=25$ & $-13<=\mathrm{h}<=11,-14<=\mathrm{k}<=14,-20<=\mathrm{l}<=20$ \\
\hline Reflections collected & 50548 & 22197 \\
\hline Independent reflections & $9347[\mathrm{R}($ int $)=0.0537]$ & $7193[\mathrm{R}($ int $)=0.1226]$ \\
\hline Completeness to theta $=$ & $99.5 \%$ & $99.5 \%$ \\
\hline Absorption correction & Numerical & Numerical \\
\hline Max. and min. transmission & 0.7788 and 0.4302 & 0.6414 and 0.3971 \\
\hline Refinement method & Full-matrix least-squares on $\mathrm{F}^{2}$ & Full-matrix least-squares on $\mathrm{F}^{2}$ \\
\hline Data / restraints / parameters & $9347 / 0 / 574$ & $7193 / 0 / 416$ \\
\hline Goodness-of-fit on $\mathrm{F}^{2}$ & 1.009 & 1.036 \\
\hline Final R indices $[I>2 \operatorname{sigma}(I)]$ & $\mathrm{R} 1=0.0322, \mathrm{wR} 2=0.0741$ & $\mathrm{R} 1=0.0509, \mathrm{wR} 2=0.1428$ \\
\hline $\mathrm{R}$ indices (all data) & $\mathrm{R} 1=0.0441, \mathrm{wR} 2=0.0778$ & $\mathrm{R} 1=0.0565, \mathrm{wR} 2=0.1470$ \\
\hline Largest diff. peak and hole & 0.414 and -0.435 e. $\AA^{-3}$ & 1.999 and -1.078 e. $\AA^{-3}$ \\
\hline
\end{tabular}




\section{Crystallographic Data}

\begin{tabular}{|c|c|c|c|c|}
\hline Label & \multicolumn{2}{|l|}{$4 \mathrm{e}$} & \multicolumn{2}{|l|}{$4 \mathrm{f}$} \\
\hline Empirical formula & \multicolumn{2}{|c|}{$\mathrm{C}_{72} \mathrm{H}_{10} \mathrm{Cl}_{4} \mathrm{~N}_{8} \mathrm{O}_{6} \mathrm{Rh}_{2}$} & \multicolumn{2}{|c|}{$\mathrm{C}_{58.50} \mathrm{H}_{68} \mathrm{~F}_{12} \mathrm{~N}_{8} \mathrm{O}_{8.5} 0 \mathrm{P}_{2} \mathrm{Rh}_{2}$} \\
\hline Formula weight & \multicolumn{2}{|l|}{1525.25} & \multicolumn{2}{|l|}{1514.97} \\
\hline Temperature & \multicolumn{2}{|l|}{$133(2) \mathrm{K}$} & \multicolumn{2}{|l|}{$133(2) \mathrm{K}$} \\
\hline Wavelength & \multicolumn{2}{|l|}{$0.71073 \AA$} & \multicolumn{2}{|l|}{$0.71073 \AA$} \\
\hline Crystal system & \multicolumn{2}{|l|}{ Monoclinic } & \multicolumn{2}{|l|}{ Triclinic } \\
\hline Space group & \multicolumn{2}{|l|}{$P 21 / \mathrm{c}$} & \multicolumn{2}{|l|}{$P-1$} \\
\hline \multirow[t]{3}{*}{ Unit cell dimensions } & $\mathrm{a}=15.41(3) \AA$ & $\alpha=90^{\circ}$ & $\mathrm{a}=10.1681(4) \AA$ & $\alpha=79.585(3)^{\circ}$ \\
\hline & $\mathrm{b}=38.29482) \AA$ & $\beta=116.87^{\circ}$ & $\mathrm{b}=12.1809(5) \AA$ & $\beta=77.163(3)^{\circ}$ \\
\hline & $c=14.671(3) \AA$ & $\gamma=90^{\circ}$ & $\mathrm{c}=13.6238(6) \AA$ & $\gamma=85.386(3)^{\circ}$ \\
\hline Volume & \multicolumn{2}{|l|}{$7538(3) \AA^{3}$} & \multicolumn{2}{|l|}{$1616.69(12) \AA^{3}$} \\
\hline Z & \multicolumn{2}{|l|}{4} & \multicolumn{2}{|l|}{1} \\
\hline Density (calculated) & \multicolumn{2}{|l|}{$1.344 \mathrm{Mg} / \mathrm{m}^{3}$} & \multicolumn{2}{|l|}{$1.556 \mathrm{Mg} / \mathrm{m}^{3}$} \\
\hline Absorption coefficient & \multicolumn{2}{|l|}{0.633} & \multicolumn{2}{|l|}{$0.654 \mathrm{~mm}^{-1}$} \\
\hline $\mathrm{F}(000)$ & \multicolumn{2}{|l|}{3192} & \multicolumn{2}{|l|}{771} \\
\hline Crystal size & \multicolumn{2}{|c|}{$0.254 \times 0.245 \times 0.115 \mathrm{~mm}^{3}$} & \multicolumn{2}{|c|}{$0.28 \times 0.18 \times 0.08 \mathrm{~mm}^{3}$} \\
\hline Theta range for data collection & \multicolumn{2}{|l|}{1.61 to $25.63^{\circ}$} & \multicolumn{2}{|l|}{1.56 to $26.81^{\circ}$} \\
\hline Index ranges & \multicolumn{2}{|c|}{$-18<=\mathrm{h}<=16,-46<=\mathrm{k}<=46,-16<=\mathrm{l}<=17$} & \multicolumn{2}{|c|}{$-12<=\mathrm{h}<=12,-15<=\mathrm{k}<=15,-17<=\mathrm{l}<=17$} \\
\hline Reflections collected & \multicolumn{2}{|l|}{11178} & 20991 & \\
\hline Independent reflections & $14071[\mathrm{R}$ (int) $=0$ & 76] & $6838[\mathrm{R}$ (int) $=0.0$ & \\
\hline Completeness to theta $=$ & $100 \%$ & & $98.7 \%$ & \\
\hline Absorption correction & Numerical & & Numerical & \\
\hline Max. and min. transmission & 0.7075 and 0.8819 & & 0.9390 and 0.8628 & \\
\hline Refinement method & Full-matrix least-s & ares on $\mathrm{F}^{2}$ & Full-matrix least-s & res on $\mathrm{F}^{2}$ \\
\hline Data / restraints / parameters & 14071 / 2 / 861 & & $6838 / 117 / 459$ & \\
\hline Goodness-of-fit on $\mathrm{F}^{2}$ & 0.960 & & 1.001 & \\
\hline Final $\mathrm{R}$ indices $[\mathrm{I}>2 \operatorname{sigma}(\mathrm{I})]$ & $\mathrm{R} 1=0.0343, \mathrm{wR} 2$ & $=0.0750$ & $\mathrm{R} 1=0.0403, \mathrm{wR} 2$ & 0.0985 \\
\hline $\mathrm{R}$ indices (all data) & $\mathrm{R} 1=0.0505, \mathrm{wR} 2$ & $=0.0791$ & $\mathrm{R} 1=0.0541, \mathrm{wR} 2$ & 0.1029 \\
\hline Largest diff. peak and hole & -0.493 and -0.706 & & 1.182 and -0.946 & \\
\hline
\end{tabular}




\begin{tabular}{|c|c|c|}
\hline Label & \multicolumn{2}{|l|}{$\left[\mathrm{HL}^{10}\right] \mathrm{Cl}$} \\
\hline Empirical formula & \multicolumn{2}{|l|}{$\mathrm{C}_{37} \mathrm{H}_{41} \mathrm{ClN}_{2} \mathrm{Si}$} \\
\hline Formula weight & \multicolumn{2}{|l|}{605.35} \\
\hline Temperature & \multicolumn{2}{|l|}{$133(2) \mathrm{K}$} \\
\hline Wavelength & \multicolumn{2}{|l|}{$0.71073 \AA$} \\
\hline Crystal system & \multicolumn{2}{|l|}{ Triclinic } \\
\hline Space group & \multicolumn{2}{|l|}{$P-1$} \\
\hline \multirow[t]{3}{*}{ Unit cell dimensions } & $\mathrm{a}=8.9189(5) \AA$ & $\alpha=88.296(4)^{\circ}$ \\
\hline & $\mathrm{b}=13.5893(7) \AA$ & $\beta=86.115(4)^{\circ}$ \\
\hline & $\mathrm{c}=14.0794(7) \AA$ & $\gamma=81.066(4)^{\circ}$ \\
\hline Volume & \multicolumn{2}{|l|}{$1681.55(15) \AA^{3}$} \\
\hline $\mathrm{Z}$ & \multicolumn{2}{|l|}{2} \\
\hline Density (calculated) & \multicolumn{2}{|l|}{$1.196 \mathrm{Mg} / \mathrm{m}^{3}$} \\
\hline Absorption coefficient & \multicolumn{2}{|l|}{$0.213 \mathrm{~mm}^{-1}$} \\
\hline $\mathrm{F}(000)$ & \multicolumn{2}{|l|}{644} \\
\hline Crystal size & \multicolumn{2}{|c|}{$0.36 \times 0.18 \times 0.15 \mathrm{~mm}^{3}$} \\
\hline $\begin{array}{l}\text { Theta range for data } \\
\text { collection }\end{array}$ & \multicolumn{2}{|l|}{1.45 to $26.83^{\circ}$} \\
\hline Index ranges & \multicolumn{2}{|c|}{$-10<=\mathrm{h}<=11,-17<=\mathrm{k}<=17,-17<=\mathrm{l}<=17$} \\
\hline Reflections collected & \multicolumn{2}{|l|}{21591} \\
\hline Independent reflections & \multicolumn{2}{|c|}{$7126[\mathrm{R}(\mathrm{int})=0.0868]$} \\
\hline Completeness to theta $=$ & \multicolumn{2}{|l|}{$100.0 \%$} \\
\hline Absorption correction & \multicolumn{2}{|l|}{ Numerical } \\
\hline Max. and min. transmission & \multicolumn{2}{|l|}{0.9625 and 0.8080} \\
\hline Refinement method & \multicolumn{2}{|c|}{ Full-matrix least-squares on $\mathrm{F}^{2}$} \\
\hline $\begin{array}{l}\text { Data / restraints / } \\
\text { parameters }\end{array}$ & \multicolumn{2}{|l|}{$7126 / 1 / 391$} \\
\hline Goodness-of-fit on $\mathrm{F}^{2}$ & \multicolumn{2}{|l|}{1.070} \\
\hline Final $R$ indices $[I>2 \operatorname{sigma}(I)]$ & \multicolumn{2}{|c|}{$\mathrm{R} 1=0.0488, \mathrm{wR} 2=0.1160$} \\
\hline $\mathrm{R}$ indices (all data) & \multicolumn{2}{|c|}{$\mathrm{R} 1=0.0720, \mathrm{wR} 2=0.1233$} \\
\hline Largest diff. peak and hole & \multicolumn{2}{|c|}{0.341 and -0.341 e. $\AA^{-3}$} \\
\hline
\end{tabular}




\section{Abbreviations}

\section{12: List of Abbreviations}

\begin{tabular}{|c|c|}
\hline$\AA$ & Angstrom \\
\hline [cat] & catalyst \\
\hline Ar & Aryl \\
\hline $\mathrm{BuLi}$ & Butyl lithium \\
\hline $\mathrm{CH}_{2} \mathrm{Cl}_{2}$ & Dichloromethane \\
\hline COD & Cyclooctadiene \\
\hline DHP & Dihydropyran \\
\hline DME & Dimethoxyether \\
\hline DMSO & Dimethylsulfoxide \\
\hline DSC & Differential Scanning Calorimetry \\
\hline EI & Electron ionization \\
\hline ESI & Electrospray ionization \\
\hline $\mathrm{Et}_{2} \mathrm{O}$ & Diethyl ether \\
\hline $\mathrm{EtOH}$ & Ethanol \\
\hline g & gram \\
\hline GPC & Gel Permeation Chromatography \\
\hline HR-MS & High Resolution Mass Spectroscopy \\
\hline $\mathrm{Hz}$ & Hertz \\
\hline${ }^{2} \operatorname{Pr}$ & Isopropyl \\
\hline IR & Infrared \\
\hline$J$ & Coupling constant \\
\hline $\mathrm{KO} \mathrm{B}^{\prime} \mathrm{Bu}$ & Potassium tert-butoxide \\
\hline $\mathrm{L}$ & Ligand \\
\hline M & Molar \\
\hline $\mathrm{m} / \mathrm{z}$ & mass to charge ratio \\
\hline $\mathrm{M}^{+}$ & Molecular ion \\
\hline MALDI & Matrix-assisted laser desorption ionization \\
\hline $\mathrm{Me}$ & Methyl \\
\hline $\mathrm{MeOH}$ & Methanol \\
\hline $\mathrm{M}_{\mathrm{n}}$ & Number average molecular weight \\
\hline MS & Mass spectroscopy \\
\hline $\mathrm{M}_{\mathrm{w}}$ & Weight average molecular weight \\
\hline
\end{tabular}




$\begin{array}{ll}\mathrm{n}-\mathrm{Bu} & \text { normal-butyl } \\ \mathrm{NMR} & \text { Nuclear Magnetic Resonance } \\ \mathrm{NaBAr}^{\mathrm{F}}{ }_{4} & \text { Sodium tetrakis[3,5-bis(trifluoromethyl)phenyl]borate } \\ \mathrm{OAc} & \text { Acetate } \\ { }^{\circ} \mathrm{C} & \text { Degree Celsius } \\ \mathrm{Ph} & \text { Phenyl } \\ \mathrm{ppm} & \text { parts per million } \\ p-\mathrm{TSA} & \text { para- toluenesulfonic acid } \\ \mathrm{Py} & \text { Pyridine } \\ \mathrm{Pz} & \text { Pyrazolyl } \\ \text { TG } & \text { Thermogravimetry } \\ \text { THF } & \text { Tetrahydrofuran } \\ \text { THP } & \text { Tetrahydropyran } \\ \text { TMS } & \text { Trimethylsilylchloride } \\ \lambda & \text { wavelength [nm] }\end{array}$




\section{13: References}

1 C. E. Tinberg, S. J. Lippard, Acc. Chem. Res. 2011, 44, 280.

2 N. Sträter, W. N. Libscomb, T. Klabunde, B. Krebs, Angew. Chem. Int. Ed. 1996, 35, 2025.

3 J. Weston, Chem. Rev. 2005, 105, 2151.

4 M. Shibasaki, Y. Yamamoto, Multimetallic Catalysts in Organic Synthesis; Wiley-VCH: Weinheim, Germany, 2004.

5 E. K. van den Beuken, B. L. Ferringa, Tetrahedron 1998, 54, 12985.

6 B. Gabriele, R. Mancuso, G. Salerno, M. Costa, Adv. Synth. Catal. 2006, 348, 1101.

7 A. Zanardi, R. Corberan, J. A. Mata, E. Peris, Organometallics 2008, 27, 3570.

8 C. P. Casey, J. D. Audett, Chem. Rev. 1986, 86, 339.

9 F. R. Lemke, D. J. Szalda, R. M. Bullock, J. Am. Chem. Soc. 1991, 113, 8466.

10 J. R. Moss, L. G. Scott, Coord. Chem. Rev. 1984, 60, 171.

11 N. D.Jones, B. R. James. Adv. Synth. Catal. 2002, 344, 1126.

12 R. C. Matthews, D. K. Howell, W.-J. Peng, S. G. Train, W. D. Treleaven, G. G. Stanley, Angew. Chem. Int. Ed. Engl. 1996, 35, 2253.

13 M. E. Broussard, B. Juma, S. G. Train, W.-J. Peng, S. A. Laneman, G. G. Stanley, Science 1993, 260, 1784.

14 H. Li, T. J. Marks, Proc. Natl. Acad. Sci. USA 2006, 103, 15295.

15 M. Delferro, T. J. Marks, Chem. Rev. 2011, 111, 2450.

16 E. Solari, S. Antonijevic, S. Gauthier, R. Scopelliti, K. Severin, Eur. J. Inorg. Chem. 2007, 367.

17 T. Weskamp, F. J. Kohl, W. A. Herrmann, J. Organomet. Chem. 1999, 582, 362.

18 K. Severin, Chem. Eur. J. 2002, 8, 1515.

19 Y. Borguet, X. Sauvage, G. Zaragoza, A. Demonceau, L. Delaude, Organometallics 2011, 30, 2730.

20 S. Matsunaga, M. Shibasaki, M. Bull. Chem. Soc. Jpn. 2008, 81, 60.

21 J. M. López-Valbuena, E. C Escudero-Adan, J. Benet-Buchholz, Z. Freixa, P.W.N.M. van Leeuwen, Dalton Trans. 2010, 39,8560.

22 D. C. Powers, T. Ritter, Acc. Chem. Res. 2012, 45, 840.

23 G. Natta, P. Pino, g. Mazzanti, U. Giannini, J. Am. Chem. Soc. 1957, 79, 2975.

24 D. S. Breslow, N. R. Newburg, J. Am. Chem. Soc. 1957, 79, 5072. 
25 F. R. Wild, F. W. P. Zolnai, L. Huttner, G. H. H. Brintzinger, J. Organomet. Chem. 1982, 232, 233.

26. J. A. Ewen, R. L. Jones, A. Razavi, J. Ferrara, J. Am. Chem. Soc. 1998, 110, 6255.

27 H. Braunschweig, F. M. Breitling, Coord. Chem. Rev. 2006, 250, 2691.

28 H. Makio, N. Kashiwa, T. Fujita, Adv. Synth. Catal. 2002, 344, 5.

29 H. Makio, H. Terao, A. Iwashita, T. Fujita, Chem. Rev. 2011, 111, 2363.

30 N. Guo, C. L. Stern, T. J. Marks, J. Am. Chem. Soc. 2008, 130, 2246.

31 J. C. Flores, T. E. Ready, J. C. W. Chien, M. D. Rausch, J. Organomet. Chem. 1998, 562, 11.

32 S. K. Kim, H. K. Kim, M. H. Lee, S. W. Yoon, Y. Han, S. Park, J. Lee, Y. Do, Eur. J. Inorg. Chem. 2007, 537.

33 S. Amin, T. J. Marks, J. Am. Chem. Soc. 2007, 129, 2938.

34 S. Amin, T. J. Marks, J. Am. Chem. Soc. 2006, 128, 4506.

35 S. K. Kim, H. K. Kim, M. H. Lee, S. W. Yoon, Y. Han, S. Park, J. Lee, Y. Do, Eur. J. Inorg. Chem. 2007, 537.

36 N. Guo, L. Li, T. J. Marks, J. Am. Chem. Soc. 2004, 126, 6542.

37 R. W. Barnhart, G. C. Bazan, J. Am. Chem. Soc. 1998, 120, 1082.

38 J. Huang, Z. Feng, H. Wang, Y. Qian, J. Sun, Y. Xu, W. Chen, G. Zheng, J. Mol. Catal. A: Chem. 2002, 189, 187.

39 F. M. Bauers, S. Mecking, Angew. Chem. Int. Ed. 2001, 40, 3020.

40 C. M. Wang, S. Friedrich, T. R. Youkin, R. T. Li, R. H. Grubbs, D. A. Bansleben, M. W. Day, Organometallics 1998, 17, 3149 .

41 G. J. P. Britovsek, V. C. Gibson, D. F. Wass, Angew. Chem. Int. Ed. 1999, 38, 428.

42 Z. Guan, P. M. Cotts, E. F. McCord, S. J. McLain, Science 1999, 283. 2059.

43 L. K. Johnson, S. Mecking, M. Brookhart, J. Am. Chem. Soc. 1996, 118, 267.

44 D. P. Gates, S. A. Svejda, E. Onate, C. M. Killian, L. K. Johnson, P. S. White, M. Brookhart, Macromolecules 2000, 33, 2320.

45 K. A. Ostoja Starzewski, J. Witte, Angew. Chem. Int. Ed. Engl. 1985, 24, 599.

46 B. L. Small, M. Brookhart, A. M. A. Bennett, J. Am. Chem. Soc. 1998, 120, 4049.

47 G. J. P. Britovsek, V. C. Gibson, B. S. Kimberly, P. J. Maddox, S. Mastroianni, S. J. McTavish, S. Redshaw, G. A. Solan, S. Strömberg, A. J. P. White, D. J. Williams, J. Am. Chem. Soc. 1999, 121, 8728. 
48 Z. Guan, W. J. Marshall, Organometallics 2002, 21, 3850.

49 P. van Leeuwen, P. C. J. Kamer, J. N. H. Reek, P. Dierkes, Chem. Rev. 2000, 100, 2741.

50 A. Tomov, J. P. Broyer, R. Spitz, Macromol. Symp. 2000, 150, 53.

51 A. Held, F. M. Bauers, S. Mecking, Chem. Commun. 2000, 301.

52 G. J. Domski, J. M. Rose, G. W. Coates, A. D. Bolig, M. Brookhart, Prog. Polymer Sci. 2007, 32, 30.

53 S. D. Arthur, A. M. A. Bennett, M. S. Brookhart, E. B. Coughlin, J. Feldman, S. D. Ittel, L. K. Johnson, C. M. Killian; K. A. Kreutzer, E. F. McCord, S. J. McLain, A. Parthasarathy, L. Wang, Z.-Y Yang; 1999, WO Patent 9623010 A2 960801.

54 P. B. MacKenzie, L. S. Moody, C. M. Killian, J. A. Ponasik, J. P. McDevitt, 1998, WO Patent 9840374.

55 V. C. Gibson, C. Redshaw, G. A. Solan, Chem. Rev. 2007, 107, 1745.

56 B.L. Small, M. Brookhart, J. Am. Chem. Soc. 1998, 120, 7143.

57 A. M. A. Bennet, (Dupont) 1998, WO Patent 98/27124.

58 F. Bauers, S. Mecking, Macromolecules 2001, 34, 1165.

59 J. Sun, Y. Shan, Y. Xu, Y. Cui, H. Schumann, M. Hummert, J. Polym. Sci., Part A: Polym. Chem. 2004, 42, 6071.

60 Y,-H Shan, J.-Q Sun, Y.-J Xu, Y-G. Cui, F. Lin, J. Chin, Polym. Sci. 2005, 23, 301.

61 H. Makio, T. Fujita, Acc. Chem. Res. 2009, 42, 1532.

62 A. Nakamura, T. Anselment, J. Claverie, B. Goodall, R. Jordan, S. Mecking, B. Rieger, A. Sen, P.W.N.M. van Leeuwen, K. Nozaki, Acc. Chem. Res. 2013, 46, 1439.

63 M. Arndt-Rosenau, 2006, US 2006/0004218 A1.

64 A. Koppl, H. G. Alt, J. Mol. Catal. A: Chem. 2000, 154, 45.

65 T. V. Laine, M. Klinga, M. Leskela, Eur. J. Inorg. Chem. 1999, 959.

66 G. Ambrosi, M. Formica, V. Fusi, L. Giorgi, M. Micheloni, Coord. Chem. Rev. 2008, 252, 1121.

67 B. A. Rodriguez, M. Delferro, T. J. Marks, J. Am. Chem. Soc. 2009, 131, 5902.

68 H. Shen, B. R. Goodall, U.S. Pat. 2006, 2006/0270811.

69 W. Dittrich, R.C. Schulz, Angew. Makromol. Chemie. 1971, 15, 109.

70 X. Mi, Z. Ma, N. Cui, L. Wang, Y. Ke, Y. Hu, J. Appl. Polym. Sci. 2003, 88, 3273.

71 E. Szuromi, H. Shen, B. L. Goodall, R. F. Jordan, Organometallics 2008, 27, 402. 
72 D. A. Barnes, G. M. Benedikt, B. L. Goodall, S. S. Huang, H. A. Kalamarides, S. Lenard, L. H. McIntosh II, K. T. Selvy, R. A. Shick, L. F. Rhodes, Macromolecules 2003, 36, 2623.

73 H.-K. Luo, H. Schumann, J. Mol. Catal. A: Chem. 2005, 227, 153.

74 B. A. Rodriguez, M. Delferro, T. J. Marks, J. Am. Chem. Soc. 2009, 131, 5902.

75 M. H. Klingele, S. Brooker, Coord. Chem. Rev. 2003, 241, 119.

76 U. Beckmann, S. Brooker, Coord. Chem. Rev. 2003, 245, 17.

77 S. Brooker, T. C. Davidson, S. J. Hay, R. J. Kelly, D. K. Kennepohl, P. G. Plieger, B. Moubaraki, K. S.

Murray, E. Bill, E. Bothe, Coord. Chem. Rev. 2001, 3, 216.

78 S. Brooker, Eur. J. Inorg. Chem. 2002, 2535.

79 W. Kaim, Coord. Chem. Rev. 2002, 230, 127.

80 S. Trofimenko, Chem. Rev. 1993, 93, 943.

81 E. K. Van Den Beuken, B. L. Feringa, Tetrahedron 1998, 54, 12985.

82 S. Trofimenko, Progr. Inorg. Chem. 1986, 34, 115.

83 G. La Monica, G. A. Ardizzoia, Progr. Inorg. Chem. 1997, 46, 151

84 S. Trofimenko, Chem. Rev. 1972, 72, 497.

85 N. Kitajima, W. B. Tolman, Prog. Inorg.Chem. 1995, 43, 419.

86 M. D. Ward, J. A. McCleverty and J. C. Jeffery, Coord. Chem. Rev. 2001, 222, 251.

87 T. A. Kaden, Coord. Chem. Rev. 1999, 190-192, 371.

88 C. Pettinari and C. Santini, in Comprehensive Coordination Chemistry II, ed. J. A. McCleverty and T. J. Meyer, Elsevier, Amsterdam, 2004, vol. 1, ch. 1.10, pp. 159-210.

89 F. Mani, Coord. Chem. Rev. 1992, 120, 325.

90 A. P. Sadimenko, S. S. Bason, Coord. Chem. Rev. 1996, 147, 247.

91 G. La Monica, G. A. Ardizzoia, Prog. Inorg. Chem. 1997, 46, 151.

92 T. N. Sorrell, D. L. Jameson, Inorg. Chem. 1982, 21, 1014.

93 F. Paap, A. Erdonmez, W.L. Driessen, J. Reedijk, Acta Crystallogr. 1986, C42, 783.

94 A. L. Spek, W. L. Driessen, W. G. R. Wiesmeijer, Acta Crystallogr. 1988, C44, 1567.

95 F. Meyer, S. Beyreuther, K. Heinze, L. Zsolnia, Chem. Ber./Recenil 1997, 130, 605.

96 T. N. Sorrell, V.A. Vankai, M.L. Garrity, Inorg. Chem. 1991, 30, 207.

97 C. M. Hartshorn, P. J. Steel, J. Chem. Soc. Chem. Commun. 1997, 541. 
98 T. N. Sorrell, A. S. Borovik, C.-C. Shen, Inorg. Chem. 1986, 25, 589.

99 S. Trofimenko, J. Am. Chem. Soc. 1967, 89,3170.

100 S. Trofimenko, J. Am. Chem. Soc. 1969, 91, 3183.

101 S. Trofimenko, Accounts Chem. Res. 1971, 4, 17.

102 C. Pettinari, R. Pettinari, Coord. Chem. Rev. 2005, 249, 525.

103 C. Pettinari, R. Pettinari, Coord. Chem. Rev. 2005, 249, 663.

104 M. A. Halcrow, Coord. Chem. Rev. 2005, 249, 2880.

105 X. Liu, J. A. McAllister, M. P. de Miranda, E. J. L. McInnes, C. A. Kilner, M. A. Halcrow, Chem.-Eur. J. 2004, 10, 1827.

106 G. B. Deacon, A. Gitlits, B. W. Skelton and A. H. White, Chem. Commun. 1999, 1213.

107 E. Sebe, I. A. Guzei, M. J. Heeg, L. M. Liable-Sands, A. L. Rheingold, C. H. Winter, Eur. J. Inorg. Chem. 2005, 3955.

108 J. C. Roder, F. Meyer and H. Pritzkow, Z. Naturforsch., B: Chem. Sci. 2002, 57, 773.

109 G. A. Ardizzoia, S. Cenini, G. La Monica, N. Masciocchi, A. Maspero, M. Moret, Inorg. Chem. 1998, 37,4284 .

110 C. Mealli, C. S. Arcus, J. L. Wilkinson, T. J. Marks, J. A. Ibers, J. Am. Chem. Soc. 1976, 98, 711.

111 G. B. Deacon, E. E. Delbridge, C. M. Forsyth, Angew. Chem. Int. Ed. 1999, 38, 1766.

112 F. Breher. H. Rüegger, Angew. Chem., Int. Ed. 2005, 44, 473.

113 G. B. Deacon, E. E. Delbridge, C. M. Forsyth, B. W. Skelton, A. H. White, J. Chem. Soc., Dalton Trans. $2000,745$.

114 W. Burger, J. Strähle, Z. Anorg. Allg. Chem. 1985, 529, 111.

115 K. R. Gust, J. E. Knox, M. J. Heeg, H. B. Schlegel, C. H. Winter, Angew. Chem., Int. Ed. 2002, 41, 1591.

116 X. Liu, J. A. McAllister, M. P. de Miranda, E. J. L. McInnes, C. A. Kilner, M. A. Halcrow, Chem.-Eur. J. 2004, 10, 1827.

117 S. L. Renard, I. Sylvestre, S. A. Barrett, C. A. Kilner, M. A. Halcrow, Inorg. Chem. 2006, 45, 8711.

118 G. B. Deacon, E. E. Delbridge, C. M. Forsyth, B. W. Skelton,A. H. White, J. Chem. Soc., Dalton Trans. $2000,745$.

119 G. B. Deacon, C. M. Forsyth, A. Gitlits, R. Harika, P. C. Junk, B. W.Skelton and A. H. White, Angew. Chem., Int. Ed. 2002, 41, 3249. 
120 M. A. Halcrow, Dalton Trans. 2009, 2059.

121 F. Meyer, Eur. J. Inorg. Chem. 2006, 3789

122 A. L. Gavrilova, B. Bosnich, Chem. Rev. 2004, 104, 349.

123 R. Mukherjee, Coord. Chem. Rev. 2000, 203, 151.

124 J. Klingele, S. Dechert, F. Meyer, Coord. Chem. Rev. 2009, 253, 2698.

125 R. Fusco, Chem. Heterocycl. Compd. 1967, 22, 3.

126 G. Coispeau, J. Elguero, Bull. Soc. Chim. Fr. 1970, 2717.

127 Y. Lin, S. A. Lang, Jnr. J. Heteroyycl. Chem. 1977, 14, 345.

128 M. Konrad, S. Wuthe, F. Meyer, E. Kaifer, Eur. J. Inorg. Chem. 2001, 9, 2233.

129 C. Dubs, A. Inagaki, M. Akita, Chem. Commun. 2004, 2760.

130 J. C. Röder, F. Meyer, R. F. Winter, E. Kaifer, J. Organomet. Chem. 2002, 641, 113.

131 W. L. Driessen, R .A. G. D. Graaff, J. Ochocki, J. Reedijk, Inorg. Chim. Acta 1988, 41, 150.

132 M. R. Malachowski, H. B. Huynh, L. J. Tomlinson, R. S. Kelly, J. W. Furbee, Jnr., J. Chem. Soc. Dalton Trans. 1995, 31.

133 G. J. van Driel, W. L. Driessen, J. Reedijk, Inorg. Chem. 1985, 24, 2919.

134 T. N. Sorrell, D. L. Jameson, Inorg. Chem. 1982, 21, 1014.

135 S. Tanaka, C. Dubs, A. Inagaki, M. Akita, Organometallics 2004, 23, 317.

136 C. Dubs, T. Yamamoto, A. Inakai, M. Akita, Organometallics 2006, 25, 1344.

137 S. Tanaka, C. Dubs, A. Inagaki, M. Akita, Organometallics 2005, 24, 163.

138 S. A. Reindle, A. Poethig, M. Drees, B. Bechlars, E. Herdtweck, W. A. Herrmann, F. E. Kuehn, Organometallics 2013, 32, 4082.

139 Y. Zhou, Z. Xi, W. Chen, D. Wang, Organometallics 2008, 27, 5911.

140 Y. Zhou, W. Chen, Organometallics 2007, 26, 2742.

141 J.C. Röder, F. Meyer, E. Kaifer, Angew. Chem. Int. Ed. 2002, 41, 2304.

142 K. Shindo, Y. Mori, K. Motoda, H. Sakiyama, N. Matsumoto, H. Okawa, Inorg. Chem. 1992, 31, 4987.

143 T. G. Schenk, J. M. Downs, C. R. C. Milne, P. B. Mackenzie, H. Boucher, J. Whelan, B. Bosnich, Inorg. Chem. 1985, 24, 2334.

144 C. Dubs, T. Yamamoto, A. Inagaki, M. Akita, Organometallics 2006, 25, 1359.

145 J. C. Röder, F. Meyer, H. Pritzkow, Organometallics 2001, 20, 811. 
146 F. Meyer, E. Kaifer, P. Kircher, K. Heinze, H. Pritzkow, Chem. Eur. J. 1999, 5, 1617.

147 J. Ackermann, F. Meyer, E. Kaifer, H. Pritzkow, Chem. Eur. J. 2002, 8, 247.

148 Y. Zhou, W. Chen, Organometallics 2007, 26, 2742.

149 Y. Zhou, X. Zhang, W. Chen, H. Qiu, J. Organomet. Chem. 2008, 693, 205

150 U. J. Scheele, M. Georgiou, M. John, S. Dechert, F. Meyer, Organometallics 2008, 27, 5146.

151 G. Noël, J. C. Röder, S. Dechert, H. Pritzkow, L. Bolk, S. Mecking, F. Meyer, Adv. Synth. Catal. 2006, $348,887$.

152 M.-C Moret, P. Chen, Organometallics 2008, 27, 4903.

153 A. Sachse, V. Daebel, A. Lange, S. Demeshko, S. Dechert, F. Meyer, Dalton Trans. 2010, 39, 3903.

154 A. Sachse, M. John, F. Meyer, Angew. Chem. Int. Ed. 2010, 49, 1986.

155 J. C. Röder, F. Meyer, E. Kaifer, H. Pritzkow, Eur. J. Inorg. Chem. 2004, 1646.

156 J. C. Röder, F. Meyer, H. Pritzkow, Chem. Commun. 2001, 2176.

157 A. Sachse, G. Noël, S. Dechert, S. Demeshko, A. Honecker, A. Alfonsov, V. Kataev, F. Meyer, Eur. J. Inorg. Chem. 2008, 5390.

158 A. Sachse, S. Demeshko, F. Meyer, Dalton Trans. 2009, 37, 7756.

159 O. Dechy-Cabaret, B. Martin-Vaca, D. Bourissou, Chem. Rev. 2004, 104, 6147.

160 O. Wolf, M. Crank, M. Patel, F. Marscheider-Weidemann, J. Schleich, B.Hüsing, G. Angerer, Technoeconomic Feasibility of Large scale Production of Bio-based Polymers in Europe, Tech. rep. EUR 22103 EN, European Commission, 2005.

161 S. Jacobsen, P. Degée, H. Fritz, P. Dubois, R. Jérôme, Polym. Eng. Sci. 1999, 39, 1311.

162 A.-C. Albertsson, I. K. Varma, Adv. Polym. Sci. 2002, 12, 1841.

163 A. -C. Albertsson, I. K. Varma, Biomicromolecules 2003, 4, 1466.

164 M. Vert in Biopolymers, Vol. 4 (Eds.: A. Steinbüchel, Y. Doi), Wiley-VCH, Weinheim, 2002. Pg. 179.

165 C. R. Hankermeyer, R. S. Tjeerdema, Rev. Environ Contam Toxicol. 1999, 159, 1.

166 Y. Tokiwa, B. P. Calabia, Biotechnol Lett. 2004, 26, 15, 1181.

167 R. W. Lenz, R. H. Marchessault, Biomacromolecules, 2005, 6, 1.

168 X. Pang, X. Zhuang, Z. Tang, X. Chen, Biotechnol J. 2010, 5, 1125.

169 R. Auras, B. Harte, S. Selke, Macromol. Biosci. 2004, 4, 835.

170 R. H. Platel, L. M. Hodgson, C. K. Williams, Polym. Rev. 2008, 48, 11. 
171 K. Fukushima, Y. Kimura, Polym. Int. 2006, 55, 626.

172 S. K. Ritter, Chem. Eng. News 2002, 80, 19.

173 O. Dechy-Cabaret, B. Martin-Vaca, D. Bourissou, Chem. Rev. 2004, 104, 6147.

174 W. Dittrich, R.C. Schulz, Angew. Makromol. Chemie. 1971, 15, 109.

175 C. M. Thomas, Chem. Soc. Rev. 2010, 39, 165.

176 H. R. Kricheldorf, M. Berl, N. Scharnagl, Macromolecules 1988, 21. 286.

177 P. Dubois, R. Jérôme, P. Teyssié, Makromol. Chem., Macromol. Symp. 1991, 42/43, 103.

178 M. H. Chisholm, M. J. Patmore, Z. Zhou, Chem. Commun. 2005, 127.

179 N. E. Kamber, W. Jeong, R. M. Waymouth, R. C. Pratt, B. G. G. Lohmeijer, J. L. Hedrick, Chem. Rev. 2007, 107, 5813.

180 C. K. Williams, Chem. Soc. Rev. 2007, 36, 1573.

181 C. A. Wheaton, P. G. Hayes, B. J. Ireland, Dalton Trans. 2009, 4832.

182 A. P. Dove, Chem. Comm. 2008, 6446.

183 H. Chen, H. Tang, C. Lin, Polymer 2007, 48, 2257.

184 D. J. Darensburg, W. Choi, C. P. Richers, Macromolecules 2007, 40, 3521.

185 M. H. Chisholm, J. C. Gallucci, G. Yaman, Inorg. Chem. 2007, 46, 8676.

186 H.-Y. Chen, J.-H, Huang, C.-C. Lin, Macromolecules 2007, 40, 8855.

187 M.-L. Shueh, Y.-S. Wang, B.-H. Huang, C.-Y. Kuo, C.-C. Lin, Macromolecules 2004, 37, 5155.

188 P. A. Cameron, D. Jhurry, V. C. Gibson, J. P. W. Andrew, D. J. Williams, S. Williams. Macromol. Rapid Commun. 1999, 20, 616.

189 D. Pospiech, H. Komber, D. Jehnichen, L. Häussler, K. Eckstein, H. Scheibner, A. Janke, H. R. Kricheldorf, O. Petermann, Biomacromolecules 2005, 6, 439.

190 M. H. Chisholm, J. C. Gallucci, C. Krempner, Polyhedron 2007, 26, 4436.

191 B. J. O’Keefe, M. A. Hillmyer, W. B. Tolman, J. Chem. Soc., Dalton Trans. 2001, 2215.

192 M. Okada, Prog. Polym. Sci. 2002, 27, 87.

193 C. A. Wheaton, P. G. Hayes, B. J. Ireland, Dalton Trans. 2009, 4832.

194 C. M. Thomas, Chem. Soc. Rev. 2010, 39, 165.

195 M. Cheng, A. B. Attygalle, E. B. Lobkovsky, G. W. Coates, J. Am.Chem. Soc. 1999, 121, 11583.

196 M. H. Chisholm, S. S. Iyer, M. E. Matison, D. G. McCollum, M. Pagel, Chem. Commun. 1997, 1999. 
197 M. H. Chisholm, N. W. Eilerts, J. C. Huffman, S. S. Iyer, M. Pacold, K. Phomphrai, J. Am. Chem. Soc. 2000, 122, 11845.

198 M. H. Chisholm, J. C. Gallucci, K. Phomphrai, Inorg. Chem. 2002, 41, 2785.

199 M. H. Chisholm, J. C. Gallucci, H. Zhen, J. C. Huffman, Inorg. Chem. 2001, 40, 5051.

200 L. E. Breyfogle, C. K. Williams, V. G. Young-Jr., M. A. Hillmyer, W. B. Tolman, Dalton Trans. 2006, 928.

201 M. S. Hill, P. B. Hitchcock, J. Chem. Soc., Dalton Trans. 2002, 4694.

202 T. R. Jensen, L. E. Breyfogle, M. A. Hillmyer, W. B. Tolman, Chem. Commun. 2004, 2504.

203 A. J. Arduengo, H. V. Rasika, D. F. Davidson, R. L. Harlow, J. Organomet. Chem. 1993, 462, 13.

204 M. D. Hannant, M. Schormann, M. Bochmann, J. Chem. Soc., Dalton Trans. 2002, 4071.

205 B. M. Chamberlain, M. Cheng, D. R. Moore, T. M. Ovitt, E. B. Lobkovsky, G. W. Coates, J. Am. Chem. Soc. 2001, 123, 3229.

206 A. P. Dove, V. C. Gibson, E. L. Marshall, A. J. P. White, D. J. Williams, J. Chem. Soc., Dalton Trans. 2004, 570 .

207 M. H. Chisholm, J. C. Gallucci, K. Phomphrai, Inorg. Chem. 2005, 44, 8004.

208 C. K. Williams, L. E. Breyfogle, S. K. Choi, W. Nam, V. G. Young Jr., M. A Hillmyer, W. B. Tolman, J. Am. Chem. Soc. 2003, 125, 11350.

209 J. Ejfler, S. Szafert, K. Mierzwicki, L. B. Jerzykiewicz, P. Sobota, Dalton Trans. 2008, 6556.

210 C.-Y Sung, C,-Y Li, J,-K Su, T,-Y Chen, C,-H Lin, B,-T Ko, Dalton Trans. 2012, 41, 953.

211 C. Zhang, Z.-X. Wang, J. Organomet. Chem. 2008, 693, 3151.

212 Z. Zheng, G. Zhao, R. Fablet, M. Bouyayhi, C. M. Thomas, T. Roisnel, O. Casagrande, Jr. and J.-F, Carpentier, New J. Chem. 2008, 32, 2279.

213 T. R. Jensen, L. e. Breyfogle, M. A. Hillmyer, W. B. Tolman, Chem. Commun. 2004, 2504.

214 J. H. Jeong, Y. H. An, Y. K. Kang, Q. T. Nguyen, H. Lee, B. M. Novak, Polyhedron 2008, 27, 319.

215 X,-Y Yu, C. Zhang, Z,-X Wang, Organometallics 2013, 32, 3262.

216 A. Otero, J. Fernández-Baeza, L. F. Sánchez-Barba, J. Tejeda, M. Honrado, A. Garcés, A. LaraSánchez, A. M. Rodríguez, Organometallics 2012, 31, 4191.

217 B. Lian, C. M. Thomas, O. L. Casagrande, Jr., C. W. Lehmann, T. Roisnel, J,-F. Carpentier, Inorg. Chem. 2007, 46, 328. 
218 T. G. Schenck, J. M. Downes, C. R. C. Milne, J. F. Sawyer, B. Bosnich, L. Miller, Inorg. Chem. 1985, 24, 2338.

219 V. J. Arán, M. Kumar, J. Molina, L. Lamarque, P. Navaro, E. Garcia-España, J. A. Ramirez, S. V. Luis, B. Escuder, J. Org. Chem. 1999, 64, 6135.

220 J. C. Röder, F. Meyer, M. Konrad, S. Sandhöfner, E. Kaifer, H. Pritzkow, Eur. J. Org. Chem. 2001, 4479.

221 A. Sachse, Dissertation, Georg-August University, Göttingen 2009.

222 A. J. Pöe, M. S. Vaidya, J. Chem. Soc. 1961, 1023.

223 F. R. Hartley, Nature Physical Science, 1972, 236, 75.

224 T. Hosokawa, C. Calvo, H. B. Lee, P. M. Maitlis, J. Am. Chem. Soc. 1973, 95, 4914.

225 D. M. Roe, C. Calvo, N. Krishnarnachari, P. M. Maitlis, J. Chem. Soc. Dalton Trans. 1975, 125.

226 M. M. Olmstead, H. Hope, L. S. Benner, A. L. Balch, J. Am. Chem. Soc. Commun. 1977, 99, 5502.

227 R. G. Holloway, B. R. Penfold, R. Colton, M. J. McCormick, J. Chem. Soc. Chem. Commun. 1976, 21, 1.

228 A. L. Balch, J. R. Boemn, H. Hope, M. M. Olmstead, J. Am. Chem. Soc. 1976, 98, 7431.

229 C. P. Casey, J. D. Audett, Chem. Rev. 1986, 86, 339.

230 W. A. Hermann, Adv. Organomet. Chem. 1982, 20, 159.

231 R. J. Puddephatt, Polyhedron 1998, 7, 767.

232 J. D. Egbert, A. Chartoire, A. M. Z. Slawin, S. P. Nolan Organometallics 2011, 30, 4494.

233 M. L. Scheuermann, D. W. Boyce, K. A. Grice, W. Kaminsky, S. Stoll, W. B. Tolman, O. Swang, K. I. Goldberg, Angew. Chem. Int. Ed. 2014, 53, 6492.

234 P. Zalleno, S. Tambarini, P. A. Vigato, Coord. Chem. Rev. 1987, 77, 165.

235 C. Fraser, B. Bosnich, Inorg. Chem. 1994, 33, 338.

236 J,-P Costes, A. Dupois, J,-P Laurent, J. Chem. Soc., Dalton Trans. 1998, 735.

237 C. Popeney, Z. Guan, Organometallics 2005, 24, 1145.

238 A. Bastero, A. Ruiz, C. Claver, B. Miliani, E. Zangrando, Organometallics 2002, 21, 8520.

239 R. E. Rülke, J. M. Ernsting, A. L. Spek, C. J. Elsevier, P. W. N. M. van Leeuwen, K. Vrieze, Eur. J. Inorg. Chem. 1993, 32,5769.

240 T. Pechmann, C. D. Brandt, H. Werner, Chem. Eur. J. 2004, 10, 728.

241 A. Sataka, H. Koshino, T. Nakata, J. Organomet. Chem. 2000, 595, 208. 
242 K. W. Muir, J. A. Ibers, Inorg. Chem. 1965, 4, 778.

243 N. A. Bailey, J. M. Jenkins, R. Mason, B. L. Shaw, J. Chem. Soc. Chem. Commun. 1965, 237.

244 (a) M. Brookhart, M. L. H. Green, J. Organomet. Chem. 1983, 250, 395.

245 R. H. Crabtree, Angew. Chem. Chem. Int. Ed. 1993, 32, 789.

246 A. Martın, J. Chem. Ed. 1999, 76, 578.

247 A. Albinati, P. S. Pregosin, F. Wombacher, Inorg. Chem. 1990, 29, 1812.

248 C. M. Wehman-OoYevaar, D. M. Grove, H. Kooijman, P.van der Sluis, A. L. Spek, G. Van Koten, J. Am. Chem. Soc. 1992, 114, 9916.

249 T. Kawamoto, I. Nagasawa, H. Kuma, Y. Kushi, Inorg. Chem. 1996, 35, 2427.

250 T. W. Hambley, Inorg. Chem. 1998, 37, 3767.

251 E. F. Connor, T. R. Younkin, J. I. Henderson, A. W. Waltman, R. H. Grubbs, Chem. Commun. 2003, 2272.

252 M. S. W. Chan, L. Deng, T. Ziegler, Organometallics 2000, 19, 2741.

253 J. S. Wang, K. Matyjaszewski, J. Am. Chem. Soc. 1995, 117, 6514.

254 H. Uegaki, Y. Kotani, M. Kamigaito, M. Sawamoto, Macromolecules 1998, 31, 6756.

255 C. Granel, Ph. Dubois, R. Jéróme, Ph. Teyssié, Macromolecules 1996, 29, 8576.

256 K. Matyjaszewski, Macromol. Symp. 1998, 134, 1 05-118.

257 D. A. Singleton, D. T. Nowlan III; N. Jahed, K. Matyjaszewski, Macromolecules 2003, 36, 8609.

258 M. C. Volger, K. Vrieze, J. Organomet. Chem. 1966, 6, 297.

259 S. Hansson, P.-O. Norrby, M. Sjögren,B. Åkermark, M. E. Cucciolito, F. Giordano, A. Vitagliano, Organometallics 1993, 12, 4940.

260 A. Gogoll, J. Örnebro, H. Grennberg, J.-E. Bäckvall, J. Am. Chem. Soc. 1994, 116, 3631-3632.

261 J. W. Faller, H. L. Stokes-Huby, M. A. Albrizzio, Helv. Chim. Act. 2001, 84, 3031.

262 J. M. Canal, M. Gómez, F. Jiménez, M. Rocamora, G. Muller, E. Duñach, D. Franco, A. Jiménez, F. H. Cano, Organometallics 2000, 19, 966.

263 A. Guerrero, F. A. Jalon, B. R. Manzano, A. Rodriguez, R. M. Claramunt, P. Cornago, V. Milata, J. Elguero, Eur. J. Inorg. Chem. 2004, 549-556.

264 A. Bastero, A. F. Bella, F. Fernández, S. Jansat, C. Claver, M. Gómez, G. Muller, A. Ruiz, M. Font-Bardía, X. Solans, Eur. J. Inorg. Chem. 2007, 132. 
265 N. B. O’Bryan, T. O. Maier, I. C. Paul, R. S. Drago, J. Amer. Chem. Soc. 1973, 95, 6640.

266 P. Zannello, S Tambarini, P. A. Vigato, Coord. Chem. Rev. 1987, 77, 165.

267 J,-P, Costes, A. Dupois, J,-P Laurent, J. Chem. Soc. Dalton Trans. 1998, 735.

268 C. Dubs, T. Yamamoto, A. Inagaki, M. Akita, Organometallics 2006, 25, 1359.

269 J. H. H. Ho, S. W. W. Choy, S. A. Macgregor, B. A. Messerle, Organometallics 2011, 30, 5978.

270 X. Yu, Y. Yamamoto, N. Miyaura. Synlett. 2009, 994.

271 K. Yoshida, M. Ogasawara, T. Hayashi, J. Org. Chem, 2003, 68, 1901.

272 M. Kondo, T. Kochi, F. Kakiuchi, J Am Chem Soc. 2011, 12;133,32.

273 C. I. Simionescu, V. Percec, J. Polym.Sci. 1980, 18, 147.

274 (a). G. B. Deacon, R. J. Phillips, Coord. Chem. Rev. 1980, 33, 227. (b) V. Zelenák, Z. Vargová,K.Györyová Spectrochim. Acta A. 2007, 66, 262.

275 J. Lewinski, M. Kościelski, K. Suwała, I. Justyniak, Angew. Chem. Int. Ed. 2009, $48,7017$.

276 A. Otero, J. Fernández-Baeza, L. F. Sánchez-Barba, J. Tejeda, M. Honrado, A. Garcés, A. LaraSánchez, and M. Rodríguez, Organometallics 2012, 31, 4191.

277 D. Brizzolara, H. J.Cantow, K. Diederichs, E. Keller, A. J. Dombk, Macromolecules 1996, 29, 191.

278 W. H. Carothers, G. L. Dorough, F. J. van Natta, J. Am. Chem. Soc. 1932, 54, 761.

279 K. A. M. Thakur, R. T. Kean, M. T. Zell, B. E. Padden, E. J. Munson, Chem. Commun. 1998, 1913.

280 F. Douin, P. O. Oguadinma, T, J. J. Whitehorne, R. E. Prud'homme, F. Schaper, Organometallics 2010, 29, 2139.

281 J. Baran, A. Duda, A. Kowalski, R. Szymanski, S. Penczek, Macromol. Rapid Commun. 1997, 18, 325.

282 O. V. Sizova, L. V. Skripnikov, A. Y. Sokolov, O. O. Lyubimova, J. Struct. Chem. 2007, 48, 28.

283 K. A. Kreisel, G. P. A. Yap, O. Dmitrenko, C. R. Landis, K. H. Theopold, J. Am. Chem. Soc. 2007, 129. 14162.

284 F. A. Cotton, R. A. Walton, Multiple Bonds between Metal Atoms, Eds., Oxford University Press, Oxford, 1993.

285 K. Das, K. M. Kadish, J. L. Bear, Inorg. Chem. 1978, 17,930.

286 M. P. Doyle, Chem Rev. 1986, 86, 919.

287 M. P. Doyle D. C Forbes, Chem Rev. 1998, 98, 911.

288 H. M. L. Davies, R. E. J. Beckwith, Chem Rev. 2003, 103, 2861. 
289 J. Hansen, H. M. L. Davies, Coord Chem Rev. 2008, 252, 545.

290 U. Siemeling, P. Jutzi, J. Organomet. Chem. 1995, 500, 175.

291 K.-S. Son, R. M. Waymouth, J. Polym. Sci. Part A: Polymer Chemistry 2010, 48, 1579.

292 K.-S. Son, F. Joge, R. M. Waymouth, Macromolecules 2008, 41, 9663.

293 M. S. Blais, J. C. W. Chien, M. D. Rausch, Organometallics 1998,17, 3775.

294 R. A. J. Postema PCT Int. Appl. 1997, WO 9742231 A1 19971113.

295 V. J. Chebny, R. Rathore, J. Am. Chem. Soc. 2007, 129, 8458.

296 A. J. Arduengo, Acc. Chem. Res. 1999, 32, 913.

297 Arduengo, A. J., Harlow, R. L., Kline, M. J. Am. Chem. Soc. 1991, 113, 361.

298 R. E. Douthwaite, M. L. H. Green, P. J. Silcock, P. J. Gomes, J. Chem. Soc., Dalton Trans. 2002, 1386.

299 F. Glorious, Ed. N-Heterocyclic Carbenes in Transition Metal Catalysis; Topics in Organometallic Chemistry, Vol. 21, Springer-Verlag, Berlin/Heidelberg, 2007.

300 P. L. Arnold, M. Rodden, K. M. Davis, A. C. Scarisbrick, A. J. Blake, C. Wilson, Chem. Commun. 2004, 1612.

301 P. L. Arnold, M. Rodden, C. Wilson, Chem. Commun. 2005, 1743.

302 A. J. Arduengo, F. Davidson, R. Krafczy, W. J. Marshall, M. Tamm, Organometallics 1998, 17, 3375.

303 R. J. Baker, M. L. Cole, C. Jones, M. F. Mahon, Chem. Soc.- Dalton Trans. 2002, 1992.

304 A. J. Arduengo, H. V. R. Dias, J. C. Calabrese, F. Davidson, Inorg. Chem. 1993, 32, 1541.

305 C. Yao, C. Wu, B. Wang, D. Cui, Organometallics 2013, 32, 2204.

306 C. Zhang, F. Luo, B. Cheng, B. Li, H. Song, S. Xu, B. Wang, Dalton Trans. 2009, 35, 7230.

307 B. Wang, D. Cui, K. Lv, Macromolecules 2008, 41, 1983.

308 B. Wang, D. Wang, D. Cui, W. Gao, T. Tang, X. Chen, X. Jing, Organometallics 2007, 26, 3167.

309 S. Mihan, I. Nifant'ev, PCT Int. Appl. 2004, WO 2004020479 A2 20040311.

310 S. P. Downing, A. A. Danopoulos, Organometallics 2006, 25, 1337.

311 S. P. Downing, P. J. Pogorzelec, A. A. Danopoulos, D. J. Cole-Hamilton, Eur. J. Inorg. Chem. 2009, 1816.

312 G. Aullo’n, L. Brammer, E. A. Bruton, A. G. Orpen Chem.Commun. 1998, 653.

313 A. Bondi, J. Phys. Chem. 1964, 68, 441.

314 C. B. Aakeröy, T. A. Evans, K. R. Seddon, I. Pálinkó, New J. Chem. 1999, $23,145$. 
315 T. Steiner, Acta Cryst. 1998, B54, 546.

316 L. S. Boffa, B. M. Novak, Chem. Rev. 2000, 100, 1479.

317 L. K. Johnson, S. Mecking, M. Brookhart, J. Am. Chem. Soc. 1996, 118, 267.

318 S. Mecking, L. K. Johnson, L. Wang, M. Brookhart, J. Am. Chem. Soc. 1998, 120, 888.

319 T. R. Younkin, E. F. Conner, J. I. Henderson, S. K. Friedrich, R. H. Grubbs, D. A. Bansleben, Science 2000, 287, 460 .

320 V. C. Gibson, A. Tomov, Chem. Commun. 2001, 1964.

321 H. Li, C. L. Stern, T. J. Marks, Macromolecules 2005, 38, 9015.

322 M. R. Salata, T. J. Marks, Macromolecules 2009, 42, 1920.

323 L. McElwee-White, D. A. Dougherty, J. Am. Chem. Soc. 1984, 106, 3466.

324 O. Meth-Cohn, E. Vourin, T. A. Modro, J. Org. Chem. 1989, 54, 4822.

325 G. Giordano, R. H. Crabtree, Inorg. Synth. 1979, 19, 218.

326 Y. Tatsuno, T. Yoshida, S. Otsuka, Inorg. Synth. 1988, 28, 342.

327 S. Imaizumi, T. Matsuhisha, Y Senda, J. Organomet. Chem. 1985, 280, 441.

328 M. Strohalm, D. Kavan, P. Novák, M. Volný, V. Havlíče: mMass 3: A Cross-Platform Software Environment for Precise Analysis of Mass Spectrometric Data. Anal Chem. 2010, 82, 4648.

329 M. Strohalm, M. Hassman, B. Košata, M. Kodíček: mMass Data Miner: an Open Source Alternative for Mass Spectrometric Data Analysis. Rapid Commun Mass Spec. 2008, 22, 905.

330 STOE \& CIE GmbH, X-AREA, Darmstadt, 2002.

331 STOE \& CIE GmbH, X-RED, Darmstadt, 2002.

332 G. M. Sheldrick, SHELXL-97 Program for Crystal Structure Refinement, University of Göttingen, 1997.

333 G. M. Sheldrick, SHELXL-97 Program for Crystal Structure Solution, University of Göttingen, 1997. 


\section{Posters and Presentations}

Workshop at Heimvolkshochschule Maria spring - Poster presentation $29^{\text {th }}$ June 2010

NiKaS 2010 - Poster presentation

$21^{\text {st }}$ and $22^{\text {nd }}$ October 2010

Workshop at Haus Hessenkopf, Goslar - Poster presentation $24^{\text {th }}-25^{\text {th }}$ June 2011

Workshop at Haus Höhenblick, Braunfels - Poster presentation $27^{\text {th }}-29^{\text {th }}$ June 2012

jointly held with Landesforschungsschwerpunkt NanoKat, TU Kaiserslautern

NiKaS 2012 - Poster presentation

$18^{\text {th }}$ and 19 th October 2012

Workshop LIKAT Rostock - Poster presentation $16^{\text {th }}-18^{\text {th }}$ September 2013

Heidelberg forum for Molecular catalysis (HFMC 2013) - Poster presentation $28^{\text {th }}$ June 2013

20th EuCheMS Conference on Organometallic Chemistry-Poster presentation 30 June 2013 - 04 July 2013

University of St. Andrews, Scotland. 


\section{Acknowledgements}

My sincere appreciation and profound gratitude to my supervisor Prof. Dr. Franc Meyer for the wonderful opportunity he granted me to work with his group under his supervision and providing an enabling working environment during my Ph.D. study.

I also express my sincere gratitude and appreciation to the members of the thesis committee, Prof. Dr. P. Vana (IPC) and Prof. Dr. D. Stalke (IAC).

- CaSuS for Funding, without which is would have been impossible to pursue the Ph.D. research.

- Dr. Sebastian Dechert, for collecting and solving most X-ray structure data related to this work (not forgetting Nicole and Anne).

CaSuS cooperation partners:

- Sebastian Primpke (IPC), for collaborative work and help with GPC measurements and analysis.

- Dr. Christian Maass, for collaborative work and efforts in handling and collecting X-ray data and solving particularly difficult structures.

- Torben Böhnisch: For help and insightful suggestions into challenging problems as well as proof reading.

Administrative and supporting staff:

- Dr. Hanna Steininger (CaSuS coordinator), for the wonderful job in coordinating all CaSuS related activities.

- Frau Petra Unger

- Jorge Teichgräber, Andreas Schwarz

- Staff at the NMR and Analytical departments in the Inorganic institute.

Colleagues at A. K. Meyer for the enabling and fun filled working environment, most especially Jann Meyer, Felix Krätzschmar and Mike Schütze who worked on various aspects of this project

To my family and most especially Maria............. say Thank You 